\title{
BIOFUEL FEEDSTOCK ASSESSMENT FOR SELECTED COUNTRIES
}

Keith L. Kline

Gbadebo A. Oladosu

Amy K. Wolfe

Robert D. Perlack

Virginia H. Dale

Matthew McMahon

OAK RIDGE NATIONAL LABORATORY 


\section{DOCUMENT AVAILABILITY}

Reports produced after January 1, 1996, are generally available free via the U.S. Department of Energy (DOE) Information Bridge.

Web site http://www.osti.gov/bridge

Reports produced before January 1, 1996, may be purchased by members of the public from the following source.

National Technical Information Service

5285 Port Royal Road

Springfield, VA 22161

Telephone 703-605-6000 (1-800-553-6847)

TDD 703-487-4639

Fax 703-605-6900

E-mail info@ntis.fedworld.gov

Web site http://www.ntis.gov/support/ordernowabout.htm

Reports are available to DOE employees, DOE contractors, Energy Technology Data Exchange (ETDE)

representatives, and International Nuclear Information System (INIS) representatives from the following source.

Office of Scientific and Technical Information

P.O. Box 62

Oak Ridge, TN 37831

Telephone 865-576-8401

Fax 865-576-5728

E-mail reports@adonis.osti.gov

Web site http://www.osti.gov/contact.html

This report was prepared as an account of work sponsored by an agency of the United States Government. Neither the United States Government nor any agency thereof, nor any of their employees, makes any warranty, express or implied, or assumes any legal liability or responsibility for the accuracy, completeness, or usefulness of any information, apparatus, product, or process disclosed, or represents that its use would not infringe privately owned rights. Reference herein to any specific commercial product, process, or service by trade name, trademark, manufacturer, or otherwise, does not necessarily constitute or imply its endorsement, recommendation, or favoring by the United States Government or any agency thereof. The views and opinions of authors expressed herein do not necessarily state or reflect those of the United States Government or any agency thereof. 


\title{
BIOFUEL FEEDSTOCK ASSESSMENT FOR SELECTED COUNTRIES
}

\author{
To Support the DOE study of \\ Worldwide Potential to Produce Biofuels with a focus on U.S. Imports
}

\author{
Keith L. Kline \\ Gbadebo A. Oladosu \\ Amy K. Wolfe \\ Robert D. Perlack \\ Virginia H. Dale \\ Environmental Sciences Division \\ Oak Ridge National Laboratory \\ Matthew McMahon \\ Appalachian State University
}

Date published: February 2008

Prepared for

U.S. Department of Energy

Office of Policy and International Programs and the

EERE Office of the Biomass Program

Budget Activity Number BM0102060

Prepared by

OAK RIDGE NATIONAL LABORATORY

Oak Ridge, Tennessee 37831

managed by UT-Battelle, LLC

for the

U.S. DEPARTMENT OF ENERGY

under contract DE-AC05-00OR22725 


\section{CONTENTS}

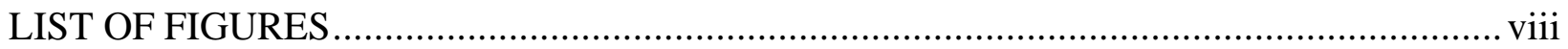

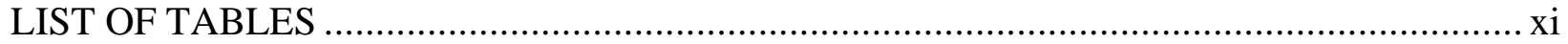

ACKNOWLEDGMENTS ................................................................................... xiv

EXECUTIVE SUMMARY ................................................................................. XV

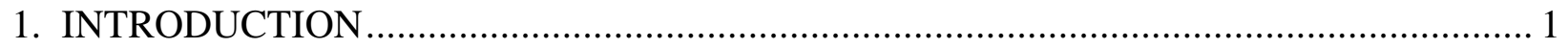

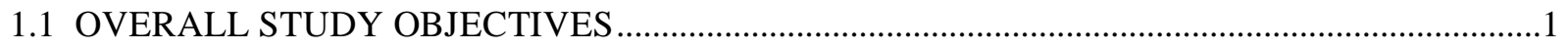

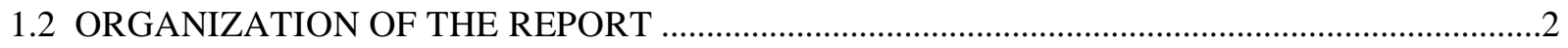

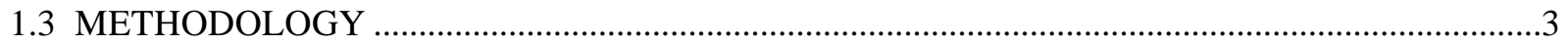

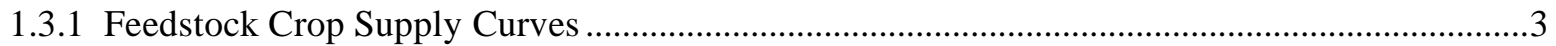

1.3.2 Estimating the Portion of Supply Available for Export and/or Biofuel Feedstock .....................5

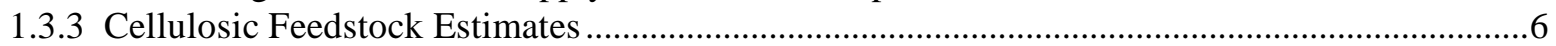

2. ORNL FEEDSTOCK ASSESSMENT - AGGREGATE RESULTS _............................ 9

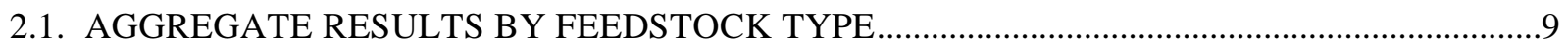

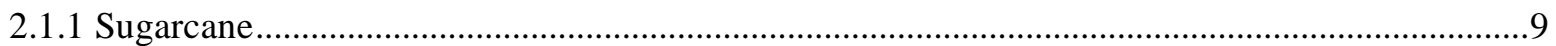

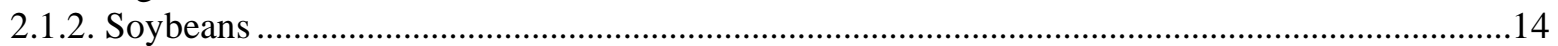

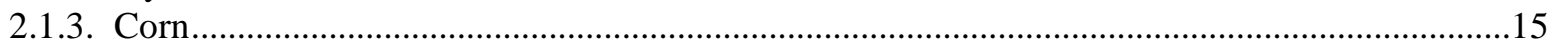

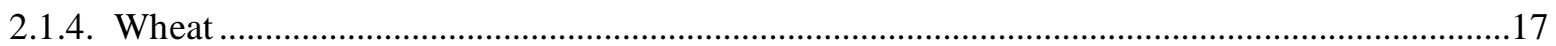

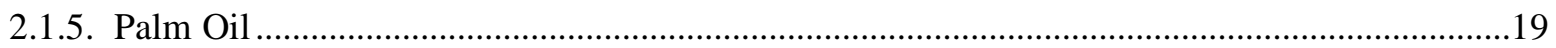

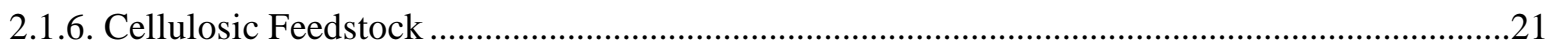

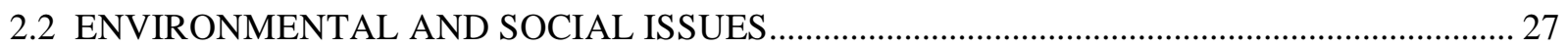

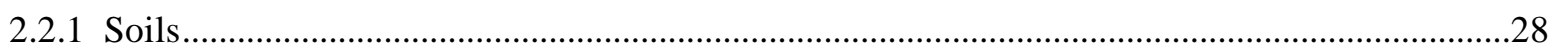

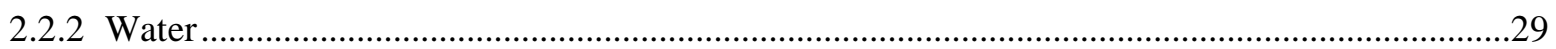

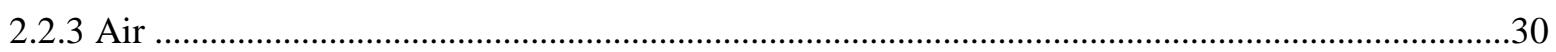

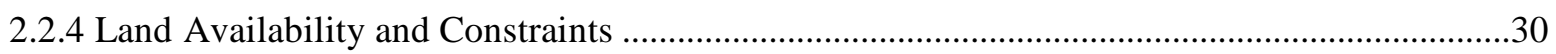

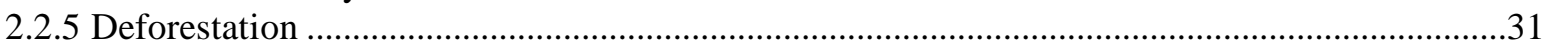

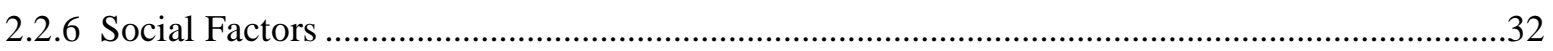

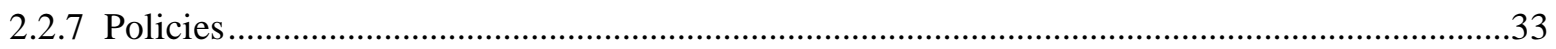

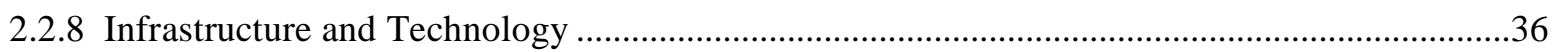

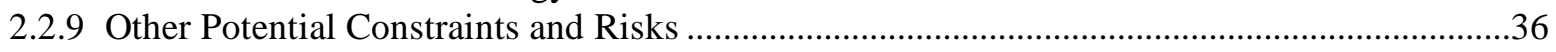

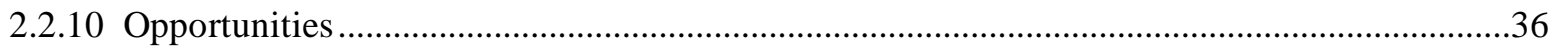

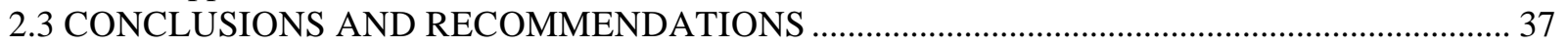

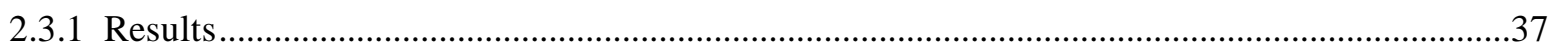

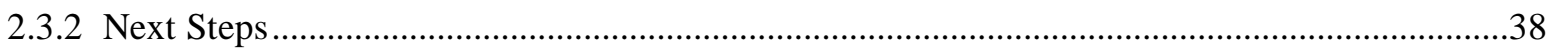

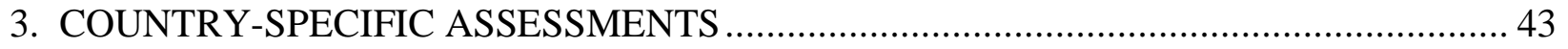

3.1 ARGENTINA - SOYBEANS, CORN, WHEAT, AND SUGARCANE ..................................... 43

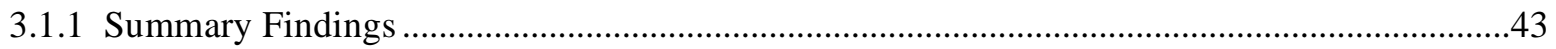

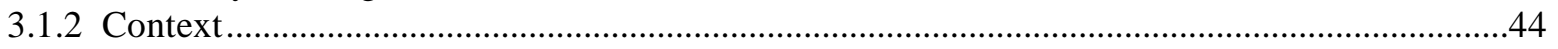

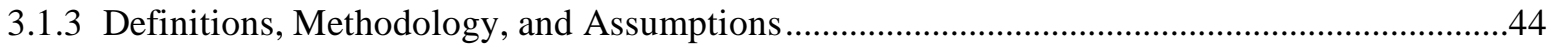

3.1.3.1 Units, Conversion Factors, and Calculations ........................................ 45

3.1.4 Wheat Supply Potential — Analysis and Projections: 2012, 2017, 2027 ................................45

3.1.4.1 Other Wheat Estimates ............................................................... 45

3.1.4.2 Biofuel Use and Competing Demands ............................................ 45

3.1.4.3 Notes on Adjustments to Standard Methodology .................................. 47

3.1.5 Soybean Supply Potential — Analysis and Projections: 2012, 2017, 2027 ............................47 


\section{CONTENTS (Cont'd)}

3.1.5.1 Other Estimates 49

3.1.5.2 Biofuel Use and Competing Demands ............................................... 49

3.1.5.3 Notes on Adjustments to Standard Methodology ................................... 50

3.1.6 Corn Supply Potential — Analysis and Projections: 2012, 2017, 2027 ...................................50

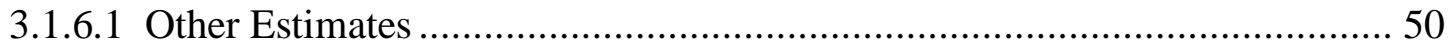

3.1.6.2 Biofuel Use and Competing Demands ............................................. 50

3.1.7 Sugarcane Supply Potential - Analysis and Projections: 2012, 2017, 2027 ............................51

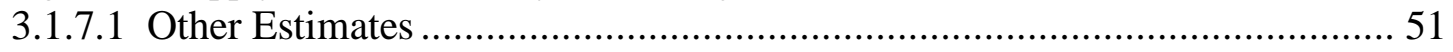

3.1.7.2 Biofuel Use and Competing Demands ............................................... 51

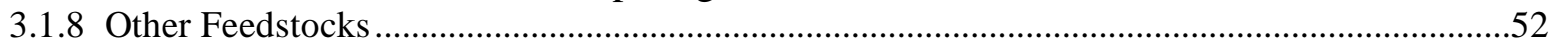

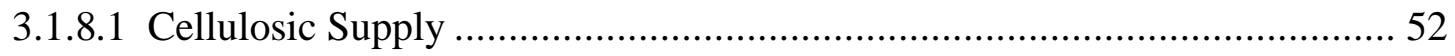

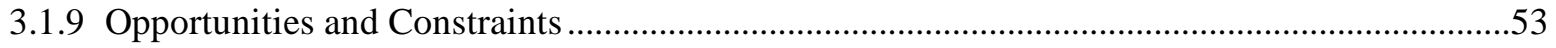

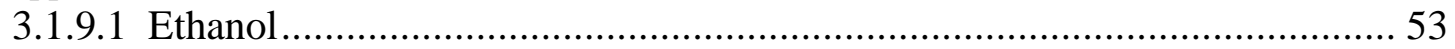

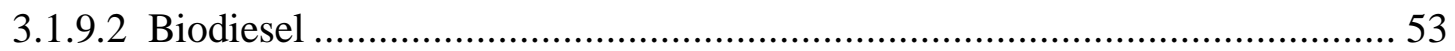

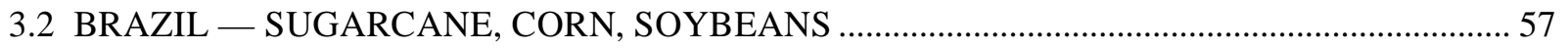

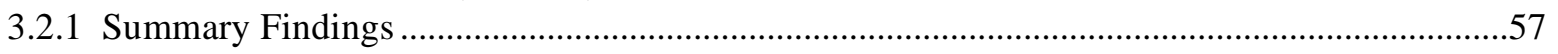

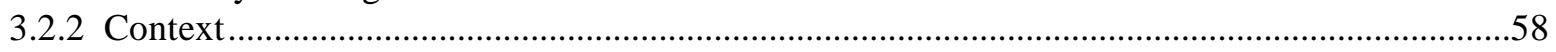

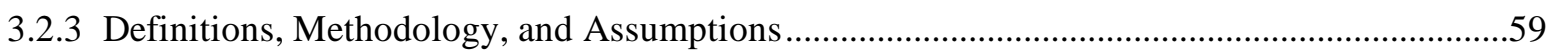

3.2.3.1 Units, Conversion Factors, and Calculations .................................... 59

3.2.4 Sugarcane Supply Potential — Analysis and Projections: 2012, 2017, 2027 .........................59

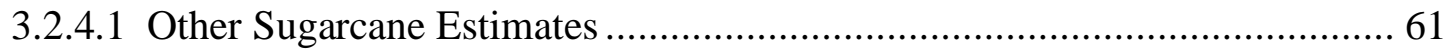

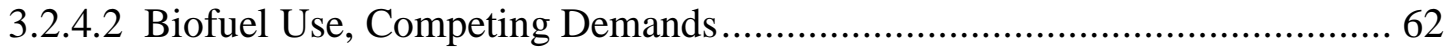

3.2.5 Corn Supply Potential — Analysis and Projections: 2012, 2017, 2027 ...............................62

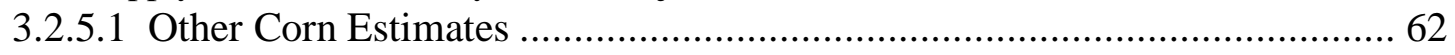

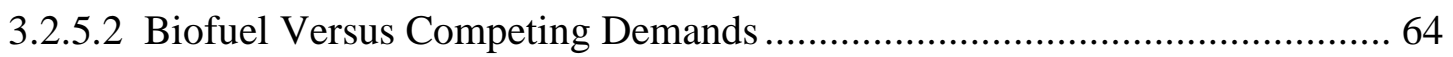

3.2.6 Soybean Supply Potential — Analysis and Projections: 2012, 2017, 2027 ............................64

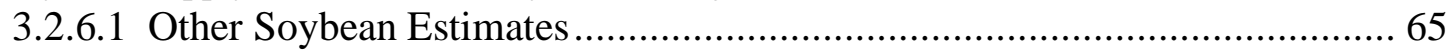

3.2.6.2 Biofuel Use and Competing Demands ............................................ 65

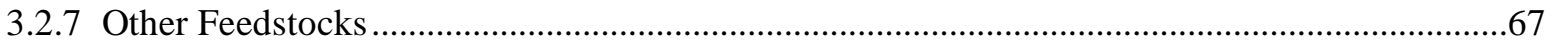

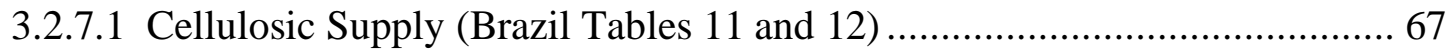

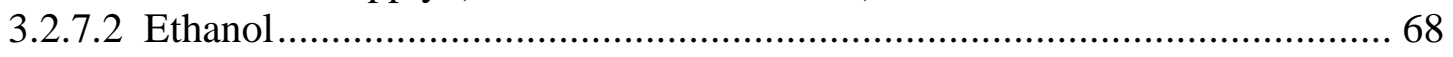

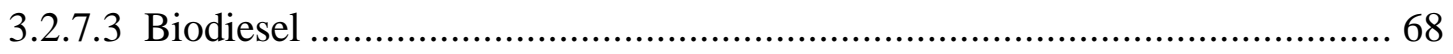

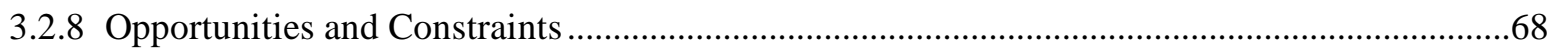

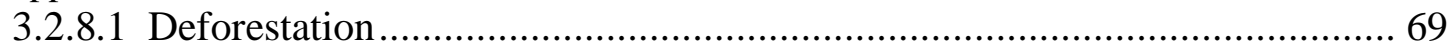

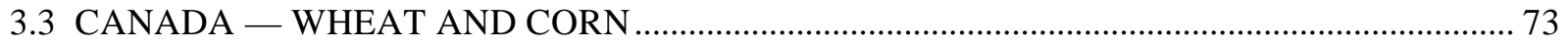

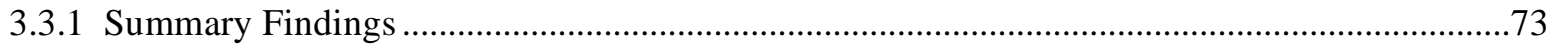

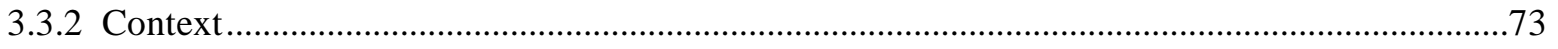

3.3.3 Definitions, Methodology, and Assumptions ..................................................................... 74

3.3.3.1 Units, Conversion Factors, and Calculations ........................................ 74

3.3.4 Wheat Supply Potential — Analysis and Projections: 2012, 2017, 2027 ..............................74

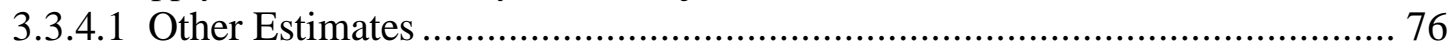

3.3.4.2 Biofuel Use and Competing Demands ........................................... 76 


\section{CONTENTS (Cont'd)}

3.3.4.3 Notes on Adjustments to Standard Methodology ................................... 77

3.3.5 Corn Supply Potential — Analysis and Projections: 2012, 2017, 2027 .................................77

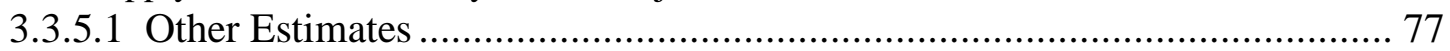

3.3.5.2 Biofuel Use and Competing Demands ................................................. 79

3.3.5.3 Notes on Adjustments to Standard Methodology …............................... 80

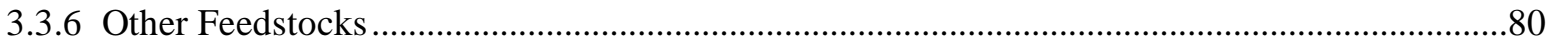

3.3.6.1 Cellulosic Supply ........................................................................ 80

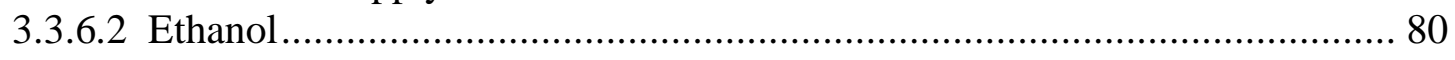

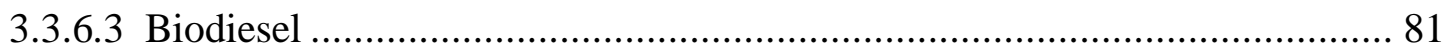

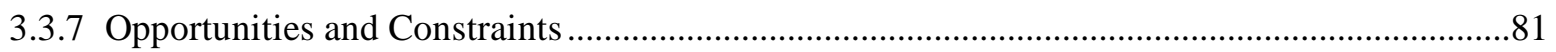

3.4 CHINA - CORN, SOYBEANS, WHEAT, AND SUGARCANE ............................................... 84

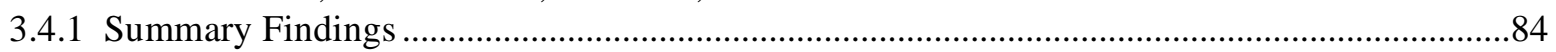

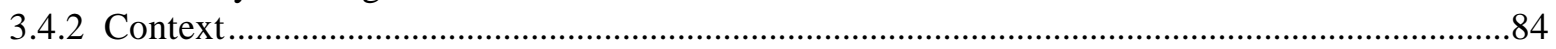

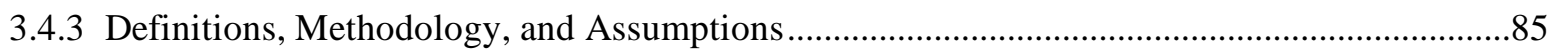

3.4.3.1 Units, Conversion Factors, and Calculations ....................................... 85

3.4.4 Corn Supply Potential — Analysis and Projections: 2012, 2017, 2027 .................................85

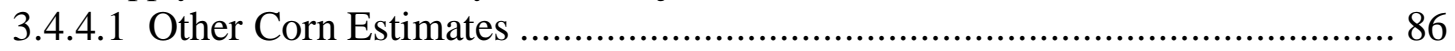

3.4.4.2 Biofuel Use and Competing Demands ........................................... 86

3.4.5 Soybean Supply Potential — Analysis and Projections: 2012, 2017, 2027 ............................86

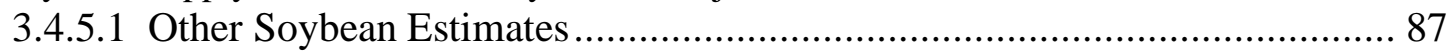

3.4.5.2 Biofuel Use and Competing Demands ........................................... 87

3.4.6 Wheat Supply Potential — Analysis and Projections: 2012, 2017, 2027 .............................87

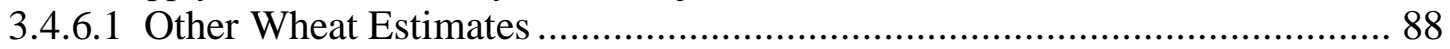

3.4.6.2 Biofuel Use and Competing Demands ............................................ 88

3.4.7 Sugarcane Supply Potential — Analysis and Projections: 2012, 2017, 2027 .........................89

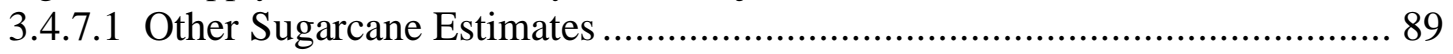

3.4.7.2 Biofuel Use and Competing Demands ........................................... 89

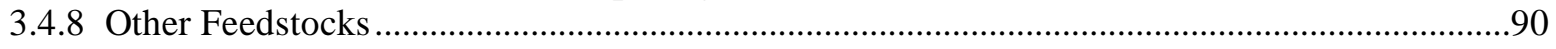

3.4.8.1 Cellulosic ............................................................................ 90

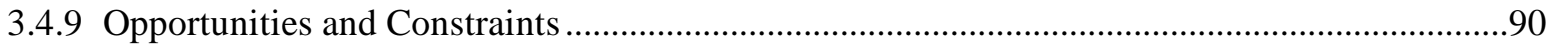

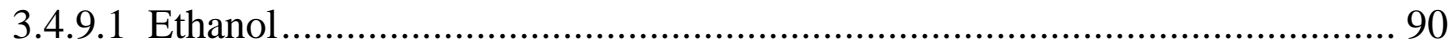

3.4.9.2 Biodiesel ................................................................................. 90

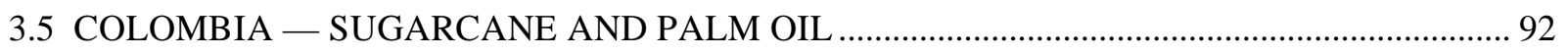

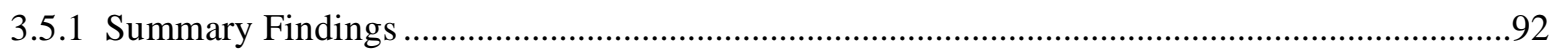

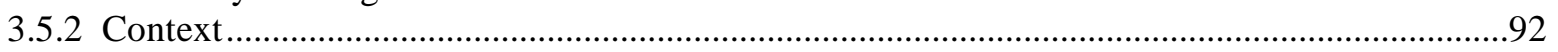

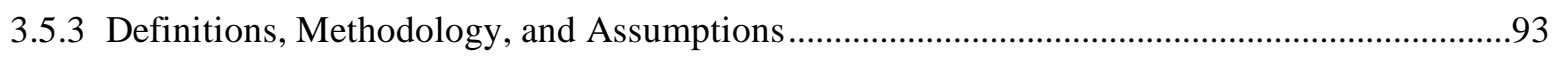

3.5.3.1 Units, Conversion Factors, and Calculations .................................... 93

3.5.4 Sugarcane Supply Potential — Analysis and Projections: 2012, 2017, 2027 ........................93

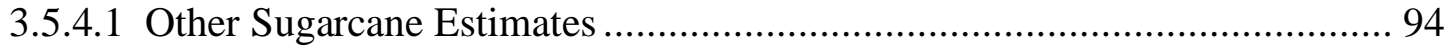

3.5.4.2 Biofuel Use and Competing Demands ................................................ 94

3.5.4.3 Notes on Adjustments to Standard Methodology .................................. 95

3.5.5 Palm Oil Supply Potential — Analysis and Projections: 2012, 2017, 2027 ..........................95

3.5.5.1 Other Palm Oil Estimates .......................................................... 96

3.5.5.2 Biofuel Use and Competing Demands ............................................. 96 


\section{CONTENTS (Cont'd)}

3.5.5.3 Notes on Adjustments to Standard Methodology ….............................. 96

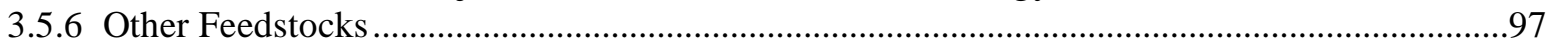

3.5.6.1 Cellulosic Supplies ..................................................................... 97

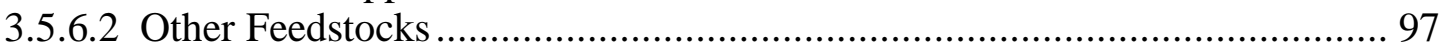

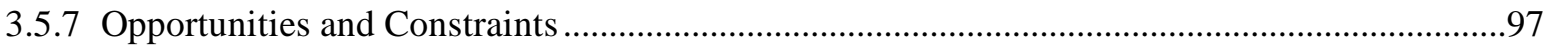

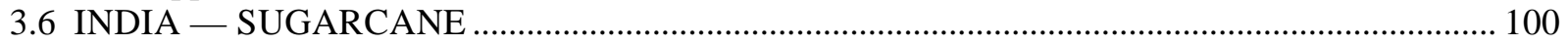

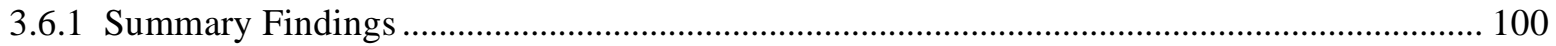

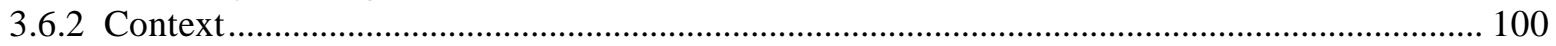

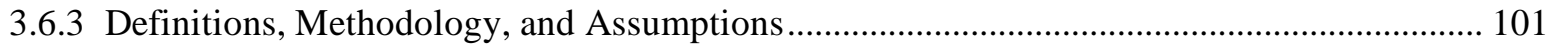

3.6.3.1 Units, Conversion Factors, and Calculations ..................................... 101

3.6.4 Sugarcane Supply Potential — Analysis and Projections: 2012, 2017, 2027 ...................... 101

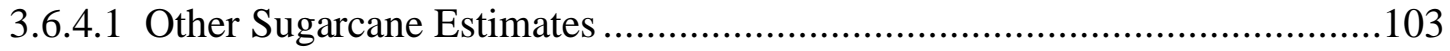

3.6.4.2 Biofuel Use and Competing Demands ................................................103

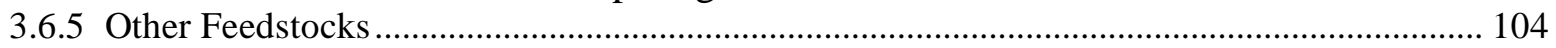

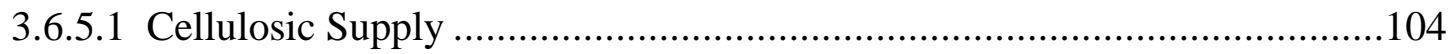

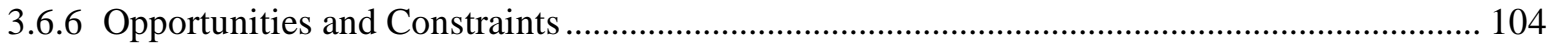

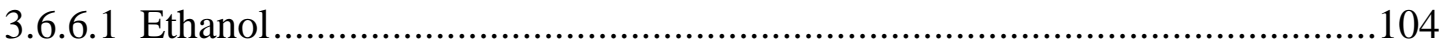

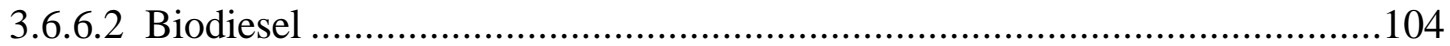

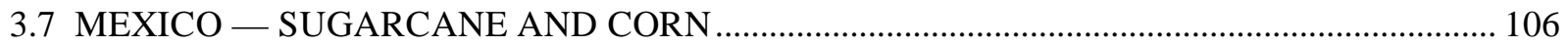

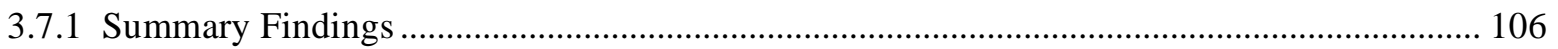

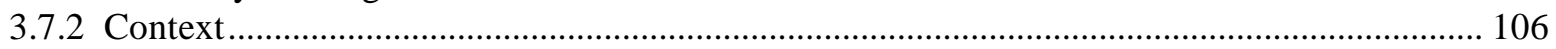

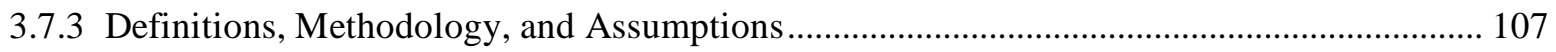

3.7.3.1 Units, Conversion Factors, and Calculations ...................................... 107

3.7.4 Sugarcane Supply Potential — Analysis and Projections: 2012, 2017, 2027 ...................... 107

3.7.4.1 Other Sugarcane Estimates ............................................................ 108

3.7.4.2 Biofuel Use and Competing Demands ...............................................108

3.7.5 Corn Supply Potential — Analysis and Projections: 2012, 2017, 2027 .............................. 110

3.7.5.1 Other Corn Estimates .......................................................................... 112

3.7.5.2 Biofuel Use and Competing Demands ............................................ 112

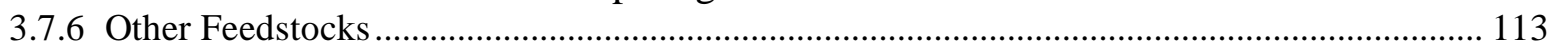

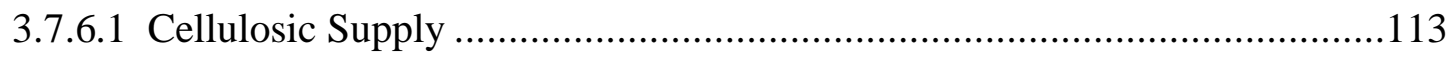

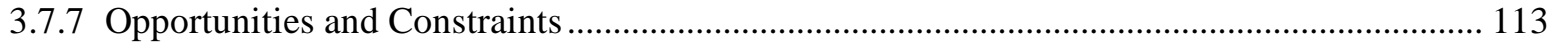

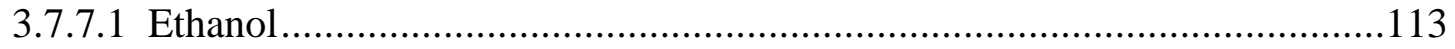

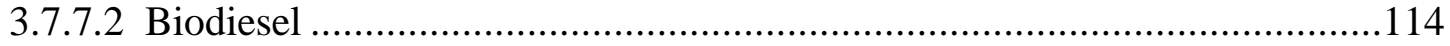

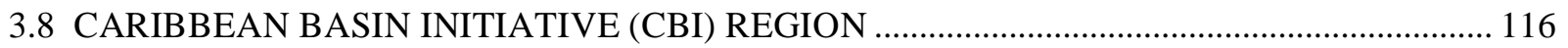

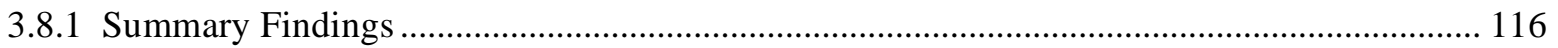

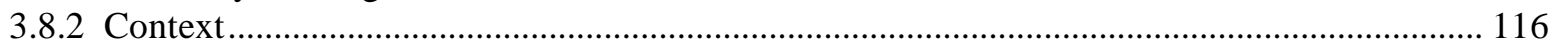

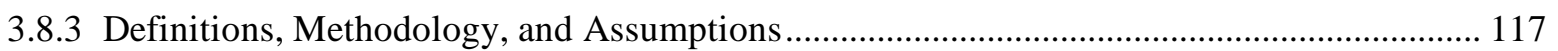

3.8.3.1 Units, Conversion Factors, and Calculations ......................................117

3.8.4 Sugarcane Supply Potential — Analysis and Projections: 2012, 2017, 2027 ........................ 117

3.8.4.1 Biofuel Use and Competing Demands ...............................................119

3.8.4.2 Notes on Adaptation of Standard Methodology .....................................119

3.8.5 Palm Oil Supply Curves — Analysis and Projections: 2012, 2017, 2027 ........................... 120

3.8.5.1 Biofuel Use and Competing Demands ............................................ 120 


\section{CONTENTS (Cont'd)}

3.8.5.2 Notes on Adaptation of Standard Methodology ....................................120

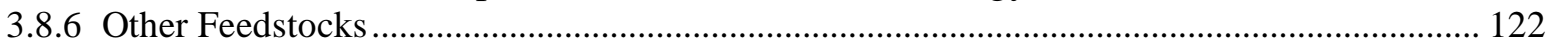

3.8.6.1 Cellulosic Supply ................................................................... 122

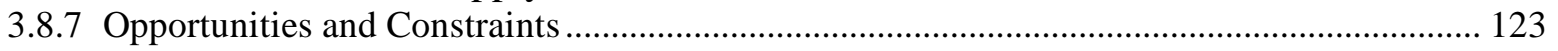

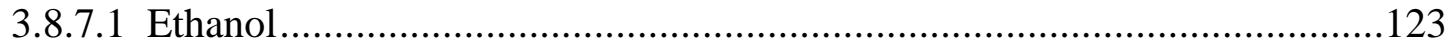

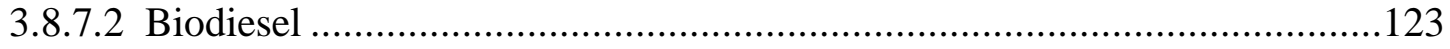

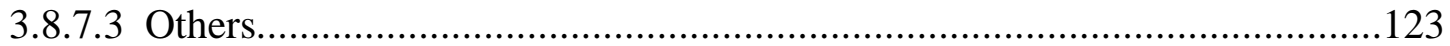

4. BIBLIOGRAPHY - REFERENCES .............................................................. 127

\section{ANNEXES}

ANNEX 1. STATEMENT OF WORK FOR ORNL UNDER THE “STUDY OF THE WORLDWIDE POTENTIAL TO PRODUCE ETHANOL AND OTHER BIOFUELS” ........ 136

ANNEX 2. SCREENING RESULTS FOR COUNTRY SELECTION ............................. 140

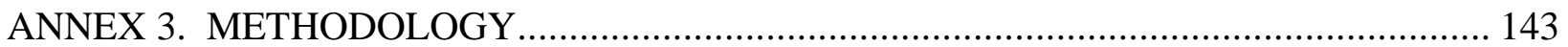

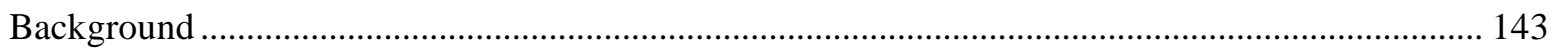

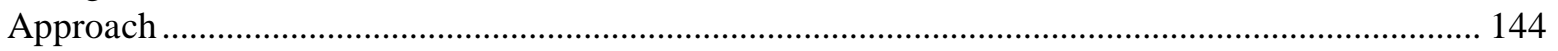

Summary Statistics for National Compound Growth Rates Derived from FAO National

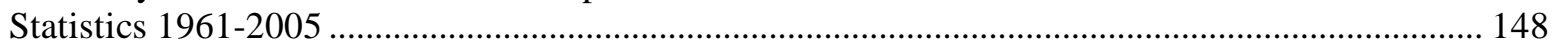

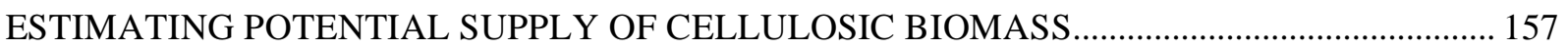

Biomass Residue as a Function of Feedstock Production: Corn, Wheat and Soybean..................... 157

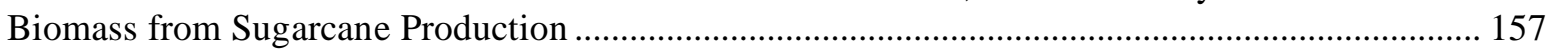

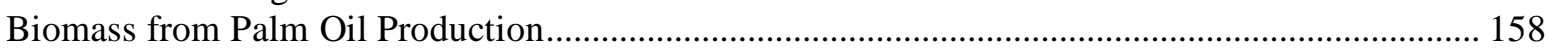

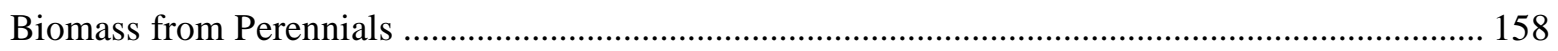

ANNEX 4. SUPPLY CURVE DATA TABLES, BY COUNTRY ...................................... 164 


\section{LIST OF FIGURES}

Figure ES-1. Example of Sugarcane Supply Curve for Brazil - Baseline Case in 2017.......... xvi

Figure ES-2. Total Feedstock Available for Export or Biofuel by Source in 2017 ....

(based on raw tonnage in millions of metric tonnes).

xviii

Figure ES-3. Total Feedstock Available for Export or Biofuel by Source in 2017

(Based on gasoline equivalent in millions of gallons). xviii

Figure ES-4. Total Crop Feedstock Available for Export or Biofuel by Country in 2017

(gasoline equivalent basis). xix

Figure ES-5. Historic and Projected Sugarcane Production - Total Aggregate Supply from

Countries Studied. $\mathrm{XX}$

Figure ES-6. Share by Country of Projected Sugarcane Supply Available for Export or

Biofuel in 2017 - by Growth Case (Baseline, Low and High). xxi

Figure ES-7. Share of Soybean Production Represented by Countries Studied.................... xxii

Figure ES-8. Aggregate Historic and Projected Soybean Production in Countries Studied. .. xxii

Figure ES-9. Aggregate Historic and Projected Corn Production in Countries Studied........ xxiii

Figure ES-10. Aggregate Historic and Projected Wheat Production in Countries Studied...... xxiv

Figure ES-11. Historic and Projected Palm Oil Production (CBI and Colombia).................. xxiv

Figure ES-12. Projected Supply Available for Export or Biofuel by Feedstock Type - 2017

Baseline (gasoline equivalent basis; total $=38$ billion gallons) ..................... xxix

Figure ES-13. Projected Supply Available for Export or Biofuel by Country - 2017 Baseline

(gasoline equivalent basis; total $=38$ billion gallons) ........................... xxix

Figure 1.1. Example of Brazilian Sugarcane Supply Curve projected to 2027

(Values in 2005 US\$)........................................................................... 5

Figure 1.2. Historic Trend and Potential Supply Projections for Brazilian Sugarcane........... 6

Figure 2.1. Total Projected Sugarcane Production Potential by Country........................... 10

Figure 2.2. Total Projected Sugarcane Supply 'Available' by Country............................ 11

Figure 2.3. Baseline Case - Sugarcane Supply Curves. ............................................. 13

Figure 2.4. Sugarcane Supply 'Available' by Country, 2017 (Gasoline Equivalent Basis)... 14

Figure 2.5. Total Projected Soybean Supply Potential by Country................................ 16

Figure 2.6. Total Projected Soybean Supply 'Available' by Country, 2017...................... 17

Figure 2.7. Total Projected Corn Potential Supply by Country......................................... 18

Figure 2.8. Total Projected Corn Supply 'Available' by Country, 2017............................ 19

Figure 2.9. Total Projected Wheat Supply Potential by Country................................... 20

Figure 2.10. Total Projected Wheat Supply 'Available' by Country, 2017........................ 21

Figure 2.11. Total Projected Palm Oil Supply Potential (CBI and Colombia)..................... 22

Figure 2.12. Total Projected Palm Oil Supply 'Available' by Country, 2017...................... 23

Figure 2.13. Aggregate Cellulosic Supply Projection from Crop Residues, by

Country - 2017................................................................................. 23

Figure 2.14. Aggregate Cellulosic Supply Projection from Crop Residues, by

Country - 2027. ................................................................................. 24

Figure 2.15. Aggregate Cellulosic Supply from Forestry and Perennials, by Country - 2017. 25

Figure 2.16. Aggregate Cellulosic Supply Projection, by Source - 2017.......................... 26

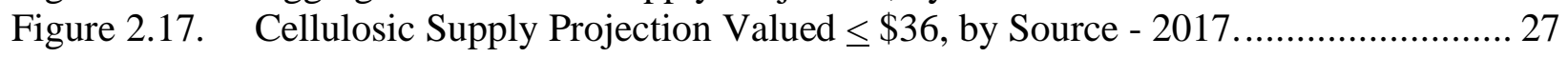

Figure 2.18. Countries with Largest Share of Primary Forests........................................ 32 


\section{LIST OF FIGURES (Cont'd)}

Argentina Figures 1-3. Baseline Case Wheat Supply Projections. ...................................... 46

Argentina Figure 4. Wheat: Historic Trend and Projections. ............................................ 47

Argentina Figures 5-7. Baseline Case Supply Projections — Soybeans............................... 48

Argentina Figure 8. Soybeans: Historic Trend and Projections.............................................. 49

Argentina Figure 9. Corn: Historic Trend and Projections.......................................... 51

Argentina Figure 10. Sugarcane: Historic Trend and Projections. ..................................... 52

Brazil Figures 1-3. Baseline Sugarcane Supply Projections............................................. 60

Brazil Figure 4. Sugarcane: Historic Trends and Projections............................................. 61

Brazil Figures 5-7. Baseline Corn Supply Curves........................................................ 63

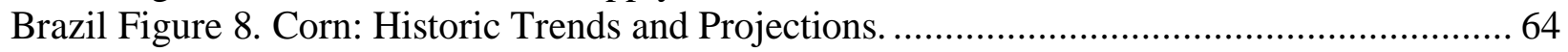

Brazil Figures 9-11. Baseline Soybean Supply Curves. ................................................ 66

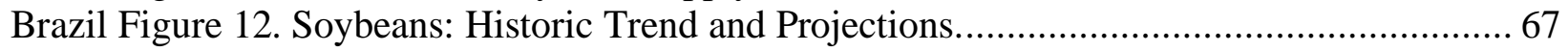

Canada Figure 4. Wheat: Historic Trend and Projections. ................................................ 76

Canada Figure 8. Corn: Historic Trend and Projections. ..................................................... 79

China Figure 1. Corn: Historic Trend and Projections.................................................. 86

China Figure 2. Soybeans: Historic Trend and Projections......................................... 87

China Figure 3. Wheat: Historic Trend and Projections. ................................................ 88

China Figure 4. Sugarcane: Historic Trend and Projections. .......................................... 89

Colombia Figure 1. Sugarcane — Historic Trend and Estimated........................................ 94

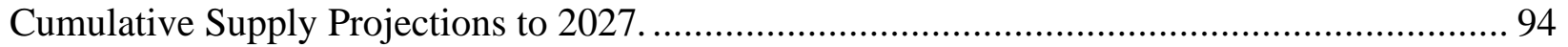

Colombia Figure 2. Palm Oil — Historic Trend and Estimated ......................................... 95

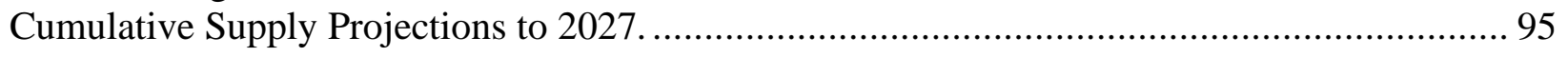

India Figure 4. Sugarcane: Historic Trend and Projections............................................ 103

Mexico Figures 1-3. Baseline Sugarcane Supply Curves.............................................. 109

Mexico Figure 4. Sugarcane Production: Historic Trends and Projections............................ 110

Mexico Figures 5-7. Baseline Corn Supply Curves. .................................................... 111

Mexico Figure 8. Corn Production: Historic Trends and Projections................................. 112

CBI Figures 1-3. Baseline Sugarcane Supply Curves. .................................................. 118

CBI Figure 4. Sugarcane Historic Trend and Projections. .............................................. 119

CBI Figure 8. Palm Oil Historic Trend and Projections (thousands of metric tonnes)............. 122

Annex 3

Figure 1. Sugarcane: 7-Year Rolling Average Production Growth Rates by Country (1968-2005). .................................................................................... 146

Figure 2a. Sugarcane: 7-Year Rolling Average Production Growth Rates by Country............ 153

Figure 2b. Soybean: 7-Year Rolling Average Production Growth Rates by Country.............. 153 


\section{LIST OF FIGURES (Cont'd)}

Page

Figure 2c. Corn: 7-Year Rolling Average Production Growth Rates by Country................... 154

Figure 2d. Palm Oil: 7-Year Rolling Average Production Growth Rates by Country.............. 154

Figure 2e. Wheat: 7-Year Rolling Average Production Growth Rates by Country.................. 155 


\section{LIST OF TABLES}

Page

Table ES-1. Share of World (non-US) Production of Crop Feedstocks Represented by Countries Assessed......................................................................................... Xv

Table ES-2. Summary of Aggregate Feedstock Projections for Countries Studied (Total projected supply in mmt and percent available for export and/or biofuel) .......... xvii

Table ES-3. Summary: Total Cellulosic Feedstock Supply in 2017 (Baseline Case) (millions of metric tonnes, $\mathrm{mmt})$............................................................... Xxv

Table ES-4. Cellulosic Supplies Valued $\leq \$ 36$ per dry tonne - 2017 Baseline Case (millions of metric tonnes, mmt)................................................................... xxvi

Table 1.1. Selected Countries and Feedstocks for Study.............................................. 2

Annex 3

Table 1a. Sugarcane - Historical Changes in Production by Country ................................. 148

Table 1b. Soybean -- Historical Changes in Production by Country ..................................... 149

Table 1c. Corn - Historical Changes in Production by Country ......................................... 150

Table 1d. Palm Oil - Historical Changes in Production by Country ................................... 151

Table 1e. Wheat -- Historical Changes in Production by Country ...................................... 152

Annex 3 - Table 2. Biomass Production, Crop Yields and Recovery Estimates ...................... 157

Annex 3 - Table 3. Calculations for Estimating Relative Potential from Perennials............... 159

Annex 3 - Table 4. Source Data for Roundwood and Fuelwood Supply Estimates ................ 160

Annex 3 - Table 5. Calculated Estimate of Residues as Factor of Roundwood Production ..... 161

Argentina Table 1. Baseline Case Supply Potential for Wheat .......................................... 165

Argentina Table 2. High Growth Case Supply Potential for Wheat .................................... 165

Argentina Table 3. Low Growth Case Supply Potential for Wheat...................................... 166

Argentina Table 4. Baseline Case Supply Data for Soybean .......................................... 166

Argentina Table 5. High Growth Case Supply Data for Soybean ....................................... 167

Argentina Table 6. Low Growth Case Supply Data for Soybean ....................................... 167

Argentina Table 7. Supply Potential Data for Corn .................................................... 168

Argentina Table 8. Supply Potential Data for Sugarcane................................................. 168

Argentina Table 9. Potential Percentage Allocation for Export \& Biofuels .......................... 168

Argentina Table 10. Estimated Cellulosic Supply from Recoverable Crop Residues

(mmt, bone-dry, annual) .................................................................... 169

Argentina Table 11. Estimated Cellulosic Supply Including Other Residues* (2017 baseline) 169

Brazil Table 1. Sugarcane - Baseline Case Supply Curve Data........................................ 170

Brazil Table 2. Sugarcane - High Growth Case Supply Curve Data.................................... 171

Brazil Table 3. Sugarcane - Low Growth Case Supply Curve Data .................................... 172

Brazil Table 4. Corn - Baseline Case Supply Curve Data ................................................. 173

Brazil Table 5. Corn - High Growth Case Supply Curve Data ............................................ 174

Brazil Table 6. Corn - Low Growth Case Supply Curve Data........................................ 175

Brazil Table 7. Soybean - Baseline Case Supply Curve Data.......................................... 176

Brazil Table 8. Soybean - High Growth Case Supply Curve Data........................................ 177

Brazil Table 9. Soybean - Low Growth Case Supply Curve Data ...................................... 178 


\section{LIST OF TABLES (Cont'd)}

Brazil Table 10. Potential Percentage Allocation for Export \& Biofuels 179

Brazil Table 11. Estimated Cellulosic Supply from Recoverable Crop Residues

(bagasse and corn only; in mmt, bone-dry, annual)

Brazil Table 12. Estimated Cellulosic Supply Including Other Residues (2017 baseline case). 179

Canada Table 1. Baseline Case Supply Data for Wheat....................................................... 180

Canada Table 2. High Growth Case Supply Data for Wheat ............................................. 180

Canada Table 3. Low Growth Case Supply Data for Wheat .............................................. 180

Canada Table 4. Baseline Case Supply Curve Data for Corn............................................... 181

Canada Table 5. High Growth Case Supply Curve Data for Corn ...................................... 181

Canada Table 6. Low Growth Case Supply Curve Data for Corn ......................................... 181

Canada Table 7. Potential Percentage Allocation for Export \& Biofuels ................................ 182

Canada Table 8. Estimated Cellulosic Supply from Recoverable Crop Residues..........................

(wheat and corn only; mmt, bone-dry, annual) ........................................... 182

Canada Table 9. Estimated Cellulosic Supply including Other Residues (2017 baseline case). 182

China Table 1. Estimated Potential Supply of Corn ...................................................... 183

China Table 2. Estimated Potential Supply of Soybean................................................... 184

China Table 3. Estimated Potential Supply of Wheat ...................................................... 185

China Table 4. Estimated Potential Supply of Sugarcane ............................................... 186

China Table 5. Potential Percentage Allocation for Export \& Biofuels................................ 187

China Table 6. Estimated Cellulosic Supply from Recoverable Crop Residues

(bagasse, corn and wheat only; in mmt, bone-dry, annual) .......................... 187

China Table 7. Estimated Cellulosic Supply Including Other Residues (2017 baseline case)... 188

Colombia Table 1. Estimated Potential Supply of Sugarcane ........................................... 189

Colombia Table 2. Estimated Potential Supply of Palm Oil .............................................. 189

Colombia Table 3. Potential Percentage Allocation for Export \& Biofuels............................ 190

Colombia Table 4. Estimated Cellulosic Supply from Recoverable Bagasse and Palm Residues

(mmt, bone-dry, annual) ................................................................................ 190

Colombia Table 5. Estimated Cellulosic Supply Summary Including Other Residues

(2017 baseline case) ......................................................................... 190

India Table 1. Baseline Case Supply Potential for Sugarcane ......................................... 191

India Table 2. High Growth Case Supply Potential for Sugarcane .................................... 192

India Table 3. Low Growth Case Supply Potential for Sugarcane ...................................... 193

India Table 4. Potential Percentage Allocation for Export \& Biofuels.................................. 194

India Table 5. Estimated Cellulosic Supply from Recoverable Bagasse Residues

(mmt, bone-dry, annual) .......................................................................... 194

India Table 6. Estimated Cellulosic Supply Including Other Residues (2017 baseline case) .... 194

Mexico Table 1. Sugarcane - Baseline Case Supply Curve Data ....................................... 195

Mexico Table 2. Sugarcane - High Growth Case Supply Curve Data ................................. 195 


\section{LIST OF TABLES (Cont'd)}

Mexico Table 3. Sugarcane - Low Growth Case Supply Curve Data.................................. 196

Mexico Table 4. Corn - Baseline Case Supply Curve Data................................................ 197

Mexico Table 5. Corn - High Growth Case Supply Curve Data........................................... 198

Mexico Table 6. Corn - Low Growth Case Supply Curve Data ......................................... 199

Mexico Table 7. Potential Percentage Allocation for Export \& Biofuels .............................. 200

Mexico Table 8. Estimated Cellulosic Supply from Recoverable Crop Residues

(bagasse and corn only; mmt, bone-dry, annual) ........................................... 200

Mexico Table 9. Estimated Cellulosic Supply Including Other Residues (2017 baseline case) 200

CBI Table 1. Sugarcane - Baseline Case Supply Curve Data Cumulative Projected Production

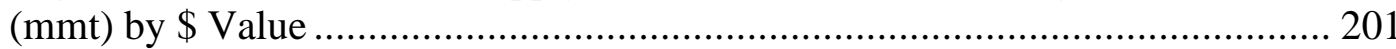

CBI Table 2. Sugarcane - High Growth Case Supply Curve Data........................................ 201

CBI Table 3. Sugarcane - Low Growth Case Supply Curve Data ....................................... 201

CBI Table 4. Palm Oil - Baseline Case Supply Curve Data ............................................ 202

CBI Table 5. Palm Oil - High Growth Case Supply Curve Data ......................................... 202

CBI Table 6. Palm Oil - Low Growth Case Supply Curve Data........................................... 202

CBI Table 7. Potential Percentage Allocation for Export \& Biofuels ................................... 203

CBI Table 8. Estimated Cellulosic Supply from Recoverable Bagasse and Palm Residues (mmt, bone-dry, annual) ............................................................................ 203

CBI Table 9. Estimated Cellulosic Supply Summary Including Other Residues

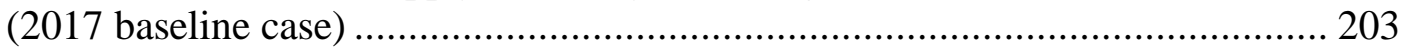

Annex 4 Sugarcane: Aggregate Supply Projections by Country ...................................... 204

Annex 4 Soybean: Aggregate Supply Projections by Country …..................................... 205

Annex 4 Soybean: Example of Supply Curve Functions by Country ................................. 206

Annex 4 Corn: Aggregate Supply Projections by Country ............................................... 207

Annex 4 Wheat: Aggregate Supply Projections by Country ............................................ 208

Annex 4 Palm Oil: Aggregate Supply Projections by Country ......................................... 208

Annex 4 Cellulosic Crop Residues: Aggregate Supply Projections by Country ..................... 209

Annex 4 Cellulosic Summary: Total Cellulosic Feedstock including Other Residues .............. 210 


\section{ACKNOWLEDGMENTS}

The work reported in this publication was made possible thanks to contributions from many people. Special thanks go to: Mike Curtis, Bhima Sastri, Tina Kaarsberg, Audrey Lee and Daniel McNeil in the DOE Office of Policy and International Programs for their proactive support, review and comments on drafts, and overall guidance. Similarly, thanks to Zia Haq, Paul Grabowski, John Ferrell and Jacques Beaudry-Losique in the DOE Office of the Biomass Program for their support and funding of the work. The authors also acknowledge ORNL coworkers Paul Leiby, Mark Downing, Latha Baskaran, Jonathan Mielenz and Lynn Wright for support with reviews and accessing relevant information from prior research, along with Stephanie Floyd for essential secretarial and administrative support throughout the process. Bob Perlack provided the vision and ongoing guidance necessary to keep the work on track and Debo Oladosu developed the methodology and led the analytical process to generate supply curves. Matthew McMahon conducted research and analysis of data for the Caribbean Basin Initiative nations as a summer intern from Appalachian State University. The work also benefited from consultations and input from colleagues Rich Bain at the National Renewable Energy Laboratory and Thomas Alfstad of Brookhaven National Laboratory, who formed part of a broader study team. Thank you all.

This publication presents the results from research jointly sponsored by the U.S. Department of Energy's Office of Policy and International Affairs (PI) and Office of the Biomass Program within the Office of Energy Efficiency and Renewable Energy. DOE oversight and guidance were provided by Mike Curtis and Bhima Sastri in DOE/PI and Zia Haq in DOE/EERE/Biomass Program. UT Battelle, LLC manages the Oak Ridge National Laboratory for the U.S. Department of Energy under contract DE-AC05$00 \mathrm{OR} 22725$. 


\section{EXECUTIVE SUMMARY}

The primary purpose of this study was to replace point estimates of potential future biomass feedstock supplies with more analytically useful 'supply curves' for selected countries and feedstocks. Such supply curves permit more detailed analysis of feedstock variables when modeling future global biofuel markets. The study scope was focused to meet time and resource requirements. A screening process identified Argentina, Brazil, Canada, China, Colombia, India, Mexico, and the Caribbean Basin Initiative (CBI) region as likely to be important players in future feedstock supply based on a number of criteria including proximity to the United States, current feedstock production and participation in global markets. ${ }^{i}$ Future feedstocks are divided into two groups: traditional crops that can be converted to biofuel and cellulosic materials such as crop and forest residues. Crop feedstocks selected for study were sugarcane, corn, wheat, soybeans, and palm oil. The total production of these crops in the countries studied as a percentage of global non-U.S. production in 2006 is presented in Table ES-1. Selected countries represent the majority of non-U.S. supplies of sugarcane, soybeans and corn, $27 \%$ of wheat, and just a small fraction $(3 \%)$ of global palm oil production. ${ }^{\text {ii }}$

Table ES-1. Share of World (non-US) Production of Crop Feedstocks Represented by Countries Assessed*

\begin{tabular}{|l|l|c|c|}
\hline Feedstock & Countries Assessed in Present Study & $\begin{array}{c}\text { 2006 Output } \\
(\mathbf{m m t})\end{array}$ & Share* $^{*}$ \\
\hline Sugarcane & Argentina, Brazil, China, Colombia, India, Mexico, CBI & 999 & $73 \%$ \\
\hline Soybeans & Argentina, Brazil, China & 108 & $81 \%$ \\
\hline Corn & Argentina, Brazil, China, Canada, Mexico & 234 & $55 \%$ \\
\hline Wheat & Argentina, Canada, China & 146 & $27 \%$ \\
\hline Palm Oil & Colombia, CBI & 1.3 & $3 \%$ \\
\hline
\end{tabular}

*Share is calculated as the percent of total world production, excluding the U.S.A., represented by countries studied based on total production data reported by FAO for 2006 in "ProdSTAT:" http://faostat.fao.org/site/339/default.aspx

This report presents the findings of the biofuel feedstock production assessments and projections of future supply. ${ }^{\text {iii }}$ The resulting supply curve functions for each selected crop in the seven countries and CBI, along with calculations to reflect estimated supplies available for export and/or biofuel production, were provided to DOE for use in an energy market allocation model as part of a broader study. ${ }^{\text {iv }}$ Potential cellulosic supplies from crop and forestry residues and perennials were also estimated for 2017 and 2027.

\section{Methodology}

Historic production trends and the structure of average production costs were analyzed by state (or province) to develop supply curves for each selected crop-country combination. ${ }^{\mathrm{v}}$ Future supply was projected for 2012, 2017 and 2027 based on compound growth rates in yields and area harvested by state over the past seven years. ${ }^{\mathrm{vi}}$ The methodology assumes that recent growth trends for yield and harvested area at a state level will continue into the future within a set of defined parameters (see Annex 3 for details). This approach permitted the construction of supply curves where each vertical increment (or 'step' up the curve) represents the next highest average state production cost and the horizontal length of the step reflects the additional supply projection for that state. Thus, any given point on the curve will represent a cumulative supply for all states producing at or below a corresponding average cost. Figure ES-1 illustrates a sugarcane supply curve calculated for Brazil's baseline case in 2017. 


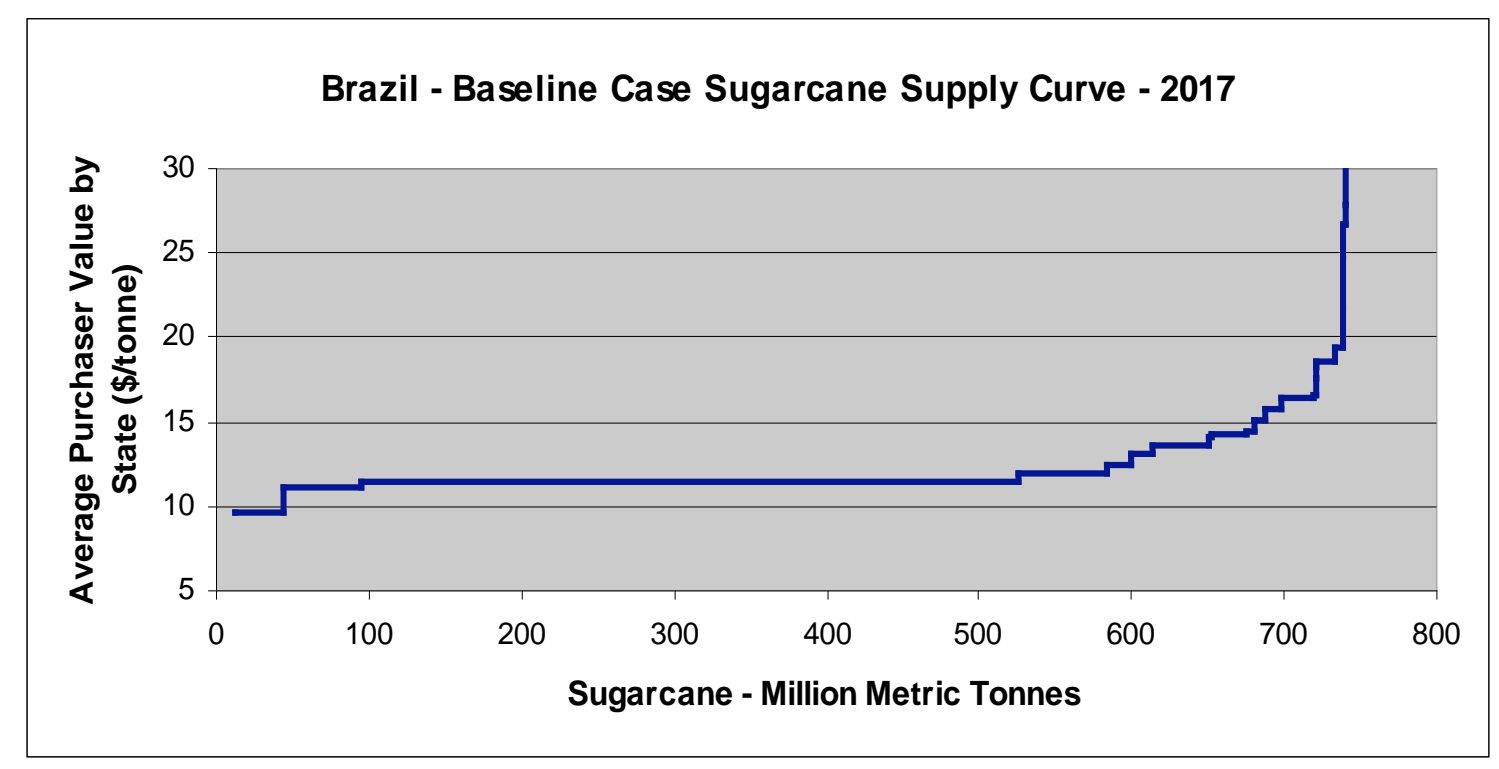

Figure ES-1. Example of Sugarcane Supply Curve for Brazil - Baseline Case in 2017.

Changes in crop varieties, farming practices, weather, prices, government policies and other variables can impact the area planted, yields and total production in a given year. Although these factors are not explicitly factored into the analysis, they are implicitly reflected by the historic trends forming the basis for future projections. Past variability is also factored into the projection of baseline, low and high growth cases for each crop-country combination. The cases are developed based on an analysis of national variability in yield, area planted and production observed over historic time periods similar to those of the projections. ${ }^{\text {vii }}$ Over 200 different supply projections were calculated for potential feedstocks in this study. ${ }^{\text {viii }}$

To estimate the amount of feedstock available for export and or biofuel production, the total potential production in the baseline case was reduced based on the percentage of production used to meet domestic food, feed and fiber demands in the most recent year with reported data (usually 2006). Annex 3 provides a complete description of the methodology and assumptions used in the study.

\section{Findings}

The total projected supply of each feedstock in millions of metric tonnes (mmt) is presented in Table ES2 along with the corresponding percentage estimated to be available for export and/or biofuel production (\% available). Supplies of all potential feedstock crops are expected to grow in the countries studied.

Future growth in production is based on increasing yields and expanding areas under cultivation. Growth rates and the portion required to meet domestic demands for food, feed and fiber, fluctuate greatly.

Figure ES-2 illustrates the share of total supply available for export or biofuel production for each feedstock studied and each case in 2017 in terms of raw tonnage ( $\mathrm{mmt}$ ). Sugarcane and soybeans dominate potential supply among crops studied, while bagasse (crushed stalk residues from sugar cane processing) and forest products are the principle sources among potential cellulosic supplies. Since the rate of conversion to fuel (gallons/tonne) varies widely among feedstock types, it is preferable to make any aggregate comparisons in terms of a common energy equivalent. 
Table ES-2. Summary of Aggregate Feedstock Projections for Countries Studied (Total projected supply in mmt and percent available for export and/or biofuel)

\begin{tabular}{|c|c|c|c|c|c|c|}
\hline \multirow[b]{2}{*}{ Feedstock/Year } & \multicolumn{2}{|c|}{ Baseline } & \multicolumn{2}{|c|}{ Low } & \multicolumn{2}{|c|}{ High } \\
\hline & $\begin{array}{c}\text { Total supply } \\
\text { mmt }\end{array}$ & $\begin{array}{c}\% \\
\text { available }\end{array}$ & $\begin{array}{c}\text { Total supply } \\
\text { mmt }\end{array}$ & $\begin{array}{c}\% \\
\text { available }\end{array}$ & $\begin{array}{c}\text { Total supply } \\
\text { mmt }\end{array}$ & $\begin{array}{c}\% \\
\text { available }\end{array}$ \\
\hline \multicolumn{7}{|c|}{ Feedstock Crop Supply } \\
\hline \multicolumn{7}{|l|}{ Sugarcane } \\
\hline 2012 & 1,225 & $47 \%$ & 1,003 & $42 \%$ & 1,508 & $57 \%$ \\
\hline 2017 & 1,457 & $48 \%$ & 1,066 & $40 \%$ & 2,030 & $63 \%$ \\
\hline 2027 & 1,932 & $51 \%$ & 1,174 & $38 \%$ & 3,353 & $72 \%$ \\
\hline \multicolumn{7}{|l|}{ Corn } \\
\hline 2012 & 280 & $7 \%$ & 241 & $2 \%$ & 328 & $20 \%$ \\
\hline 2017 & 325 & $7 \%$ & 257 & $2 \%$ & 428 & $29 \%$ \\
\hline 2027 & 427 & $7 \%$ & 290 & $1 \%$ & 692 & $42 \%$ \\
\hline \multicolumn{7}{|l|}{ Soybeans } \\
\hline 2012 & 155 & $65 \%$ & 130 & $62 \%$ & 188 & $71 \%$ \\
\hline 2017 & 202 & $66 \%$ & 147 & $58 \%$ & 288 & $76 \%$ \\
\hline 2027 & 314 & $67 \%$ & 178 & $49 \%$ & 652 & $84 \%$ \\
\hline \multicolumn{7}{|l|}{ Wheat } \\
\hline 2012 & 153 & $18 \%$ & 136 & $17 \%$ & 183 & $32 \%$ \\
\hline 2017 & 160 & $19 \%$ & 136 & $16 \%$ & 208 & $38 \%$ \\
\hline 2027 & 176 & $19 \%$ & 137 & $15 \%$ & 268 & $47 \%$ \\
\hline \multicolumn{7}{|l|}{ Palm Oil } \\
\hline 2012 & 2 & $41 \%$ & 2 & $18 \%$ & 3 & $53 \%$ \\
\hline 2017 & 3 & $41 \%$ & 2 & $9 \%$ & 5 & $59 \%$ \\
\hline 2027 & 7 & $40 \%$ & 2 & $0 \%$ & 12 & $66 \%$ \\
\hline \multicolumn{7}{|l|}{ Total Crops } \\
\hline 2017 & 2,144 & & 1,606 & & 2,955 & \\
\hline 2027 & 2,850 & & 1,778 & & 4,965 & \\
\hline \multicolumn{7}{|l|}{ Cellulosic Supply } \\
\hline \multicolumn{7}{|l|}{ Crop Residues $^{a}$} \\
\hline 2017 & 246 & & 182 & & 344 & \\
\hline 2027 & 326 & & 201 & & 569 & \\
\hline \multicolumn{7}{|l|}{ Other Residues $^{\mathrm{b}}$} \\
\hline 2017 & 242 & & 242 & & 242 & \\
\hline 2027 & 294 & & 294 & & 294 & \\
\hline \multicolumn{7}{|l|}{ Total Cellulosic } \\
\hline 2017 & 488 & & 424 & & 586 & \\
\hline 2027 & 621 & & 495 & & 863 & \\
\hline
\end{tabular}

a/ Recoverable crop residues are derived from the crop feedstock production projected in each case and country for crops listed above. Crop residues include a percentage of bagasse (the most prominent crop residue available), corn stover, wheat straw and palm oil processing wastes. See Methodology in Annex 3.

b/ Other residues include estimates based on forestry residues, fuelwood supplies and perennial harvests. 


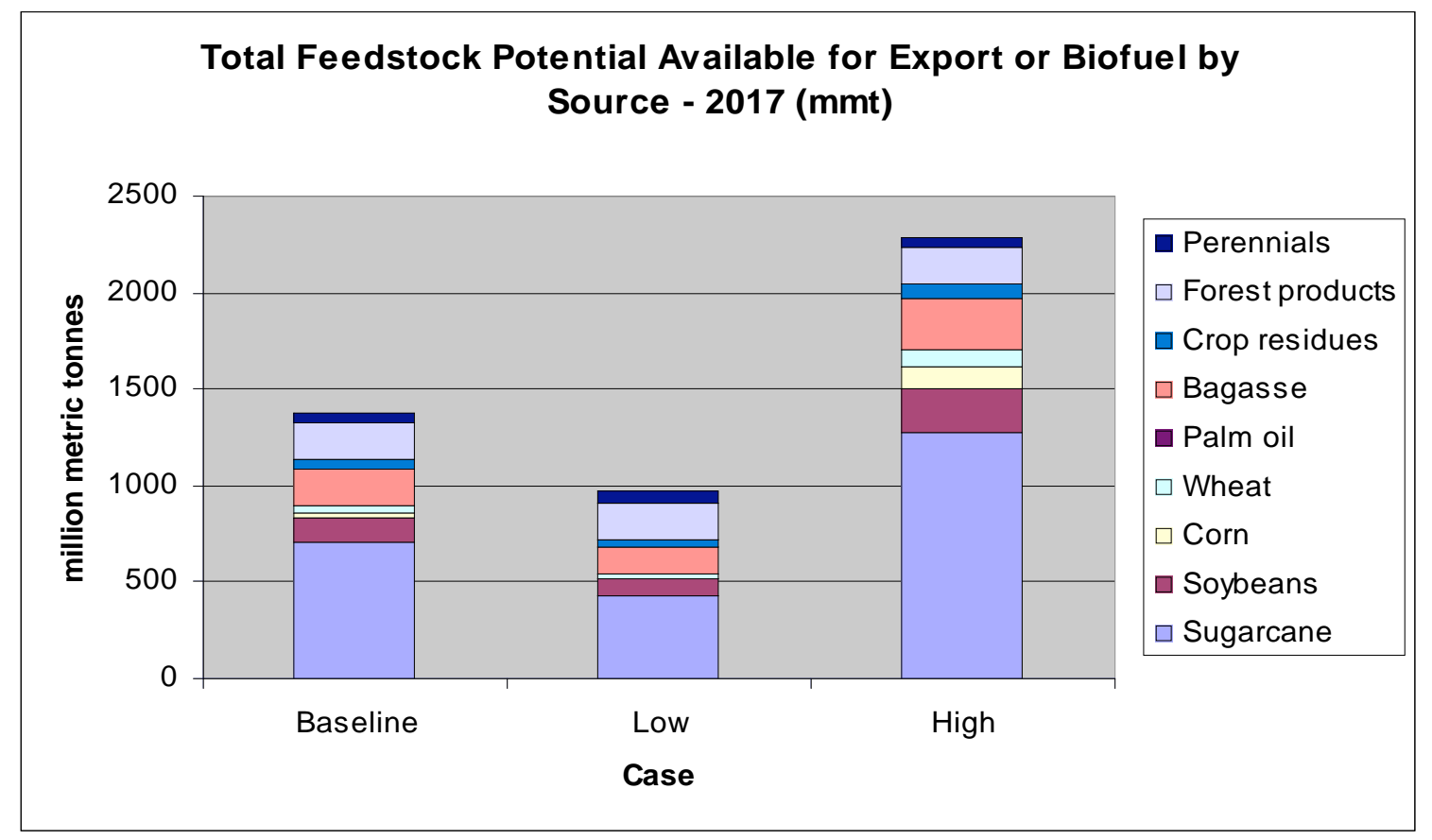

Figure ES-2. Total Feedstock Available for Export or Biofuel by Source in 2017 (based on raw tonnage in millions of metric tonnes).

The feedstock supplies in Figure ES-2 above are represented in ES-3 on a "gasoline equivalent basis.",ix Sugarcane and bagasse combined dominate among potential sources of supply studied, representing $45 \%$ of the total in the 2017 baseline case.

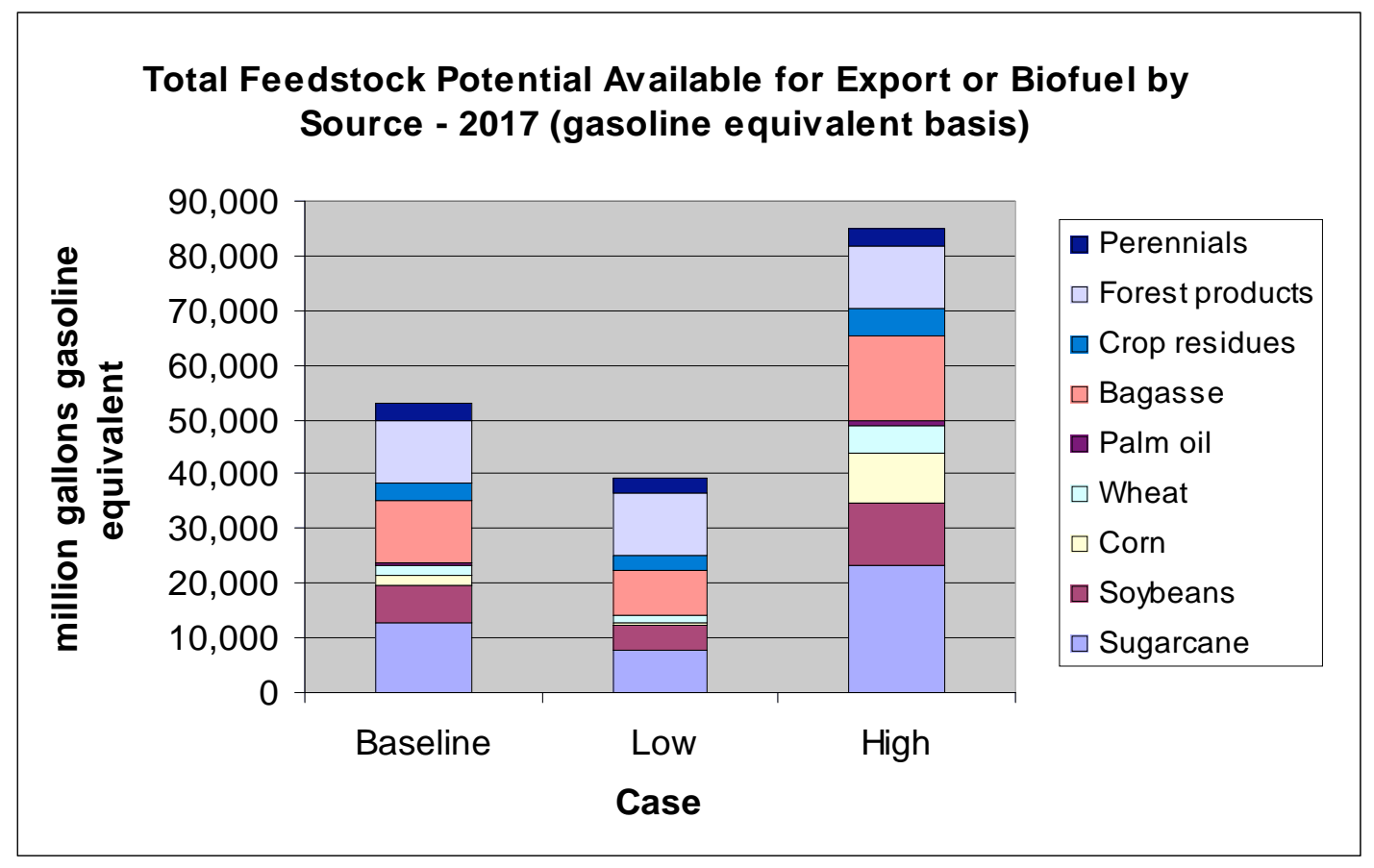

Figure ES-3. Total Feedstock Available for Export or Biofuel by Source in 2017 (based on gasoline equivalent in millions of gallons). 
The projected cellulosic supplies from crop and forestry residues and perennials represent $55 \%$ of the total projected 'available' supply in the 2017 baseline case on a gasoline equivalent basis (Fig. ES-3). ${ }^{\mathrm{x}}$ Projections surrounding cellulosic supplies, costs, and conversion to ethanol, are less certain than for the other crops with established supply chains supporting existing biofuel plants. Figure ES-4 illustrates the 2017 projection data for only crop feedstocks 'available' by country of origin (this figure excludes the cellulosic supplies). The strategic importance of sugarcane and soybeans is evident, as they represent $83 \%$ of the total in the baseline case, and virtually all available supplies in the low growth case. The relative shares among feedstocks are similar under the supply projections for other years (2012 and 2027).

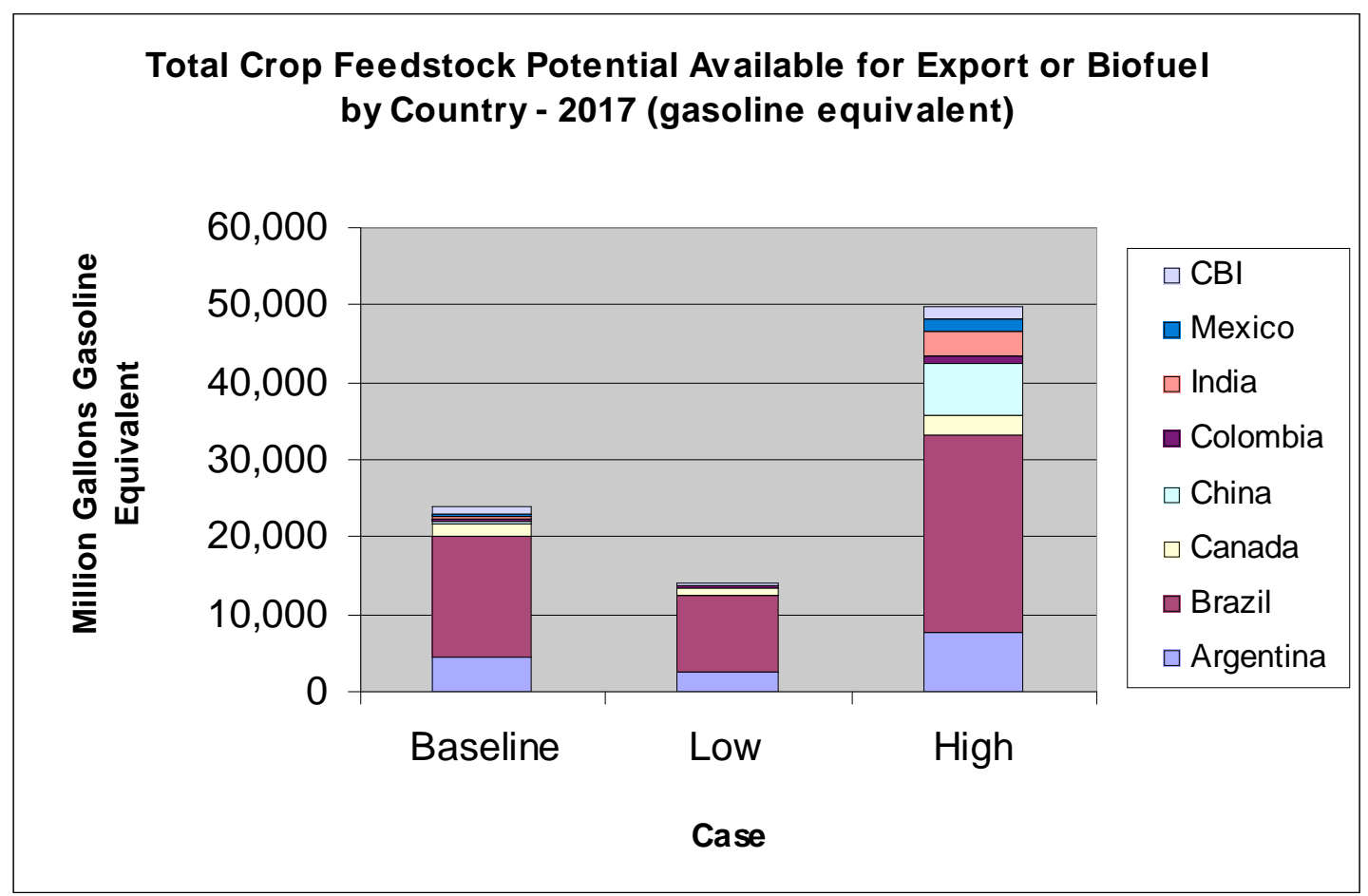

Figure ES-4. Total Crop Feedstock Available for Export or Biofuel by Country in 2017 (gasoline equivalent basis).

While the capacity to increase yields through improved crop varieties, technology, and production practices is applicable to all feedstock crops and countries, capacity for expansion of area under cultivation varies greatly among the feedstocks and nations studied. Growth in cultivated area for biofuel can occur by displacing other crops or using new land. A few nations such as Brazil are exceptionally favored with ample arable land available for crop expansion (mostly underutilized pasture). ${ }^{\mathrm{xi}}$ Among the countries studied, Brazil has the greatest potential for increasing supply for any of the feedstock crops. Argentina and Colombia also have relatively large amounts of underutilized arable land, along with capital and agricultural production technology which could enable them to quickly respond to policies and market signals for production.

Aggregate results for each potential feedstock studied are presented below followed by highlights of cross-cutting issues and recommendations. Further analysis of results in the global context is provided in Chapter 2 while details for each country and crop assessed are provided in Chapter 3 and Annexes. 
Sugarcane supplies are projected to grow by $50-100 \%$ over the coming decade (Fig. ES-5). As reflected in Table ES-2 and the Figures above, of the crops studied, sugarcane offers the greatest potential as a biofuel feedstock and represents over half of potential future supplies available for export to global markets and/or conversion to ethanol (on a gasoline equivalent basis) over the next two decades. ${ }^{\text {xii }}$ The countries studied represent about three quarters of the world's sugarcane production (Table ES-1) and nearly all cane-derived fuel ethanol in global markets.

The present analysis estimates that sugarcane output in these countries could grow from 999 million metric tonnes (mmt) in 2006 to about $1460 \mathrm{mmt}$ in 2017 and nearly $2000 \mathrm{mmt}$ by 2027 in the baseline case (Fig. ES-5). If conditions are more favorable, the high growth case estimates that supplies could more than double by 2017, exceeding $2000 \mathrm{mmt}$ ten years earlier than in the baseline case. Growth in sugarcane production is led by Brazil where, compared to 2006 production, supply projections increase $75 \%$ by 2017 in the baseline case and over $130 \%$ in the high growth case. While Colombia and some CBI nations are expected to have similarly high growth rates in percentage terms, total available supplies are small relative to Brazil. And a majority of Brazil's production is concentrated in the center-south region, in and around the state of Sao Paulo.

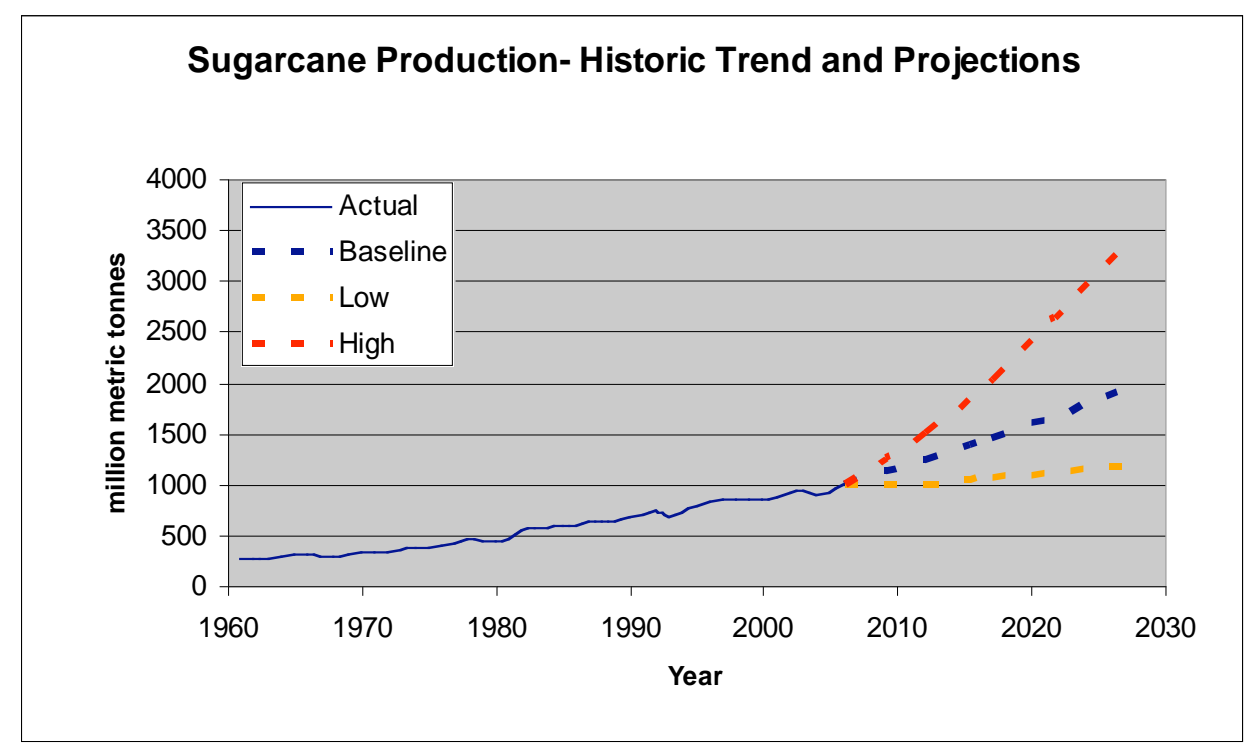

\section{Figure ES-5. Historic and Projected Sugarcane Production - Total Aggregate Supply from Countries Studied.}

Figure ES-6 shows the share of each country studied in sugarcane output that is estimated to be available for export or biofuel production in 2017. ${ }^{\text {xii }}$ In the baseline case, for example, Brazil represents $86 \%$ of a total projected 'available' supply of $706 \mathrm{mmt}$, while CBI represents 6\%, India 3\% and all other nations studied $2 \%$ or less. ${ }^{\text {xiv }}$ In low growth cases, only Brazil and CBI are projected to have significant supply available for export or biofuel, whereas in high growth cases, all countries could contribute to biofuel supplies in global markets. 


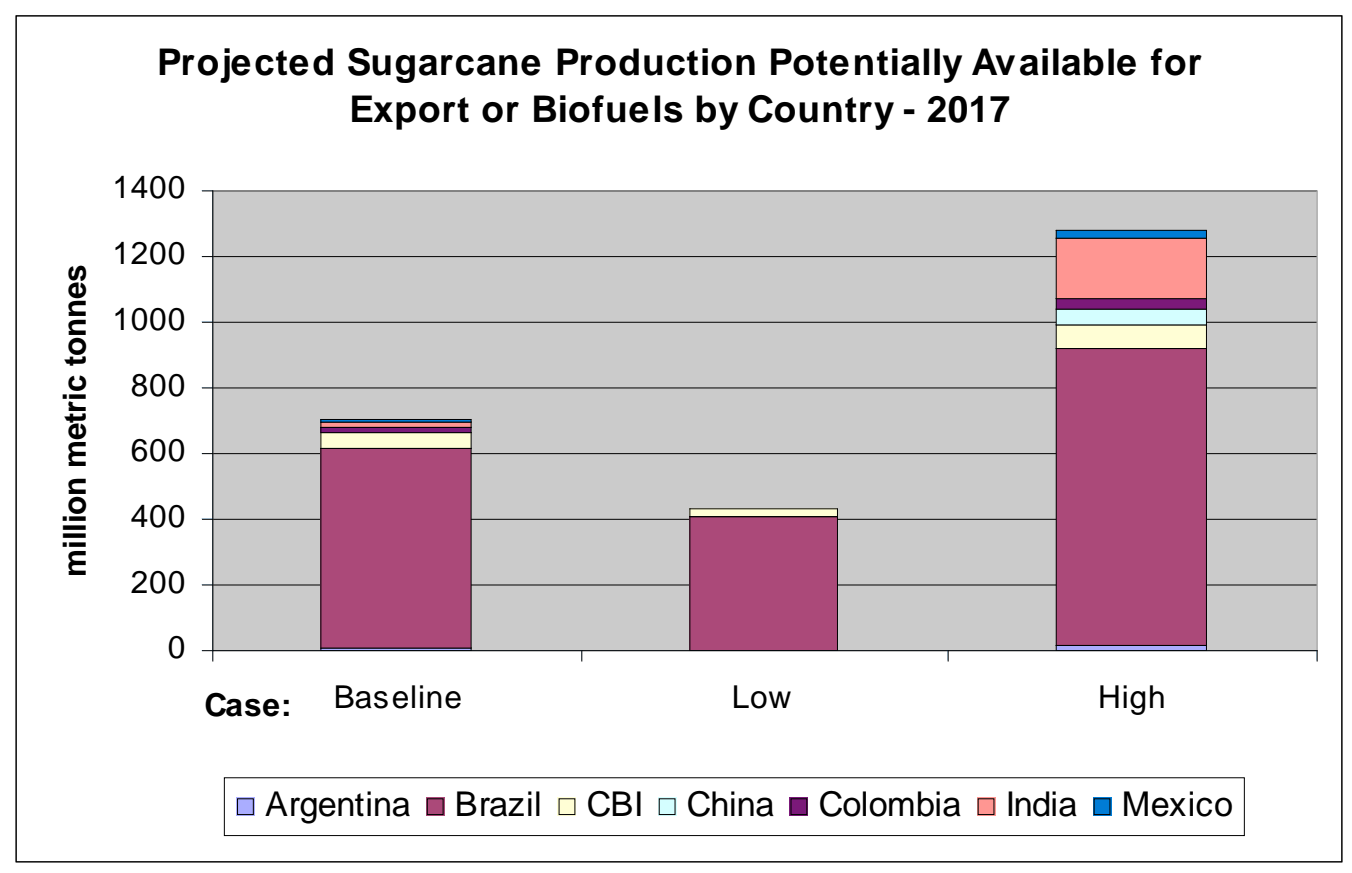

Figure ES-6. Share by Country of Projected Sugarcane Supply Available for
Export or Biofuel in 2017 - by Growth Case (Baseline, Low and High).

Efficient and competitive sugarcane production is restricted by climate and soils to limited geographic areas, which is why Canada and the U.S. are not major producers. This also explains why some countries with ample land resources, such as Argentina, are more limited than others in terms of potential to expand in areas that meets requirements for sugarcane. Brazil is unique among the countries studied because the amount of available, previously-cleared and underutilized land that is suited for rain-fed sugarcane production is estimated to be several times greater than the present land area dedicated to sugarcane. ${ }^{\mathrm{xv}}$

$\underline{\text { Soybeans }}$ were studied as a potential feedstock for biodiesel production and represent the second most abundant potential crop feedstock available in the countries studied. ${ }^{\text {xvi }}$ As shown in Table ES-1 and Figure ES-7, the countries studied represent over $80 \%$ of global soybean production outside the U.S.

The present analysis estimates that aggregate soybean production in the countries studied will increase rapidly from 2006 levels of about $108 \mathrm{mmt}$ to over $200 \mathrm{mmt}$ in the coming decade (See Fig. ES-8). Baseline case supply in 2017 represents an 87\% increase over 2006 production. Total supplies range from $147 \mathrm{mmt}$ in the low growth case to $288 \mathrm{mmt}$ in the high growth case for 2017. Most of the increase is from Brazil and Argentina, the world's two top exporters of soybeans and soy products respectively. Given relatively limited domestic demands, most of the increasing production in these countries will be available for export markets and/or biofuel production. ${ }^{\text {xvii }}$

Brazil and Argentina are taking distinct approaches to expanding bio-diesel production capacities. Brazil is looking into native palm and shrub species that could facilitate participation of small farmers in the supply chain to meet local biodiesel blending targets. Brazil also created incentives for biodiesel production in some remote agricultural areas where availability of fossil fuels is limited and costly. Production in those areas is initially based primarily on soybean oil. Argentina plans to use its substantial infrastructure and capacity for soy oil production to diversify market options by producing biodiesel for both export and to meet recently enacted targets for biodiesel blending. 


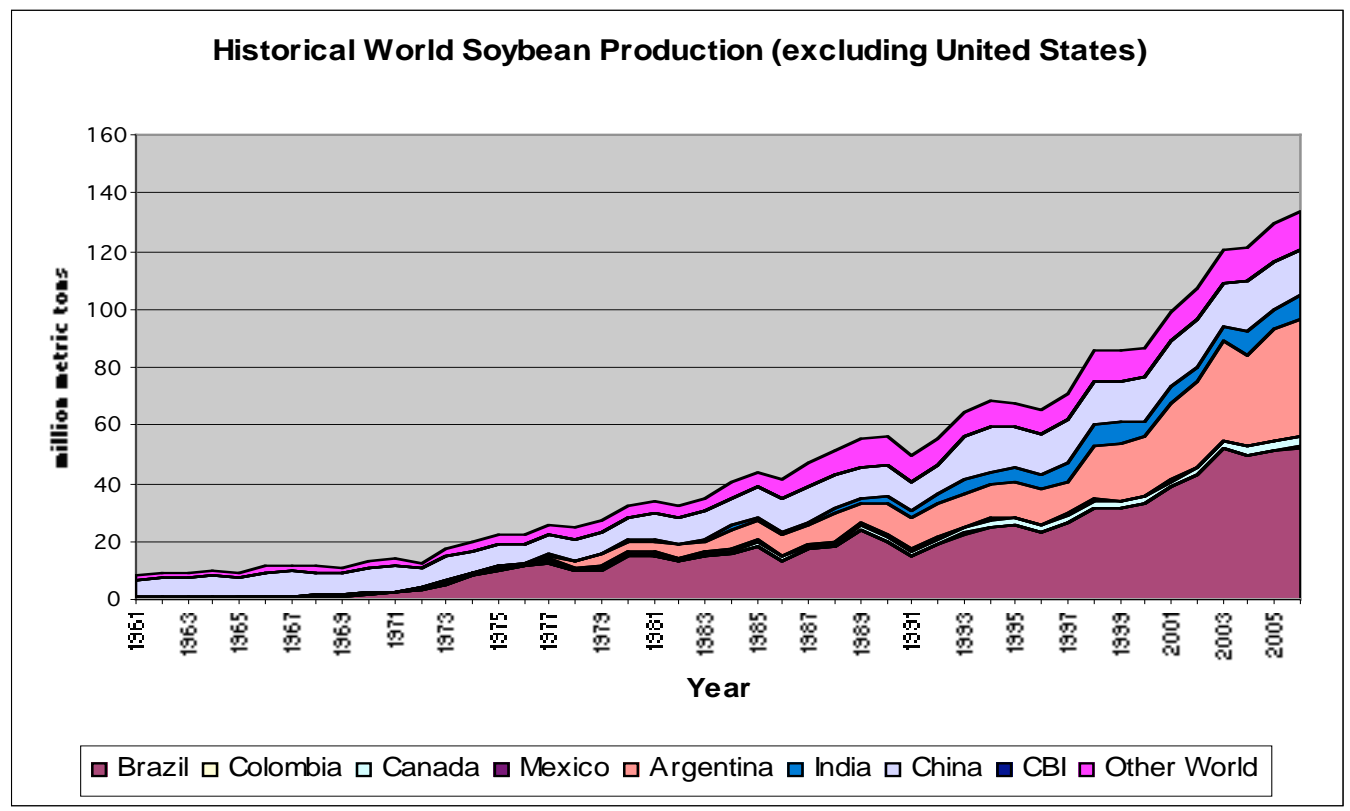

Figure ES-7. Share of Soybean Production Represented by Countries Studied.

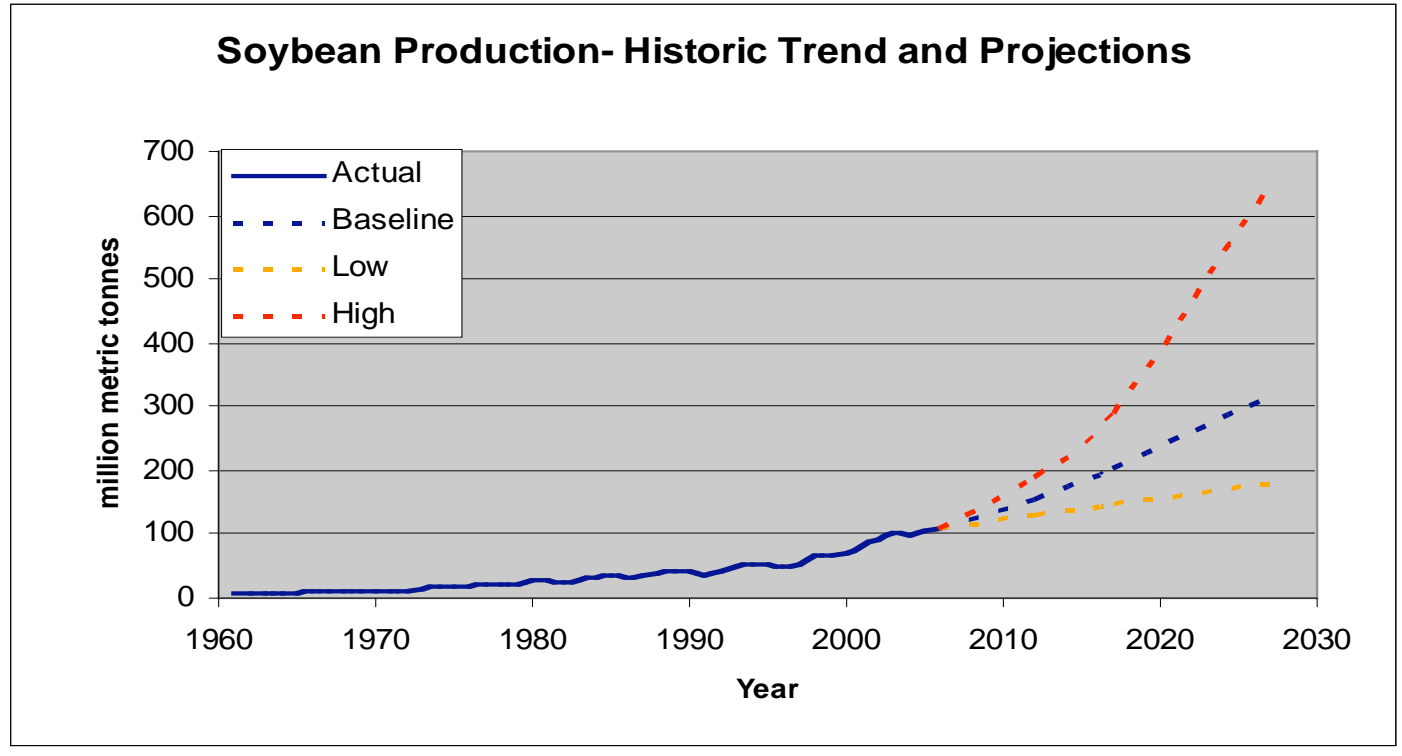

Figure ES-8. Aggregate Historic and Projected Soybean Production in Countries Studied.

Corn output is also projected to grow steadily in the countries studied (Argentina, Brazil, Canada, China, Mexico) which represent about 55\% of global corn production outside the U.S. (See Table ES-1). The projected increase in the baseline case, 39\% from 2006 to 2017, is less than that for sugarcane and soybeans. Furthermore, as noted in Table ES-2, after domestic demand for food and feed is accounted for, only a small amount of projected corn production remains for export or biofuel production; about $7 \%$ in the baseline case and 1-2\% in the low growth case. Figure ES-9 compares the aggregate supply projections for corn in the baseline, low and high cases with the historic supply from these five countries. 


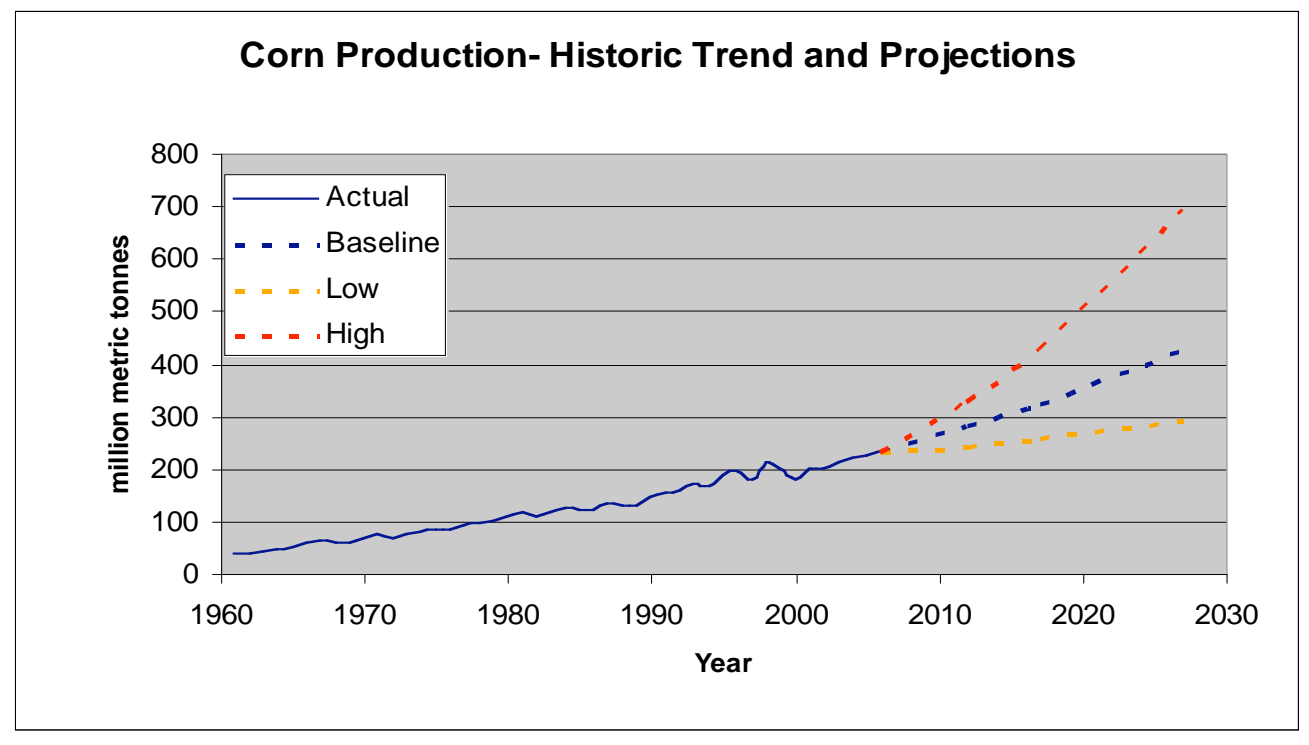

Figure ES-9. Aggregate Historic and Projected Corn Production in Countries Studied.

Baseline projections indicate that the five countries could increase supply from $234 \mathrm{mmt}$ in 2006 to about $325 \mathrm{mmt}$ in 2017, and $427 \mathrm{mmt}$ in 2027 (Fig.ES-9). Canada plans to continue using corn as its primary ethanol feedstock in coming years. Argentina is also looking at potential ethanol production from corn both to help it meet recent domestic fuel-blending targets and as a potential export commodity. China has used corn as feedstock for biofuel production in the past, but recent policies will focus future production on alternatives that do not compete directly with food production. The cost of producing ethanol from corn is high relative to Brazilian sugarcane, partly due to increasing commodity prices. Given national policies, higher prices, and increasing global demand for corn as a food/feed staple, its future use as a biofuel feedstock outside of North America may be limited.

Wheat output in the countries studied (Argentina, China and Canada) is projected to grow more slowly than other crops assessed. Figure ES-10 compares the aggregate supply projections for wheat in the baseline, low and high cases with the historic supply from these three countries (representing about 27\% of global, non-U.S. wheat production per Table ES-1). Applying the study methodology to recent trends in wheat output, future supplies are estimated to grow by about $10 \%$ from 2006 to 2017 in the baseline case (Fig. ES-10). This growth rate is significantly lower than that of other crops studied and reflects recent years with declining or stagnant production in the nations studied. The lower historic growth is attributed to several factors including poor weather, low relative prices and government policies. However, if global demand and incentives improve, the high growth case reflects potential for supply to increase $43 \%$ above 2006 levels of $146 \mathrm{mmt}$, to $208 \mathrm{mmt}$ by 2017.

Wheat is primarily grown as a food staple and it has seen limited use as a biofuel feedstock to date. An exception is in the western provinces of Canada where the use of wheat as feedstock in ethanol plants is established and growing. As a result, the present study estimates that $2.5 \mathrm{mmt}$ of Canadian wheat could be dedicated to ethanol as early as 2012, representing about $9 \%$ of projected national supply that year in the baseline case (See Canada in Chapter 3). One advantage of these plants for producers is their use of lower quality ("downgraded") varieties of feed wheat that otherwise would be difficult to market. 


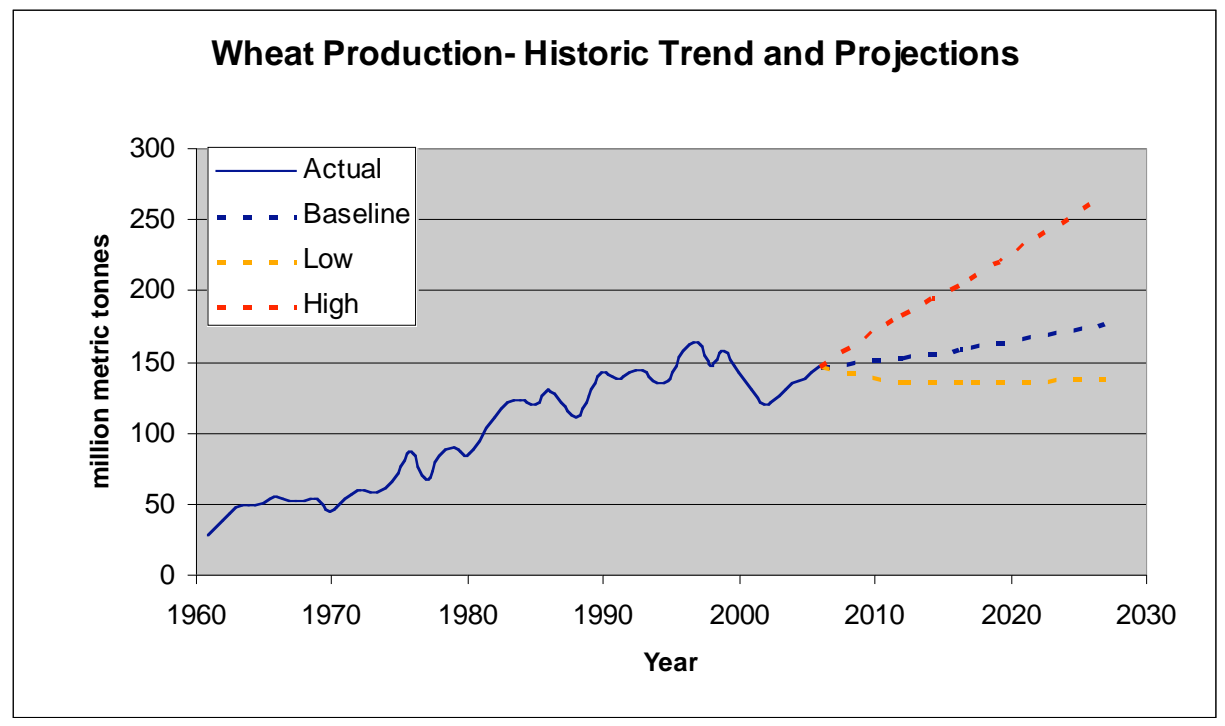

Figure ES-10. Aggregate Historic and Projected Wheat Production in Countries Studied.

The majority ( $72 \%$ in 2006) of the aggregate wheat supply illustrated in Figure ES-10 comes from China where, although some wheat has been used as a biofuel feedstock in the past, present policies dictate that future wheat production be allocated to domestic food markets.

Palm oil is a rapidly growing feedstock used for biodiesel production. The majority of world supply originates in Southeast Asia. While the total supply in the countries studied (Colombia and CBI region) is small relative to other feedstock crops and only represents about $3 \%$ of global production, palm oil projections show the highest rates of growth in percentage terms of any feedstock studied. Palm oil supplies in Colombia and CBI are estimated to increase over $150 \%$ by 2017 when compared to 2006 in the baseline case, and as much as $250 \%$ in the high growth case (Fig. ES-11). ${ }^{\text {xiii }}$

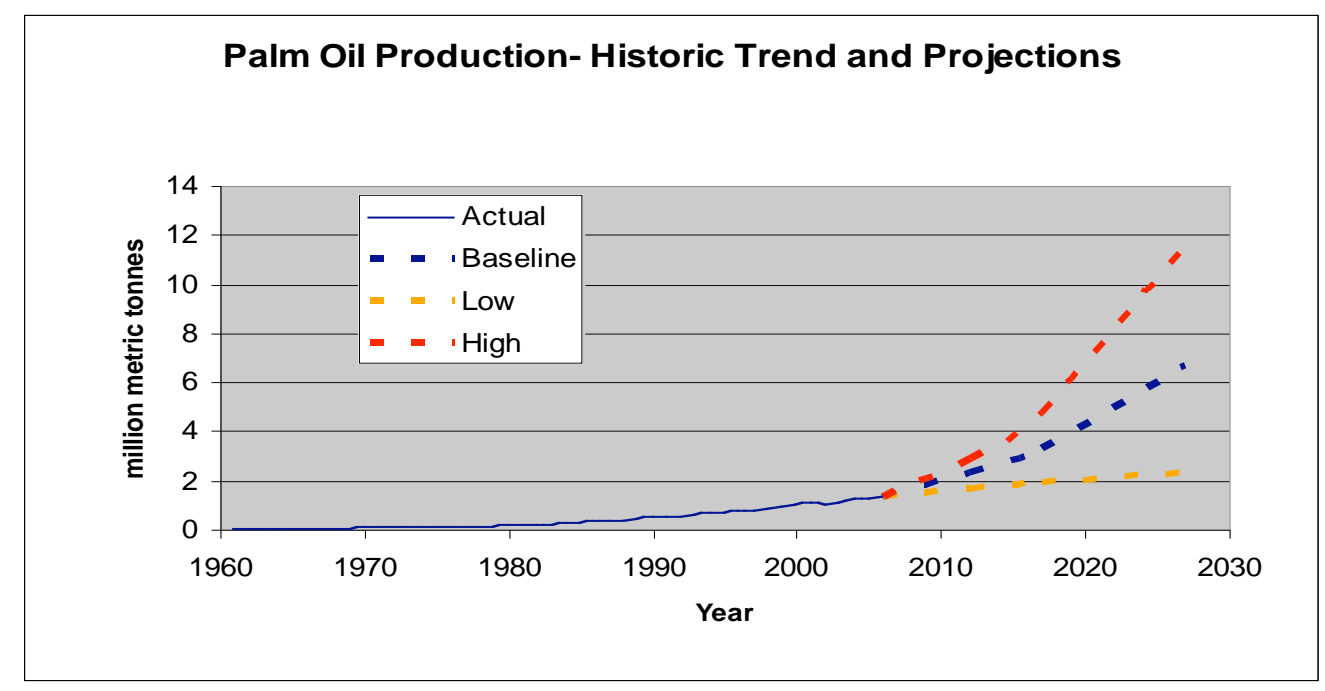

Figure ES-11. Historic and Projected Palm Oil Production (CBI and Colombia). 
Cellulosic supply projections are derived from three broad categories. Resources potentially available for biofuel production in the 2017-2027 time-frame were estimated based on: (1) recoverable residues as a function of the projected feedstock crop supplies in 2017 and 2027 (based on the results for each crop and case in this study); (2) a percentage of wastes and biomass associated with current forestry activities and fuelwood supplies; and (3) the potential to harvest perennial biomass crops as a function of estimated productivity and arable land availability. Using available data, the projections for the latter two categories are preliminary estimates of the relative importance of potential supplies from these cellulosic sources among the countries studied.

Total cellulosic supply projections for low, baseline and high cases were calculated for crop residues and presented in Table ES-2 for 2017 and 2027. A breakdown of estimated cellulosic supply by country is presented in Table ES-3 for the 2017 baseline case. In the countries studied, estimated cellulosic feedstock availability within the range of costs assumed in the study (generally under $\$ 100 /$ dry tonne) sum to $488 \mathrm{mmt}$, with just over half of this total derived from crop processing residues (Table ES-3). ${ }^{\text {xix }}$

\section{Table ES-3. Summary: Total Cellulosic Feedstock Supply in 2017 (Baseline Case) (millions of metric tonnes, mmt)}

\begin{tabular}{|c|c|c|c|c|c|}
\hline $\begin{array}{l}\text { Country } \\
\text { Studied }\end{array}$ & $\begin{array}{l}\text { Agriculture } \\
\text { Residues }^{\mathrm{a}}\end{array}$ & $\begin{array}{l}\text { Forestry } \\
\text { Residues }^{b}\end{array}$ & $\begin{array}{l}\text { Fuel - } \\
\text { wood }^{\text {b }}\end{array}$ & $\begin{array}{c}\text { Peren- } \\
\text { nials }\end{array}$ & Total \\
\hline Argentina & 14 & 0.5 & 1 & 5 & 21 \\
\hline Brazil & 112 & 7.8 & 31 & 37 & 187 \\
\hline Canada & 11 & 6.0 & 1 & 3 & 20 \\
\hline China & 33 & 8.7 & 29 & 1 & 72 \\
\hline Colombia & 6 & 0.3 & 2 & 5 & 13 \\
\hline India & 50 & 10.0 & 75 & 0 & 135 \\
\hline Mexico & 10 & 1.4 & 7 & 1 & 19 \\
\hline CBI & 10 & 1.5 & 7 & 1 & 20 \\
\hline Total & 246 & 36 & 154 & 52 & 488 \\
\hline
\end{tabular}

Bagasse is by far the most important single cellulosic resource identified in the study, representing about $75 \%$ of all agricultural crop residues in 2017 and about $40 \%$ of total cellulosic supplies estimated in that year. More importantly, bagasse is conveniently available at sugar-ethanol refineries and, therefore, along with much smaller supplies of palm oil processing wastes and on-site wood mill residues, is estimated to be the most economic cellulosic resource, with opportunity costs in the range of $\$ 8$ to $\$ 17$ per dry tonne (in 2005 US\$). When costs are considered, bagasse represents $78 \%$ of all cellulosic supply (241 mmt) with an estimated value equal or below US\$36/dry tonne (2017 baseline case; see Table ES-4).

The price range for bagasse reflects the estimated opportunity cost given current use as a fuel (direct combustion) and fiber. Although most bagasse is currently burned as boiler fuel for sugar processing, improving efficiencies over the coming decade will allow an increasing portion of bagasse to be allocated to other uses, including biofuel, and will contribute to improving sugar-ethanol plant economics. 
Table ES-4. Cellulosic Supplies Valued $\leq \$ 36$ per dry tonne - 2017 Baseline Case (millions of metric tonnes, mmt)

\begin{tabular}{|l|c|c|c|c|c|}
\hline $\begin{array}{l}\text { Country } \\
\text { Studied }\end{array}$ & Bagasse & $\begin{array}{c}\text { Palm Oil } \\
\text { Wastes }\end{array}$ & Fuelwood & $\begin{array}{c}\text { Mill Wood } \\
\text { Residues }\end{array}$ & Total \\
\hline Argentina & 4 & - & 1 & 0 & 5 \\
Brazil & 104 & - & 31 & 2 & 138 \\
Canada & - & - & - & 2 & 2 \\
China & 9 & - & - & 3 & 12 \\
Colombia & 5 & 1 & - & 0 & 6 \\
India & 50 & - & - & 3 & 53 \\
Mexico & 6 & - & - & 0 & 6 \\
CBI & 10 & 1 & 7 & 0 & 18 \\
\hline Total & $\mathbf{1 8 7}$ & $\mathbf{2}$ & $\mathbf{4 0}$ & $\mathbf{1 1}$ & $\mathbf{2 4 1}$ \\
\hline \% of total & $\mathbf{7 8 \%}$ & $\mathbf{1 \%}$ & $\mathbf{1 7 \%}$ & $\mathbf{5 \%}$ & $\mathbf{1 0 0 \%}$ \\
\hline
\end{tabular}

Similarly, palm oil processing plants already handle cellulosic waste in volumes of one-to-two times palm oil output. The wastes exceed thermal process needs and often present disposal costs, making them ideal candidates for future biofuel feedstock. Sugarcane-ethanol and palm oil biodiesel are the two fastest growing biofuel sectors identified in the study and their on-site endowments of biomass wastes will facilitate transition to cellulosic-based production with relative ease in the future. Given that conditions for sugar and palm oil production are correlated with high biomass productivity, producing states are likely to enjoy advantages in other cellulosic feedstock (high yields for perennials, for example) if and when the technology and costs permit this line of production to become competitive.

The average estimated costs for cellulosic supplies are subject to extreme variations depending on assumptions related to productivity, collection and transportation. ${ }^{\mathrm{xx}}$ The other cellulosic feedstock supplies projected in Table ES-3 (those with estimated average prices above \$36/dry tonne) include projections of sustainable recovery of corn stover, wheat straw, fuelwood, a portion of wastes associated with industrial forestry and potential from perennials harvested for biofuel. The assessment of perennial supply potential illustrates the differences in relative scale among the countries studied. Brazil, Colombia and Argentina represent about $90 \%$ of the total estimated perennial supplies due to large areas of underutilized arable land available in these nations (see Methodology for details and assumptions).

\section{Environmental and Social Issues}

Social, environmental and political constraints associated with increasing biofuel feedstock production vary in scope and degree with crop and country. The interactions among government policies, social and environmental issues may impact future feedstock production positively or negatively. An overview of issues (below) reflects topics discussed in terms of potential impacts on supply projections in Chapters 2 and 3.

A recent book, Biofuels for Transport, notes that biofuels offer tremendous potential benefits "if policies are enacted to steer developments in the right direction." "xxi Several studies have examined environmental and social issues associated with expanding biofuel production, including food security, greenhouse gases, and poverty reduction, finding both risks and opportunities. ${ }^{\text {xxii }}$ There appears to be growing consensus that if best practices for socially and environmentally sound development are applied, then biofuels could offer farmers enhanced employment and incomes while reducing the burden of foreign oil imports on developing nations. Best practices include using efficient feedstock crops (such as sugarcane 
in Brazil) and optimizing system efficiency by minimizing and recycling wastes. But any rapid agricultural expansion poses risks if it distorts markets and disregards local needs, human rights and sustainability.

Capacity for land use planning and enforcement is important to avoid or minimize detrimental impacts. Brazil, for example, has enacted progressive environmental protection regulations but faces many challenges in achieving compliance. Agricultural expansion in Brazil (particularly soybeans) has generated concern among stakeholders about potential contributions to deforestation in the Amazon and other sensitive ecosystems. And while increases in the area used for sugarcane typically come from previously cleared land (primarily pastures), it is difficult to determine what impact this may have on more distant agricultural frontiers. ${ }^{\text {xiii }}$

Deforestation, land tenure, water use and pollution represent important and politically delicate issues in most countries studied. In some countries, concerns have been raised over small-farmer and indigenous land rights and loss of biodiversity, especially in the context of rapid expansion of palm oil plantations. Such issues merit consideration. A positive trend is that recent growth in biofuel feedstock production has been accompanied by increased attention to what are often long-standing social and environmental challenges. ${ }^{\text {xiv }}$ Stakeholder participation has been supported by various sectors (industrial, government and environmental) and is producing growing networks of practitioners at multiple scales. The increased transparency is generating a better understanding of the issues and mechanisms to address them.

At the global scale, a series of "Roundtables" have evolved, including the Roundtable for Sustainable Biofuels (RSB), Sustainable Palm Oil (RSPO), and Responsible Soy (RRS). ${ }^{x x v}$ The RSPO, for example, has developed and is testing a set of sustainability principles that address a broad range of concerns related to the overall supply chain for palm oil and palm oil derived biodiesel. Similar efforts, often coordinated with the global roundtables, are forging ahead at national levels, both in producer and importer nations. In Brazil, a recent stakeholder workshop developed recommendations for expanding sugarcane for biofuels while contributing to environmental and social development goals. Colombia has worked to address small farmer concerns related to palm oil plantations.

Governments see the potential for multiple benefits from domestic biofuel production programs. In addition to invigorating rural economies and increasing energy security by reducing imported oil, efficient biofuel production could contribute to goals for reducing green house gas emissions. In Brazil, for example, ethanol from sugarcane is produced with an 'energy balance' of approximately 1:8 meaning that 8 equivalent units of fossil energy are produced for each unit consumed in production. This is several times more fossil-energy efficient than average ethanol production in other countries and using other feedstock. ${ }^{\text {xvi }}$

\section{Policies}

Most countries studied have established targets or mandates for between $2 \%$ and $10 \%$ bio-ethanol and/or bio-diesel blends with fossil fuels in coming years, partly in response to high crude oil prices. These targets appear to be aimed at providing investors with increased security based on assurances of local market demand. Many nations (such as Brazil, Argentina, Colombia and several in the CBI region) also encourage investment through reduced tariffs and tax-credit incentives. China and India appear to be taking a more cautious approach and have discouraged the use of food crops and prime farm land for biofuel production. Wheat and corn feedstock may be seen as an interim strategy that allows producing countries to build domestic biofuel industries and gear-up for transition to other technologies and feedstocks when they become available. 
The emergence of biofuels has led to stronger integration of food, fuel and fiber markets. While this integration affects consumer prices, it also creates opportunities for increased rural incomes, greater economic efficiencies, and more sustainable systems of production. The increased integration of energy and food markets is reflected in several manners. For example, while Brazil is rapidly expanding sugarcane cultivation for biofuel, the area planted in soybeans is growing even faster. The expansion of soybeans is not for biofuel production per se, but illustrates Brazil's capacity to respond to global market signals.

\section{Next Steps}

The present study developed supply curves based on historic production data for traditional feedstock crops in seven selected countries and the CBI region, focusing primarily on ethanol production. Other nations have significant biofuel programs and merit inclusion in a global assessment (Australia, Malaysia, Thailand and Indonesia, for example). Additionally, new crops are being developed and planted specifically for biofuels. ${ }^{\text {xxvii }}$ China and India have announced policies to focus future biofuel production on non-food crops such as tree oilseeds (Jatropha ${ }^{\text {xxviii }}$, sorghum (an annual crop) and agricultural residues and byproducts including molasses. Detailed historic production data such as that used in the methodology for this analysis are not readily available for these potential feedstock sources. Considering such limitations and the findings thus far, proposed next steps include:

a) Conduct a systematic review to update remaining single-point supply data supporting the MARKAL world Energy Technology Perspectives (ETP) model. ${ }^{\text {xxix }}$

b) Expand state-level land-use and environmental analyses in priority production areas (e.g. Sao Paulo and center-south region of Brazil).

c) Adapt the methodology to include potential supply from other feedstock crops and improve the assessment of potential cellulosic supply in priority nations.

d) Apply the methodology to the next set of priority nations from the original screening process: Australia, South Africa and major palm oil producers in Southeast Asia.

e) Adapt results from the feedstock assessments to other models that allow the integration of food, fuel and fiber in global markets.

f) Assess the implications of recent adjustments in world prices and exchange rates in relation to projected supply functions for bioenergy feedstocks and related commodities.

\section{Conclusions}

Supply curve functions were developed for selected feedstocks in priority nations to replace single point estimates in a global energy market allocation model (see Chapter 3). The analysis identified capacity to potentially double or triple feedstock production by 2017 in some cases. A majority of supply growth is derived from increasing the area cultivated (especially sugarcane in Brazil). This is supplemented by improving yields and farming practices.

Most future supplies of corn and wheat are projected to be used to meet domestic food and feed demand in the nations studied. Larger shares of future supplies of sugarcane, soybean and palm oil production will be available for export and/or biofuel (Table ES-2). Figures ES-12 and ES-13 illustrate the share of total aggregate supply 'available' for export or biofuel by type of feedstock and country, based on all crops studied plus cellulosic supplies with estimated values under $\$ 36$ per dry metric tonne. The values in these 


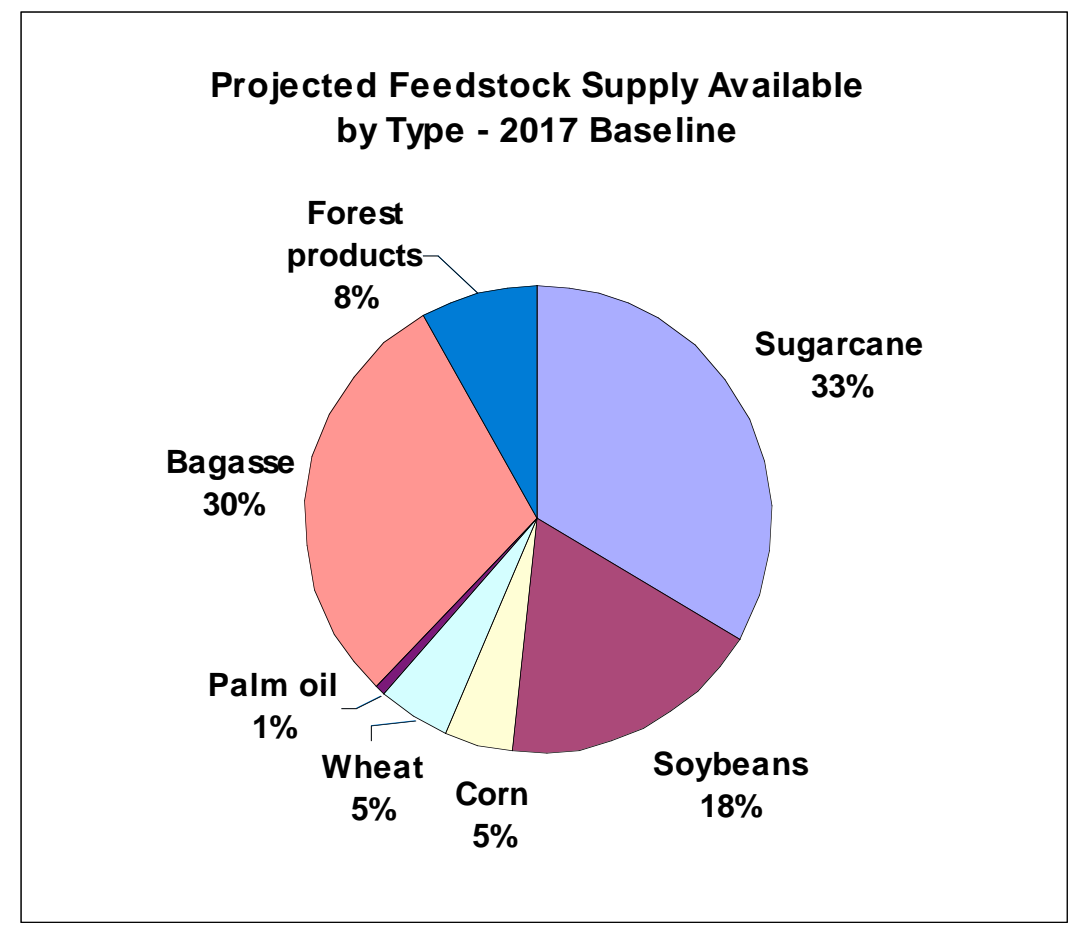

Figure ES-12. Projected Supply Available for Export or Biofuel by Feedstock Type - 2017 Baseline (gasoline equivalent basis; total $=\mathbf{3 8}$ billion gallons).

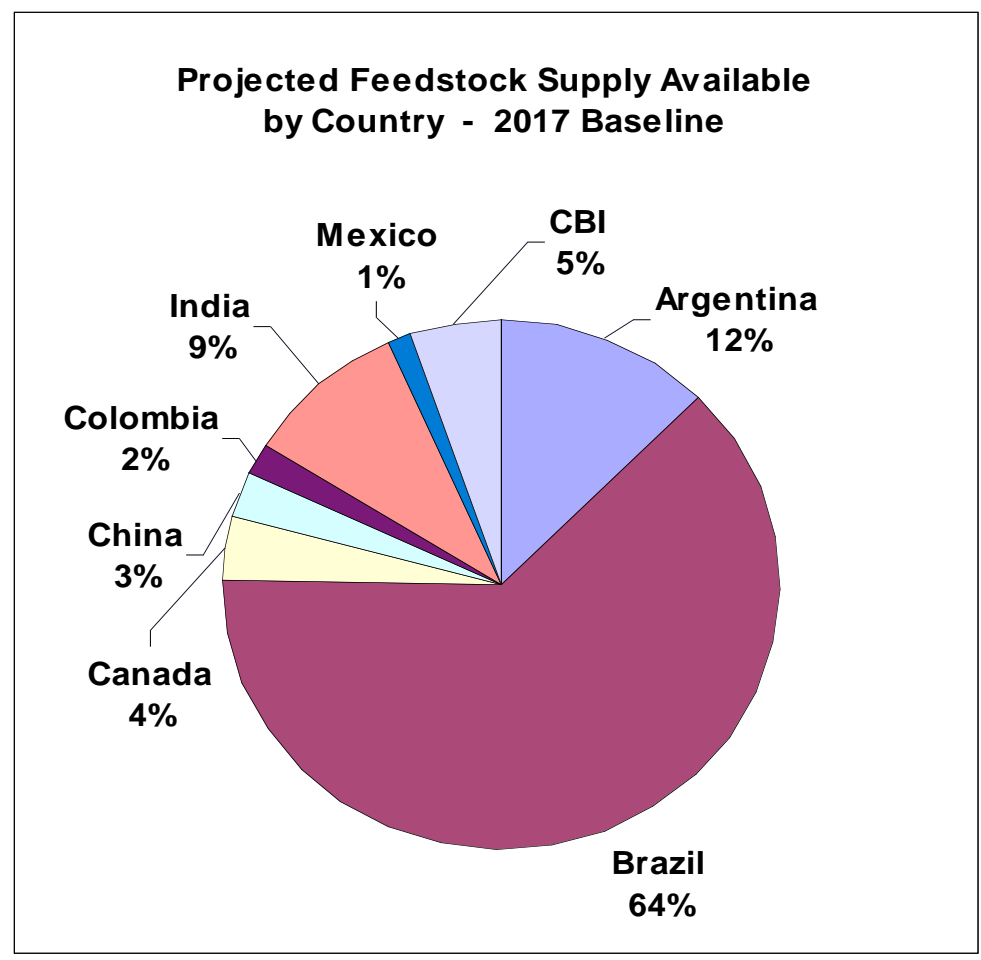

Figure ES-13. Projected Supply Available for Export or Biofuel by Country - 2017 Baseline (gasoline equivalent basis; total $=\mathbf{3 8}$ billion gallons). 
two Figures are presented in a "gasoline equivalent basis" with total supply equivalent to 38 billion gallons. ${ }^{\mathrm{xx}}$ The total supply projected in Figures 12 and $13-38$ billion gallons - is less than that of Figure 4 due to the exclusion of cellulosic supplies with estimated values exceeding \$36 per dry metric tonne. In Figure ES-12, sugarcane and bagasse combined dominate the total 'available' supply, representing 64\%. Figure ES-13 illustrates that among the nations studied, Brazil is the source of $64 \%$ of total 'available' supplies, followed distantly by Argentina (12\%), India and CBI. Within Brazil, the central-south region dominates national production. Therefore, supply trends in central-south Brazil and especially the state of Sao Paulo could have significant influence on national and global markets.

National policies are catalyzing investments in biofuel industries to meet targets for fuel blending that generally fall in the 5-10\% range. While social and environmental concerns associated with rapid expansion of feedstock production are recognized, the sugarcane sector poses lower risks than other feedstocks studied and offers the possibility for expansion with sustainable production systems. Policies in countries such as China and India reflect a strategy where feedstock crops that compete with food are expected to transition to alternative crops that can grow on more marginal lands than food crops and, eventually, to a cellulosic-based biofuel industry. 


\section{Chapter Endnotes for Executive Summary}

\footnotetext{
${ }^{\mathrm{i}}$ The screening process and results are described in Annex 2.

ii The emphasis of this initial assessment was on feedstock crops capable of producing ethanol to displace U.S. gasoline consumption in meeting the "20 in 10" targets (see Study Objectives in Chapter 1). Follow-on analysis is proposed for additional countries as recommended in "Next Steps," Chapter 2.

iii ORNL deliverables initially focused on individual supply functions (Annex 4) completed June-August 2007 for use in a broader DOE study. Subsequent tasks included the analysis of aggregate results (Chapter 2), social and environmental issues, and development of the Executive Summary as a stand-alone report. Results and issues for each country studied are presented in Chapter 3. The methodology is detailed in Annex 3.

${ }^{i v}$ Data tables reflecting supply functions for each crop and country are presented in Annex 4.

${ }^{v}$ Available data did not allow state-level supply curve construction for China and Colombia. For the CBI region, producing countries represented the steps in CBI supply curves rather than states within each country.

${ }^{\mathrm{vi}}$ See Methodology in Annex 3. Supply curves were based on best available data; these varied by state, crop and country. When available, trend data for the most recent seven years of production were used to project future growth at state levels. Plausible limits to growth, and high and low case scenarios, were derived from a statistical analysis of national historic production. Supply trend analysis does not explicitly account for future policies affecting prices, incentives and production levels.

${ }^{\text {vii }}$ In general, the baseline case falls within one-standard deviation of the national rate calculated from the historical data, while the alternative cases are one-standard deviation below and above the baseline case.

${ }^{\text {viii }}$ Nine projections are calculated - high, low and baseline cases in 2012, 2017 and 2027 - for each of 20 cropcountry combinations, producing 180 crop supply estimates. Assessments of potential for recoverable crop residues from each crop studied and from other biomass resources in 2017 and 2027 resulted in over 50 additional cellulosic supply projections. Supply curve data are presented in Annex 4, where each column reflects cumulative production calculated for a given country, feedstock, year and case.

${ }^{\mathrm{ix}}$ Conversion rates assumed for each feedstock in gallons per metric tonne are: 18.2 for sugarcane; 52 for soybeans; 76 for corn; 63 for wheat; 280 for palm oil; and 60 gallons per dry tonne for cellulosic supplies.

${ }^{\mathrm{x}}$ This represents total projected cellulosic supplies converted at a rate of 60 gallons/dry metric tonne.

${ }^{x i}$ FAO (2002): In 2000, the majority of all remaining land on the planet suitable for agricultural expansion was found in just seven countries, including Brazil, Argentina and Colombia. The other four nations with significant area for agricultural expansion were Bolivia and three African nations with historic political instability: Sudan, Angola and the Democratic Republic of the Congo. See http://www.fao.org/docrep/004/y3557e/y3557e08.htm\#m

${ }^{x i i}$ Calculated from Table ES-2 as a percentage of feedstock crops (not including cellulosic supply). In 2017 sugarcane represents $54 \%$ of the total available crop feedstock in the baseline, $56 \%$ in the low case, and $46 \%$ in the high case, because the high case projection for corn creates a surplus and increases its relative importance as an 'available' feedstock. The importance of sugarcane is a product of historic production trends in the countries studied. Sugarcane has been the primary source of fuel ethanol outside the U.S. over the past decade. Virtually all fuel ethanol traded in global markets has been derived from sugarcane; the vast majority coming from Brazil.

xiii This study focuses on feedstock supply, not ethanol. However, to put this amount of feedstock into context: if the supply in 2017 'available for export or biofuel' is converted to ethanol at a rate of 85 liters per metric tonne of cane, it produces 60 billion liters in the baseline case and over 100 billion liters in the high growth case. The actual allocation of sugarcane production to ethanol versus other products could vary depending on relative market prices and national policies. In Brazil, a little over 50\% is now allocated to biofuel and the government expects the biofuel allocation to increase as most future growth in production will be dedicated to ethanol. In India, however, most sugarcane is dedicated to sugar-based products and ethanol is produced primarily from low-grade molasses. The estimates of the percent available for export or biofuel take these factors into consideration.

${ }^{\text {xiv }}$ While the CBI contribution is small in percentage terms, $6 \%$ of the total available supply for export and/or biofuel represents over $43 \mathrm{mmt}$ of sugarcane and up to 3.7 billion liters of ethanol (at 85 liters/tonne). This is nearly six times greater than the record level of CBI ethanol exports to the U.S. in 2006 of 628 million liters (CBI exports discussed in CRS 2007).

${ }^{x v}$ Macedo 2007, IDB (Rothkopf) 2007, Bradley 2006 and AgraFNP 2007. About 6 million hectares of sugarcane were harvested in 2006. If all expansion were dedicated to biofuel, about 6 million additional hectares could triple ethanol output. Noted references estimate that from 7 to 22 million additional hectares are available that are "ideal" or well-suited for sugarcane (able to produce above-average yields without irrigation) and another 60-100 million
} 
hectares are available that meet requirements for average yields. In both cases, the estimates assume no deforestation for sugarcane expansion. See the Brazil section of Chapter 3 for details.

${ }^{x v i}$ Following the study methodology which subtracts the estimated domestic demands for food, feed and fiber from total projected supply, about $130 \mathrm{mmt}$ of soybeans are available from the countries studied for export or biofuel production in the 2017 baseline case. This represents nearly a third of total available crop feedstock supplies on a gasoline equivalent basis in the baseline and low growth cases (and 23\% of total in the high growth case). The present feedstock supply analysis does not attempt to determine what portion of future supplies entering global markets will actually be used for biofuel but current use of imported soybeans for biofuel production is minimal. ${ }^{x v i i}$ Brazil recently overtook the U.S. as the world's leading exporter of soybeans. Increasing acreage planted in soybeans responds to increasing demand and prices in global markets that in turn are influenced by shifts in U.S. planting and production.

${ }_{\text {xviii }}$ These optimistic projections are the product of estimating future supply based on recent production trends in a relatively young palm oil industry that is scaling up rapidly in the countries studied. Such growth rates are unlikely to be sustainable in the long term.

${ }^{\text {xix }}$ Aggregate results are discussed further in Chapter 2, while country-level estimates are discussed in Chapter 3. ${ }^{\mathrm{xx}}$ Opportunity costs for bagasse were estimated to range from US\$8-\$17 per dry tonne. Average costs per dry tonne for other cellulosic supplies ranged from: $\$ 1$ for a portion of palm residues available at processing plants; to $\$ 18-\$ 36$ for wood mill residues; $\$ 13-\$ 50$ for fuelwood; $\$ 39-\$ 52$ for corn stover and wheat straw; and $\$ 52-\$ 100$ for dedicated perennials and forest harvest residues. See country-level discussions in Chapter 3 for details.

${ }^{x x i}$ See Worldwatch Institute (WWI) 2007; Preface pg. xx.

xxii References include: WWI 2007, OECD 2007, UN-Energy 2007, IDB 2006, IFPRI 2006, FBDS and CI 2007, USDA 2007b, ESMAP 2005, IEA 2004, Smeets et.al. 2004. See discussion in Chapter Two.

${ }^{x x i i i}$ See Brazil in Chapter 3. Generally, sugarcane is expanding on previously cleared land near sugar mills and major roads. A study of sugar cane expansion in the most important producing state, Sao Paulo (1990-2004), found that forest cover increased along with increasing area planted in sugarcane as more effort was made to comply with forest reserve and riparian protection regulations (Macedo, 2007).

${ }^{x x i v}$ For example, in "Sustainability of ethanol from Brazil in the context of demanded biofuels imports by The Netherlands" (Rodrigues and Ortiz, 2006), the authors note that companies targeting international markets pay more attention to environmental and social issues as a good business practice. And recent workshops in Brazil brought parties together to develop recommendations for socially and environmentally sound expansion of sugarcane ethanol production (FBDS 2007).

${ }^{\mathrm{xxv}}$ The movements to develop industry standards and indicators have been active in the past 2-3 years. For draft principles, meetings, and progress with the Roundtable on Sustainable Biofuels (RSB) see:

http://www.bioenergywiki.net/index.php/Roundtable_on_Sustainable_Biofuels . For the Roundtable on Responsible Soy, see: http://www.responsiblesoy.org/eng/index.htm. Also see van Dam et.al. "Overview of recent developments in sustainable biomass certification,” prepared for IEA Bioenergy Task 40, December 2006.

${ }^{x x v i}$ Net energy balance depends on several factors related to the biofuel production process including energy intensity of agricultural inputs and sources of energy for processing and fuel production. These factors vary greatly. WWI 2007 reported that in China the energy balance (energy in:energy out) for ethanol production was 1:1.1 for corn and 1:2.1 for sugar cane, while in Brazil it was calculated as 1:8.3 for sugarcane (and other sources report 1:9 or more for Brazil). In the U.S. it has been estimated at 1:1.2 for corn. In part due to the higher efficiency, Brazil's costs per liter of ethanol are also much lower than any other producers. OECD 2007 reports current ethanol production costs of approximately US\$0.20/liter from sugarcane in Brazil while the costs for grain-based ethanol in the U.S. and Europe range from US\$0.30 to over $\$ 0.40$ per liter.

${ }^{x x v i i}$ Promising new crops include tropical sugar beets and sweet sorghum. Projects in India and Colombia suggest that tropical sugar beets could produce more sugar per unit of land and water than sugarcane, along with the possibility of two harvests per year. Sorghum, cassava and sweet potatoes are also being used as feedstock for ethanol production. See country level discussions in Chapter 3 for more information.

xxviii Jatropha is a genus of hardy plants and shrubs from the family Euphorbiaceae native to the Caribbean. The seeds from Jatropha curcas are being used and promoted in many parts of the world as a source of biodiesel. ${ }^{x x i x}$ ETSAP www.etsap.org/documentation and Alfstad 2007.

${ }^{\mathrm{xxx}}$ The total supply in gasoline equivalent reflects a maximum potential 'available' in the 2017 baseline case independent of other factors. A broader study will apply assumptions related to prices, tariffs and other variables to estimate what portion of this potential supply could enter the market under different scenarios. 


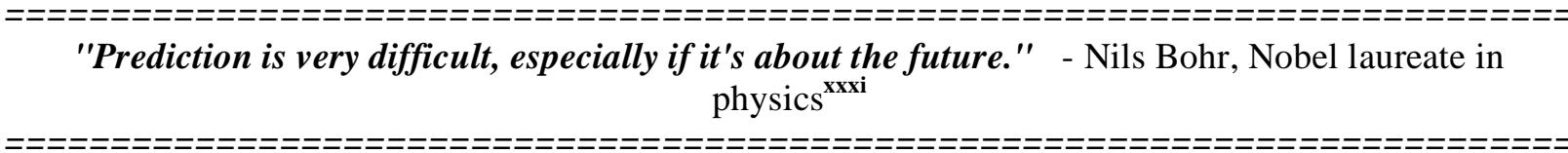

\title{
BIOFUEL FEEDSTOCK ASSESSMENT FOR SELECTED COUNTRIES
}

\author{
To support the DOE study of \\ "Worldwide Potential to Produce Biofuels, with a focus on U.S. Imports" \\ Prepared for the U.S. Department of Energy \\ by \\ Oak Ridge National Laboratory $(\text { ORNL) })^{\text {xxxii }}$ \\ Keith L. Kline \\ Gbadebo A. Oladosu \\ Amy K. Wolfe \\ Robert D. Perlack \\ Matthew McMahon \\ Virginia H. Dale
}

\section{INTRODUCTION}

\subsection{OVERALL STUDY OBJECTIVES}

The U.S. Department of Energy (DOE) ${ }^{\mathrm{xxxiii}}$ sponsored a meta-analysis to estimate the worldwide ${ }^{\mathrm{xxxiv}}$ potential to produce and transport ethanol and other biofuels that could be imported to the U.S. to help reach the President's "20 in 10" goal of 35 billion gallons of renewable and alternative fuels by 2017 (see Scope of Work in Annex 1). The overall DOE study, "Worldwide Potential to Produce Biofuels, with a focus on U.S. Imports," represents a collaborative effort among two offices in DOE and three National Laboratories to complete the following general tasks ${ }^{\mathrm{xxxv}}$ :

1. Identify the range of countries to be updated with more detailed analysis (See Annex 2).

2. Assess the resource potential (supply curves) for production of ethanol from sugar and starchbased feedstocks, and biodiesel for these countries.

3. Assess the resource potential (supply curves) for production of other biofuels including cellulosic-based ethanol.

4. Integrate results into the International Energy Agency (IEA) Global Market Allocation (MARKAL) - Energy Technology Perspectives (ETP) model. ${ }^{\text {xxvi }}$ 
The study aims to improve capabilities to assess the degree to which foreign supplies of biofuels could contribute to meeting future U.S. targets to reduce dependence on imported oil. ${ }^{\mathrm{xxvvii}}$

Given limited time and resources, the first step in the study involved a screening process to select an initial set of countries for feedstock analysis. Representatives from DOE and the three National Laboratories on the project team applied criteria to conduct the screening. These criteria included the following factors related to future biofuel export potential:

- Current feedstock and biofuel production

- Export infrastructure

- Processing capacity

- Proximity to the U.S.

- Forecast production potential

- Need for more information

As a result of the screening process, seven countries and one region were selected as areas for initial study: Argentina, Brazil, Canada, China, Colombia, India, Mexico and the Caribbean Basin Initiative region, hereinafter referred to as CBI. (The screening process is documented in Annex 2). Table 1.1 lists the countries and feedstocks selected for study.

Table 1.1. Selected Countries and Feedstocks for Study

\begin{tabular}{|c|c|c|c|c|c|c|c|c|}
\hline \multirow[b]{2}{*}{ Selected Countries } & \multicolumn{5}{|c|}{ Feedstock supply potential: 2012, 2017, 2027} & \multicolumn{3}{|c|}{$\begin{array}{c}\text { Qualitative estimates } \\
2017-2027\end{array}$} \\
\hline & Sugarcane & Palm Oil & Soybeans & Corn & Wheat & Bagasse & $\begin{array}{l}\text { Ag. Crop } \\
\text { Residues }\end{array}$ & $\begin{array}{l}\text { Other } \\
\text { Woody }\end{array}$ \\
\hline Argentina & $\mathrm{X}$ & & $\mathrm{x}$ & $\mathrm{x}$ & $\mathrm{X}$ & $\mathrm{X}$ & $x$ & $x$ \\
\hline Brazil & $\mathrm{x}$ & & $x$ & $\mathrm{x}$ & & $\mathrm{x}$ & $\mathrm{x}$ & $\mathrm{x}$ \\
\hline Canada & & & & $\mathrm{X}$ & $\mathrm{X}$ & & $\mathrm{x}$ & $\mathrm{X}$ \\
\hline China & $\mathrm{x}$ & & $\mathrm{x}$ & $\mathrm{x}$ & $\mathrm{x}$ & $x$ & $\mathrm{x}$ & $\mathrm{x}$ \\
\hline Colombia & $\mathrm{x}$ & $\mathrm{x}$ & & & & $\mathrm{x}$ & & $x$ \\
\hline India & $\mathrm{x}$ & & & & & $\mathrm{x}$ & & $\mathrm{x}$ \\
\hline Mexico & $\mathrm{x}$ & & & $\mathrm{x}$ & & $\mathrm{x}$ & $\mathrm{x}$ & $\mathrm{x}$ \\
\hline Caribbean Basin (CBI) & $\mathrm{x}$ & $\mathrm{X}$ & & & & $\mathrm{x}$ & & $\mathrm{x}$ \\
\hline
\end{tabular}

Key sources of information for this analysis include online resources from the U.S. Department of Agriculture (USDA), the Food and Agriculture Organization of the United Nations (FAO), the U.S. DOE, and the International Energy Agency, as well as national agricultural services and organizations in the countries studied. Country-specific analyses of the feedstock crops shown in Table 1.1 identified several unique considerations for generating projected commodity supply curves for the 2012-2027 timeframe (see Chapter 3).

\subsection{ORGANIZATION OF THE REPORT}

ORNL's contributions to the overall study focus on future potential feedstock supplies and are organized as follows:

- An Executive Summary provides a brief illustration of aggregate results for the areas studied in terms of historic trends and projected growth in feedstock supplies. 
- This Introduction (Chapter One) presents the overall study objectives and summarizes the methodology and assumptions that generally are applicable to the development of the supply curves and findings.

- Chapter Two consolidates results of the country-level analyses by feedstock crop and depicts the proportional contributions from the various countries studied. It discusses overarching constraints and opportunities that may affect future feedstock supplies and places the issues and results within a global context. It also provides some general recommendations for establishing or maintaining sustainable production systems and proposes follow-on steps for research.

- Chapter Three presents country- (and CBI region-) specific analyses, noting any special considerations or methodological adaptations required due to the availability of data. Chapter 3 provides feedstock supply curves for 2012, 2017 and 2027 for each selected crop. (Data tables corresponding to the supply curve functions in Chapter Three are available in Annex 4.) Chapter 3 also discusses results, constraints and opportunities specific to the feedstocks in each of the selected countries and the CBI region. The portion of total projected future production that is assumed to be available for export or biofuel production is calculated. Finally, future cellulosic supplies are estimated and compared with other results.

- Chapter Four presents a consolidated list of references (alphabetically) for the overall report.

The report is supplemented with the following annexes:

1. Statement of Work for ORNL under the "Study of the Worldwide Potential to Produce Ethanol and other Biofuels"

2. Summary of Screening Results for Country Selection

3. Methodology, Data Limitations and Assumptions

4. Supply Curve Data Tables, by Country

\subsection{METHODOLOGY}

This section outlines the approaches used to develop the supply curves and other data presented in the report. The approach for developing supply curves involved many discrete calculations and steps. In some cases, data limitations required additional steps and adjustments in the standard approach described here. Any such deviations are noted in the corresponding country-specific sections of Chapter 3 . After developing projected supply curves for selected crops, other steps are necessary for the data to be used in the MARKAL global energy trade model. The model needs predetermined estimates of the portion of total feedstock supplies that will be available for potential biofuel production. ${ }^{\text {xxviii }}$ Finally, cellulosic supplies were estimated for each country. The methodology used for each of these calculations - crop supply curves, portion available for export and/or biofuel production, and cellulosic supply estimates is summarized below. A more detailed discussion of the methodology, assumptions and data limitations related to the feedstock assessments is presented in Annex 3.

\subsubsection{Feedstock Crop Supply Curves}

In economic theory, the supply curve for a given good/service can be expressed as the sum of the marginal cost curves of the individual producers. Supply curves normally have increasing cost on the vertical axis and cumulative supply on the horizontal axis. The curves usually are upward-sloping due to the concept of diminishing marginal returns. In practice, data are lumped together by groups of producers 
so that empirical supply curves are step functions depicting cumulative production at different average costs/values. Incremental production on each segment of the curve represents the contribution of a technology, production unit, or group of producers with that average cost/value of production. The economic relationship underpinning a supply curve assumes that other factors remain equal. In practice, many other factors, ranging from weather to alternative crops, influence the supply-price relationship.

The present study was designed to use existing data. While acceptable statistics on average production and prices at the national level are usually available, ${ }^{\mathrm{xxxix}}$ detailed data on costs of production by individual producer groups are difficult or impossible to find in most cases. An initial exploration of data sources revealed that the most detailed and consistent data on crop production are usually generated at the province/state level. ${ }^{\mathrm{xl}}$ Corresponding state-level average prices or costs are available for most of the traditional feedstock crops and countries selected for study. Therefore, the supply curves developed here are based on the state-level data whenever possible. These supply curves are projected from the most recent year with complete data (usually 2005) into the future to 2012, 2017, and 2027, based on the statelevel costs and historic trends in production for the selected crop. The primary steps involved in generating feedstock crop supply curves are summarized below and detailed in Annex 3.

- States/provinces serve as the individual segments or production units of the projected supply curves. ${ }^{\text {xli }}$

- A base-year supply curve for each country and crop combination is generated using the most recent year for which cost/value (in 2005 US\$) and production (in million metric tonnes, mmt) statistics are available (usually 2005). The supply curve is generated by ranking the state-level production of a crop in order of increasing unit value and cumulating the resulting supply data. In the case of CBI, average cost and supply data from producing CBI-member nations were used instead of states, following the same methodology described here.

- State-level cost data were unavailable for a few crop-country combinations and in those cases the national average price/cost of production was estimated and used to make single point supply projections.

- The prices/costs associated with supply in the base year are assumed to be constant into the future, allowing the analysis to focus on projecting crop production to 2012, 2017, and 2027.

- The future supply projections are based on compound growth rates of harvested area and yield calculated from historic trends at the state level over the most recent seven years of data. ${ }^{x l i i}$ This 7-year interval matches the time period between the most common recent year of data available (2005) and 2012, the first year of projected production.

- Supply projections reflect a range of projected production through low-growth, baseline and high-growth cases. These are established as follows:

o Independent of the state-level projections, national average growth rates and standard deviations are calculated from FAO historical data for total production of each crop (see Annex 3).

- The initial projection based on state trend data is classified as the baseline if its implied national growth rate between the base year and 2012 falls within one standard deviation of the range of the national 7-year compound growth rate. (In rare cases where it falls outside this range, the initial projection may be classified as the high or low case).

- Low- and high-growth cases are estimated for each crop and country combination to reflect one standard deviation above and below the baseline case. 
- Given the possibility of wide variations in crop production within a state from year to year, long-term national data for each crop-country combination are used to establish an upper limit for state growth rates used for the projections. In addition, limits are defined for the percentage of a state's area that can be assumed to be allocated to a single crop and for future yield levels. For the purposes of this report, the percentage of a state's land allocated for a single crop is not allowed to exceed $30 \%$, while the maximum yield in 2027 is set at twice the maximum of state-level yields reported in the United States. ${ }^{\text {xliii }}$ In cases where state-level historic rate projections result in land allocations or yields that exceed these limits, projected growth rates are adjusted downward until the results fall within these parameters.

- Finally, total feedstock projections predicted by the supply curves in this study are compared with those from other sources such as the USDA 2007 baseline projections for world crop production, the FAPRI model projections ${ }^{\text {xliv }}$ and other country-specific sources when available.

As an example, Figure 1.1 presents the projected sugarcane supply curve for Brazil in 2027 for the baseline case. Data tables for all supply curve functions are presented in Annex 4. In these curves, a given point represents the projected cumulative supply for all purchase values (prices) up to that point.

Figure 1.2 illustrates historic sugarcane production compared to total projected supply under this study for the range of cases: low growth, baseline and high growth projections. Similar figures are presented for each crop-country combination in the study (see Chapter 3 ).

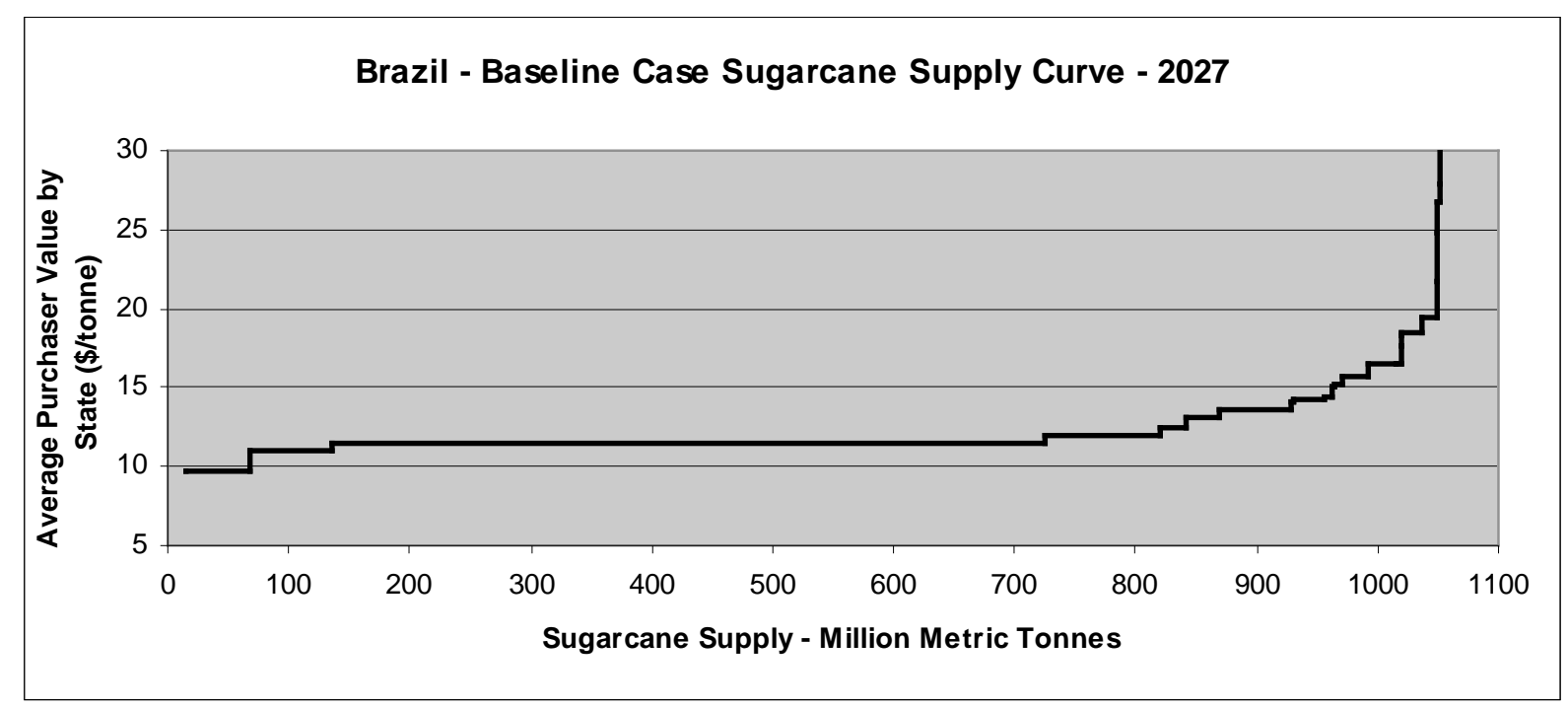

Figure 1.1. Example of Brazilian Sugarcane Supply Curve projected to 2027 (Values in 2005 US\$).

\subsubsection{Estimating the Portion of Supply Available for Export and/or Biofuel Feedstock}

The supply curve projections described above provide estimates of total crop production for any potential end use. For use in the MARKAL-ETP model, the percentage of supply that could enter global markets and potentially serve biofuel feedstock purposes is estimated by subtracting a portion of the total projected supply allocated for domestic demand for food, feed and fiber in each country. This calculation is made as follows: 


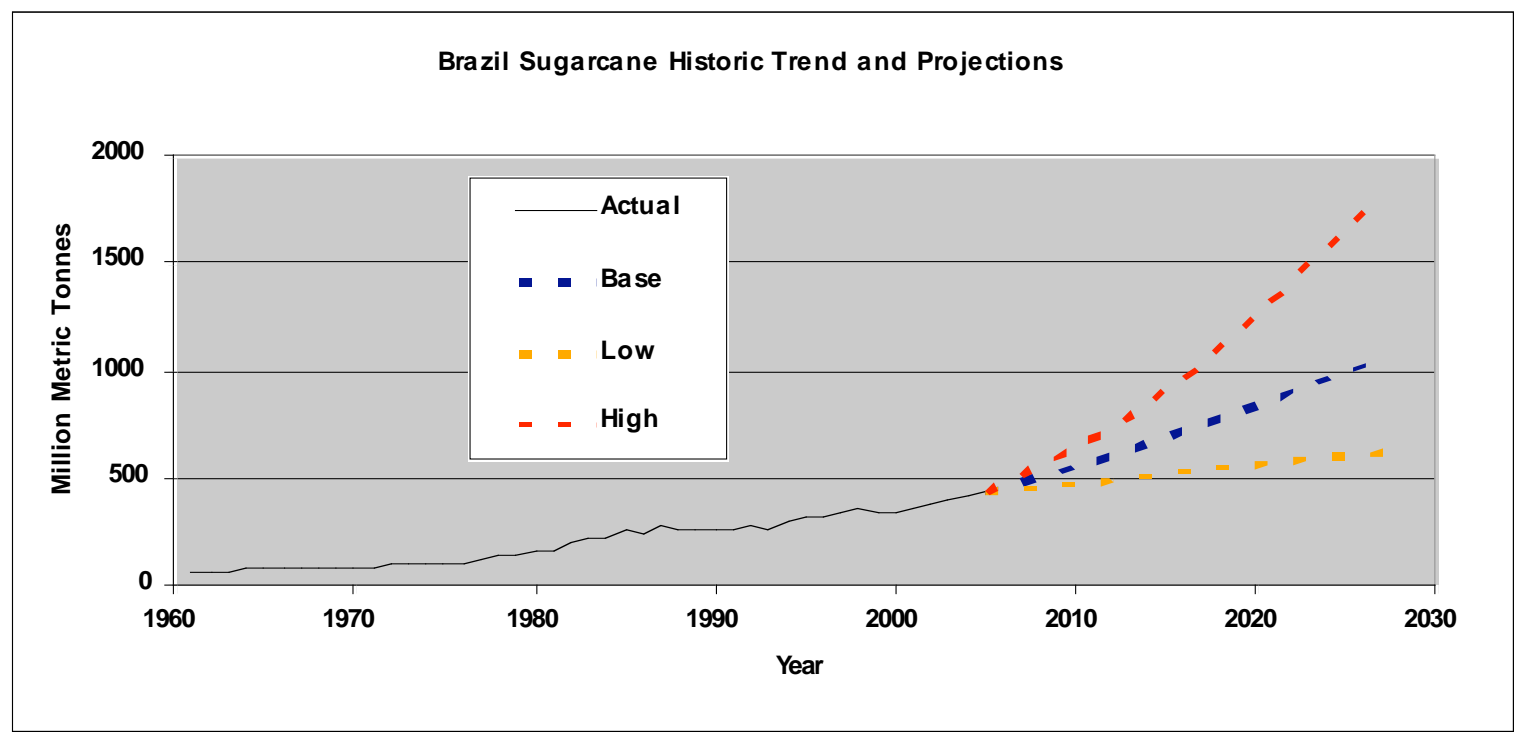

Figure 1.2. Historic Trend and Potential Supply Projections for Brazilian Sugarcane.

- The share of all domestic food, feed and fiber (non-biofuel) uses is calculated as a percentage of total supply for the most recent year with available data (usually based on USDA reports for 2006). The remainder includes reported allocations for domestic biofuel production and exports. In cases where part of the supply is exported after processing, the domestic demand numbers are adjusted to reflect only the domestic consumption of the processed product. For example, Brazil's sugarcane is crushed entirely in the country with about half allocated for sugar production and about half allocated for ethanol. However, since much of the sugar is subsequently exported, the share set aside for domestic food, feed and fiber is calculated at $18 \%$, leaving about $82 \%$ of total sugarcane production available for conversion to products for export in global markets and/or biofuels.

- Domestic demand for food, feed and fiber is assumed to grow at "typical" rates which, for the purpose of this calculation, are assumed to maintain a proportional relationship to the growth in supply under the baseline projections. Thus, the percentage calculated for domestic (nonbiofuel) use is subtracted from the baseline case supply projections for 2012, 2017, and 2027. The remainder is assumed to be available for export and/or biofuel feedstock use.

- The amounts (in metric tonnes) set aside for domestic food, feed and fiber in the baseline case in 2012, 2017 and 2027 are then also subtracted from the projected supplies in the low and high growth cases for the corresponding years.

These procedures provide the MARKAL-ETP model with an estimate of the total potential future supply of feedstock crops that is projected to be available for international markets.

\subsubsection{Cellulosic Feedstock Estimates}

Potential cellulosic feedstock availability from agricultural residues associated with the projected supplies of crops considered in this study is based primarily on the set of assumptions employed in the "Billion Ton Study" "xlv and national data, especially for the production and utilization of bagasse and palm oil processing residues. Costs per tonne for cellulosic feedstock supplies are estimated based both on 
parameters of the "Billion Ton Study" and country-specific sources. See Annex 3 and individual country assessments for details.

Forestry residues and fuelwood feedstock estimates are derived from FAO 2005 forest products data. ${ }^{\text {xlvi }}$ These data include roundwood, wood residue and fuelwood statistics for several (but not all) countries studied. Estimates of the "realistic" supply of forestry residues that could be available as biofuel feedstock were derived from a comprehensive survey for Canada (Bradley, 2006). Availability of fuelwood as a potential biofuel feedstock was estimated at $50 \%$ of the production reported by FAO for 2005 . Estimates were also generated for potential cellulosic supplies from perennial woody crops harvested from 5 and 10 percent of the area reported as available (under-utilized or unused) arable land.

Given that technologies for cellulosic ethanol production are still being developed and preferred feedstock characteristics are not yet defined, and considering the limited scope and time for conducting this initial assessment, the estimates of cellulosic supplies for forestry residues, fuelwood and perennials should be regarded as merely indicative of relative scales of future potential. 


\section{Endnotes for Chapter 1}

${ }^{\mathrm{xxxi}}$ This or very similar quotes are also attributed to Mark Twain, Robert Storm Peterson and Yogi Berra.

xxxii ORNL authors acknowledge and thank the following individuals for contributions in the review of draft reports: Mike Curtis, Tina Kaarsberg, Bhima Sastri, Audrey Lee and Daniel McNeil from the DOE Office of Policy and International Affairs (PI); Zia Haq from the DOE Office of Energy Efficiency and Renewable Energy's (EERE) Biomass Program and Rich Bain from the National Renewable Energy Laboratory (NREL).

xxxiii This study is jointly sponsored by DOE EERE and PI offices. The study is led by Michael R. Curtis, DOE-PI. Representatives from the U.S. Department of Agriculture (USDA), Environmental Protection Agency (EPA) and other offices also participated in the planning and development of this study through conference calls. For more information on EERE and PI, see http://www.eere.energy.gov/ and http://www.pi.energy.gov/enhancingGHGregistry/index.html.

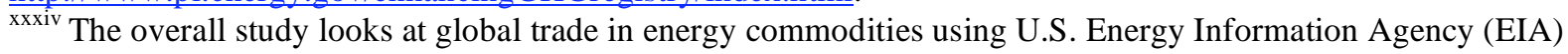
data for supply. The assessments presented in this report were designed to update single-point supply data with supply curve functions for a set of selected countries and feedstocks based on analysis of more detailed and recent data sources from each country.

${ }^{\mathrm{xxx}}$ ORNL collaborated with DOE and other DOE national laboratories to facilitate and document the prioritization and selection process, and to conduct the analyses of potential feedstock supplies from selected countries to develop supply curves (e.g., portions of Tasks 1, 2 and 3). DOE's National Renewable Energy Laboratory (NREL) was responsible for data on conversion costs and identified drivers for, and barriers to, development of biofuels (portions of Tasks 2 and 3). Brookhaven National Laboratory (BNL) was responsible for the modeling in Task 4.

${ }^{x x x v i}$ IEA ETSAP and Alfstad 2007. The MARKAL Users' Guide is available from the IEA Energy Technology Systems Analysis Programme (ETSAP) website under "documentation" at http://www.etsap.org/index.asp. The guide provides background to principles embodied in MARKAL and descriptions for input data and model structure. xxxvii The objective of the overall study is to estimate the worldwide potential to produce and transport ethanol and other biofuels that could displace the use of conventional petroleum-based fuels such as gasoline under various scenarios. This potential depends on the amount of biofuel feedstocks that could be grown on available land, as well as the ability of biofuels from various feedstocks to be produced and compete in the marketplace. The overall study will project the quantity of biofuel that can be produced in the future (5-, 10-, and 20-year timeframes) under various scenarios.

xxxviii It should be noted that for the purpose of the overall study, ORNL feedstock supply data were further processed by other DOE Laboratory team members. Feedstock supply and price were adjusted to integrate transportation and conversion costs into final supplier costs for biofuels that could be available for world export. These supply/cost figures supported the subsequent MARKAL-ETP modeling.

${ }^{x x x i x}$ FAO 2007 statistical data:. ProdSTAT, http://faostat.fao.org

${ }^{\mathrm{xl}}$ The nomenclature for internal political divisions varies among countries. Some countries such as Brazil, Mexico and India use "state" and others use "province." For simplicity, when referring to these internal political units generically, "state" or "state-level" means either state or province, as appropriate for the given country.

xli In the CBI region, the study methodology treated each producing nation like a "state."

${ }^{x l i i}$ A seven year period was used whenever data were available. In a few cases, state-level statistics went back only 5 years. Also, in rare cases, production of a crop was new in a state and data were available for shorter time spans.

xliii These "plausible limits" came into play in a small percentage of cases, typically where production was new to a state and therefore recent growth trends, if projected over longer periods, became unreasonable.

${ }^{x l i v}$ USDA 2007a and FAPRI 2007. See http://www.fapri.org/outlook2007/

${ }^{x l v}$ Perlack et al. 2005. The assumptions from the Billion Ton Study were used as a starting point and further adjusted in many cases based on national data and estimates of differences in availability or access to supplies, opportunity costs, and costs of collection and transport.

${ }^{x l v i}$ FAO 2007 statistical data: ForeSTAT, http://faostat.fao.org/default.aspx. Accessed 08/2007. 


\section{ORNL FEEDSTOCK ASSESSMENT - AGGREGATE RESULTS}

The role of Oak Ridge National Laboratory (ORNL) in the overall study is primarily to assess the feedstock production potential for the eight selected areas of study and develop supply curves for biofuel feedstock grown in those nations. During the course of the study, the ORNL contribution evolved to consist of three sub-tasks:

1. Generate and project feedstock supply curves for each country-crop combination as reflected in Table1.1 for the years 2012, 2017, and 2027.

2. Estimate the potential availability of the projected feedstock supply for export and/or biofuel use.

3. Estimate potential availability and cost of cellulose feedstock from crop residues, forests residues, and perennials for 2017 and 2027.

This chapter briefly reviews aggregate results of the assessment by feedstock type. Unless noted otherwise, references to "total" supplies refer to the sum of supplies from the countries and feedstocks studied, as listed in Table 1.1. "Cumulative" refers to total supply up to a given price point or the maximum price observed in a country studied. Chapter Three provides a discussion of the results for each crop-country combination assessed, including individual feedstock supply curves and estimates of the portion available for export or biofuel. Corresponding data tables are presented by country in Annex 4 .

\subsection{AGGREGATE RESULTS BY FEEDSTOCK TYPE}

\subsubsection{Sugarcane}

In 2005, the base year for projections, aggregate production from the countries assessed for sugarcane was about $900 \mathrm{mmt}$. These countries represent $73 \%$ of global production outside the U.S (Table ES-1). Total baseline case production based on this analysis is projected to rise to over 1,200 $\mathrm{mmt}$ by 2012 , $1,460 \mathrm{mmt}$ in 2017, and 1,900 mmt in 2027. The three charts in Figure 2.1 (one for each time period) illustrate the cumulative projected production for each case (baseline, low and high growth), showing the contributions from each country. Brazil's projected supply in the 2017 baseline case, $742 \mathrm{mmt}$, is almost double its 2006/2007 sugarcane harvest. Brazil represents roughly one half of the total projected supply in all cases and years of the study, with India ranked second among producers with about $25 \%$, and China third with $10 \%$. The CBI represents only about $6 \%$ of total production.

While India's total supply is significant at $360 \mathrm{mmt}$ (2017 baseline), 95\% of this production is estimated to go toward serving internal demand for sugar and related products, leaving only about $20 \mathrm{mmt}$ 'available' for export and/or biofuel. For the same case (2017 baseline), the CBI region is projected to have $43 \mathrm{mmt}$ available for export or biofuel, more than twice that of India, although it's total production is much smaller. And at $14 \mathrm{mmt}$, Colombia also offers potential supply available for export or biofuel. As noted in Table ES-2, the percentage available for export and/or biofuel varies by year and case. In Brazil, about $82 \%$ of feedstock supply in the 2017 baseline case is available for export or biofuel. Figure 2.2 illustrates the cumulative projected supply available for export and/or biofuel for each case, by country. The differences between Figures 1 and 2 in supplies reflect the estimated domestic demand for sugar and other non-fuel products in the producing countries. 

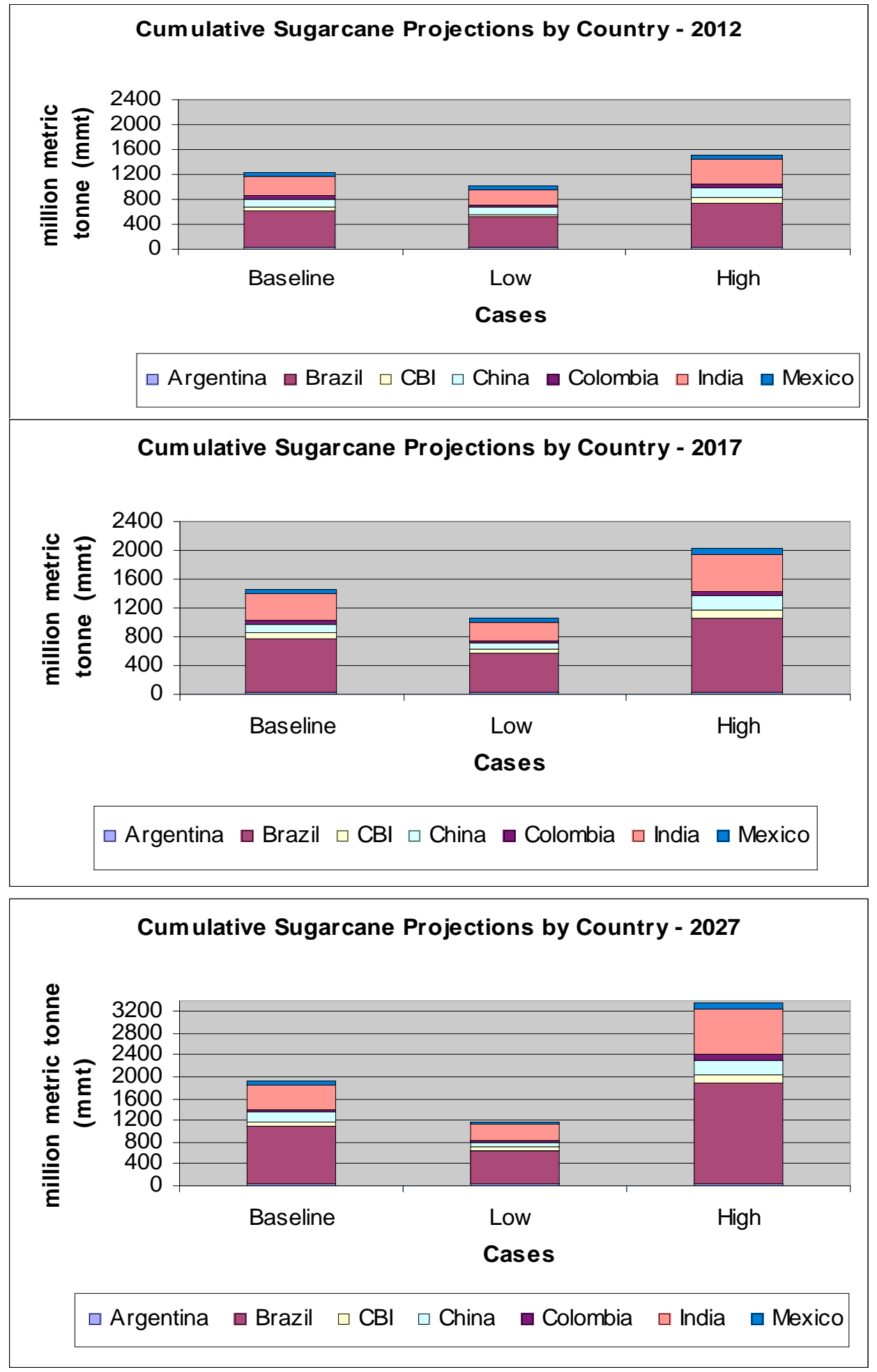

Figure 2.1. Total Projected Sugarcane Production Potential by Country. 


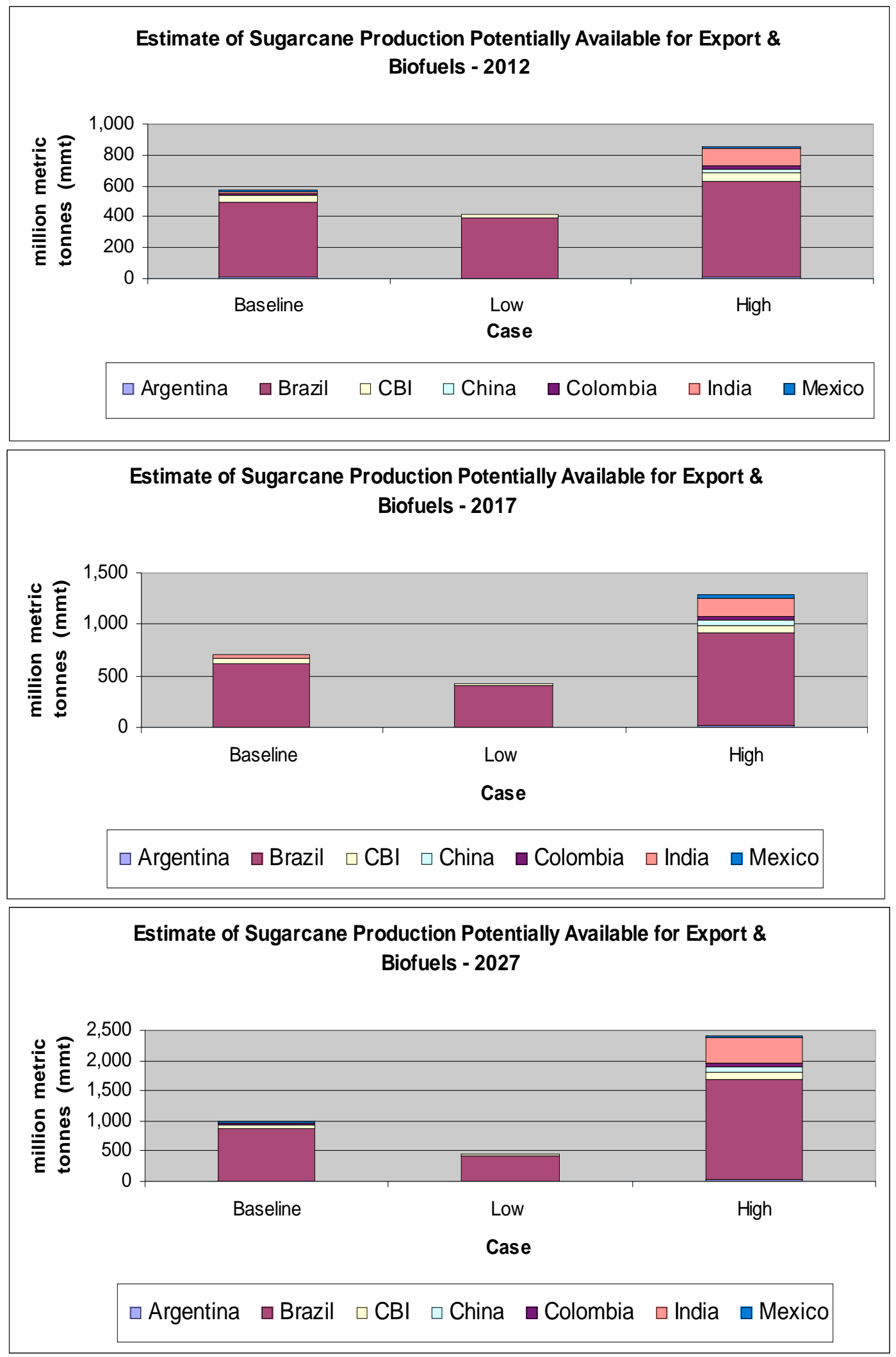

Figure 2.2. Total Projected Sugarcane Supply 'Available’ by Country. 
Brazil is currently the world's largest producer of sugarcane and offers the greatest potential for growth, due primarily to the availability of suitable lands for expanding sugarcane cultivation. Other countries lack similar land resources with appropriate soils and climate for sugarcane. In India and China, most of the cultivable land area is already in use and government policies discourage reallocation of arable land for biofuel production. While Argentina and Colombia have significant underutilized arable lands available, these resources generally do not have soil and climate characteristics suited for sugarcane production. Brazil's sugarcane expansion is occurring primarily in mildly sloping former pasture and crop lands in the Southeast and Center-South. Most new cultivation targets land that permits mechanized harvest and offer soils and climate well-adapted to growing sugarcane without the need for irrigation. In other countries, such as Colombia and India, significant irrigation requirements raise the financial and environmental costs of production.

Figure 2.3 illustrates the projected supply curves in the baseline case for each country. The scale reflects the total potential supply from Brazil in 2027, which approaches 1.1 billion metric tonnes. Brazil's curve also lies below all others, reflecting lower reported production costs. The supply curve for India reflects a somewhat higher cost, with total potential supply approaching $450 \mathrm{mmt}$ in 2027 . The CBI nations reported costs ranging from $\$ 14-\$ 45$ and production levels that produce a steeply sloped curve when presented on the same scale with Brazil. The cumulative supply projected from CBI is over $100 \mathrm{mmt}$ by 2027. Reliable data were not available to construct state-level supply curves for sugarcane in China, Colombia and Argentina. Therefore, these supplies are represented as points, with modest outputs and higher costs compared to Brazil and India.

The approach for this study attempts to use the best data available at the state level from national sources. Most often, this involved local prices and currencies as reported by a ministry or department responsible for agriculture. The approach provided updated estimates of costs and supply for the model, regardless of whether the data are in a supply curve by state or based on a national analysis (in cases where state data were unavailable). However, the system used by the different sources to collect and report local price data varied. And conversion to 2005 US dollars using official exchange rates adds another factor of variability to the calculations. These variables reduce the reliability of cost comparisons across countries. Also, extremely high costs were observed for a few states (reaching over $\$ 100 / \mathrm{mt}$ ), these high-cost producers make negligible contributions to total sugarcane production.

The U.S. and Brazil are the world's top producers of fuel-ethanol. Brazil is the world leader in caneethanol production and fuel ethanol exports. Current sugarcane production in Brazil is split about equally between ethanol and sugar production, but the government predicts that most growth in production over the next decade will be dedicated to ethanol. And given that more than half of Brazil's sugar is exported, about $610 \mathrm{mmt}$ of sugarcane, or $82 \%$ of total feedstock supply in the 2017 baseline case, is calculated to be available for exports and/or biofuel production. When other cases are considered, the amount "available" from Brazil in 2017 ranges from $900 \mathrm{mmt}$ in the high growth case to $410 \mathrm{mmt}$ in the low growth case.

India's current ethanol production is derived mainly from molasses, a by-product of sugar-milling, rather than directly from sugarcane. Molasses was not assessed as a separate feedstock in this phase of the study. Based on the methodology, about 5\% of India's sugarcane production in the baseline case is estimated to be available for export or conversion to biofuel in 2017. In the low growth case, all sugarcane production is dedicated to food and feed uses, while in the high growth case, up to $35 \%$ could be available for export and/or biofuel. Similarly, only $2 \%$ of China's sugarcane harvest is expected to be available for biofuel uses in baseline projections, none in the low-growth case, and up to $29 \%$ in the high-growth case. 


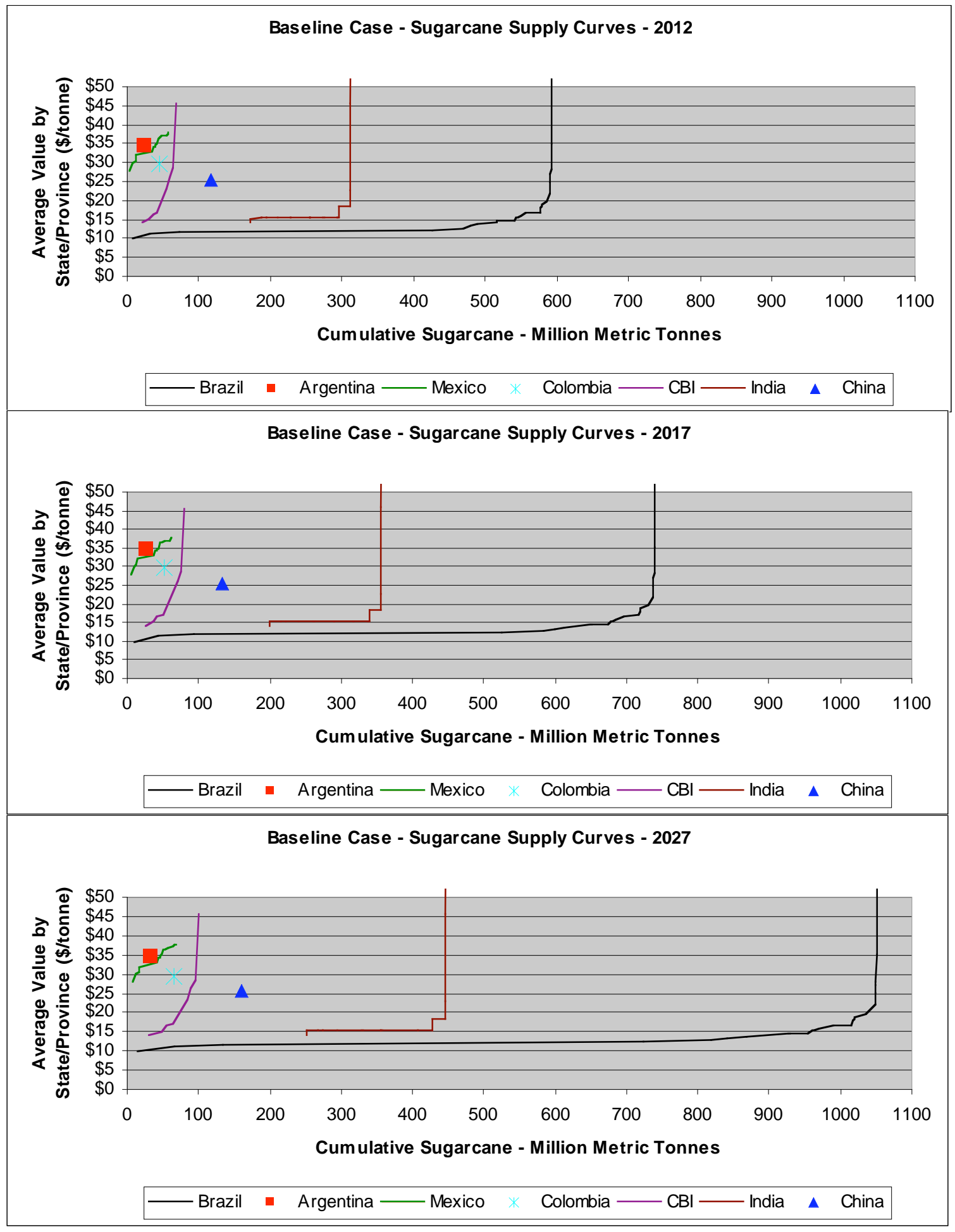

Figure 2.3. Baseline Case - Sugarcane Supply Curves. 
Although projected sugarcane production from other countries is small relative to Brazil and India, these countries could make substantial portions of their national production available for export and/or biofuel. In 2017 under the baseline case, the percentage of total national cane production "available" ranges from $13 \%$ for Mexico to 54\% for CBI, where it reaches $60-70 \%$ in the high growth case. The estimated supply availability for each country, crop and case is presented in the data tables in Annex 4. Figure 2.4 illustrates the estimated supply of sugarcane available for export and/or biofuel in 2017, converted to a gasoline equivalent basis, by source country.

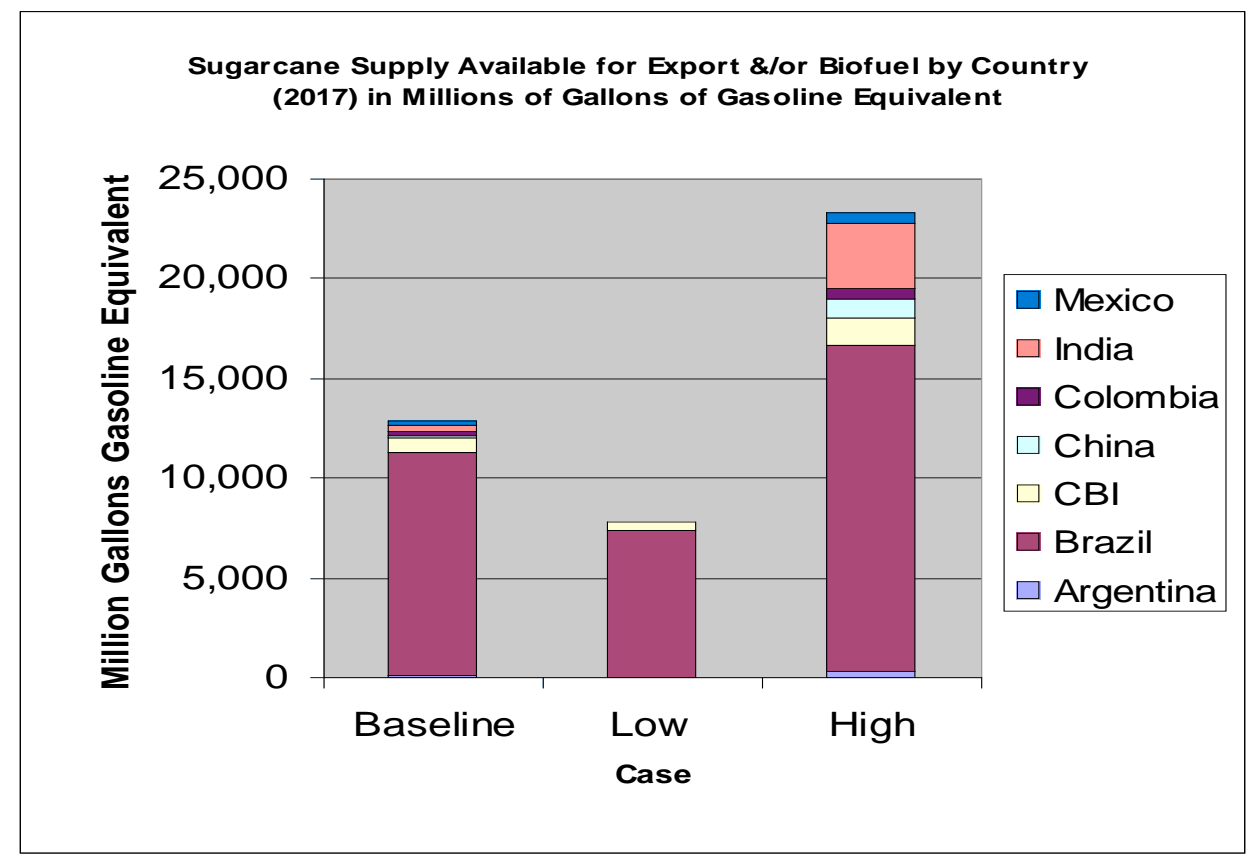

Figure 2.4. Sugarcane Supply 'Available' by Country, 2017 (Gasoline Equivalent Basis).

\subsubsection{Soybeans}

Total baseline case production by Argentina, Brazil and China, the three major producing countries considered for soybean feedstock, is projected at $156 \mathrm{mmt}$ in 2012, $202 \mathrm{mmt}$ in 2017, and $314 \mathrm{mmt}$ in 2027 (Figure 2.5). According to FAO, this group of countries produced about $108 \mathrm{mmt}$ of soybean in 2006. Brazil and Argentina account for more than $80 \%$ of the total projected supply. The study also considered Colombia's production, but it was negligible, at less than $1 \mathrm{mmt}$ in the high growth case.

Brazil, Argentina, and China are important players in the world soybean market, but for different reasons. Brazil and Argentina are the second and third largest soybean producers in the world, respectively, after the United States. And Brazil is the world's top exporter of soybeans, while Argentina is the largest exporter of soybean oil. China, on the other hand, is the world's largest importer of oilseed products, including soybeans. Brazil and Argentina displayed considerable potential to increase their soybean production. Brazil and Argentina also reported lower production costs than China and Colombia. In Brazil, soybeans often are the first choice when converting extensive low-intensity pastureland to annual crop production. 
In Argentina, soybean production is the dominant agricultural land use. Production is concentrated in the central region of Argentina, where flat terrain and climate make the land ideal for mechanized annual crops. In addition, unlike sugarcane, whose expansion potential is restricted in Northern provinces, the soybean producing states of Argentina have significant land available for expansion.

Soybeans currently are used for producing small amounts of biodiesel in Brazil and Argentina, but biofuel production could expand rapidly in the future if government targets for fuel blending are to be met. Argentina produced about 200 million liters of soybean-based biodiesel in 2007, and there are over 20 announced soy-based biodiesel projects with a potential capacity of 2 billion liters. Investors behind these projects are reportedly targeting the export market (USDA-AR 7016).

In Brazil, modest amounts of biodiesel are currently produced and consumed in the Center-West region where the importation of petroleum based fuels is expensive and soybeans are plentiful. However, the government has announced a mandatory $2 \%$ blend with fossil diesel by 2008 . Only 40 million liters were produced in 2005, but capacity increased to 730 million liters in 2006, and is planned to increase to 1.7 billion liters by the end of 2007. Between 60 and $80 \%$ of total Brazilian soybean production is available for exports and/or biofuel production, depending on the case and year. In Argentina, the estimated proportion is greater than $80 \%$ in all cases. In China, there currently are no plans to promote diesel production from soybeans. Figure 2.6 presents the estimated amounts of production available for export and/or biofuel from these three nations.

\subsubsection{Corn}

Total baseline case production by the five countries considered for corn feedstock is projected at 280 $\mathrm{mmt}, 325 \mathrm{mmt}$, and $427 \mathrm{mmt}$ in 2012, 2017, and 2027, respectively (see Figure 2.7). According to the FAO, this group of countries produced $234 \mathrm{mmt}$ of corn in 2006. China is the dominant producer among these countries, accounting for almost two-thirds of the $325 \mathrm{mmt}$ projected in the 2017 baseline case. Brazil, is the second-largest corn producer with an estimated $55 \mathrm{mmt}$ in the 2017 baseline case.

Corn is a major global market commodity but among the countries considered in this study, nearly all production is used for domestic feed and food purposes, leaving very little for biofuel unless production can approach high growth case levels. The exception is Argentina, which exports about $60 \%$ of its output. In 2017, none of the projected corn supply from the other nations is expected to be available for export or biofuel under the low-growth case and less than $10 \%$ of supply is "available" in the baseline cases.

Corn-based ethanol production in most of the countries assessed is limited, especially compared to the United States. Only Canada reported explicit plans for significant future development of corn-based ethanol, although China has used corn as a feedstock in the past and Argentina is looking at the possibility of corn as biofuel feedstock in the future. Policies prioritizing food security make it unlikely that large amounts of future corn supplies would be used for biofuel in most other countries. But producing countries with capacity to increase production may do so to fill the market niche that is expanding as the U.S. and Canada allocate more corn to biofuel.

Considerable variation was observed in the reported average production values across states in each country, but the implied national average value per tonne for most countries was in the $\$ 140-\$ 160$ range (in 2005 US\$). For Canada, state level data necessary to construct supply curves were obtained from the Agricultural Income Support program and reportedly reflect "fair market value" of production. These values were consistently lower than those reported from other countries, ranging from $\$ 88-\$ 124$ per tonne. State level prices were not available for corn in Argentina and China, so average national price data were used. 

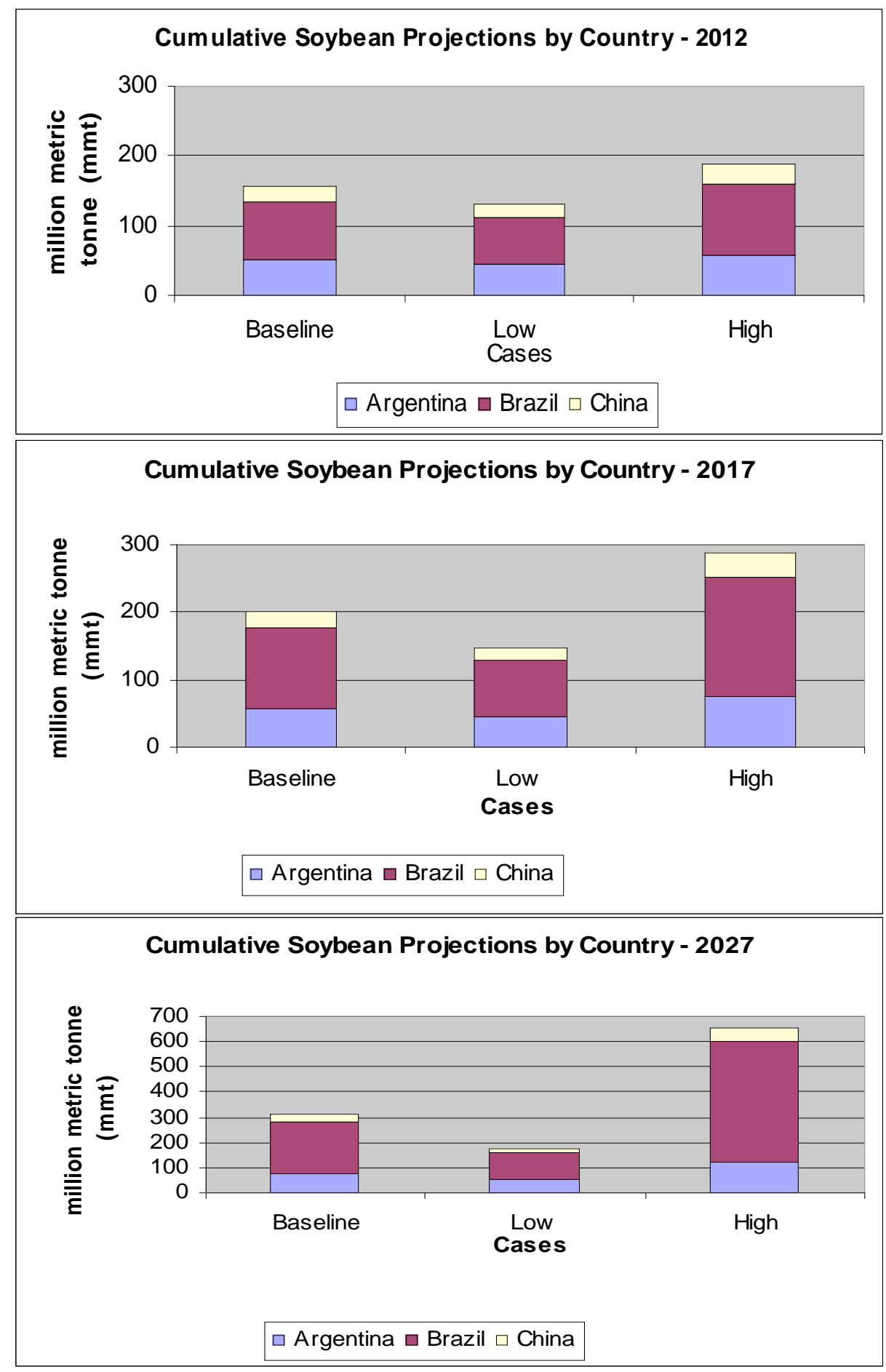

Figure 2.5. Total Projected Soybean Supply Potential by Country. 


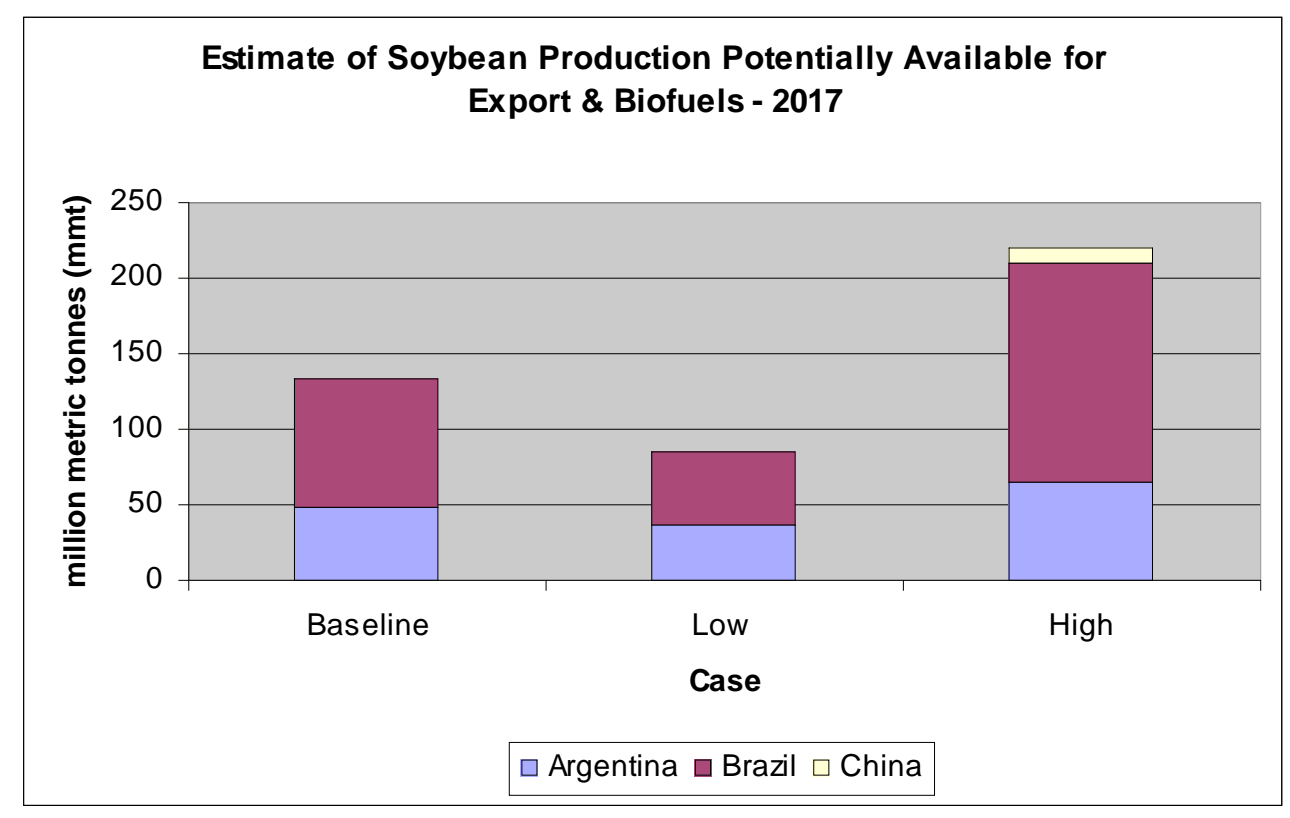

Figure 2.6. Total Projected Soybean Supply 'Available’ by Country, 2017.

\subsubsection{Wheat}

Total baseline case production from China, Canada and Argentina, the three countries considered for wheat feedstock in this study, is projected at $153 \mathrm{mmt}, 160 \mathrm{mmt}$, and $176 \mathrm{mmt}$ in 2012, 2017, and 2027, respectively (Figure 2.9). According to the FAO, this group of countries produced about $146 \mathrm{mmt}$ of wheat in 2006. China, the world's second largest producer of wheat, accounts for about two-thirds of the total projection in the 2017 baseline case. China is traditionally a net importer of wheat, although increasing production has allowed imports to fall steadily in the late 1990's and permitted modest exports in a few more recent years. Canada and Argentina exported about $52 \%$ and $82 \%$ of their outputs in 2005, respectively, suggesting that a large share of their future production would be available for export and/or biofuel. As shown in Figure 2.10, Canada and Argentina are projected to have about $30 \mathrm{mmt}$ of wheat available for export or biofuel in the 2017 baseline case. China's production would only become significant in terms of exports under the high growth case projections. Average wheat production costs reported in Canada and Argentina are considerably lower than in China.

Western provinces in Canada currently use wheat as feedstock for ethanol. It accounted for about $20 \%$ of national bio-ethanol production in 2006. Several new plants are planned or under construction and this study estimates that $2.5 \mathrm{mmt}$ of wheat could be dedicated to ethanol in Canada by 2012. Ethanol plants allow producers to market lower quality, "downgraded" feed wheat. Given ambitious fuel-blending targets, the use of wheat for biofuel is expected to be allocated to meet domestic ethanol demand in Canada. There were no specific plans to use future wheat supplies in China or Argentina for biofuel production. 


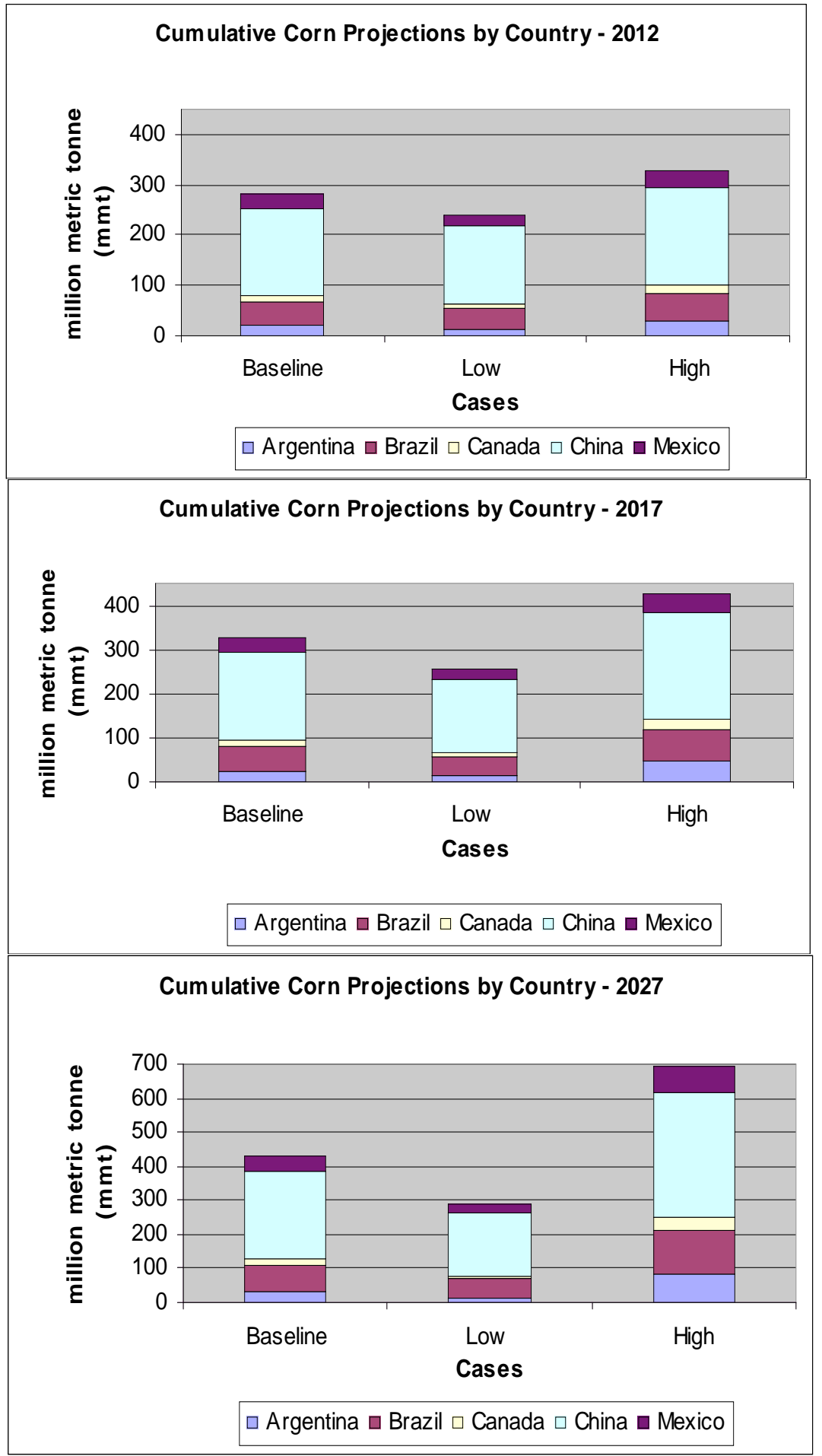

Figure 2.7. Total Projected Corn Potential Supply by Country. 


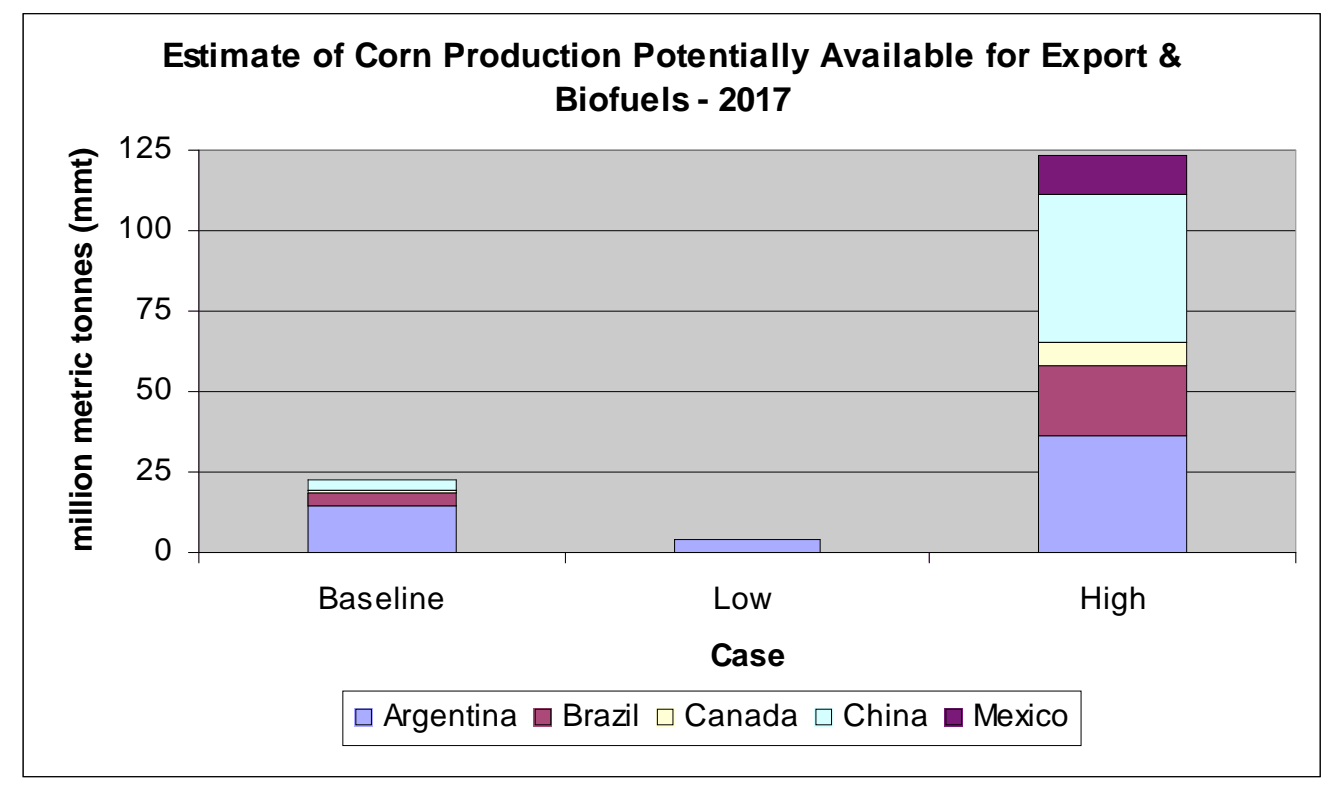

Figure 2.8. Total Projected Corn Supply ‘Available’ by Country, 2017.

\subsubsection{Palm Oil}

Palm oil production among the countries considered in this phase of the study is small relative to Southeast Asia where most supply in global markets originates. Data were available for Colombia and several nations in the CBI region, led by Guatemala and Honduras. Total baseline case production in these countries is projected at $2.3 \mathrm{mmt}$ in 2012, $3.3 \mathrm{mmt}$ in 2017, and $6.6 \mathrm{mmt}$ in 2027 (Figure 2.11). In 2006, these countries produced about $1.3 \mathrm{mmt}$ of palm oil. Reported costs of production varied widely, ranging from $\$ 240-\$ 450 /$ tonne of crude palm oil, reflecting both differences in data collection among countries and in plantation operations. While total supply in the countries studied is small relative to other feedstock crops, and only represents about $3 \%$ of global palm oil production, the projections show the highest rates of growth in percentage terms of any feedstock studied. Palm oil supplies in Colombia and CBI are estimated to increase over $150 \%$ by 2017 when compared to 2006 in the baseline case, and as much as $250 \%$ in the high growth case

Palm oil plantations are expanding rapidly in the region to support biodiesel production to meet new local mandates for biodiesel blends. For example, tax incentives have spurred expansion in Colombia where the government has targeted a 5\% biodiesel blend in national diesel consumption by 2008. Reports from Guatemala indicated that palm plantations doubled in size between 2005 and 2007, from about 20,000 hectares to 55,000 hectares. Nearly half of the production from the countries studied is expected to be available for export and/or biofuel in the baseline case (Figure 2.12). 

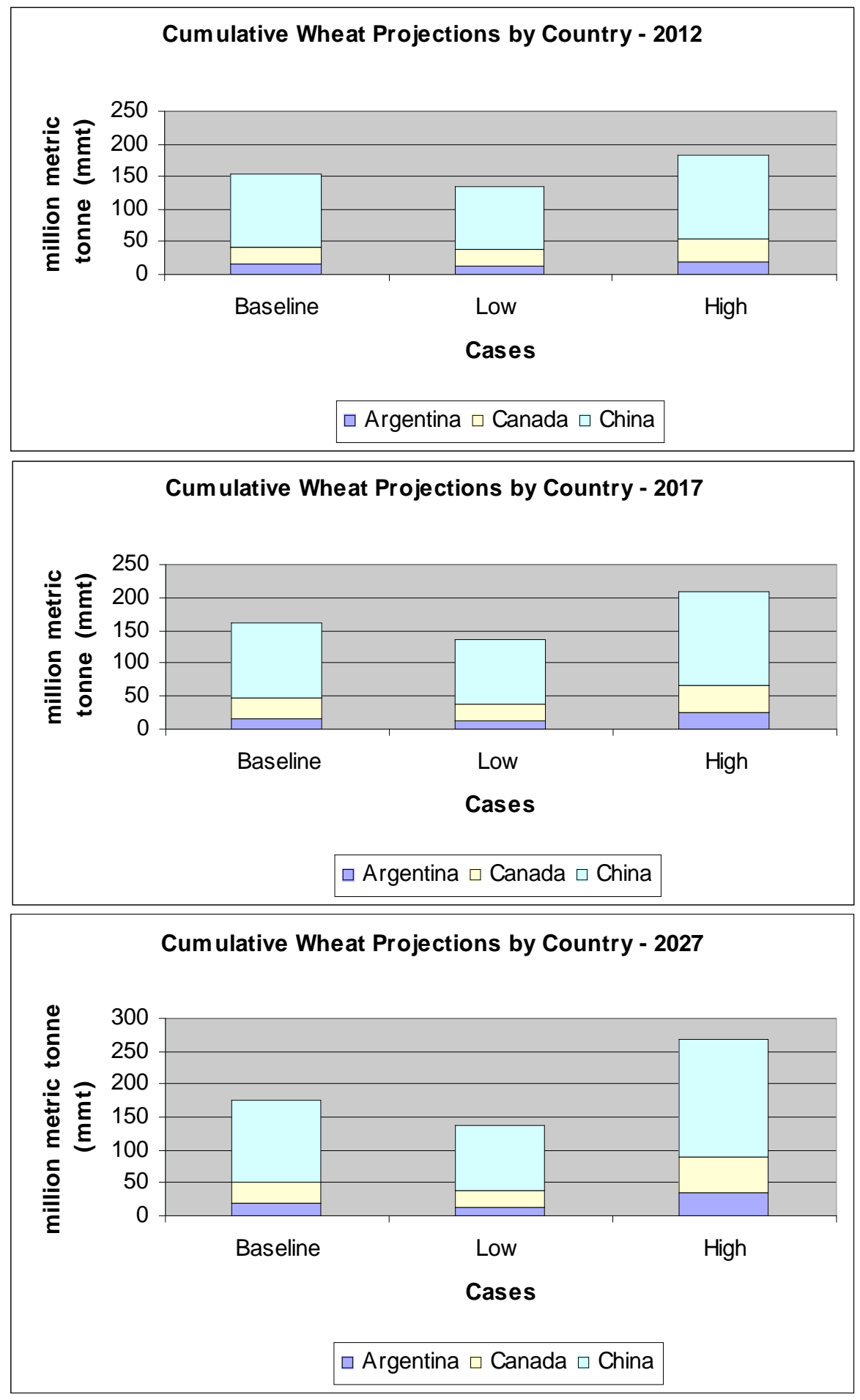

Figure 2.9. Total Projected Wheat Supply Potential by Country. 


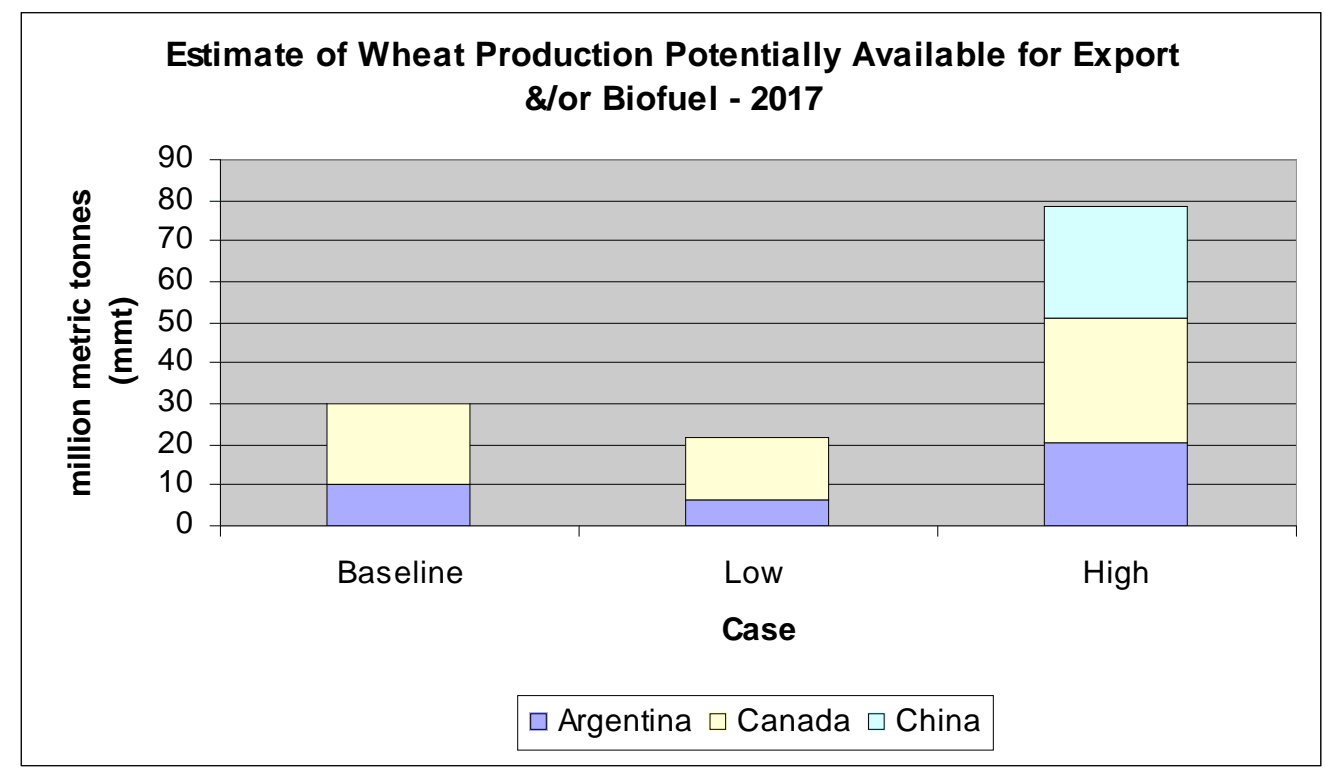

Figure 2.10. Total Projected Wheat Supply ‘Available’ by Country, 2017.

\subsubsection{Cellulosic Feedstock}

Cellulosic material is not presently a significant feedstock for liquid biofuel production. Global efforts to develop cost-effective conversion technologies are underway with the goal of creating opportunities for cellulosic wastes to become a major source of feedstock in the future. This study offers indicative estimates of potential cellulosic feedstock available from three broad categories in the 2017-2027 timeframe: (1) recoverable residues as a function of the projected feedstock crop supplies in 2017 and 2027 (based on the results for each crop and case in this study); (2) a percentage of wastes and biomass associated with current forestry activities and fuelwood supplies; and (3) the potential to harvest perennial biomass crops as a function of estimated productivity and arable land availability. Using available data, the cellulosic projections for the latter two categories provide a preliminary estimate of the relative importance of potential supplies from these sources among the countries studied. Cellulosic feedstock supplies are presented in bone-dry metric tonnes.

Crop Residues. The amount of recoverable residues as a function of the projected crop production in 2017 ranges from $182 \mathrm{mmt}$ in the low growth case to $344 \mathrm{mmt}$ in the high growth case, and sums to $246 \mathrm{mmt}$ in the baseline case. The baseline estimate includes $187 \mathrm{mmt}$ from bagasse, $40 \mathrm{mmt}$ from corn stover, 17 $\mathrm{mmt}$ from wheat straw and $2 \mathrm{mmt}$ from palm oil processing wastes. Due to environmental considerations, none of the wastes from soybean harvesting is assumed to be recoverable. Total crop residues recoverable in 2027 are projected at $326 \mathrm{mmt}$, ranging from $200 \mathrm{mmt}$ to $570 \mathrm{mmt}$ in the low and high growth cases. The recoverable crop residue estimates summarized here are based solely on the crop-country combinations studied. The distribution of estimated recoverable crop residues by country is presented in Figures 2.13 and 2.14 (for all three cases in 2017 and 2027, respectively). 

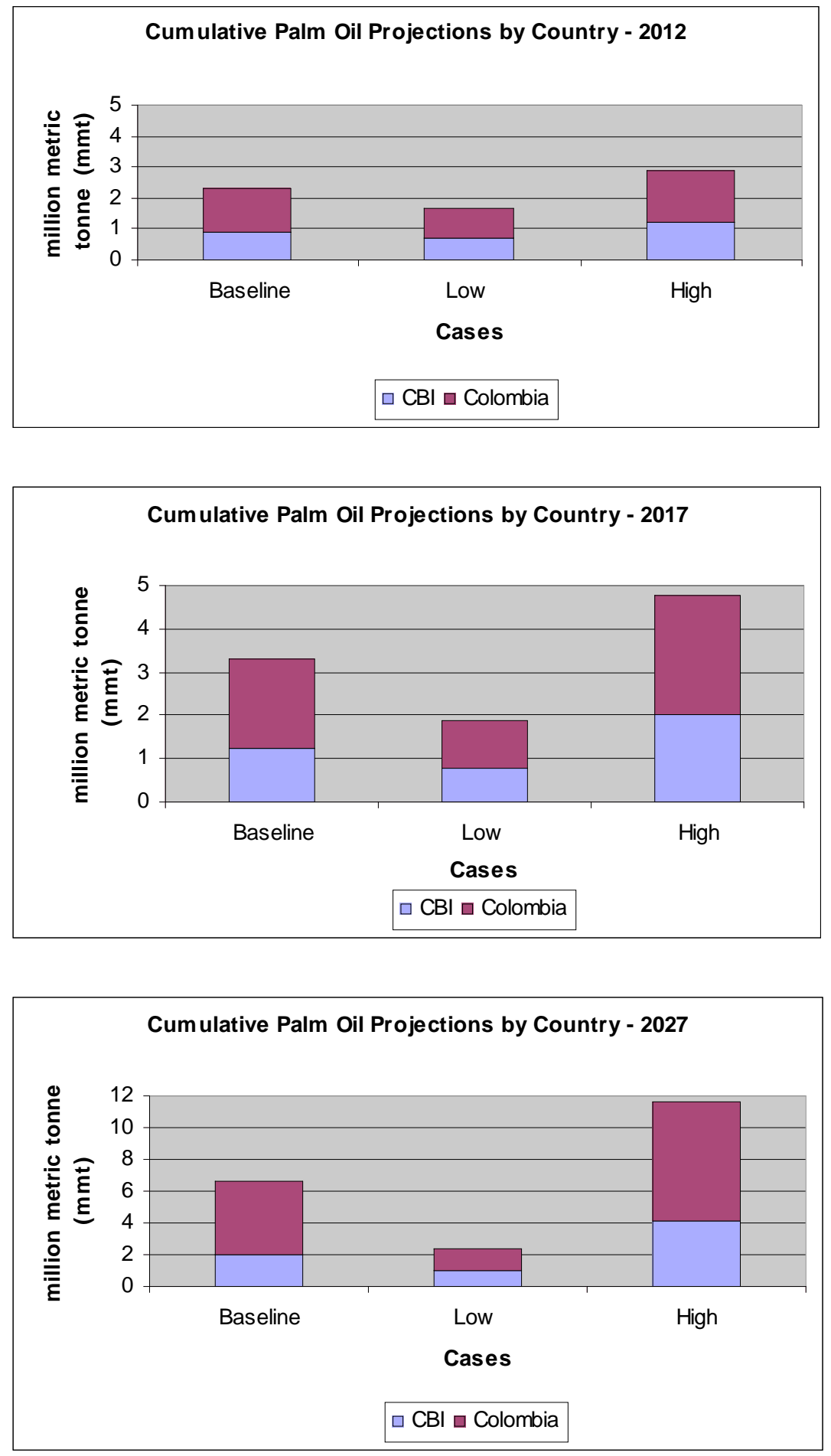

Figure 2.11. Total Projected Palm Oil Supply Potential (CBI and Colombia). 


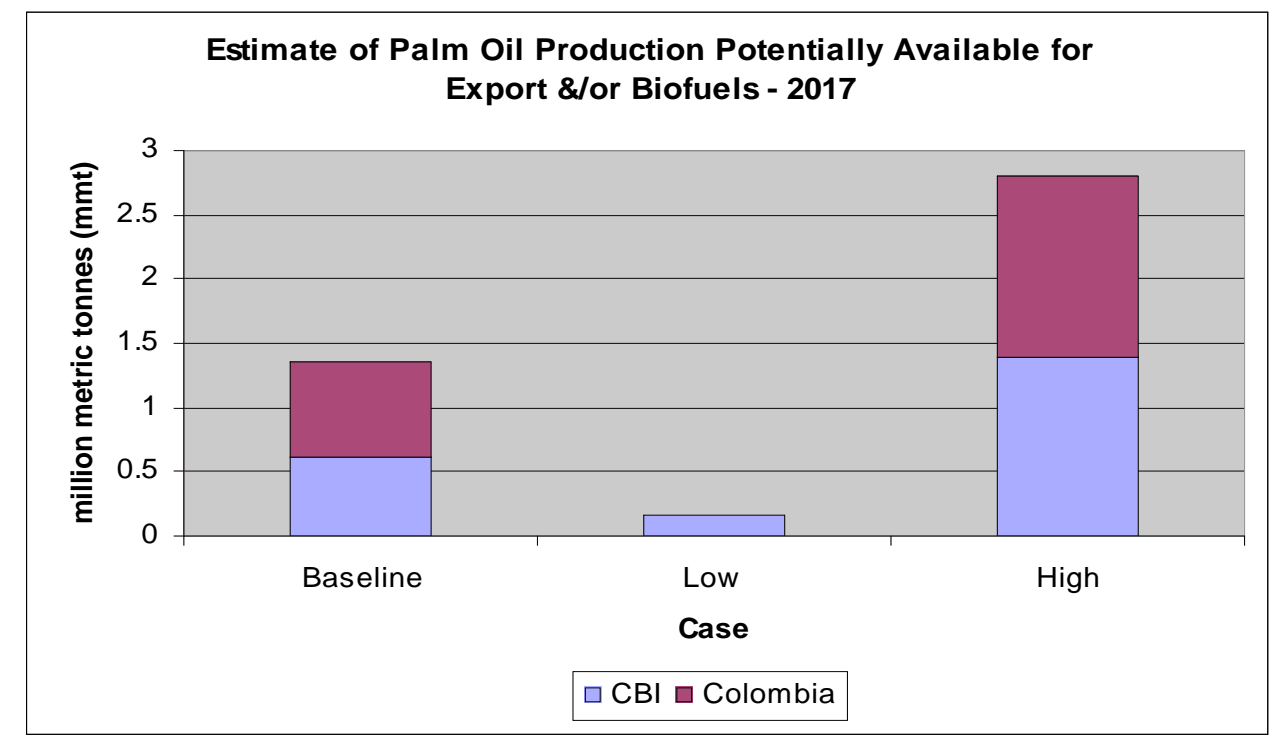

Figure 2.12. Total Projected Palm Oil Supply 'Available’ by Country, 2017.

Bagasse - the crushed stalk residue from sugarcane processing — is by far the most important single cellulosic resource identified in the study, representing about $75 \%$ of all agricultural crop residues in 2017 and about $40 \%$ of total cellulosic supplies estimated in that year. More importantly, bagasse is conveniently available at sugar-ethanol refineries and, therefore, along with much smaller supplies of palm oil processing wastes and on-site wood mill residues, is estimated to be the most economic cellulosic resource, with opportunity costs in the range of $\$ 8$ to $\$ 17$ per dry tonne (in 2005 US\$).

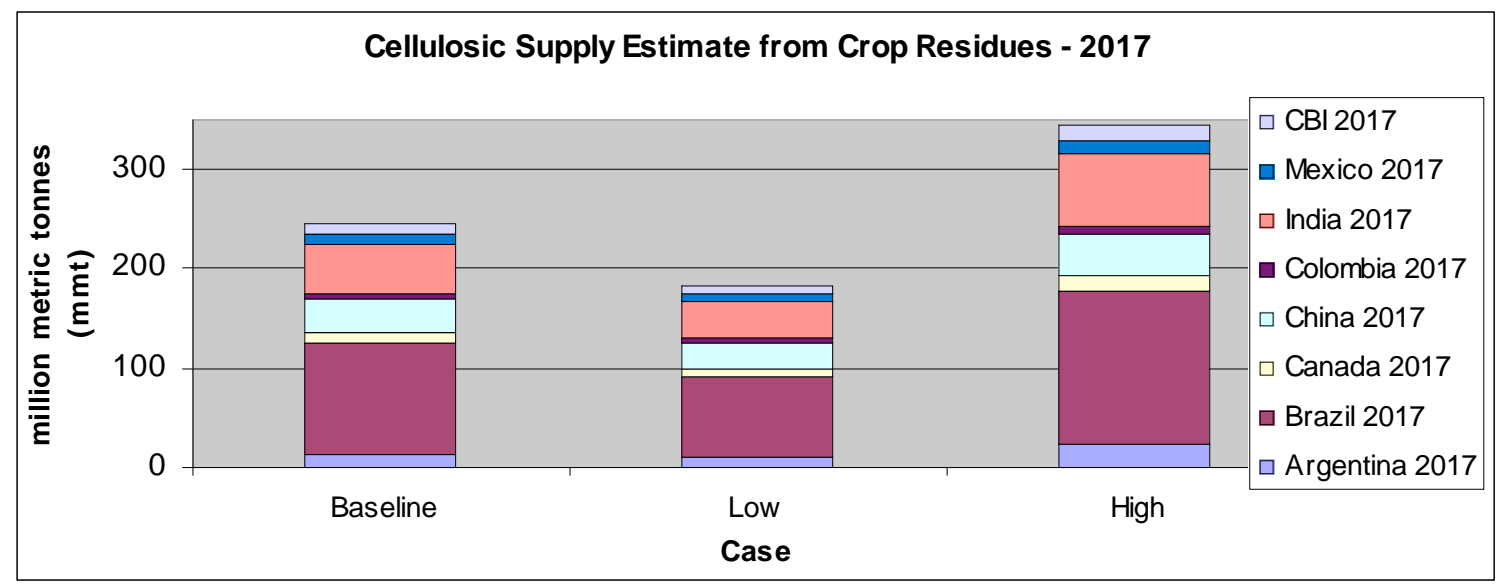

Figure 2.13. Aggregate Cellulosic Supply Projection from Crop Residues, by Country - 2017. 


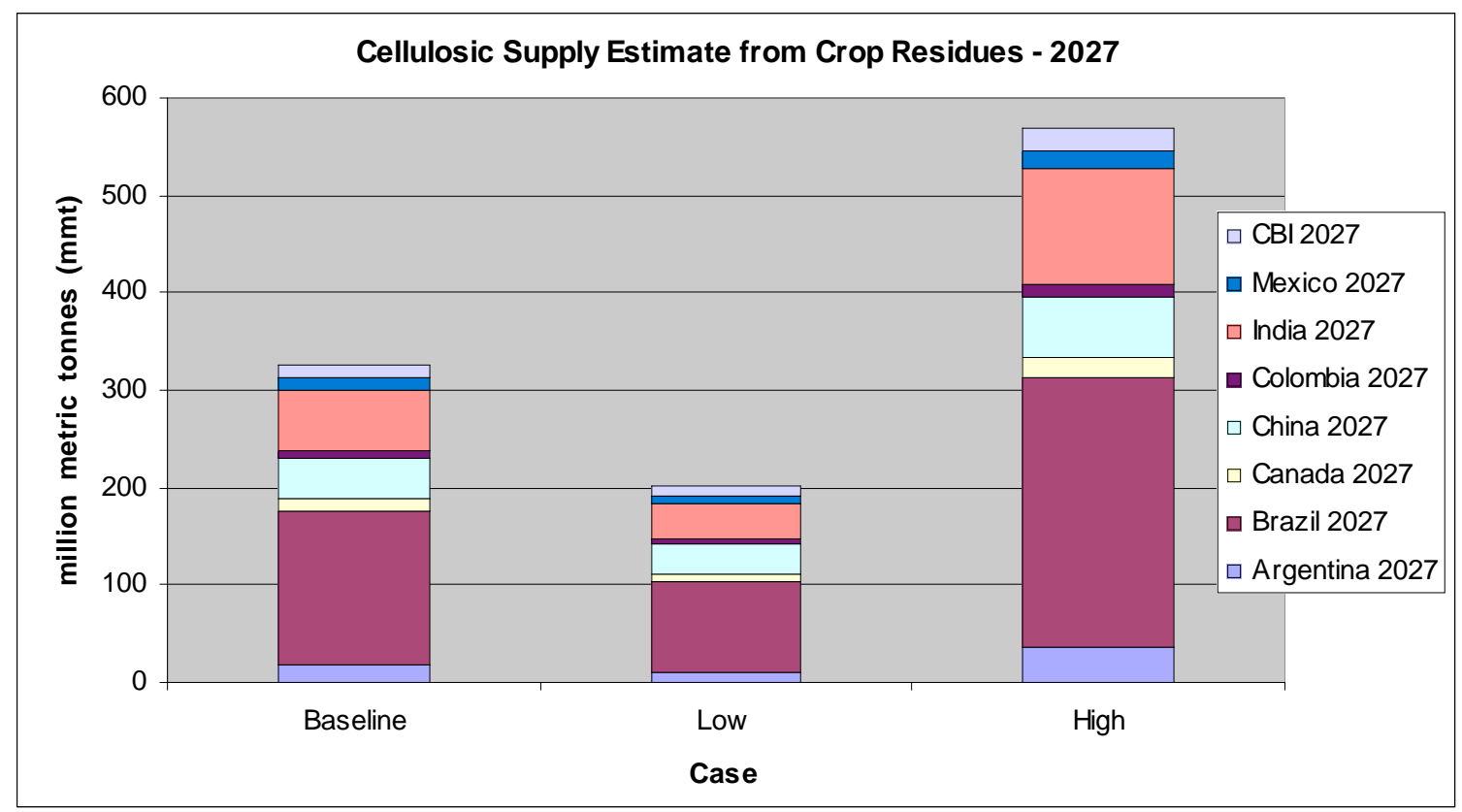

Figure 2.14. Aggregate Cellulosic Supply Projection from Crop Residues, by Country - 2027.

Forest Sector and Perennials. Other cellulosic supplies from forestry activities and potential perennial production were estimated for each country studied. Potential supply projections from fuelwood industries were based on 50\% of current reported supplies (FAO 2005), resulting in an aggregate estimate of $154 \mathrm{mmt}$. As discussed in the country-specific analyses, prices for fuelwood can vary greatly and if consumption of fuelwood for basic cooking in a country remains constant or grows over the next decade, that market is likely to prevail over biofuel. An additional $36 \mathrm{mmt}$ of wood residues are projected to be recoverable from other existing forestry industry activities such as mill wastes and recoverable forest harvest residues. Perennial production as feedstock for biofuel was projected as a function of estimated land availability in the countries studied. Supplies from perennials are estimated to range from 50-100 $\mathrm{mmt}$. The perennial and forest sector estimates were designed primarily to show the relative potential among the countries studied. The relative potential from forestry activities and perennials is illustrated in figure 2.15. It can be observed that Brazil predominates under potential from perennials based on land availability (Brazil represents $70 \%$ of potential among countries studied, with Argentina and Colombia at $10 \%$ each, representing most of the remainder). The scale of forest industry activities in India, China, Brazil and Canada offers relatively large potential wood residue supplies in those countries compared to others studied. A more refined analysis of cellulosic supplies is recommended as a future task, based on better definition of the feedstock characteristics desired for cost-effective conversion. 


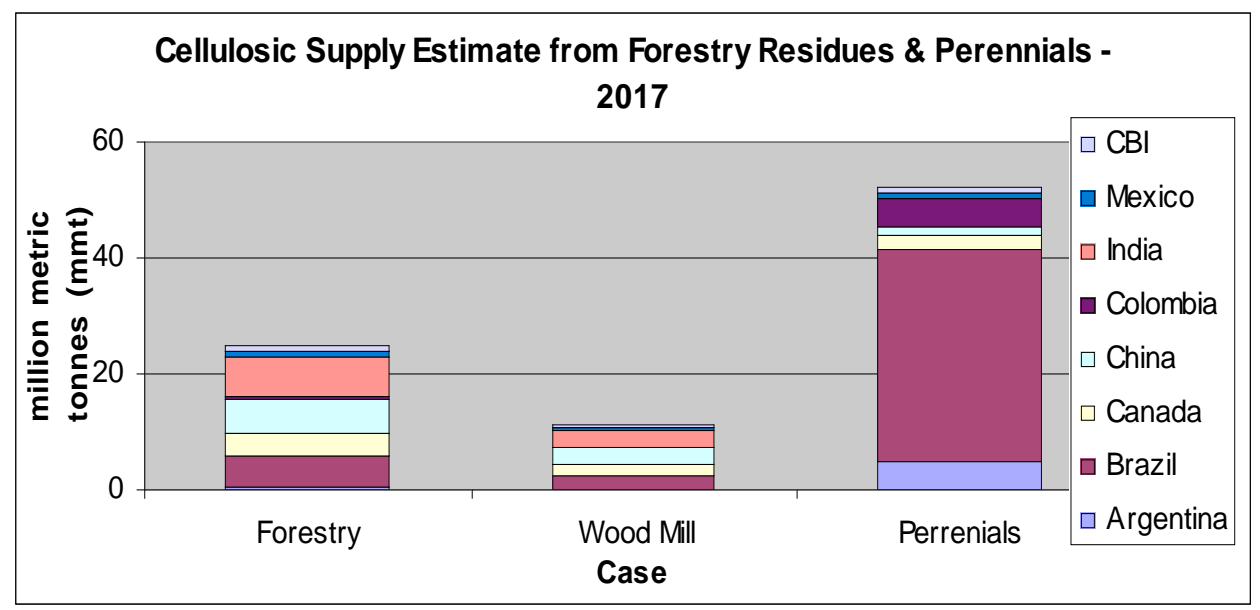

Figure 2.15. Aggregate Cellulosic Supply from Forestry and Perennials, by Country - 2017.

All potential cellulosic supplies as projected under the 2017 baseline case in this study are summarized in Table 2.1. (See Table ES-3 for disaggregated data by country and source.) Table 2.1 includes supply projections within estimated price ranges that vary by source and country. The projected supply values reflect estimates of cellulosic feedstock availability within a range of costs assumed in the study, as described in more detail in the country reports and Annex 3 (Methodology).

Table 2.1. Cellulosic Supply Projections within Study Price Ranges (2017 Baseline Case)

\begin{tabular}{|c|c|c|}
\hline \multicolumn{3}{|c|}{$\begin{array}{c}\text { Cellulosic Potential from Selected Sources and Countries - } \\
\text { Estimated Quantity within Price Range (2017 Baseline) }\end{array}$} \\
\cline { 1 - 2 } & $\begin{array}{c}\text { Price Range } \\
\text { Feed US\$ per } \\
\text { dry mt) }\end{array}$ & $\begin{array}{c}\text { Recoverable } \\
\text { Amount } \\
(\mathrm{mmt})\end{array}$ \\
\hline Palm Oil Waste & $\$ 1$ & 2 \\
\hline Sugarcane Bagasse & $\$ 8-\$ 17$ & 188 \\
\hline Wood Mill Residues & $\$ 18-\$ 36$ & 11 \\
\hline Fuelwood & $\$ 13-\$ 50$ & 154 \\
\hline Wheat Straw & $\$ 39-\$ 52$ & 17 \\
\hline Corn Stover & $\$ 39-\$ 52$ & 40 \\
\hline Soybean residues & $\$ 39-\$ 52$ & 0 \\
\hline Forestry Harvest Residues & $\$ 50-\$ 100$ & 25 \\
\hline Perennials & $\$ 52$ & 52 \\
\hline Total & & $\mathbf{4 8 8}$ \\
\hline
\end{tabular}

The average estimated costs for cellulosic supplies in a given country are subject to variations depending on assumptions related to productivity, collection and transportation. ${ }^{\text {xlvii }}$ The cellulosic feedstock supplies projected in Table 2.1 include projections of sustainable recovery of corn stover and wheat straw, and portions of fuelwood supply and wastes associated with industrial forestry activities. The sum of all cellulosic supplies estimated for the 2017 baseline case is $488 \mathrm{mmt}$. As illustrated in Figure 2.16, the majority of this supply is derived from sugarcane bagasse (39\%), fuelwood (32\%) and perennials (11\%). 
The estimates for fuelwood and perennial cellulosic supplies have much higher projected costs than bagasse and palm oil wastes (Table 2.1). And the projections for bagasse and palm wastes are subject to less uncertainty. Diverse supply and household demands for fuelwood may limit its availability for biofuel while there is very limited experience with perennials for biofuel production.

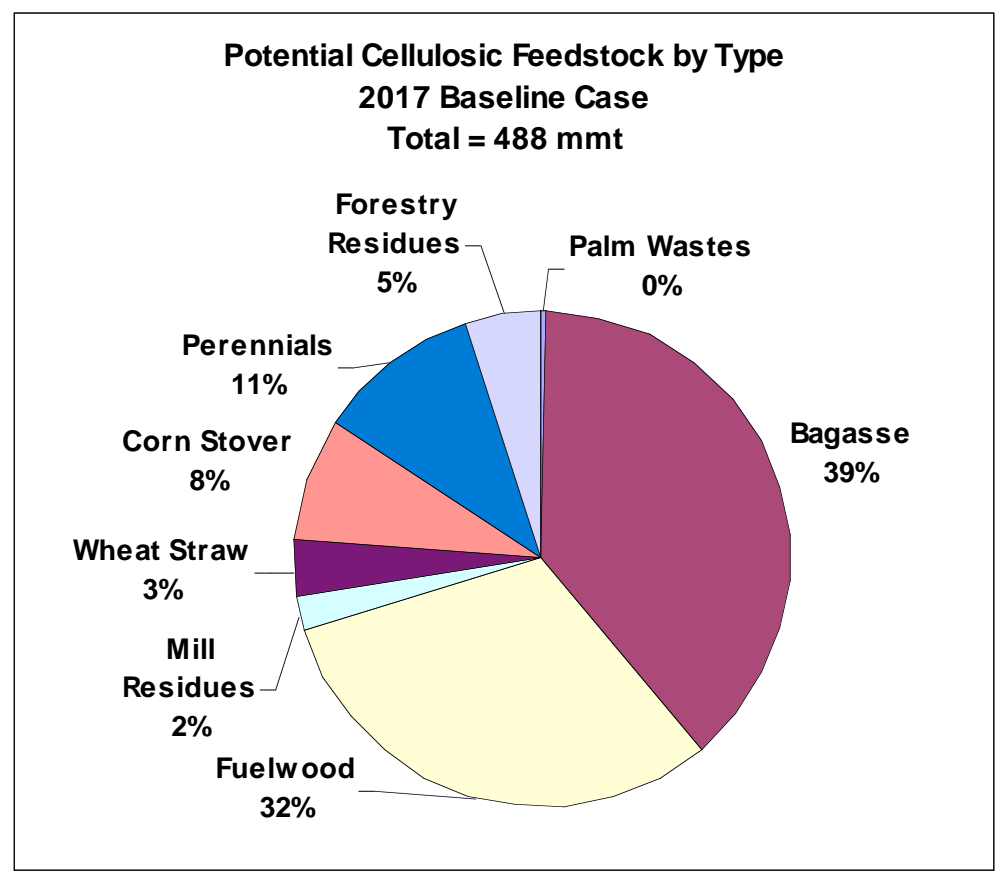

Figure 2.16. Aggregate Cellulosic Supply Projection, by Source - 2017.

Of the $488 \mathrm{mmt}$ total cellulosic supply projection, about half $(241 \mathrm{mmt})$ is projected to be valued at US\$ $36 /$ dry tonne or less in the 2017 baseline case. Figure 2.17 shows the distribution of feedstocks in this more economical range. Bagasse represents over three quarters of the lower cost cellulosic supplies, followed by fuelwood. If fuelwood availability is limited by household demands, bagasse will represent an even greater share of economical cellulosic supplies. The price range for bagasse reflects the estimated opportunity cost given current uses as a fuel (direct combustion) and fiber. Although most bagasse is currently burned as boiler fuel for sugar processing, improving efficiencies over the coming decade is expected to allow an increasing portion of bagasse to be allocated to other uses, including biofuel, and will contribute to improving sugar-ethanol plant economics. And the availability of bagasse is a factor of the size and growth of sugarcane industries discussed above, where Brazil represents over half of the future supply among countries studied.

Although available in much smaller quantities in the countries studied, palm oil processing plants handle cellulosic waste in volumes of one-to-two times palm oil output. The wastes exceed thermal process needs and can present disposal costs, making them ideal candidates for future biofuel feedstock. 


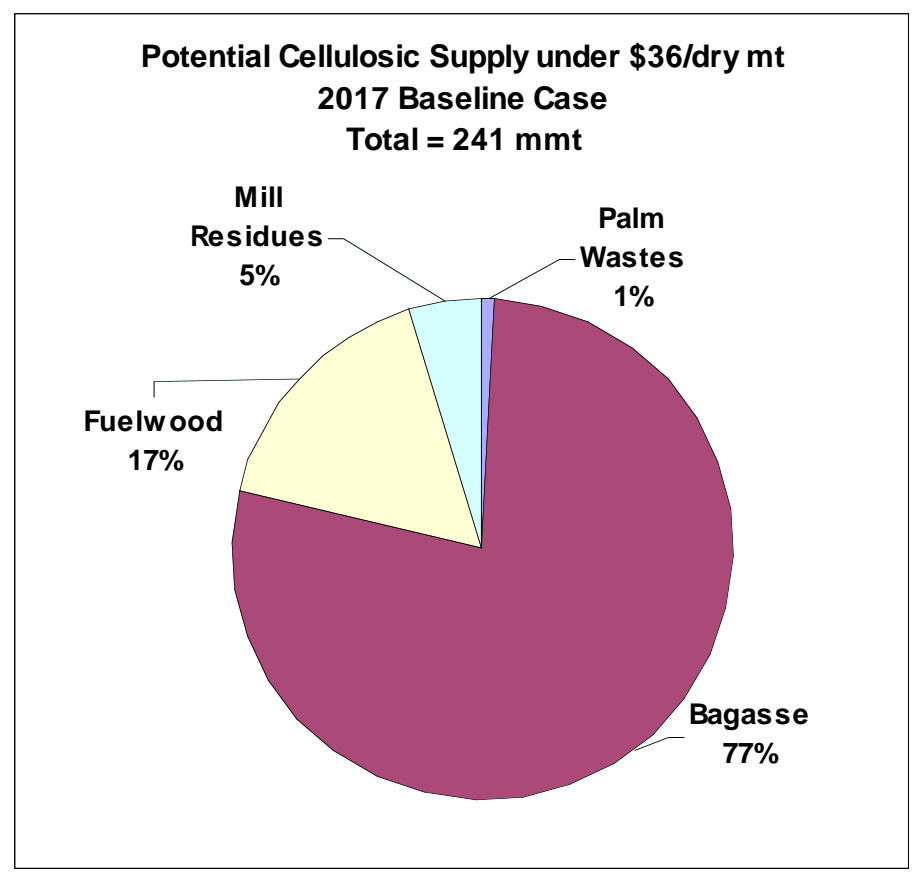

Figure 2.17. Cellulosic Supply Projection Valued $\leq \$ 36$, by Source - 2017 .

Sugarcane-ethanol and palm oil biodiesel are the two fastest growing biofuel sectors identified in the study and their on-site endowments of biomass wastes will facilitate transition to cellulosic-based production with relative ease in the future. Given that conditions for sugar and palm oil production are correlated with high biomass productivity, producing states are likely to enjoy comparative advantages in other cellulosic feedstock (high yields for perennials, for example) if and when the technology and costs permit this line of production to become competitive.

\subsection{ENVIRONMENTAL AND SOCIAL ISSUES}

Biofuel feedstock production can have negative or positive effects depending upon the local situation and factors such as crop type, the methods used to cultivate and harvest it, and what the alternative land use would be. A recent book, Biofuels for Transport, notes that biofuels offer tremendous potential benefits "if policies are enacted to steer developments in the right direction." environmental and social issues associated with expanding global biofuel production, including food security, greenhouse gases, expansive monoculture production systems, and poverty, finding both risks and opportunities. ${ }^{\text {xlix }}$ Although several concerns are observed in specific instances, there appears to be a growing consensus that if best practices for socially and environmentally sound development can be applied, then appropriate biofuel feedstock crops could offer farmers enhanced employment and incomes while reducing the burden of foreign oil imports on developing nations. Best practices should guide production systems to be increasingly socially responsible and environmentally sound. Optimizing system efficiency by minimizing and recycling wastes in a manner that maintains productivity is important and some feedstock crops (such as sugarcane in Brazil) appear to be moving in that direction. But any rapid agricultural expansion poses risks if it distorts markets and disregards local needs, or undermines human rights, equity and long-term sustainability. 
The scope and degree of social, environmental and political constraints associated with increased biofuel feedstock production vary depending on the crop and the country. Capacity for land use planning and enforcement is important to avoid or minimize detrimental impacts associated with expanding areas under any form of cultivation. Brazil, for example, has enacted progressive environmental protection regulations but faces many challenges in achieving compliance. Agricultural expansion in Brazil (particularly soybeans) has generated concern among stakeholders about potential contributions to deforestation and pollution in the Amazon and other sensitive ecosystems. And while increases in the area used for sugarcane typically come from previously cleared land (primarily pastures), it is difficult to determine what impact this may have on more distant agricultural frontiers. ${ }^{1}$

Deforestation, land tenure, water use and pollution represent important and politically delicate issues in most countries. In some countries, concerns have been raised over small-farmer and indigenous land rights and the loss of biodiversity due to expanding palm oil plantations in tropical low lands. A positive trend is that recent growth in biofuel feedstock production has been accompanied by increased local and international attention to what are often long-standing social and environmental development challenges. ${ }^{\text {li }}$ Stakeholder participation in discussing the issues of expanding production of biofuel feedstock has been supported by various sectors (industrial, government and environmental) and is producing growing networks of practitioners at multiple scales. The increased transparency is generating a better understanding of the issues and mechanisms to address them. These may serve as important mechanisms to promote more sustainable systems for feedstock production, harvest and transformation.

This report focuses on feedstock production as one phase in a much larger biofuel industry. The methodology makes future projections of potential feedstock supply based on historic trends and averages. These historic trends reflect the variations and increasing yields due to changing technology, cultivars and other factors. Using average numbers often masks short term fluctuations caused by a suite of factors including weather, markets and policies. Furthermore, the ability to produce feedstock does not necessarily translate into its conversion and availability as a biofuel. The country level analyses partially account for this by providing an estimate of "available" supply that excludes domestic demand for food, feed and fiber from the baseline case projections. This represents an amount of total supply calculated to be available for export or biofuel allocation. The allocation of "available" supply to biofuel will greatly depend on future market, social and political factors.

The following sections discuss a range of social, economic, institutional, and environmental factors that may affect the types and quantity of feedstock or biofuel that can be supplied for future export to global markets. General trends and examples are cited from the countries studied related to soil, water, land use, policies and social factors. This study attempted to make reasonable supply projections while considering and acknowledging these issues in the methodology and individual country analyses. Some of these issues, particularly the policies, are evolving and the discussion here reflects information available at the time research was undertaken (June-August, 2007).

\subsubsection{Soils}

Any agricultural system needs to maintain soil health and productivity to be sustainable in the long term. Traditional annual feedstock production including intensive corn and soybean cultivation, has often been associated with soil degradation and erosion. Negative impacts tend to be more severe in large scale operations where machinery is heavier (leading to soil compaction) and tillage is more expansive and intensive thereby creating more opportunity for erosion from wind and rain. Improved crop varieties combined with the use of fertilizers, pesticides, herbicides and irrigation, has compensated for negative soil impacts as reflected in consistent yield increases over time (on average and thus far). Expansion of annual crops for biofuel will likely have negative consequences on long-term soil health and productivity unless more sustainable practices are employed. Studies referenced in country analyses (Chapter 3) 
specifically note some of the concerns associated with expanding corn and annual cultivation in Argentina, Colombia and Canada. Other cultural practices including site preparation, irrigation, and the use of fire, fertilizers, pesticides and herbicides, can impact soil health. Furthermore, if cultivation takes place in environmentally sensitive ecosystems (wetlands or tropical forests) or on marginal lands (steep slopes or shallow soils), negative soil impacts may be unavoidable and special precautions may be required to mitigate them both for site productivity and to reduce damage to surrounding ecosystems.

Over several decades, the sugarcane industry has researched options to return liquid and solid processing residues to fields and has developed sophisticated procedures and guidelines for recycling wastes and maintaining productivity. Sugarcane industries in some nations, such as Guatemala and Colombia, have consistently improved yields, in part by ongoing improvements in soil management. Studies in Brazil have suggested that commercial sugarcane plantations reduced erosion and improved soil quality when compared to prior land uses. However, traditional cane operations often involve annual burning of fields prior to harvest, with associated loss of nutrients and increased proclivity for subsequent erosion.

The use of crop residues as a cellulosic feedstock poses serious consequences if removal exceeds sustainable levels - e.g. if it contributes to erosion or loss of productivity due to reduced nutrients and soil quality (texture, beneficial microbial life and water retention capacity). The methodology used in this study assumes zero sustainable cellulosic recovery from soybean harvesting because residues are necessary to mitigate erosion and soil degradation. About two-thirds of corn residues are assumed to be needed for similar reasons, leaving $33 \%$ as stover available for sustainable recovery. And 14\% of wheat residue is assumed to be recoverable as straw (see Methodology). However, the costs associated with collection and transport of harvest residues may create incentives for "all or none" approaches where residues are collected at higher (unsustainable) rates from the most economical locations and the majority of residues (that are more distant from processing plants or more costly to collect) are not recovered at all. The economics of collection make it difficult to insure that appropriate proportions of annual crop harvest residues are left in fields to maintain soil quality and productivity.

Any parcel of land requires management appropriate to the site conditions to control erosion and maintain or improve soil health and quality. Well managed perennial crops such as sugarcane, perennial grasses and trees are more likely to curb erosion than crops that require more intensive annual tillage. The longterm sustainability of biofuel feedstock production will depend on the development of crops and practices that preserve or improve soil productivity. Based on historic trends and available options to manage this issue, loss of soil quality was not identified as a major constraint to feedstock supply over the coming decade.

\subsubsection{Water}

In some geographic areas, water availability and costs are expected to increasingly become limiting factors for expanding agricultural production, including most feedstocks studied. The local climate combined with a crop's water requirements and other economic factors help to dictate the need for and use of irrigation. Crops with high value and high input costs are often irrigated even though they are produced in areas where average rainfall could support a fair level of production. Irrigation in these cases reduces uncertainty and the risk of loss due to drought and allows more intensive cultivation and precise planning of inputs. Growing climate variability and climate change increase the amount of land area where irrigation (and drainage) infrastructure are required to reduce risk to acceptable levels. Climate change may eventually cause shifts in where crops can be grown successfully without irrigation and generally, will require additional irrigation in traditional production areas. Once irrigation is established, cultivation intensity (crop density) increases to reap the most from the infrastructure investment. This in turn creates increased demand for water, fertilizer and other inputs. 
Brazil's sugar industry center, Sao Paulo Province, offers a climate well suited to the crop and yields have steadily increased without the need for increasing irrigation. In many other areas, irrigation will often be necessary for expansion of sugarcane. With the notable exception of Brazil, the countries studied have relatively little land available that is appropriate for rain-fed sugarcane expansion. Argentina, Colombia, China and India are likely to expand sugarcane production to some degree but it will likely require irrigation and therefore higher production costs than Brazil. Most commercial sugarcane in Colombia already depends on irrigation to insure desired productivity. Given competing demands for water among industry, urban centers, agriculture and other uses, water is expected to increasingly be seen as a constraint to expanding biofuel feedstock production using today's crops in many parts of the world. This is the case in Mexico where water availability limits opportunities to increase sugarcane production. Future feedstock crops such as perennial grasses and trees that are more drought-resistant and adapted to local soils and climate variation will be advantageous under these conditions.

Although it does not directly limit potential feedstock production, water pollution is another factor where intensively cultivated annual crops such as corn and soybeans have documented negative impacts (as will any crop that involves high levels of fertilizer and chemical applications that can eventually reach local water tables). Monitoring and minimizing runoff or leaching of agricultural chemicals is an important component of best practices for sustainable production. Erosion and run off can have detrimental impact on urban water supplies, freshwater ecosystems and, in some cases such as CBI nations, damage marine ecosystems and coral reefs as well. The use of improved (more sustainable) agricultural practices is vital to avoid or mitigate these impacts.

\subsubsection{Air}

Most air quality issues are associated with post harvest processing and use of biofuel rather than feedstock production. The largest exception is the burning that often precedes a sugarcane harvest and releases large amounts of particulates, $\mathrm{CO} 2$ and other pollutants. Modern sugarcane industries are beginning to employ machines that facilitate harvesting without the need for burning. The transition to mechanized harvesting is proceeding slowly due to tradition, costs, employment concerns and topography. Most sugarcane fields established in the past were not planned and prepared (leveled) to facilitate mechanized harvest. In a few localities, concerns about burning sugarcane fields could limit expansion but this is not expected to significantly restrict the projected growth in supply over the coming decade.

\subsubsection{Land Availability and Constraints}

The countries and region studied vary in the amount of arable land that could be available to produce feedstock. A combination of physical attributes (e.g., soil, slope, climate, water), tenure, prior use, economics and policies will influence what lands could become available for expansion of biofuel feedstock production. At one end of the spectrum, Brazil has an estimated 100-200 million hectares of underutilized or undeveloped arable land suitable for feedstock that could be available without deforestation and with little impact on other productive sectors. At the other extreme, availability of arable land in countries such as India and China pose severe constraints on biofuel feedstock production given national priorities for food security. Following Brazil, Argentina and Colombia are considered to possess relative abundance of underutilized arable land. But in both of these nations, land suitable for sugarcane is already developed leaving little room for expansion without relatively high costs and displacement of other productive systems. Within Central America over the next decade, expansion in sugarcane and ethanol production is expected to be led by Guatemala and Nicaragua based on suitable lands, existing industries and the limitations of land and climate in other parts of the region. ${ }^{\text {lii }}$ 
Most nations use their best available land (in terms of climate, soils and access) for existing food, feed and fiber sectors. Thus, to achieve increasing biofuel production targets will often require trade-offs and shifts in farming practices such as: expansion to marginal (less productive) lands, changes in the proportion of land dedicated to different crops, rotation and tillage practices. These shifts bring associated changes in fertilizer and pesticide use, water demand and land use intensity that could contribute to negative impacts on soil, water and ecological services - and impinge on sustainability, if not carefully managed. Some countries plan to improve land use while simultaneously increasing biofuel feedstock production. This can occur when prior land use is less sustainable than systems used for feedstock - such as the use of perennials in areas that might otherwise be prone to erosion. China hopes to promote the production of biofuel feedstock using drought resistant tree crops on marginal lands that do not compete with food and feed related production. And lands cleared and abandoned or repeatedly burned for pasture can be more productively managed for sugarcane or perennial crop production.

Corn and soybeans have similar climate and soil requirements. In many of the countries studied, most of the land being used for increased production of soybeans and corn is former pastureland and significant areas of underutilized pastures remain available for expansion. (In Latin America, this is an artifact of former land tenure regimes that required claimants to show land "improvement" in order to gain ownership. The "improvement" was nearly always clearing/burning the land and calling it "pasture.") While sugarcane is also expanding on former pastures, it will tend to displace any land use of lesser value while focusing in localities that offer appropriate climate, soil, topography and infrastructure (including processing plants).

With the exception of Brazil, land availability represents a growing constraint to the expansion of feedstock supplies in most countries studied. Land is a more important constraint to sugarcane (outside of Brazil) than for other feedstocks due to its more demanding site requirements for competitive production. A transition to cellulosic feedstock would substantially alleviate the land constraint in most nations, but Brazil would still be best-positioned for low-cost supply due to the size of its sugarcane-ethanol industry and corresponding availability of bagasse as feedstock in the mills and distilleries.

\subsubsection{Deforestation}

Leaders in biofuel production (Brazil and the United States) along with four countries with plans for future biofuel feedstock expansion - Colombia, Indonesia, Canada and Peru - contain the majority of the world's remaining primary forests. This raises serious concerns among national and global environmental constituencies about potential impacts of biofuel feedstock expansion on world forest resources and biodiversity. Among the nations studied, this concern is most evident in Brazil and Colombia.

A review of literature conducted for this study suggests the following: (a) deforestation is a product of a complex set of factors including access, land speculation, social injustice and weak law enforcement capabilities; (b) expansion of sugarcane production can occur without directly contributing to further deforestation; (c) expansion of other feedstock crop areas is likely to occur on land more recently cleared of forest; (d) of the crop-country combinations studied, the expansion of palm oil plantations (generally) and soybean production in Brazil (not for biofuel per se, but in response to global markets), appear to be most strongly associated with deforestation; and (e) other factors being equal, when alternative uses of cleared land are considered, expansion of well-managed biofuel feedstock production may often be environmentally preferred. ${ }^{\text {liii }}$ Concerns about deforestation will influence where future feedstock expansion takes place and will increasingly present constraints to expansion in ecosystems of concern. Of feedstocks studied, this is most likely to influence future palm plantations. 


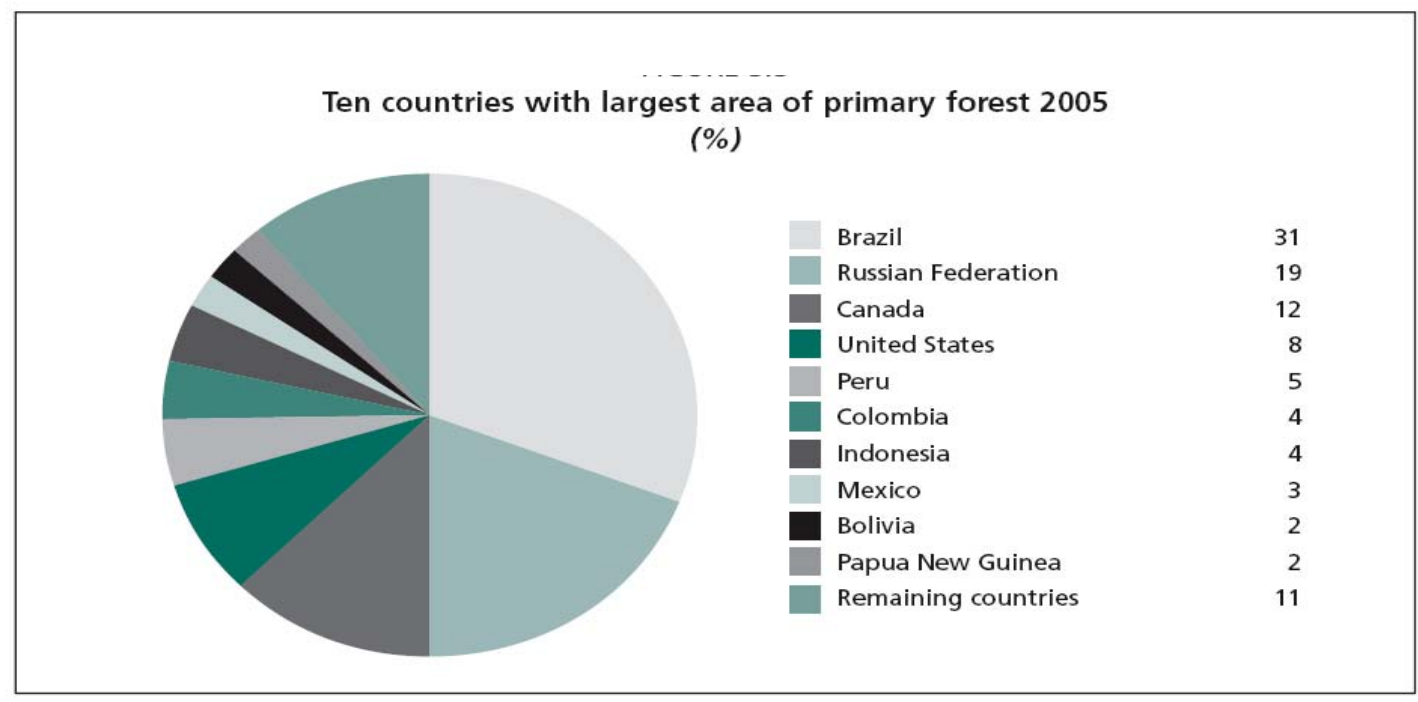

Source: FAO Global Forest Resources Assessment 2005 ${ }^{\text {liv }}$

Figure 2.18. Countries with Largest Share of Primary Forests.

Brazil has established a legal framework for forestry and environmental protection that some observers consider to be among the most progressive in the world. ${ }^{\text {lv }}$ Private land holders are required to set aside property as forest reserves (ranging from $20 \%$ to $80 \%$ depending on location) and to protect all riparian areas. Brazil is also working to provide better incentives for sustainable forest management, promoting native tree species and castor beans for biodiesel, and providing secure tenure rights to small farmers and indigenous groups. These policies are designed to slow deforestation and improve participation of small farmers in diversified agricultural markets including biofuel. In Brazil, recent experience suggests that sugarcane production for biofuel could expand significantly while contributing to reforestation and increased protection of natural resources in production areas when compared to prior land use. This is due in part to the location of land suitable for sugarcane production and processing. But there are also signs of improved compliance with local environmental regulations and international guidelines that are associated with increasing awareness of improved land management practices and international interest in biofuel production operations.

\subsubsection{Social Factors}

Social factors are a potential constraint to the growth of biofuel feedstock supplies in some sectors and countries, especially where a large percentage of the local population perceives impacts. Social concerns related to feedstock production revolve around two key areas: changing land use and loss of employment. Related to land use, issues derive from the displacement of traditional small farmers by large commercial agricultural enterprises typically associated with biofuel production. While such displacement could be applicable to any feedstock crop, it appears to be most severe in cases such as the conflicts publicized when new palm plantations displace forest dwelling indigenous groups. ${ }^{\text {lvi }}$ Sugarcane and soybean operations also tend to acquire large, concentrated holdings by buying-out prior small holders who typically used more labor intensive and diversified agricultural systems. And as industries expand and become more mechanized, employment opportunities may be reduced. This is a large concern as sugarcane operations switch from manual to mechanized harvests. In any of these scenarios, compensating employment and income opportunities are needed to avoid social problems that could begin to undermine or constrain the industry. 
Relative to other countries in this study, Mexico is expected to have higher production costs, lower yields, and lower growth in feedstock supplies over the coming decade. Mexico's potential feedstock production is primarily from small, rain-dependent parcels with relatively limited access to technology, capital, inputs, and markets. Additional cultural and social issues that may influence production include the role of corn as staple and symbol of self-sufficiency in society, and the impacts of NAFTA. Trade liberalization in countries that lack adequate capacity to insure social and environmental protection may have negative consequences. ${ }^{\text {lvii }}$ A recent study looking at the potential impact of the proposed U.S.Colombia free trade agreement on corn production in Colombia concluded that it could contribute to reducing the small farm economy, biodiversity (natural and agricultural) and food security. Alternatively, institutional infrastructure and policies could be put in place to better incorporate small farmers into the new systems of production and allow them to share in the benefits of new markets and improved prices.

\subsubsection{Policies}

Many governments see potential for multiple benefits from domestic biofuel production programs. They aim to invigorate rural economies and increase energy security by reducing imported oil. And efficient biofuel production could contribute to national goals for reducing green house gas emissions. In Brazil, for example, ethanol from sugarcane is presently produced with an 'energy balance' of approximately 1:8 meaning that 8 equivalent units of fossil energy are produced for each unit consumed in production. This is several times more efficient than average ethanol production in other countries and using other feedstock. ${ }^{\text {lviii }}$ And Brazil continues to invest in research and technology to improve the efficiency and economics of the sugarcane-ethanol process, leading analysts to predict that the energy balance will exceed 1:10 within the coming decade. ${ }^{\text {lix }}$

The U.S. Presidential " 20 in 10" goal has many parallels internationally (See Table 2.2). Nearly all countries investigated are developing biofuel policies, programs and targets. These policies - their substance, maturity, and enforcement — form an evolving backdrop within which to analyze potential availability of biofuel or their feedstocks for export to the U.S. Some nations, such as Brazil, have mature and growing programs, while others are just starting (such as Colombia and Argentina) or in planning stages (Mexico).

Brazil's biofuel policies have been credited with spurring technological innovation, creating a successful renewable energy industry and hundreds of thousands of jobs, while reducing dependence on and expenditures for imported fuel. The program has evolved considerably since the 1970s and has established institutional and technological capabilities that continue to grow and now serve as models for the rest of the world. ${ }^{\mathrm{lx}}$ The Brazilian fuel-ethanol program has expanded most rapidly in the past few years as the government reduced subsidies and regulations, allowed more private-sector involvement, and facilitated the introduction of flex-fuel vehicles. These adjustments, combined with growing sugar harvests and high oil prices, have allowed Brazil to meet growing domestic ethanol demand while simultaneously quadrupling exports over the past five years. Industry sources predict that the growth will continue and could supply over 30 billion liters of ethanol by 2012/13 (compared with 17 billion liters in 2006/07) to meet a domestic demand reaching 25 billion liters and exports exceeding 6 billion liters. ${ }^{\text {lxi }}$

The maturity of Brazil's biofuel industry sets that country apart from others in this study that are responding to rising oil prices with more recent biofuel policies and programs. For example, Colombia began promoting biofuel production in 2001 and has set targets for 5\% biodiesel and 10\% ethanol blending for diesel and gasoline, respectively, by 2008. These targets combined with generous tax incentives and government support for research and development, have led to rapid investment and 


\begin{tabular}{|c|c|c|c|c|c|}
\hline \multirow[t]{2}{*}{ Country } & \multicolumn{2}{|c|}{ Primary Feedstock } & \multicolumn{2}{|c|}{$\begin{array}{c}2007 \text { Forecast } \\
\text { (million gallons) }\end{array}$} & \multirow{2}{*}{$\begin{array}{c}\text { Blending targets for ethanol } \\
\text { and biodiesel }\end{array}$} \\
\hline & Ethanol & Biodiesel & Ethanol & Biodiesel & \\
\hline Argentina & $\begin{array}{l}\text { molasses, } \\
\text { sugarcane, } \\
\text { corn }\end{array}$ & soybeans & 66 & 53 & $\begin{array}{l}5 \% \text { blends in all gasoline and } \\
\text { diesel, } 2010\end{array}$ \\
\hline Brazil & sugarcane & $\begin{array}{l}\text { soybeans, } \\
\text { palm oil, } \\
\text { castor oil }\end{array}$ & 4,967 & 64 & $\begin{array}{l}25 \% \text { blend in gasoline in } 2007 \\
\text { (adjustable); } 2 \% \text { in diesel by } \\
2008 \text { and } 5 \% \text { by } 2013 \text {. }\end{array}$ \\
\hline Canada & $\begin{array}{l}\text { corn, } \\
\text { wheat, } \\
\text { straw }\end{array}$ & $\begin{array}{l}\text { animal fat, } \\
\text { vegetable } \\
\text { oils }\end{array}$ & 264 & 25 & $\begin{array}{l}5 \% \text { in motor vehicle fuel by } \\
2010 ; 2 \% \text { in diesel by } 2012 \text {. }\end{array}$ \\
\hline China & $\begin{array}{c}\text { corn, } \\
\text { wheat, } \\
\text { cassava } \\
\end{array}$ & $\begin{array}{l}\text { vegetable } \\
\text { oils, } \\
\text { Jatrophaxiii }\end{array}$ & 423 & 30 & $\begin{array}{l}\text { Five provinces use } 10 \% \text { blend } \\
\text { with gasoline; five more } \\
\text { provinces targeted for future }\end{array}$ \\
\hline Colombia & $\begin{array}{l}\text { sugarcane, } \\
\text { cassava, } \\
\text { sugar beet }\end{array}$ & palm oil & 100 & 13 & $\begin{array}{c}10 \% \text { in gasoline and } 5 \% \text { in } \\
\text { diesel by } 2008 .\end{array}$ \\
\hline EU & $\begin{array}{l}\text { grains, } \\
\text { sugar beet }\end{array}$ & $\begin{array}{l}\text { rapeseed, } \\
\text { sunflower, } \\
\text { soybeans }\end{array}$ & 608 & 1,732 & $\begin{array}{c}5.75 \% \text { biofuel share of all } \\
\text { transportation fuel by } 2010 \\
10 \% \text { by } 2020 \text {. }\end{array}$ \\
\hline India & $\begin{array}{l}\text { molasses, } \\
\text { sugarcane }\end{array}$ & $\begin{array}{l}\text { Jatropha } \\
\text { imported } \\
\text { palm oil }\end{array}$ & 106 & 12 & $\begin{array}{l}10 \% \text { in gasoline by } 2008 ; 5 \% \\
\text { in diesel by } 2012 \text { (soft targets). }\end{array}$ \\
\hline Indonesia & $\begin{array}{l}\text { sugarcane, } \\
\text { cassava }\end{array}$ & $\begin{array}{l}\text { palm oil, } \\
\text { Jatropha }\end{array}$ & -- & 108 & $10 \%$ biofuel by 2010 . \\
\hline Malaysia & & palm oil & -- & 87 & $\begin{array}{c}5 \% \text { in diesel (target date under } \\
\text { discussion) }\end{array}$ \\
\hline Mexico & $\begin{array}{l}\text { molasses, } \\
\text { sugarcane }\end{array}$ & $\begin{array}{l}\text { animal fat, } \\
\text { recycled } \\
\text { oils }\end{array}$ & 25 & 1 & $\begin{array}{l}\text { Proposed legislation (pending } \\
\text { signature) did not include firm } \\
\text { targets. }\end{array}$ \\
\hline Thailand & $\begin{array}{c}\text { sugarcane, } \\
\text { molasses }\end{array}$ & palm oil & 79 & 69 & $\begin{array}{l}10 \% \text { in gasoline (soft target) } \\
\text { and } 10 \% \text { in diesel by } 2012 \text {. }\end{array}$ \\
\hline $\begin{array}{l}\text { United } \\
\text { States }\end{array}$ & corn & $\begin{array}{l}\text { soybeans, } \\
\text { other } \\
\text { oilseeds, } \\
\text { wastes } \\
\end{array}$ & 6,499 & 445 & $\begin{array}{c}15 \text { billion gallons of biofuel by } \\
2012 ; 24 \text { b. gal. by } 2017 ; 36 \text { b. } \\
\text { gal. by } 2022 .\end{array}$ \\
\hline & & & & & \\
\hline
\end{tabular}

expansion of biofuel production capacity in Colombia. Although the capacity in 2006/07 was still short of the targets, many new plants are planned or under construction and future feedstock and conversion capacities are expected to produce sufficient biofuel to meet domestic demand and provide surplus for exports targeting the United States market by $2009 / 10$. ${ }^{\text {liv }}$

While Canada began to implement policies aimed at promoting the production and use of ethanol in the 1980s, more recent policies offer incentives and set specific targets for fuel blending: gasoline is to contain $5 \%$ bioethanol by 2010 and diesel a $2 \%$ blend of biodiesel by 2012 . As a result, by 2008 , ethanol production rates are projected to rise to 1.3 billion liters/yr from fairly stable production of about 230 million liters/yr in 2001-2005. Similarly, biodiesel production would increase to 100 million liters/yr from 9 million liters/year in 2001-2005. Achieving these goals would affect Canadian agriculture substantially, dramatically increasing the domestic demand for corn and wheat as biofuel feedstock. 
Several other national programs are more recent and evolving. Argentina implemented new laws and regulations in February 2007 that aim to promote the growth of a biofuel industry capable of supplying a $5 \%$ blend by 2010 in all domestic gasoline and diesel fuel. Although government policies aim to catalyze a domestic market, most investors are looking at Argentina's feedstock and comparative advantages as a potential producer and exporter of biofuel, particularly biodiesel to the EU. Mexico and several CBI nations have commissioned studies and made policy pronouncements in support of biofuel development.

Sometimes, government policies appear to be at odds or too confusing to implement. The Mexican congress passed a Bio-Fuels Promotion and Development Law in April, 2007, but the legislation was returned to Congress by the President for modification and had not been signed into law as of August. Biofuel development in Mexico has been contentious as the energy sector criticized the law for lacking specific targets and mandates, while others expressed concerns about negative impacts on food security. Amid highly publicized opposition to corn being diverted to biofuel, the most recent version of the law states that feedstock will be sourced from "products derived from agricultural, forestry, marine, biotechnology and enzymatic activities, without compromising the country's food supply." Meanwhile, the sugarcane industry's infrastructure is outdated, inefficient, dispersed and periodically embroiled in labor issues. The sector remains highly regulated with large government participation. High sugarcane and/or sugar prices maintained by government policies are not conducive to competitive ethanol production. To be a competitive player in global markets, Mexico's biofuel industry will need substantial investment and greater involvement from the energy sector.

The governments of China and India have set prior targets for biofuel production and blending that were not consistently met. Their most recent policies favor food security as a priority and direct future biofuel development toward more marginal lands that do not compete with food production, and to oil-seed trees such as Jatropha and other non-food crops. In countries such as China with established customs and traditions of central planning, special incentives may be necessary for farmers to switch to new energy feedstock production.

Finally, although not the subject of this study, U.S. agricultural and biofuel policies impact world markets, prices, and the patterns of production in other nations around the globe. U.S. policies combined with trade agreements create special opportunities for some nations to access the U.S. biofuel market, as is the case with the CBI region. The proximity to the U.S. combined with free trade agreements will also allow Canada and Mexico to become integrated participants in corresponding U.S. biofuel markets and vice-versa. As biofuel programs grow in Canada and Mexico, they may find advantageous market segments in the U.S. based on NAFTA and proximity that facilitate efficient distribution. ${ }^{1 \times v}$ For example, despite constraints discussed elsewhere, Mexico may have a unique opportunity to develop a relationship with California if it can offer biofuel at competitive prices while meeting that State's criteria for environmentally sound production. And a proposed trade agreement is expected to result in acceleration of biofuel production in Colombia for export to the U.S.

In conclusion, government policies in the countries studied generally appear to be designed to create incentives for investment and to accelerate expansion of national biofuel industries. Some appear more effective than others. Policies and funding for the development and implementation of national standards for biofuel production, distribution, and blending, are instrumental in facilitating the development of domestic biofuel markets. To be successful in the long term, the industries will require research and development to facilitate continual improvement, competitive production, and systems for social and environmental sustainability. 


\subsubsection{Infrastructure and Technology}

Governments of several of the countries studied support research and development to enhance productivity, yield, and the ability to refine or convert feedstocks. This study focuses on feedstock production, where yields for the crops studied have increased consistently in the past, albeit at varying rates among the countries studied. Agricultural sectors associated with biofuel feedstocks were fairly well organized and financed in most countries, although some (such as Brazil, Canada and Argentina) appear to be investing more in related $R \& D$ than others. The use of genetically modified (GM) crops offers potential to increase yields and reduce environmental impacts and has grown rapidly in some countries, while also raising environmental concerns. Recent endorsement in Brazil for the use of GM sugarcane cultivars is expected to help that nation retain its status as the lowest cost producer in the world.

While infrastructure does not appear to be a major barrier for feedstock production per se, each country's ability to expand capacity to refine and transport feedstock and biofuel is dependent upon a suite of factors including financial markets, infrastructure and technologies. These issues were not within the scope of the feedstock supply curve projections. The review of literature conducted in preparing this report, however, suggests that infrastructure (feedstock crushing/processing plants, road/rail/pipeline transport, energy grid, port facilities and biofuel distilleries) represents the most significant constraint to nascent biofuel programs in the short to medium term. Reports from countries such as Argentina (with recent legislation to promote biofuel production), indicated that equipment required was back-ordered and could delay planned upgrades in sugar mills and distilleries for several years in some cases.

\subsubsection{Other Potential Constraints and Risks}

The concentration of a major percentage of the world's traded commodities in just a few countries, and the cultivation of these crops in large monoculture plantations, exposes globally important supplies to significant vulnerabilities from severe weather events, political unrest, plagues and pests. A majority of biofuel feedstock supply expansion is expected to occur in the tropics where extreme weather events such as hurricanes, droughts and floods have disrupted past production and caused unforeseen spikes in prices. For example, the sugar content in a harvest is influenced by weather and an untimely tropical storm and flooding can cause an unexpected decline in the total annual harvest despite expanding area under cultivation. ${ }^{\text {lxvi }}$ The supply curves developed for the baseline cases in this study assume that growth within a given state or nation continues based on past average rates within a defined set of parameters. However, in any given year, supplies will likely be somewhat higher or lower than the baseline, moving up and down in response to the many variables discussed, but probably within the range bracketed by the high and low growth cases. If future conditions differ greatly from the past, the assumptions behind projections based on past trends will no longer be valid. And the risks posed by the concentrated production of key commodities may increase as a consequence of increasing climatic change.

\subsubsection{Opportunities}

Several other potential feedstock crops, and many other countries, could contribute to future biofuel supplies in the timeframe of these projections. This study reflects a selected sample of the total potential supply. New crop varieties are being developed specifically for biofuel production, such as tropical sugar beets in Colombia or sweet sorghum and Jatropha in China. Innovative technologies and practices are being investigated including: algae and marine plant feedstock; "closed systems" that integrate dairy, meat, corn, fertilizer and energy (biogas and liquid biofuel) production; coupled landfill systems with gasto-energy, aquaponic food production and water desalination, among many others. ${ }^{\text {lxvii }}$ An algal culture may be used to assimilate $\mathrm{CO}_{2}$ from the turbine exhaust into biomass, which then may be used as a biofuel, thus making the system largely self-contained. By recycling energy and materials, the system 
could displace fossil fuel use, mitigate negative environmental impacts such as greenhouse gas emissions, and generate less waste in need of disposal.

The comprehensive book, Biofuels for Transport, offered the following "key overarching recommendations" for decision makers: (a) Develop the market; (b) Speed the transition to nextgeneration technologies (with lower costs and environmental impacts); (c) protect the resource base (soil productivity, water quality, and other ecosystem services); (d) facilitate sustainable international biofuel trade..."coupled with social and environmental standards and a credible system to certify compliance"; and (e) distribute benefits equitably. ${ }^{\text {lxviii }}$

Sustainability is often raised as either an opportunity or a constraint; what are the implications? The answer depends upon the crop and the circumstances. But many organizations have joined forces to try and reach consensus on what sustainable production systems should entail and how they can be monitored. At the global scale, a series of "Roundtables" have evolved, including the Roundtable for Sustainable Biofuels (RSB), Sustainable Palm Oil (RSPO), and Responsible Soy (RRS). ${ }^{\text {lxix }}$ The RSPO, for example, has developed and is testing a set of sustainability principles that address a broad range of concerns related to the overall supply chain for palm oil and palm oil derived biodiesel. Similar efforts are forging ahead at national levels, often coordinated with the global roundtables, both in producer and importer nations. In Brazil, a recent stakeholder workshop developed recommendations for expanding sugarcane for biofuels while contributing to environmental and social development goals. Colombia has worked to address small farmer concerns related to palm oil plantations. And the Netherlands has commissioned studies to identify sustainable (environmentally and socially responsible) sources for biofuel imports.

The U.S. has the opportunity to make major contributions in this context. Given its strong tradition of development assistance programs in many potential biofuel export nations coupled with its expanding market for biofuel consumption, the U.S. could facilitate stronger linkages between its international development assistance and responsible trade, while promoting more sustainable production systems, something that has received scant attention in the past. For example, development assistance could contribute to programs that build local capacity for sustainable production systems and support for local efforts to improve capacity to implement laws protecting the environment. As noted by Worldwatch Institute, "The establishment of national and international environmental sustainability principles and certification is important in protecting resources, as well as in maintaining public trust regarding the merits of biofuels." ${ }^{\mathrm{lxx}}$ In that context it behooves stakeholders - producers and consumers alike - to facilitate the implementation of these agreements.

\subsection{CONCLUSIONS AND RECOMMENDATIONS}

\subsubsection{Results}

Supply curves were developed for use in a global energy market allocation model. Single point estimates of cost and supply were replaced with updated supply functions for selected feedstocks in priority nations. The analysis identified capacity to potentially double or triple feedstock production by 2017 in some cases. A majority of supply growth is derived from increasing the area cultivated (especially sugarcane in Brazil). This is complemented by improving yields and farming practices.

Most future supplies of corn and wheat are projected to be used to meet domestic food and feed demand in the nations studied. Larger shares of future supplies of sugarcane, soybean and palm oil production will be available for export and/or biofuel (Table ES-2). Figures ES-12 and ES-13 illustrate the share of total aggregate supply 'available' by type of feedstock and country, based on all crops studied and cellulosic 
supplies with estimated values under \$36/ dry metric tonne. If all of the 2017 projected feedstock supply "available" were converted to biofuel, it would represent the equivalent of 38 billion gallons of gasoline.

lxxi Sugarcane and bagasse combined dominate the total 'available' supply, representing $64 \%$ of the gasoline equivalent. Figure ES-13 illustrates that among the nations studied, Brazil is the source of $64 \%$ of total 'available' supplies, followed distantly by Argentina (12\%), India and CBI.

National policies are catalyzing investments in biofuel industries to meet targets for fuel blending that generally fall in the 5-10\% range (Table 2.2). While social and environmental concerns associated with rapid expansion of feedstock production are recognized, the sugarcane sector poses lower risks than other feedstocks studied and offers the possibility for sustained expansion over the coming decade. Policies in countries such as China and India reflect a strategy where feedstock crops that compete with food are expected to transition to alternative crops that can grow on more marginal lands than food crops and, eventually, to a cellulosic-based biofuel industry.

\subsubsection{Next Steps}

In the present study, ORNL's primary task was to develop supply functions for a set of selected countries and primary feedstocks using readily available data. In the process of completing that task, valuable data were collected, collated and analyzed related to feedstock production trends and costs at the state/province level in selected nations. Several gaps in data were also identified. To build upon the present study and improve future efforts related to international biofuel market analysis, the following activities are recommended. Each topic is further discussed below.

1. Systematic review of MARKAL-ETP bio-feedstock data

2. Expand state-level environmental analysis in priority countries

3. Improve methodology for crop and cellulosic feedstock analysis

4. Expand study to include additional countries (and feedstocks) - particularly Asia and Africa

5. Integrate supply curves with broader market allocation model

6. Assess implications of recent increases in world prices (energy and related commodities)

\section{Systematic review of MARKAL feedstock data}

The present analysis worked to identify data sources and project supply curves for specific countries, feedstocks and time periods $(2012,2017,2027)$ independent of the existing data sets supporting the MARKAL-ETP model. The ETP model is based on a different set of parameters to define trade regions, a different set of feedstock classifications, and different time periods. A systematic review of the data points that presently support the ETP model should be conducted using the experience and findings from the present study. This could enhance the data quality for feedstock supplies in the remaining regions and time periods for ETP model.

\section{Expand state-level environmental analysis in priority countries}

To develop a methodology that could generate a "quick estimate" (within the time and resource constraints of this study), limits were established somewhat arbitrarily for the maximum levels of growth in area for a given crop in a given state/province. This procedure was necessary because sufficient data 
and time were not available to complete a more detailed analysis and because that detailed level of analysis is not warranted for all countries. However, in a few nations identified as important for their potential to expand biofuel production to supply US markets, such as Brazil, Argentina, and Colombia, assessing more detailed land-use factors at the state level will make the projections more robust and improve the value of the data for future use and analysis. Some key issues that could build upon the existing state-level data sets include: additional and more detailed analysis of present land uses, land-use capacity, zoning (including physical limits due to topography, protected reserves), and ownership issues; projected interactions among land uses over time; and the trade-offs among the feedstock projections within the more accurately defined "available areas" for expansion (e.g., not every feedstock is likely to grow simultaneously in every state).

\section{Improve methodology for crop and cellulosic feedstock analysis}

Certain assumptions were made to provide a rapid assessment of feedstock availability in this phase of the study. Potential improvements in this approach include incorporating price sensitivity in feedstock projections and including more detailed factors that could determine the production of feedstock in a given country. The approach used to estimate cellulosic feedstock supplies did not allow for exhaustive research of the potential sources in each country. A relatively small amount of effort could improve the initial estimates and fill this gap, making the results more comprehensive and useful, as well as more consistent with the "billion ton study" for the U.S.

\section{Expand to include additional countries (and feedstocks)}

The initial study was constrained by time and funding. An obvious next step is to expand the number of countries studied based on the original screening or other criteria. The definition of feedstocks for analysis could also be expanded to better reflect the diversity of supplies being studied and developed as biofuel feedstock for the near future. Additional countries to which the present methodology could be applied include the cluster of nations ranking next in priority during the initial "screening." These nations were: Thailand, Australia, Indonesia, Malaysia, and South Africa.

Southeast Asia (primarily Malaysia, Thailand, Indonesia) is the world's most important source of palm oil (and palm-oil based biodiesel), producing over $90 \%$ of the supply to global markets. Australia is a major agricultural power with incentives coming into effect to promote biofuel domestic production in the near future. Sugarcane and other crops are also expanding for ethanol production. And the cellulosic wastes from palm oil, sugar, rice and other crops in this region offer plentiful supply at relatively low costs, setting the stage for a competitive position in future cellulosic-based biofuel production. These four countries are important actors in future production and trade for biofuels and are proposed for inclusion in the next phase of the global assessment.

Africa is a land of persistent potential. Available land, soils and climate offer great possibilities for biofuel production, second only to Latin America in potential based on projections of future biomass productivity. Political, social and economic factors, as well as environmental factors in parts of the continent (e.g. availability of water), will limit the ability of many African nations to realize this potential in the coming decade. There may be some exceptions. For example, South Africa has a long tradition of synfuel production capacity, ethanol exports, strong finance sector and existing export infrastructure, as well as an established sugarcane industry. Other countries (such as Ghana and Tanzania) have nascent programs supported by international donors with the hope of improving rural livelihoods and producing biofuels to support local economic development. A few others (Namibia, Kenya) are reportedly preparing projects with the support of international development banks and the EU for large scale commercial production in plantations, with the hope of supplying domestic, 
African and European demand for biofuel. Based on the initial screening, South Africa is proposed for analysis in the next phase. One or two other African nations could be considered if funding allows

Other specific feedstocks, such as molasses, cassava, tropical sugar beets and new dedicated bioenergy woody crops such as Jatropha, also should be analyzed in a follow-on effort.

5. Integrate supply curves with broader market allocation model

A model that focuses solely on the market allocation of fuel supplies (such as MARKAL) has inherent limitations when the primary feedstock supplies predominantly are used for food and fiber. Supply curves will be much more valuable if they are integrated in a model that allows competition among end uses based on price. Given the need to pre-define an allocation of feedstock to biofuels, the assumptions used in the present study were designed so as not to constrain the model. The portions of feedstock supplies allocated to potential use for bioenergy therefore are overstated by design, being based primarily on the current amount of feedstock exported into global markets (see Methodology). This approach allowed a consistent formula to be applied in making estimates for each country, but there are several ways in which the approach could be improved. The most important is to collaborate and integrate feedstock supply curve data with an existing model that incorporates all global trade in feedstock crops to enable a more realistic estimate of the potential for biofuel uses in competition with other uses (a model such as that developed in the Global Trade Analysis Project - GTAP - might be an options). Another approach would be to work with existing allocation models that permit competing demands within a given national market under study (a more manageable approach), and apply that to the priority countries.

\section{Assess implications of recent increases in world prices}

Strong and growing linkages among nations and commodities in the new global economy are leading to interactions among energy and food markets that appear unprecedented in recent history. Agricultural commodity prices are undergoing a significant upward adjustment as reflected in The Economist's global "food-price index" that is higher today than at any time since its inception in 1845 . ${ }^{\text {lxxii }}$ With projections for affluence and population to continue growing in key parts of the world such as Asia, real prices for agricultural commodities may remain at significantly higher levels for decades. The present analysis used historic price information and generally projected supply curves based on real prices in 2005. Further study to consider the sensitivity of results to likely future adjustments in those prices could improve subsequent analytical and modeling efforts. 


\section{Endnotes for Chapter 2}

${ }^{x l v i i}$ Opportunity costs for bagasse were estimated to range from US\$8-\$17 per dry tonne. Average costs per dry tonne for other cellulosic supplies ranged from: $\$ 1$ for palm residues available at plant; to $\$ 18$ - $\$ 36$ for wood mill residues; \$13-\$50 for fuelwood; \$39-\$52 for corn stover and wheat straw; and \$52-\$100 for dedicated perennials and forest harvest residues. See country-level discussions in Chapter 3 for details.

xlviii See WWI 2007; Preface pg. xx.

xlix References include: WWI 2007, OECD 2007, UN-Energy 2007, IDB 2006, IFPRI 2006, FBDS and CI 2007, USDA 2007b, ESMAP 2005, IEA 2004, and Smeets et.al. 2004.

${ }^{1}$ See Brazil in Chapter 3. Generally, sugarcane is expanding on previously cleared land near sugar mills and major roads. A study of sugar cane expansion in the most important producing state, Sao Paulo (1990-2004), found that forest cover increased along with increasing area planted in sugarcane as more effort was made to comply with forest reserve and riparian protection regulations (Macedo, 2007).

${ }^{\text {li }}$ For example, in "Sustainability of ethanol from Brazil in the context of demanded biofuel imports by The Netherlands" (Rodrigues and Ortiz, 2007), the authors note that companies targeting international markets pay more attention to environmental and social issues as a good business practice. And recent workshops in Brazil brought parties together to develop recommendations for socially and environmentally sound expansion of sugarcane ethanol production (FBDS and CI 2007).

lii CEPAL 2007 (Fortuny): http://www.eclac.org/cgibin/getProd.asp?xml=/publicaciones/xml/9/28019/P28019.xml\&xsl=/mexico/tpl/p9f.xsl\&base=/mexico/tpl/topbottom.xslt

liii With the exception of palm plantations, biofuel feedstock production generally enters relatively late in the process of an advancing agricultural frontier, at which point it usually offers an opportunity for more sustainable

productivity, employment, and compliance with environmental regulations when compared to existing use and other options. See discussions in Chapter three under CBI and Brazil for examples.

liv See: ftp://ftp.fao.org/docrep/fao/008/A0400E/A0400E04.pdf

${ }^{\text {lv }}$ See for example, Downey 2007,pg. 38.

${ }^{\text {lvi }}$ See Avendano, 2007. Palm plantations in several tropical areas including Colombia have been accused of forcing traditional users off the land and disrupting more sustainable forest-based production systems. News articles on this topic include http://ipsnews.net/news.asp?idnews $=35722$

${ }^{\text {lvii }}$ UNEP (2006), Colombia: Integrated assessment of agricultural trade...

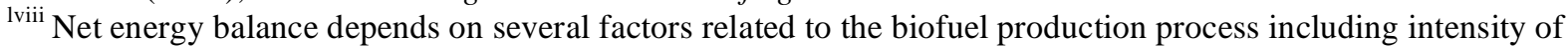
agricultural inputs and sources of energy for processing and fuel production. These factors vary greatly. WWI 2007 reported that in China, the energy balance (energy in:energy out) for ethanol production was 1:1.1 for corn and 1:2.1 for sugar cane, while in Brazil it was calculated as 1:8.3 for sugarcane (and other sources report 1:9 or more for Brazil). In the U.S. it has been estimated at 1:1.2 for corn. In part due to the higher efficiency, Brazil's costs per liter of ethanol are also much lower than any other producers. OECD 2007 reports current ethanol production costs of approximately US\$0.20/liter from sugarcane in Brazil while the costs for grain-based ethanol in the U.S. and Europe range from US $\$ 0.30$ to over $\$ 0.40$ per liter.

${ }^{\text {lix }}$ WWI 2007, pg. 343.

${ }^{\mathrm{lx}}$ Many of the references provide a description of the evolution of the Brazilian biofuel model. See AgraFNP (2007) or Puppim and de Oliveira (2002) for a synopsis.

${ }^{1 x i}$ Several similar projections are cited in the references. This one is from Agra FNP 2007 (pg. 133) citing UNICA.

lxii This summary table is adapted from USDA ARS, November, 2007 issue of Amber Waves for all countries listed except Argentina, Colombia and Mexico (which were not included in the ARS article). Information on latter three nations is summarized based on references and sources in the country level analyses in Chapter Three. Note that the production data for Argentina, Colombia and Mexico reflects total ethanol reported (including that for traditional beverage and industrial use).

lxiii Several nations have announced programs to promote Jatropha - a fast growing tree species native to the American tropics that produces an oil seed - in agro-forestry activities, especially where it can serve conservation purposes on marginal lands otherwise prone to erosion and as "living fences" for small farms. Most projects are recent and commercial scale seed processing for biodiesel is envisioned for the future.

${ }^{\text {lxiv }}$ See the Colombia section of Chapter 3 and the related USDA reference GAIN C07011. 
${ }^{\mathrm{lxv}}$ See Chapter 3 section on Canada and referenced GAIN Report CA7005: "The free trade on ethanol between Canada and the US ... and continued US incentives such as a 16 cent Cdn\$ per liter (51 cent US per gallon) excise tax, have rendered the U.S. a significant potential ethanol and biodiesel market for Canada."

${ }^{\text {lxvi }}$ This aberration was most evident in CBI nations where tropical storms and hurricanes had significant impacts on national production in past years.

${ }^{\text {lxvii }}$ For example, see Janes et al. 2005; and GAIN Report AR7016.

lxviii WWI 2007, pg. 325.

lxix The movements to develop industry standards and indicators have been active in the past 2-3 years. For draft principles, meetings, and progress with the Roundtable on Sustainable Biofuels (RSB) see:

http://www.bioenergywiki.net/index.php/Roundtable_on_Sustainable_Biofuels . For the Roundtable on Responsible Soy, see: http://www.responsiblesoy.org/eng/index.htm. Also see van Dam et.al., "Overview of recent developments in sustainable biomass certification” prepared for IEA Bioenergy Task 40, December 2006. ${ }^{1 x x}$ WWI 2007, pg. 325.

${ }^{1 x x i}$ The total supply in gasoline equivalent reflects a maximum potential 'available' in the 2017 baseline case independent of other factors. A broader study will apply assumptions related to prices, tariffs and other variables to estimate what portion of this potential supply could enter the market under different scenarios.

lxxii The Economist, 2007. 


\section{COUNTRY-SPECIFIC ASSESSMENTS}

Chapter 2 summarized aggregate assessment findings across the suite of countries studied. This chapter provides more detailed assessments for each of the selected countries and the CBI region. The purpose of these country-specific assessments is to estimate the potential future production of selected biofuel feedstocks and provide supply curve functions for use in the analysis of global markets. Country assessments are presented here in alphabetical order: Argentina, Brazil, Canada, China, Colombia, India, and Mexico, followed by the assessment of the Caribbean Basin Region. All data tables are presented in Annex 4.

\subsection{ARGENTINA — SOYBEANS, CORN, WHEAT, AND SUGARCANE}

\subsubsection{Summary Findings}

Argentina is the world's third largest producer of soybeans and the largest exporter of soybean oil. It is also the world's second largest exporter of corn. The sugar industry experienced a revival over the last few years in response to favorable market conditions and authorization of a domestic biofuel blending law. Recent growth in the biofuel industry is expected to continue with a focus on the export market, positioning Argentina as an up-and-coming global player in biofuel production.

Estimated baseline case cumulative primary feedstock production in Argentina for the year 2017 is projected at approximately $58 \mathrm{mmt}$ of soybeans from 5 million ha; $25 \mathrm{mmt}$ of corn from 3.3 million ha; $28 \mathrm{mmt}$ of sugarcane from 3.3 million ha; and $16.5 \mathrm{mmt}$ of wheat from 5.6 million ha.

Allocating feedstock to biofuel production would compete with current uses in the near term. In the medium term, crop production is expected to respond to the greater demand for biofuels in domestic and global markets, and increasing exports could be allocated for biofuel purposes under competitive terms. Argentina has the land resources to meet such increases in production and currently is a significant exporter of the crops under study. In the 2017 baseline case, the percentages of total feedstock production available for export are: $62 \%$ of Argentine wheat, over $80 \%$ of soybeans, about $60 \%$ of corn, and $30 \%$ of sugarcane.

Argentina also produces a large amount of potential cellulosic feedstock annually. Estimated recovery of cellulosic feedstock from residues of wheat, corn, and sugarcane totals about $14 \mathrm{mmt}$ in 2017 under the baseline case.

With available land, mature financial systems, improving infrastructure and technology, Argentina is poised to contribute significantly to a new domestic market and growing global markets for biofuel using soybeans, corn, and sugarcane as primary feedstocks. The large share of these crops that currently is exported implies that feedstock for biofuel production will be available in Argentina if market prices for biofuels become competitive with alternative allocations.

\section{$\underline{\text { Argentina Figures }}$}

1-3: Baseline Projections for Wheat Supply

4: Wheat: Historic Trend and Projections

5-7: Baseline Projections for Soybean Supply

8: Soybeans: Historic Trend and Projections

9: Corn: Historic Trend and Projections

10: Sugarcane: Historic Trend and Projections 


\section{Argentina Tables (See Annex 4)}

1-3: Wheat Supply Potential for Baseline, High and Low Growth Cases

4-6: Soybean Supply Potential for Baseline, High and Low Growth Cases

7: Corn Supply Potential for Baseline, High and Low Growth Cases

8: Sugarcane Supply Potential for Baseline, High and Low Growth Cases

9: Potential Percentage Allocation for Export \& Biofuels

10: Estimated Cellulosic Supply from Recoverable Crop Residues

11: Estimated Cellulosic Supply Including Other Residues

\subsubsection{Context}

Argentina has excellent potential to expand feedstock production for biofuel due to its abundant arable land, efficient agricultural production systems, and sophisticated infrastructure. ${ }^{\text {lxxiii }}$ Argentina is the world's largest exporter of soy oil, is second only to the U.S. in exports of corn, and is among the top four exporters of wheat with Canada, U.S. and Australia. Argentina currently meets most of its energy needs from domestic sources and is a net exporter of crude oil. However, given current extraction and use rates, the country is expected to become a net importer of oil in the next few years. The primary biofuel feedstocks in Argentina are soybeans for biodiesel and sugarcane and derivatives (molasses) for ethanol. However, corn is being considered as a possible future ethanol feedstock and wheat has been used in other nations (China, Canada). Given expansive modern agricultural production, technology and infrastructure, there is long-term potential for cellulosic biofuel production from agricultural residues.

Recent laws and regulations (passed in February 2007) are intended to promote a national biofuel industry that achieves a 5\% blend by 2010 in all domestic gasoline and diesel fuel. The corresponding domestic demand is forecast at 250 million liters of ethanol and 700 million liters of biodiesel. Meanwhile, high oil prices and external demand have led investors to plan for supplying domestic and export markets. Some analysts believe exports could exceed the levels needed to meet domestic blending requirements. ${ }^{\text {lxiv }}$

Given the abundant resources, supportive policies, and history of successful adaptation to international agricultural markets, Argentina is poised to become a significant biofuel feedstock producer and exporter over the coming decades.

\subsubsection{Definitions, Methodology, and Assumptions}

Background, definitions, and a description of the general approach used to estimate projected feedstock supplies are provided in the Introduction (Chapter 1). For Argentina, the analysis was based on historic production data by province from 1998-2005. ${ }^{\text {Ixx }}$

Unit costs and price data by province were not available in the Ministry database. The USDA Foreign Agricultural Service in Buenos Aires provided average production costs for selected wheat and soybean crop regions in 2007 that were used as a starting point for establishing supply curves in this analysis. ${ }^{\text {lxxvi }}$ These data were reported as average farm production costs rather than price or "value" data as used in other country analyses. ${ }^{\text {lxxvii }}$ The resulting production cost estimates were far lower than reported internal prices in 2005. Therefore, the production cost estimates were converted to approximate internal prices by taking the difference between the 2005 national average price for Argentina and the maximum reported production cost, and adding this adjustment factor (the difference) to the reported costs for each province. This approach preserves the cost differentiation among producing provinces. The December 2005 average internal prices for soybeans and wheat reported by the Argentine Ministry of Agriculture were \$238/mt and $\$ 131 / \mathrm{mt}$, respectively. ${ }^{1 \times x v i i i}$ For corn and sugarcane, this study estimates an average national price 
based on the FAO production and price database. ${ }^{\text {lxix }}$ Projections for sugarcane were based on production data through 2004 because 2005 data were not yet available by province.

\subsubsection{Units, Conversion Factors, and Calculations}

Supply is stated in harvested millions of metric tonnes (mmt).

Land is measured in hectares (ha), and yield in metric tonnes per hectare (mt/ha).

Prices are in 2005 US Dollars (calculated as described above).

\subsubsection{Wheat Supply Potential — Analysis and Projections: 2012, 2017, $2027^{\mathrm{lxx}}$}

Argentina's total wheat harvest from the 2005/06 season was about $14.5 \mathrm{mmt}$ from 5 million ha. ${ }^{\text {lxxi }}$ This figure reflected above-average yields due to favorable weather. Since then, although the wheat area expanded to 5.2 million ha in 2006, production fell to about $14.2 \mathrm{mmt}$. The potential future production is projected in this study for 2012, 2017, and 2027, with estimated potential total supply in the baseline case of approximately 15, 16.5 and $18 \mathrm{mmt}$, respectively (see Argentina Table 1). Argentina Figures 1-3

illustrate estimated supply curves in the baseline case for the three periods under study at purchaser values (ranging from US $\$ 121$ to $\$ 131 / \mathrm{mt}$ ) calculated as described above from farm production costs and internal market prices. In supply curves, a given point represents the projected cumulative supply for all purchase values (prices) up to that point.

Low and high growth cases illustrate a range of potential supply based on past trends and fluctuations in production which were significant for wheat (see Argentina Figure 4 and Argentina Tables 2 and 3). For example, in 2017 the estimated total supply ranges from less than $13 \mathrm{mmt}$ (low growth case) to nearly 27 mmt (high growth case). The baseline case (Argentina Table 1) estimates a total cumulative potential supply in 2017 of $16.5 \mathrm{mmt}$ from 5.6 million ha.

\subsubsection{Other Wheat Estimates}

USDA projections suggest that Argentina's total wheat production will grow somewhat faster than the baseline case over the near term and then level off, with estimated supplies of $18.2 \mathrm{mmt}$ in 2012 and 18.5 $\mathrm{mmt}$ in 2016 (falling between the baseline and high growth case of this analysis). The FAPRI (2007) model estimates wheat harvests of about $15.6 \mathrm{mmt}$ in 2012 and $16.7 \mathrm{mmt}$ in 2016, similar to this study.

Given Argentine policies restricting exports and greater farmer confidence in potential profit margins from other crops (corn and soybeans), the estimated area being planted in wheat in 2007 was expected to decrease by about $10 \%$ with a corresponding reduction in supply. ${ }^{\text {lxxii }}$ If this decline were to continue, production could stagnate (low growth case in this study). Future growth will depend on government policies, market prices and farmers' perceptions of the relative potential margins from their crop options. At present, policies and prices appear more favorable for corn and soybeans than for wheat.

\subsubsection{Biofuel Use and Competing Demands}

Currently, about $60 \%$ of wheat produced in Argentina is exported, and almost a quarter is used for feed. Domestic food uses account for about $10 \%$ (flour, bread, pasta). Food use per capita is relatively stable and assumed to increase with population. A majority of Argentine wheat enters global markets and potentially could be used for whatever purpose future market prices dictate, including biofuel production. ${ }^{\text {lxxxii }}$ As described in the Methodology, between 46 and 80 percent of total supply is estimated to be available for export and/or biofuel, depending on the case and year (Argentina Table 9). In practice, however, most future wheat exports are likely to continue to meet food and feed demand as more efficient feedstocks such as sugarcane will be available for biofuel production. 


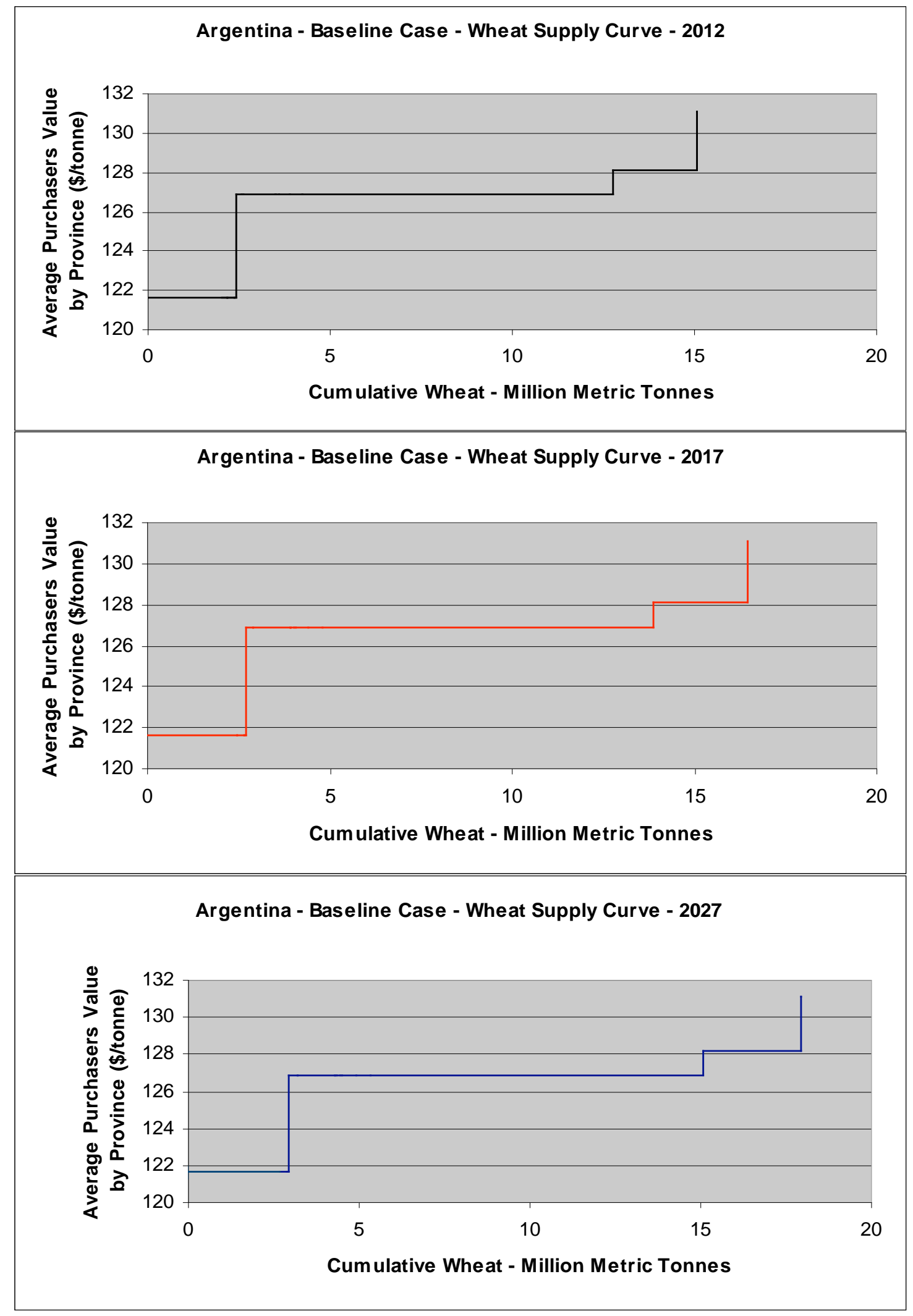

Argentina Figures 1-3. Baseline Case Wheat Supply Projections. 


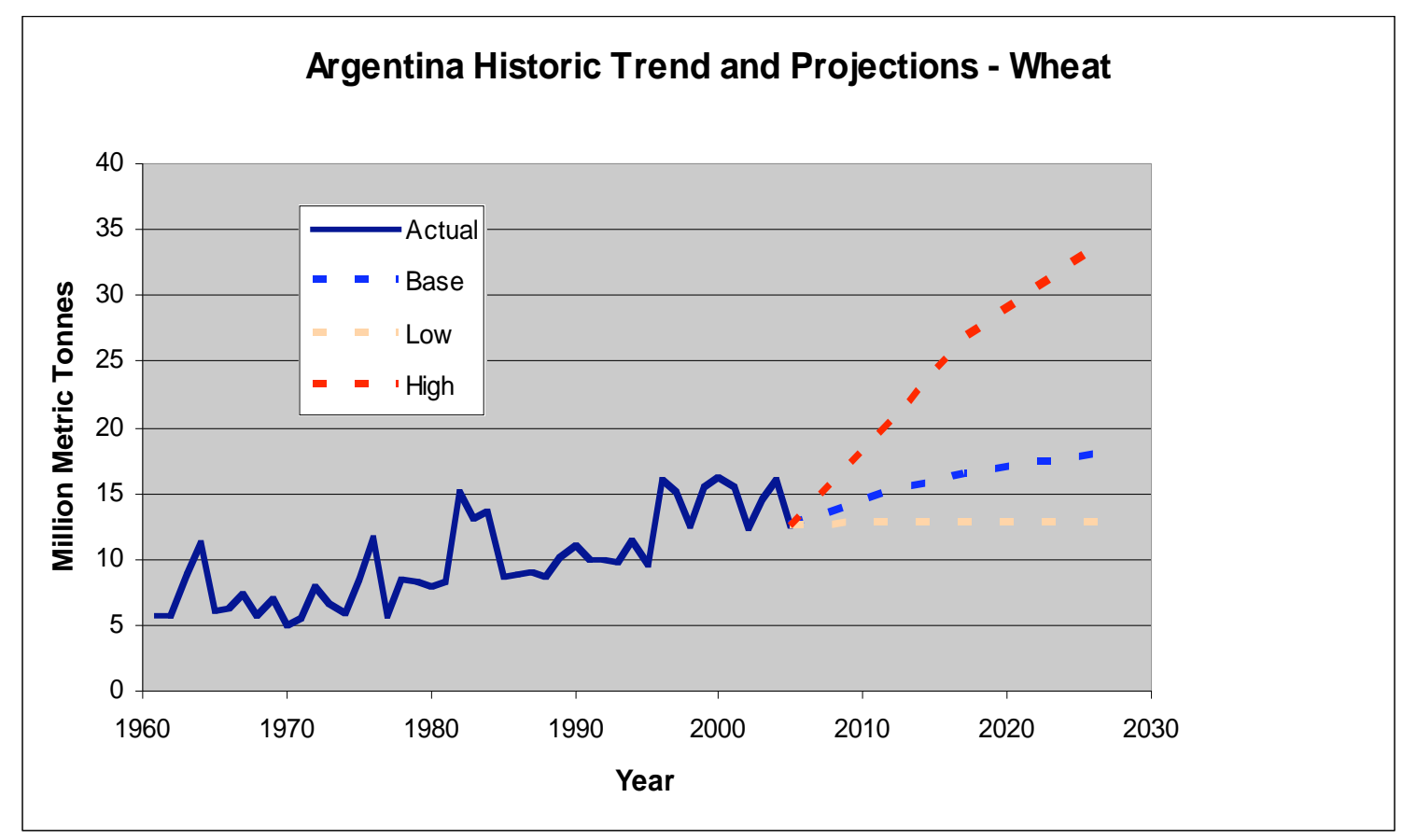

Argentina Figure 4. Wheat: Historic Trend and Projections.

\subsubsection{Notes on Adjustments to Standard Methodology}

As noted above, limited availability of provincial price and production data required adjustments to the standard methodology. Reported costs from 2007 were combined with average internal market prices to generate purchaser values for supply curves. In long-term projections of future production, "maximum plausible limits" to growth were applied in some provinces, as defined in the Methodology. The approach still allows several provinces to expand the area harvested in wheat at over 7\% per year in the high growth case, producing optimistic projections when compared to the long-term trend and estimates from Argentina for 2007 .

\subsubsection{Soybean Supply Potential — Analysis and Projections: 2012, 2017, 2027}

Argentina is the world's third largest producer of soybeans and, due to its extensive, well-established crushing and grain handling infrastructure, the world's largest exporter of soybean oil. The country's total soybean harvest from the 2005/06 season was about $40.5 \mathrm{mmt}$ from 15.2 million ha. ${ }^{\text {lxxxv }}$ Since then, area planted to soybeans has continued to increase rapidly, reaching an estimated 17 million ha in 2007 with projected output of $46 \mathrm{mmt}$. $^{\text {lxxvi }}$

Potential future production is projected in this study for 2012, 2017, and 2027. Estimated potential supply in the baseline case is approximately 50,58, and $74 \mathrm{mmt}$, respectively (see Argentina Table 4). Argentina Figures 5-7 depict estimated supply curves in the baseline case for the three periods under study at purchaser values (ranging from US\$213 to $\$ 238 / \mathrm{mt}$ ) calculated as described above from farm production costs and internal market prices. Additionally, low and high growth cases illustrate a range of potential supply based on past trends and fluctuations in production (Argentina Figure 8 and Argentina Tables 5 and 6). In 2017 the estimated total supply ranges from about $46 \mathrm{mmt}$ (low growth case) to nearly $75 \mathrm{mmt}$ (high growth case). The baseline case (see Argentina Table 4) estimates a total cumulative potential supply in 2017 of $58.3 \mathrm{mmt}$ from 20 million harvested hectares. 

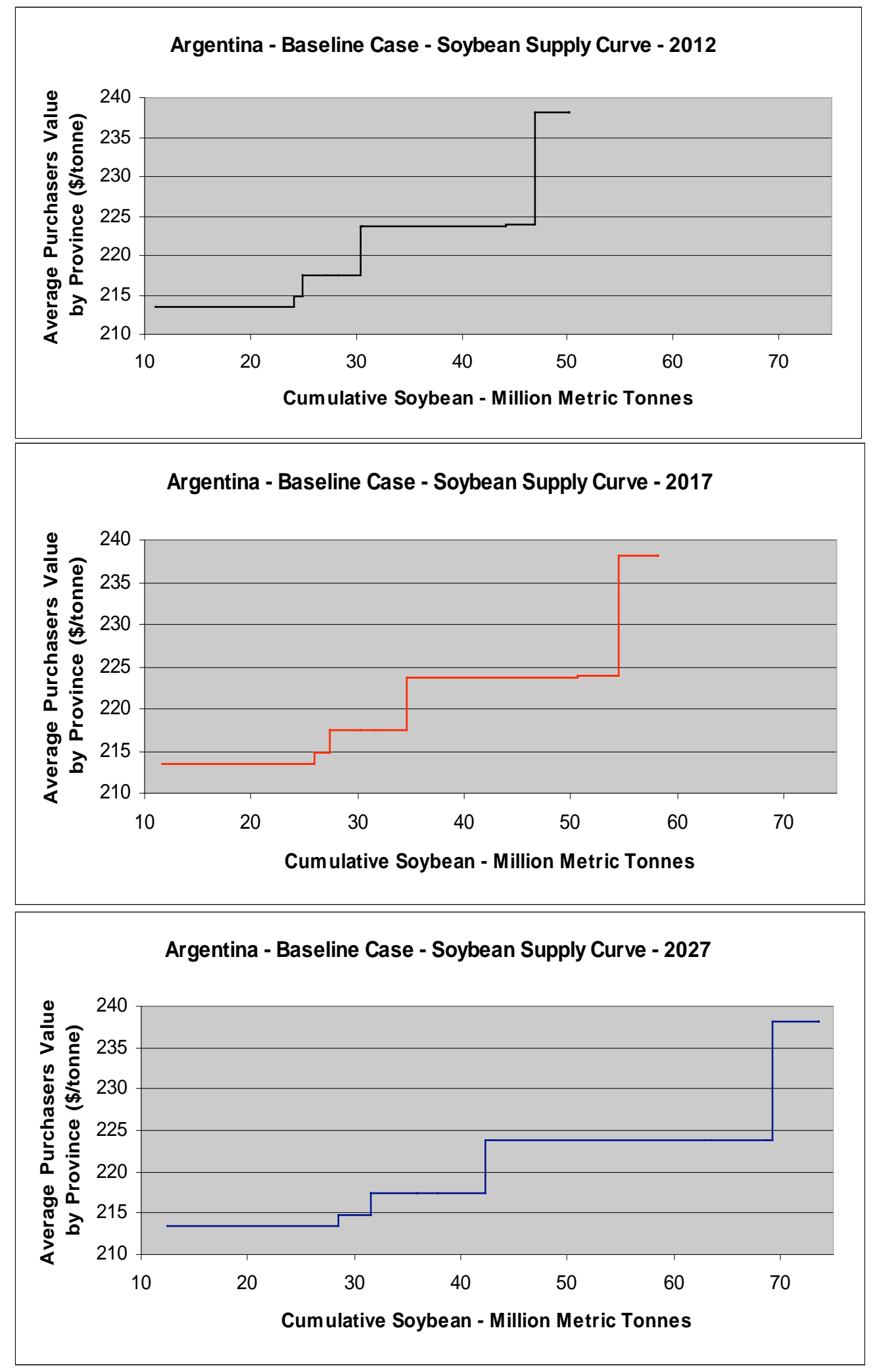

Argentina Figures 5-7. Baseline Case Supply Projections - Soybeans. 


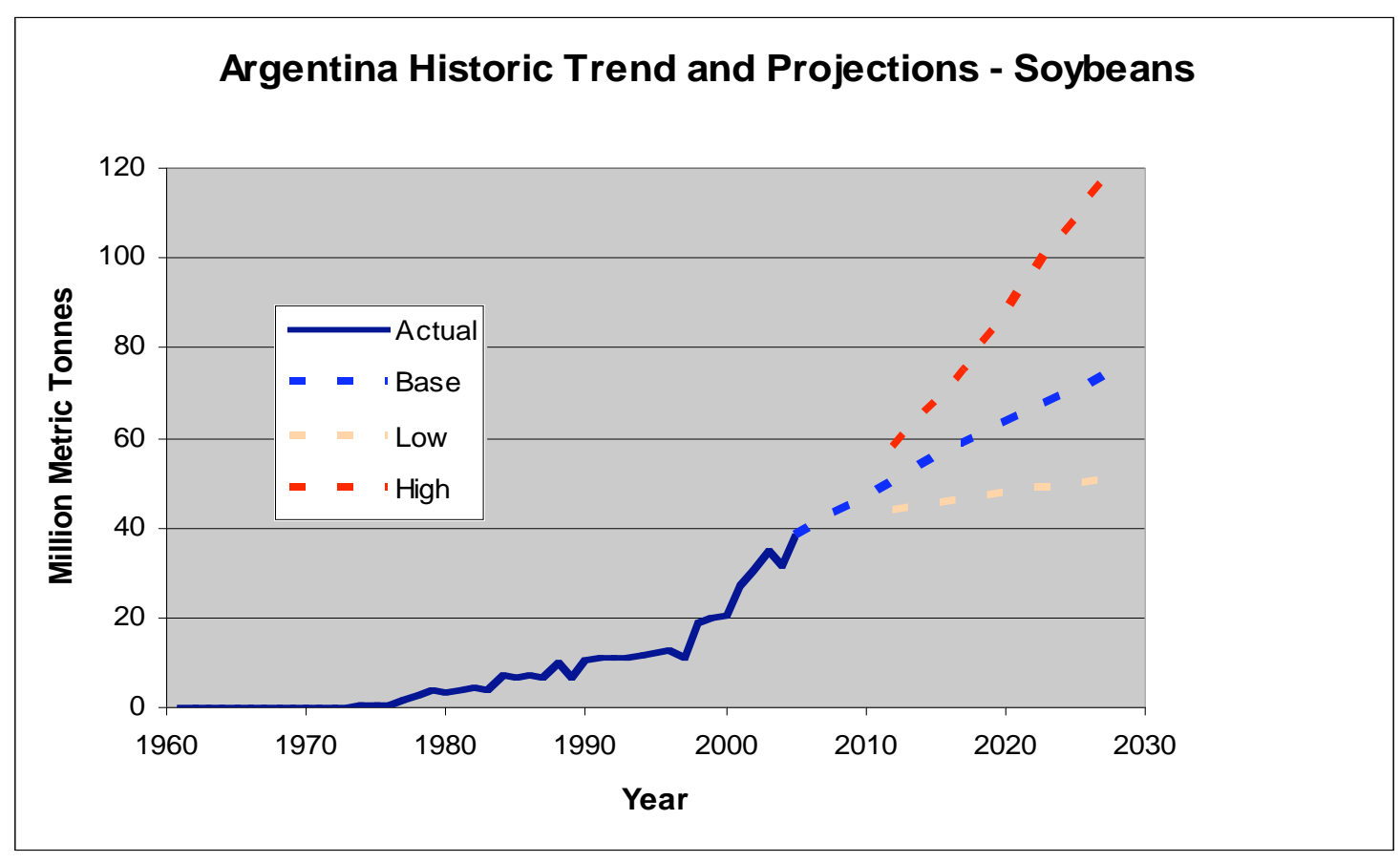

Argentina Figure 8. Soybeans: Historic Trend and Projections.

\subsubsection{Other Estimates}

USDA projections for Argentina show soybean production increasing at a slightly more moderate rate than the baseline case here, with supplies of $48 \mathrm{mmt}$ in 2012 and $50 \mathrm{mmt}$ in 2016. The FAPRI (2007) model projected an increase in soybean production similar to the present analysis, with about $49 \mathrm{mmt}$ in 2012 and $54 \mathrm{mmt}$ in 2016. If international market prices and demand remain strong, and exchange rates are favorable, soybean production could shift toward the high growth case over the next five years.

Argentina is investing in technology to improve yields (via shorter crop cycles, herbicide-ready varieties and cultivation technology) and facilitate double cropping to increase soybean production without necessarily increasing the land area under cultivation. ${ }^{\text {lxxxvii }}$ No-tillage farming practices have allowed farmers to expand into less suitable dry land. Increased use of fertilizer, irrigation, mechanization, and improved seeds are expected to result in continued growth in yields of over $1 \%$ per year. Additionally, as a process of intensification continues in the cattle industry, up to 8 million additional hectares of lowintensity pasture are estimated to become available for other crops. Soybeans traditionally are the first crop to rotate into former pastures. ${ }^{\mathrm{lxx} x \mathrm{xiii}}$ An export tax on soybeans and soybean meal has kept domestic soy prices below international market prices and enhanced global competitiveness. Argentina's agriculture sector has demonstrated its capacity to increase efficiency throughout the crop lifecycle from planting through harvesting, storage, and transportation. .xxix $^{\text {. }}$

\subsubsection{Biofuel Use and Competing Demands}

Soybean production in Argentina currently is export-oriented, with as much as 95 percent of the soybeans produced being exported as beans, meal, or oil. ${ }^{\mathrm{xc}}$ Most of the country's 42 crushing plants are located close to major ports. The government of Argentina charges differential taxes on soybeans, soybean meal, and oil exported to encourage domestic processing of the crop. All soybean production in Argentina is 
priced as if it will be exported, lowering domestic soybean prices. ${ }^{x c i}$ The recent biofuel law encourages domestic production of biodiesel (mainly from soybeans) with an export tax of 5 percent and a rebate on biodiesel exports as compared to the rates on soybeans, meal, and oil, which are about 20 percent higher. Applying the standard methodology for estimating a portion of supply available for export into global markets and/or biofuel, results in 80-88\% of the total 2017 soybean production projected to be available, and $77-90 \%$ in 2027, depending on the case (see Argentina Table 9).

\subsubsection{Notes on Adjustments to Standard Methodology}

As noted above, due to the limited price data available, production costs from were adjusted to 2005 purchaser values. Incorporating recent production trends into the standard methodology resulted in such high rates of increase for areas planted to soybeans as to require the use of "maximum plausible limits," as defined in the Methodology for total land area in some provinces. To stay within caps, an initial growth rate of 6\% from 1995 to 2012 was used as an upper limit. This figure is less than the cap calculated using the standard methodology based on FAO data (25\%). The initial projection was classified as the "high case."

\subsubsection{Corn Supply Potential — Analysis and Projections: 2012, 2017, 2027}

Corn production in Argentina during the 2005/06 season was about $14.5 \mathrm{mmt}$ from 2.5 million ha. This production level is down from almost $20 \mathrm{mmt}$ the previous year. This decline was attributed to a combination of weather factors including drought (estimated to cause a $20 \%$ loss of planted area) and a late-year frost in Buenos Aires. ${ }^{x \text { cii }}$ In addition, high production costs, expensive transportation and low market prices made corn relatively more expensive for growers.

The future production is projected in this study for 2012, 2017, and 2027, with estimated potential supply in the baseline case of approximately 21, 25, and $31 \mathrm{mmt}$, respectively (see Argentina Table 7). Additionally, low and high growth cases illustrate a range of potential supply based on past trends and fluctuations in production (see Argentina Figure 7). For example, in 2017 the estimated total supply ranges from $14.5 \mathrm{mmt}$ (low growth case) to nearly $47 \mathrm{mmt}$ (high growth case). The baseline case estimates a cumulative potential supply in 2017 of about $25 \mathrm{mmt}$ from 3.3 million harvested hectares.

\subsubsection{Other Estimates}

The USDA 2007 baseline projection for Argentina is less optimistic than the baseline case in this study at $18 \mathrm{mmt}$ in 2012 and about $19 \mathrm{mmt}$ in 2016. On the other hand, FAPRI (2007) model projections are more optimistic - $25 \mathrm{mmt}$ in 2012 and $26 \mathrm{mmt}$ in 2016.

\subsubsection{Biofuel Use and Competing Demands}

The largest domestic use of corn in Argentina is for feed, accounting for about $30 \%$ of total production, while food use is a little over 10 percent. The remaining 59 percent is exported. However, corn export depends on location of producers and grain elevators relative to ports because of high transportation costs. $^{\text {xiii }}$ Biofuel potentially could compete for a portion of current Argentinean corn exports. Increasing the competitiveness of corn exports will depend in part on reducing transportation costs. The future portion of corn supply available for export and/or biofuel uses is estimated at 30-78 percent of projected crop production in 2017, depending on the case (see Argentina Table 9). Given its relatively large production capacity compared to domestic demand, Argentina offers much greater potential to supply corn to international markets than the other countries included in this study (see Figure 2.8, baseline case). 


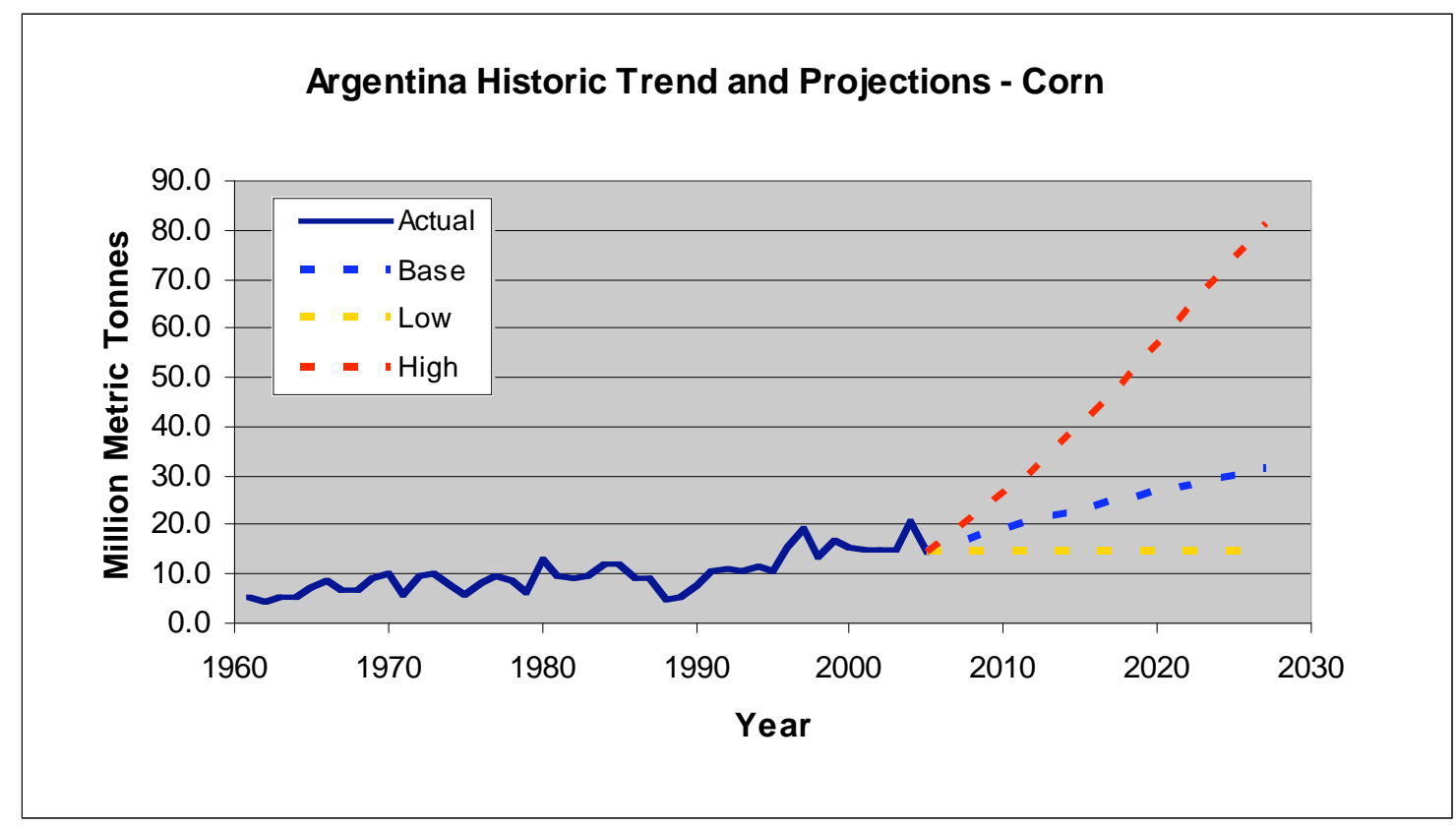

Argentina Figure 9. Corn: Historic Trend and Projections.

\subsubsection{Sugarcane Supply Potential - Analysis and Projections: 2012, 2017, 2027}

Sugarcane production in Argentina is located in six Northern provinces, with the provinces of Tucuman, Jujuy, and Salta accounting for about $64 \%, 23 \%$, and 12\% of total production, respectively. In 2004 (the most recent year with provincial production data, on which this study's projection is based), the total harvest was $18.8 \mathrm{mmt}$ from about 285 thousand ha.

The future production is projected in this study for 2012, 2017, and 2027, with estimated potential supply in the baseline case of approximately 21, 28, and $38 \mathrm{mmt}$, respectively (see Argentina Table 8).

Additionally, low and high growth cases illustrate a range of potential supply based on past trends and fluctuations in production (see Argentina Figure 10). For example, in 2017 the estimated total supply ranges from $21 \mathrm{mmt}$ (low growth case) to $38 \mathrm{mmt}$ (high growth case). The baseline case estimates a total cumulative potential supply in 2017 of $28 \mathrm{mmt}$ from 3.3 million harvested hectares.

\subsubsection{Other Estimates}

The FAPRI (2007) model produces less optimistic growth projections of $21 \mathrm{mmt}$ in 2012 and $22 \mathrm{mmt}$ in 2016.

\subsubsection{Biofuel Use and Competing Demands}

Most sugarcane production in Argentina has historically been used for domestic sugar consumption, which accounted for about $70 \%$ of total 2006 production, with $30 \%$ going to exports. ${ }^{\text {xciv }}$ Historic ethanol production has been based primarily on molasses. However, both domestic and export demands for sugar have grown rapidly in recent years and sugarcane production is increasing accordingly. Argentina is 
expected to continue to export increasing volumes of raw and refined sugar and to begin processing sugarcane directly to ethanol in the 2007-08 year. Russia and Chile are Argentina's top two sugar customers. Domestic consumption is expected to remain relatively flat, given competition from other sweeteners. ${ }^{\mathrm{xcv}}$ Based on the methodology and projected supplies, the percentage of total sugarcane production available for export and/or biofuel is estimated at 30\% in the baseline case and ranges from 648 percent in the 2017 low and high growth cases (see Argentina Table 9).

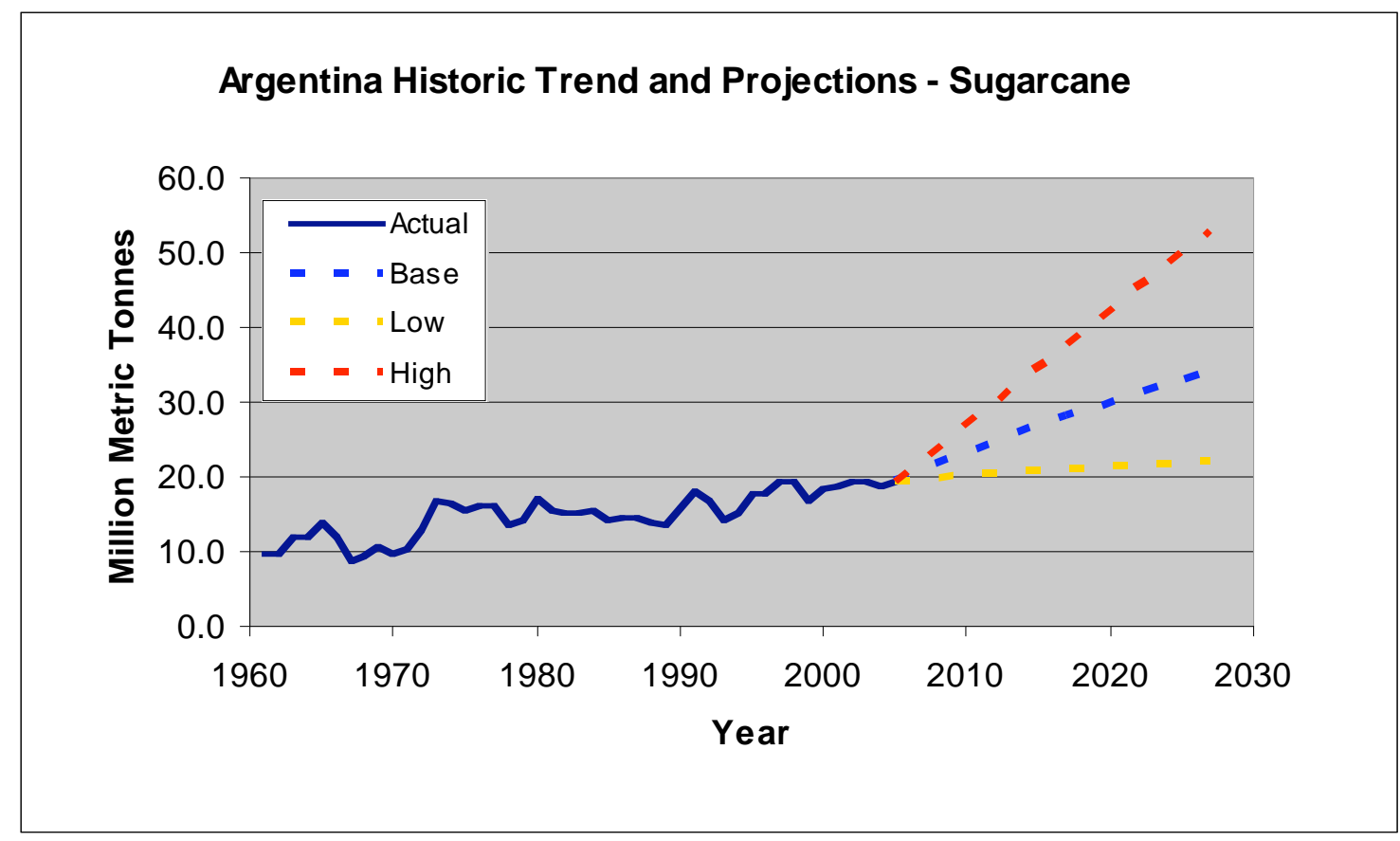

Argentina Figure 10. Sugarcane: Historic Trend and Projections.

\subsubsection{Other Feedstocks}

\subsubsection{Cellulosic Supply}

Potential biomass feedstock supply from agricultural residues is estimated assuming that technology and costs for residue recovery in Argentina will be similar to that in the U.S. ${ }^{\text {xcvi }}$ Using the methodology described in the Introduction, the total cellulosic biomass that could be recovered annually from wheat, corn, and sugarcane residues in Argentina was estimated at $14.3 \mathrm{mmt}$ (all cellulosic supplies are presented as dry weight). Bagasse from sugarcane is expected to be the least-cost and most readily available potential source of cellulosic supply, being on hand at the mills. The total amount of bagasse available at an estimated opportunity cost of US\$10/tonne is projected to be nearly $4 \mathrm{mmt}$ in the 2017 baseline case. The estimated wheat straw and corn stover that could be recovered in the baseline case was calculated to be an additional $10.4 \mathrm{mmt}$ and $12.5 \mathrm{mmt}$ in 2017 and 2027, respectively. The amount of recoverable residue by crop, year and case is shown in Argentina Table 10 (Annex 4).

Cellulosic feedstock from forest products including wood mill residues, harvest residues and a portion of fuelwood supplies is estimated at about $2 \mathrm{mmt}$ per year. Argentina also has vast areas of land with potential for future perennial crop production for biofuel. Although dwarfed by Brazil, it has one of the largest available land resources among other countries studied, with over 90 million ha of potential arable 
land and only $30 \%$ under cultivation in $2006 .{ }^{\text {xcvii }}$ Much of the available land presently is shrub and grassland or extensive cattle pastures. If demand for cellulosic feedstock supply for biofuel were to grow, Argentina's available land resources offer significant opportunities to expand supply further. For example, if $10 \%$ of the uncultivated arable land were to be harvested for biomass at a conservative rate, the dry biomass yield would be an additional $9.5 \mathrm{mmt}$ per year (see Argentina Table 11).

\subsubsection{Opportunities and Constraints}

Argentina possesses vast land resources, a well-educated population, active private sector involvement (financial and industrial), and suitable climate for key biofuel feedstock, as well as good infrastructure and supportive government policies. These factors contribute to Argentina's potential to become an important future producer and exporter of biofuel. The government's active support includes the recent law aimed at $5 \%$ biofuel blending of gasoline and diesel fuel by 2010, though some details of how that law will be implemented remain somewhat unclear. Present regulations include a mixture of tax incentives and rebates to promote domestic biofuel production and government research programs to support improved varieties, alternative feedstock (including rapeseed and sunflower for biodiesel), and more sustainable production systems.

\subsubsection{Ethanol}

A recent USDA report on biofuels in Argentina ${ }^{\text {xcviii }}$ provides a good overview of recent developments and future plans. New distilleries are being planned and under construction. For example, a large ethanol distillery in Tucuman will begin production in 2007 and is expected to add 80-100 million liters to the existing capacity of 250 million liters when fully completed. This plant is expected to use primarily molasses and sugarcane as feedstock, while corn will be used to fill gaps between sugarcane harvests. Another sugar mill is adding ethanol production capacity of 30 million liters to existing production, aimed at the export market. Many sugar mills still are operating with outdated technology acquired decades ago. While there are plans to upgrade and expand capacity, implementation to increase supply in response to the new law has reportedly been delayed due to back-orders for equipment and supply constraints on modern technology. While suitable land and climate for sugarcane production are restricted to a few Northern provinces, there is considerable potential for these states to expand feedstock production.

There is also considerable interest in corn-based ethanol in Argentina because it allows rotation with (and an alternative to) soybeans due to similar climate and soil requirements. A national farmers' association has estimated that their costs for corn ethanol production would be equal or lower than those associated with ethanol production from sugarcane in Argentina. As a result, there are many proposed new projects and plans but none were under construction as of June 2007. ${ }^{\text {xcix }}$

There are currently no reports of plans to allocate wheat to biofuel production in Argentina.

\subsubsection{Biodiesel}

Argentina's current production infrastructure situates the country well to become a significant future exporter of biodiesel derived mainly from soybean oil. Four large biodiesel plants are expected to come on-stream in 2007-08 and should increase production capacity in Argentina from 200 million liters to over 800 million liters. There are another 20 announced biodiesel projects which, if completed, would increase Argentina's total production to about 2 billion liters annually. Plans call for using soybeans as the primary feedstock, although sunflower seeds also are being considered in much smaller quantities.

Soybean production dominates agricultural land use in Argentina and is concentrated in the central region. The flat terrain, soils and climate make the land ideal for mechanized crop production. Argentina 
introduced genetically modified (GM) soybeans in 1996, which currently account for more than half of total production. The introduction of GM soybeans has increased yield, reduced cost and simplified production due to their resistance to selective herbicides. However, the success of GM crops led to increased monoculture planting of soybeans, which can result in depletion of soil nutrients and therefore, soybean fertilization with sulfur and phosphorus applications are projected to increase. Shorter-cycle varieties and no-till cultivation also have raised productivity and profits for some farmers. Farmers currently are experimenting with intercropping and double cropping. ${ }^{\mathrm{c}}$

There are soil erosion issues in some regions of Argentina, which are expected to worsen as cultivation of annual crops expands and intensifies. ${ }^{\mathrm{ci}}$

Biofuel production has not affected the domestic market for food/feed so far, for two reasons. First, most of the land being used for increased production of soybeans and corn is former pastureland. There still is a significant amount of such land available for further expansion. Second, the industry remains small and the largest potential biofuel feedstock is soybeans, which mainly are produced for the export market. Thus, competition for biodiesel feedstock is between exports (of soybean and soybean products) and biodiesel. 


\section{Argentina Endnotes}

lxxiii IDB (Inter-American Development Bank), 2007 accessed at: http://www.iadb.org/biofuels/.

${ }^{1 \times x i v}$ USDA GAIN AR7016 (Argentina Biofuels Report)

${ }^{1 x x v}$ Historic data on production levels by Province were obtained from the Argentine Secretary of Agriculture (SAGPyA), http://www.sagpya.mecon.gov.ar/new/0-0/agricultura/otros/estimaciones/basestima.php.

${ }^{\text {Ixxvi }}$ Dwight Wilder and Franciso Pirovano (OAA-FAS-USDA, US Embassy, Buenos Aires +55-11-5777-4644) provided regional wheat and soy production costs for 2007. Data were derived from the most recent cost data published by "Margenes Agropecuariros" and compiled by USDA. See http://www.margenes.com/

Ixxvii Notes on Argentine agricultural feedstock prices versus reported production costs:

- Argentine internal market prices are from the Ministry of Agriculture's (SAGPyA) website reporting "historical series" and "monthly prices by market." See http://www.sagpya.mecon.gov.ar/new/0$\underline{0 / n u e v o s i t i o / a g r i c u l t u r a / p r e c i o s / m e n s u a l e s . p h p ? f o n d o ~ a g r i ~} 01=$ Precios\&fondo agri precios=mensuales for the sources of average reported prices of wheat and soybean.

- For the source of reported production costs by region, see: http://www.margenes.com/.

- For provinces where production costs were not available, the average costs in neighboring provinces were used as a starting point for calculations described below.

- The reported production costs in US dollars of July 2007 were deflated at the US inflation rate (3\%) to calculate the 2005 values.

- The average national prices for wheat and soybeans were obtained in 2005US\$ from the SAGPyA data. Wheat was reported at US $\$ 131 /$ tonne compared to average regional production costs (calculated from local currency and deflated to 2005 values) of about US $\$ 56 /$ tonne. The average national price for soybeans was US $\$ 238 /$ tonne.

- Prices are in 2005 US Dollars. Unless noted otherwise, prices are based on reported prices in Argentine Pesos in 2005 and converted at 2.904 Pesos per 1 US Dollar (average nominal exchange rate in 2005 from the ERS/USDA exchange rate database).

- The average market prices reported by the Ministry fall below average national prices reported by FAO for the same year ( $\$ 319$ for soybean and $\$ 250$ for wheat).

${ }^{\text {lxxviii }}$ See explanation above and sources from internal markets at: http://www.sagpya.mecon.gov.ar/new/00/nuevositio/agricultura/precios/mensuales.php?fondo_agri_01=Precios\&fondo_agri_precios=mensuales

${ }^{1 x x i x}$ FAOStat, PriceStat: http://faostat.fao.org/site/351/default.aspx

${ }^{1 \times x x}$ Data about current and potential biofuel feedstock production in this analysis are drawn in part from the USDA Foreign Agricultural Service (FAS) Global Agriculture Information Network (GAIN) web-based reports accessed at http://www.fas.usda.gov/scriptsw/AttacheRep/default.asp. As a GAIN fact sheet states, "Production, Supply, and Distribution (PSD) data contained in GAIN reports are NOT official USDA data, but represent estimates made by FAS Attachés.” See http://www.fas.usda.gov/info/factsheets/reports.asp. The following GAIN reports, hereafter cited by their report number, were used in developing the report on Argentina, all preceded with "USDA 2006 GAIN Report":

AR6010 Argentina Grain and Feed Annual

AR6011 Argentina Sugar Annual

AR6016 Argentina Oilseeds Annual

AR7008: Argentina Grain and Feed Annual

AR7009: Argentina Sugar Annual

AR7011: Argentina Oilseeds Annual

AR7016: Argentina Bio-Fuels Report

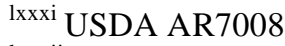

lxxxii Ibid. Some sources suggested that the area planted in wheat for 2007-08 may fall by as much as 1 million ha, or about $18 \%$, due to uncertainties related to government interventions and a ban on exports.

lxxxiii The discussion of a portion of supply potentially "available" for export and/or biofuel is included in each country analysis because the MARKAL-ETP model requires an estimate of the future allocation of feedstocks available for energy markets (biofuel). To avoid constraining the model, the baseline estimates in this report are based on total supply less domestic consumption and are intended to reflect the upper limit of potential feedstock allocation for export and/or biofuel.

${ }^{1 \times x x i v}$ USDA AR7008 
${ }^{\operatorname{lxxxv}}$ USDA AR7011

lxxxvi Ibid.

lxxxvii IDB 2007. Also see USDA FAS (Foreign Agricultural Service) International Trade Report: Argentina's Soybean Complex Competitiveness, April 14, 2006.

lxxxviii USDA AR7008

${ }^{\text {lxxxix }}$ USDA FAS April, 2006.

${ }^{\mathrm{xc}}$ USDA AR6016

${ }^{\mathrm{xci}}$ USDA AR6016, USDA AR7016

${ }^{x c i i}$ USDA AR6010

xciii Ibid.

${ }^{\text {xciv }}$ USDA AR7009

${ }^{\mathrm{xcv}}$ USDA AR7009; USDA AR6011

${ }^{x c v i}$ The amount of crop residues that could be removed annually without harming future crop productivity (a "sustainable removal rate") was estimated for the U.S. in the "Billion Ton" study (Perlack et al. 2005). The same parameters were applied to the projected supplies in this study for wheat, soy, and corn. See Methodology for more information.

xcvii IDB 2007

xcviii USDA AR7016

xcix Ibid.

c AR7011, AR6016

${ }^{\mathrm{ci}}$ Lamers, P. 2006. Emerging liquid biofuel markets: A donde va la Argentina? Masters Thesis, Lund Sweden. 


\subsection{BRAZIL - SUGARCANE, CORN, SOYBEANS}

\subsubsection{Summary Findings}

Brazil is the world's largest producer of sugarcane and cane-derived ethanol, and also the world's leading grower and exporter of soybeans. Similarly, although Brazil does not use corn for ethanol (sugarcane is much cheaper and more efficient as a feedstock), its corn production is substantial and likely to become increasingly important in global markets. This analysis projects cumulative supply of Brazilian sugarcane in 2017 under the baseline case at slightly over $742 \mathrm{mmt}$ from 8.7 million harvested hectares, a $75 \%$ increase over the $428 \mathrm{mmt}$ produced in the 2006/07 season from about 6 million ha. Based on past trends, low and high growth rates also are estimated in the study, with potential supply in 2017 ranging from about 540 to over $1030 \mathrm{mmt}$. Projections for cumulative potential soybean supply in 2017 are $118 \mathrm{mmt}$ in the baseline case, ranging from 81 to $178 \mathrm{mmt}$ in the low and high growth cases; compared with $57 \mathrm{mmt}$ in 2006. For corn, estimated total cumulative production in 2017 baseline case is approximately $54 \mathrm{mmt}$ from 14 million ha.

Given that about $50 \%$ of Brazil's sugarcane is converted to ethanol and more than half of total sugar production is exported, exports and biofuel use combined account for $82 \%$ of total sugarcane production in the baseline case. Brazil's infrastructure offers flexibility to produce sugar or ethanol and adjust output up or down relatively quickly in response to market signals (relative prices for sugar and ethanol, domestic and foreign). Regarding soybeans, the study estimates that $72 \%$ of total supply is available for exports and/or biofuel in the baseline case. And the calculations suggest that only $7 \%$ of corn supply is available for export in the baseline case, although this increases to about $30 \%$ of production in the high growth case.

Brazil's cellulosic feedstock potential dwarfs that of all other countries in the study. Low-cost residues from sugarcane (bagasse) are expected to play an increasingly important role in biofuel production over the time period under study, 2012-2027. In 2017, the supply of bagasse is equivalent to over $100 \mathrm{mmt}$ of dry cellulose and it is already on site in sugar-ethanol processing mills (baseline case). Bagasse is an important biomass fuel for direct combustion and cogeneration (heat and electric power) in most large mills. With improvements in efficiency, bagasse could continue to meet needs for heat and power while contributing significantly to cellulosic ethanol production. Additional feedstock potential is estimated in the 2017 baseline case from a large forestry sector $(40 \mathrm{mmt})$, crop residues $(10 \mathrm{mmt})$, and extensive under-utilized pasture and grasslands offering potential cellulosic supplies from perennial biomass production systems.

\section{$\underline{\text { Brazil Figures }}$}

1-3: Baseline Sugarcane Supply Curves

4: Sugarcane: Historic Trend and Projections

5-7: Baseline Corn Supply Curves

8: Corn: Historic Trend and Projections

9-11: Baseline Soybean Supply Curves

12: Soybeans: Historic Trend and Projections

\section{Brazil Tables (see Annex 4)}

1-3: Sugarcane Supply Potential for Baseline, High and Low Growth Cases

4-6: Corn Supply Potential for Baseline, High and Low Growth Cases

7-9: Soybean Supply Potential for Baseline, High and Low Growth Cases

10: Potential Percentage Allocation for Export \& Biofuels 
11: Estimated Cellulosic Supply from Recoverable Crop Residues

12: Estimated Cellulosic Supply Including Other Residues

\subsubsection{Context}

Brazil has long been involved with biofuel production and has grown to become the dominant source of fuel ethanol in international trade, with exports in 2006 estimated at 3.5 billion liters. ${ }^{\text {cii }}$ Beginning in the 1970s, spurred by the oil crisis and its associated sharp increase in fuel prices, the Brazilian government intensified policies to promote the substitution of sugarcane alcohol for gasoline in automobile use through a National Alcohol Policy (ProAlcool). ${ }^{\text {ciii }}$ With substantial governmental interventions to increase alcohol demand and supply, Brazil created assets and developed institutional and technological capabilities for using renewable energy on a large scale. By 1984, a majority of new cars sold in Brazil required hydrous ethanol as fuel. ${ }^{\text {civ }}$ Changing markets and policies affected the relative production of sugar and ethanol, and impacted consumers who were dependent upon fuel ethanol. As the sugar-ethanol industry matured, policies evolved and the ProAlcool program was phased out in 1999, permitting more incentives for private investment and reducing government intervention in allocations and pricing. Widespread availability of flex-fuel vehicles (promoted through tax incentives) combined with rising oil prices have led to rapid growth in ethanol and sugar production since $2000 .^{\mathrm{cv}}$

Brazil has set blending targets of 2\% and 5\% biodiesel in total diesel supplies by 2008 and 2013, respectively. The government can adjust the portion of ethanol blending with gasoline which has ranged from $20-25 \%$ in recent years. ${ }^{\text {cvi }}$ And hydrous ethanol continues to be marketed nationally as pure ethanol fuel. The Brazilian government also initiated a new biomass program after experiencing a power shortage in 2001. The 'Programme of Incentives to Alternative Sources' (PROINFA), launched in 2002, focuses mainly on the development of biomass resources for power generation. PROINFA supports assessments of the viability of existing biomass resources and evaluates the technical, economic, and environmental competitiveness of biodiesel in relation to the commercially available diesel oil. ${ }^{\text {cvii }}$

In recent years, private-sector involvement, combined with the flex-fuel vehicle revolution and high oil prices, has resulted in a dramatic expansion of the biofuel industry - nearly doubling Brazil's ethanol output between 2000 and 2007. Brazil's domestic market for ethanol is expected to continue to grow rapidly with high oil prices. ${ }^{\text {cviii }}$ Sugarcane production is the only significant ethanol feedstock in Brazil. Production costs are relatively low, conversion efficiency is high, and environmental impacts are relatively low compared to existing annual crop alternative feedstocks. These factors combine to create conditions in which sugarcane is likely to remain the primary feedstock supporting growth in global fuel ethanol trade over the next decade. The demand for sugar within Brazil is estimated to increase at a rate of $1.8 \%$ to $2 \%$ per year. Ethanol domestic demand could reach 25 billion liters and export demand could be over 6 billion liters by 2012/13. ${ }^{\text {cix }}$ In addition, bagasse is expected to evolve as a major future source of cellulosic ethanol. Plentiful soybeans offer locally available feedstock for biodiesel production and presently represent about $90 \%$ of biodiesel feedstock. The government's national biodiesel program seeks to promote additional feedstock options and facilitate diversified, small farmer participation.

Brazil's prominence in biofuel production and its potential for future expansion derive largely from a tremendous endowment of land, soils, and climate. ${ }^{c x}$ Even assuming that $60 \%$ of the territory is set aside for reserves and conservation, Brazil remains one of the few nations with significant areas of land appropriate for agricultural expansion, including an estimated 100-220 million ha of underutilized or undeveloped arable land. Only about 7\% of Brazil's territory (and 20\% of its arable land) is cultivated. Of this, nearly half is dedicated to just two crops, soybeans and corn. Sugarcane represents about $10 \%$ of "cultivated land" and 2\% of agricultural lands. Ample areas suitable for expanding sugarcane cultivation are available without the need for deforestation, primarily on lands now classified as "pastures." 


\subsubsection{Definitions, Methodology, and Assumptions}

Background, definitions, descriptions of approach, and assumptions are provided in the Introduction. Data for projections by state were obtained from the Brazilian Institute for Geography and Statistics (IBGE). ${ }^{\text {cxi }}$ State production data and total purchaser's values were available from the IBGE database. Projections were based on data for 1998-2005.

\subsubsection{Units, Conversion Factors, and Calculations}

Sugarcane supply is stated in harvested millions of metric tonnes (mmt).

Land is measured in hectares (ha), and yield in metric tonnes per hectare ( $\mathrm{mt} / \mathrm{ha})$.

Prices are in 2005 US Dollars, based on reported prices in Brazilian Reales in 2005 and converted at 2.433 Reales per 1 US Dollar (average nominal exchange rate in 2005 from the ERS/USDA exchange rate database).

\subsubsection{Sugarcane Supply Potential — Analysis and Projections: 2012, 2017, 2027}

Brazil currently dominates world sugar and ethanol markets. It is the world's largest producer of sugarcane and exporter of sugar, the least-cost producer, and the fifth largest consumer of sugar. ${ }^{\text {cxii }}$ Sugarcane plays a major role in national employment and economics, and has even greater potential as a bioenergy crop. Sugarcane is one of the fastest growing tropical grasses in cultivation. It produces a large amount of biomass, partitions carbon into sucrose at up to $42 \%$ of the dry weight of the stalk, has a mobile pool of hexose sugars through most of its life cycle, is easily propagated vegetatively, and can be harvested multiple times before replanting. ${ }^{\text {cxiii }}$ Brazil's sugarcane production has expanded rapidly in the last few years, particularly with increasing crude oil prices. Most of Brazil's sugarcane - approaching $90 \%$ - is produced in the Central-South region. ${ }^{\text {cxiv }}$ The 2006/2007 sugarcane harvest, about 428 million metric tons $(\mathrm{mmt})$ represented an increase of about $9 \%$ over the previous year due to a combined 5.4 percent increase in planted area and a gain of $3.4 \%$ in productivity. ${ }^{\text {cxv }}$ Projections for $2007 / 08$ are for another increase in production of nearly $10 \%$. ${ }^{\text {cxi }}$

The great expansion of the sugarcane and ethanol industry in Brazil is a result of several factors: cxvii $^{\text {i }}$

- Favorable climate and soil condition for high productivity of sugarcane

- Two crops per year in each of the two distinct production regions (the central south and the north/northeast)

- Abundant low-priced land

- Few environmental, regulatory, economic, or agrarian restrictions on crop expansion

- Highly developed technology applied to the Brazilian conditions

- Available and developing biotechnology

- Low-cost labor

- Established agro-industrial infrastructure and financing

Together with the high cost of oil and the government's drive to develop biofuels, these factors have allowed Brazil to develop into the global leader in the use of sugarcane for ethanol.

Brazil's total sugarcane production from the 2006/07 season was $428 \mathrm{mmt}^{\text {cxviii }}$ from approximately 5.9 million harvested hectares. Potential future production is projected in this study for 2012, 2017, and 2027, with an estimated potential supply in the baseline case of approximately 600,740 , and $1050 \mathrm{mmt}$, respectively. These totals reflect the cumulative supply from harvests that are projected to be 

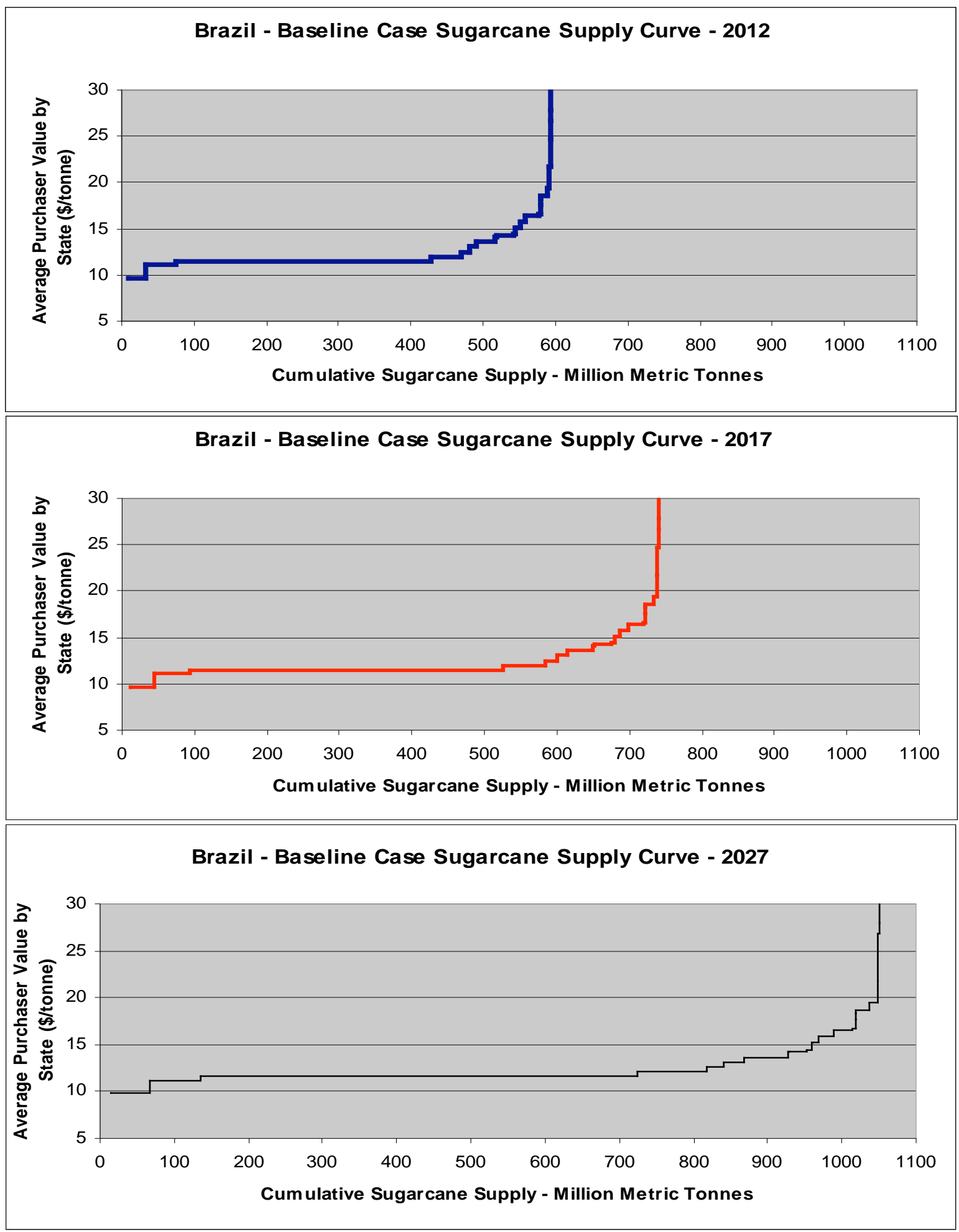

Brazil Figures 1-3. Baseline Sugarcane Supply Projections. 


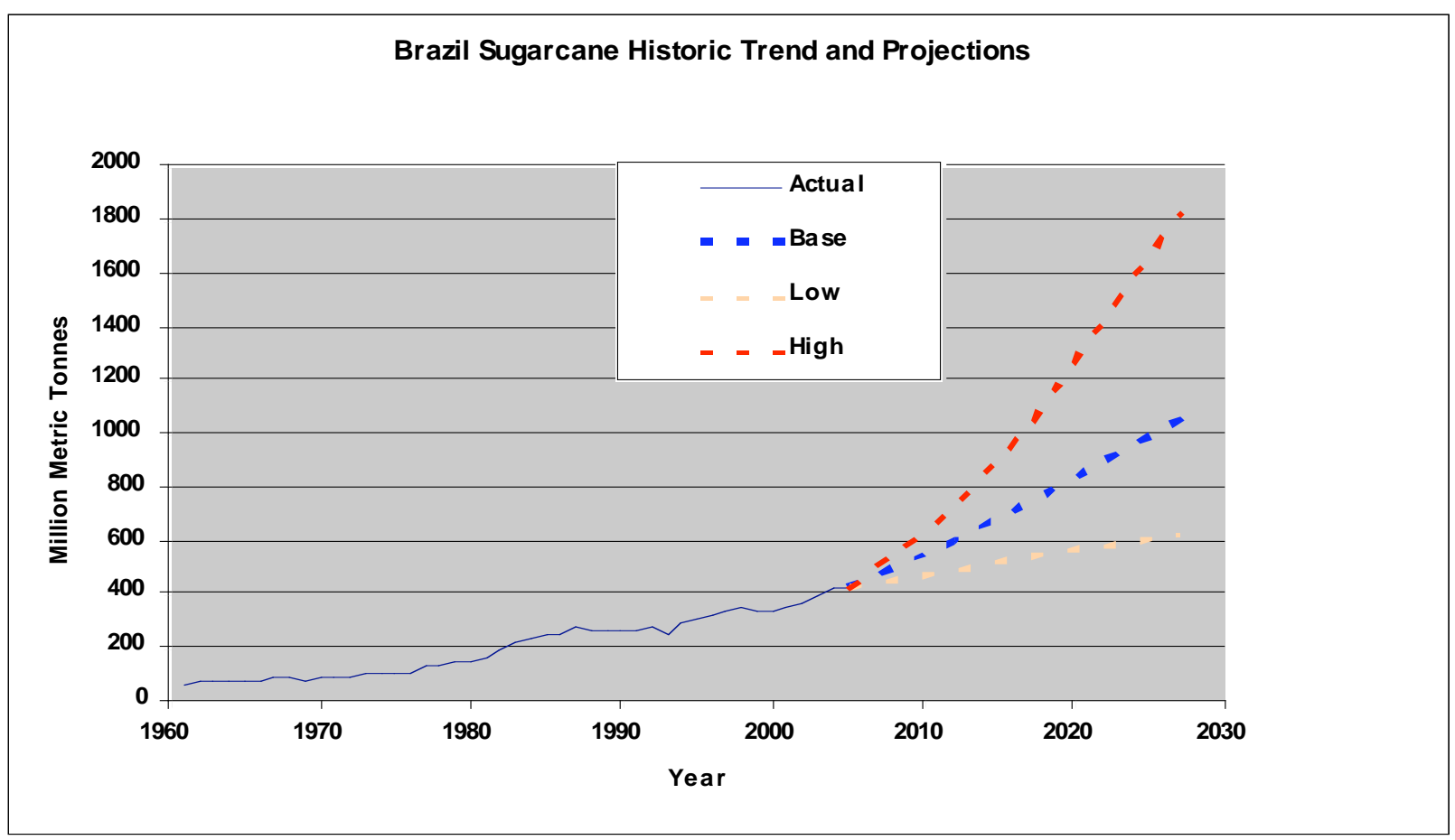

Brazil Figure 4. Sugarcane: Historic Trends and Projections.

available at any price in a given year. Brazil Figures 1-3 illustrate estimated sugarcane supplies available at different value levels in the baseline case for the three time periods under study. The longest segment of the curve represents Sao Paulo State, where trends will likely influence national and global markets

Additionally, low and high growth cases illustrate a range of potential supply, based on past trends and fluctuations in production (see Brazil Tables 2 and 3). For 2017, the estimated total supply ranges from $538 \mathrm{mmt}$ (low growth case) to $1030 \mathrm{mmt}$ (high growth case) from harvests on 6.9-11 million ha, respectively. The baseline case (presented in Brazil Table 1) estimates a total cumulative production in 2017 of over $740 \mathrm{mmt}$ from 8.7 million harvested hectares. Given recent forecasts and reports, it appears that Brazilian production over the short term is trending toward the high-growth case, which estimates a supply of $720 \mathrm{mmt}$ in 2012.

\subsubsection{Other Sugarcane Estimates}

The FAPRI (2007) model projected sugarcane harvests of $480 \mathrm{mmt}$ in 2012 and $533 \mathrm{mmt}$ in 2016, numbers that appear conservative compared to the present analysis and recent trends. AgraFNP (2007) suggests that Brazil will have installed capacity to process $560 \mathrm{mmt}$ of cane by $2010 / 11$. The Sao Paulo Sugarcane Industry Union (UNICA) estimated that Brazil could expand sugarcane area to 10 million ha by 2012/13 and produce over $700 \mathrm{mmt}$ of cane. The latter two estimates of future production reflect the recent rapid growth in this sector and are 14-18\% higher than the baseline case in the present feedstock analysis.

Recent USDA GAIN "Sugar Annual” reports on Brazil's crop adjusted production levels upward for the 2006-2008 period, based on revised reports from producers and increases in area planted to sugarcane. ${ }^{\text {cxix }}$ The USDA reports estimate $07 / 08$ production at $478 \mathrm{mmt}$, more than $11 \%$ higher than the $06 / 07$ production of $428 \mathrm{mmt}$. Future production is forecast at about $580 \mathrm{mmt}$ for the $09 / 10$ season. The harvested area is expected to grow from 5.9 million ha in 2006/07 to 6.5 million ha in 2007/08. The 
USDA-GAIN reports illustrate a recent surge in production due to high oil prices, Brazilian policies, and ethanol demand. The current growth trends, if maintained, would result in production levels approaching the high growth case in this study (see Brazil Table 2).

\subsubsection{Biofuel Use, Competing Demands}

Historically, the percentage of national sugarcane production allocated to ethanol has varied from about $15 \%$ in the early 1970 s, to over $70 \%$ in the late 1980 s (under ProAlcool), to about $50 \%$ over the past five years. The portion dedicated to ethanol is expected to increase to about 53\% for the 2007/08 market year. The portion not used for biofuel is converted to sugar and a series of related byproducts. About $62 \%$ of the sugar is exported around the world; the remainder meets domestic demand. For the purposes of providing potential supply available for the MARKAL-ETP model, this study estimates the percentage of total feedstock supply that could be available for export and/or biofuel production for each year and case, as shown in Brazil Table 10. ${ }^{\mathrm{cxx}}$ The percentage of total sugarcane available for allocation varies from about $70 \%$ to $90 \%$, depending on the case and year.

The rapid expansion of Brazilian sugarcane and biofuel production are not expected to have significant impacts on domestic food and feed markets. Sugar supplies have been growing sufficiently to meet demand and maintain exports concurrently with biofuel expansion. And the land expansion has been focused around existing centers of sugarcane cultivation (mostly Sao Paulo state) and displaces pasture land (primarily) and other crops with lower values. ${ }^{\text {cxxi }}$ Analysis of Brazil's past expansion of sugarcane cultivation (1990 and 2004) showed that the expansion was concentrated in and around Sao Paulo state in the Center-South. This state is represented by the long, low-cost steps on the supply curves above. Studies showed that in this state, sugarcane primarily replaced degraded pastures, along with some annual and permanent crops (grains, oranges, coffee). And a study of land use and erosion found that conversion from annuals or pastures to sugarcane contributed to net improvements in soil quality. ${ }^{\text {cxii }}$

\subsubsection{Corn Supply Potential — Analysis and Projections: 2012, 2017, 2027}

Total corn production in Brazil's 2005 harvest was about $42.5 \mathrm{mmt}$ from 13 million ha. ${ }^{\text {cxiii }}$ Because sugarcane is more economical as an ethanol feedstock in Brazil, corn is not used for biofuel production. However, given Brazilian production and the importance of corn for biofuel in the U.S. and other temperate climates, Brazilian supply plays a role in global markets. Total corn supply potential projected in the baseline case is estimated for 2012, 2017, and 2027 to be approximately 45, 54, and $77 \mathrm{mmt}$, respectively (Brazil Figures 4-6). Low and high growth cases (Brazil Tables 5-6) illustrate a range of potential supply based on past market and production fluctuations for the crop in this country. For example, in 2017, the estimated total supply ranges from about $43 \mathrm{mmt}$ (low growth case) to $72 \mathrm{mmt}$ (high growth case). The baseline case (Brazil Table 4) estimates a total cumulative production in 2017 of $54 \mathrm{mmt}$ from 13.9 million harvested hectares.

\subsubsection{Other Corn Estimates}

USDA (2007) baseline agricultural projections for Brazil estimated total production levels similar to the present analysis, at approximately 50 and $53 \mathrm{mmt}$ for 2012 and 2017, respectively. The FAPRI (2007) model produced estimates similar to the USDA baseline. However, recent reports from the USDA in Brazil indicate that production in 2007 will reach approximately $48 \mathrm{mmt}$, in part due to favorable weather. That level of production, combined with high world prices, is expected to prompt an expansion in corn acreage, especially in the Central-West region. This expectation suggests that production will be closer to the high growth case (Brazil Table 5) over the next five years and leveling off in the longer time frame. 

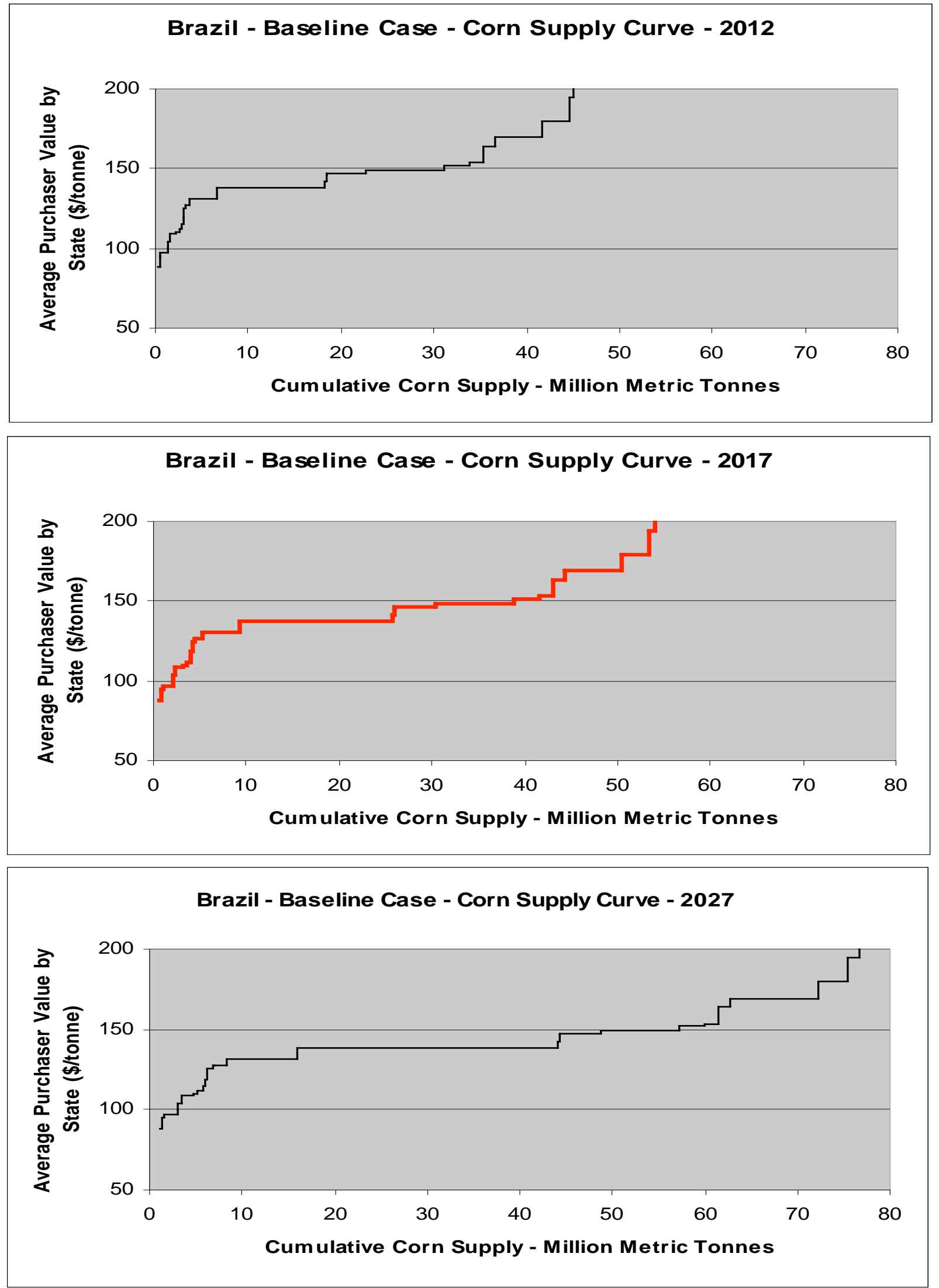

Brazil Figures 5-7. Baseline Corn Supply Curves. 


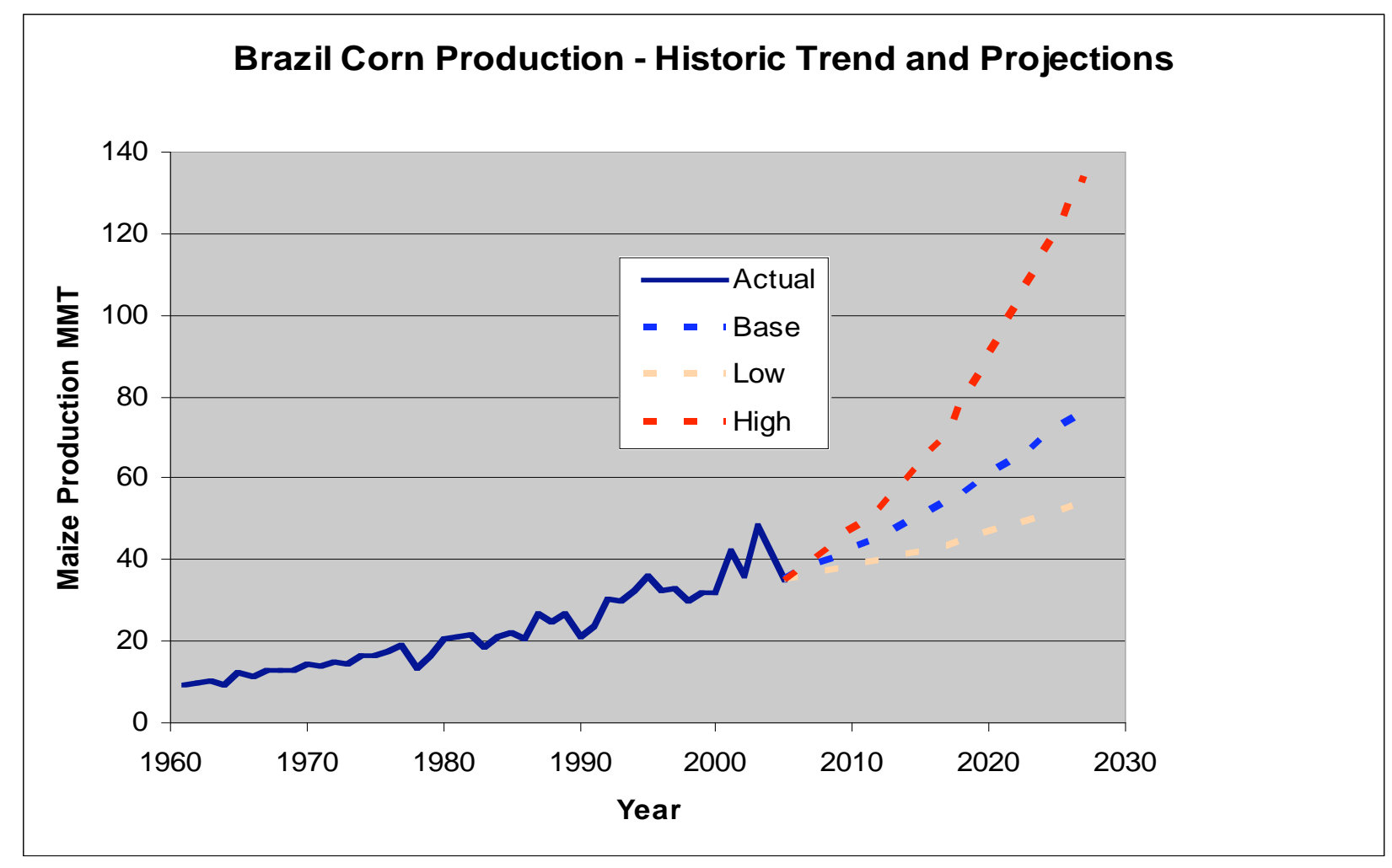

Brazil Figure 8. Corn: Historic Trends and Projections.

\subsubsection{Biofuel Versus Competing Demands}

Based on current domestic demand and net corn exports, future availability of corn for export and/or biofuel are estimated as a percentage of the projected corn supply in Brazil under the growth cases and time periods of study (Brazil Table 10). Corn consumed domestically is used primarily for feed and food. This amount is projected as a constant in the baseline case, representing over $90 \%$ of projected supply. The percentage represented by these domestic demands varies considerably in other projections, from $100 \%$ in the low growth case to about $50 \%$ in the high growth case (2027). Therefore, the percentage available for export and/or potential diversion to biofuel use ranges from zero in the low growth case, to $7 \%$ in the baseline and $20-47 \%$ in the high growth cases (depending on the year). Traditional exports are to Iran, the EU and some non-GMO markets, primarily serving animal feed demand. ${ }^{\text {cxiv }}$

\subsubsection{Soybean Supply Potential - Analysis and Projections: 2012, 2017, 2027}

As the world's largest exporter of soybeans, Brazil plays a significant role in global markets. ${ }^{\text {cxxv }}$ Moreover, soybeans are a major contributor to Brazil's biofuel production, constituting over two-thirds of oil-based biofuel production. Use of soybeans is concentrated primarily in the Central-West region, where a recent study indicates it is the lowest cost feedstock for commercial biodiesel. Historically, an insignificant fraction of Brazilian soybean production was used as a biodiesel feedstock. The impact of continued, localized use of soybeans for biofuel is likely to be small compared with total soybean output, even though local production of soy-based biodiesel could grow exponentially. The national biodiesel program is expected to increase biodiesel demand (and projected production) to about 20 times 2005 levels over the next few years. However, modernization of domestic transportation and ports is critical to 
the growth of the biodiesel export market. A number of projects are underway to improve the transportation system.

Brazil's relatively low historic production costs have been a major advantage in the international market for soybeans. Soybean production in Brazil and Argentina increased from negligible levels in the 1960s to about $50 \%$ of the global market, while the US declined from being the world's leading soybean exporter (about $80 \%$ of the market) to contributing about $35 \%$ of the global market by $1999-2001{ }^{\text {cxxvi }}$ This decline is particularly noteworthy because US farmers planted a record area to soybeans in four consecutive years stating in $1998 .^{\text {cxxvii }}$

Brazil's national research network was successful in adapting temperate-zone soybeans to the tropical conditions while retaining high-yield potentials. Previously, acidic soils and the humid tropical climate served as a barrier to successful production, but these new varieties greatly expand the commercial soybean agriculture in Brazil's interior. Brazil's biotechnology policies were changed in 2006, removing regulatory barriers to GMO soybeans. As a result over 50\% of the 2006/07 crop was estimated to be GMO varieties, although premium prices for traditional soybeans are increasing in some areas to $\$ 10 / \mathrm{mt}$, leading to debate over systems to segregate supplies and exploit non-GMO niche markets. ${ }^{\text {cxxviii }}$

Brazil's total soybean production in the 2005 season was about $56 \mathrm{mmt}$ from approximately 22 million harvested hectares. ${ }^{\text {cxxix }}$ If trends are maintained, total soybean supply potential projected in the baseline case is estimated for 2012, 2017, and 2027 to be approximately 82, 118, and $209 \mathrm{mmt}$, respectively (Brazil Figures 7-9). These totals reflect the cumulative supply from harvests projected to be available at various prices in the given year (Brazil Table 7). Low and high growth cases (Brazil Tables 8 and 9) illustrate a range of potential supply based on past market and production fluctuations for the crop in this country. For example, in 2017, the estimated total supply ranges from about $80 \mathrm{mmt}$ (low growth case) to $178 \mathrm{mmt}$ (high growth case). The baseline case (Brazil Table 7) estimates a total cumulative production in 2017 of $118 \mathrm{mmt}$ harvested from over 40 million ha; the doubling of supply in this time frame reflects the rapid growth of this industry over the past decade.

\subsubsection{Other Soybean Estimates}

USDA (2007) baseline projections for Brazil estimate total production levels of about 89 and $105 \mathrm{mmt}$ for 2012 and 2017, respectively, somewhat below the estimates in this analysis. Other USDA reports ${ }^{\text {cxxx }}$ highlight the rapid short-term growth in soybean planting in Brazil (>4\%/year), and indicate that soybean exports from Brazil are expected to double over the next 5-8 years, even as domestic consumption increases. The most recent USDA estimate is for soybean production to reach $61 \mathrm{mmt}$ in 2008. Like sugarcane, this increase reflects a shift from the baseline case in this study toward the high growth case in the near term (to 2012). The FAPRI (2007) model estimated production more conservatively at 79 and 93 $\mathrm{mmt}$ for 2012 and 2016, respectively.

\subsubsection{Biofuel Use and Competing Demands}

Currently, the vast majority of soybeans produced in Brazil are exported, largely as soybeans, soymeal, and soyoil. The remainder is used primarily as feed, with food use representing a minimal fraction. Future soybean supplies available for export and/or biofuel are estimated as a percentage of the total projected supply in Brazil under the three growth cases, based on current net exports and domestic demand (See Brazil Table 10). The supplies available are about $70 \%$ of the total in the baseline case, and range from $45 \%$ to $88 \%$ in other cases. 

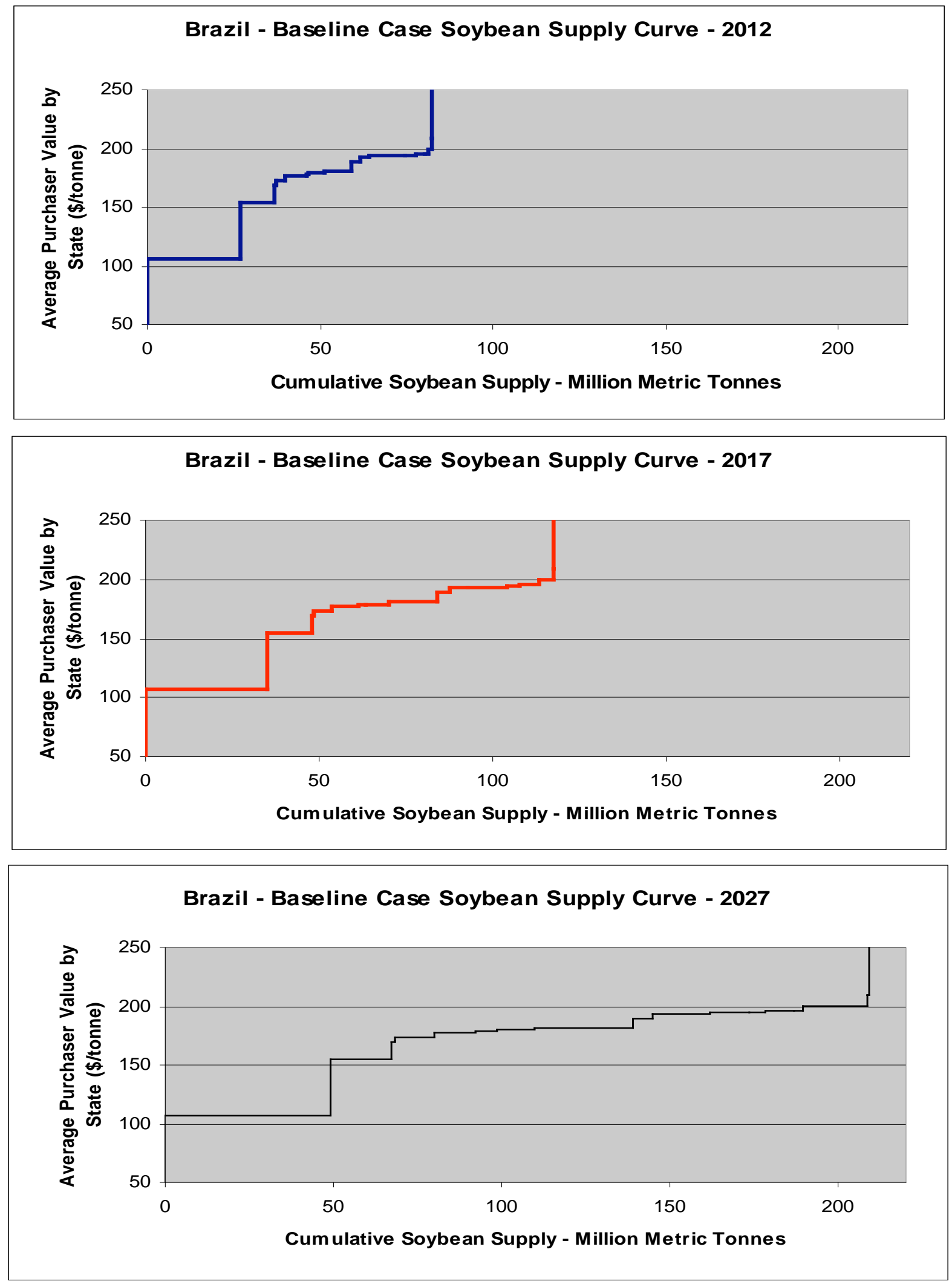

Brazil Figures 9-11. Baseline Soybean Supply Curves. 


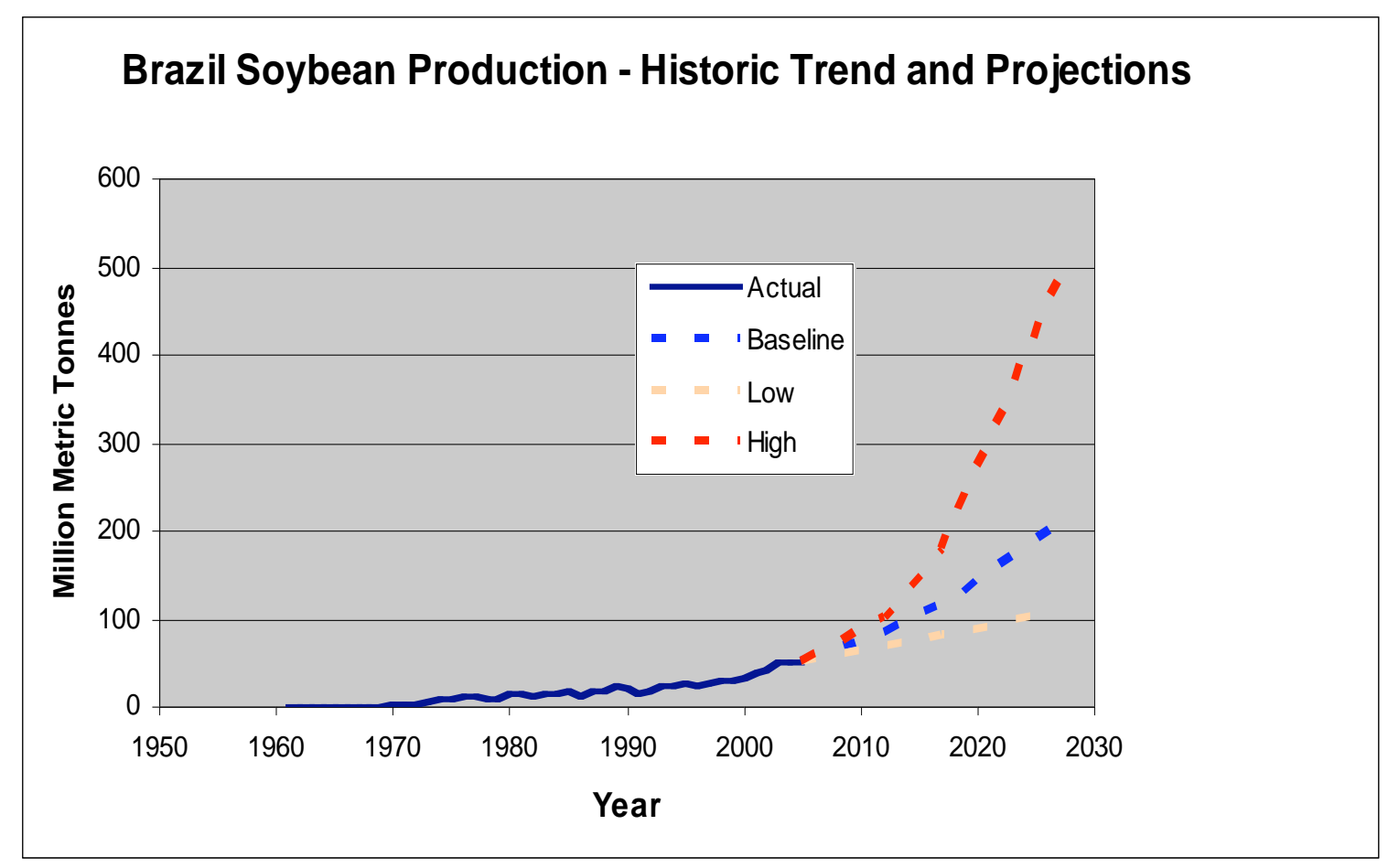

Brazil Figure 12. Soybeans: Historic Trend and Projections.

\subsubsection{Other Feedstocks}

\subsubsection{Cellulosic Supply (Brazil Tables 11 and 12)}

Bagasse, the biomass residue from sugarcane stalks after processing, currently is used for process steam and, in some cases, electricity generation. Brazil has a significant and convenient supply of bagasse at cane crushing mills. And the energy value from bagasse and other cane residue is double that of the juices, per tonne of cane harvested. Therefore, bagasse is expected to become a major future source of cellulosic feedstock for ethanol with very low costs as it is already delivered to the plants.

Brazil Table 11 provides estimates of cellulosic supply available from crop residues associated with the projected levels of sugarcane and corn production in the study. Soybeans are assumed to not permit sustainable recovery of residues (see Methodology). The supply of bagasse in 2017 ranges from 100 to nearly $150 \mathrm{mmt}$ (baseline and high growth cases) of dry cellulosic material delivered to ethanol plants. Corn offers another $10 \mathrm{mmt}$ although the estimated price for collection and transport is much higher. The forestry sector offers another source of significant cellulosic supplies, about $40 \mathrm{mmt}$ in 2017 at prices ranging from \$14-100 per dry $\mathrm{mt}$. Land and climate offer Brazil tremendous potential from dedicated biofuel perennial crops, estimated conservatively at 36 to $73 \mathrm{mmt}$ per year.

At current levels of sugarcane production in Brazil, there is an estimated potential to produce 16,000 MW of electricity from bagasse plus $50 \%$ of the crop residues (which are currently not harvested or utilized). ${ }^{\text {cxxxi }}$ To reach such high levels of utilization and production would require dedicated support from the government for energy diversification, including support for co-generated power, improving efficiency of energy consuming processes and new technology and integration, allowing more surplus 
power for the grid. ${ }^{\text {cxxii }}$ Thus, using bagasse to produce ethanol implies an opportunity cost due to its value as a fuel for direct combustion. Improving efficiencies will free up increasing amounts of bagasse for use as biofuel. In efficient mills, with cogeneration of electricity and process heat for sugar and ethanol production, it is possible that cellulosic supplies could be sorted and processed for end uses based on seasonal availabilities, prices and adaptation to a specific process.

Brazil is rich in biomass supply and productivity and farms are required to maintain forest reserves ranging from $20-80 \%$ of land holdings, so potential cellulosic supply does not appear to be a limiting factor.

\subsubsection{Ethanol}

Ethanol production in Brazil is expected to continue to be based on sugarcane with bagasse becoming a future complimentary source of feedstock for cellulosic conversion. If cellulosic technologies prove successful, other sugarcane residues, nearby forest products and residues, and other agricultural wastes will likely come into the mix. The final technology and costs for cellulosic conversion are not yet well enough defined to allow a determination of ideal feedstock and economic feasibility, but Brazil is at the forefront of developing processes based on bagasse. Given the growing sugarcane production in Brazil, sugarcane processing wastes including low-grade molasses will offer potential sources of feedstock supply at mills. Rapidly growing corn production may also contribute to cellulosic supplies in the form of corn stover.

\subsubsection{Biodiesel}

Through mandates and tax incentives, Brazil established biodiesel blending targets of $2 \%$ (B2) in January, 2008 and 5\% (B5) in 2013, to increase self-sufficiency and reduce costs and diesel imports, especially in the interior and more remote regions of the country. While estimates of recent production levels vary, it is clear that biodiesel output is growing quickly from approximately 1 million liters in 2005, increasing to

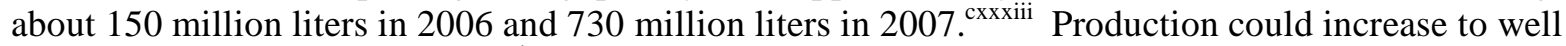
over the B2 mandate by $2008{ }^{\text {cxxxiv }}$ Under the new legislation, at the $5 \%$ mixture rate, the domestic market is estimated to be 2.4 billion liters in 2013.

The majority of plant oil-based biofuel production in Brazil is from soybeans (see discussion, above). Another small fraction comes from cotton seed, and still smaller fractions from castor oil, sunflower seeds, palm oil, peanuts and animal fats. A government program, biodiesel "social fuel stamp" is designed to provide incentives for small, family farmers in more isolated and disadvantaged areas (such as the Northeast) to participate in this emerging industry. Approximately 224,000 family farmers were contracted through the program for over 300 million liters of biofuel. The feedstock for small family farm production is primarily castor seed (50\%), soybeans $(25 \%)$, and palm oil $(15 \%){ }^{\text {cxxxv }}$ Jatropha is under study to learn its potential as a feedstock for arid regions. Other possible feedstocks under investigation are rapeseed (canola), native palms ("babacu" and coconut) and other native oil-seed trees and plants. Palm oil has not been a traditional biofuel feedstock in Brazil and reported production has been modest (0.16 mmt/year). ${ }^{\text {cxxxvi }}$

\subsubsection{Opportunities and Constraints}

After setting aside over $60 \%$ of the nation for forests and reserves, Brazil has an estimated 320 million ha of potential arable land. Sugarcane occupies little over $2 \%$ of arable land, soybeans and corn about $11 \%$, and abandoned or under-utilized pastures the vast majority. Several studies suggest that Brazil has over 35 million ha of land (primarily low-intensity grazing land) that could be available for sugarcane production without conflicting with forests or soybean and other grain production increases. ${ }^{\text {cxxxvii }}$ The USDA Foreign 
Agriculture Service reports also suggest that sugarcane for ethanol does not compete with soybeans and corn for cropland, because these crops generally are planted in different portions of the country. ${ }^{\text {cxxxviii }}$ In short, land is not a significant constraint for expansion of bioethanol production in Brazil over the coming decade.

A major opportunity in Brazil is represented by increasing investment, private and public, in technology and efficiency improvements. For example, a consortium of private and public sector partners is supporting projects to improve ethanol-sugarcane manufacturing processes including rapid hydrolysis and solvents to convert bagasse cellulose to sugars. ${ }^{\text {cxxxix }}$

In the world view, environmental considerations may create constraints on some types of production. For example, intensive soybean cultivation practices that include significant use of fertilizers, pesticides, and herbicides may adversely affect ecosystems. ${ }^{\text {cxl }}$ Several new laws, policies and regulations have been put in place over the past decade to protect the Amazon and other ecologically sensitive areas and to promote more sustainable development - including forestry and agricultural production. In fact, Brazil has developed and put into place some of the most progressive forestry and environmental protection laws in the world. ${ }^{\text {cxli }}$ Within the Amazon, farmers are now required to set aside $80 \%$ of their property as a forest preserve (up from $50 \%$ under previous legislation) and to permanently protect all riparian areas. Providing secure land tenure rights to small farmers and indigenous groups is supported by the policies and has been shown to be another important factor to slow deforestation. But the resources to support the application and enforcement of the new laws and regulations may be insufficient in the short term to counter the momentum and power of local vested interests.

\subsubsection{Deforestation}

Deforestation is a particularly important issue for Brazil. The Amazon, which supports the largest tropical forest on Earth, has undergone rapid deforestation for the last four decades. An estimated $20 \%$ of the Amazon forest was lost during that period. Selective logging and small clearings are estimated to impact large additional areas, but these are not easily quantified. Pastures occupy the bulk of deforested Amazon lands. For example, more than 70 percent of deforested area in the Amazon has been cleared for — or has been classified as - cattle pasture. Roads provide access to the landilii their presence thus is a precursor of deforestation. Nearly all roads in the Amazon are unauthorized. As roads open, the typical sequence of events is as follows: the forest is high-graded for the most valuable tropical hardwoods for export; loggers move in to cut remaining marketable timber; land speculators facilitate widespread clearing for "xipasture" and only later, larger numbers of settlers attempt to make a living from agriculture.

Forestland also has been cleared to create farmland, such as soybeans. From 2001 to 2004, analysis of $f_{\text {cxlv }}$ satellite imagery documented about 1.3 million acres of southern Amazon forest cleared for farmland. Changes in Brazilian agriculture intensity have coincided with the emergence of new production centers for soybeans and cattle bordering the Amazon. These centers signal future pressures on the Amazon as soybean cropping in Brazil moves north ${ }_{1}$ and annual soybean production growth rates in the Amazon exceed those of the rest of the country. Virtually all soybeans from the Amazon are exported for use as animal feed. These factors lead some to suggest that global demand for beef and grain-fed meat, rather than biofuel, is the major force behind clearing the Amazon.

Transportation infrastructure - roads - plays a large role in deforestation. Roads reflect a combination of microeconomic (e.g., poorly defined lease agreements, failure to define property rights, and government policies) and mackgefonomic (e.g., population growth, market conditions) factors that constrain options for land use. In the Brazilian Amazon, large-scale pasture for cattle ranching and soybean production now are the main uses of cleared land and lead to a yearly deforestation rate that is 
estimated at $0.5 \%$. ${ }^{\text {cxlviii }}$ Clearing spreads out from the roads, eventually leading to new settlements and subsequent social and economic pressures for services, road improvements, and additional roads. Few roads - perhaps $1 \%$ of total road miles in the Amazon - have been built by the government, including the controversial BR-163 that splits the Amazon. BR-163, along with investments in electrical power, credit for large farmers and cattle ranchers, andlipast land reform policies, has encouraged expansion of the soy farms and pasturelands in that region. The government also has improved roads to permit access to mining and hydro energy development areas.

The continued loss of the Amazon is a global concern. Given past trends, another 20\% of the Amazon forest could be lost over the next two decades. ${ }^{\text {cl }}$ Scientists fear that loss could lead to decreasing rainfall, increasing fires, and accelerating loss of the remaining productive ecosystems. ${ }^{\text {cli }}$ Such local climatic changes would be calamitous for the remaining forests and the burgeoning agricultural economy that is developing around them. One mechanism for stemming deforestation and increasing sustainability of production is to provide market incentives through a "certification" process based on internationally recognized standards that reflect socially and environmentally sound production practices. The approach has been developed for other globally traded products and services, including lumber, bananas, coffee and eco-tourism, and more recent efforts are underway for palm oil and sugarcane biofuel industries. ${ }^{\text {clii }} \mathrm{A}$ pilot system of standards and certification has been initiated for ethanol production in Brazil. ${ }^{\text {cliii }}$

International concerns about the loss of Amazon forests and the relationship with increasing soybean production led to a moratorium beginning in July 2006 by the major soybean traders on the purchase of soybeans from newly deforested areas. The moratorium is to be evaluated after two years. Mechanisms are being tested to ensure traceability of product, apply methods of certification and avoid sourcing from recently cleared lands. Pressures for corporate responsibility were applied by environmental groups and the European food industry to the major multi-national corporations trading Brazilian soybeans. ${ }^{\text {cliv }}$ One finding from a pilot certification program for soybean farmers was the importance — and challenge — of bringing growers into compliance with basic Brazilian land-use laws as a first step toward improving sustainable production. ${ }^{\text {clv }}$ The moratorium appears to be having the desired impact as reports this year indicate that rapid expansion of soybean cultivation in the Amazon frontier areas (Northeast region and states of Tocantins and Rondonia) came to a halt. ${ }^{\text {clvi }}$ This is one of several examples where growing awareness at an international scale is fomenting collaboration among private industry, local governments and NGOs in support of slowing the pace of deforestation. ${ }^{\text {clvii }}$

In the case of sugarcane, it was found that forest cover in Sao Paulo state increased along with the area planted in sugarcane as more land owners worked toward compliance with legislation requiring private forest reserves and protection of riparian areas. ${ }^{\text {clviii }}$ This, combined with analyses showing expansive areas of underutilized pastures suitable for sugarcane, led to a conclusion among stakeholders that continued expansion of sugarcane cultivation could be sustainable and environmentally beneficial in comparison with other likely land uses, if guidelines are followed. ${ }^{\text {clix }}$ In addition, the social and political trends in Brazil are conducive to biofuel production. For example, national and international groups working in Brazil have facilitated discussions among environmental, labor, industry and government stakeholders that include recommendations for sustainable production based on environmental and social criteria. ${ }^{\text {clx }}$ 


\section{Brazil Endnotes}

${ }^{\text {cii }}$ USDA GAIN BR7011 (2007); see below. AgraFNP, 2007, pg. 128.

Data about current and potential biofuel feedstock production in this analysis are drawn in part from the USDA Foreign Agricultural Service (FAS) Global Agriculture Information Network (GAIN) reports, accessible at: http://www.fas.usda.gov/scriptsw/AttacheRep/default.asp. As a GAIN fact sheet states, "Production, Supply, and Distribution (PSD) data contained in GAIN reports are NOT official USDA data, but represent estimates made by FAS Attachés" - see http://www.fas.usda.gov/info/factsheets/reports.asp. The following GAIN reports (hereafter, cited by their report numbers) were used in developing the assessment for Brazil:

USDA 2005 GAIN Report BR5020: Brazil Sugar Annual, 2005.

USDA 2006 GAIN Report BR6008: Brazil Bio-Fuels Annual, 2006.

USDA 2007 GAIN Report BR7003: Brazil Sugar Annual, 2007.

USDA 2007 GAIN Report BR7610: Brazil Oilseeds and Products, Soybean Update, 2007.

USDA 2007 GAIN Report BR7011: Brazil Bio-Fuels Annual - Ethanol, 2007.

USDA 2007 GAIN Report BR7612: Brazil Grain and Feed, Grain Annual, 2007.

USDA 2007 GAIN Report BR7618: Brazil Oilseeds and Products, Annual Soybean Report, May 2007.

USDA 2007 GAIN Report BR7014: Brazil Sugar Semi-Annual, 2007.

${ }^{\text {ciii }}$ Puppim, J. A. and J. A. P. de Oliveira, 2002. The policymaking process for creating competitive assets for the use of biomass energy: the Brazilian alcohol programme...

${ }^{\text {civ }}$ Pessoas-Jr, A., I. C. Roberto, M. Menossi, R. R. Dos Santos, S. Ortega, and T. C. V. Penna, 2005.

${ }^{\mathrm{cv}}$ AgraFNP (2007): Measures adopted by the Brazilian government that have been instrumental in promoting the use of ethanol in Brazil included: mandatory use of $20 \%$ anhydrous ethanol mixed with gasoline; lower tax on ethanol cars; lower excise tax on ethanol and introduction of flex-fuel vehicles.

${ }^{\text {cvi }}$ USDA BR7011 - The mandated ethanol blend in gasoline rose to $25 \%$ as of June, 2007.

${ }^{c v i i}$ Ramos, L. P. and H. M. Wilheim, 2005 (current status of biodiesel development in Brazil).

${ }^{c v i i i}$ AgraFNP, 2007. Sugar and Ethanol in Brazil: A Study of the Brazilian Sugarcane, Sugar and Ethanol Industries. ${ }^{\text {cix }}$ Ibid.

${ }^{c x}$ See Smeets, E., A. Faaij, and I. Lewandowski, 2004, for comparisons of "global bio-energy potentials to 2050: an analysis of the regional availability of biomass resources for export in relation to the underlying factors."

${ }^{c x i}$ IBGE 2007 (Brazilian Institute for Geography and Statistics) was the primary source of state data.

cxii Schmitz T.G., J. L. Seale Jr. and J. Peter, 2007.

${ }^{c x i i i}$ Brumley, S. M., M. P. Purnell, L. A. Petrasovits, L. K. Nielsen, and P. H. Twine, 2007. Developing the sugarcane biofactory for high-value biomaterials.

${ }^{\text {cxiv }}$ USDA BR7003.

${ }^{\mathrm{cxv}}$ Rodrigues, D. and L. Ortiz, 2007, offer a "Case study sugar cane ethanol from Brazil: Sustainability of ethanol from Brazil in the context of demanded biofuels imports by The Netherlands."

cxvi USDA BR7011.

cxvii AgraFNP 2007 pg. 133.

cxviii USDA 2007 "Agricultural Baseline Projections."

${ }^{c x i x}$ USDA BR5020, BR7003, BR7014.

${ }^{c x x}$ The discussion of a portion of supply potentially "available" for export and/or biofuel is included in each country analysis because the MARKAL-ETP model requires an estimate of the future allocation of feedstocks available for energy markets (biofuel). To avoid constraining the model, the estimates in this report are based on total supply less domestic consumption and are intended to reflect the upper limit of potential feedstock allocation for export and/or biofuel.

${ }^{c x x i}$ USDA BR7011,pg. 7.

${ }^{\text {cxxii }}$ Macedo 2007. Paper presented in Stakeholders Workshop on Biofuels (see also BPSD 2007 in Bibliography) and based on the book "Sugar Cane's Energy (UNICA 2005)". Accessed at

http://www.fbds.org.br/Apresentacoes/Constatacoes_Recom_ingl.pdf.

cxxiii USDA BR7612

cxxiv Ibid.

${ }^{c x x v}$ USDA BR7610

${ }^{\text {cxxvi }}$ Schnepf R. D., E. Dohlman, and C. Bolling, 2001. Agriculture in Brazil and Argentina: Developments and Prospects for Major Field Crops. 
cxxvii Ibid. Schnepf, Dohlman, and Bolling 2001

cxxviii USDA BR7618, pg. 33.

${ }^{\text {cxxix }}$ USDA BR7618, pg. 5, reports: 22.3 million hectares harvested, $56.2 \mathrm{mmt}$ produced.

cxxx Trostle 2007. "Global Aspects of USDA's Baseline Projections for Biofuels."

cxxxi de Oliverio, J. L. and J. E. Ribeiro, 2006.

cxxiii Ibid. de Oliverio and Ribeiro 2006.

cxxxiii Brazil's annual biodiesel production was estimated at 700,000 liters for CY2005, 155 million liters in 2006 and $730 \mathrm{~m}$ liters in 2007, per the 2007 USDA-GAIN Biofuels Report BR7012 (pg. 3). Other reports estimated 2005 production at $40 \mathrm{~m}$ liters (BR7618), or over 100 million liters according to AgraFNP (2007).

${ }_{\text {cxxxiv }}$ USDA BR7012, pg.5 notes installed capacity in 2007 at 1.6 billion liters with plans to reach a capacity of 3.4 b liter/year by the end of 2008 .

${ }^{\mathrm{cxxxv}}$ Ibid.

${ }^{\text {cxxxvi }}$ FAO ProdStat (accessed July, 2007).

cxxxvii Jank, M.S. 2007. "Potential Supply and Demand for Biofuels in the Coming Decade: Towards a U.S.-Brazil

Partnership."

cxxxviii USDA BR6008.

${ }^{\text {cxxxix }}$ USDA BR7011.

${ }^{\mathrm{cxl}}$ Alho and Vieira, 1997. Also see:

Downey 2007, “Amazon Harvest — Can European Pressure Stop the Creep of Soy Fields into Brazil's Rainforests?" and

Wallace 2007, "Last of the Amazon.".

cxli Downey 2007

cxlii Wallace 2007

cxliii Ibid. Wallace 2007

${ }^{\text {cxliv }}$ As examples, see: Cardille, J. A. and J. A. Foley, 2003. Agricultural land-use change in Brazilian Amazonia between 1980 and $1995 \ldots$ and

Dale, V. H., R. V. O'Neill, M. A. Pedlowski, F. Southworth, 1993. Causes and effects of land-use change in central Rondônia, Brazil... and

Fearnside, P. M., 2007. Brazil's Cuiaba-Santarem (BR-163) Highway: The environmental cost of paving a soybean corridor through the Amazon...

cxlv Downey 2007.

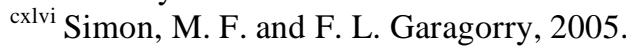

cxlvii Kahn, J. R. and J. A. McDonald, 1997. "The role of economic factors in tropical deforestation."

cxlviii Mertens, B., R. Poccard-Chapuis, M. G. Piketty, A. E. Lacques, and A. Venturieri, 2002.

cxlix Ibid. Mertens et al. 2002

${ }^{\mathrm{cl}}$ Downey 2007

${ }^{\text {cli Wallace } 2007}$

clii See the discussion of certification efforts in Chapter Two (Section 2.2.10).

${ }^{c l i i i}$ FBDS and CI 2007. "Agro-Energy Expansion and its Impact on Brazilian Natural Ecosystems Workshop."

Summary accessible at http://www.fbds.org.br/Apresentacoes/Constatacoes_Recom_ingl.pdf and proceedings at http://www.conservacao.org/publicacoes/workshop_agronegocios.php.

${ }^{c l i v}$ Wallace 2007

${ }^{\mathrm{clv}}$ Downey 2007.

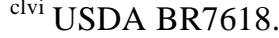

clvii Wallace 2007

clviii Macedo 2007.

clix FBDS and CI 2007. http://www.fbds.org.br/Apresentacoes/Constatacoes_Recom ingl.pdf.

${ }^{c l x}$ Ibid. 


\subsection{CANADA - WHEAT AND CORN}

\subsubsection{Summary Findings}

Estimated total cumulative production of Canadian wheat in 2017 is about $30 \mathrm{mmt}$ from 10 million ha, compared with $27 \mathrm{mmt}$ from 9.8 million ha in 2005/06. For corn, estimated total cumulative production in 2017 is $15.5 \mathrm{mmt}$ from 1.3 million ha, compared with $9.5 \mathrm{mmt}$ from 1.1 million ha in 2005/06. These figures reflect a baseline growth case, while recent corn planting appears to be more in line with the high growth case. Regardless, Canada's demand for corn and ethanol is likely to remain greater than domestic supply. The country's ambitious biofuel production and use initiatives impose substantial challenges on Canadian agriculture and significantly increase demand for wheat and corn. Meeting targets for fuel blending likely will require corn and/or ethanol imports. Thus, while the use of grains for biofuel production is expected to mushroom over the next decade to meet domestic targets, Canada is not expected to be a significant net biofuel exporter in that time period.

Given competing demands for feed and food, the amount of grains dedicated to biofuels is unlikely to exceed the amount required to meet national production targets. Assuming that targets are met primarily through domestic production of corn and wheat in 2017, and that half of the requirement would be met by alternative sources (ligno-cellulosic) in 2027, the amount of grain dedicated to biofuel would represent up to $25 \%$ of baseline case corn supply in 2017 and $15 \%$ in 2027 . Despite a rapidly growing share of wheat as a feedstock in Canadian ethanol production, the total harvest allocation is not expected to exceed $10 \%$ of the baseline case supply in any year. ${ }^{\text {clxi }}$

Canada is well-endowed with cellulosic feedstock, which is expected to play an important role in biofuel production by 2027 . With total potential supplies of approximately 55 million dry tonnes per year, and about 22 million dry tonnes per year identified as "realistic" for recovery, cellulosic feedstock availability per se is not likely to be a limiting factor in the time period under study.

\section{Canada Figures}

1-3: Baseline Projections for Wheat Supply

4: Wheat: Historic Trend and Projections

5-7: Baseline Projections for Corn Supply

8: Corn: Historic Trend and Projections

\section{Canada Tables (See Annex 4)}

1-3: Wheat Supply Potential for Baseline, High and Low Growth Cases

4-6: Corn Supply Potential for Baseline, High and Low Growth Cases

7: Potential Percentage Allocation for Export \& Biofuels

8: Estimated Cellulosic Supply from Recoverable Crop Residues

9: Estimated Cellulosic Supply Including Other Residues

\subsubsection{Context}

Although Canada began to implement a variety of policies promoting the production and use of ethanol in the 1980s, recent initiatives (e.g., Ethanol Expansion Program and ecoEnergy for Biofuels) aim to increase dramatically the production and use of biofuel. Though these initiatives establish goals, provide incentives, and promote research and development, many details and associated funding decisions were still uncertain when this analysis was conducted. Canada's goal states that by $2010,5 \%$ of motor vehicle fuels must contain renewable content and, by 2012, $2 \%$ renewable content in diesel fuel and heating oil. 
Thus, compared with 2001-2005 production rates of approximately 230 million liters/yr for ethanol and 9 million liters/yr for biodiesel, production rates would to climb to 1.3 billion liters/yr (1.5 billion liters/yr capacity) and 100 million liters/yr, respectively, by 2008. Likewise, demand would grow to 3 billion liters/yr from 300 million liters in 2005, some of which is would most likely be met through imports from the US. Achieving these goals will affect Canadian agriculture substantially, dramatically increasing the demand for corn and wheat. Since corn production will be insufficient to meet the demand in the absence of imports, greater emphasis may be placed on wheat production for ethanol in the short term, and cellulosic feedstock in the long term.

\subsubsection{Definitions, Methodology, and Assumptions}

Background, definitions, and a description of the general approach used to estimate projected feedstock supplies are provided in the Introduction.

For Canada, the analysis was based on historic production data through 2006 , as these data were the most recent available. Standard data on farm-gate production costs were not available. The Canadian Agricultural Income Stabilization (CAIS) Program's farm price ${ }^{\text {clxii }}$ data were used for six provinces and other provincial agricultural reports on farm prices were used to complete data for the remaining producing provinces, as referenced below.

\subsubsection{Units, Conversion Factors, and Calculations}

Supply is stated in harvested millions of metric tonnes (mmt).

Land is measured in hectares (ha), and yield in metric tonnes per hectare (mt/ha).

Prices are in 2005 US Dollars, based on reported prices in Canadian C\$ in 2005 and converted at 1.213 C \$ per 1 US Dollar (average nominal exchange rate in 2005 from the ERS/USDA exchange rate database). ${ }^{\text {clxii }}$

\subsubsection{Wheat Supply Potential — Analysis and Projections: 2012, 2017, $2027^{\text {clxiv }}$}

From a global perspective, Canada is a major wheat producer. In 2005/06, Canada exported nearly 15 mmt of wheat and wheat flour, representing over half of the total wheat production that year for the nation. The percent of total production exported varies year-by-year according to weather conditions and fluctuating world-wide supply and domestic demand. For example, wheat exports are expected to increase to about $20 \mathrm{mmt}$ in 2007, because of lower world supplies, but decrease to $17 \mathrm{mmt}$ in 2007/08 due to increased domestic demand. ${ }^{\text {clxv }}$ Japan, Sri Lanka, Indonesia, Mexico, and Peru are the major importers of Canadian wheat. ${ }^{\mathrm{clxvi}}$

The crop is grown throughout Canada but the western provinces are the major wheat-growing areas. The highest yields come from Saskatchewan, Alberta, and Manitoba. Canada's total wheat harvest from the 2005/06 season was about $26.8 \mathrm{mmt}$ from approximately 9.8 million ha. ${ }^{\text {clxvii }}$ This level was above the average due to good weather and high yields.

Potential future production is projected in this study for 2012, 2017, and 2027, with estimated potential supply in the baseline case of approximately 28,30 , and $33 \mathrm{mmt}$, respectively. Canada Figures 1-3 illustrate estimated supply curves in the baseline case (See Canada Table 1 for data). Low and high growth cases illustrate a range of potential supply based on past trends and fluctuations in production (see Figure 4 and Canada Tables 2 and 3). For 2017, the estimated total supply ranges from about $25 \mathrm{mmt}$ (low growth case) to approximately $40 \mathrm{mmt}$ (high growth case). The baseline case (Canada Table 1) estimates a total cumulative production in 2017 of nearly $30 \mathrm{mmt}$ from $10.3 \mathrm{million}$ ha. 

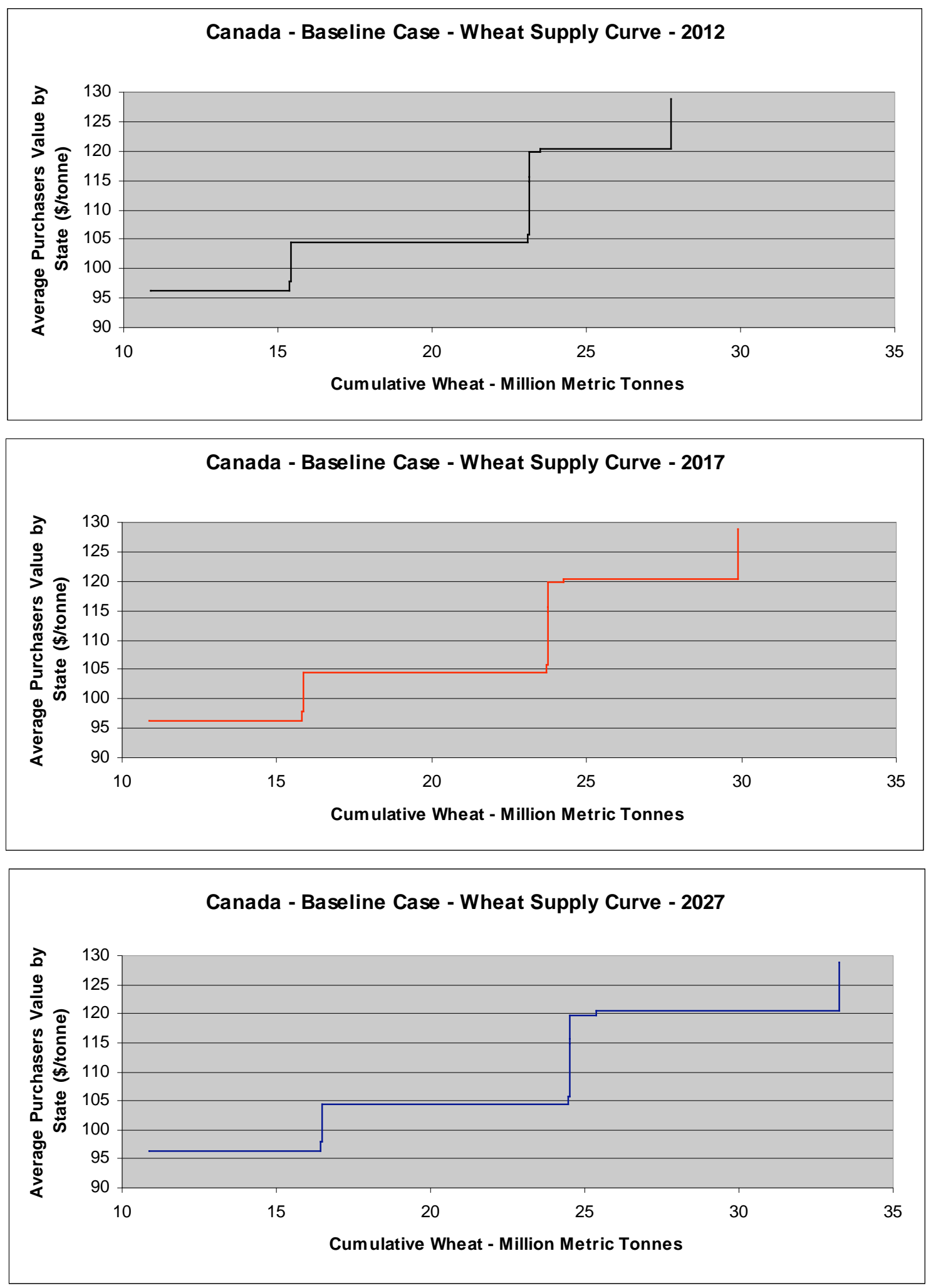

Canada Figures 1-3. Baseline Case Wheat Supply Curve Projections. 


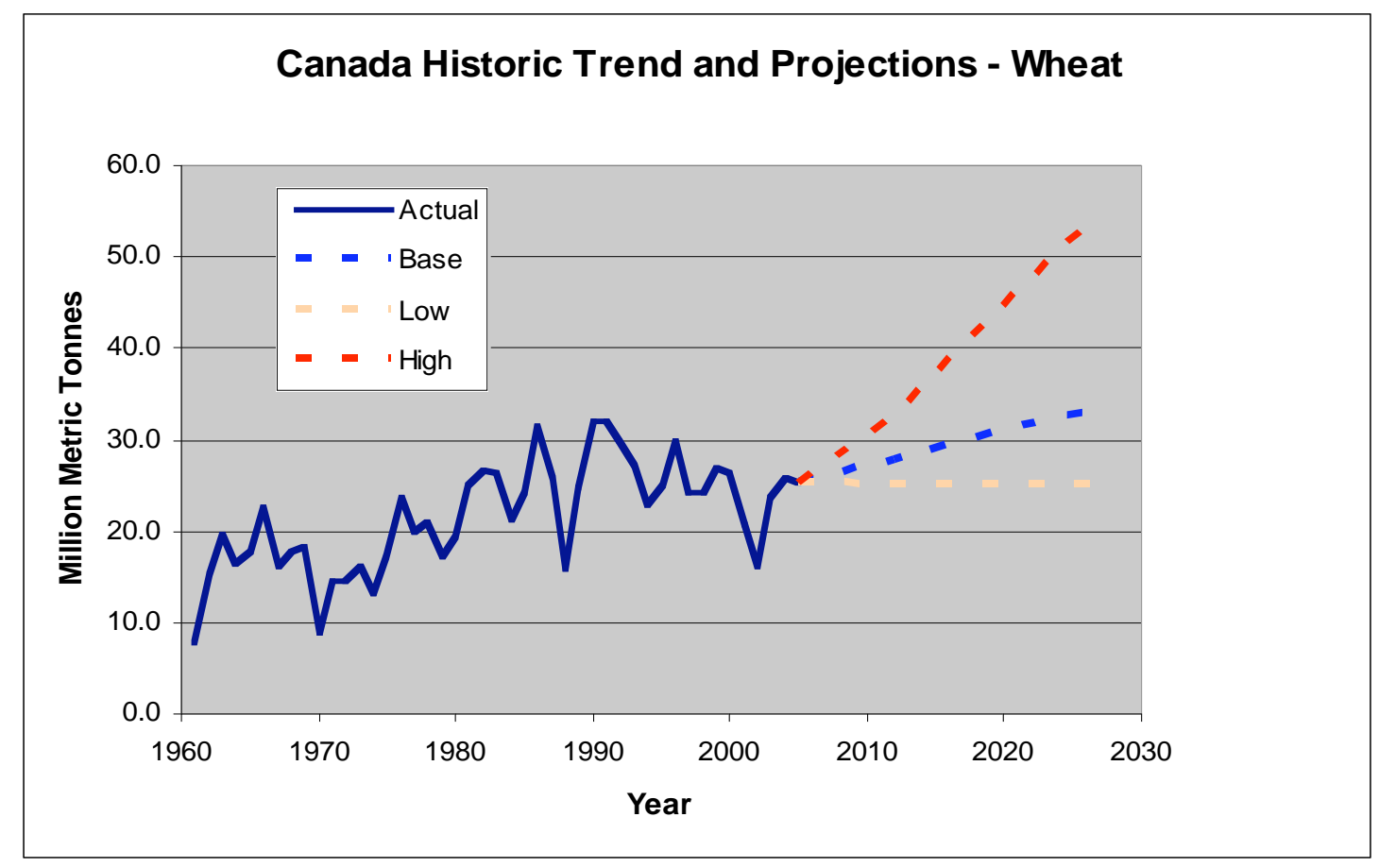

Canada Figure 4. Wheat: Historic Trend and Projections.

\subsubsection{Other Estimates}

The FAPRI (2007) model projected wheat harvests of about $27.5 \mathrm{mmt}$ in 2012 and $28.63 \mathrm{mmt}$ in 2016 just a little less than the baseline case in this study. USDA baseline projections for Canada estimate flat or declining wheat production over the period of study, with $25.5 \mathrm{mmt}$ in 2012 and $25.2 \mathrm{mmt}$ in 2016, closer to the "low growth case" in this study.

\subsubsection{Biofuel Use and Competing Demands}

Wheat traditionally has been grown for food and feed. It is playing an increasingly prominent role in Canadian ethanol production - though still smaller than corn - because corn production is insufficient to meet demands associated with the country's biofuel production and use initiatives. Increased use of wheat for ethanol is concentrated in the western wheat growing provinces. The location of these provinces may lead to a situation where the markets for ethanol produced in western Canada are stronger in the western United States than eastern Canada. ${ }^{\text {clxviii }}$

Increased use of wheat for ethanol could result in more of the crop being grown, as well as a shift toward lower protein/high starch wheat from higher protein/lower starch wheat. Dramatic increases in the use of wheat for ethanol may prompt competition among wheat end users, most notably between ethanol and livestock producers. Hog producers, for example, typically use the same varieties of wheat as ethanol producers. ${ }^{\text {clxix }}$

To meet the national targets, an estimated 2.5 and $2.8 \mathrm{mmt}$ of wheat could be dedicated to ethanol production in 2012 and 2017, respectively, representing less than $10 \%$ of the baseline case supply projection for those years. In 2027, the potential use of wheat will depend on many other factors, 
especially the cost-effectiveness of competing processes that use lower cost feedstock, such as cellulosic ethanol production. Assuming that such new processes and feedstock meet about 50\% of demand in 2027, about $8 \%$ of wheat supply (baseline case) in that year could still be dedicated to biofuels along with corn to meet the existing 5\% domestic target. Given that Canada currently exports a majority of its wheat production, about $67 \%$ of the baseline supply case is estimated to be available for export and/or biofuel use. The percentage available for export and/or biofuel ranges from $56 \%$ to $80 \%$ in other cases and years as shown in Canada Table 7.

\subsubsection{Notes on Adjustments to Standard Methodology}

Due to limited data availability, multiple sources were used to establish price estimates for production by province. ${ }^{\text {clxx }}$ The average reported year-end price, converted to 2005 US\$ was used in each case.

\subsubsection{Corn Supply Potential — Analysis and Projections: 2012, 2017, 2027}

The role of corn in Canadian agriculture is distinct from wheat. Whereas Canadian wheat plays a major role in global export markets, Canada is an insignificant global producer of corn and Canada is a net importer of corn (from the United States). Although wheat is grown mainly in the country's western provinces, corn is grown in its eastern provinces, Ontario and Quebec.

Nevertheless, corn is presently the primary Canadian ethanol feedstock. Most current ethanol production is located in Ontario, the largest corn-producing province. The government-initiated expansion in ethanol production will have major implications for Canadian corn production. Though the production of Canadian corn increased $15 \%$ in 2006/07 over the previous crop-year, with production growth attributed in part to strong prices associated with ethanol-related demand, the anticipated 2007/08 imports drop only slightly. ${ }^{\text {clxxi }}$

Canada's total corn harvest from the 2005/06 season was about $9.5 \mathrm{mmt}$ from approximately $1.1 \mathrm{million}$ ha. ${ }^{\text {clxxii }}$ Yields were above average due in part to favorable weather. The potential future production is projected in this study for 2012, 2017, and 2027, with estimated supply in the baseline case of approximately 12.5, 15.5, and $21.5 \mathrm{mmt}$, respectively. Canada Figures 5-7 illustrate estimated supply curves in the baseline case (See Canada Table 1 in Annex 4 for data). Low and high growth cases illustrate a range of potential supply based on past trends and fluctuations in production (see Figure 8 and Canada Tables 2 and 3). For 2017, the estimated total supply ranges from $9.6 \mathrm{mmt}$ (low growth case) to $21.6 \mathrm{mmt}$ (high growth case). The baseline case (presented in Canada Table 1) estimates a total cumulative production in 2017 of $15.5 \mathrm{mmt}$ from 1.3 million ha.

\subsubsection{Other Estimates}

The FAPRI (2007) model projected corn harvests of about $11.3 \mathrm{mmt}$ in 2012 and $11.9 \mathrm{mmt}$ in 2016. USDA baseline projections for Canada estimated corn production over the period of study remain steady at about $10.5 \mathrm{mmt}$ in 2012 and 2016. The most recent USDA report on Canadian production highlights a $20 \%$ increase for the 2007/2008 season, with production estimated to exceed $11 \mathrm{mmt}$, due to the high market prices. ${ }^{\text {clxxiii }}$ 

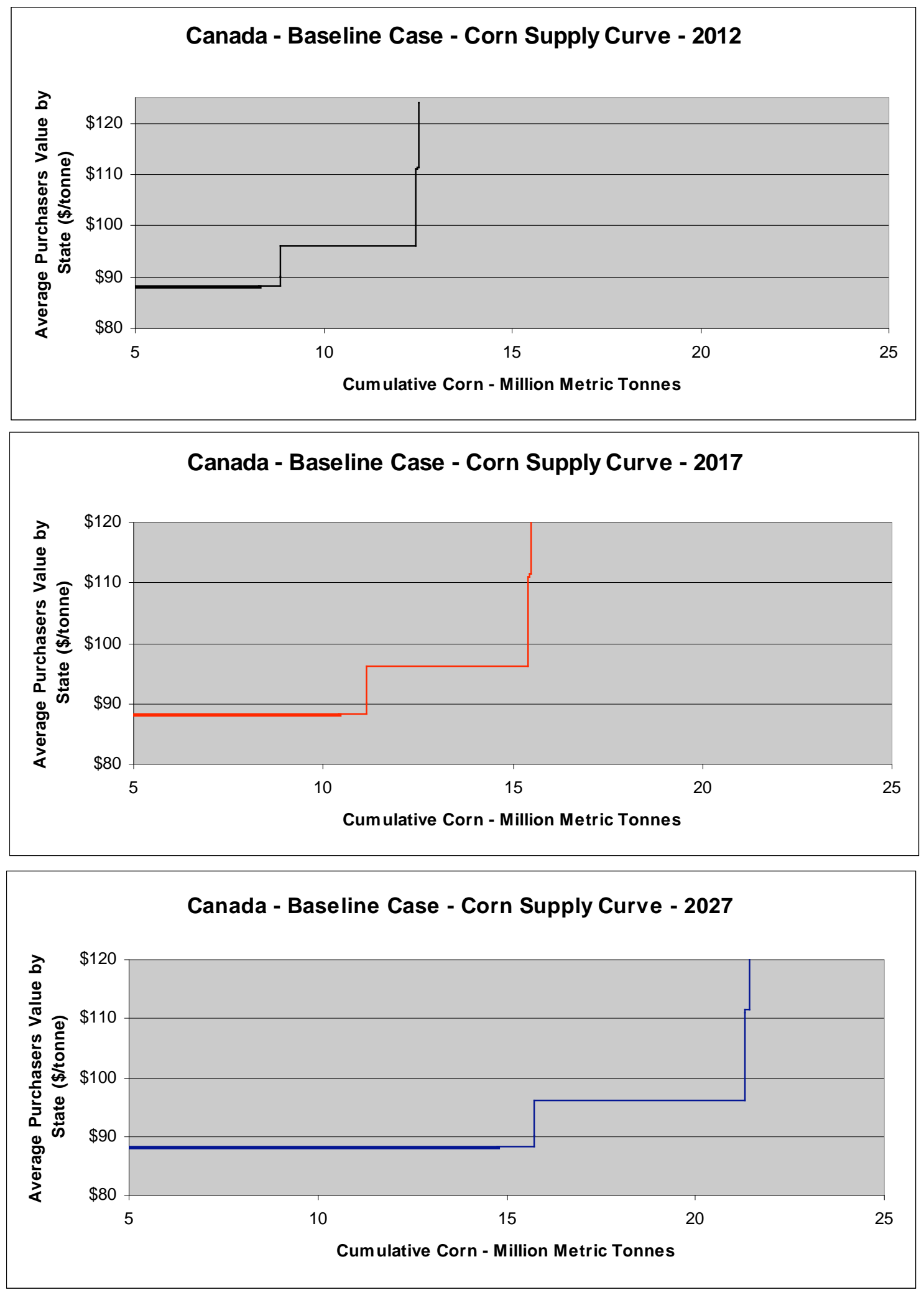

Canada Figures 5-7. Baseline Case Corn Supply Curve Projections. 


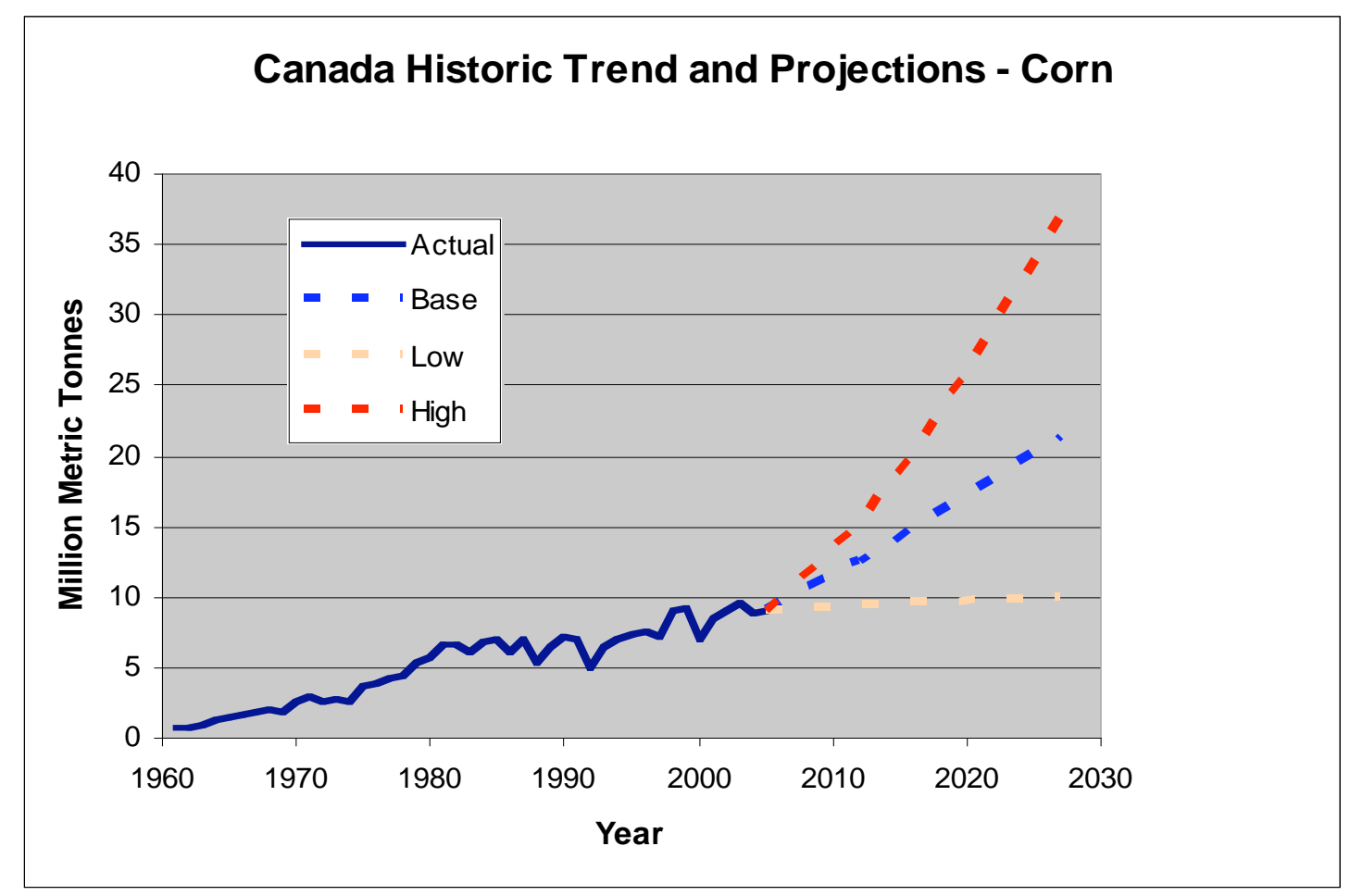

Canada Figure 8. Corn: Historic Trend and Projections.

\subsubsection{Biofuel Use and Competing Demands}

Corn traditionally has been grown for feed but will play an increasingly prominent role in Canadian ethanol production. Since Canadian corn production will be insufficient to meet increased demand, the country will need to import more corn from the US or other sources and increase reliance on wheat as an ethanol feedstock. This situation creates two inter-related kinds of competition: (a) for US corn/ethanol, at a time when the US demand for corn-based ethanol also is increasing; and (b) for the Canadian cornbased ethanol industry, which will face greater economic pressures that may challenge its viability. Both situations may result in increased prices. ${ }^{\text {clxxiv }}$

To meet the national targets, up to $3.8 \mathrm{mmt}$ of corn could be dedicated to ethanol production in 2012 and 2017 , representing about 30 and $25 \%$ of the baseline case supply projection for those years, respectively. In 2027, the potential use of corn will depend on many other factors, especially the cost-effectiveness of competing processes that use lower cost feedstock, such as cellulosic ethanol production. Assuming such new processes meet about 50\% of ethanol demand in 2027, and contributions from wheat as described above, up to $15 \%$ of the projected corn supply in the 2027 baseline case could still be dedicated to biofuel.

Using this study's standard methodology for estimating how much feedstock would be available for export and/or biofuel after meeting traditional domestic demand for food, feed and fiber, only about 5\% of corn production would be available for diversion to ethanol production in 2017 under the baseline case and none in the low growth case. In the high case about 32\% could be available for export and/or biofuel production (see Canada Table 7). However, given government mandates and announced plans, larger portions of total corn supplies are likely to be used for ethanol as discussed in the preceding paragraph, at least in the short to medium term. 


\subsubsection{Notes on Adjustments to Standard Methodology}

Due to limited data availability, several sources were used to establish price estimates for production by province. ${ }^{\text {clxxv }}$ The average year end price, converted to 2005 US\$ was used in each case.

Applying the standard methodology based on historic data by province through 2006 (the most recent data available), resulted in negative or zero growth in the primary corn-growing areas of Canada Ontario and Quebec - that represent about $95 \%$ of national production. Therefore, the provincial growth rate for corn was based on the between 2000-2005 data. This methodology did not have much effect on the growth rates for other provinces, but resulted in a positive rate for Quebec. However, it still produced a negative rate for Ontario. Given that the USDA indicated significant growth, and the Ontario Agriculture Ministry reported that the area planted to corn in Ontario increased 34 percent between 2006 and 2007, a positive growth rate of $3 \%$ for Ontario was adopted for the baseline case for the projection between 2006 and 2012.

\subsubsection{Other Feedstocks}

\subsubsection{Cellulosic Supply}

Potential biomass feedstock supply from agricultural residues is estimated assuming that technology and costs for residue recovery in Canada will be similar to those in the U.S. The amount of crop residues that could be removed annually without detriment to future crop productivity (a "sustainable removal rate") was estimated for the U.S. in the "Billion Ton" study. ${ }^{\text {clxxvi }}$ The same parameters were applied to the projected supplies in this study to estimate the total cellulosic biomass that could be recovered from wheat and corn production in Canada (see Annex 4, Canada Table 8). The total estimated wheat straw and corn stover that could be supplied to local processing plants at up to US\$52/mt (dry weight) was calculated to be approximately $11 \mathrm{mmt}$ in 2017 and $13 \mathrm{mmt}$ in 2027 in the baseline case. In the high growth case, these supplies increase to $14 \mathrm{mmt}$ in 2017 and about $22 \mathrm{mmt}$ in 2027.

Canada has one of the world's leading forestry industries. Wood processing industries in several provinces produce residues in sufficient quantities to generate 1.5 billion liters of ethanol per year or more. ${ }^{\text {clxxvii }}$ Considering these and other "realistic" recovery rate estimates for forestry residues identified an additional $22 \mathrm{mmt}$ of cellulosic feedstock potential, although most of it would be at higher cost than the agricultural residues. ${ }^{\text {clxxviii }}$ Canada's extensive forests and grasslands offer potential for significant additional cellulosic supplies from bioenergy plantations, but the varieties and technologies needed to grow, harvest and process these potential resources economically for biofuels are not yet defined.

The total potential cellulosic supply — without concern for costs or technology — could exceed 50 $\mathrm{mmt} /$ year in residues and perennials growing on marginal or under-utilized land, if all biomass resources are considered. Cellulosic supply per se does not appear to be a limiting factor in Canada over the next $10-20$ years.

\subsubsection{Ethanol}

Wheat and corn are the major ethanol feedstocks in Canada; sugarcane and sugar beets are not used as a feedstock in the country. Potatoes have been suggested as an alternative feedstock in some areas but the vast majority of production is expected to rely on corn and wheat. 


\subsubsection{Biodiesel}

Canadian biodiesel production capacity is forecast to grow up to 600 million liters/year in 2012, from 70 million liters in 2006, and then plateau. ${ }^{\text {clxxix }}$ Most current Canadian biodiesel feedstocks are animal fats, recycled cooking oils, and vegetable and marine oils. Half of the future biodiesel production likely will be from oilseeds and half from yellow grease and tallow. ${ }^{\text {clxxx }}$ Rapeseed (canola) will be the predominant oilseed feedstock. Canada can grow sufficient quantities of canola, estimated to range from about 0.7 to $1.1 \mathrm{mmt}$ per year. However, the current impediment to using canola for biodiesel production is insufficient crushing capacity. Either the country will have to invest to increase its own crushing capacity or send the crop to the US for crushing. ${ }^{\text {clxxxi }}$

\subsubsection{Opportunities and Constraints}

Canada has technology, resources, and growing government commitment to develop a domestic biofuel industry and move toward its 5\% blended fuel target by 2012. A Natural Resources Canada resource assessment concludes that these increased demands for bioenergy can be met without impinging upon the production of food or traditional products. ${ }^{\text {clxxxii }}$ The recent increase in government support was reflected in the 2007 federal budget that tagged 1.5 billion dollars over several years for incentives. ${ }^{\text {clxxxiii }}$ These incentives are available for investments in up to 2.5 billion liters of new capacity for renewable fuel production. This volume of additional capacity is expected to be required to meet the renewable fuel content mandate by 2010 , with a total of about 3 billion liters of biofuels $(2.5 \mathrm{bl}$ ethanol and $0.5 \mathrm{bl}$ biodiesel). ${ }^{\text {clxxxiv }}$

Additionally, Canada is supporting research and development to establish technically and economically effective and efficient cellulosic ethanol conversion processes that use agricultural and forest wastes. For example, the government has supported a full-scale commercial demonstration conversion facility in Ottawa.

Because most of the productive arable land in Canada already is under cultivation, ${ }^{\text {clxxxv }}$ shifts in agricultural production to achieve target biomass goals may require shifts in farming practices such as changes in: the proportions of land dedicated to different crops; crop rotation, tillage practices, associated fertilizer and pesticide use, and their combined effects on erosion control and water quality; timing and amount of irrigation needed; and the expansion into less productive, marginal lands. Such changes could impinge upon sustainability, if not carefully managed. The potential increases in soil erosion and nutrient loading associated with increased corn production in the US ${ }^{\text {clxxxvi }}$ also would be likely to become evident in Canada. Water and irrigation requirements for three of the major crops of interest range from $500 \mathrm{~mm}$ (20 inches) for silage corn, to $400-450 \mathrm{~mm}$ (16-18 inches) for wheat, to $450 \mathrm{~mm}$ (18 in.) for canola. ${ }^{\text {clxxxvii }}$ Although wheat uses water more efficiently than canola, except during times of drought, the amount of water needed to grow wheat is approximately the same as canola crops, according to the Canola Council of Canada. ${ }^{\text {clxxxviii }}$

The factors driving up capacity of ethanol production and diesel production in Canada also are linked to the proximity with the U.S. market and demand. "The free trade on ethanol between Canada and the US... and continued US incentives such as a 16 cent Cdn\$ per liter (51 cent US per gallon) excise tax [credit], have rendered the U.S. a significant potential ethanol and biodiesel market for Canada." clxxix Given favorable policies and incentives, Canadian grain supply dedicated to meet rising biofuel demand is forecast to rise significantly over the next 5 years. The proximity to the U.S. combined with free trade agreements make Canada an integrated participant in the corresponding U.S. markets, and vice-versa. 


\section{Canada Endnotes}

clxi To meet the same biofuel output targets, the percentage of projected supply is higher in the low-growth case, and lower in the high-growth case. The relative amount of wheat and corn supply dedicated to biofuel could vary somewhat depending on differential prices and availability of other potential feedstocks (including potatoes and eventual cellulosic resources).

clxii "Values in the CAIS Program Price and Code List are provincial prices collected from Statistics Canada, Agriculture and Agri-Food Canada (AAC), the Canadian Wheat Board (CWB), provincial agriculture departments, and commodity organizations. These prices represent the year-end price for each commodity."

http://www.agr.gc.ca/caisprogram/apps/pricelists/index.

${ }^{c l x i i i}$ See http://www.agr.gc.ca/caisprogram/docs/pdf/2005/ for CAIS prices by province; exceptions noted below.

${ }^{c l x i v}$ Data about current and potential biofuel feedstock production in this analysis are drawn in part from the USDA Foreign Agricultural Service (FAS) Global Agriculture Information Network (GAIN) reports that are accessible at http://www.fas.usda.gov/scriptsw/AttacheRep/default.asp. As a GAIN fact sheet states, "Production, Supply, and Distribution (PSD) data contained in GAIN reports are NOT official USDA data, but represent estimates made by FAS Attachés." See http://www.fas.usda.gov/info/factsheets/reports.asp. The following GAIN reports (hereafter, cited by their report numbers) were used to collect about Canada:

USDA 2006 GAIN Report CA6029: Canada Bio-Fuels, Bio Fuels Canada, 2006.

USDA 2007 GAIN Report CA7018: Canada Grain and Feed Annual Report, 2007.

USDA 2007 GAIN Report CA7024: Canada Oilseeds and Products, Oilseeds Annual Report 2007.

USDA 2007 GAIN Report CA7038: Canada Grain and Feed Quarterly Report, 2007.

USDA 2007 GAIN Report CA7005. Canada — This Week in Canadian Agriculture, Issue 3, 2007.

${ }^{c l x v}$ USDA CA 7018, USDA CA7038

clxvi Canadian Grain Commission, 2005-2006. Canadian Grain Exports, Crop Year 2005-2006.

http://www.grainscanada.gc.ca/pubs/exportsyearly/annual/exports05-06-e.pdf.

clxvii USDA CA7038

clxviii USDA CA6029.

clxix USDA CA6029.

${ }^{c l}$ xx Price data sources:

\begin{tabular}{|ll|}
\hline Province & Source used for price data \\
\hline Alberta & Alberta Ag Statistics 2005 \\
British Columbia & CAIS \\
Manitoba & CAIS \\
New Brunswick & CAIS \\
Nova Scotia & CAIS \\
Ontario & Provincial Ministry of Agriculture \\
Prince Edward Island & Provincial Government CAIS \\
& Guidelines for 2005 End of Year \\
& Fair Market Value \\
Quebec & Agriculture \& Agrifood Canada \\
& (AAC) and FPCCQ \\
Saskatchewan & CAIS \\
\hline
\end{tabular}

Links to price data referenced above:

CAIS: http://www.agr.gc.ca/caisprogram/docs/pdf/2005/cais05ncyepl12.pdf

Alberta: http://www1.agric.gov.ab.ca/\$department/deptdocs.nsf/all/sdd10995/\$FILE/value.pdf

Ontario: http://www.omafra.gov.on.ca/english/stats/crops/index.html

Quebec: http://www.fpccq.qc.ca/pdf/statistiques/prix_Cr_grains.pdf

Prince Edward Island: http://www.gov.pe.ca/photos/original/af_cais_graifor.pdf

${ }^{c l} \times{ }^{2}$ USDA CA7018, USDA CA7038

clxxii USDA CA7018

clxxiii USDA CA7038 
${ }^{\text {clxxiv }}$ USDA CA6029

clxxv See "price data sources," above.

clxxvi Perlack et al. 2005

clxxvii Bradley 2006.

clxxviii Ibid.

${ }^{\text {clxxix }}$ OECD-FAO (Organisation for Economic Co-operation and Development, Food and Agriculture Organization of the United Nations), 2007. OECD-FAO Agricultural Outlook, 2007-2016.

${ }^{\text {clxxx }}$ OECD-FAO 2007.

clxxxi USDA CA6029

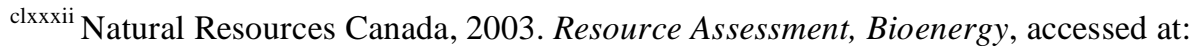
http://www.canren.gc.ca/resou_asse/index.asp?CaId=53\&PgId=57

clxxxiii USDA CA7038. The incentive rates will be up to $\$ C \mathrm{dn} 0.10 / \mathrm{L}$ for renewable alternatives to gasoline, and up to $\$ 0.20 / \mathrm{L}$ for renewable alternative for diesel for the first three years, declining thereafter.

${ }^{\text {clxxxiv }}$ USDA CA7038

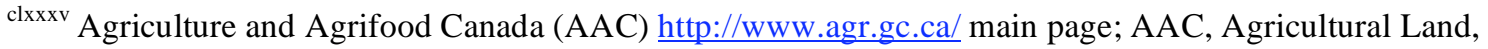
http://www.agr.gc.ca/pfra/land/agland_e.htm. For total production levels see: and http://www.agr.gc.ca/maddam/index e.php?s1=pubs\&s2=go-co\&page $=$ go-co-hist\&PHPSESSID=5a1b3d33c170380fa0cd4ef87682f5f3 clxxxvi NAS 2007 and NAS 2003.

clxxxvii Peterson, H. G., 1999. Accessed at: http://www.agr.gc.ca/pfra/water/fieldirr_e.htm.

clxxxviii See: http://www.canola-council.org/watercomparison.aspx

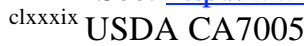




\subsection{CHINA - CORN, SOYBEANS, WHEAT, AND SUGARCANE}

\subsubsection{Summary Findings}

China is among the top producers (and consumers) of corn, soybeans, sugarcane, and wheat in the world, producing $139 \mathrm{mmt}, 16 \mathrm{mmt}, 89 \mathrm{mmt}$, and $97 \mathrm{mmt}$ in 2005, respectively. The baseline cumulative production of corn, soybeans, sugarcane, and wheat in 2017 are projected in this study at approximately $200 \mathrm{mmt}$ of corn, $26 \mathrm{mmt}$ soybeans, $114 \mathrm{mmt}$ sugarcane, and $133 \mathrm{mmt}$ of wheat. Most future production is expected to be used for domestic purposes, given that China currently is a net importer of these crops. As a result, this study's calculations suggest that minimal domestic production of these crops would be used for biofuel production in the low and baseline growth cases, with two exceptions. A small percentage of corn and sugarcane (and molasses derived from sugarcane) could be available for biofuel production in 2012, 2017, and 2027. According to the Worldwatch Institute (2006), the likely impact of China's need to import biofuel will be higher prices on international biofuel markets.

Cellulosic feedstock from corn, sugarcane, and wheat production could amount to an estimated $36 \mathrm{mmt}$ in 2017 under the baseline case. In addition, forest harvest and wood residues could generate an additional 9 mmt of cellulosic feedstock. If half of China's 2005 production of fuelwood were allocated to biofuel it would represent about 29 dry mmt of cellulosic supply. This assumes that a similar portion of domestic fuelwood use for cooking is replaced by alternative energy sources by 2017 .

\section{$\underline{\text { China Figures }}$}

1: Corn: Historic Trend and Projections

2: Soybeans: Historic Trend and Projections

3: Wheat: Historic Trend and Projections

4: Sugarcane: Historic Trend and Projections

China Tables (See Annex 4)

1: Corn Supply Potential for Baseline, High and Low Growth Cases

2: Soybean Supply Potential for Baseline, High and Low Growth Cases

3: Wheat Supply Potential for Baseline, High and Low Growth Cases

4: Sugarcane Supply Potential for Baseline, High and Low Growth Cases

5: Potential Percentage Allocation for Export \& Biofuels

6: Estimated Cellulosic Supply from Recoverable Crop Residues

7: Estimated Cellulosic Supply Including Other Residues

\subsubsection{Context}

China's energy use has increased rapidly in the last 25 years as its economy has boomed. Although $70 \%$ of this energy is supplied from coal, petroleum use has grown as well. Diesel use has increased six-fold, while gasoline use has increased four-fold since 1980. Although biofuels are considered a strategic aspect of sustaining the economy, aggressive efforts to develop biofuels using traditional staples such as corn and wheat were put on hold due to food security concerns. New policies and plans now are being put in place to promote the production of biofuel feedstocks on non-agricultural lands, and to increase the use of wastes and non-edible seeds. ${ }^{\text {cxc }}$ Due to economic needs and environmental pressures to reduce dependence on coal, biofuels are expected to play an important role in China's future energy mix. Nevertheless, present projections suggest that China is likely to be a net importer of biofuel over the coming decade. ${ }^{\text {cxci }}$ 
Nearly all ethanol production in China from 2000-2006 was based on corn and, to lesser degree, wheat with production of fuel ethanol in 2006 estimated at $1.3 \mathrm{mmt}^{\text {cxcii }}$ The feedstocks are expected to change over time with new facilities coming online to use tubers (potatoes and cassava) and sorghum. A new national policy and plan indicate that biofuel feedstocks should not compete with agriculture for food production. The plan promotes future ethanol production from agricultural waste, including crop residues and molasses. Biodiesel production has been limited (300,000 MT in 2007) and was based primarily on animal fats and waste vegetable oils. Future production is expected to rely on non-edible oilseeds and tree-nuts grown on marginal lands (Jatropha and several local tree varieties).

China does not use significant amounts of sugarcane or soybeans for direct conversion to ethanol and biodiesel. Its new policy proposes to expand the use of byproducts from crops, such as corn stover, cobs, straw, and molasses. Still, China plays a major role in world markets for all four of the potential feedstocks studied.

\subsubsection{Definitions, Methodology, and Assumptions}

Background, definitions, and a description of the general approach used to estimate projected feedstock supplies are provided in the Introduction. The analysis for China was based on 1998-2005 production data by province from the USDA. For corn, 1995-2002 data by province were used due to nonavailability of the 2004 and 2005 data and an apparent anomaly in the 2003 data. ${ }^{\text {cxiii }}$ Because USDA data did not include sugarcane, the sugarcane projection was based on national production data from the FAO.

It was not possible to construct price-based curves due to lack of access to any consistent sets of provincial level price or cost data. Average farm-gate price data for the four crops were obtained from USDA foreign agricultural service reports. ${ }^{\text {cxciv }}$ When necessary, reported prices in 2005 Chinese Yuan were converted into 2005 US dollars using the nominal exchange rate of 8.20 Yuan per \$ from the USDA ERS exchange rate database.

\subsubsection{Units, Conversion Factors, and Calculations}

Supply is stated in harvested millions of metric tonnes (mmt).

Land is measured in hectares (ha), and yield in metric tonnes per hectare ( $\mathrm{mt} / \mathrm{ha})$.

Prices are in 2005 US Dollars.

\subsubsection{Corn Supply Potential — Analysis and Projections: 2012, 2017, 2027}

China's total corn harvest from the 2005/06 season was about $140 \mathrm{mmt}$ from 26.3 million ha. Corn output in China mainly is used for feed, accounting for about 70 percent in 2006. A little over $20 \%$ was used for industrial production of sugar, starch and biofuel, although only about $3 \mathrm{mmt}(2 \%)$ was diverted to fuel ethanol. ${ }^{\text {cxv }}$ About $10 \%$ of corn production from northeastern provinces was used for biofuel production in 2006, but the government's new policy prohibits continued use of corn for ethanol production, instead allocating corn to feed and food needs. ${ }^{\text {cxcvi }}$

The future corn production is projected in this study for 2012, 2017, and 2027, with estimated potential supply in the baseline case of approximately 175, 200, and $256 \mathrm{mmt}$, respectively (see China Figure 1 and China Table 1 in Annex 4).

Additionally, low- and high growth cases illustrate a range of potential supply based on past trends and fluctuations in production. For example, in 2017 the estimated total supply ranges from nearly $167 \mathrm{mmt}$ (low growth case) to slightly over $242 \mathrm{mmt}$ (high growth case). The baseline case estimates a total cumulative potential supply in 2017 of $200 \mathrm{mmt}$ from 33 million ha. 


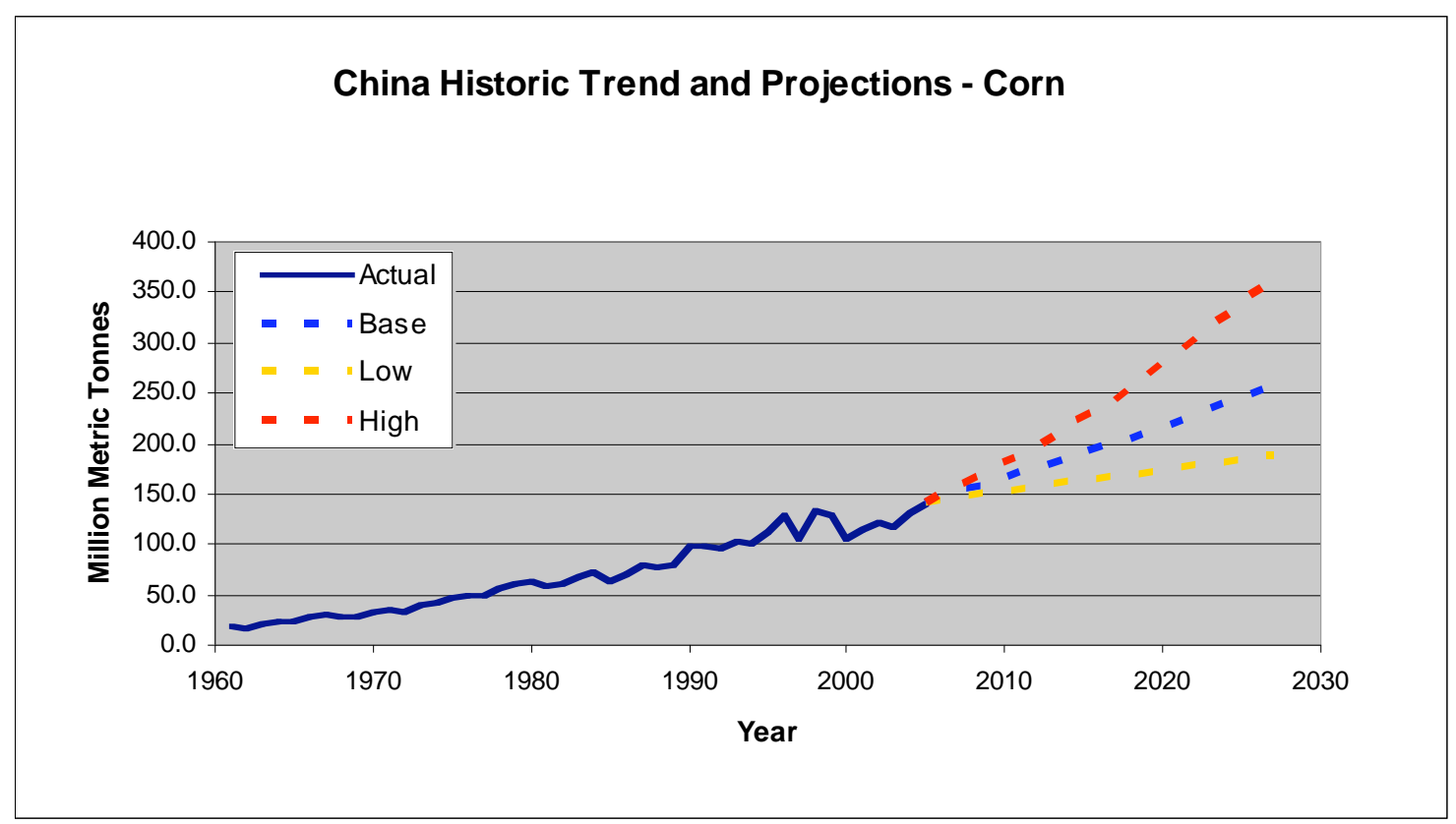

China Figure 1. Corn: Historic Trend and Projections.

\subsubsection{Other Corn Estimates}

The FAPRI (2007) model's projections of total supply estimates for China's future corn harvests are closer to the low case in this study, with projections of $157 \mathrm{mmt}$ in 2012 and $164 \mathrm{mmt}$ in 2016. The USDA 2007 baseline projections for China are higher than FAPRI, but slightly below the baseline case in this study, at 170mmt in 2012 and and $180 \mathrm{mmt}$ in 2016.

\subsubsection{Biofuel Use and Competing Demands}

Given that China is a net importer of most food crops, including corn, the country's biofuel policy is directed at non-food crops. This study's calculations suggest that only about $2 \%$ of projected total corn production could be available for export and/or biofuel use in the baseline case. Under the study's assumptions for high growth, about $19 \%$ of corn production could be available for export and/or biofuel production in 2017 and 30\% in 2027. See China Table 5 for the estimated allocation of future crop supplies available for export and/or biofuels.

\subsubsection{Soybean Supply Potential — Analysis and Projections: 2012, 2017, 2027}

Soybeans are an important source of feed meal for meeting the needs of the surging animal products industry in China. Annual feed demand growth between 2002 and 2006 averaged nearly 6\%. To meet this demand, imports as a percentage of consumption grew from zero in 1990 to 61 percent by 2006, making China the world's leading importer of soybeans. In 2005, Brazil supplied $41 \%$ of China's soybean imports, while the United States provided $34 \%$ or $9.7 \mathrm{mmt}$. Currently, soybeans are not used in biofuel production in China. Their use is unlikely to be encouraged by the government, which sets a higher priority on their use to fulfill animal feed needs. ${ }^{\text {cxcvii }}$

China's total soybean harvest from the 2002/03 season (the year on which this study's projections are based) was about $16.5 \mathrm{mmt}$ from 8.7 million ha. The potential future production is projected in this study 
for 2012, 2017, and 2027, with estimated potential supply in the baseline case of approximately 23, 26, and $31 \mathrm{mmt}$, respectively (see China Figure 2 and Annex 4, China Table 2). Low and high growth cases illustrate a range of potential supply based on past trends and fluctuations in production. For example, in 2017 the estimated total supply ranges from about $19 \mathrm{mmt}$ (low growth case) to approximately $35 \mathrm{mmt}$ (high growth case). The baseline case estimates a total cumulative potential supply in 2017 of nearly 26 mmt from 10.7 million ha.

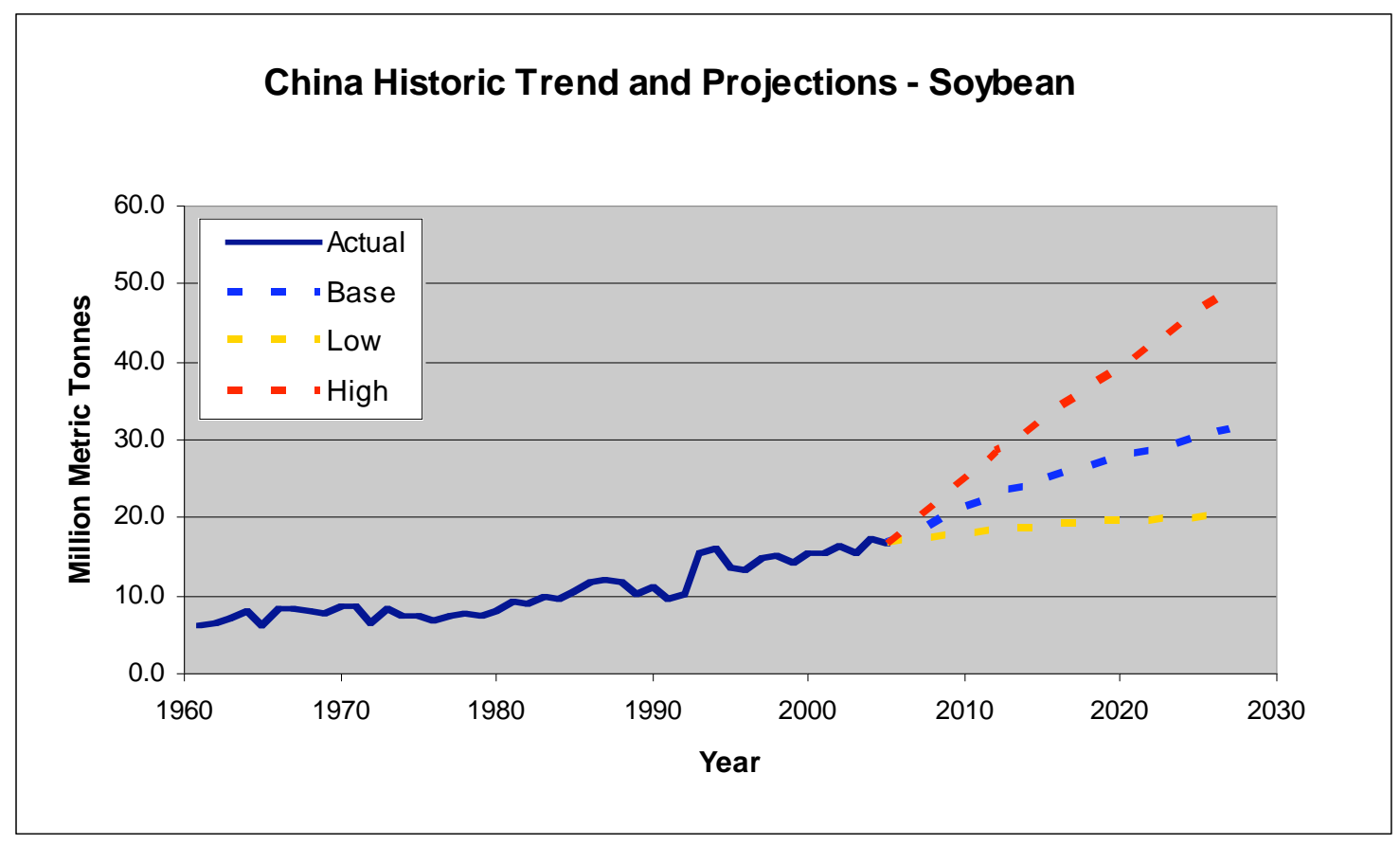

China Figure 2. Soybeans: Historic Trend and Projections.

\subsubsection{Other Soybean Estimates}

The FAPRI (2007) model projected total supply estimates for China's future soybean harvests closer to the low growth case in this study, with projections of $18 \mathrm{mmt}$ in 2012 and $18.7 \mathrm{mmt}$ in 2016. The USDA 2007 baseline projections are similar, at $18.7 \mathrm{mmt}$ and $20 \mathrm{mmt}$ in 2012 and 2016, respectively.

\subsubsection{Biofuel Use and Competing Demands}

China is a net importer of most food crops, including soybeans. Biofuel policy directs that future production should be based on non-food crops. This study's calculations suggest that none of the projected soybean production would be available for export and/or biofuel uses in the baseline and low growth cases in 2017. Under the study's high growth case assumptions, about $27 \%$ of China's soybean production could be available for export and/or biofuel markets in 2017 , and $36 \%$ in 2027 . See China Table 5.

\subsubsection{Wheat Supply Potential — Analysis and Projections: 2012, 2017, 2027}

Wheat primarily is used as a staple food in China. Its production has been quite volatile over the past 10 years. In 1997, production reached record levels following a self-sufficiency campaign designed to address rising imports - representing $10 \%$ of total world trade in wheat. However, by 2003, production 
had fallen by $30 \mathrm{mmt}$. Imports recorded a record high $12 \mathrm{mmt}$ in 1995, but have remained at less than 1 mmt since 1997 cxcviii $^{\text {ch }}$

China's total wheat harvest from the 2005/06 season was about $97.5 \mathrm{mmt}$ from 22.8 million ha. The potential future production is projected in this study for 2012, 2017, and 2027, with estimated potential supply in the baseline case of approximately 110, 114, and $125 \mathrm{mmt}$, respectively (see China Figure 3 and Annex 4, China Table 3). Additionally, low and high growth cases illustrate a range of potential supply based on past trends and fluctuations in production. For example, in 2017 the estimated total supply ranges from about $99 \mathrm{mmt}$ (low growth case) to approximately $141 \mathrm{mmt}$ (high growth case). The baseline case estimates a total cumulative potential supply in 2017 of nearly $114 \mathrm{mmt}$ from about 23 million ha.

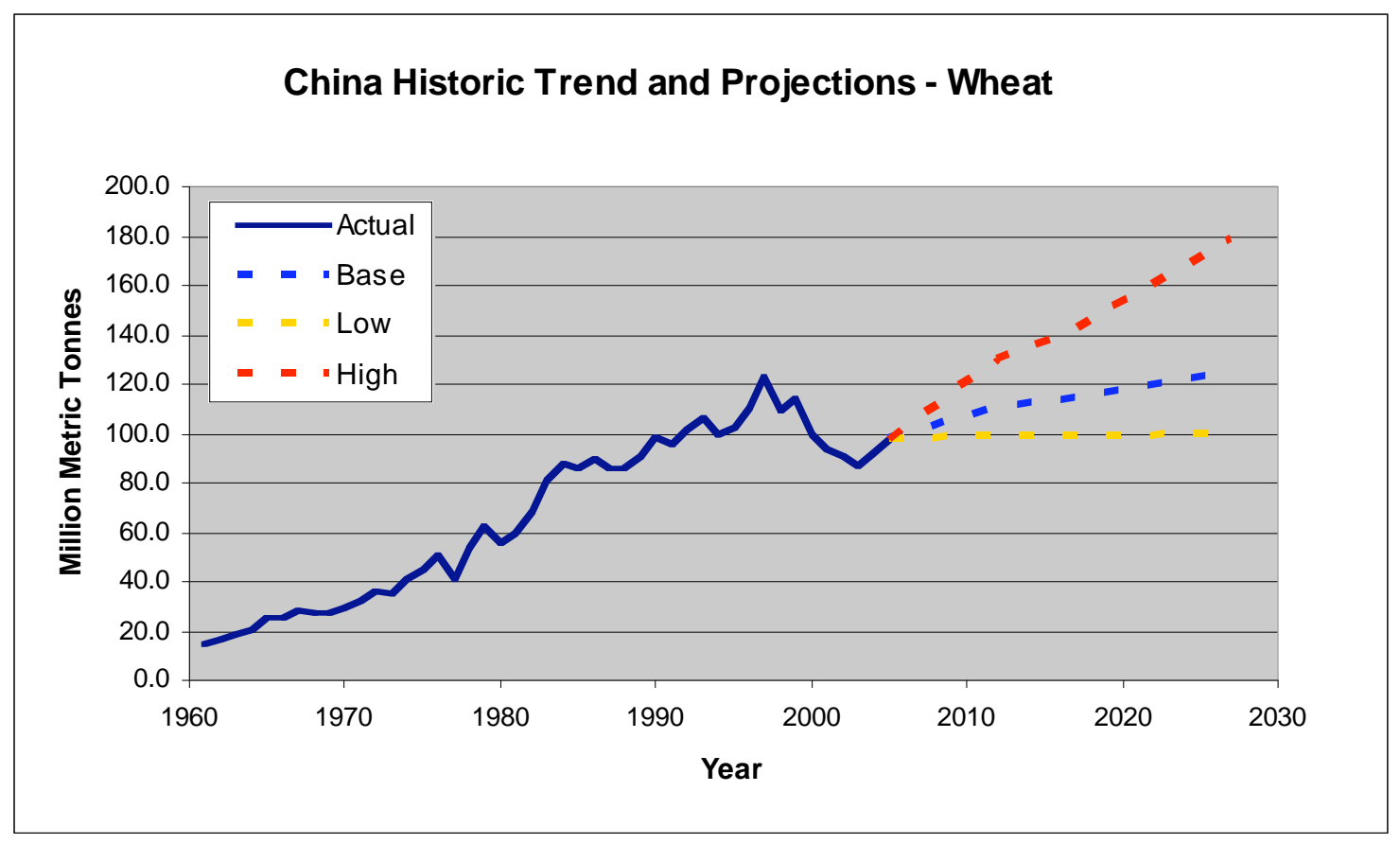

China Figure 3. Wheat: Historic Trend and Projections.

\subsubsection{Other Wheat Estimates}

The FAPRI (2007) model estimates that future wheat harvests in China will fall slightly, with projections of $101 \mathrm{mmt}$ in 2012 and $100 \mathrm{mmt}$ in 2016 (close to the low growth case here). The USDA 2007 baseline agricultural projection is more pessimistic, with $97 \mathrm{mmt}$ and $94 \mathrm{mmt}$ in 2012 and 2016, respectively. ${ }^{\text {cxcix }}$

\subsubsection{Biofuel Use and Competing Demands}

China is a net importer of most food crops including wheat. This study's calculations suggest that none of the projected wheat production would be available for biofuel uses in the baseline and low growth cases. Under the study's high growth case assumptions, about $19 \%$ of wheat production could be available for export and/or biofuel markets in 2017 and up to 30\% in 2027. See China Table 5. 


\subsubsection{Sugarcane Supply Potential — Analysis and Projections: 2012, 2017, 2027}

Sugarcane output in China is mainly used for sugar production. The food processing, beverage, and pharmaceutical industries account for domestic use and segments of these industries have recorded double-digit growth in recent years. China is a net importer of sugar and is not expected to use significant amounts of sugarcane directly as biofuel feedstock. ${ }^{\mathrm{cc}}$ However, sugarcane processing byproducts such as molasses and bagasse are included in the future plans for ethanol feedstock. And, given China's potentially large demand for sugar imports, its production and net balance of trade could influence global sugarcane markets.

China's total sugarcane harvest from the 2005/06 season was about $88 \mathrm{mmt}$ from 1.4 million ha. The potential future production is projected in this study for 2012, 2017, and 2027, with estimated potential supply in the baseline case of approximately 118, 133, and $160 \mathrm{mmt}$, respectively (see China Figure 4 and Annex 4, China Table 4). Low and high growth cases illustrate a range of potential supply based on past trends and fluctuations in production. For example, in 2017 the estimated total supply ranges from about $96 \mathrm{mmt}$ (low growth case) to approximately $183 \mathrm{mmt}$ (high growth case). The baseline case estimates a total cumulative potential supply in 2017 of $133 \mathrm{mmt}$ from 1.8 million ha.

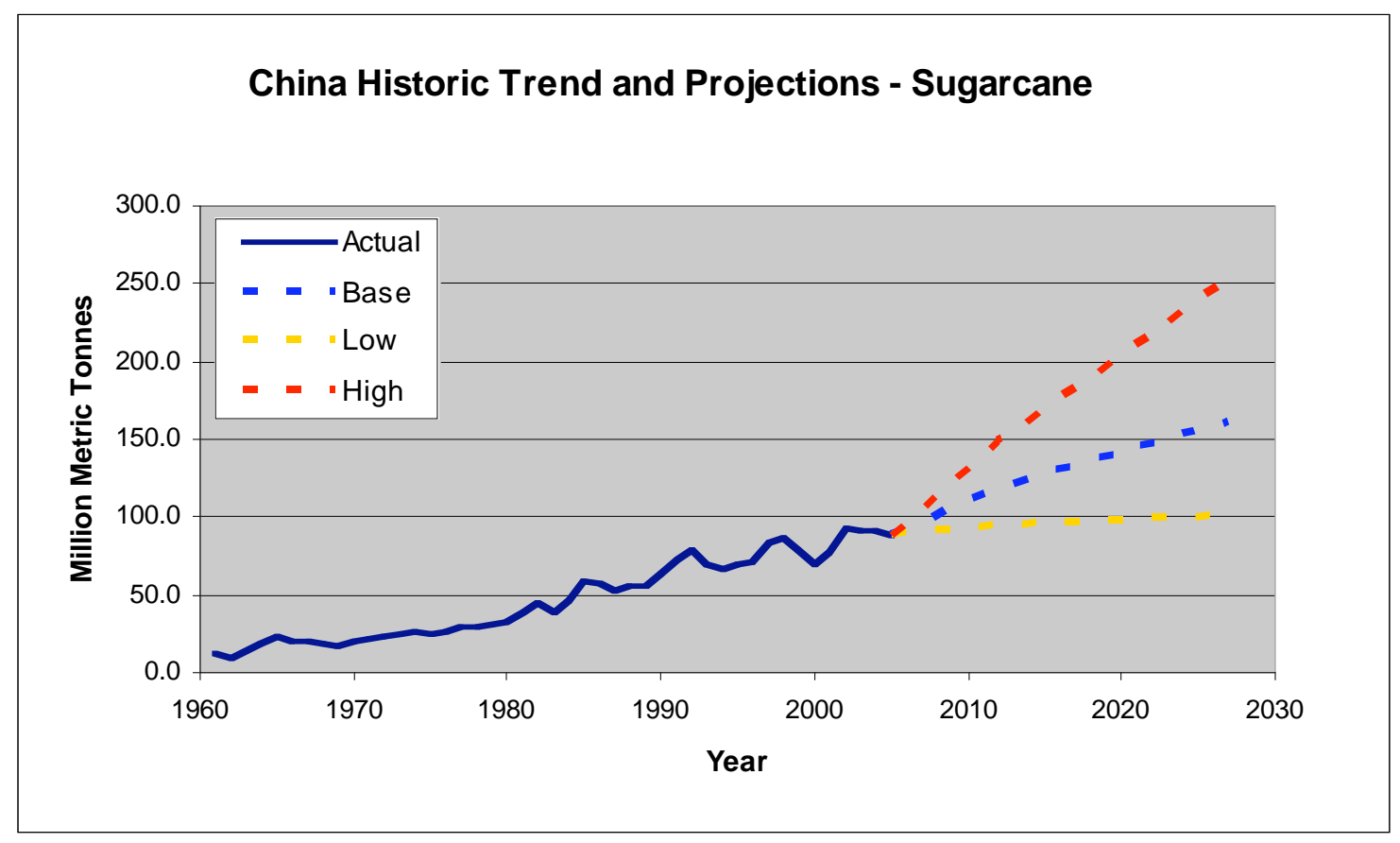

China Figure 4. Sugarcane: Historic Trend and Projections.

\subsubsection{Other Sugarcane Estimates}

The FAPRI (2007) model projected total supply for China's future sugarcane harvests at $102 \mathrm{mmt}$ in 2012 and $106 \mathrm{mmt}$ in 2016, somewhat lower than the projections in this study.

\subsubsection{Biofuel Use and Competing Demands}

China is a net importer of most food crops, including sugarcane. Based on the methodology in this study, only about $2 \%$ of projected sugarcane production in the baseline case would be available for export and/or biofuel use, and none under the low growth case. Under the study's high growth case assumptions, about 
$29 \%$ of sugarcane production could be available for export and/or biofuel markets in 2017 and $38 \%$ in 2027. See Annex 4, Table 5.

\subsubsection{Other Feedstocks}

\subsubsection{Cellulosic}

Crops produced in China generate considerable quantities of cellulosic residue that could be utilized in the future as biofuels. Indeed, large quantities of residues are presently used as fuel for direct combustion. The methodology in this study projects that bagasse, corn stover, and wheat straw cellulose could mount to about $36 \mathrm{mmt}$ of dry cellulosic supply in 2017 under the baseline case. In addition, forest harvest and wood processing residues could contribute another $9 \mathrm{mmt}$ of dry material. China's fuelwood use is large, with estimates ranging from 30-60 mmt of equivalent dry biomass. Given strong demand, fuelwood is unlikely to be diverted to ethanol production in the short term since it meets an essential domestic need. If in the future, alternative energy supplies were available for cooking, the methodology estimated that 29 mmt of dry cellulosic supplies could be available, representing about $50 \%$ of traditional fuelwood harvesting. In addition, China is a large nation with potential land resources for perennial crop production. If $5-10 \%$ of available potential land were dedicated to perennial biomass production, additional cellulosic feedstock amounts of $1.2-2.4 \mathrm{mmt}$ (dry weight) could be available.

\subsubsection{Opportunities and Constraints}

\subsubsection{Ethanol}

With the new policies for production from "non-arable" lands in the 2006-2010 plan, China's fuel ethanol output is projected to reach about 2.5 billion liters by 2010, contributing a small amount share toward China's rapidly increasing transportation fuel needs. ${ }^{\text {ci }}$ Estimates of available land resources need to be fine-tuned to account for accessibility, necessary technological improvement, and required investment. In addition, government- or market-based incentives may be necessary before farmers and communities grow crops for energy, in part due to the country's established customs and traditions of central planning. The development and implementation of national standards for biofuel production and distribution could speed the development of the biofuel market in China. The current dominance of the fossil fuel industry in transportation fuels also constitutes a barrier to the development of transportation biofuel distribution infrastructure that can support national, instead of local, distribution and use. Although reported Chinese production costs are relatively low in a global context, internal demand and the inadequacy of the infrastructure necessary at ports mean that, realistically, prospects for international trade are limited. ${ }^{\text {ccii }}$

\subsubsection{Biodiesel}

Biodiesel production capacity reached about 1 billion liters in 2006 using waste cooking oil, rapeseed, cottonseed, tallow and other sources. ${ }^{\text {ciii }}$ The demand for biodiesel in China is increasing substantially and is expected to outstrip supply. Research is ongoing with tree seeds such as Jatropha. China is not expected to be an exporter of biodiesel in the time frame of this study. 


\section{China Endnotes}

${ }^{\mathrm{cxc}}$ GBC (Global Biofuels Center), 2007. Flash Report - China: Agricultural Biofuel Industry Plan...

${ }^{\text {cxci }}$ USDA CH7039. Data about current and potential biofuel feedstock production in this analysis are drawn in part from USDA Foreign Agricultural Service (FAS) Global Agriculture Information Network (GAIN) reports that are accessible at: http://www.fas.usda.gov/scriptsw/AttacheRep/default.asp. As a GAIN fact sheet states, "Production, Supply, and Distribution (PSD) data contained in GAIN reports are NOT official USDA data, but represent estimates made by FAS Attachés." See http://www.fas.usda.gov/info/factsheets/reports.asp. The following GAIN reports (hereafter, cited by their report numbers) were used to collect about China:

USDA 2006 GAIN Report CH6081: Sugar Annual

USDA 2007 GAIN Report CH7012: Oil Seeds and Products Annual 2007

USDA 2007 GAIN Report CH7015: Grain and Feed Annual, 2007

USDA 2007 GAIN Report CH7029: Sugar Annual

USDA 2007 GAIN Report CH7031: Corn Production Estimates, 2007

USDA 2007 GAIN Report CH7039: Bio-Fuels Annual, 2007

cxcii USDA CH7039

cxciii Provincial data from USDA, accessed at: http://www.ers.usda.gov/Data/China/ProvincialForm.aspx.

cxciv USDA CH7031, CH7015, CH6081, CH7029, and CH7012

${ }^{\text {cxcv }}$ USDA CH7015

${ }^{\text {cxcvi }}$ GBC 2007; USDA CH7039

cxcvii USDA CH7039

cxcviii USDA/ERS, 2004. China's Wheat Economy: Current Trends and Prospects for Imports.

${ }^{c x c i x}$ USDA 2007a. As described in the methodology (see Introduction) the model used in the present feedstock analysis is designed to illustrate potential future supplies at a given price based on past production trends. This approach identifies maximum cumulative production levels under different cases and does not attempt to project decreases in future production.

${ }^{\mathrm{cc}}$ USDA CH6081

${ }^{c c i}$ USDA CH7039

ccii GTZ 2006. Liquid Biofuels for Transportation (China).

cciii GBC 2007. 


\subsection{COLOMBIA - SUGARCANE AND PALM OIL}

\subsubsection{Summary Findings}

Colombia is the seventh largest sugarcane producer in the world. Because Colombia's sugarcane production depends on irrigation, production is more expensive than places like Brazil where crops mostly are rain-fed. Colombia also is the largest palm oil producer in the Americas, and the fifth largest in the world. Colombia is seeking to position itself in the global fuel industry. It is representative of "up and coming" smaller producing nations.

Baseline cumulative production of sugarcane in Colombia in 2017 is projected at about $52 \mathrm{mmt}$ from about 554 thousand ha of land, compared with $34 \mathrm{mmt}$ from 437 thousand ha in 2005 . Palm oil production, which was $0.8 \mathrm{mmt}$ in 2005, is projected at just over $2 \mathrm{mmt}$ in 2017 under the baseline case. Soybean production is very small at only $0.05 \mathrm{mmt}$ in 2005 , and is not elaborated upon in this report.

Through a series of laws beginning in 2001, the Colombian government has provided support for biofuel production. The government set a target of $10 \%$ blend of ethanol with gasoline, and 5\% blend of biodiesel with fossil diesel by 2008. Meeting these objectives requires substantial increases in biofuel production. Sugarcane and palm oil are the primary feedstocks being considered for this purpose; targets could be met by diverting a substantial share of current exports to biofuel production. Feedstocks used for biofuel exports potentially could constitute $36 \%$ of palm oil production and $26 \%$ of sugarcane production as projected in 2017 under the baseline case.

Residues from the production of sugar cane and palm oil could provide about $6 \mathrm{mmt}$ of low-cost, cellulosic feedstock available at production plants, under the 2017 baseline case.

Colombia's large and predominately undeveloped potential resource in arable land provides a foundation for future expansion and potential to generate close to 5-10 $\mathrm{mmt}$, should a small percentage be harvested for perennial feedstock. Forestry products and residues could supply another 1-2 mmt of dry biomass for cellulosic fuel production.

\section{Colombia Figures}

1: Sugar Cane: Historic Trend and Projections

2: Palm Oil: Historic Trend and Projections

\section{Colombia Tables (See Annex 4)}

1: Sugarcane Supply Potential for Baseline, High and Low Growth Cases

2: Palm Oil Supply Potential for Baseline, High and Low Growth Cases

3: Potential Percentage Allocation for Export \& Biofuels

4: Estimated Cellulosic Supply from Recoverable Bagasse and Palm Residues

5: Estimated Cellulosic Supply Including Other Residues

\subsubsection{Context}

Although Colombia's potential arable land (cultivable soil) resources amount to about 21 million ha, only 4 million (almost 20\%) are under cultivation. Thus, there is significant potential for expansion of agricultural production, including for biofuel purposes. Currently, about $64 \%$ of Colombian sugar production and $27 \%$ of palm oil is exported. Colombia's energy mix is highly dependent on fossil fuels, and it is a net exporter of crude oil. Starting in 2001, the government began promoting biofuel use and 
efficiency in fossil fuel use through laws, regulations, and public campaigns. Recent requirements for 5\% biodiesel in diesel fuel and 10\% ethanol in gasoline by 2018 have spurred investment in a new domestic biofuel industry. Although domestic production still falls short of meeting these requirements, there have been positive impacts on the sugar industry resulting from the removal of 15-25\% of surplus sugar from the market with guaranteed prices. Future planned capacities are expected to produce surplus biofuel that could be sold on the international market. ${ }^{\text {cciv }}$

\subsubsection{Definitions, Methodology, and Assumptions}

Background, definitions, and a description of the general approach used to estimate projected feedstock supplies are provided in the Introduction. For Colombia, the analysis and projections were based on historic production data by department (state) from 1995 through 2005, the most recent data available. The source for department-level production data is the Colombian Ministry of Agriculture. ${ }^{\mathrm{ccr}}$

Supply curve charts are not presented because adequate unit costs and price data were unavailable for each producing department in Colombia. Estimates of national average prices were obtained for Sugarcane and Palm Oil from the Ministry of Agriculture and Rural Development and through the FAO. ${ }^{\text {ccvi }}$

\subsubsection{Units, Conversion Factors, and Calculations}

Supply is stated in harvested millions of metric tonnes (mmt). Land is measured in hectares (ha), and yield in metric tonnes per hectare ( $\mathrm{mt} / \mathrm{ha})$. Prices are in 2005 US Dollars.

\subsubsection{Sugarcane Supply Potential — Analysis and Projections: 2012, 2017, 2027}

There are diverse estimates for historical sugarcane production in Colombia due to different assumptions about defined seasons (Colombia harvests continually throughout the year), assumed yields, and national reports that are segregated according to end use (centrifugal sugar, non-centrifugal sugar or panela, and other). ${ }^{\text {ccvii }}$ USDA estimates Colombia's total sugarcane harvest from the 2005/06 season to be $32.4 \mathrm{mmt}$ from about 396,000 harvested hectares. ${ }^{\text {ccviii }}$ The overall average sugarcane yield per hectare was about 82 t/ha. However, production falls into two distinct classes: (a) large-scale commercial operations with intense production, irrigation, and high yields (125 mt/ha) and (b) thousands of smaller production systems making up about $60 \%$ of total sugarcane acreage, but with much lower yields ( $40-50 \mathrm{mt} / \mathrm{ha})$. Area planted to sugarcane has been expanding in the past few years in conjunction with the introduction of a new national biofuel program and the construction of ethanol production facilities around the country.

Future production is projected in this study for 2012, 2017, and 2027, with estimated potential supply in the baseline case of about 45, 52, and $65 \mathrm{mmt}$, respectively (see Colombia Table 1). Additionally, low and high growth cases illustrate a range of potential supply based on past trends and fluctuations in production (Colombia Figure 1). For example, in 2017 the estimated total supply ranges from almost $40 \mathrm{mmt}$ (low growth case) to about $69 \mathrm{mmt}$ (high growth case). The baseline case estimates a total cumulative supply in 2017 of just over $52 \mathrm{mmt}$ from 550,000 ha. Figure 1 illustrates the national historic trend and the projected supply of sugarcane in Colombia under the baseline, low and high growth cases for the three periods under study. 


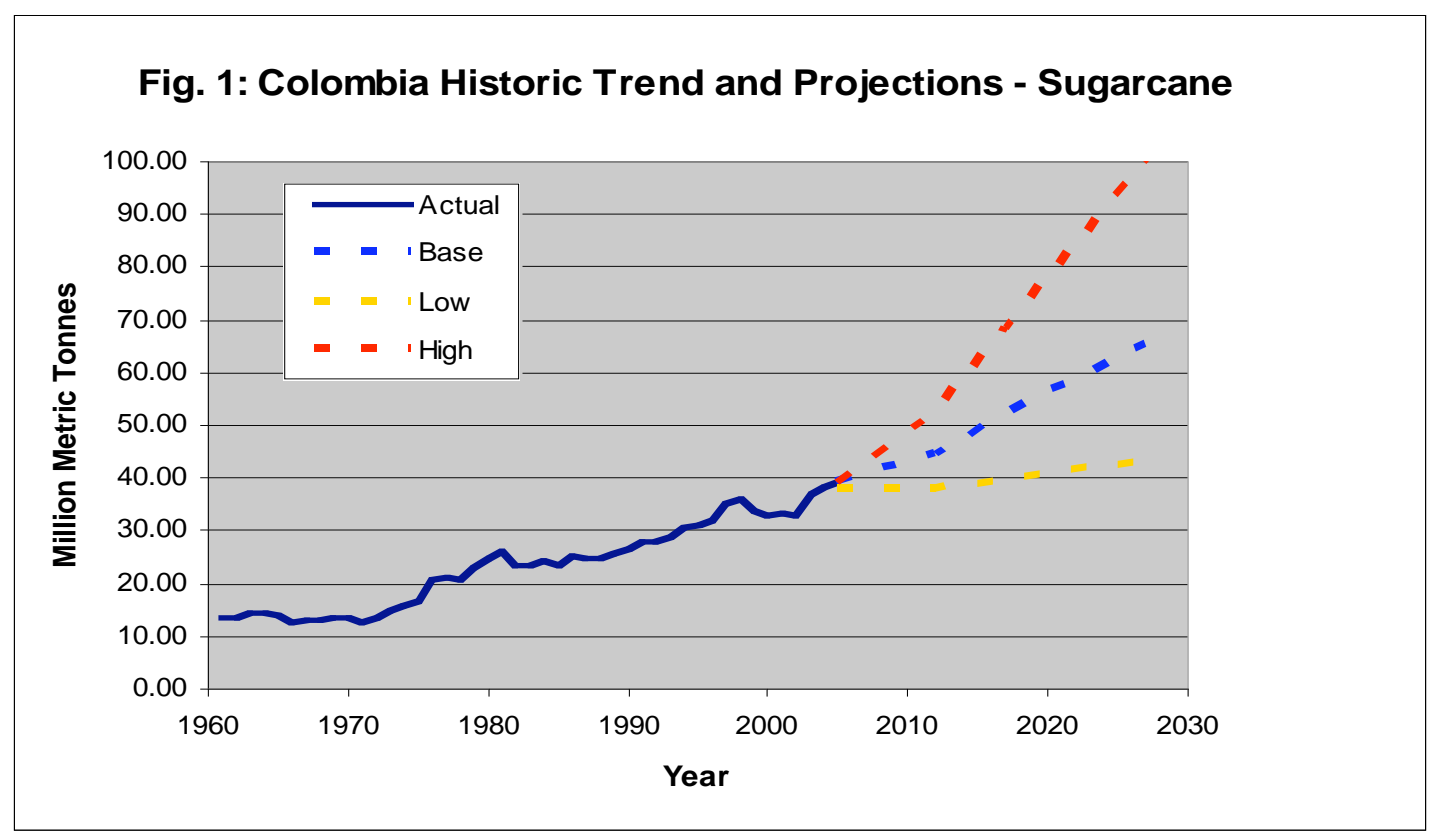

\section{Colombia Figure 1. Sugarcane - Historic Trend and Estimated Cumulative Supply Projections to 2027.}

\subsubsection{Other Sugarcane Estimates}

The FAPRI (2007) model projected more conservative sugarcane harvests of about $35 \mathrm{mmt}$ in 2012 and $38 \mathrm{mmt}$ in 2016. Other sources not that sugarcane and other biofuel feedstocks are receiving renewed interest and new sugarcane plantings are reported outside the traditional center of production in the Cauca Valley. ${ }^{\text {cix }}$

The sugar industry hopes to maintain sugar production and exports while meeting domestic demand for ethanol and supplying export markets in the region and the U.S. To meet these goals by 2017 would require expansion of sugarcane (or alternative feedstocks) at rates similar to the high growth case in this study.

\subsubsection{Biofuel Use and Competing Demands}

Currently, about a third of Colombia's sugarcane production ends up in the export market as sugar. However, increases in ethanol production due to the recent biofuel program that mandates a $10 \%$ ethanol blend in gasoline beginning in 2008, have caused significant changes in Colombia's sugar market. The sugar market has become tight, leading to imports of small amounts of raw sugar from Brazil. Colombia also uses sugarcane for non-centrifugal sugar production (panela), and is second only to India in this respect. This accounted for more than a third of total sugar produced in Colombia during 2005. Diversion of panela sugar cane for ethanol is one of the options being considered for meeting Colombia's biofuel mandates. Using this study's methodology, an estimated $26 \%$ of Colombia sugarcane would be available for export and/or biofuel production under the baseline case. Under the high growth case, from 38-52\% of national production would be available for export and/or biofuels. 


\subsubsection{Notes on Adjustments to Standard Methodology}

Future production was estimated following the standard methodology using historic data from 23 cane producing departments in Colombia. Source data were reported in terms of total sugar production from centrifugal and non-centrifugal (panela) processes. Data from USDA-FAS reports from Bogota were applied to convert these department-level production rates to a sugarcane equivalent using an average conversion of $13.5 \%$ for centrifugal sugar and $11.7 \%$ for panela. As noted above, due to insufficient data, it was not possible to construct cost-based supply functions.

\subsubsection{Palm Oil Supply Potential - Analysis and Projections: 2012, 2017, 2027}

Colombia's total palm oil production from the 2005 season is estimated at 794,000 tonnes from about 234,000 harvested ha. This total includes both crude palm oil $(697,000 \mathrm{mt})$ and palm kernel oil (66 mt). Average yields from 2002-2006 were 4.2 tonnes/ha for the combined oil output. ${ }^{c c x}$ Palm oil plantations have expanded rapidly in the past few years; USDA estimates that total area planted to be 315,000 ha in 2007, representing a 35\% expansion compared to the area harvested in 2005.

Future cumulative potential production is projected in this study for 2012, 2017, and 2027, with estimated potential supply in the baseline case of about 1.4, 2.1, and $4.7 \mathrm{mmt}$, respectively (see Colombia Table 2). The low- and high growth cases illustrate a range of potential supply based on past trends and fluctuations in production. For example, in 2017 the estimated total supply ranges from about $1 \mathrm{mmt}$ (low growth case) to approximately $2.7 \mathrm{mmt}$ (high growth case). The baseline case estimates a total potential cumulative supply in 2017 of $2 \mathrm{mmt}$ and a planted area of about 560,000 ha.

Colombia Figure 2 illustrates the national historic trend and the projected estimated supply of palm oil in Colombia under the baseline, high-, and low growth cases for the three periods under study.

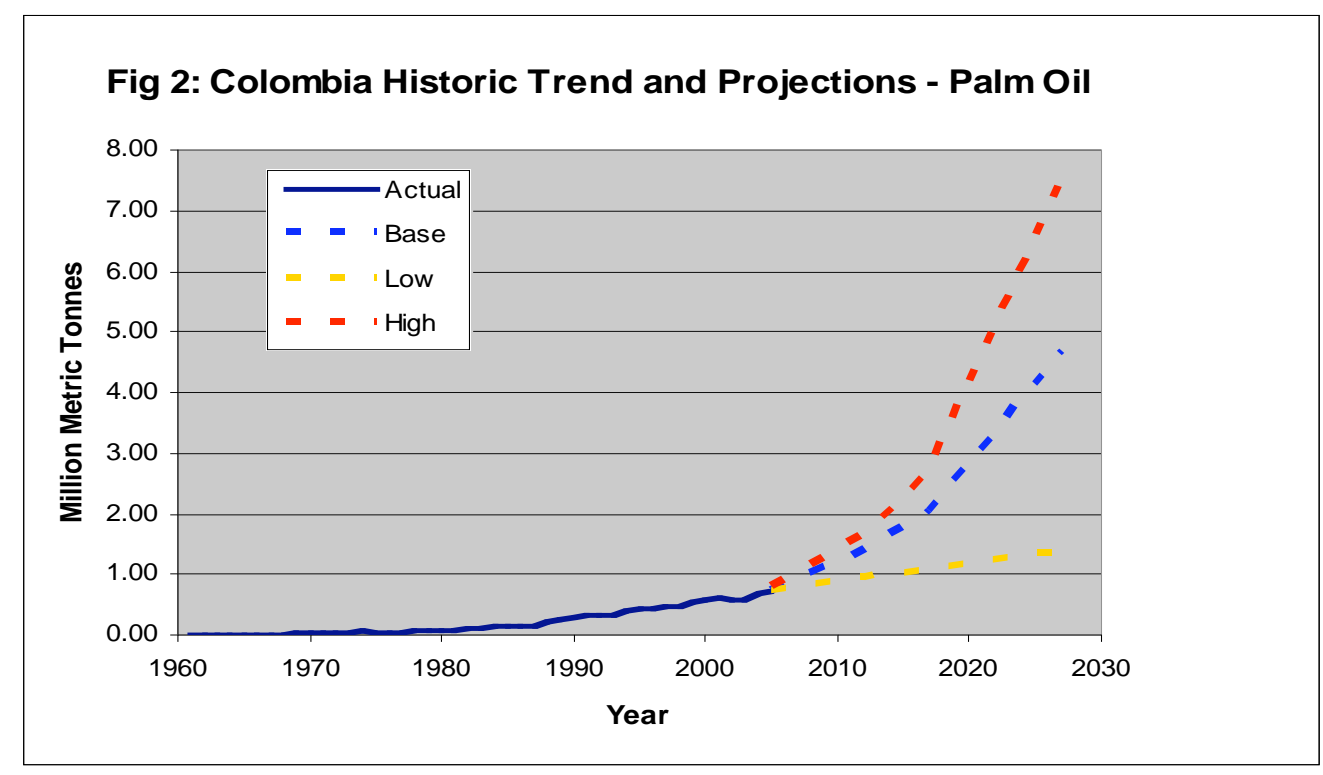

Colombia Figure 2. Palm Oil - Historic Trend and Estimated Cumulative Supply Projections to 2027. 


\subsubsection{Other Palm Oil Estimates}

USDA estimates that $2007 / 08$ crude palm oil production will reach $830,000 \mathrm{mt}$, about double the production levels from 1995-2002. ${ }^{\text {ccxi }}$ USDA and other sources note that investors are expanding palm oil acreage and biodiesel production facilities due to government policies mandating a 5\% biodiesel blend in diesel fuels beginning in January 2008 coupled with a set of incentives that includes price guarantees for biodiesel producers, subsidized credit, 14-year income tax exemptions for plantation operations and continuing export subsidies through a price-stabilization fund.

The national palm growers federation, Fedepalma, indicates that plans are in place to bring biodiesel production to 645,000 tonnes/year by 2008 , and for plantations to expand to 900,000 ha by 2020 (a rate significantly higher than this study's baseline case and a bit higher than the study's projected high growth case). An IDB report ${ }^{\text {ccxii }}$ suggests that most growth will be in the north (Caribbean coast). In the bananagrowing department of Uraba alone, there reportedly are over 700,000 has of potential arable land not yet in cultivation. Despite this land availability, recent expansion of African palm plantations has produced concerns among environmental and social justice groups.

\subsubsection{Biofuel Use and Competing Demands}

Vegetable oil consumption has been increasing in Colombia. A marketing campaign to expand local consumption by the palm oil growers' federation has contributed to the increase in vegetable oil consumption. To meet the new biodiesel requirements, initial plans are to convert 200,000 tonnes of palm oil exports to biodiesel production by 2018 . The total capacity of biodiesel plants in Colombia is 400,000 tonnes, representing about $10 \%$ of current diesel consumption.

Over 200,000 tonnes of palm oil were exported in 2005. Based on the methodology, about $36 \%$ of Colombia palm oil production could be available for allocation to exports and/or biofuel production in the baseline case. Under the high growth case, 50-60 percent would be available for export and/or biofuel (and even more, if Fedepalma's optimistic growth projections are realized).

In 2005, the Government of Colombia implemented measures that had the effect of increasing African Palm prices and encouraging investment in biodiesel plants. These measures included a 14-year income tax exemption for new permanent crops (e.g., palm oil) planted within the decade beginning in 2004 and a price structure that bounded the price paid to biodiesel (or, palm oil) producers. ${ }^{\text {cxxiii }}$ Further, a new biodiesel policy will go into effect in January 2008, effectively diverting 200,000 tons of palm oil to biodiesel production that otherwise would be exported for industrial use. The country's palm oil producers are developing a total of 8 actual or proposed biodiesel plants, to begin operation starting in the 2007/2008 time frame. Collectively, these facilities will consume an estimated 400,000 tons of palm oil, and produce the equivalent of about 10 percent of current diesel consumption. ${ }^{\text {cxiv }}$

\subsubsection{Notes on Adjustments to Standard Methodology}

Future production for the baseline case was estimated following the standard methodology for each of the palm oil producing departments in Colombia. ${ }^{\text {ccxv }}$ The high and low growth cases were adjusted to use one-half of one standard deviation above and below the baseline case, rather than the one-standard deviation normally used. This adjustment was necessary due to the high standard deviation (12\%) calculated from the rolling average growth rates. Also, as noted above, due to insufficient data, it was not possible to construct cost-based supply functions. ${ }^{\text {ccxvi }}$ 


\subsubsection{Other Feedstocks}

\subsubsection{Cellulosic Supplies}

Bagasse from sugarcane production is expected to be readily available at sugar mills with supply in the 2017 baseline case estimated at $5 \mathrm{mmt}$ (dry weight) and an opportunity cost of US\$17/dry mt. Sugarcane residues and bagasse currently are used for a variety of purposes in Colombia ranging from animal feed, to fertilizer, to products like paper and bricks. Palm oil residue is estimated at about $1 \mathrm{mmt}$ in 2017 with an opportunity cost of US $\$ 1 /$ dry mt (See Methodology for details). Forestry products and residues from existing industries are estimated to provide another 9-10 $\mathrm{mmt}$ (dry weight) per year with collection and transportation costs that are highly variable. And Colombia's expansive and underutilized land resources offer potential for another 5-10 $\mathrm{mmt}$ of cellulosic supplies from dedicated biomass perennial crops.

\subsubsection{Other Feedstocks}

Colombia is pioneering the use of cassava and sugar beets as commercial feedstocks for ethanol production and the preliminary results appear promising. Cassava and sugar beets are grown in other parts of the country and require much less water than sugarcane. In a trial north of Bogota, tropical sugar beets yielded $120 \mathrm{mt} / \mathrm{ha}$ per harvest and two harvests were obtained per year. The long-term yields of the sugar beets, with high sugar content, are projected to exceed $200 \mathrm{mt} / \mathrm{ha}$-year.

Soybean production in Colombia was assessed but is minimal (about $0.05 \mathrm{mmt} / \mathrm{yr}$ ) compared to other nations. Colombia is expected to remain a net importer of soybeans and soy products for the foreseeable future; imports from the United States have escalated in the past few years (about two-thirds of the country's total soybean and soybean meal imports in 2006). This trend is expected to continue, partly as a result of the 2006 Colombian Trade Promotion Act (CTPA). ${ }^{\text {ccxvii }}$ Biodiesel production is expected to continue to be based on palm oil.

\subsubsection{Opportunities and Constraints}

The national policies and incentives discussed above have created opportunities and led to rapid investment and expansion of a biofuel market and industry within Colombia.

The sugarcane industry is relatively advanced and continually improves its practices for managing wastes and maintaining soil productivity. The rapid expansion of African palm plantations presents potential environmental and social issues. A combination of aggressive palm oil production goals and market potential within and beyond Colombia's borders contribute to situations in which populations have reportedly been displaced involuntarily. This displacement has been accompanied by land-clearing for palm oil tree planting; destruction and disappearance of structures, roads, and paths used by indigenous groups; and as a result, the destruction of local social fabric and the instigation of lawsuits. ${ }^{\text {ccxviii }}$

A recent UNEP study ${ }^{\text {ccxix }}$ focused on corn as an example of the small farm economy in Colombia to analyze the impacts of trade liberalization. This study concluded that agricultural trade liberalization would affect small farm economies, biodiversity (natural and agricultural), and food security significantly. Food security could diminish in part because of reduced farm incomes. Trade liberalization could have the effect of shrinking the number of small farms, and the concomitant effect of shrinking attention to traditional conservation practices currently undertaken only by indigenous communities. Alternatively, institutional infrastructure could be altered to incorporate small farmers into modified production systems and successful biofuel programs could create opportunities to increase farm incomes. 


\section{Colombia Analysis Endnotes}

${ }^{\text {cciv }}$ USDA C07011. Data about current and potential biofuel feedstock production in this analysis are drawn in part from USDA Foreign Agricultural Service (FAS) Global Agriculture Information Network (GAIN) reports that are accessible at: http://www.fas.usda.gov/scriptsw/AttacheRep/default.asp. As a GAIN fact sheet states, "Production, Supply, and Distribution (PSD) data contained in GAIN reports are NOT official USDA data, but represent estimates made by FAS Attachés." See http://www.fas.usda.gov/info/factsheets/reports.asp. The following GAIN reports (hereafter, cited by their report numbers) were used to collect about Colombia:

USDA 2002 GAIN Report CO2009: Colombia Sugar Annual, 2002.

USDA 2004 GAIN Report CO4004: Colombia Sugar Annual, 2004.

USDA 2005 GAIN Report CO5005: Colombia Sugar Annual, 2005.

USDA 2007 GAIN Report CO7001: Colombia Oilseeds and Products Annual, 2007.

USDA 2007 GAIN Report CO7007: Colombia Sugar Annual, 2007.

USDA 2007 GAIN Report C07011: Colombia Bio-Fuels, Annual, 2007.

${ }^{c c v}$ The data were accessed through the National Department of Planning (DNP) page: www.dnp.gov.co/. This site offers access to many data sets including national and departmental production statistics from the Ministry of Agriculture and Rural Development: http://www.dnp.gov.co/paginas detalle.aspx?idp=88.

ccvi Observatorio AgroCadenas Colombia, Ministerio de Agricultura y Desarrollo Rural (Ministry of Agriculture and Rural Development) http://www.agrocadenas.gov.co/oleaginosas/Documentos/caracterizacion oleaginosas.pdf. The price data for Colombia from different sources were extremely divergent. For example, the palm oil price from the above source was about $\$ 449 /$ tonne for December 2005 , while the FAO price was $\$ 770.8$. The Inter-American Institute for Cooperation on Agriculture (IICA) supports a program in Colombia called, "Observatorio de Territorios Rurales," whose purpose is to promote rural development with better information. The IICA Agricultural Information system database http://www.territoriosrurales.org.co/03_indicadores/Docs/Prod_Agrop_Dptal03.xls had a price estimate for palm Africana for 2003 (the most recent in that system) that appears to be erroneous at about $\$ 59 /$ tonne when converted from local currency. The average nominal exchange rate in 2003 from the ERS/USDA database is 2877.653 Pesos per US Dollar. This same source had a price for sugarcane that was about $\$ 10 /$ tonne, while both the FAO and the Colombia Ministry of Agriculture implied an estimate of about \$30/tonne; see http://www.agrocadenas.gov.co/azucar/documentos/caracterizacion_azucar.pdf. Note: the ERS/USDA database shows that the Colombian Peso also gained value against the dollar from 2003-2005.

ccvii This study used national statistics at a departmental level from the Government of Colombia which summed to $34 \mathrm{mmt}$ for 2005, consistent with USDA data. FAO data were consistently about $15 \%$ higher.

ccviii USDA GAIN “Colombia Annual Sugar” Reports (2002-07). Earlier reports contain sugarcane data separate from sugar. The total area planted is significantly higher than areas harvested. Data tables and yields are disaggregated by centrifugal and panela production. Some sugarcane is grown along the border and exported directly to neighboring Venezuela. See: http://www.fas.usda.gov/scriptsw/AttacheRep/default.asp.

${ }^{\text {ccix }}$ USAID is supporting a program for social reintegration of ex-combatants involving sugarcane production and three new ethanol plants in the Caribbean zone and other feedstocks are going in to the highlands (see: http://es.biz.yahoo.com/10072007/185/colombia-aumentara-produccion-etanol-tres-nuevas-plantas.html).

Several new yucca-based ethanol plants are planned to begin production in 2007 and 2008, and one is also planned that will use a special variety of tropical sugar beets:

http://www.minminas.gov.co/minminas/prensa.nsf/72d20655189fca0b05256a0900571b2e/7d581a2d7de9ebf005257 20c003eafe2?OpenDocument.

ccx Ibid.

${ }^{c c x i}$ USDA CO7011. FAPRI and USDA agricultural baseline data sets offered estimates of future production for many crops, but not Colombian palm oil.

ccxii IDB (Inter-American Development Bank), 2007. http://www.iadb.org/biofuels/

ccxiii USDA CO7001

ccxiv Ibid.

${ }^{c c x v}$ The "historic trend" rate of plantation growth in some departments was $100 \%$, so these figures were adjusted to the rolling 7-year mean growth rate of $13.3 \%$, per the approach described in the Introduction.

${ }^{c c x v i}$ See note above on sources for estimating producer values.

ccxvii USDA CO7001 
ccxviii Several articles on this topic appeared in the press in 2006 and 2007. For example, see: Avendano 2007. Colombia's Palm Oil Biodiesel Push; Tatiana Roa Avendaño. Article published Feb. 2, 2007 on www.biodiversidadla.org and accessed in July 2007 at http://americas.irc-online.org/am/3962

${ }^{c c x i x}$ UNEP 2006. Colombia: Integrated assessment of agricultural trade liberalization: With a focus on the corn sector. Accessed July 2007 at http://www.unep.ch/etb/areas/pdf/Colombia\%20ReportFINAL.pdf 


\subsection{INDIA - SUGARCANE}

\subsubsection{Summary Findings}

India is the second largest producer of sugarcane in the world, after Brazil. Baseline cumulative production of sugarcane in 2017 is projected at about $358 \mathrm{mmt}$ from 5.9 million ha compared with approximately $233 \mathrm{mmt}$ from 3.9 million ha in 2003. Despite the growth and substantial levels of production, India's sugarcane likely will be dedicated primarily to human consumption and biofuel production will remain limited to offsetting a relatively small percentage of domestic demand for imported fuels.

Given past trends, India is not expected to be a significant biofuel exporter in the next decade, and may be a net importer. ${ }^{\text {ccxx }}$ This study's calculations suggest that about $5 \%$ of projected sugarcane production in the 2017 baseline case could be available for export and/or biofuel. India currently has the capacity to produce about 1.3 billion liters of biofuel from molasses, a by-product of sugarcane. However, only about one tenth of that capacity was dedicated to fuel ethanol in 2005 and the government's soft targets for a $5 \%$ blend (if commercially viable) in selected states has not been met. The lack of progress was initially attributed to short supplies (from droughts and pests) and more recently, with surplus sugarcane, taxes, mill prices and state regulations are identified as obstacles and the blending program is only meeting about $30 \%$ of the initial target. ${ }^{\text {cxxi }}$

Bagasse residues at sugar mills are estimated to provide about $50 \mathrm{mmt}$ of dry cellulosic feedstock by 2017 under the baseline case. Forest harvest and milling residues could produce another $10 \mathrm{mmt}$ of dry cellulosic feedstock. A large amount of wood fuel is traditionally used in India, approximately $150 \mathrm{mmt}$ per year. These biomass fuels are not expected to be diverted to ethanol production unless alternative energy supplies effectively replace them for meeting daily human needs. India's potential arable land is fully cultivated, so no significant potential for dedicated perennial biomass harvesting was calculated using the standard approach in this study.

\subsubsection{Context}

India imports over $70 \%$ of the petroleum it requires and would like to reduce the costs and future growth of imports with biofuel. However, because food security is a higher priority, the government's biofuel program is being implemented cautiously so as not to displace food production. India is one of the world's largest importers of vegetable oils. The country recently has required imports of grains as well. The biofuel program will be used to help off-set petroleum imports to the extent that feedstock surpluses are available that will not undermine efforts toward self-reliance in food supply. Therefore, India (similar to China) plans to focus future biofuel feedstock production on non-edible oils, animal fats and food processing byproducts that will not compete with food crops for agricultural land. Examples include molasses for ethanol and Jatropha and other tree-based oils for biodiesel. The ethanol program has begun modestly, coincidentally during good sugarcane harvest years. In contrast, the biodiesel program is yet to get off the ground.

\section{$\underline{\text { India Figures }}$}

1-3: Baseline Projections for Sugarcane Supply

4: Sugarcane: Historic Trend and Projections 
India Tables (in Annex 4)

1-3: Sugarcane Data for Baseline, High and Low Growth Cases

4: Potential Percentage Crop Production for Biofuels

5: Estimated Cellulosic Supply from Recoverable Bagasse Residues

6: Estimated Cellulosic Supply including Other Residues

\subsubsection{Definitions, Methodology, and Assumptions}

Background, definitions, and a description of the general approach used to estimate projected feedstock supplies are provided in the Introduction. For India, the analysis was based on historic production data by state from 1999-2003 from the Ministry of Agriculture. ${ }^{\text {ccxxii }}$ Average sugarcane price data by state for 2003 were available for 9 of 25 sugarcane producing states. These states account for about $60 \%$ of total production, including the largest producing state of Uttar Pradesh. The average price of sugarcane computed from the nine states with data was assigned as the price for the remaining states. Prices reported in 2003 Indian Rupees were converted into 2003 US dollars using the nominal exchange rate of 46.6 Rupees per $\$$ from the USDA ERS exchange rate database. The resulting values then were inflated at the U.S. inflation rate (3\%) to calculate the 2005 values in the Tables.

The initial projection of future production to 2012 was classified as the low growth case rather than the baseline case (see Methodology). Historic production data by state were limited and only available up to 2003 - a period with relatively low or falling production that influenced the projections. More recent national level data show that production is rising, as do most official forecasts of growth.

\subsubsection{Units, Conversion Factors, and Calculations}

Supply is stated in harvested millions of metric tonnes (mmt).

Land is measured in hectares (ha), and yield in metric tonnes per hectare (mt/ha).

Prices are in 2005 US Dollars.

\subsubsection{Sugarcane Supply Potential — Analysis and Projections: 2012, 2017, 2027}

India is the world's second largest producer of sugarcane and sugar products, after Brazil. India's present ethanol industry is based on molasses, a byproduct of sugar production. In 2006, partial implementation of a government policy for $5 \%$ ethanol blend with gasoline resulted in production of about 250 million liters of ethanol and that amount is forecast to double, to 500 million liters in $2007 .{ }^{\text {ccxxiii }}$ India reports that it has about 110 distilleries capable of producing up to 1.3 billion liters of ethanol per year from molasses. ${ }^{\text {ccxiv }}$ However, the high price of molasses dampens its use for biofuel production. To use other byproducts (cane juice) as an alternative would require technological modification. ${ }^{\text {ccxxv }}$

India's total sugarcane harvest from the 2003/04 season was about $232 \mathrm{mmt}$ from 4 million ha, according to Ministry of Agriculture data, the source used as the basis for projections in this study. Similar, but different, numbers are reported by other sources, including the USDA with $237 \mathrm{mmt}$ and $235 \mathrm{mmt}$ in 2004 and 2005, and the FAO with 287, 237, and $232 \mathrm{mmt}$ for 2003, 2004, and 2005, respectively. ${ }_{\text {.cxxvi }}$

India's future sugarcane production is projected in this study for 2012, 2017, and 2027, with estimated potential supply in the baseline case of approximately 315,360 , and $450 \mathrm{mmt}$, respectively (see India Table 1). India Figures 1-3 illustrate estimated supply curves in the baseline case for the three periods under study. 

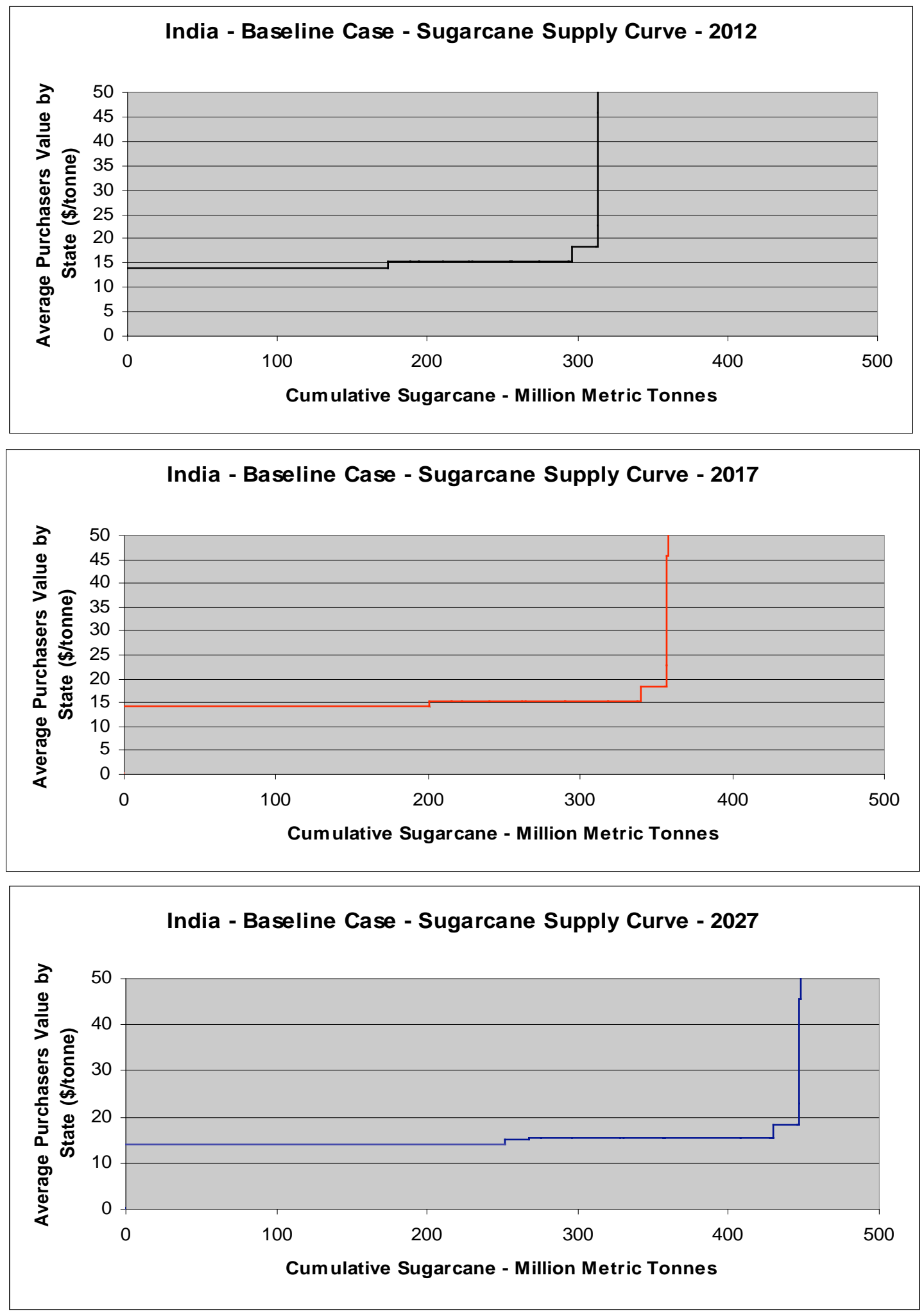

India Figures 1-3. Baseline Case Sugarcane Supply Projections. 


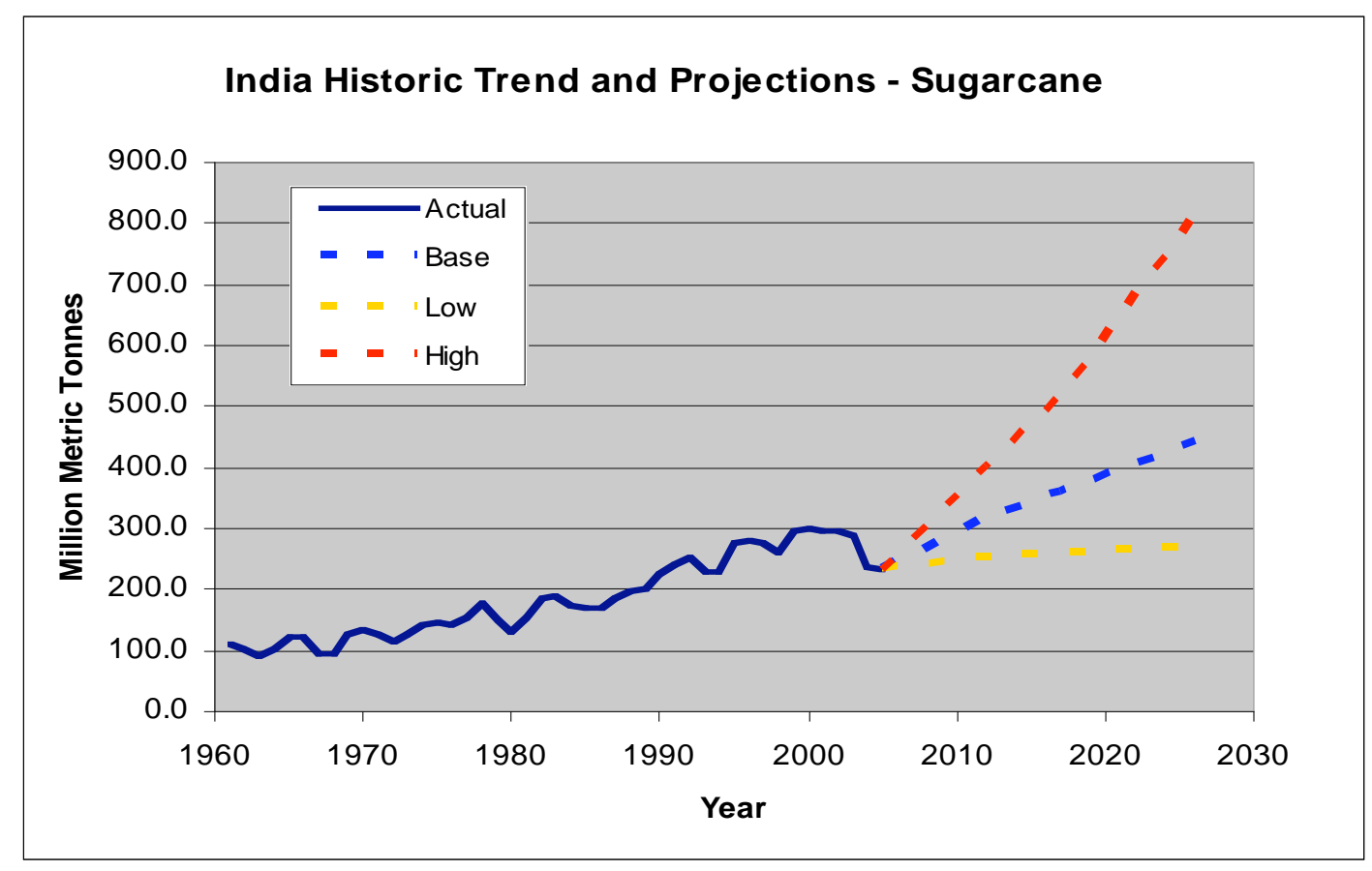

India Figure 4. Sugarcane: Historic Trend and Projections.

Low and high growth cases illustrate a range of potential supply based on past trends and fluctuations in production (see Figure 4 and Annex 4, India Tables 2 and 3). For example, in 2017 the estimated total supply ranges from about $260 \mathrm{mmt}$ (low growth case) to about $521 \mathrm{mmt}$ (high growth case). The baseline case (presented in India Table 1) estimates a total cumulative potential supply in 2017 of approximately $358 \mathrm{mmt}$ from 5.9 million ha.

\subsubsection{Other Sugarcane Estimates}

The FAPRI (2007) model projected similar total supply estimates for India's future sugarcane harvests as the baseline case in this study, with projections of $326 \mathrm{mmt}$ in 2012 and $351 \mathrm{mmt}$ in 2016 . The referenced USDA reports note that poor weather conditions and local market disruptions resulted in a sharp decline in sugarcane and sugar production between 2001 and 2004. This trend combined with the standard methodology used in the study resulted in relatively conservative estimates for future production. Production now is rebounding and USDA predicts the 2007/08 harvest to reach $325 \mathrm{mmt}$, which is about the same level of production as projected by FAPRI for 2012. Thus, over the near term, a production level shift toward the "high growth case" as estimated in this study would appear to reflect more accurately the current trend in production for India.

\subsubsection{Biofuel Use and Competing Demands}

India's sugarcane production almost entirely is used for domestic consumption as either centrifugal sugar or gur (crude sugar in lump form produced by open pan evaporation). Consumption has been increasing in recent years due to a high economic growth rate (about $8 \%$ ) and steady population growth (1.8\%). This demand combined with a fall in production (as illustrated in Figure 4) resulted in the need for imports to satisfy demand in the first half of this decade. Domestic sugar prices are high enough that mills tend to import raw sugar to process. The government tries to support improving yields via new varieties and technologies. Although biofuel production is encouraged by the Indian government with a $5 \%$ target for 
ethanol blending with gasoline in selected states, there are no direct financial or tax incentives and targets have not been met. Most fuel ethanol is produced from molasses, a by-product of sugar milling, rather than from sugarcane. Although there is enough capacity to meet this target, reaching it has been slow due to the high prices required by ethanol producers. ${ }^{\text {ccxxvii }}$ This study's calculations indicate that approximately $5 \%$ of sugarcane produced in India (the amount currently exported as sugar) could be available for export and/or biofuel production in the baseline case. In practice, given domestic demand and prices, future production will more likely continue to fluctuate based on the availability and price of molasses, at least until new feedstocks and technologies come into commercial operations.

\subsubsection{Other Feedstocks}

The government of India is supporting research into alternative feedstocks including sweet sorghum, sugar beet, sweet potatoes, and cellulosic crop wastes. The government also is supporting efforts to develop improved cultivars of feedstock, such as cane suitable for marginal soils and arid lands to avoid competition with land for food crops.

\subsubsection{Cellulosic Supply}

Processing one tonne of sugarcane produces about $280 \mathrm{~kg}$ of bagasse with about $50 \%$ average moisture and $13-15 \%$ dry fiber. ${ }^{\text {ccxxviii }}$ Crushing produces more bagasse than sugar mill processing requires as thermal input. Therefore, the combustion processes in mills traditionally have been inefficient. ${ }^{\text {ccxxix }}$ Although there are not consistent markets for bagasse, an estimated opportunity cost is assigned for this analysis of $\$ 10 /$ dry mt of bagasse. ${ }^{\text {ccxxx }}$ The amount of bagasse potentially available is calculated based on the projected amounts of sugarcane processed. The resulting potential cellulosic feedstock supply is presented in India Table 5. Given India's large sugarcane production, the numbers are significant: over 50 mmt dry weight of bagasse could be available for cellulosic feedstock in the 2017 baseline case and 73 $\mathrm{mmt}$ in the high growth case. By 2027 these values increase to $63 \mathrm{mmt}$ (baseline) and $118 \mathrm{mmt}$ (high growth).

\subsubsection{Opportunities and Constraints}

\subsubsection{Ethanol}

Bioethanol production in India is constrained by limited availability and high prices for molasses. Although the government has encouraged production of fuel ethanol through blending targets, progress has been slow in the absence of hard mandates and direct incentives. Expanding sugarcane acreage is possible, but costly because of limited suitable land available and the intensive use of water necessary in sugarcane production.

\subsubsection{Biodiesel}

While there currently is little or no biodiesel production in India, research is underway on the most promising tree based oil seed sources for large-scale production: non-edible Jatropha and pongamia. These oils are currently used in a variety of consumer products and, among the nation's poor, as fuel for lighting. Overall, however, a small percentage of total available oil seed is used, so there is considerable room for growth. Climate, soils and other conditions and practices can affect seed yields, which range from 1-5 tonne/ha for Jatropha and from 4-90 kg seeds/tree for pongamia. There are some indications that significantly higher Jatropha yields could be achieved, but these have yet to be demonstrated on a consistent basis. ${ }^{\text {ccxxxi }}$ 


\section{India Endnotes}

${ }^{c c x x}$ Worldwatch Institute, 2006. Biofuels for Transport: Global Potential and Implications for Energy and Agriculture, prepared by Worldwatch Institute for the German Ministry of Food, Agriculture and Consumer Protection (BMELV) in coordination with the German Agency for Technical Cooperation (GTZ) and the German Agency of Renewable Resources (FNR). London: Earthscan.

${ }^{c c x x i}$ USDA IN7047. Data about current and potential biofuel feedstock production in this analysis are drawn in part from USDA Foreign Agricultural Service (FAS) Global Agriculture Information Network (GAIN) reports that are accessible at http://www.fas.usda.gov/scriptsw/AttacheRep/default.asp. As a GAIN fact sheet states, "Production, Supply, and Distribution (PSD) data contained in GAIN reports are NOT official USDA data, but represent estimates made by FAS Attachés." See http://www.fas.usda.gov/info/factsheets/reports.asp. The following GAIN reports (hereafter, cited by their report numbers) were used to collect information about India:

USDA 2005 GAIN Report IN5034. India Sugar Annual Report, 2005

USDA 2006 GAIN Report IN6029: India Sugar Annual Report, 2006

USDA 2007 GAIN Report IN7035. India Sugar Annual Report, 2007

USDA 2007 GAIN Report IN7047: India Bio-Fuels Annual Report, 2007

${ }^{c c x x i i}$ See http://dacnet.nic.in/apy/crop fryr toyr.aspx. The historic data on production levels by state were accessed from the India Ministry of Agriculture website http://agricoop.nic.in/Agristatistics.htm.

ccxxiii USDA IN7047.

ccxxiv Ibid.

${ }^{c c x x v}$ USDA IN5034.

${ }^{c c x x v i}$ USDA GAIN “India Sugar Annual” Reports from 2007, 2006 and 2005; and India Biofuels Annual 2007, available from http://www.fas.usda.gov/gainfiles/. Also, the India Ministry of Agriculture "Crop Production Statistics" http://dacnet.nic.in/apy/crop_fryr_toyr.aspx / and http://agricoop.nic.in/Agristatistics.htm. ccxxvii USDA IN7047

ccxxviii Based on an analysis for Brazil (AgraFNP 2007). An additional $110 \mathrm{~kg}$ of straw and other residue are estimated to be potentially available for each tonne of sugarcane processed, but this material is not included in the present analysis as it is assumed to serve environmental purposes (soil conditioner) and it would require additional collection and handling (higher cost). Bagasse already is available at the mill and is commonly used for diverse purposes. Wastes remaining after processing are often applied to fields as fertilizer under existing operations. ${ }_{\text {ccxxix }}$ Bagasse is highly utilized in India for fuel and fiber. See below; depending on local markets, the value of bagasse and efficiency of its utilization can vary significantly.

${ }^{\text {ccxxx }}$ The opportunity cost could vary significantly from site to site, depending on how much bagasse is required for primary processing, whether the facility is set up for cogeneration, relative prices for electricity versus biomass for combustion, and the availability and costs of alternative fuels in the locality of the plant.

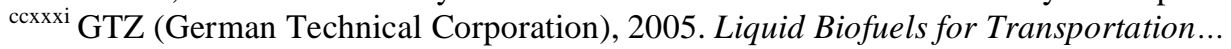




\subsection{MEXICO - SUGARCANE AND CORN}

\subsubsection{Summary Findings}

Mexico is a net importer of corn, but exports about $10 \%$ of its sugar production. Estimated baseline case cumulative production of sugarcane in Mexico in 2017 is about $63 \mathrm{mmt}$ from 760 thousand ha, compared with $52 \mathrm{mmt}$ from 670 thousand ha in 2005/06. For corn, estimated total cumulative production in 2017 is nearly $32 \mathrm{mmt}$ from 7.2 million ha, compared with $19.3 \mathrm{mmt}$ from 6.6 million ha in 2005/06.

Achieving the goal of $6 \%$ ethanol blend of gasoline use in three major cities would require a 20 -fold increase in Mexico's ethanol production. Although a new Biofuels Promotion and Development Law offers few specific incentives, a new National Sugar Program aims to produce about $6.5 \mathrm{mmt}$ of sugarcane for ethanol purposes by 2012. There are about 10 corn ethanol plant proposals, but only one was reportedly under construction. Given the role of corn as a Mexican food staple, any corn used for ethanol production may have to be obtained by imports or by rapidly expanding production. Imports currently meet about $25 \%$ of domestic consumption needs, and a recent diversion of about $1.2 \mathrm{mmt}$ of corn from food to the livestock industry contributed to rapid increases in tortilla prices in 2007.

Mexico is a dry country with variable weather conditions. Thus, it appears unlikely that Mexico would be able to contribute significantly to ethanol production from corn in the coming years. Sugarcane is considered to be the best biofuel feedstock option in Mexico, but there currently are only 13 sugar mills producing ethanol for non-fuel purposes. Increasing ethanol production both for export markets and domestic fuel blending would require substantial technology and infrastructure investments.

Cellulosic feedstock from sugarcane and corn production as well as forest residues could be used for ethanol production with the availability of technology. However, a significant amount of the bagasse from sugar production currently is used for power generation, while other biomass resources (wood fuels) are used for domestic cooking purposes in Mexico. These uses are unlikely to be displaced by bioethanol production in the near to medium time frame.

\section{$\underline{\text { Mexico Figures }}$}

1-3: Baseline Sugarcane Supply Curves

4: Sugarcane Production: Historic Trends and Projections

5-7: Baseline Corn Supply Curves

8: Corn Production: Historic Trends and Projections

\section{Mexico Tables (See Annex 4)}

1-3: Sugarcane Supply Potential for Baseline, High and Low Growth Cases

4-6: Corn Supply Potential for Baseline, High and Low Growth Cases

7: Potential Percentage Allocation for Export \& Biofuels

8: Estimated Cellulosic Supply from Recoverable Crop Residues

9: Estimated Cellulosic Supply Including Other Residues

\subsubsection{Context}

At the time this report was prepared, Mexico did not have a well-defined program to promote biofuels. It had conducted several feedstock studies and proposed measures in support of the production and use of biofuel. The government's interest in biofuel stems from a desire to stimulate rural economic development, reduce dependence on a dwindling oil supply, and reduce greenhouse gas emissions. A 
government-commissioned study on the feasibility of ethanol and biodiesel production and use, conducted in 2006, was followed by Congressional passage of a Bio-Fuels Promotion and Development bill in April, 2007. This legislation has yet to be signed. Further, its lack of specifics (e.g., targets and mandates) contributes to uncertainty among private-sector investors interested in developing ethanol facilities that use domestic and imported feedstocks. ${ }^{\text {ccxxxii }}$ Still, the law represents an initial effort to establish a legal framework within which to regulate the country's biofuel industry. Earlier, in December 2005 , legislation set a target of $8 \%$ renewable use by 2012, along with a fund to support renewable energy projects. This law was followed in 2006 by a government mandate of $10 \%$ ethanol fuel blend in the country's main urban centers (Mexico City, Monterey, and Guadalajara) and measures promoting biofuel development and production.

Mexico, currently the highest fossil fuel emitter in Latin America, is a net exporter of crude oil but importer of refined gasoline and gasoline additives. These gasoline additives, such as MTBE (methyl tertbutyl ether), constitute an obstacle to meeting biofuel targets, because ethanol would have to substitute for MTBE and current production facilities are not equipped to do so ${ }^{\text {ccxxxiii }}$ Additionally, the country's fuel infrastructure, including its network of gas stations, would have to be modernized, inspected, and maintained to handle ethanol. Mexico has established a technical cooperation relationship with Brazil with regard to ethanol and Gulf of Mexico crude oil reserves, where Brazil provides technical assistance.

The North American Free Trade Agreement (NAFTA) eliminates some protections for corn and other feedstock crops by 2008 , creating concerns and uncertainties as to the impacts on local markets, domestic production, and trade in feedstock crops and ethanol. Mexico currently produces between 56 and 82 million liters of ethanol annually, ${ }^{\text {ccxxiv }}$ though it has the capacity to produce nearly 170 million liters per year. ${ }^{\text {cxxxv }}$ That ethanol generally is not used for fuel and is insufficient to meet the projected 20 -fold increase in demand the blending targets imply.

Mexico is a net importer of ethanol from the US, Brazil, and, recently, China. Mexico likely would continue to rely on imports, primarily from the US and Brazil, to meet future ethanol demand. Nevertheless, Mexico has the natural resources, arable land, and history of cultivating viable feedstock crops (sugarcane, corn, sorghum, wheat, sugar beet, cassava, and oilseeds) that could allow the country to achieve its biofuel production goals. Meeting this demand would require a substantial investment, shift in domestic agricultural production, and changes in legislation, institutions, and infrastructure.

\subsubsection{Definitions, Methodology, and Assumptions}

Background, definitions, and descriptions of the approach and assumptions are provided in the Introduction. Historic data by state on production and prices were obtained from the national Information Service on Agriculture and Fishing. ${ }^{\text {ccxxxvi }}$

\subsubsection{Units, Conversion Factors, and Calculations}

Supply is stated in millions of metric tonnes (mmt) harvested.

Land is measured in hectares (ha), and yield in metric tonnes per hectare ( $\mathrm{mt} / \mathrm{ha}$ ).

Prices are in 2005 US Dollars, based on reported prices in Mexican Pesos in 2005 and converted at 10.898 Pesos per 1 US Dollar (average nominal exchange rate in 2005 from the ERS/USDA exchange rate database).

\subsubsection{Sugarcane Supply Potential — Analysis and Projections: 2012, 2017, 2027}

Although sugarcane is among the most expensive of Mexico's potential biofuel crops, the country's sugar industry probably is best-suited for producing ethanol. Sugarcane is a key component of Mexico's sugar 
industry. The seventh-largest global producer of sugar, Mexico produces about 5 million tons of sugar annually from approximately 633 million ha, and the industry directly or indirectly employs 12 million people. Land holdings typically are small, held by individual growers or through communal ownership of 3-5 ha farms. Most of the country's sugarcane is used to produce centrifugal sugar. Nevertheless, the BioFuels Promotion and Development Law and the National Sugar Development Plan encourage the use of sugarcane for ethanol. The Sugar Development Plan seeks to diversify the sugar industry and envisions building up to a 120 million gallon/year ethanol production capacity by 2012 . $^{\text {ccxxxvii }}$

Mexico's total sugarcane production from the 2006/07 season was about $47 \mathrm{mmt}^{\text {ccxxxviii }}$ from approximately 660,000 harvested hectares. This figure was less than prior years due to irregular weather, industrial logistics, and social issues (including labor strikes). The potential future production is projected in this study for 2012, 2017, and 2027, with an estimated potential supply in the baseline case of approximately 59,63, and $69 \mathrm{mmt}$, respectively. The average price obtained by rural producers, as reported by the Mexican government for each state, ranges from \$27-\$38 per mt. Mexico Figures 1-3 illustrate the supply curves for the baseline case.

Mexico Tables 1-3 (Annex 4) proved data reflecting the projected sugarcane supplies available at different value levels in the baseline, high and low growth cases. Final totals reflect the cumulative supply from harvests that are projected to be available at any price in a given year under the baseline case. The low and high growth cases illustrate a range of supply based on past trends and, in the case of Mexico, significant fluctuations in production. For 2017, the estimated total supply ranges from $52 \mathrm{mmt}$ (low growth case) to nearly $80 \mathrm{mmt}$ (high growth case) from harvested areas of 670-880 thousand ha, respectively. The baseline case (represented in supply curves Figures 1-3 and Mexico Table 1) estimates a total potential cumulative production in 2017 of about $63 \mathrm{mmt}$ from 757,000 harvested hectares.

\subsubsection{Other Sugarcane Estimates}

In 2007, the Government of Mexico released a new agricultural policy, passed a new biofuel law, and established a national program to promote growth in the sugar industry. These policies and programs set targets for expanding production through improved yields and expanding area, to reach $61 \mathrm{mmt}$ by 2012 with the goal of supplying sugar and ethanol for both domestic and export (California-ethanol) markets. The baseline estimate in the present report falls below this target.

The FAPRI (2007) model projected sugarcane harvests of about $54 \mathrm{mmt}$ in 2012 and $57 \mathrm{mmt}$ in 2016, numbers a bit more conservative than the baseline case here and much more conservative than the Mexican Government targets.

\subsubsection{Biofuel Use and Competing Demands}

Current sugarcane production in Mexico mainly is for domestic sugar consumption. However, about $13 \%$ of the sugar production is exported in either raw or refined form. The Mexican sugar industry is undergoing a number of changes that may affect sugarcane uses for ethanol fuel. These changes include implementation of NAFTA provisions in 2008, a pending Supreme Court decision on a new sugar law, the launching of a new National Sugar Program by the government, privatization of sugar mills, and the enactment of a Biofuel Law that encourages sugarcane use for ethanol fuel production. One of the targets of the new National Sugar Program is to allocate about $11 \%$ of the total sugarcane production target for 2012 of $61 \mathrm{mmt}$ to ethanol. ${ }^{\text {ccxxxix }}$

Using this study's methodology, about $13 \%$ of the baseline supply projection would be available for exports and/or biofuel production. None would be available in the low growth case while from 25-39\% of supply would be available under the high growth case, depending on the year. See Mexico Table 7. 

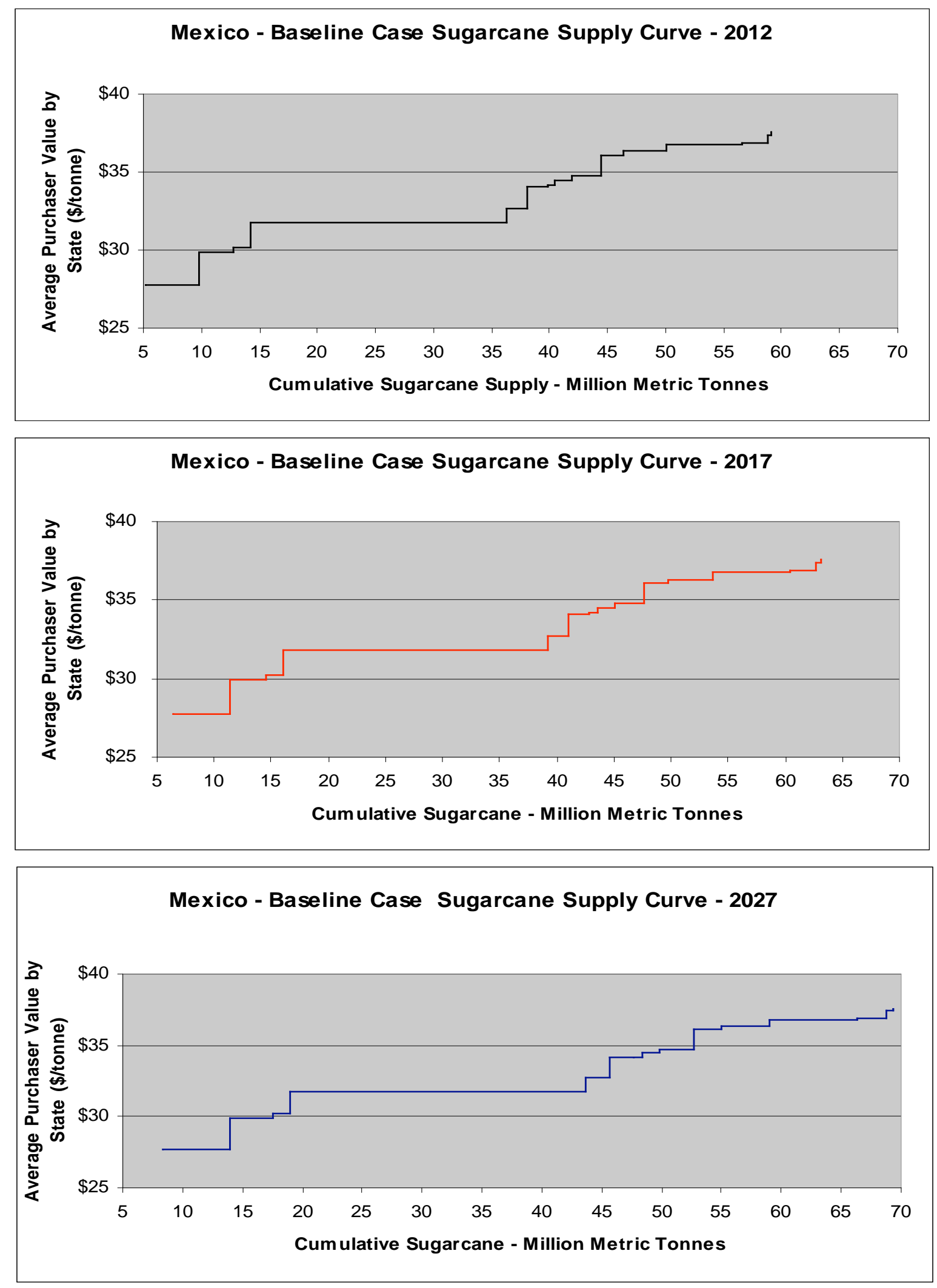

Mexico Figures 1-3. Baseline Sugarcane Supply Curves. 


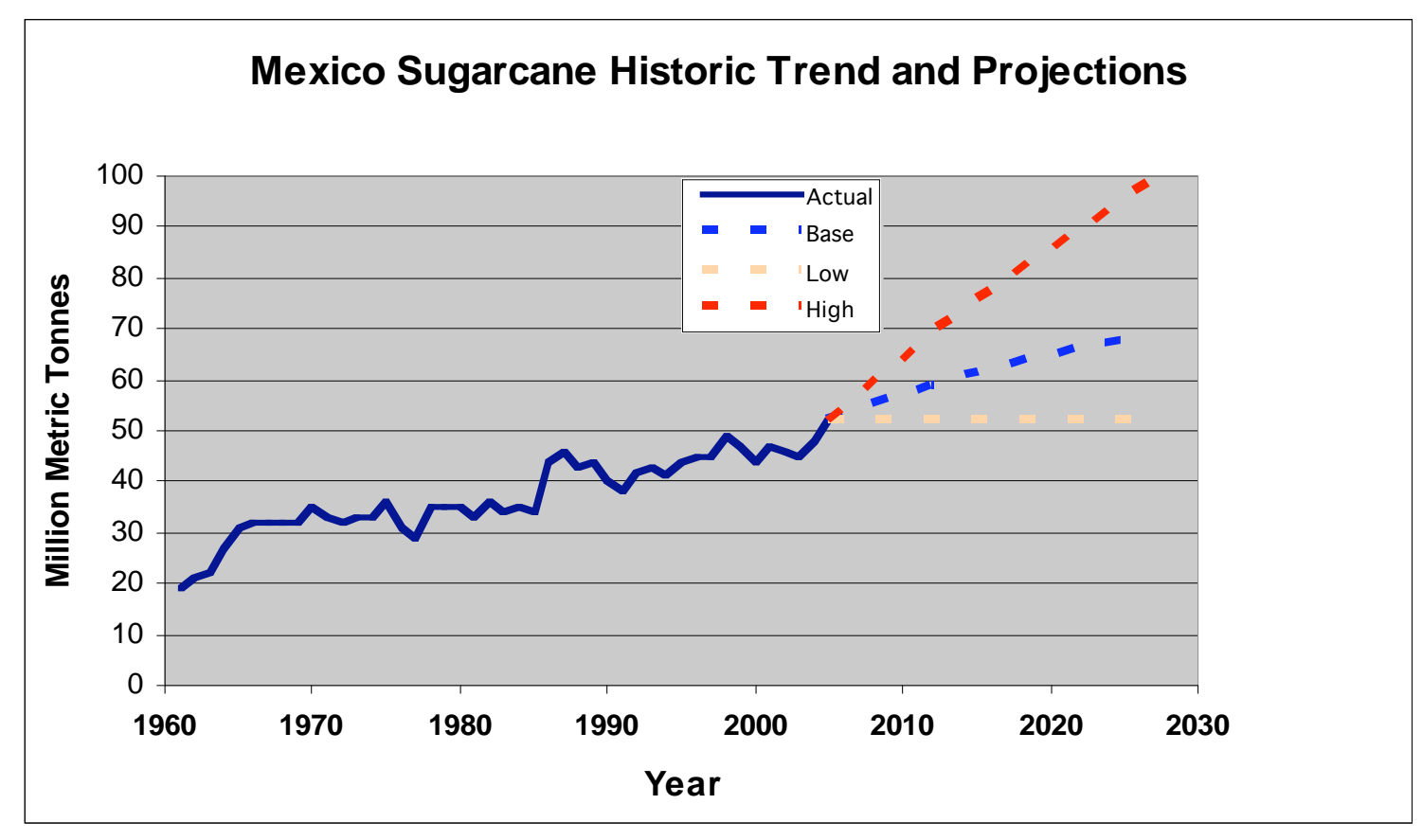

Mexico Figure 4. Sugarcane Production: Historic Trends and Projections.

\subsubsection{Corn Supply Potential — Analysis and Projections: 2012, 2017, 2027}

Mexico is a large producer and consumer of corn and, under NAFTA, its market is closely tied to the U.S. Mexico's total corn production was $19.5 \mathrm{mmt}$ from approximately 6.6 million ha in the 2005 season, ${ }^{\text {ccxl }}$ and is forecast to increase to $23.2 \mathrm{mmt}$ from a larger area harvested in 2006/07. Estimated corn consumption in Mexico in 2006/07 is $30.3 \mathrm{mmt}$, and is expected to increase to about $33.3 \mathrm{mmt}$ in 2007/08. This large increase partially is due to the inclusion of cracked corn, which historically was not included consumption figures and which previously was imported both to help meet demand and to help avoid over-quota duties. ${ }^{\text {ccxli }}$ Full implementation of NAFTA is expected to end Mexico's importation of cracked corn.

In 2006, Mexico produced about $22 \mathrm{mmt}$ and imported about $10 \mathrm{mmt}$ (including cracked corn) from the US. Corn production is highly dependent on weather conditions, but high corn prices may encourage farmers to plant more corn than in the past. Mexico is expected to remain a net importer of corn in the near to medium term. The country is unlikely to be able to meet the combined demands for food, feed and bioenergy in the absence of substantial additional investments to produce more corn or alternative crops.

The potential future production is projected in this study for 2012, 2017, and 2027. Mexico Figures 5-7 illustrate total corn supply potential projected in the baseline case at different values. Supply estimates for 2012, 2017, and 2027 are approximately 27, 32, and $42 \mathrm{mmt}$, respectively, in the baseline case. These are the cumulative supply figures projected to be available at any price in a given year. Low and high growth cases illustrate a range of potential supply based on past market and production fluctuations for the crop in this country. Mexico Tables 5 and 6 provide the data for low and high growth cases. For example, in 2017, the estimated total supply ranges from approximately $23 \mathrm{mmt}$ (low growth case) to about $46 \mathrm{mmt}$ (high growth case). The baseline case (Table 4) estimates a total cumulative production in 2017 of nearly $32 \mathrm{mmt}$ from about 7 million harvested hectares. 

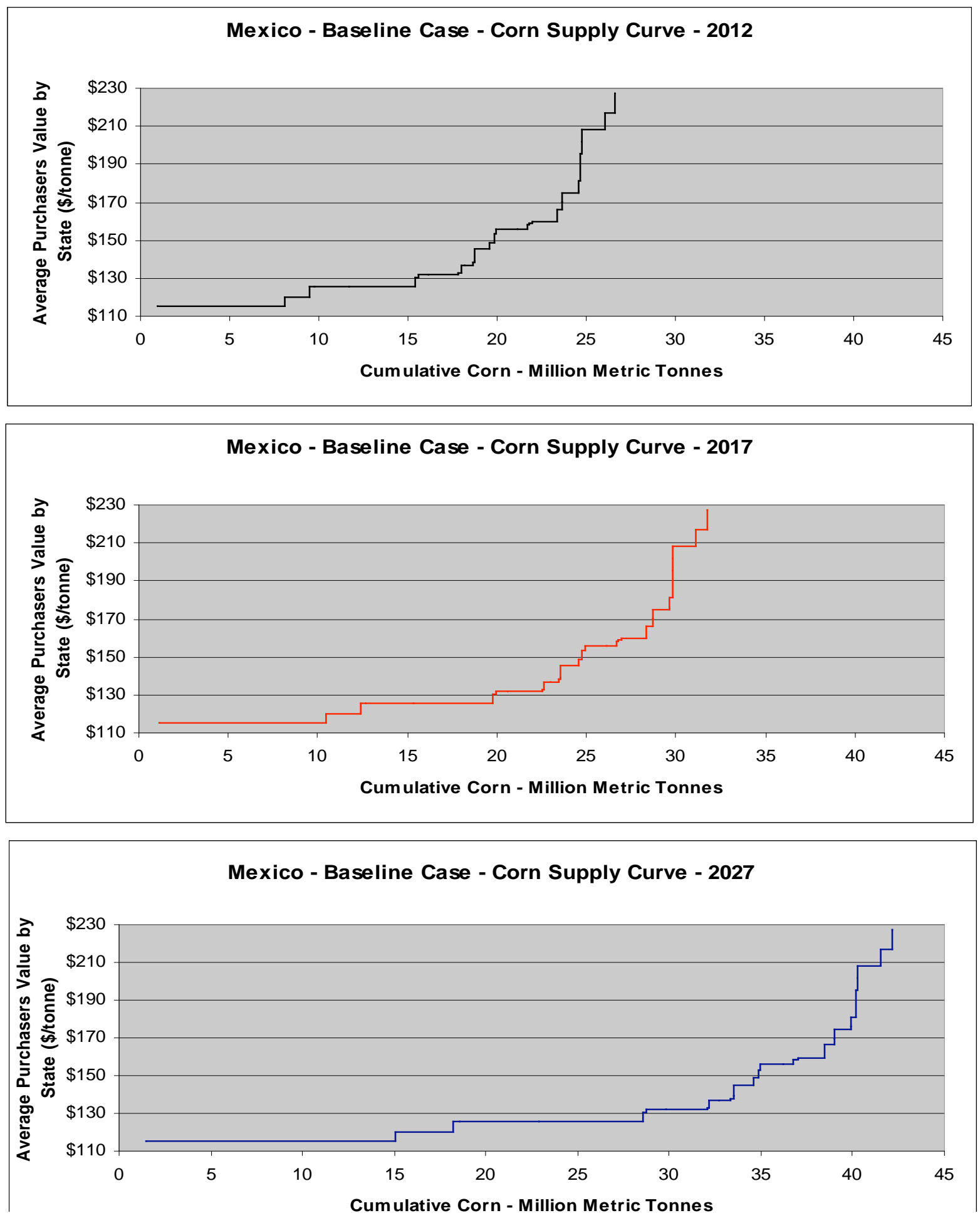


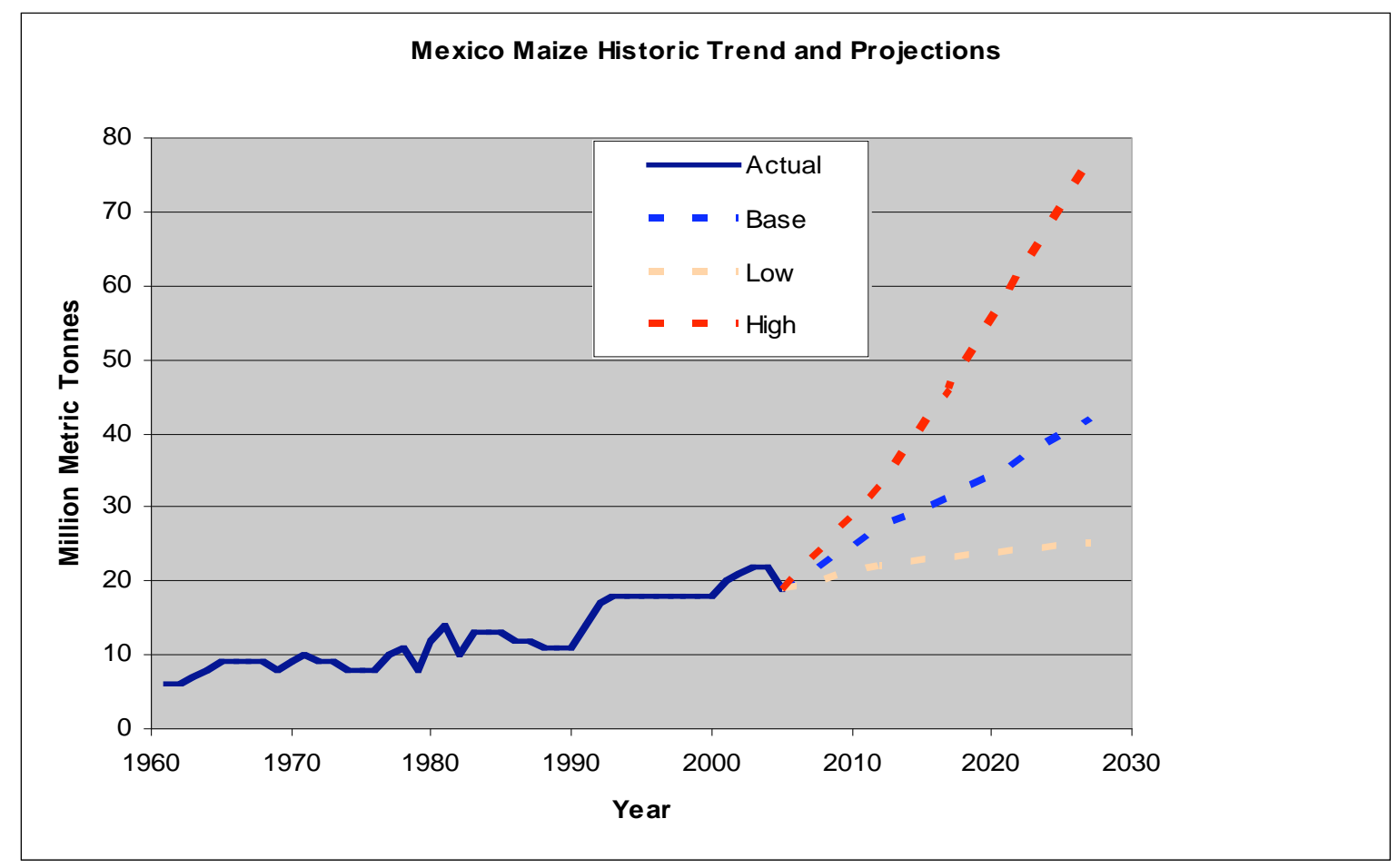

Mexico Figure 8. Corn Production: Historic Trends and Projections.

\subsubsection{Other Corn Estimates}

The USDA Economic Research Service (2007) baseline agricultural projections for Mexico estimated total production levels a little below those in this analysis, at approximately 25 and $27 \mathrm{mmt}$ for 2012 and 2017, respectively. A more recent USDA-FAS report from Mexico, however, notes that the area planted to corn has increased more rapidly than expected due to higher local prices and production is expected to exceed $23 \mathrm{mmt}$ in 2007 - nearly a $20 \%$ increase over 2005 levels. ${ }^{\text {ccxlii }}$ The FAPRI (2007) model produced more conservative estimates for 2012 and 2017 of 22.9 and $23.1 \mathrm{mmt}$, respectively.

\subsubsection{Biofuel Use and Competing Demands}

Corn is a staple foodstuff in Mexico. Per capita consumption averages 65 kilograms annually. In tortillas, it constitutes the major portion of the caloric intake for lower income individuals. Corn likely will become even more important for dietary consumption as the Mexican population grows. Further, increasing corn prices impose pressures on individuals and organizations involved in the livestock industry - for swine, poultry, and beef. The major livestock consumers of corn (and sorghum) are poultry. Depending on the highly variable production of corn in Mexico, about a quarter of these domestic uses is met through imports. A recent diversion of $1.2 \mathrm{mmt}$ of corn from food to livestock due to lower domestic prices relative to import prices contributed to a rapid and contentious increase in tortilla prices. ${ }^{\text {ccxliii }}$ Still there are ten known project proposals to produce ethanol fuel from corn in Mexico, and one was reportedly under construction.

Mexico recently set an objective of $6 \%$ ethanol blend in gasoline for Mexico City, Monterey, and Guadalajara. Reaching this objective would require a 20 -fold increase from current production levels of 
21 million gallons under the assumption that these cities account for 30\% of Mexico's total gasoline use. Applying the methodology for this assessment, Mexico would not have domestic corn supply "available for export and/or biofuel" under the low and baseline case assumptions, but could make $27-40 \%$ of supply available in the high growth case (in 2017 and 2027, respectively). See Mexico Table 7.

\subsubsection{Other Feedstocks}

\subsubsection{Cellulosic Supply}

Bagasse from sugarcane production is expected to be readily available at the sugar mills and its supply is estimated at $6 \mathrm{mmt}$ (dry weight) in 2017 under the baseline case. The opportunity cost for bagasse in Mexico was estimated at $\$ 17 / \mathrm{mt}$ given that most is presently used for combustion (heat and power generation) or other uses. Corn stover is estimated at about $4 \mathrm{mmt}$ in 2017 at costs up to $\$ 39 / \mathrm{mt}$ (see Mexico Table 8). The forest sector potential for cellulosic supply from mill and harvest residues is estimated at about $1.3 \mathrm{mmt}$ per year (dry weight). In addition, if half of present wood fuel supplies were available, that would represent another $7 \mathrm{mmt} / \mathrm{yr}$ (dry weight) of cellulosic potential. Applying the standard calculations to Mexico's potential and unutilized arable land would generate an additional 1-2 mmt dry biomass per year from dedicated perennial production.

\subsubsection{Opportunities and Constraints}

The proximity to the California market, combined with state targets for environmentally friendly fuel use and access to markets under NAFTA, offers future opportunities for Mexico to export biofuel to California. These exports most likely would consist of modest quantities based on sugarcane, sorghum and recycled oils and oilseed for feedstocks.

Several factors contribute to higher production costs, lower yields, and lower potential growth for biofuel feedstock sectors in Mexico when compared to other countries in this assessment. Mexico's feedstock production primarily is from small, rain-dependent parcels with relatively limited access to technology, capital, inputs, and markets. Additional cultural and social issues that can influence production include the role of corn in society and the impacts of NAFTA. Finally, physical conditions including climate and weather variability, soils, and limited availability of water, create significant constraints to rapid agricultural expansion for biofuel crops such as sugarcane. Crop yields are highly susceptible to weather conditions. Furthermore, Mexico is expected to remain a net importer of key feedstock products for the foreseeable future and is unlikely to use corn for biofuel. The Mexican government has signaled that, in the food versus fuel controversy, it will favor food and not support policies to produce ethanol from corn.

\subsubsection{Ethanol}

Mexico completed a major biofuel study that considered alternative feedstocks and production costs in conjunction with the new laws and polices noted above. That study suggested that corn was a slightly more economical feedstock for ethanol than sugarcane in Mexico, and that sorghum was the least-cost feedstock available. However, the use of corn is controversial and the government has indicated that it will not support policies to produce ethanol from corn. The national assessment report concluded that the most feasible feedstock is sugarcane. It recommended that distilling plants be built as part of the proposed revitalization of the sugar industry. ${ }^{\text {ccxliv }}$ The economics, institutions, and infrastructure associated with sugarcane and sugar production constrain the use of that crop for bioenergy. High, governmentmaintained sugarcane prices are not conducive to ethanol production. And, substantial changes to the country's plants and infrastructure, and greater involvement by its energy sector, would be needed to support and sustain sugarcane-derived biofuel production. Any significant increase in production will require financing and incentives which are not presently apparent. 


\subsubsection{Biodiesel}

Biodiesel production in Mexico is just beginning to develop, cautiously, based on the new policies and legislation. Biodiesel production historically has been limited to small operations that primarily use beef tallow, with total production estimated at 3.7 million liters/year. ${ }^{\text {cxlv }}$ Though Mexico produces oilseeds, particularly soybeans and rapeseed (canola), it also imports these products from the U.S. These oilseeds typically are used for dietary consumption and higher corn prices may encourage planting corn instead of soybeans. Currently, biodiesel plants in Mexico are limited to relatively small private operations and research facilities. 


\section{Mexico Endnotes}

ccxxxii USDA MX7042. Data about current and potential biofuel feedstock production in this analysis are drawn in part from USDA Foreign Agricultural Service (FAS) Global Agriculture Information Network (GAIN) reports that are accessible at http://www.fas.usda.gov/scriptsw/AttacheRep/default.asp. As a GAIN fact sheet states,

"Production, Supply, and Distribution (PSD) data contained in GAIN reports are NOT official USDA data, but represent estimates made by FAS Attachés." See http://www.fas.usda.gov/info/factsheets/reports.asp. The following GAIN reports (hereafter, cited by their report numbers) were used to collect information about Mexico:

USDA 2007 GAIN Report MX7024, Mexico, Grain and Feed, Annual Report, 2007.

USDA 2007 GAIN Report MX7028, Mexico, Oilseeds and Products, Oilseeds Annual Report, 2007. USDA 2007 GAIN Report MX7031, Mexico, Sugar, Sugar Annual, 2007.

ccxxxiii USDA MX7042

ccxxxiv IDB 2007 and USDA MX7042, respectively.

${ }^{c c x x x v}$ USDA MX7042

${ }^{c c x x x v i}$ Mexico national data and information service for agriculture and fishing, accessed May 2007 at:

http://www.siap.gob.mx/aagricola siap/icultivo/index.jsp

ccxxxvii USDA MX7042

ccxxxviii USDA MX7031

ccxxxix Ibid.

${ }^{\mathrm{ccxl}}$ USDA MX7024

ccxli Ibid.

ccxlii Ibid.

ccxliii USDA MX7024

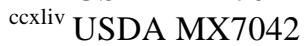

${ }^{c c x l v}$ Ibid. Historic data on production levels were obtained from the Mexican Information Service on Agriculture and Fishing, accessed in May, 2007 at: http://www.siap.gob.mx/aagricola_siap/icultivo/index.jsp 


\subsection{CARIBBEAN BASIN INITIATIVE (CBI) REGION}

\subsubsection{Summary Findings}

The Caribbean Basin Initiative (CBI) region consists of 24 countries. Governments are interested in biofuel to improve energy security, environmental preservation, and socio-economic development. Total sugarcane production by the CBI nations in 2005 was about $51 \mathrm{mmt}$. The top three sugarcane producers in the CBI are Guatemala with about $19 \mathrm{mmt}$, Honduras with $5.6 \mathrm{mmt}$, and the Dominican Republic with about $5 \mathrm{mmt}$. Total palm oil production by the CBI nations is less than $0.7 \mathrm{mmt}$. This study estimates baseline cumulative production of sugarcane by the CBI countries to be over $80 \mathrm{mmt}$ from about 850 thousand ha in 2017, while palm oil production is projected at about $1.3 \mathrm{mmt}$ in the same year.

Ethanol production and processing in the CBI region occurs on a significant scale but biodiesel production is less common. Costa Rica, El Salvador, and Guatemala are the best suited for expansion of biofuel industries due to their current production capabilities, strong organization of agro-industry and finance sectors and governmental capacities. However, Honduras, Nicaragua, and Panama also have potential for growth based on their climate, existing sugarcane industry, and incentives due to dependence on foreign oil.

Cellulosic feedstock estimates from the production of sugarcane and palm oil is over $10 \mathrm{mmt}$ in 2017 under the baseline case.

\section{$\underline{\text { CBI Figures }}$}

1-3: Baseline Sugarcane Supply Curves

4: Sugarcane Historic Trend and Projections

5-7: Baseline Palm Oil Supply Curves

8: Palm Oil Historic Trend and Projections

\section{CBI Tables (See Annex 4)}

1-3: Sugarcane Supply Potential for Baseline, High and Low Growth Cases

4-6: Palm Oil Supply Potential for Baseline, High and Low Growth Cases

7: Potential Percentage Allocation for Export \& Biofuels

8: Estimated Cellulosic Supply from Recoverable Bagasse and Palm Residues

9: Estimated Cellulosic Supply Including Other Residues

\subsubsection{Context}

CBI member countries benefit from a duty free quota for export of ethanol to the U.S. of up to $7 \%$ of U.S. ethanol consumption. In 2005, that represented about 910 million liters although the quota level was not nearly attained. ${ }^{\text {ccxlvi }}$ Several groups have formed to promote the use and development of biofuel in the CBI. For example, the Mesoamerican Biofuels Group (comprised of Mexico, Guatemala, Belize, El Salvador, Honduras, Nicaragua, Costa Rica, Panama, the Dominican Republic, and Colombia) has developed action plans to introduce biofuel into the region. ${ }^{\text {ccxlvii }}$ The Energy and Environment Partnership with Central America seeks to develop accessible energy services for marginalized groups in rural areas to promote the sustainable use of renewable energy source and clean technologies. The Caribbean Community and Common Market, in conjunction with the Caribbean Development Bank and the InterAmerican Development Bank, promote biofuel development in the Caribbean via a technical cooperation program. 
Most of the CBI region's transportation sector relies on imported fuel. Furthermore, sugarcane and palm oil have been important for CBI economies for centuries. Therefore, government and private industry are interested in considering options to facilitate a large-scale increase in biofuel production using CBI's sugarcane and palm oil feedstocks.

\subsubsection{Definitions, Methodology, and Assumptions}

Background, definitions, and descriptions of the general approach used to estimate feedstock supplies are provided in the Introduction. For the CBI study, out of a total of 24 Caribbean Basin Initiative nations, the top-producing nations were analyzed and treated as if they were different states within a single country using the general methodology described in the Introduction. In the case of sugarcane, the top seven producers plus "others" are analyzed for a total of eight production units. ${ }^{\text {ccxlviii }}$ For palm oil, the top four plus "others" are analyzed.

Because some CBI nations only recently have begun significant feedstock production, when the historic growth rates described in the methodology were applied, some of the plausible limits also came into effect (see Methodology).

\subsubsection{Units, Conversion Factors, and Calculations}

Supply is stated in harvested millions of metric tonnes (mmt) unless noted otherwise. Land is measured in hectares (ha), and yield in metric tonnes per hectare (mt/ha). Prices are in 2005 US Dollars, based on reported prices from the FAO.

\subsubsection{Sugarcane Supply Potential — Analysis and Projections: 2012, 2017, 2027}

Total sugarcane production in the CBI region from the 2005 season was about $55 \mathrm{mmt}$, harvested from approximately 750,000 ha. ${ }^{\text {ccxlix }}$ The potential future production is projected in this study for 2012, 2017, and 2027, with estimated supply in the baseline case reaching approximately 69, 80, and $102 \mathrm{mmt}$, respectively. Additionally, low and high growth cases are estimated to illustrate a range of potential supply based on past trends and fluctuations in production in CBI nations. For 2017, the estimated total supply ranges from $60 \mathrm{mmt}$ (low growth case) to $109 \mathrm{mmt}$ (high growth case) from harvests on about 770,000 to 970,000 ha, respectively. The baseline case (CBI Table 1) projects a total cumulative production in 2017 of $80 \mathrm{mmt}$ from 850,000 harvested hectares.

CBI Figures 1-3 illustrate estimated sugarcane supplies available at different average prices for the three time periods in the baseline case. The majority of CBI production falls within a competitive $\$ 13-23 / \mathrm{mt}$ value range. Smaller producers reported higher costs $(\$ 25-\$ 40 / \mathrm{mt})$. CBI Tables 1-3 (Annex 4) provide the corresponding value and supply data for baseline, low and high growth cases. As a point of reference, CBI Figure 4 illustrates the historic sugarcane production trend for CBI nations along with the maximum cumulative potential production estimated under the three different cases of this study.

Future growth in CBI production levels is expected to be driven by increasing yields across the region and by increasing areas planted in sugarcane, primarily in Nicaragua and Guatemala. These two countries have few limits to growth compared to other nations in the region, according to a recent diagnostic looking at biofuel production potential. ${ }^{\mathrm{cl}}$ The expanding area dedicated to sugarcane is expected to displace abandoned and underutilized pasturelands. ${ }^{\text {cli }}$ Yields are projected to continue to increase at historic rates - approximately $2.3 \%$ /year on average across the region. These anticipated increases are due to investments intended to (a) improve varieties, technology, cultivation and harvesting practices, and (b) extend the seasons for harvesting and processing. These changes will allow mills to run longer during 

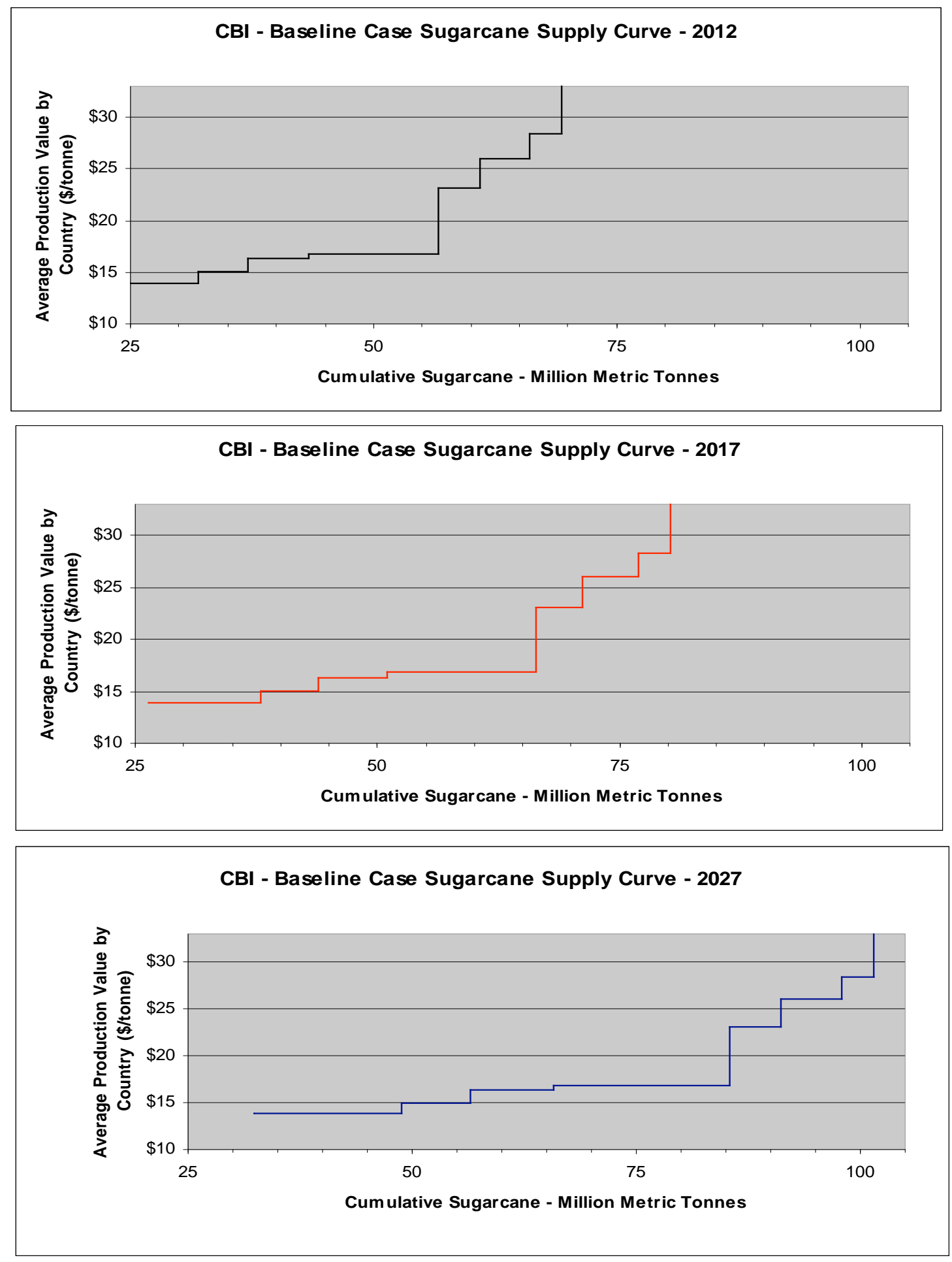

CBI Figures 1-3. Baseline Sugarcane Supply Curves. 


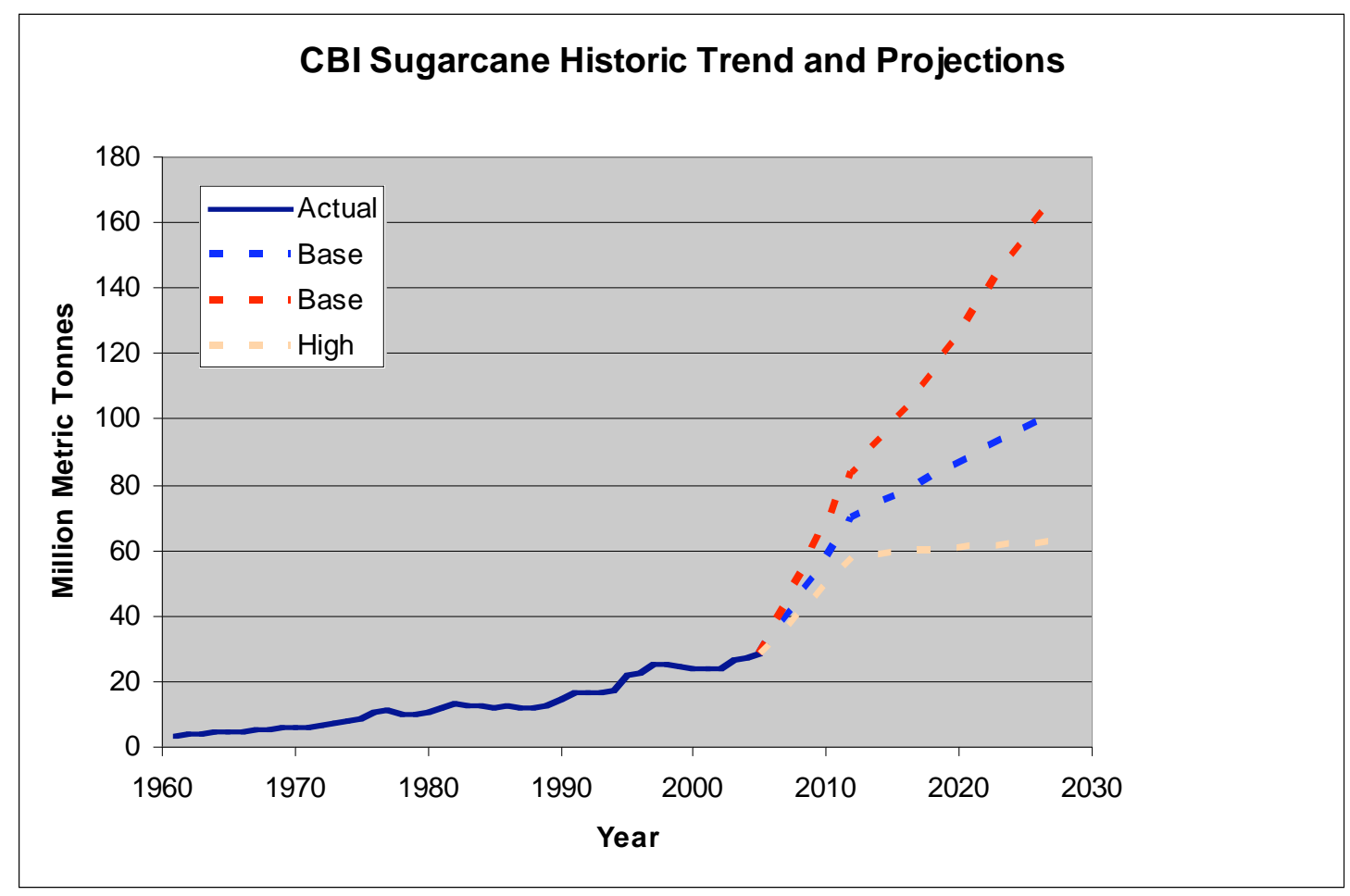

CBI Figure 4. Sugarcane Historic Trend and Projections.

each season. ${ }^{\text {cclii }}$ Such high growth is not anticipated in other traditional producing nations such as El Salvador, Costa Rica, and the Dominican Republic. In these countries, the limited amount of appropriate land, soils, and water combine with relatively high land costs to impose constraints on expanding the area under production.

\subsubsection{Biofuel Use and Competing Demands}

The CBI countries collectively consume a little less than half of the sugar produced from their sugarcane harvests. Applying the standard methodology, it is estimated that $54 \%$ of sugarcane production in the baseline case would be available for export and/or biofuel. The percentage available varies from $25-44 \%$ in the low growth case and 60-72\% in the high growth case, depending on the year.

\subsubsection{Notes on Adaptation of Standard Methodology}

Reviewing available information for CBI nations makes clear that the time-series data used in the standard methodology (1961-2005) fail to reflect recent trends in two CBI nations, Costa Rica and Nicaragua. In these two cases, the standard approach projects minimal or zero growth. That trend contrasts with more recent reports on the sugarcane industry in these two countries showing significant

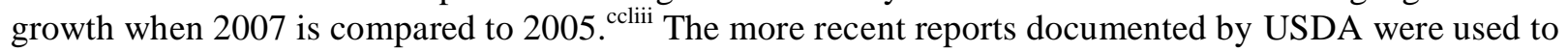
adjust projected rates for growth in Costa Rica's yields and area from zero to $2 \%$ and $0.5 \%$ per annum, respectively. Similarly, the projected rate for growth in area harvested in Nicaragua was adjusted from zero to $2 \%$ per year. 


\subsubsection{Palm Oil Supply Curves - Analysis and Projections: 2012, 2017, 2027}

Palm oil is obtained from the fruit of the African Oil Palm, Elaeis guineensis and is widely traded as edible oil. With rising fuel prices, it has increasingly been used as feedstock for biodiesel production. About 40 million metric tons of palm oil were produced worldwide in 2006 with over $80 \%$ of global production is from two nations, Malaysia and Indonesia. ${ }^{\text {cliv }}$

Under the baseline case of this study, potential CBI production in 2012, 2017, and 2027 is estimated to reach $0.9 \mathrm{mmt}, 1.3 \mathrm{mmt}$, and $1.9 \mathrm{mmt}$, respectively. Low and high growth cases were estimated to illustrate a range of potential supply based on past trends and fluctuations in CBI nations (CBI Tables 5 and 6). For 2017, the estimated total supply ranges from $0.8 \mathrm{mmt}$ (low growth case) to $2 \mathrm{mmt}$ (high growth case). The baseline case (CBI Table 4) projects a total cumulative production in 2017 of $1.3 \mathrm{mmt}$ from 228,000 harvested hectares.

Palm oil plantations and production are expanding rapidly, especially in Honduras and Guatemala. Nicaragua is expected to join in this trend soon. In 1999, CBI nations produced 270,000 metric tonnes of palm oil, increasing to $450,000 \mathrm{mt}$ by 2005 . Honduras, alone, increased production from 90,000 to 175,000 tonnes during this period. ${ }^{\text {cclv }}$ Recent reports indicate that Guatemala expanded its palm oil plantation area by more than $100 \%$ between 2005 and 2007, from about 20,000 ha to 55,000, with plans to reach 100,000 ha by $2017 .^{\text {cclvi }}$

CBI Figures 5-7 illustrate estimated palm oil supplies available at different average prices for the three time periods in the baseline case. CBI Tables 4-6 provide the corresponding value and supply data for baseline, low and high growth cases. As a point of reference, CBI Figure 8 illustrates the historic palm oil production trend for $\mathrm{CBI}$ nations along with the maximum cumulative potential production estimated under the three different cases of this study.

Future growth in CBI production levels is expected to be driven by increased areas planted for palm oil production, primarily in Honduras and Guatemala. These countries are characterized by relatively fewer limits to growth, according to a recent regional diagnostic looking at biofuel production potential. ${ }^{\text {cclvii }}$ Similar to sugarcane, the expanding area is expected to displace abandoned and underutilized pasturelands. ${ }^{\text {cclviii }}$ Present expansions are motivated by domestic policies and markets. If international prices remain high, many CBI producers appear eager to continue expanding production to permit export to the US and other nations in the Americas.

Given the proximity to markets and access under trade agreements, CBI feedstocks likely will remain competitive as sources for biofuel production and export to the U.S.

\subsubsection{Biofuel Use and Competing Demands}

Similar to sugar production, about half of the palm oil produced in the CBI region currently ends up in the export market. However, imports account for about a quarter of consumption. This study estimates that about half of the palm oil produced in the CBI region would be available for export and/or biofuel production under the baseline case. This figure increases under the high growth case to $62-76 \%$ depending on the year. See Annex 4, CBI Table 7.

\subsubsection{Notes on Adaptation of Standard Methodology}

Reviewing available information for the CBI region makes clear that the time-series data used in the standard methodology (1961-2005) fail to reflect recent trends in palm oil production for most CBI 

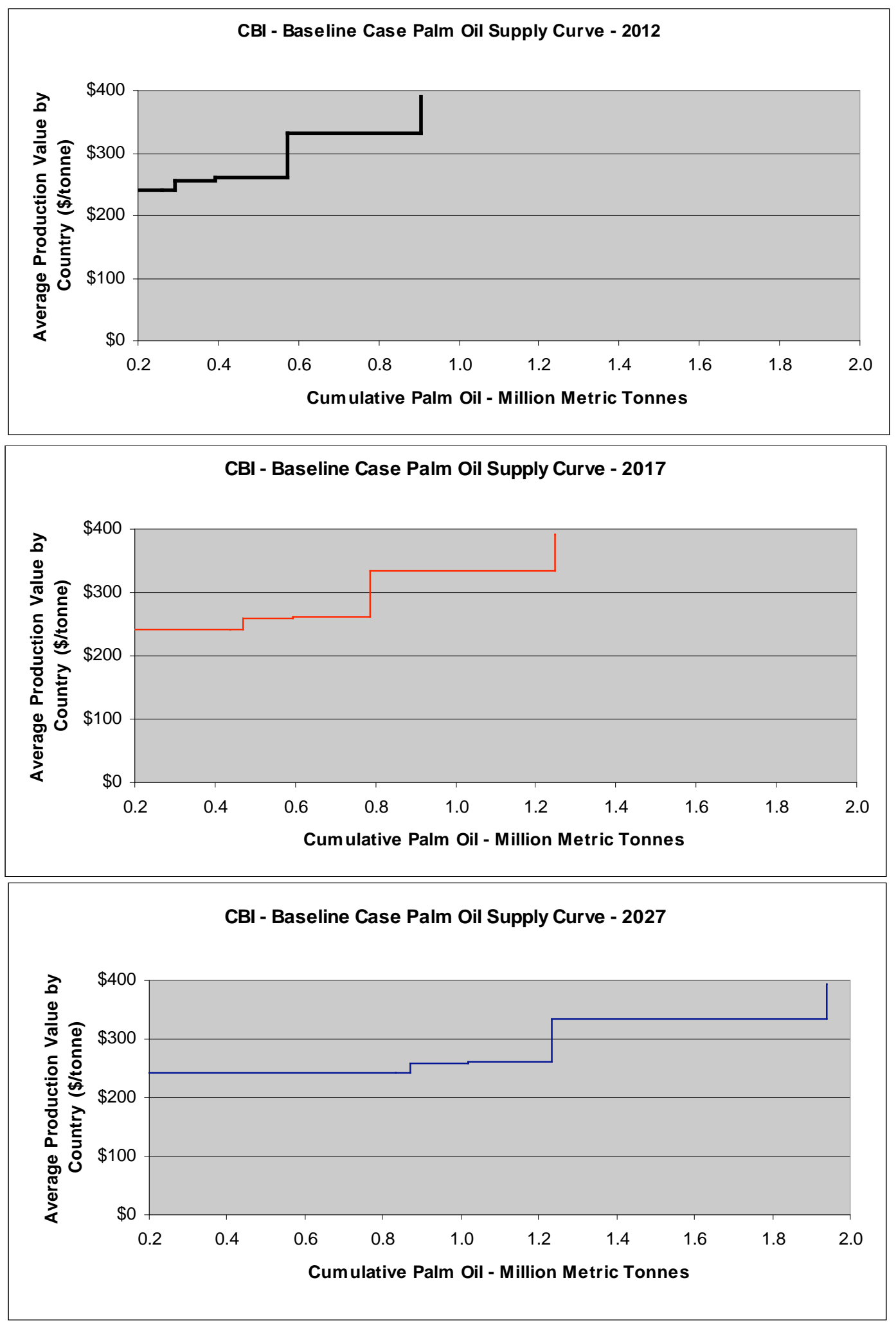

CBI Figures 5-7. Baseline Palm Oil Supply Curves. 


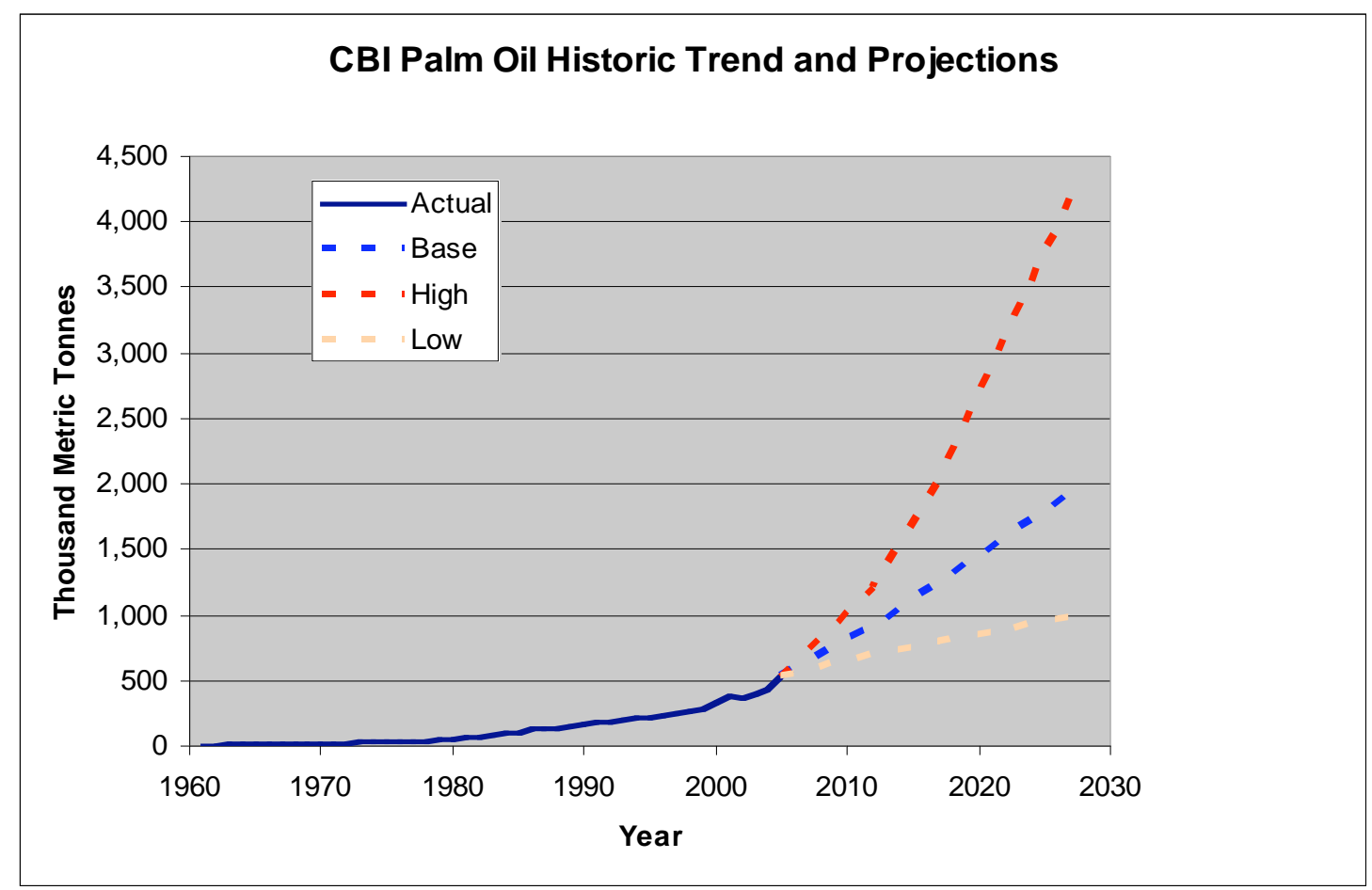

\section{CBI Figure 8. Palm Oil Historic Trend and Projections. (Note that units are thousands of metric tonnes).}

nations. The standard approach projects minimal or zero growth for many countries where recent data (discussed above) indicate strong growth over the past two years. Therefore, projected rates for growth in yields and area for Guatemala, Honduras, and "others" were adjusted from at or near zero to rates that conservatively reflect more recent trends and plans underway. This adjustment allows for more realistic growth rates that remain within the "plausible limit" caps established by the standard methodology. ${ }^{\text {clix }}$

\subsubsection{Other Feedstocks}

\subsubsection{Cellulosic Supply}

Given the small territories of most countries in the CBI region, cellulosic supply estimates are small compared to other nations in this study. Residues from sugarcane and palm oil production are estimated to offer about $10 \mathrm{mmt}$ (dry) of cellulosic feedstock in 2017 under the baseline case. This increases to about $14 \mathrm{mmt}$ in the high growth case. See CBI Table 8.

Forest sector products and residues could add another 8-9 mmt (dry) regionally. This is primarily based on potential supply estimates from $50 \%$ of current fuelwood consumption. There is a great deal of uncertainty in these data and since the estimates involve diverse production across 24 small nation states, the scale of production may not be economical in many areas. And unless economical alternatives are available for cooking, fuel wood supplies will most likely continue to meet domestic needs. 


\subsubsection{Opportunities and Constraints}

\subsubsection{Ethanol}

Land is a primary constraint in the region. One study (CEPAL 2007) suggests that most growth in sugarcane and ethanol production in Central America over the next decade will come from expansion in Guatemala and Nicaragua where land is still available. Panama and Costa Rica also present growth potential, at slower rates and over longer terms. Costa Rica's expansion would occur in new states because traditional production areas have reached physical land limits. While limited land is available for expansion in Panama, it is in areas with less desirable climatic conditions and a shorter harvest season. El Salvador and Honduras are expected to have lower growth potential than the other countries due to such factors as land availability, land tenure, and other socio-economic conditions. ${ }^{\text {clx }}$

In 2007, Guyana was named an Inter-American Development Bank (IDB) grant recipient for developing and screening bioenergy proposals. Thus, Guyana has the opportunity to become a regional pioneer in biofuel. The country plans to establish and support a Caribbean Renewable Energy, Energy Efficiency and Bioenergy Action Program.

Frequent extreme weather conditions also create uncertainty and constraints on production in the region. Sugarcane production in any given year may be limited by hurricanes or tropical storms such as occurred in 2006 in Guatemala, when production declined by $4 \%$ as compared to 2005 .

\subsubsection{Biodiesel}

Honduras has the largest palm oil plantations in Central America. Many plantations are located along the country's coastal plains, covering about 68,000 ha. Agricultural plantations on this plain are associated with adverse environmental impacts to the adjacent coral reef system (which forms part of the largest coral reef system in the Americas and the second largest in the world). Improved environmental management is being promoted to address these concerns. For example, a June 2007 memorandum of understanding between the World Wildlife Fund and palm oil producer groups in Honduras specifies improved agricultural management practices to protect the coral reef system. These practices include proper disposal of agro-chemical containers; increasing plant cover to avoid soil erosion; reducing use of herbicides and fertilizers, especially nitrogen; etc. The region produces about a third of Honduras's palm oil, which currently is used for preparation of food products but there are plans to produce palm oil biodiesel in the future.

Large-scale planting of biodiesel crops such as oil palm may contribute to deforestation. This is one of the primary environmental concerns in the region associated with the industry.

Because of high costs for biodiesel refineries and the low production levels in many CBI countries, it may not be practical for individual countries to establish their own biodiesel refining industry. Also, the healthy development of domestic markets for biofuel is an important opportunity (and lack thereof a constraint). Some vehicles in El Salvador already run on biodiesel.

\subsubsection{Others}

Some innovative biofuel options are being explored in the region. For example, a coupled landfill system involving gas-to-energy, aquaponic production of feedstock and desalination of water is being studied. ${ }^{\text {cclxi }}$ An algal culture may be used to assimilate $\mathrm{CO}_{2}$ from the turbine exhaust into biomass, which then may be used as biofuel, thus making the system largely self-contained. By recycling energy and materials, the 
system could displace fossil fuel use, mitigate negative environmental impacts such as greenhouse gas emissions, and generate less waste in need of disposal.

Land use and management affects pests, and pest management or eradication efforts. For example, having land under sugar production (such as occurs on St. Kitts) rather than allowing feral or free ranging cattle has helped to eradicate the tropical bot tick (TBT), Amblyomma variegatum. ${ }^{\text {clxii }}$

Some CBI countries already use a significant amount of renewable energy from biomass due to necessity. For example, Haiti creates $74 \%$ of its energy from renewables and waste (e.g., using firewood and plant based charcoal). 


\section{CBI Endnotes}

ccxlvi IDB (Inter-American Development Bank), 2007. A Blueprint for Green Energy Development in the Americas by Garten Rothkoph, http://www.iadb.org/biofuels/.

Also see USDA GT7012 2007 (below) which explains that the quota is equal to 7\% of U.S. ethanol consumption and as consumption goes up, the quota increases. As of 2006, the region had not surpassed $50 \%$ of the available quota. Data about current and potential biofuel feedstock production in this analysis are drawn in part from USDA Foreign Agricultural Service (FAS) Global Agriculture Information Network (GAIN) reports that are accessible at: http://www.fas.usda.gov/scriptsw/AttacheRep/default.asp. As a GAIN fact sheet states, "Production, Supply, and Distribution (PSD) data contained in GAIN reports are NOT official USDA data, but represent estimates made by FAS Attachés." See http://www.fas.usda.gov/info/factsheets/reports.asp. The following GAIN reports (hereafter, cited by their report numbers) were used to collect information about the CBI region:

USDA GAIN CS7005 Costa Rica Sugar Annual 2007

USDA GAIN DR7008 Dominican Republic Sugar Annual 2007

USDA GAIN GT6002 Guatemala Oilseeds and Products Annual 2006

USDA GAIN GT7006 Guatemala Sugar Annual 2007

USDA GAIN GT7012 Guatemala Bio-Fuels Annual, 2007

ccxlvii IDB 2007

USDA GAIN NU7005 Nicaragua Sugar Annual Report, 2007

ccxlviii The methodology is described in the Introduction. Out of 24 CBI nations, the top seven producing states represent $87 \%$ of total reported CBI sugarcane production (see below). These countries, in order of importance, are Guatemala, Honduras, Nicaragua, Dominican Republic, Costa Rica, El Salvador, and Guyana. The CBI supply curve applies the same standard methodology as described in the Introduction except that it treats each of these seven nations as a state, creating a step in the supply curve based on the information obtained on costs, yields, area growth, and production trends for each. An eighth step on the supply curve represents "other" CBI nations aggregated as a single step. These 17 countries represent only $13 \%$ of total reported past production and very limited data were available for historic prices and production in those smaller states. An average value from states with data was applied to represent the "other" group's costs and projected growth in the supply analysis.

\begin{tabular}{|l|c|c|}
\hline CBI Nations & $\begin{array}{c}\text { 2005 Sugarcane } \\
\text { Production MMT }\end{array}$ & $\begin{array}{c}\text { \% of } \\
\text { total }\end{array}$ \\
\hline Guatemala & 19.07 & 37 \\
Honduras & 5.63 & 11 \\
Dominican Republic & 4.95 & 10 \\
El Salvador & 4.40 & 9 \\
Nicarauga & 3.82 & 7 \\
Costa Rica & 3.62 & 7 \\
Guyana & 3.02 & 6 \\
Others & 6.82 & 13 \\
\hline Total & 51.32 & 100 \\
\hline
\end{tabular}

${ }^{\text {ccxlix }}$ FAOStat Production data (accessed June, 2007).

${ }^{\mathrm{ccl}}$ CEPAL 2007.

ccli Ibid.

cclii Ibid.

${ }^{\text {ccliii }}$ USDA GAIN Annual Sugar Reports referenced above: CS7005 and NU7005.

${ }^{\text {ccliv }}$ FAO 2007 and USDA 2007a.

${ }^{c c l v}$ Enrique Arriola, General manager Palmas del Ixcan, personal communication with K.Kline on July 24, 2007.

cclvi Ibid. Enrique Arriola in personal communication with K.Kline on July 24, 2007.

cclvii CEPAL 2007

cclviii Ibid.

${ }^{\text {cclix }}$ See Chapter 1 for Methodology. Regarding recent growth, source is Enrique Arriola, personal communication with K.Kline 7/24/07. For example, Guatemala plans to have 100,000 ha planted by 2017 . The growth rate in the 
model was adjusted up from the standard methodology level (of zero) to allow area planted to reach 100,000 by 2027.

${ }^{\text {cclx }}$ CEPAL 2007

cclxi Janes, H., J. Cavazzoni, G. Alagappan, D. Specca, and J. Willis, 2005.

${ }^{\text {cclxii }}$ Pegram, R., L. Indar, C. Eddi, and J. George, 2004. 


\section{BIBLIOGRAPHY - REFERENCES}

AAC (Agriculture and Agrifood Canada) http://www.agr.gc.ca/ main page. Accessed 7/2007.

Alfstad, T., 2007. "World Biofuels Study: Scenario analysis of global biofuels markets." Brookhaven National Laboratory; draft document under review in December, 2007; to be released in 2008.

AgraFNP, 2007. Sugar and Ethanol in Brazil: A Study of the Brazilian Sugarcane, Sugar and Ethanol Industries. Agra Informa Ltd, São Paulo, Brazil.

Alberta Agriculture and Food, 2005. Alberta Agriculture Statistics Yearbook, 2005. Accessed 7/2007, from http://www1.agric.gov.ab.ca/\$department/deptdocs.nsf/all/sdd10995.

Alho, C. J. R. and L. M. Vieira, 1997. Fish and wildlife resources in the Pantanal wetlands of Brazil and potential disturbances from the release of environmental contaminants. Environmental Toxicology and Chemistry 16 (1): 71-74.

Anuario estadístico del sector agropecuario - Ministerio de Agricultura, Información agrícola (Statistics annual for agriculture-livestock sector - Ministry of Agriculture, agricultural information). Accessed 7/2007, from http://www.dnp.gov.co/paginas_detalle.aspx?idp=88.

Argentine Secretary of Agriculture (SAGPyA) accessed May, 2007 at: http://www.sagpya.mecon.gov.ar/new/0-0/agricultura/otros/estimaciones/basestima.php

Arrieta, F.R.P., F. Teixeira, E. Yanez, et.al. "Cogeneration potential in the Columbian palm oil industry: Three case studies. Biomass and Bioenergy, Vol:31, Issue7; July 2007. Pages 503-511.

Avendano 2007. Colombia's Palm Oil Biodiesel Push, by Tatiana Roa Avendaño. Article published Feb. 2, 2007 on www.biodiversidadla.org and accessed in July 2007 at http://americas.irconline.org/am/3962

Berg, C., 2006. (F.O. Licht). "World Fuel Ethanol — Analysis and Outlook (prepared for METI)." Accessed 4/27/2007, from http://www.meti.go.jp/report/downloadfiles/g30819b40j.pdf.

Bradley, D. 2006. European Market Study for BioOil (Pyrolysis Oil). Prepared by Doug Bradley, CCS (Climate Change Solutions), December 15, 2006.

Brumley, S. M., M. P. Purnell, L. A. Petrasovits, L. K. Nielsen, and P. H. Twine, 2007. Developing the sugarcane biofactory for high-value biomaterials. International Sugar Journal 109 (1297).

Canadian Grain Commission, 2005-2006. Canadian Grain Exports, Crop Year 2005-2006. Accessed 7/2007, from http://www.grainscanada.gc.ca/pubs/exportsyearly/annual/exports05-06-e.pdf.

CAIS (Canadian Agricultural Income Stabilization), 2005. Canadian Agricultural Income Stabilization (CAIS) Program, December 2005, Accessed 7/2007, from http://www.agr.gc.ca/caisprogram/docs/pdf/2005/cais05ncyepl12.pdf.

Canola Council of Canada webpage accessed June, 2007 at: http://www.canolacouncil.org/watercomparison.aspx 
Cardille, J. A. and J. A. Foley, 2003. Agricultural land-use change in Brazilian Amazonia between 1980 and 1995: Evidence from integrated satellite and census data. Remote Sensing of Environment 87 (4): 551-562.

CEC, 1999. "Maize in Mexico: Some environmental implications of the North American Free Trade Agreement," Assessing Environmental Effects of the North American Free Trade Agreement (NAFTA): An Analytic Framework (Phase II) and Issue Studies. Environment and Trade Series \#6 - Issue Study 1 (A. Nadal et.al.). Report edited and compiled by the Secretariat of the Commission for Environmental Cooperation (CEC), Montreal, Canada; March, 1999. Accessed May, 2007 from: http://www.cec.org/files/PDF/ECONOMY/engmaize_EN.pdf

CEC (California Energy Commission), 2003. Appendix 3, Att. C: Ethanol Demand and Supply Analysis. Reducing California's Petroleum Dependence. Sacramento, California Energy Commission.

CEPAL 2007 (ECLAC-Economic Commission for Latin America and the Caribbean). Diagnóstico preliminar de los aspectos agrícolas para producción local de etanol, a base de caña de azúcar en América Central (Preliminary study of agricultural issues for the local production of ethanol from sugarcane in Central America). Unpublished consultant report by J. E. L. Fortuny. Accessed 6/07: http://www.eclac.org/cgibin/getProd.asp?xml=/publicaciones/xml/9/28019/P28019.xml\&xsl=/mexico/tpl/p9f.xsl\&base=/m exico/tpl/top-bottom.xslt

Colombia National Department of Planning (DNP) webpage accessed June, 2007: www.dnp.gov.co/

Colombia Ministry of Agriculture and Rural Development "Observatorio AgroCadenas, Ministerio de Agricultura y Desarrollo Rural" accessed at: http://www.dnp.gov.co/paginas_detalle.aspx?idp=88 and http://www.agrocadenas.gov.co/oleaginosas/Documentos/caracterizacion oleaginosas.pdf.

CRS (Congressional Research Service), 2007. Congressional Research Service Reports for Congress, Ethanol Imports and the Caribbean Basin Initiative, Brent Yacobucci. Updated April 24, 2007. http://www.ncseonline.org/NLE/CRSreports/07May/RS21930.pdf Accessed 10/07.

Dale, V. H., R. V. O'Neill, M. A. Pedlowski, F. Southworth, 1993. Causes and effects of land-use change in central Rondônia, Brazil. Photogrammetric Engineering \& Remote Sensing 59:997-1005.

de Oliverio, J. L. and J. E. Ribeiro, 2006. Cogeneration in Brazilian sugar and bioethanol mills: Past, present and challenges. International Sugar Journal 108 (1291): 391-+.

Downey A., 2007. "Amazon Harvest - Can European Pressure Stop the Creep of Soy Fields into Brazil's Rainforests?" in The Nature Conservancy Magazine, Autumn 2007. Accessed 7/2007, from http://www.nature.org/magazine/autumn2007/features/art21918.html.

ESMAP (Energy Sector Management Assistance Programme), 2005. Potential for Biofuels for Transport in Developing Countries. Washington: The World Bank Group.

Fearnside, P. M., 2007. Brazil's Cuiaba-Santarem (BR-163) Highway: The environmental cost of paving a soybean corridor through the Amazon. Environmental Management 39 (5): 601-614.

FAO, 2007. United Nations Food and Agricultural Organization. Statistical Data online: http://faostat.fao.org/default.aspx. Accessed periodically from April-Oct/2007. 
FAO (Food and Agricultural Organization), 2005. Forest Resource Assessment 2005. Accessed Aug/2007 at: http://www.fao.org/docrep/008/a0400e/a0400e00.htm

FAO, 2002. FAO World Agriculture: towards 2015/2030 Summary Report. FAO Corporate Document Repository (online) Accessed 7/07 at: http://www.fao.org/docrep/004/y3557e/y3557e08.htm\#m.

FAO, 2000. World Soil Resources Report, "LAND RESOURCE POTENTIAL AND CONSTRAINTS AT REGIONAL AND COUNTRY LEVELS.” Food and Agricultural Organization reports accessed July/2007 at: ftp://ftp.fao.org/agl/agl1/docs/wsr.pdf

FAPRI (Food and Agricultural Policy Research Institute), 2007. The Agricultural Outlook 2007: World Biofuels, Iowa State University. Accessed 7/2007, from http://www.fapri.org/outlook2007/.

FBDS [Brazilian Foundation for Sustainable Development] and CI [Conservation International] 2007. "Agro-Energy Expansion and its Impact on Brazilian Natural Ecosystems Workshop" March 2627, 2007. In press. Rio de Janeiro, Brazil — Fundação Brasileira para Desenvolvimento Sustentável [Brazilian Foundation for Sustainable Development] (FBDS) and Conservation International (CI). Accessed 7/2007, from http://www.fbds.org.br/Apresentacoes/Constatacoes Recom ingl.pdf, http://www.conservacao.org/publicacoes/workshop_agronegocios.php.

GBC (GLOBAL BIOFUELS CENTER), 2007. FLASH REPORT - CHINA: AGRICULTURAL BIOFUEL INDUSTRY PLAN RELEASED, REPORT \#175, JULY 12, 2007

GTZ (German Technical Corporation), 2006. Liquid Biofuels for Transportation: Chinese Potential and Implications for Sustainable Agriculture and Energy in the $21^{\text {st }}$ Century. Bry Wang Gehua et.al., Tsinghua University, Bejiing, China. February, 2006.

GTZ, 2005. Liquid Biofuels for Transportation: India Country Study on Potential and Implications for Sustainable Agriculture and Energy. The Energy and Resources Institute (TERI), New Delhi, India, 2005.

IBGE (Brazilian Institute of Geography and Statistics). Historic production data including: Tabela 2.9 Áreas plantada e colhida, quantidade produzida, rendimento médio e valor da produção de Canade-açúcar, segundo as Unidades da Federação produtoras Brasil - 2005; Tabela 8.9 - Quantidade produzida (t) de Cana-de-açúcar, segundo as Grandes Regiões e Unidades da Federação produtoras Brasil - 2001-2005; Accessed June, 2007. http://www.ibge.gov.br/servidor arquivos est/ and http://www.ibge.gov.br/english/estatistica/indicadores/agropecuaria/lspa/default.shtm

IEA (International Energy Agency), 2004. Biofuels for Transport - an International Perspective. IEA: Paris.

IEA-ETSAP (Energy Technology Systems Analysis Programme) website. Accessed June, 2007 at: http://www.etsap.org/index.asp.

IDB (Inter-American Development Bank), 2007. A Blueprint for Green Energy Development in the Americas by Garten Rothkoph. Accessed 7/2007, from http://www.iadb.org/biofuels/.

IFPRI (2006). Bioenergy and Agriculture: Promises and Challenges. 2020 Vision. P. Hazell, R.Pachauri. Washington, D.C., International Food Policy Research Institute, The Energy and Resources Institute, FAO-CGIAR. 
IICA (Inter-American Institute for Cooperation on Agriculture), Territorios Rurales. Accessed 7/2007, from http://www.territoriosrurales.org.co/.

India Ministry of Agriculture "Crop Production Statistics.” Accessed 7/2007, from http://dacnet.nic.in/apy/crop_fryr_toyr.aspx / and http://agricoop.nic.in/Agristatistics.htm.

Janes, H., J. Cavazzoni, G. Alagappan, D. Specca, and J. Willis, 2005. Landfill gas to energy: A demonstration controlled environment agriculture system. Hortscience 40(2): 297-282.

Jank, M.S. 2007. Potential Supply and Demand for Biofuels in the Coming Decade: Towards a U.S.Brazil Partnership, a presentation to the Woodrow Wilson International Center for Scholars' Seminar on "Global Dynamics of Biofuels," February 20, 2007. Washington, D.C. Prepared by Jank and L. Amaral, for the Institue of International Trade Negotiations (ICONE), Brazil

Kahn, J. R. and J. A. McDonald, 1997. The role of economic factors in tropical deforestation. In Laurance WF and Bierregaard (editors), Tropical Forest Remnants. Chicago: University of Chicago Press, pp. 13-28.

Lamers P. 2006. Emerging liquid biofuel markets: A donde va la Argentina? Masters Thesis, Lund Sweden.

Licht, F. O., 2007. World Ethanol \& Biofuels Report-May 8, 2007. C. Berg. United Kingdom Agra Informa, Ltd.: 32 .

Macedo, I.(organizer), 2007. Theme 9, Ethanol Producers' Experience, based on the book "Sugar Cane's Energy" (UNICA 2005). Workshop presentation made by Laura Tetti in "Agro-energy Expansion and its Impact on Brazilian Natural Ecosystems Workshop" (see FBDS and CI above). See http://www.fbds.org.br/Apresentacoes/12_Cana_de_Acucar_I_Maceo_Ingles.pdf Accessed 7/07.

Mertens, B., R. Poccard-Chapuis, M. G. Piketty, A. E. Lacques, and A. Venturieri, 2002. Crossing spatial analyses and livestock economics to understand deforestation processes in the Brazilian Amazon: the case of Sao Felix do Xingu in South Para. Agricultural Economics 27 (3): 269-294.

Mexico Information Service on Agriculture and Fishing (SIAP). Accessed May, 2007 at: http://www.siap.gob.mx/aagricola_siap/icultivo/index.jsp.

NEPO, 2000. "Thailand Biomass-Based Power Generation and Cogeneration within Small Rural Industries" prepared by the National Energy Policy Office (NEPO) of Thailand NEPO and Black \& Veatch; November, 2000. Accessed June/07 from: http://www.nepo.go.th/encon/index.html

NAS, 2003. Frontiers in agricultural research: food, health, environment and communities: National Academies of Sciences, Washington, D.C. Report brief accessed at: http://books.nap.edu/html/agricultural_research/reportbrief.pdf

NAS, 2007. Water Implications of Biofuels Production in the United States. National Academies of Sciences, Washington, D.C. Report brief accessed at: http://dels.nas.edu/dels/rpt_briefs/biofuels_brief_final.pdf

Natural Resources Canada, 2003. Resource Assessment, Bioenergy. Accessed 7/2007, from http://www.canren.gc.ca/resou asse/index.asp?CaId=53\&PgId=57. 
OECD, 2007. Biofuels: Is the Cure Worse than the Disease? SG/DR/RT(2007)3, prepared by Richard Doornbosch and Ronald Steenblik for the Roundtable on Sustainable Development, Paris, September, 2007.

OECD-FAO (Organisation for Economic Co-operation and Development, Food and Agriculture Organization of the United Nations), 2007. OECD-FAO Agricultural Outlook, 2007-2016.

Ontario Ministry of Agriculture, Food and Rural Affairs, Field Crop Statistics. Accessed 7/2007, from http://www.omafra.gov.on.ca/english/stats/crops/index.html.

Pegram, R., L. Indar, C. Eddi, and J. George, 2004. The Caribbean Amblyomma program — Some ecologic factors affecting its success. Impact of Ecological Changes on Tropical Animal Health and Disease Control Annals of the New York Academy of Sciences, 1026: 302-311.

Perlack, R. D., L. L. Wright, R. L. Graham, A. Turhollow, B. Stokes, and D. Erbach, 2005. Biomass as Feedstock for a Bioenergy and Bioproducts Industry: The Technical Feasibility of a Billion-Ton Annual Supply. ORNL/TM-2005/66, DOE/GO-102005-2135. April 2005.

Pessoas-Jr, A., I. C. Roberto, M. Menossi, R. R. Dos Santos, S. Ortega, and T. C. V. Penna, 2005. Perspectives on bioenergy and biotechnology in Brazil. Applied Biochemistry and Biotechnology 121: 59-70.

Peterson, H. G., 1999. Field Irrigation and Water Quality. Agriculture and Agri-Food Canada — Prairie Farm Rehabilitation Administration. Accessed 7/2007, from http://www.agr.gc.ca/pfra/water/fieldirr_e.htm.

Prince Edward Island, Canada, 2005. Provincial Government web page, Prince Edward Island Guidelines for 2005 End of Year Fair Market Value. Accessed 7/2007, from http://www.gov.pe.ca/photos/original/af_cais_graifor.pdf.

Puppim, J. A. and J. A. P. de Oliveira, 2002. The policymaking process for creating competitive assets for the use of biomass energy: the Brazilian alcohol programme. Renewable \& Sustainable Energy Reviews 6 (1-2): 129-140.

Ramos, L. P. and H. M. Wilheim, 2005. Current status of biodiesel development in Brazil. Applied Biochemistry and Biotechnology 121: 807-819.

RFA (Renewable Fuels Association), 2007. Ethanol Industry Outlook 2007: Building New Horizons. RFA Outlook. Washington, D.C., Renewable Fuels Association: 26.

Rodrigues, D. and L. Ortiz, 2006. "Sustainability of ethanol from Brazil in the context of demanded biofuels imports by The Netherlands," Sao Paulo, Brazil. October 2006.

Rodrigues, D. and L. Ortiz, 2007. Case study sugar cane ethanol from Brazil: Sustainability of ethanol from Brazil in the context of demanded biofuels imports by The Netherlands, Instituto Ekos Brasil.

RSB (Roundtable on Sustainable Biofuels). Accessed 7/2007, from http://www.bioenergywiki.net/index.php/Roundtable on_Sustainable Biofuels.

Roundtable on Responsible Soy. Accessed 7/2007, from http://www.responsiblesoy.org/eng/index.htm. 
Rupilius, W. and S. Ahmad, 2007. "Palm oil and palm kernel oil as raw materials for basic oleochemicals and biodiesel." European journal of lipid science and technology: 2007 vol:109 iss:4 pg:433 -439

SAGPyA (Argentine Secretary of Agriculture). Accessed 7/2007, from http://www.sagpya.mecon.gov.ar/new/0-0/agricultura/otros/estimaciones/basestima.php.

Schmitz T.G., J. L. Seale Jr. and J. Peter, 2007. Brazil's Domination of the World Sugar Market, Faculty Working Paper Series, Morrison School of Agribusiness and Resource Management, Arizona State University 02-07.

Schnepf R. D., E. Dohlman, and C. Bolling, 2001. Agriculture in Brazil and Argentina: Developments and Prospects for Major Field Crops. USDA Agriculture and Trade Report WRS-01-3.

Simon, M. F. and F. L. Garagorry, 2005. The expansion of agriculture in the Brazilian Amazon. Environmental Conservation 32 (3): 203-212.

Smeets, E., A. Faaij, I. Lewandowski, 2005. The Impact of sustainability criteria on the costs and potentials of bioenergy production. Report NWS-E-2005-6. Utrecht, The Netherlands.

Smeets, E., A. Faaij, I. Lewandowski, 2004. A quickscan of global bio-energy potentials to 2050: An analysis of the regional availability of biomass resources for export in relation to the underlying factors. Report NWS-E-2004-109. Copernicus Institute, Utrecht University, The Netherlands.

Soccol, C. R., L. P. S. Vandenberghe, B. Costa, A. L. Woiciechowski, J. C. De Carvalho, A. B. P. Medeiros, A. M. Francisco, and L. J. Bonomi, 2005. Brazilian biofuel program: An overview. Journal of Scientific \& Industrial Research 64 (11): 897-904.

The Economist, 2007. "The end of cheap food." December 8, 2007 (pg. 11-12).

Tilman D, Reich PB, Knops J, et al., 2001. "Diversity and productivity in a long-term grassland experiment," in Science: 2001 vol:294 iss:5543 pg:843 -845.

Trostle, 2007. "Global Aspects of USDA's Baseline Projections for Biofuels" for the "Biofuels, Food and Feed Tradeoffs" conference, April 12-13, 2007. St. Louis, MO. Ron Trostle, United States Department of Agriculture, Economic Research Service (USDA/ERS).

UN-Energy, 2007. "Sustainable Bioenergy: A Framework for Decision-Makers," United Nations Energy consortium, April, 2007. New York.

UNEP, 2006. Colombia: Integrated assessment of agricultural trade liberalization: With a focus on the corn sector. United Nations Environment Programme (UNEP) report accessed July 2007 at: http://www.unep.ch/etb/areas/pdf/Colombia\%20ReportFINAL.pdf

USDA, 2007a. "Agricultural Baseline Projections: Global Agricultural Trade, 2007-2016." United States Department of Agriculture, Feb 2007: http://www.ers.usda.gov/Briefing/Baseline/trade.htm. Accessed April-July/2007.

USDA, 2007b. "An Analysis of the Effects of an Expansion in Biofuel Demand on U.S. Agriculture," United States Department of Agriculture, Economic Research Service and Office of the Chief Economist; May, 2007. 
USDA/ERS, 2004. China's Wheat Economy: Current Trends and Prospects for Imports. Prepared by Bryan Lohmar, USDA Economic Research Service (ERS), WHS-04D-01, May, 2004. Accessed 7/2007, from http://www.ers.usda.gov/publications/whs/may04/whs04D01/whs04D01.pdf.

USDA Foreign Agricultural Service (FAS) Global Agricultural Information Network (GAIN) reports. Accessed 7/2007 and 8/2007, from http://www.fas.usda.gov/info/factsheets/reports.asp):

USDA 2006 GAIN Report AR6010: Argentina Grain and Feed Annual

USDA 2006 GAIN Report AR6011: Argentina Sugar Annual

USDA 2006 GAIN Report AR6016: Argentina Oilseeds Annual

USDA 2007 GAIN Report AR7008: Argentina Grain and Feed Annual

USDA 2007 GAIN Report AR7009: Argentina Sugar Annual

USDA 2007 GAIN Report AR7011: Argentina Oilseeds Annual

USDA 2007 GAIN Report AR7016: Argentina Bio-Fuels Report

USDA 2005 GAIN Report BR5020: Brazil Sugar Annual, 2005.

USDA 2006 GAIN Report BR6008: Brazil Bio-Fuels Annual, 2006.

USDA 2007 GAIN Report BR7003: Brazil Sugar Annual, 2007.

USDA 2007 GAIN Report BR7610: Brazil Oilseeds and Products, Soybean Update, 2007.

USDA 2007 GAIN Report BR7011: Brazil Bio-Fuels Annual - Ethanol, 2007.

USDA 2007 GAIN Report BR7612: Brazil Grain and Feed, Grain Annual, 2007.

USDA 2007 GAIN Report BR7618: Brazil Oilseeds, Annual Soybean Report, May 2007.

USDA 2007 GAIN Report BR7014: Brazil Sugar Semi-Annual, 2007.

USDA 2006 GAIN Report CA6029: Canada Bio-Fuels, Bio Fuels Canada, 2006

USDA 2007 GAIN Report CA7018: Canada Grain and Feed Annual Report, 2007

USDA 2007 GAIN Report CA7024: Canada Oilseeds and Products, Oilseeds Annual Report 2007

USDA 2007 GAIN Report CA7038: Canada Grain and Feed Quarterly Report, 2007

USDA 2007 GAIN Report CA7005. Canada - This Week in Canadian Agriculture, Issue 3, 2007

USDA 2006 GAIN Report CH6081: China Sugar Annual

USDA 2007 GAIN Report CH7012: China Oil Seeds and Products Annual 2007

USDA 2007 GAIN Report CH7015: China Grain and Feed Annual, 2007

USDA 2007 GAIN Report CH7029: China Sugar Annual

USDA 2007 GAIN Report CH7031: China Corn Production Estimates, 2007

USDA 2007 GAIN Report CH7039: China Bio-Fuels Annual, 2007

USDA 2002 GAIN Report CO2009: Colombia Sugar Annual, 2002.

USDA 2004 GAIN Report CO4004: Colombia Sugar Annual, 2004.

USDA 2005 GAIN Report CO5005: Colombia Sugar Annual, 2005.

USDA 2007 GAIN Report CO7001: Colombia Oilseeds and Products Annual, 2007.

USDA 2007 GAIN Report CO7007: Colombia Sugar Annual, 2007.

USDA 2007 GAIN Report CO7011: Colombia Bio-Fuels, Annual, 2007.

USDA 2005 GAIN Report IN5034. India Sugar Annual Report, 2005

USDA 2006 GAIN Report IN6029: India Sugar Annual Report, 2006

USDA 2007 GAIN Report IN7035. India Sugar Annual Report, 2007

USDA 2007 GAIN Report IN7047: India Bio-Fuels Annual Report, 2007

USDA 2007 GAIN Report MX7024. Mexico Grain and Feed, Annual Report, 2007.

USDA 2007 GAIN Report MX7028. Mexico Oilseeds and Products, Oilseeds Annual 2007. 
USDA 2007 GAIN Report MX7031. Mexico, Sugar, Sugar Annual, 2007.

USDA 2007 GAIN Report MX7042. Mexico Bio-Fuels Annual Report, 2007. and for CBI Region:

USDA 2007 GAIN Report CS7005 Costa Rica Sugar Annual 2007

USDA 2007 GAIN Report DR7008 Dominican Republic Sugar Annual 2007

USDA 2007 GAIN Report GT6002 Guatemala Oilseeds and Products Annual 2006

USDA 2007 GAIN Report GT7006 Guatemala Sugar Annual 2007

USDA 2007 GAIN Report GT7012 Guatemala Bio-Fuels Annual 2007

USDA 2007 GAIN Report NU7005 Nicaragua Sugar Annual Report 2007

USDA FAS (Foreign Agricultural Service), 2006. International Trade Report: Argentina's Soybean Complex Competitiveness, April 14, 2006.

van Dam, J., M. Junginger, A. Faaij, I.Jurgens, G.Best, and U.Fritsche, 2006. "Overview of recent developments in sustainable biomass certification." Draft discussion paper written in the frame of IEA Bioenergy Task 40.

Wallace S., 2007. "Last of the Amazon" in January 2007 National Geographic magazine, pgs. 40-71.

Worldwatch Institute (WWI), 2007. Biofuels for Transport: Global Potential and Implications for Energy and Agriculture, prepared by Worldwatch Institute for the German Ministry of Food, Agriculture and Consumer Protection (BMELV). London: Earthscan. 
ANNEXES 


\title{
ANNEX 1. STATEMENT OF WORK FOR ORNL UNDER THE "STUDY OF THE WORLDWIDE POTENTIAL TO PRODUCE ETHANOL AND OTHER BIOFUELS” Joint EERE-PI Project
}

\author{
Statement of Work for \\ Oak Ridge National Laboratory
}

\section{BACKGROUND}

The overall objective of the joint EERE-PI project is to estimate the worldwide potential to produce and the transport ethanol and other biofuels. The project identifies three specific project tasks:

- Assess the resource potential for production of ethanol from sugar and starch-based feedstocks, and biodiesel

- Assess the resource potential for production of other biofuels, including lignocellulosic ethanol and other biofuels, such as biomass gasification with gas-to-liquids technology.

- Integrate results into the MARKAL energy policy model.

The first two tasks, which are largely data collection, analysis, and synthesis, will be integrated into the MARKAL model to improve its global representation of biofuels. ORNL and NREL will be responsible for the completion of the first two tasks while BNL will be responsible for the DOE global MARKAL model integration.

The overall scope of the ORNL and NREL tasks is largely discussed in the joint EERE-PI work study plan objective. Specifically, ORNL and NREL will be responsible for the following:

- Quantifying the current availability and potential for producing biofuel feedstocks taking into consideration competing demands (i.e., food, feed, and fiber), land and labor constraints, and environmental sustainability criteria.

- Estimating the likely range of costs for producing feedstocks and converting these feedstocks into biofuels in relation to the costs of producing conventional fuels.

- Evaluating the barriers to developing biofuels production in other counties and regions.

The scope of the study will consider two time frames designed to coincide with the President's "20 in 10" initiative and thus will be focused on what can be produced in 5 years and 10 years. The study will also consider a longer-term period of 20 years in which barriers, constraints, and study assumptions (e.g., crop yields) can be somewhat more relaxed. The longer time period will allow consideration of scenarios more comparable to the joint DOE-USDA billion-ton assessment. The level of ORNL and NREL staff effort will be relatively the same. ORNL will largely be responsible for quantifying the feedstock potential, feedstock production costs, assessing competing demands (i.e., food vs. fuel), and evaluating environmental sustainability criteria. The NREL effort will focus on the conversion technologies for the ethanol and biodiesel pathways, conversion scale-up and infrastructure requirements, and estimating costs of ethanol and biodiesel in the context of conventional fuels and financial operating conditions. Both Labs will address barriers and constraints as they relate to feedstock production (ORNL) and transport/conversion (NREL), respectively. 
The remainder of this statement of work discusses the ORNL specific tasks, deliverables and schedule, and budget.

\section{ORNL TASKS}

\section{Task 1 - Assess Availability of Biofuel Feedstocks}

This task will identify the range of viable feedstocks and their current availability for each of the regions and countries identified in the joint EERE-PI work plan. ${ }^{\text {cclxiii }}$ The task will focus on feedstocks having the greatest large-scale potential for conversion into biofuels. The task will generally avoid consideration of feedstocks that are largely in-use, such as those generated in processing of primary products or those discarded as post-consumer wastes (tertiary feedstocks). Specific feedstocks will include sugar and starch crops for ethanol production; primary lignocellulosic crop residues, forest residues, and perennial energy crops for ethanol production; and palm oil and oil seed crops for biodiesel production. In each of the regions and countries, there will be specific discussion of the land base (e.g., cropland, pasture land, marginal and degraded lands, and forest lands), trends in the use of land (i.e., population growth), and any constraints to the availability of labor and specialized feedstock production equipment. The following data and information will be assembled for each of the regions and countries identified in the joint EEREPI work plan.

- Current and potential availability of conventional sugar and starch crops for ethanol production for the 2012, 2017, and 2027 periods - The discussion will include the potential technological advances regarding crop yields, improved cultivars, and changes in the choice of varieties and crop management practices. Consideration will be given to the expansion of these to marginal lands.

- Availability of lignocellulosic crops (crop residues, forest residues, perennial energy crops) for ethanol production for the 2012, 2017, and 2027 periods - Discussion will include choice of perennial energy crop species (grasses and trees), likely crop yields, and the potential to increase yields over time. Perennial energy crops are also potentially important crops for use on marginal lands and improving degraded lands.

- Availability of palm oil and oil seed crops for the production of biodiesel - Discussion of biodiesel feedstocks will also include the three periods including the potential technological advances regarding crop yields and improved cultivars as well as the potential for using marginal lands.

\section{Task 2 - Identify Competing Demands for Biofuel Feedstocks}

The large-scale production of biofuels often raises numerous questions as to its impact on food, feed, and fiber production including how such production may affect prices of food domestically consumed or exported. This task will discuss these issues for each of the identified regions and countries. The task will utilize extant projections for food, feed, and fiber demands and evaluate how these demands may be affected by different levels of biofuel production identified in the previous task. The FAPRI Agricultural Outlook, USDA Baseline Projections, OECD/FAO Agricultural Outlook, World Bank, and possibly others will be used to provide context for future food, feed, and fiber demands.

\section{Task 3 - Identify Constraints To Production of Biofuel Feedstocks}

The deployment of a large-scale biorefinery industry, especially outside of countries where there is existing ethanol production, may face significant barriers. These constraints will no doubt differ among 
the selected regions and countries. This task will identify these constraints and discuss how they might impact and limit biofuel feedstock production. These constraints could include a variety of institutional, economic and financial, and technical factors; however, for the production of biofuel feedstocks, environmental sustainability constraints, such as the availability of water and potential for erosion, may be the most limiting.

\section{Task 4 - Costs of Production and Feedstock Supply Curves}

For each class of biofuel feedstock in each region and country, production costs and supply curves will be estimated. The supply curves will provide an indication of the quantity of feedstock (i.e., sugar and starch crops, lignocellulosic residues and crops, palm oil, and oil seeds) that could be available at differing prices. Depending on the specific feedstock, production costs will include all factor inputs and yield assumptions. The boundary for the analysis will be the farm-gate or forest landing exclusive of any transport and handling costs to the biorefinery or conversion facility. Costs of production will be estimated for each of the time periods $(2012,2017$, and 2030) and include sensitivity analysis of key variables, such as crop productivity, and assumptions. Supply curves will be conditioned on meeting projections for competing demands identified in Task 2 and constraints identified in Task 3.

\section{DELIVERABLES}

Within 3 months of receipt of project funds, ORNL will complete all data requirements needed to support the integration necessary for improving the representation of biofuels in the MARKAL model. For the identified regions and counties, this will be a series of time dependent supply curves conditioned on alternative scenarios. ORNL will work closely with NREL and BNL as to data format and underlying assumptions and scenarios.

Within 4 months of receipt of funds, ORNL will submit a written report. 


\section{Chapter Endnotes for Annex 1}

cclxiii The range of countries and/or regions identified in the joint EERE-PI project includes Brazil, the Caribbean Basin, Central America, Mexico, Europe, China, India, and Sub-Saharan Africa. These countries and regions are not entirely consistent with those used in the global MARKAL-ETP model which normally divides the world into 15-regions for energy analysis. An agreed upon list of countries and regions is needed to carry-out the assessment and analysis. 


\section{ANNEX 2. SCREENING RESULTS FOR COUNTRY SELECTION}

\section{BACKGROUND}

DOE is sponsoring a study of the worldwide potential to produce biofuel to better understand potential sources of supply for meeting U.S. targets including the goal for replacing 20\% of transport fuels by 2017 (See SOW). The approach will use available data from IEA, FAO, USDA and other sources, along with more detailed assessments of feedstock production potential and costs in a few priority countries/regions. Given time and resource constraints, the more detailed feedstock assessments will focus on a half dozen regions/nations. Data from these assessments will supplement the more general data from other sources and support the development of supply curves to be used in a model (MARKAL) and permit analysis of biofuel markets under varying scenarios. For a detailed explanation of this work, please refer to the Work Plan.

\section{SCREENING METHODOLOGY}

A screening methodology was designed to identify a selected group of countries for more detailed assessment of the potential production for biofuels. The screening prioritized geographic areas for more to answer the question, "Where can DOE support more detailed feedstock assessments that will improve understanding of future potential and limitations related to production capacity for export to the US biofuel market?" A set of scoring criteria and guidelines for scoring were developed by the project team including staff members for DOE's Biomass Program, Policy and International Affairs, Oak Ridge National Lab, and the National Renewable Energy Lab (see the attached table and instructions). The eight criteria selected reflect past feedstock and biofuel production, export infrastructure, processing capacity, proximity to the US, the relative need for more information and forecasted production and export potential (2010-12).

\section{RESULTS}

The project team members were invited to submit scores using the eight criteria and referencing source information for scores. Three sets of scores with references were used to prepare the summary table below. The final ranking shown is based on the sum of individual rankings. The results reflect strong consensus on the top priorities for feedstock analysis.

The first priority group includes the primary biofuel feedstock producer outside the US (Brazil) and present exporters to the US based on preferential tariffs: CBI (Caribbean Basin including Central America) and NAFTA (Canada/ Mexico). The next group includes major feedstock producers in the region with potential to become significant exporters to the US in the next five-ten years (Argentina, Colombia) and the two other major global producers (China and India). Although China was not initially ranked high in terms of export potential (due to large and growing internal demands) the project team agreed to include China in the feedstock study given their importance in global markets. Detailed feedstock assessments will be conducted for the countries highlighted in the table. 


\section{SENSITIVITY TO WEIGHTING}

Eight criteria were scored using three "weight" scenarios for each of 15 pre-selected regions and countries. Reviewing the scores from individuals under the three weights showed that there was no difference in the composite results under the different weighting scenarios in terms of the top six priorities. For the collated table above, the un-weighted scores and ranking were used.

\begin{tabular}{|c|c|c|c|c|c|c|}
\hline \multicolumn{6}{|c|}{ Ranking based on referenced sources (Lab inputs) and study SOW } & \multirow{3}{*}{$\begin{array}{l}\text { Primary References } \\
\text { regarding } \\
\text { Importance for this Study }\end{array}$} \\
\hline \multirow{2}{*}{\multicolumn{2}{|c|}{ Scoring Results (un-weighted) }} & \multicolumn{3}{|c|}{ Ranking } & \multirow{3}{*}{$\begin{array}{c}\begin{array}{c}\text { Composite } \\
\text { Rank }\end{array} \\
1.0\end{array}$} & \\
\hline & & A & $\mathrm{B}$ & $\mathrm{C}$ & & \\
\hline 1 & Brazil & 1 & 1 & 1 & & 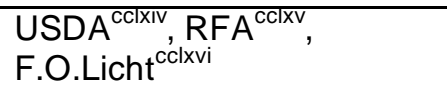 \\
\hline 2 & $\begin{array}{l}\mathrm{CBI} \text { (Caribbean Basin, Central } \\
\text { America) }\end{array}$ & 4 & 2 & 3 & 3.0 & $\begin{array}{l}\text { USDA, Smeets } \\
\text { F.O.Licht }\end{array}$ \\
\hline 3 & NAFTA (Canada, Mexico) & 3 & 3 & 5 & 3.7 & $\begin{array}{l}\text { USDA, CEC } \\
\text { sources }^{\text {ccllix }}\end{array}$ \\
\hline 4 & Argentina & 5 & 5 & 2 & 4.0 & USDA, industry sources \\
\hline 5 & Colombia & 2 & 4 & 8 & 4.7 & USDA, Smeets, RFA, Licht \\
\hline 6 & India & 6 & 6 & 4 & 5.3 & USDA, FAPRI ${ }^{\text {ccl|xx }}$, IFPRI $^{\mathrm{ccl} \mid \times x i}$ \\
\hline 7 & Thailand & 13 & 7 & 6 & 8.7 & USDA, RFA, F.O.Licht \\
\hline 8 & EU & 10 & 11 & 7 & 9.3 & USDA, RFA, F.O.Licht \\
\hline 9 & Australia & 8 & 10 & 10 & 9.3 & USDA, RFA, F.O.Licht \\
\hline 10 & China & 11 & 9 & 12 & 10.7 & USDA, RFA, F.O.Licht \\
\hline 11 & Indonesia/Malaysia & 7 & 12 & 14 & 11.0 & USDA, FAPRI, IFPRI \\
\hline 12 & South Africa & 9 & 13 & 11 & 11.0 & USDA, RFA, F.O.Licht \\
\hline 13 & Russia/FSU & 12 & 14 & 9 & 11.7 & USDA, RFA, F.O.Licht \\
\hline 14 & Peru & 14 & 8 & 13 & 11.7 & Berg $^{\text {ccllxxil }}$ (F.O.Licht) \\
\hline
\end{tabular}

\section{OTHER NATIONS}

Europe and other nations are important in terms of global demand and production and will be included and influence the MARKAL model. There is general consensus that the EU will be a net importer during the period in question (2012-17) and that there will be significant trade within Southeast Asia and among European states. Energy Outlook 2007 (with projections to 2030) was just released by IEA and several commercial studies looked at these regions in reports released this year.

For the purposes of the present work (which will look at supply, demand, constraints and costs, $\mathrm{x}$ four feedstock classes, over three time periods) Europe would be complicated and costly due to the large number of nations in the overall region and the variety of feedstock being used. The evolving EU membership status also complicates historic data. The EC supports several bioenergy committees and networks that monitor production and related issues in the EU. USDA recently initiated a monitoring and reporting system for EU biofuels (see: http://useu.usmission.gov/agri/Biofuels.htm ). Given the challenges and the short time frame for the present work scope, and that other parties are better positioned to document Europe's potential, Europe was excluded from the detailed feedstock analysis. 


\section{Endnotes for Annex 2}

cclxiv The USDA February 2007 Agriculture Exports update provides a set of data tables quantifying projected exports of major products through 2017. USDA. (2007). "Agricultural Baseline Projections: Global Agricultural Trade, 2007-2016." Feb 2007. Retrieved 4/27/2007, from http://www.ers.usda.gov/Briefing/Baseline/trade.htm ${ }^{c c l x v}$ The Renewable Fuels Association produces an annual report on projected U.S. production, imports, exports and related issues. RFA (2007). Ethanol Industry Outlook 2007: Building New Horizons. RFA Outlook. Washington, D.C., Renewable Fuels Association: 26.

${ }^{\text {cclxvi }}$ F.O.Licht produces the biweekly "World Ethanol \& Biofuels Report" and special sector and country-specific studies. Licht, F. O. (2007). World Ethanol \& Biofuels Report-May 8, 2007. C. Berg. United Kingdom Agra Informa, Ltd. : 32.

${ }^{\text {cclxvii }}$ A recent global study of underlying factors that will impact feedstock availability for export between present and 2050. Smeets, E., A.Faaij, I.Lewandowski (2004). A quickscan of global bio-energy potentials to 2050: An analysis of the regional availability of biomass resources for export in relation to the underlying factors. Report NWS-E-2004-109. Utrecht, The Netherlands, Copernicus Institute, Utrecth University 122.

cclxviii The State of California studied potential sources for ethanol under its alternative fuels research program. CEC (2003). Appendix 3, Att. C: Ethanol Demand and Supply Analysis. Reducing California's Petroleum Dependence. Sacramento, California Energy Commission.

cclxix See K.Kline "Ranking Basis" justification table and "Screening Sources" narrative for additional references to national industry sources.

${ }^{c c l x x}$ See http://www.fapri.org/outlook2007/ FAPRI (2007). The Agricultural Outlook 2007: World Biofuels, Iowa State University, Food \& Agriculture Policy Research Institute.

${ }^{c c l x x i}$ See http://www.ifpri.org/2020/focus/focus14.asp IFPRI (2006). Bioenergy and Agriculture: Promises and Challenges. 2020 Vision. P. Hazell, R.Pachauri. Washington, D.C., International Food Policy Research Institute, The Energy and Resources Institute, FAO-CGIAR.

cclxxii Berg made a presentation to the Government of Japan on world ethanol markets: Berg, C. (2006, F.O. Licht). "World Fuel Ethanol - Analysis and Outlook (prepared for METI)." Retrieved 4/27/2007, from http://www.meti.go.jp/report/downloadfiles/g30819b40j.pdf. 


\section{ANNEX 3. METHODOLOGY}

\section{METHODOLOGY FOR GENERATION OF CROP FEEDSTOCK SUPPLY CURVES}

\section{Background}

Supply curves depict changes in a commodity's unit or marginal cost of production as cumulative production increases. Unlike smooth theoretical marginal cost curves, empirical supply curves are usually step functions due to lumping of technologies or production units, and use of average rather than marginal costs. In general, these curves are snapshots over a given time interval of the structure of costs and breakeven production that would result from discrete increments in the price of a commodity until each available production unit is operating at its maximum capacity. Over time, changes in capacity and cost and addition of new production units lead to changes in the supply curve.

An ideal approach to constructing agricultural supply curves over a period of 5-20 years as in this study would involve estimation of production and cost levels for each production unit, projection of each unit's production and cost into the future, and estimation of the number of new production units. Such an exercise would need to account for the myriad of supply and demand factors that drive production area, productivity and new entries. On the supply side, these factors include land availability and quality, input availability and costs, climate and water conditions, production technology, plant genetics, choice of farming practices, environmental conditions, and social considerations. The competition for land means that supply curves for a given crop would also need to account for changes in land allocations for other crops and uses.

In addition, the supply-side factors interact with a host of demand-related factors that make it difficult to estimate supply curves from the observed data. The agricultural sector of nations around the world is influenced by a mix of subsidies, tariffs, quotas or other mechanisms that directly affect production and prices. In many countries, industries are vertically integrates so that farmers/producers and buyers/consumers of a harvested crop are closely related or one in the same.

In Brazil, for example, 75 percent of the sugarcane is produced by the same companies that "buy" the cane to process it in sugar mills (AgraFNP 2007). The Brazilian government plays significant roles in markets and prices through interventions such as adjusting the required percentage of ethanol to be blended in national gasoline supplies. Similarly, in Mexico it has been estimated that 64 percent of corn producers do not sell surpluses in markets and that these farmers often appear to operate at a loss (CEC 1999).

Furthermore, because of inertia and common lag times in the response of agricultural supply to demand changes, signals from domestic and world agricultural markets are capable of generating mismatched fluctuations in production, costs and price levels. Producers may misinterpret or fail to foresee signals and make production decisions that result in shortages or surpluses with attendant price implications.

Therefore, it is reasonable to assume that significant differences can be found between theoretical supply curve projections over long time spans and the actual price and supply at a particular moment in time.

The aim of the current study is to generate supply curves using readily available data. Given this, and the number of countries and crops in the study, an approach that explicitly accounts for all the factors highlighted above is beyond the scope of this study. As a result, the methodology described here was developed and adapted to use the best available data, within the time and funding constraints of the study, while implicitly accounting for these factors that influence production. 


\section{Approach}

Supply curves for the countries in this study are projected to 2012, 2017 and 2027 according to the methodology described below. The final results - total projected levels of production in 2012 and beyond - are also compared to other independent analyses (USDA baseline, FAPRI and other national projections) when such information is available. These comparisons are found in the individual country analyses of Chapter 3.

Overview of the Available Data: An initial exploration of data sources was conducted. It was found that the most detailed and consistent data on crop production covering an individual country is usually at the state (or province) division. In addition, matching average prices or costs generally were available at this level of detail and often from the same sources. Based on this, state divisions were adopted as individual segments or production units of the projected supply curves.

Construction of the Base Year Supply Curve: A base year supply curve for each country-crop combination can be generated directly from the above data on current production and average prices/costs. The base year is the most recent year for which these data are available — most often, 2005. The supply curve was generated by ranking the state level production of each crop in order of increasing price, and cumulating the resulting data over the states. For a number of country-crop combinations, it was not possible to generate supply curves in this manner because the state level price/cost data were unavailable. For these countries, the national average price/cost of production was estimated using the best data available.

Assumptions on Cost/Price Structure: The structure of supply prices/costs constructed from the base year data is assumed to remain constant into the future. In addition, only states producing in the base year are assumed also to be producing over the projection period. Thus, the methodology focuses on projecting crop production from the base year to 2012, 2017 and 2027, independent of changes in costs/prices and entrance of new states into production. Baseline, low and high cases were projected for each period. The low and high cases provide bounds around the baseline case to account for uncertainties due to changes in prices and other factors that determine the ultimate future evolution of crop supply. These bounds are based on historic standard deviations as described below.

The Projection Model: The approach for projecting crop production in each producing state is given by the following equations:

$$
\begin{aligned}
& H_{s, f y r}=H_{s, c y r} \times\left(1+g_{s, a r e a, f y r}\right)^{y r-c y r} \\
& Y_{s, f y r}=Y_{s, c y r} \times\left(1+g_{s, y i e l d, f y r}\right)^{y y r-c y r} \\
& Q_{s, f y r}=H_{s, f y r} \times Y_{s, f y r}
\end{aligned}
$$

$\begin{array}{lll}\text { where } & & \\ s & = & \text { State } \\ c y r & = & \text { Current year from which production is to be projected forward } \\ f y r & = & \text { Future year to which production is to be projected } \\ H_{\mathrm{s}, \mathrm{cyr}}= & \text { Harvested area in state } s \text { in the current year } c y r \\ H_{\mathrm{s}, \mathrm{fyr}}= & \text { Harvested area in state } s \text { in future year } f y r\end{array}$


$Q_{\mathrm{s}, \mathrm{cyr}}=\quad$ Production in state $s$ in the current year cyr

$Q_{\mathrm{s}, \mathrm{fyr}}=$ Production in state $s$ in future year $f y r$

$\mathrm{Y}_{\mathrm{s}, \mathrm{cyr}}=$ Average yield in state $s$ in the current year $c y r$

$\mathrm{Y}_{\mathrm{s}, \mathrm{fyr}}=$ Average yield in state $s$ in future year $f y r$

$\mathrm{g}_{\mathrm{s}, \mathrm{area}, \mathrm{fyr}}=\quad$ Compound annual growth in harvested area between the current year cyr and future year fyr in state $s$

$\mathrm{g}_{\mathrm{s}, \mathrm{yiel}, \mathrm{fyr}}=\quad$ Compound annual growth in yield between the current year cyr and future year fyr in state $s$

Given the base year data, projections with the above model require estimates of the compound growth rates for each state in the years 2012, 2017 and 2027, and for the three alternative cases (Baseline, Low and High). Estimation of these rates involved two sets of supporting calculations:

1. Compound growth rates were calculated from the most recent state-level data series available for past years and used to make initial projections to 2012, subject to appropriate bounds (see below).

2. Compound growth rates were calculated from long-term national data to complement the statelevel rates in three ways:

a. Establish bounds on state-level compound growth rates;

b. Extend state-level compound rates to 2017 and 2027, and

c. Generate alternative cases from initial state-level projections.

The above steps are described in more detail below.

Calculation of State Level Compound Growth Rates: Compound growth rates for each state were calculated from the most recent 7 years of data where available. It was sometimes a shorter period depending on the country, data set and particular state (a few states only recently began recording production of some crops). Most countries and states had historic data for at least the five year period from 2000-2005. Seven years was chosen primarily because this is the time period between the most common recent year of data available in a country (2005) and the projection year (2012). In addition, it is long enough to smooth out some of the annual fluctuations in agricultural output due to unusual events, such as droughts, or crop rotation cycles. For example, a single planting of sugarcane is typically harvested for 4 or more years after initial maturation.

The growth rates derived from the historic data are used with equations 1-3 in the model above to project crop production to 2012 (subject to certain bounds described further below). Negative growth rates are not used in the projections. If the historic rates produce a negative in a given state, the rate for that state is set to zero, essentially holding production constant at the base year level.

Calculation of National Compound Growth Rates: Data on crop production, area and yield from 19612005 were obtained from the Food and Agricultural Organization (FAO) database. ${ }^{\text {clxxiii }}$ These data were used to produce distributions of the historical compound growth rate for each crop at the national level. Three distributions representing compound growth rates over 7, 12 and 22 years were generated based on a "rolling average" principle from statistical forecasting. These correspond to the intervals between 2005 and the projections years 2012, 2017 and 2027, respectively.

The accuracy of statistical models can be improved by performing forecasts over short periods into the future. Forecasts for successive future periods are obtained after rolling the data forward and reestimating the parameters of the forecasting model. This approach generates more accurate forecasts because it gradually removes the influence of past data, and updates the data to reflect more recent trends. Based on this principle, the distribution of 7-, 12- and 22-year compound growth rates (rolling averages) for production, harvested area, and yield for each crop-country combination was generated from the FAO 
data. Figure 1 illustrates the 7-year calculation for sugarcane for 1968-2005. In this case, the first year is 1968 since the first compound growth rate is calculated over years 1961-1968. Afterwards, the data is rolled forward by one year, so that the 1969 rate is calculated over years 1962-1969, and so on. For the 12-year and 22-year calculation the first years are 1973 and 1983, respectively. Maximum, minimum, mean and standard deviation values of the three distributions are calculated.

The approach described above identifies episodic trends in production, harvested area and yield at the national level. These episodes in turn were the overarching drivers of production behavior at the subnational level. For example, a look at the distribution for sugarcane in Brazil in Figure 1 clearly identifies several episodes. Launching of the National Fuel Alcohol program following the oil price shock of the 1970s and the subsequent rapid growth in sugarcane production is evident in the calculated rates for 19751987. Similarly, the collapse of world oil prices in the late 1980s and early 1990s corresponds to an episode of declining sugarcane production growth in Brazil. The latest episode which began with the liberalization of ethanol prices in 1999 and the increase in oil prices can also be seen in Figure 1, but growth rates have slowed down compared with the 1970s, given that the industry has matured. Summary statistics for the full set of rolling 7-year compound growth rates are presented in Tables 1a-1e and Figures $2 \mathrm{a}-2 \mathrm{e}$.

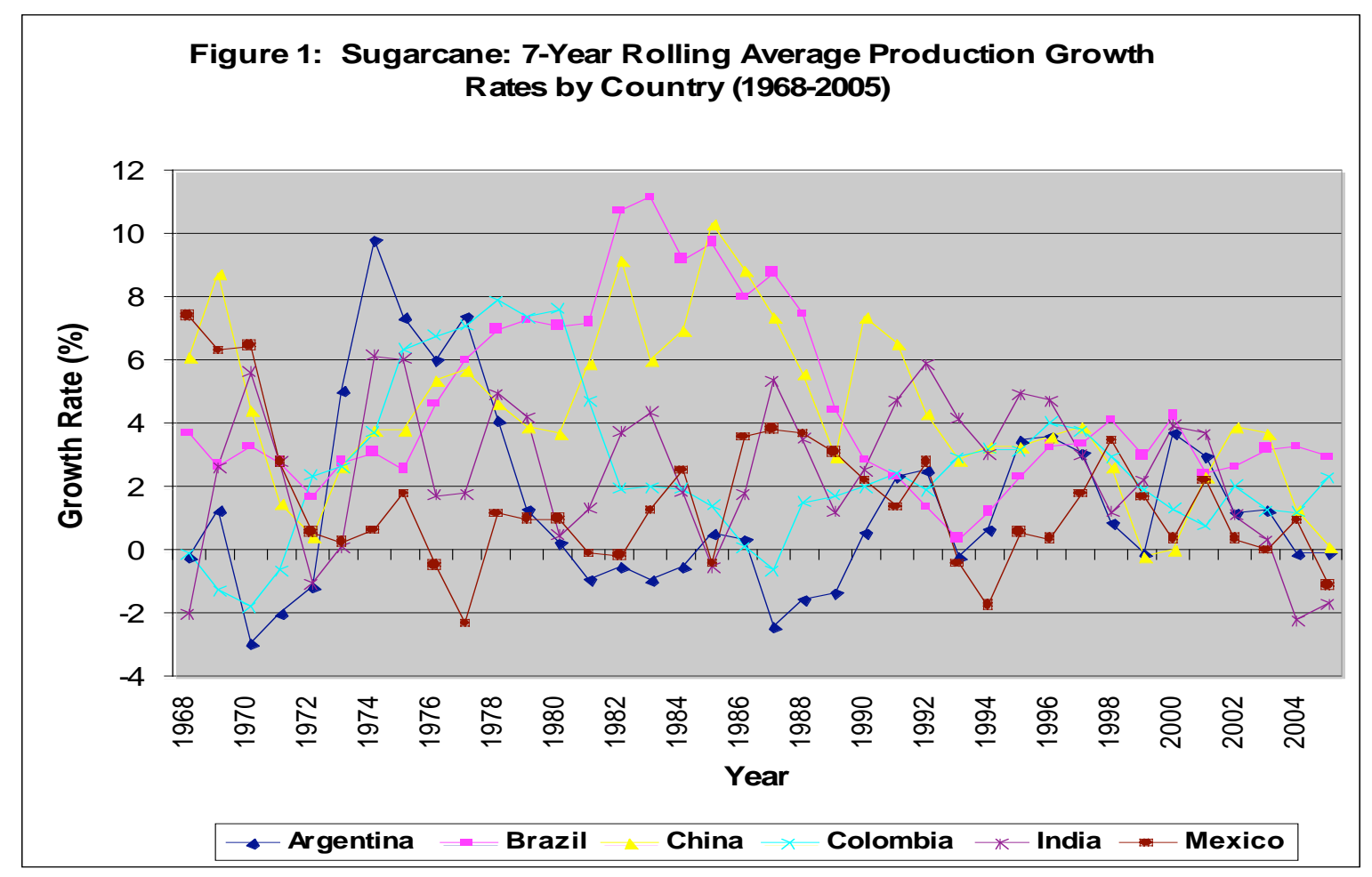

\section{Annex 3 - Figure 1. Sugarcane: 7-Year Rolling Average Production Growth Rates by Country (1968-2005).}

Bounds on State/Province Level Growth Rates: Growth rates for some states/provinces could not be calculated from the state-level data series, while in other cases the resulting values appeared implausibly high. This situation was limited to cases where data were missing or a state had only recently begun production of the given crop. Therefore, it was necessary to estimate values for such states and provide bounds for others to ensure that production growth rates are plausible. Summary statistics from the longterm national data were used for this purpose. In general, state-level growth rates for projections to 2012 
were restricted to be no greater than the mean plus two standard deviations of the national 7-year compound growth rate.

Projections to 2017 and 2027: Because historic data at the state-level dating back $12-22$ years were unavailable, the corresponding set of compound growth rates could not be calculated over these periods. An alternative is to use the rates for projections to 2012 as a starting point for calculating for the 2017 and 2027 projections. However, since the latter two years are considerably more distant in the future than 2012, the model approach described above tended to produce excessive sustained growth. This trend was reduced somewhat by applying scaling factors to the state-level rates from the initial 2012 projections when extending them to future years. The scaling factor for 2017 is the ratio of the mean plus twostandard deviation from the 12-year national compound growth rate distribution to that from the 7-year distribution. The scaling factor for 2027 is calculated similarly. These factors were in general progressively lower than 1 . The resulting growth rates were then used to project state-level production from 2012 to 2017 and from 2017 to 2027 , using the same specification as in the model equations 1-3.

Baseline, Low and High Growth Cases: The national historical compound growth rate series were used to generate the baseline, low growth and high growth cases for feedstock supply in each state/province as follows:

- The national compound growth rate implied by the initial projection to 2012 was compared with the mean of the 7-year compound growth rate from the historical data. If the implied rate falls within one standard deviation of the mean historical rate, then the initial projection is classified as the "Baseline" case. If the implied rate is more than one standard deviation above or below the mean historical rate, the initial projection is classified as the "High" or "Low" growth case, respectively.

- Once the initial projection was classified as the Low, Baseline or High growth case, the two additional cases were generated by subtracting/adding one or two standard deviations from/to the national compound growth rate from the initial projection. Thus, if the initial projection was classified as the Baseline, the Low and High rates are one standard deviation below and above the Baseline levels, respectively. These values were used to scale the initial state level growth rates, which are in turn used to generate projections for the corresponding alternative cases.

Bounds on Land Area and Yield Levels: Although bounds were established on the estimated compound growth rates for state-level area and yield, the results still appeared implausibly high in for some states. Again, this was generally due to limited data for the state and/or very low initial numbers for area and yield. Plausible limits for yield levels and the percentage of a total state area that can be allocated to any crop were set. The percentage maximum land allocation was set at 30\% of state area, while the yield level was generally set at twice the maximum of current state-level yields in the United States. If these limits were exceeded, the calculated growth rates were adjusted to ensure that land and yield estimates fell close to these limits. 


\section{Summary Statistics for National Compound Growth Rates Derived from FAO National Statistics 1961-2005}

Annex 3 - Table 1a. Sugarcane - Historical Changes in Production by Country

\begin{tabular}{|c|c|c|c|c|}
\hline & Maximum & Minimum & Mean & $\begin{array}{c}\text { Standard } \\
\text { Deviation }\end{array}$ \\
\hline \multicolumn{5}{|c|}{ 7-Year Rolling Compound Annual Production Growth Rate } \\
\hline Argentina & 9.83 & -2.94 & 1.45 & 2.89 \\
\hline Brazil & 11.14 & 0.36 & 4.59 & 2.83 \\
\hline CBI & 9.62 & -0.85 & 4.83 & 2.64 \\
\hline China & 10.39 & -0.14 & 4.41 & 2.61 \\
\hline Colombia & 7.88 & -1.81 & 2.63 & 2.45 \\
\hline India & 6.13 & -2.21 & 2.57 & 2.32 \\
\hline Mexico* & 7.44 & -2.32 & 1.55 & 2.14 \\
\hline \multicolumn{5}{|c|}{ 7-Year Rolling Compound Annual Area Harvested Growth Rate } \\
\hline Argentina & 8.96 & -4.15 & 0.76 & 3.37 \\
\hline Brazil & 7.52 & -0.30 & 3.26 & 2.09 \\
\hline CBI & 7.64 & -2.27 & 3.12 & 2.37 \\
\hline China & 7.79 & -3.21 & 3.46 & 2.49 \\
\hline Colombia & 3.34 & -4.01 & 0.99 & 1.95 \\
\hline India & 5.07 & -2.32 & 1.43 & 1.76 \\
\hline Mexico* & 5.49 & -2.33 & 1.09 & 1.68 \\
\hline \multicolumn{5}{|c|}{ 7-Year Rolling Compound Annual Yield Growth Rate } \\
\hline Argentina & 4.33 & -3.43 & 0.72 & 2.10 \\
\hline Brazil & 3.84 & -0.14 & 1.27 & 0.90 \\
\hline CBI & 5.45 & -2.10 & 1.67 & 1.63 \\
\hline China & 6.25 & -3.13 & 0.94 & 2.18 \\
\hline Colombia & 6.57 & -2.76 & 1.65 & 2.48 \\
\hline India & 3.45 & -1.63 & 1.12 & 1.18 \\
\hline Mexico* & 2.33 & -1.19 & 0.45 & 0.98 \\
\hline
\end{tabular}

Source: Calculations based on Food and Agricultural Organization (FAO) Data; http://faostat.fao.org/default.aspx

* Data not available for 2005 in Mexico; in this case results are based on 1961-2004 series. 
Table 1b. Soybean -- Historical Changes in Production by Country

\begin{tabular}{lcccr} 
& Maximum & Minimum & Mean & $\begin{array}{c}\text { Standard } \\
\text { Deviation }\end{array}$ \\
\hline 7-Year Rolling Compound & Annual Production & Growth Rate & \\
Argentina & 75.97 & 0.40 & 24.65 & 21.83 \\
Brazil & 47.40 & -0.56 & 13.59 & 13.03 \\
Canada & 16.63 & -4.46 & 7.06 & 4.07 \\
China & 6.55 & -2.57 & 2.14 & 2.47 \\
Colombia & 26.03 & -14.74 & 1.62 & 10.36 \\
India & 54.86 & -1.78 & 19.76 & 12.95 \\
Mexico & 45.70 & -33.67 & 2.99 & 16.63
\end{tabular}

7-Year Rolling Compound Annual Area Harvested Growth Rate

$\begin{array}{lrrrr}\text { Argentina } & 63.81 & 3.69 & 21.55 & 18.65 \\ \text { Brazil } & 35.54 & -2.40 & 11.00 & 11.39 \\ \text { Canada } & 13.18 & 1.52 & 6.51 & 2.72 \\ \text { China } & 3.19 & -3.51 & -0.02 & 1.82 \\ \text { Colombia } & 20.74 & -16.07 & 0.82 & 9.45 \\ \text { India } & 46.65 & 2.21 & 17.40 & 11.34 \\ \text { Mexico } & 44.84 & -28.02 & 3.59 & 16.28\end{array}$

7-Year Rolling Compound Annual Yield Growth Rate

\begin{tabular}{lrrrr} 
Argentina & 10.84 & -3.29 & 2.28 & 3.07 \\
Brazil & 9.38 & -3.06 & 2.26 & 2.68 \\
Canada & 5.06 & -8.01 & 0.51 & 2.48 \\
China & 6.39 & -0.97 & 2.16 & 1.93 \\
Colombia & 6.22 & -4.28 & 0.75 & 1.74 \\
India & 12.28 & -5.93 & 2.02 & 5.41 \\
Mexico & 3.41 & -7.85 & -0.65 & 2.41 \\
\hline
\end{tabular}

Source: Calculations based on Food and Agricultural Organization (FAO) Data; http://faostat.fao.org/default.aspx 
Table 1c. Corn - Historical Changes in Production by Country

\begin{tabular}{|c|c|c|c|c|}
\hline & Maximum & Minimum & Mean & $\begin{array}{c}\text { Standard } \\
\text { Deviation }\end{array}$ \\
\hline \multicolumn{5}{|c|}{ 7-Year Rolling Compound Annual Production Growth Rate } \\
\hline Argentina & 16.30 & -9.16 & 2.87 & 5.42 \\
\hline Brazil & 7.16 & -0.58 & 3.42 & 1.86 \\
\hline Canada & 16.23 & -4.96 & 5.46 & 5.04 \\
\hline China & 9.35 & -1.38 & 4.57 & 2.40 \\
\hline Colombia & 13.90 & -7.21 & 1.35 & 3.71 \\
\hline India & 7.33 & -3.17 & 2.66 & 2.51 \\
\hline Mexico & 8.61 & -3.89 & 2.47 & 2.98 \\
\hline \multicolumn{5}{|c|}{ 7-Year Rolling Compound Annual Area Harvested Growth Rate } \\
\hline Argentina & 11.82 & -8.79 & -0.25 & 4.56 \\
\hline Brazil & 4.84 & -2.96 & 1.06 & 1.71 \\
\hline Canada & 13.39 & -3.78 & 4.25 & 4.67 \\
\hline China & 3.24 & -1.68 & 1.29 & 1.25 \\
\hline Colombia & 5.64 & -8.11 & -0.61 & 3.22 \\
\hline India & 3.56 & -1.09 & 0.96 & 1.26 \\
\hline Mexico & 3.17 & -3.75 & 0.04 & 1.74 \\
\hline \multicolumn{5}{|c|}{ 7-Year Rolling Compound Annual Yield Harvested Growth Rate } \\
\hline Argentina & 7.59 & -0.81 & 3.12 & 2.10 \\
\hline Brazil & 6.43 & -1.33 & 2.35 & 1.89 \\
\hline Canada & 4.93 & -2.55 & 1.17 & 1.66 \\
\hline China & 6.70 & -1.10 & 3.24 & 2.07 \\
\hline Colombia & 7.81 & -0.84 & 1.98 & 2.02 \\
\hline India & 5.58 & -2.76 & 1.69 & 2.18 \\
\hline Mexico & 7.07 & -1.60 & 2.42 & 2.00 \\
\hline
\end{tabular}

Source: Calculations based on Food and Agricultural Organization (FAO) Data; http://faostat.fao.org/default.aspx 
Table 1d. Palm Oil - Historical Changes in Production by Country

\begin{tabular}{lcccc} 
& Maximum & Minimum & \multicolumn{3}{c}{ Mean } & Standard \\
\cline { 2 - 5 } Deviation
\end{tabular}

Source: Calculations based on Food and Agricultural Organization (FAO) Data; http://faostat.fao.org/default.aspx

* For China, data not available for 1961-1984; China based on 1985-2006 series. 
Table 1e. Wheat -- Historical Changes in Production by Country

\begin{tabular}{|c|c|c|c|c|}
\hline & Maximum & Minimum & Mean & $\begin{array}{c}\text { Standard } \\
\text { Deviation }\end{array}$ \\
\hline \multicolumn{5}{|c|}{ Wheat 7-Year Compound Production Growth Rate } \\
\hline Argentina & 13.45 & -9.87 & 2.01 & 4.54 \\
\hline Brazil & 24.74 & -17.19 & 5.37 & 10.12 \\
\hline Canada & 12.59 & -10.55 & 1.17 & 5.03 \\
\hline China & 11.47 & -4.10 & 4.17 & 3.65 \\
\hline Colombia & 10.55 & -17.43 & -2.37 & 7.35 \\
\hline India & 13.45 & 0.55 & 5.07 & 3.10 \\
\hline Mexico & 11.07 & -6.29 & 1.46 & 4.46 \\
\hline \multicolumn{5}{|c|}{ Wheat 7-Year Compound Area Harvested Growth Rate } \\
\hline Argentina & 5.44 & -5.93 & 0.53 & 3.37 \\
\hline Brazil & 17.50 & -16.37 & 2.70 & 9.25 \\
\hline Canada & 10.43 & -10.70 & -0.25 & 3.83 \\
\hline China & 1.88 & -4.59 & -0.03 & 1.59 \\
\hline Colombia & 6.01 & -16.22 & -4.33 & 6.47 \\
\hline India & 6.44 & -0.29 & 1.86 & 1.63 \\
\hline Mexico & 10.86 & -5.54 & -0.55 & 3.70 \\
\hline \multicolumn{5}{|c|}{ Wheat 7-Year Compound Yield Growth Rate } \\
\hline Argentina & 7.83 & -5.16 & 1.46 & 2.72 \\
\hline Brazil & 14.75 & -8.07 & 2.66 & 4.85 \\
\hline Canada & 10.20 & -6.69 & 1.42 & 3.16 \\
\hline China & 10.62 & 0.51 & 4.18 & 2.55 \\
\hline Colombia & 6.75 & -4.21 & 2.03 & 2.27 \\
\hline India & 8.67 & 0.15 & 3.13 & 1.74 \\
\hline Mexico & 6.66 & -1.85 & 2.01 & 2.16 \\
\hline
\end{tabular}

Source: Calculations based on Food and Agricultural Organization (FAO) Data; http://faostat.fao.org/default.aspx 


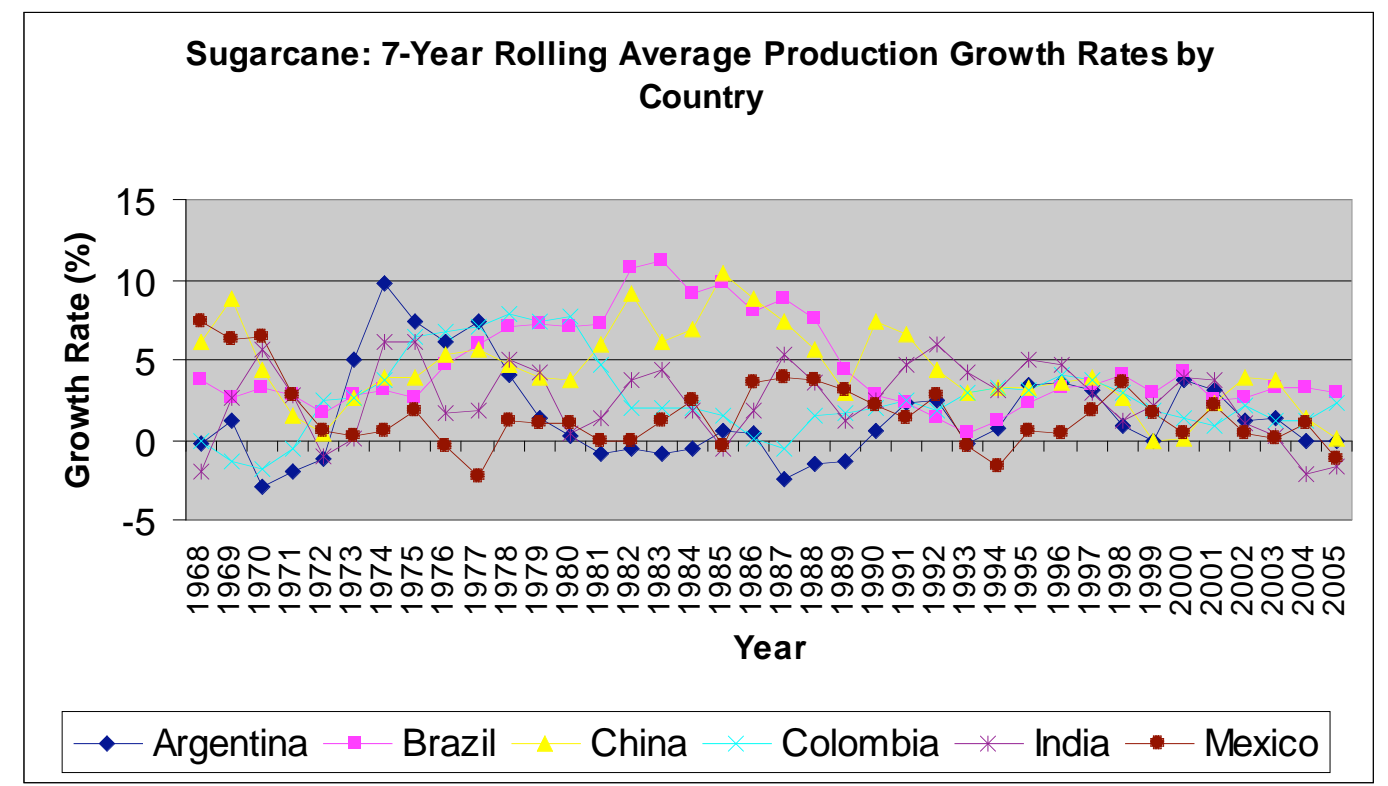

Figure 2a. Sugarcane: 7-Year Rolling Average Production Growth Rates by Country.

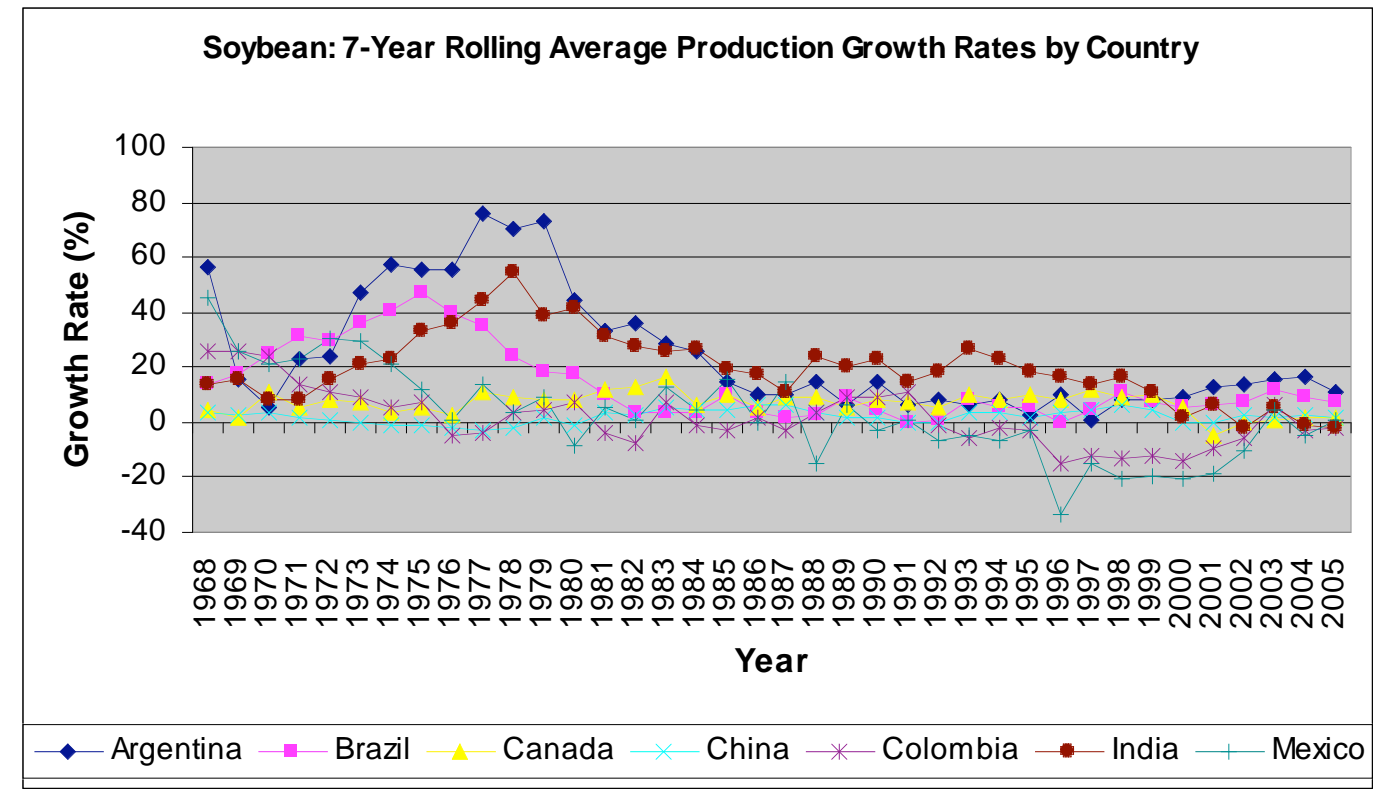

Figure 2b. Soybean: 7-Year Rolling Average Production Growth Rates by Country. 


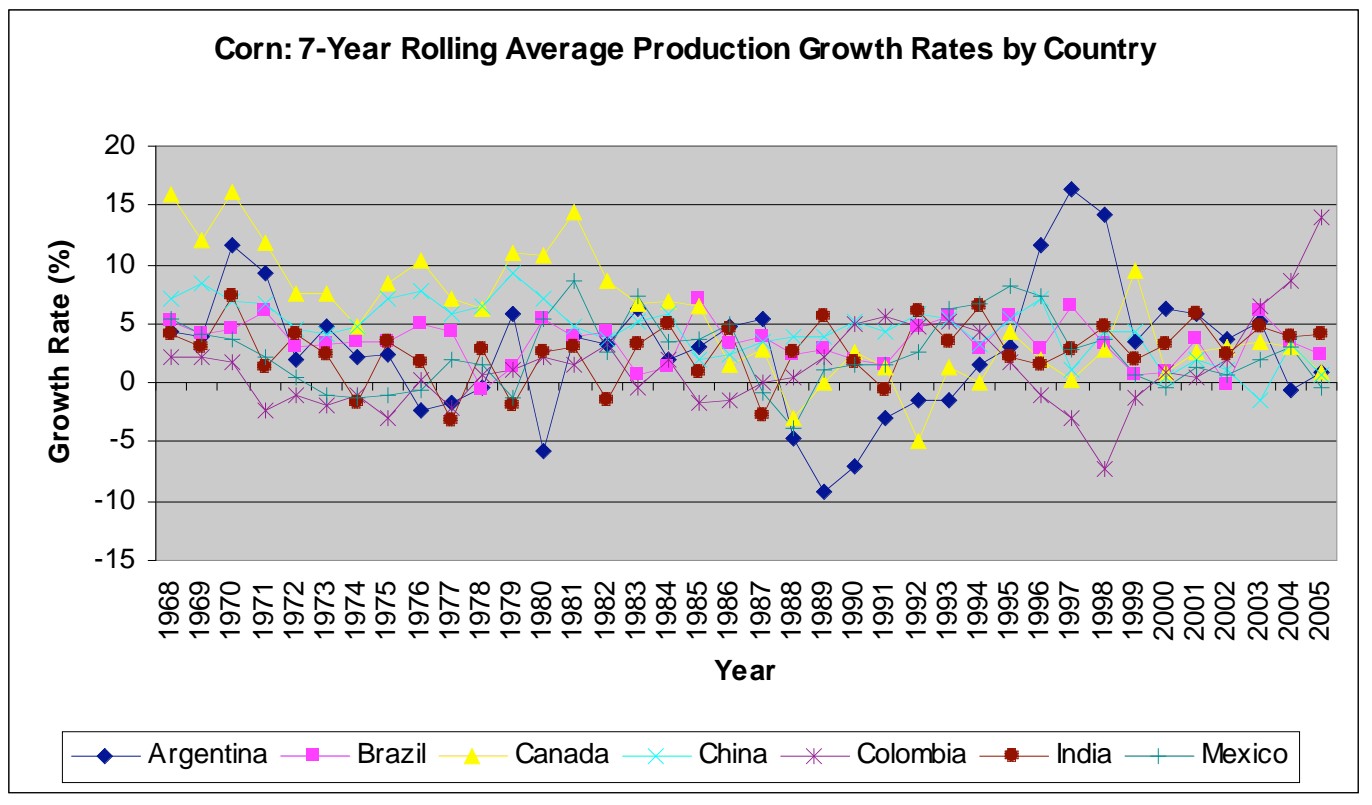

Figure 2c. Corn: 7-Year Rolling Average Production Growth Rates by Country.

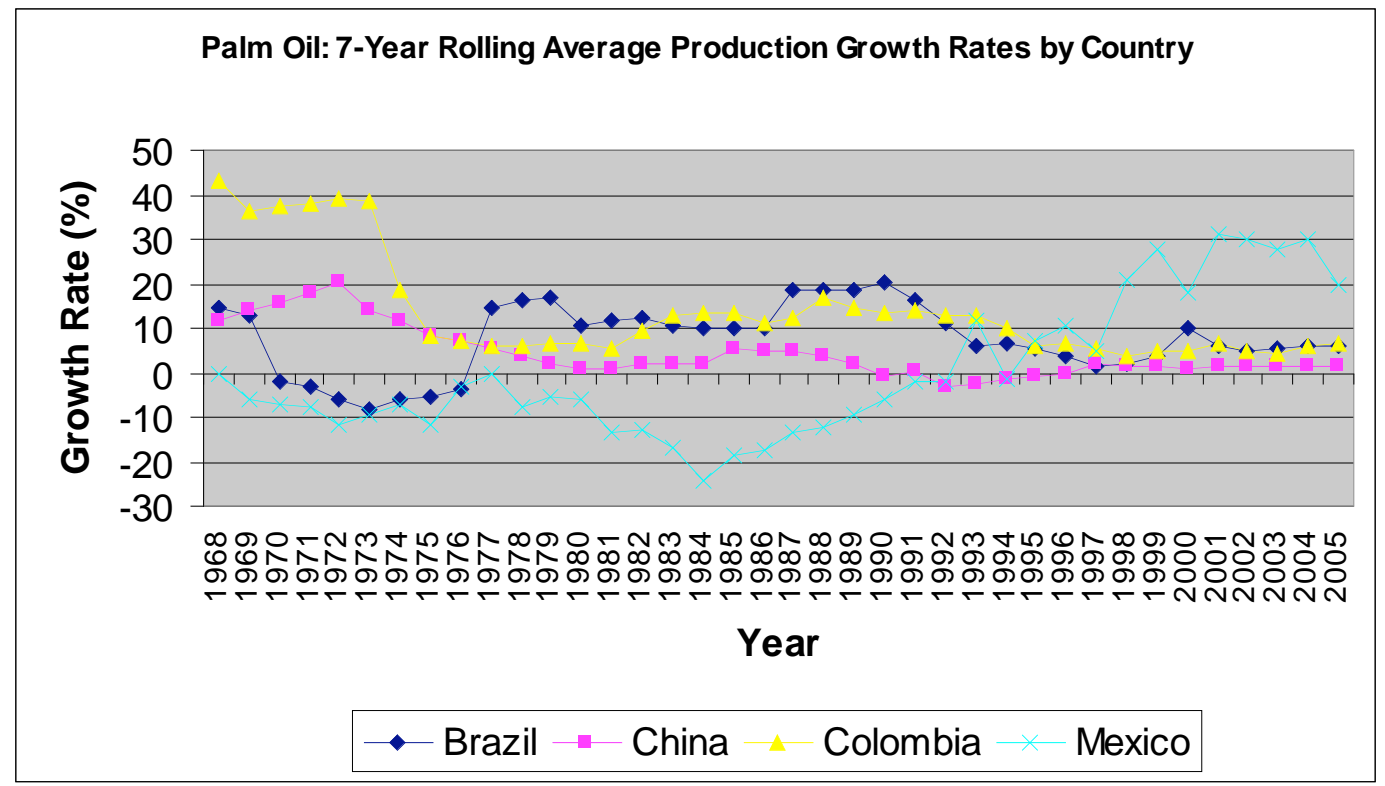

Figure 2d. Palm Oil: 7-Year Rolling Average Production Growth Rates by Country. 


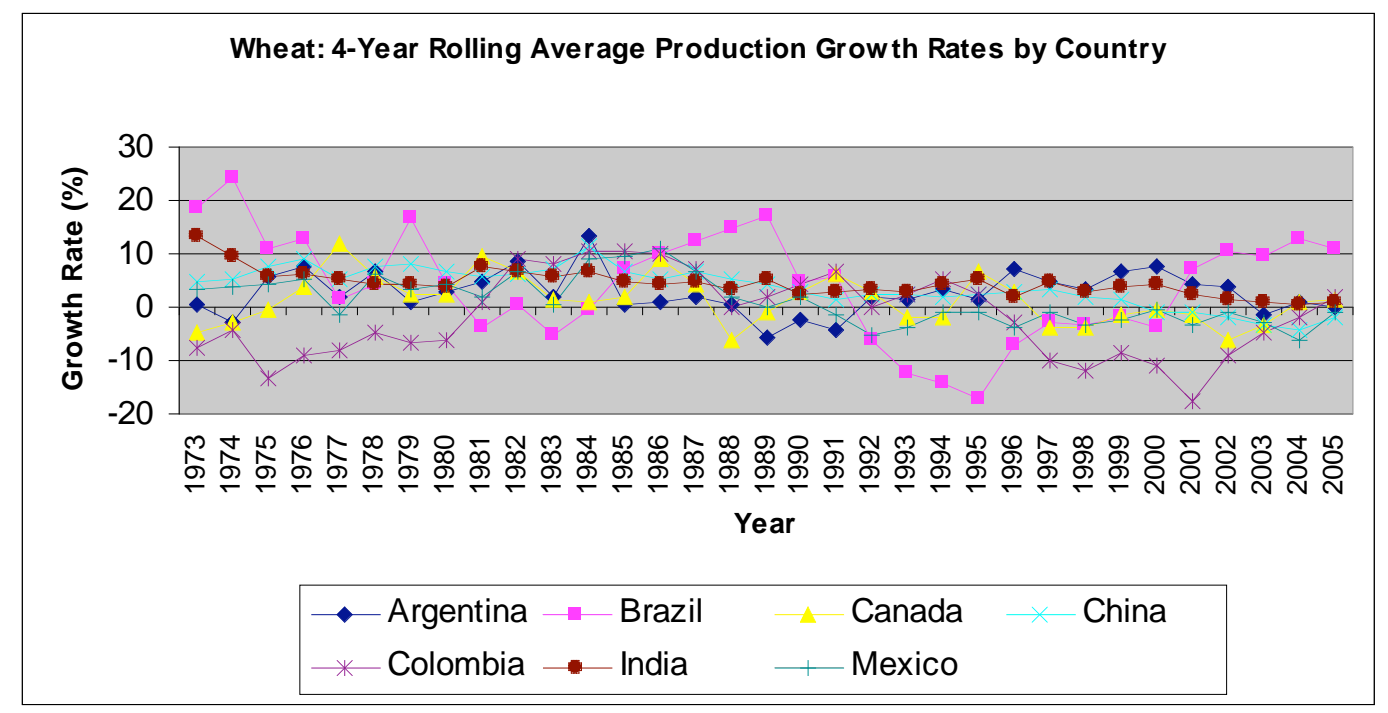

Figure 2e. Wheat: 7-Year Rolling Average Production Growth Rates by Country.

\section{Limitations of the Projection Model and Approach}

In a broad sense, the analysis is limited by time and resources to a sample of selected countries and traditional feedstock crops within those countries. The methodology uses historic production and price data that does not lend itself to new or novel crops only recently being developed for biofuel production, such as tropical sugar beets and cassava in Colombia or Jatropha in India and China. Several data limitations and assumptions are described in the methodology above. The lack of access to a consistent set of state-level data on production and prices was a problematic limitation for several country-crop combinations. Assumptions and limitations that influence the approach and resulting projections include the following.

1. In some states, the historic trend data produce initial calculations of negative rates of growth in area harvested. The methodology does not project these negative rates into the future. The falling rates are typically found in "high cost" producing states. The methodology holds production in these states constant at the "starting point" level (usually 2005). This assumption maintains a state's production potential in the supply projections at the most recent reported values and basically assumes that any future reductions in harvested area would be off-set by land returning to production in the state. This assumption reflects the intent of this study to illustrate total future production potential at various prices in the supply curves. However, allowing these states to maintain production levels in the face of historic declines may tend to inflate the estimated future supplies.

2. Growth is assumed to continue at recent historic rates throughout the time periods of study, subject to the bounds described above. This, combined with the long term nature of the projections and the assumption above, will tend to generate an optimistic result for commodities that have experienced recent surges in growth or large shifts in production across states during the 2000-2005 period.

3. The approach assumes that the price/value structure for producers in each state remains the same as the year on which the projections are based (i.e. 2005 in most cases) throughout the period of study. This is not likely to be the case, but this limitation cannot be remedied without better data on unit costs of production. The supply curve projections' sensitivity to this assumption is off-set somewhat 
by applying the "plausible limits" to state growth rates and by setting the overall baseline to be within one standard deviation of the calculated mean of the 7-year rolling averages, as described above.

4. The net effect of the three prior assumptions is likely to be amplified over longer term projections (2017 and 2027) where the constant growth rates result in large potential production levels.

Additional research could adjust these longer term projections based upon finer analysis of physical, environmental and social constraints.

5. The use of historic data to estimate plausible limits for growth could deflate potential supply capacity if market and price structures or government policies change substantially compared to the past.

6. The upper limits for yields and area under cultivation in a state were set using informed judgment based on broad trends and averages rather than empirical data for a given state. As recommended under "Next Steps," it would be preferable to conduct additional research in priority nations to improve the basis for establishing plausible limits on a case-by-case basis.

7. Different definitions for costs, prices and producer "values" in the various data sets available from sources in each nation, as discussed earlier, adds uncertainty to any cost comparisons across commodities and especially across nations. Vertically integrated industries, fluctuating exchange rates, and different national systems to collect and report price and value data tend to reduce the reliability of cost information. In some cases, state data were not available and average national data had to be used. While the methodology attempts to convert all measures of costs to a purchaser's value to reflect the input price that would be paid for biofuel uses, it may be misleading to make comparisons across nations based on value data derived from different sources.

The approach used the best data available at a state level whenever this level of detail was available. Despite many limitations, the approach offered an effective mechanism for improving and updating data inputs for modeling feedstock supplies. 


\section{ESTIMATING POTENTIAL SUPPLY OF CELLULOSIC BIOMASS}

\section{Biomass Residue as a Function of Feedstock Production: Corn, Wheat and Soybean}

Potential biomass feedstock supply from agricultural residues is estimated here using a set of assumptions developed in the "Billion Ton Study" (DOE 2005) as a starting point. Parameters calculated in that study include an estimated ratio for total biomass produced per unit of grain harvested, total recoverable biomass, and a factor for the amount of biomass crop residues that could be removed without detriment to future crop productivity (a "sustainable removal rate"). These factors, as calculated for US production of corn, wheat and soybeans, ${ }^{\text {cclxxiv }}$ are summarized in the first three columns of Annex 3, Table 2 below. They provide a starting point for estimating similar factors for residue availability adjusted to local conditions as described in each country specific analysis in this study.

\section{Annex 3 - Table 2. Biomass Production, Crop Yields and Recovery Estimates}

\begin{tabular}{|c|c|c|c|c|c|c|}
\hline Baseline residue recovery potential & corn & wheat & $\begin{array}{l}\text { Soy } \\
\text { bean }\end{array}$ & $\begin{array}{l}\text { Sugar } \\
\text { cane } \\
\text { cclxxv }\end{array}$ & $\begin{array}{c}\text { Palm } \\
\text { Oil } \\
\text { cclxxvi }\end{array}$ & $\begin{array}{l}\text { Peren- } \\
\text { nial }^{\text {cllxxii }}\end{array}$ \\
\hline $\begin{array}{l}\text { Total production ratio of } \\
\text { residue/product }^{\text {cllxvviii }}\end{array}$ & 1 & 1.7 & 1.5 & - & - & $4.4 \mathrm{mt} / \mathrm{ha}$ \\
\hline Residue/product ratio available at mill & 0 & 0 & 0 & .25 & $1-2$ & \\
\hline $\begin{array}{l}\text { Potential sustainable residue removal (as } \\
\% \text { of total residue noted above) }\end{array}$ & $33 \%$ & $14 \%$ & $0 \%$ & $56 \%$ & $50 \%$ & $50 \%$ \\
\hline $\begin{array}{l}\text { Sustainable residue recovery as } \% \text { of total } \\
\text { production (of grain, sugarcane, palm } \\
\text { oil) }\end{array}$ & $28 \%$ & $21 \%$ & $0 \%$ & $14 \%$ & $60 \%$ & n.a. \\
\hline $\begin{array}{l}\text { Avg. biomass supply potential - } \\
\text { recoverable - dry } \mathrm{mt} / \mathrm{ha}^{\mathrm{ccl} \times \mathrm{x} x \mathrm{i}}\end{array}$ & 2.4 & 0.5 & 0 & $\begin{array}{c}10.5 \\
\text { ccllxxxii }\end{array}$ & 2.4 & 2.2 \\
\hline $\begin{array}{l}\text { Avg. estimated cost delivered to mill } \\
\text { (US } \$ / \text { mt dry weight) }\end{array}$ & $\$ 52$ & $\$ 52$ & n.a. & $\underset{\text { cclxxxiv }}{\$ 8.4}$ & $\$ 1$ & $\underset{c c 1 \times x \times v}{\$ 52}$ \\
\hline
\end{tabular}

\section{Biomass from Sugarcane Production}

The processing of one tonne of sugarcane produces about $280 \mathrm{~kg}$ of bagasse with about $50 \%$ average moisture and 13-15\% dry fiber. ${ }^{\text {cllxxxvi }}$ There is an additional estimated 50-250 kg of "trash" (leaves and straw) potentially available with the wide range depending on the harvest and collection process used. Most of this is usually left in the fields. The sugar mills and ethanol plants are usually designed to crush the sugarcane and process the solid cane residue, bagasse, for combustion on site. The energy value in the bagasse is greater than sugar mill processing thermal requirements. Therefore, the combustion processes in mills was traditionally thermally inefficient because there was a need to dispose of the bagasse on site. As the value of energy and bagasse has increased, many sugarcane processing plants are upgrading their equipment to make more efficient use of bagasse and other byproducts. There is growing use of efficient co-generation systems that produce heat for processing and electric power that can serve the mill and in many areas, be sold back to the grid. This transition is catalyzed where higher prices and government regulations facilitate profitable participation of private power producers such as sugar mills in national electricity markets. ${ }^{\text {cclxxxvii }}$

The total amount of bagasse that could be available is calculated based on the projected amount of sugarcane production. Available bagasse is reported on an equivalent dry biomass basis at the rate of 140 $\mathrm{kg}$ of bagasse for each tonne of sugarcane (half the total weight generated). With efficient systems, researchers suggest that only $25-30 \%$ of available bagasse will be needed to meet process heat needs at a 
processing plant, leaving the majority available as a potential feedstock for cellulosic biofuel production while maintaining a self-sufficient energy supply system for the plant. ${ }^{\text {clxxxviii }}$ Although there are not formal or consistent markets for bagasse, spot markets can occur. Excess bagasse is also used as a fiber feedstock for paper production in some localities. An estimated opportunity cost is assigned for this analysis based on reported values occasionally observed in Brazil of approximately $\$ 1 / \mathrm{MJ}$, or $\$ 8.40$ per metric tonne. This value is adjusted somewhat based on information about demand and markets in each country studied. ${ }^{\text {cllxxxix }}$

\section{Biomass from Palm Oil Production}

Biomass residue from palm oil production that could be available for cellulosic conversion to biofuel is estimated based on the following assumptions ${ }^{\text {ccxc }}$ :

(a) Approximately 20 metric tonnes (mt) of fresh fruit bunches are harvested per hectare (Colombia, 2005 average) producing about $4 \mathrm{mt}$ of raw palm oil. The average ratio of the weight of fresh fruit bunches processed to palm oil produced is 5:1.

(c) Total biomass availability: Processing palm oil generates approximately $44 \%$ of the fresh fruit bunch weight as solid residue in the form of empty fruit bunches, shells, and fiber. The remaining residues are in liquid effluent form after processing. Thus, for each tonne of palm oil produced, approximately $1.2 \mathrm{mt}$ of solid biomass residues (equivalent dry basis) are available at the processing plant.

Assuming $4 \mathrm{mt}$ of palm oil per hectare, this is an average of $4.8 \mathrm{mt}$ of residue per hectare. Additional biomass residues generated by a palm oil plantation includes the solids suspended in effluents and large amounts of biomass left in the fields in the form of palm fronds, thinned vegetation, and the palm trees themselves that are periodically replaced.

(d) An estimate of "sustainable recovery" under typical operations in this case assumes that $50 \%$ of the biomass residue available will either be returned to fields as additional fertilizer/conditioner or used for thermal processing (combustion on site).

(e) The biomass (equivalent dry basis) assumed to be readily available on site with zero or minimal opportunity costs is $2.4 \mathrm{mt}$ per hectare or $0.6 \mathrm{mt}$ for every tonne of palm oil produced. This is the amount assumed to be sustainably recoverable for potential use as cellulosic feedstock based on existing practices. This fraction could increase significantly in the future with improved processing plant efficiency such as that taking place in sugar mills.

Processing plants are usually centrally located among large palm plantations and this limits the viability of alternate (off-site) markets for excess biomass residues. The assumptions used for the sustainable recovery rate above allow for a significant portion of total residues to return to fields for soil conservation as well as a portion for direct combustion to meet thermal needs of the mill. At that recovery rate, the opportunity cost is assumed to be minimal for this biomass since it is already at the mill with no alternative markets or demands. Any additional handling costs on site would be off-set by avoiding the handling needed for disposal. The amount available could double assuming higher opportunity costs.

\section{Biomass from Perennials}

In this study, estimates of potential perennial biomass production are included for illustrative purposes. The methodology for calculating the potential from perennials is designed to provide an estimate of the relative scale among the countries studied based upon the amount of land available. In several countries, large expanses of uncultivated arable lands are reported as being available for future productive purposes. Because the productive capacity of these lands varies considerably, the methodology used a data set from 
FAO "TerraStat" that adjusted total potential arable land according to productivity factors to put it on a more comparable basis. ${ }^{\text {ccxci }}$

Annex 3 - Table 3. Calculations for Estimating Relative Potential from Perennials

\begin{tabular}{|c|c|c|c|c|c|c|c|}
\hline $\begin{array}{c}\text { Land Units } \\
\text { in millions of } \\
\text { hectares } \\
\text { Country }\end{array}$ & $\begin{array}{l}\text { Total land } \\
\text { available } \\
\text { "equivalent } \\
\text { suitable for } \\
\text { cultivation" }\end{array}$ & $\begin{array}{c}\text { Actually } \\
\text { Cultivated } \\
\text { or in } \\
\text { Permanent } \\
\text { Crops }\end{array}$ & $\begin{array}{c}\text { Available } \\
\text { Equivalent } \\
\text { Arable } \\
\text { Land }\end{array}$ & $\begin{array}{c}\mathbf{5 \%} \text { of } \\
\text { "available" } \\
\text { m ha } \\
(\mathbf{2 0 1 7})\end{array}$ & $\begin{array}{c}10 \% \text { of } \\
\text { "available" } \\
\text { m ha } \\
(2027)\end{array}$ & $\begin{array}{c}\text { Potential } \\
\text { Cellulosic } \\
\text { Supply } \\
2017 \text { (dry } \\
\text { mmt) }\end{array}$ & $\begin{array}{c}\text { Est. } \\
\text { Potential } \\
\text { Cellulosic } \\
\text { Supply 2027 } \\
\text { (dry mmt) }\end{array}$ \\
\hline Argentina & 71 & 29 & 42 & 2.1 & 4.2 & 4.7 & 9.5 \\
\hline Brazil & 394 & 67 & 327 & 16.4 & 32.7 & 36.6 & 73.3 \\
\hline Canada & 76 & 52 & 24 & 1.2 & 2.4 & 2.7 & 5.3 \\
\hline China & 138 & 127 & 11 & 0.5 & 1.1 & 1.2 & 2.4 \\
\hline Colombia & 48 & 4 & 44 & 2.2 & 4.4 & 4.9 & 9.9 \\
\hline India & 169 & 170 & 0 & 0.0 & 0.0 & 0.0 & 0.0 \\
\hline Mexico & 36 & 27 & 9 & 0.5 & 0.9 & 1.0 & 2.1 \\
\hline CBI & \multicolumn{5}{|c|}{ (not calculated for individual countries -- an estimate is included) } & 1.0 & 2.1 \\
\hline Total & & & & 22.9 & 45.7 & 52.2 & 104.5 \\
\hline
\end{tabular}

The "Available equivalent arable land" is based on the total potential (from TerraStat) less the land reported as in use per FAOStat [(available area) $-($ arable land + permanent crops $)=$ available equivalent]. The same standard percentage is applied in each country (5\% in 2017 and 10\% in 2027) to provide an estimate of the relative scale of land that could potentially serve for biomass production. In practice, land already in use in permanent crops could be converted to biomass production if markets and policies support it, especially if land is only marginally productive under existing land use regimes. To estimate the cellulosic supply available per hectare, a conservative factor of about 2.2 dry mt per hectare per year was used as an average rate of recovery, as explained below.

The recover rate assumes that perennial production and harvest for biofuel would be from less productive lands and that the average cumulative future production potential (estimated here over large total available land areas) will be significantly less than that which would be expected from a "bioenergy plantation" in an intensive operation. Tables 2 and 3 assume an average annual productivity of 4.5 dry $\mathrm{mt} / \mathrm{ha}$ (or $2 \mathrm{dt} / \mathrm{acre}$ ) and a "50\% sustainable recovery" rate equivalent to an average of $2.24 \mathrm{dt} / \mathrm{ha}-\mathrm{yr}$. This conservative average recovery rate assumes that a significant portion of the perennial production will be from multiple-use lands where management could include goals for conservation of watersheds, biodiversity and other ecosystem services, producing significant benefits independent from biomass yields. Biomass harvesting also may derive from integrated management plans including thinning and fire control on these lands. In the long term, assuming that economic conversion technologies become available, perennial biomass production offers the potential to increase the economic benefits from marginal lands and, when properly managed, could simultaneously enhance benefits such as erosion control and carbon sequestration. Even after harvest, these benefits can be derived from the roots, stumps and forest litter that remain.

Projections of perennial biomass potential for cellulosic biofuel production can be improved significantly in the future. With better definition of the relationships between technology costs and feedstock characteristics, the assumptions regarding species, productivity, harvesting and associated costs can be greatly improved. In this study, the purpose is to merely give a general idea of the relative scale of future 
potential related to land availability. If additional country-level data are available for projections, these are also noted. Average productivity will vary significantly by country, climate zone and local conditions.

\section{Biomass from Forest Residues}

Harvesting, processing and use of trees produce a considerable amount of residues. These include branches, stumps and leaves that are usually separated from the tree trunk and left in the field during logging. Sawmill processing and carpentry also generates bark, sawmill rejects and trimming residues. In many developing countries these residues are a major source of domestic cooking fuel.

Estimates of potential cellulosic feedstock from forest residues are based on FAO data on non-coniferous (NC) roundwood production and fuelwood supplies in each country, as shown below. Residues from harvests and sawmills were estimated by applying factors based on a Canadian study (Bradley, 2006) to the overall roundwood production data. Estimated prices for forest industry and mill residues were also based on the same source (Bradley). A standard conversion factor used for forestry reporting by FAO was applied for non-coniferous fuelwood: $725 \mathrm{~kg} / \mathrm{CUM}$ and $30 \%$ average moisture content was assumed. The proportion of current fuelwood uses potentially available for future bioenergy feedstock is assumed to be $50 \%$. Prices for fuelwood were estimated using prices reported in the FAO database. ${ }^{\text {cxcii }}$ The corresponding supply estimates and costs are presented in Chapter Three for each country.

\section{Annex 3 - Table 4. Source Data for Roundwood and Fuelwood Supply Estimates}

\begin{tabular}{|c|c|c|c|c|c|}
\hline \multirow[b]{2}{*}{ Country } & $\begin{array}{r}\text { Roundwood } \\
\text { Production }\end{array}$ & $\begin{array}{r}\text { FAO 2005: } \\
\text { Fuelwood } \\
\text { (NC) }\end{array}$ & $\begin{array}{r}\text { Calculated } \\
\text { fuelwood } \\
\text { equivalent }\end{array}$ & $\begin{array}{l}\text { Estimate } \\
50 \% \text { mkt } \\
\text { available }\end{array}$ & $\begin{array}{r}\text { Estimated } \\
\text { Avg. } \\
\text { Price (a) }\end{array}$ \\
\hline & million CUM & million CUM & dry $\mathrm{mmt}$ & $\mathrm{mmt}$ & US\$/mt \\
\hline Argentina & 14.92 & 5.56 & 2.82 & 1.41 & $\$ 13$ \\
\hline Brazil & 255.88 & 123.99 & 62.92 & 31.46 & $\$ 14$ \\
\hline Canada & 199.35 & 2.46 & 1.25 & 0.62 & $\$ 42$ \\
\hline China & 286.10 & 113.73 & 57.72 & 28.86 & $\$ 42$ \\
\hline Colombia & 9.66 & 8.02 & 4.07 & 2.04 & $\$ 42$ \\
\hline India & 328.68 & 296.30 & 150.37 & 75.19 & $\$ 42$ \\
\hline Mexico & 44.65 & 26.91 & 13.66 & 6.83 & $\$ 50$ \\
\hline $\begin{array}{l}\mathrm{CBI} \text { - estimate based } \\
\text { on available FAO Data }\end{array}$ & 48.39 & (estimated) & & 7.4 & $\$ 27$ \\
\hline Total & & & & 154 & \\
\hline
\end{tabular}


Annex 3 - Table 5. Calculated Estimate of Residues as Factor of Roundwood Production

\begin{tabular}{|lrrr|}
\hline \multicolumn{4}{|r|}{ Forest Sector Residues } \\
$\begin{array}{r}\text { Amts in } \\
\text { bone dry } \\
\text { mmt per yr }\end{array}$ & $\begin{array}{r}\text { Residues at } \\
\text { mills }(\$ 18- \\
36 / d m t)\end{array}$ & $\begin{array}{r}\text { Harvest } \\
\text { residues } \\
(\$ 50-\end{array}$ \\
$100 / \mathrm{dmt})$ & $\begin{array}{r}\text { Total forest } \\
\text { residues }\end{array}$ \\
\hline Argentina & 0.14 & 0.31 & 0.5 \\
Brazil & 2.41 & 5.36 & 7.8 \\
Canada & 1.87 & 4.17 & 6.0 \\
China & 2.69 & 5.99 & 8.7 \\
Colombia & 0.09 & 0.20 & 0.3 \\
India & 3.09 & 6.88 & 10.0 \\
Mexico & 0.42 & 0.94 & 1.4 \\
\hline CBI $^{*}$ & 0.45 & 1.01 & 1.5 \\
\hline Total & 11.2 & 24.9 & 36.0 \\
\hline
\end{tabular}




\section{Chapter Endnotes for Methodology, Annex 3}

cclxxiii This study often uses FAO data available online at http://faostat.fao.org/default.aspx. This webpage includes links to data sets on agricultural production (ProdStat), forestry (ForeStat), natural resources (soil and water) (ResourceStat), prices (PriceStat) and land use (TerraStat).

cclxxiv Perlack et.al. 2005: the baseline and current availability of biomass from agricultural land are based on USDA 2001 data and are presented in the "Billion Ton Study" as Appendix B, Tables B.1 and B.2.

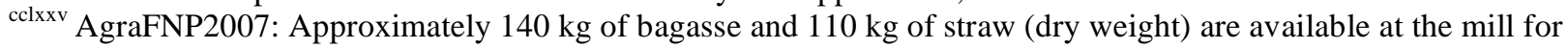
every tonne of sugarcane processed.

${ }_{\text {cclxxvi }}$ Arrieta et.al. 2007; Rupilius and Ahmad 2007; and NEPO 2000: Total palm oil residues include empty fruit bunches, fibers and shells (solid by-products) and palm mill liquid effluents. This estimate reflects the total dry weight biomass equivalent per tonne of palm oil, but only the solids are considered to be available for sustainable recovery in this analysis.

${ }^{\text {cclxxvii }}$ Many broad assumptions underpin these estimates: land not used for crops is less productive, marginal lands. A variety of perennials may be harvested including natural mixed stands. The assumed average productivity is 4.5 $\mathrm{mt} / \mathrm{ha}$ (dry weight; or 2 short tons/acre) of biomass per year. This reflects the baseline estimate of productivity from conservation set-aside or "CRP" lands in the Billion-Ton Study Table B.2 (Perlack et.al. 2005). Since some portion of typical unused crop land may be inaccessible for harvest or merit management for conservation of riparian areas, wildlife and biodiversity, this average productivity rate is combined with a 50\% "sustainable" recovery rate. These levels of production and recovery are conservative compared to other estimates. For example, Tillman 2001 calculated that up to 6.7 dry tons/ha-year of mixed biomass could be harvested as a sustainable yield from perennials in Minnesota. These rates will vary greatly in practice and may be adjusted for specific conditions in the countries under study.

cclxxviii This ratio is on a dry weight basis and represents the total biomass produced and available in the field at time of harvest for corn, wheat and soybeans, following the example in Perlack et.al.2005. A smaller amount can be recovered, still smaller amounts can be "sustainably recovered," and final amounts recoverable will depend on defining price tiers, which in turn depend on density and many other factors that impact the economics of recovery. For bagasse and palm oil, this ratio is calculated differently as it represents the amount of biomass that is typically harvested and delivered to the processing plant. Here it is calculated as the ratios of: bagasse to sugarcane and palm residues to palm oil.

${ }^{\text {cclxxix }}$ See the analysis and references in the Billion Ton Study (Perlack et.al. 2005). This percentage allows for a majority of the residue to remain in the field for soil conservation, conditioning, and nutrient replenishment.

${ }^{\text {cclxxx }}$ This percentage incorporates a factor for moisture content in harvested grain, assuming corn is $15.5 \%$ moisture, and wheat at $13.5 \%$ moisture.

${ }_{\text {cclxxxi }}$ This factor is shown for reference only. It represents the calculated average "sustainable recovery rate" of biomass for the crop at the given price. Given that this factor was derived from average US data, it is only applicable to assumed production from agricultural systems with yields, costs and operations comparable to the baseline used in the Billion Ton Study (average farm yields in the U.S. in 2001).

cclxxxii For sugarcane, this estimate assumes an average production of 75 metric tons $(\mathrm{mt})$ of sugarcane per hectare and 0.14 dry $\mathrm{mt}$ of bagasse per $\mathrm{mt}$ of sugarcane processed. This is conservative compared to efficient producers today and the estimates made in this study will be based on the projected future yields in each country analyzed. The large quantity of available biomass per unit of land illustrates the significance of bagasse as a potential feedstock for future cellulosic ethanol processing.

cclxxxiii This reflects the cost of collection and transport from field to processing plant, and therefore can vary widely depending on harvest methods and distances. An average value is included for reference in the Table based on the calculations used for the Billion Ton Study. This value was adjusted when there was evidence of differences in the local economies of the countries studied.

cclxxxiv This reflects an estimated "opportunity cost" for using the bagasse for biofuel rather than other uses.

${ }^{c c l x x x v}$ This assumes that perennial production costs are more or less the same as those for commercial agricultural residues after taking into account the lower yield per hectare for residues, the value of removed nutrients and other benefits, and considerations as to where perennials would compete.

cclxxxvi Based on Brazil analysis (AgraFNP2007): An additional $110 \mathrm{~kg}$ of straw and other residue are estimated to be potentially available for each tonne of sugarcane processed, but this material is not included in the present analysis as it is assumed to serve environmental purposes (soil conditioner) and it would require additional collection and 
handling (higher cost); the bagasse is already available on the production site and final residues after sugar processing are normally applied to fields as fertilizer under existing operations.

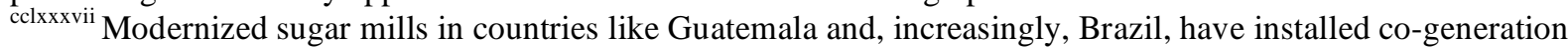
systems to be self-sufficient for thermal and electric power and export excess electricity at a profit to the national grid. This power is supplied when its value is at a premium due to the dry season and alternate hydro sources.

During the dry season, sugar mills are running at full capacity while run-of-river hydro is at lowest capacity. In these operations, bagasse has a higher opportunity cost (based on electricity rates) and its utilization is much more efficient.

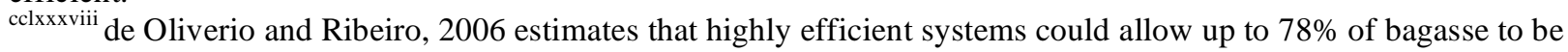
available for other purposes after thermal needs are met; that appears optimistic for the medium term.

${ }^{\text {cclxxxix }}$ Bradley 2006 reported US\$1/MJ as an approximate value (in 2005 US\$) observed occasionally in Brazil. AgraFNP 2007 reported occasional spot markets for bagasse reaching prices similar to raw sugar cane. But more often, it is given very little value. The actual opportunity cost could vary significantly from site to site, depending on how much bagasse is required for primary processing, whether the facility is set up for cogeneration, relative prices for electricity versus alternate potential products (including, eventually, cellulosic ethanol), and the availability and costs of alternate fuels in the locality of the plant. If data are available, the local value for fuelwood may also offer a reference point.

${ }^{\text {ccxc }}$ Arrieta et.al. 2007 and NEPO 2000.

${ }^{\text {ccxci }}$ Based on definitions for agricultural potential from rain-fed arable lands as defined in the Food and Agricultural Organization (FAO) 2000 World Soil Resources Report, "LAND RESOURCE POTENTIAL AND CONSTRAINTS AT REGIONAL AND COUNTRY LEVELS.” See: ftp://ftp.fao.org/agl/agll/docs/wsr.pdf

${ }^{\text {ccxcii }}$ Avg. fuelwood prices derived from \$/CUM prices in FAO Forest Resource Assessment 2005 http://www.fao.org/docrep/008/a0400e/a0400e00.htm 


\title{
ANNEX 4. SUPPLY CURVE DATA TABLES, BY COUNTRY
}

\author{
Argentina \\ Brazil \\ Canada \\ China \\ Colombia \\ India \\ Mexico \\ and \\ Caribbean Basin Initiative (CBI) Region \\ and \\ AGGREGATE SUPPLY DATA TABLES \\ Sugarcane \\ Soybeans \\ Corn \\ Wheat \\ Palm Oil \\ Cellulosic Resources
}


Argentina Table 1. Baseline Case Supply Potential for Wheat

\begin{tabular}{ccccc}
\hline $\begin{array}{c}\text { Production } \\
\text { Unit } \\
\text { (Province) }\end{array}$ & $\begin{array}{c}\text { Average Cost } \\
\text { (US\$/tonne) }\end{array}$ & $\begin{array}{c}\text { Cumulative } \\
\text { Production } \\
(\mathbf{m m t})\end{array}$ & $\begin{array}{c}\text { Cumulative } \\
\text { Production } \\
(\mathbf{m m t})\end{array}$ & $\begin{array}{c}\text { Cumulative } \\
\text { Production } \\
(\mathbf{m m t})\end{array}$ \\
\hline & $\mathbf{2 0 0 5}$ & $\mathbf{2 0 1 2}$ & $\mathbf{2 0 1 7}$ & $\mathbf{2 0 2 7}$ \\
\hline $\mathrm{a}$ & $\$ 121.6$ & 2.2 & 2.5 & 2.7 \\
$\mathrm{~b}$ & $\$ 121.6$ & 2.4 & 2.7 & 2.9 \\
$\mathrm{c}$ & $\$ 126.8$ & 2.5 & 2.8 & 3.0 \\
$\mathrm{~d}$ & $\$ 126.8$ & 2.6 & 2.9 & 3.2 \\
$\mathrm{e}$ & $\$ 126.8$ & 2.6 & 2.9 & 3.2 \\
$\mathrm{f}$ & $\$ 126.8$ & 3.5 & 3.9 & 4.3 \\
$\mathrm{~g}$ & $\$ 126.8$ & 3.5 & 3.9 & 4.3 \\
$\mathrm{~h}$ & $\$ 126.8$ & 3.5 & 4.0 & 4.4 \\
$\mathrm{i}$ & $\$ 126.8$ & 3.6 & 4.1 & 4.5 \\
j & $\$ 126.8$ & 3.6 & 4.1 & 4.5 \\
$\mathrm{k}$ & $\$ 126.8$ & 3.9 & 4.4 & 4.9 \\
l & $\$ 126.8$ & 4.3 & 4.8 & 5.4 \\
$\mathrm{~m}$ & $\$ 128.1$ & 12.8 & 13.9 & 15.1 \\
$\mathrm{n}$ & $\$ 131.1$ & 15.1 & 16.5 & 17.9 \\
\hline
\end{tabular}

Argentina Table 2. High Growth Case Supply Potential for Wheat

\begin{tabular}{ccccc}
\hline $\begin{array}{c}\text { Production } \\
\text { Unit } \\
\text { (Province) }\end{array}$ & $\begin{array}{c}\text { Average Cost } \\
\text { (US\$/tonne) }\end{array}$ & $\begin{array}{c}\text { Cumulative } \\
\text { Production } \\
(\mathbf{m m t})\end{array}$ & $\begin{array}{c}\text { Cumulative } \\
\text { Production } \\
(\mathbf{m m t})\end{array}$ & $\begin{array}{c}\text { Cumulative } \\
\text { Production } \\
(\mathbf{m m t})\end{array}$ \\
\hline & $\mathbf{2 0 0 5}$ & $\mathbf{2 0 1 2}$ & $\mathbf{2 0 1 7}$ & $\mathbf{2 0 2 7}$ \\
\hline $\mathrm{a}$ & $\$ 121.6$ & 3.34 & 4.55 & 5.78 \\
$\mathrm{~b}$ & $\$ 121.6$ & 3.56 & 4.77 & 5.99 \\
$\mathrm{c}$ & $\$ 126.8$ & 3.68 & 4.98 & 6.32 \\
$\mathrm{~d}$ & $\$ 126.8$ & 3.99 & 5.55 & 7.16 \\
$\mathrm{e}$ & $\$ 126.8$ & 4.00 & 5.56 & 7.17 \\
$\mathrm{f}$ & $\$ 126.8$ & 5.29 & 7.26 & 9.51 \\
$\mathrm{~g}$ & $\$ 126.8$ & 5.30 & 7.29 & 9.58 \\
$\mathrm{~h}$ & $\$ 126.8$ & 5.33 & 7.36 & 9.71 \\
$\mathrm{i}$ & $\$ 126.8$ & 5.53 & 7.72 & 10.25 \\
j & $\$ 126.8$ & 5.57 & 7.83 & 10.48 \\
$\mathrm{k}$ & $\$ 126.8$ & 6.19 & 8.95 & 12.16 \\
1 & $\$ 126.8$ & 6.73 & 9.70 & 13.09 \\
$\mathrm{~m}$ & $\$ 128.1$ & 17.43 & 22.36 & 28.39 \\
$\mathrm{n}$ & $\$ 131.1$ & 20.73 & 26.68 & 34.27 \\
\hline
\end{tabular}


Argentina Table 3. Low Growth Case Supply Potential for Wheat

\begin{tabular}{ccccc}
\hline $\begin{array}{c}\text { Production } \\
\text { Unit } \\
\text { (Province) }\end{array}$ & $\begin{array}{c}\text { Average } \\
\text { Cost } \\
(\mathbf{U S} \mathbf{\$} / \text { tonne) }\end{array}$ & $\begin{array}{c}\text { Cumulative } \\
\text { Production } \\
(\mathbf{m m t})\end{array}$ & $\begin{array}{c}\text { Cumulative } \\
\text { Production } \\
(\mathbf{m m t})\end{array}$ & $\begin{array}{c}\text { Cumulative } \\
\text { Production } \\
(\mathbf{m m t})\end{array}$ \\
\hline a & $\mathbf{2 0 0 5}$ & $\mathbf{2 0 1 2}$ & $\mathbf{2 0 1 7}$ & $\mathbf{2 0 2 7}$ \\
\hline $\mathrm{b}$ & $\$ 121.6$ & 1.7 & 1.7 & 1.7 \\
$\mathrm{c}$ & $\$ 126.6$ & 1.9 & 2.0 & 2.0 \\
$\mathrm{~d}$ & $\$ 126.8$ & 2.0 & 2.0 & 2.0 \\
$\mathrm{e}$ & $\$ 126.8$ & 2.1 & 2.1 & 2.1 \\
$\mathrm{f}$ & $\$ 126.8$ & 2.1 & 2.1 & 2.1 \\
$\mathrm{~g}$ & $\$ 126.8$ & 2.8 & 2.8 & 2.8 \\
$\mathrm{~h}$ & $\$ 126.8$ & 2.8 & 2.8 & 2.8 \\
$\mathrm{i}$ & $\$ 126.8$ & 2.9 & 2.8 & 2.8 \\
$\mathrm{j}$ & $\$ 126.8$ & 2.9 & 2.9 & 2.9 \\
$\mathrm{k}$ & $\$ 126.8$ & 3.0 & 2.9 & 2.9 \\
1 & $\$ 126.8$ & 3.3 & 3.1 & 3.1 \\
$\mathrm{~m}$ & $\$ 128.1$ & 10.8 & 3.3 & 3.3 \\
$\mathrm{n}$ & $\$ 131.1$ & 12.7 & 10.8 & 10.9 \\
\hline
\end{tabular}

Argentina Table 4. Baseline Case Supply Data for Soybean

\begin{tabular}{ccccc}
\hline $\begin{array}{c}\text { Production } \\
\text { Unit } \\
\text { (Province) }\end{array}$ & $\begin{array}{c}\text { Average Cost } \\
\text { (US\$/tonne) }\end{array}$ & $\begin{array}{c}\text { Cumulative } \\
\text { Production } \\
(\mathbf{m m t})\end{array}$ & $\begin{array}{c}\text { Cumulative } \\
\text { Production } \\
(\mathbf{m m t})\end{array}$ & $\begin{array}{c}\text { Cumulative } \\
\text { Production } \\
\text { (mmt) }\end{array}$ \\
\hline a & $\mathbf{2 0 0 5}$ & $\mathbf{2 0 1 2}$ & $\mathbf{2 0 1 7}$ & $\mathbf{2 0 2 7}$ \\
\hline b & $\$ 213.4$ & 11.2 & 11.7 & 12.5 \\
c & $\$ 214.7$ & 24.2 & 26.0 & 28.6 \\
d & $\$ 217.7$ & 24.9 & 27.1 & 31.0 \\
e & $\$ 217.3$ & 25.1 & 27.5 & 31.6 \\
f & $\$ 217.3$ & 25.1 & 27.5 & 31.6 \\
g & $\$ 217.3$ & 28.3 & 30.4 & 36.0 \\
h & $\$ 223.6$ & 30.6 & 31.8 & 37.9 \\
i & $\$ 223.6$ & 30.7 & 34.7 & 42.4 \\
j & $\$ 223.8$ & 44.3 & 34.9 & 42.9 \\
k & $\$ 223.8$ & 44.4 & 50.8 & 63.1 \\
l & $\$ 223.8$ & 46.9 & 51.1 & 63.7 \\
m & $\$ 238.0$ & 47.0 & 54.4 & 68.9 \\
n & $\$ 238.0$ & 50.3 & 54.6 & 69.4 \\
o & $\$ 238.0$ & 50.3 & 58.3 & 73.8 \\
\hline
\end{tabular}


Argentina Table 5. High Growth Case Supply Data for Soybean

\begin{tabular}{ccccc}
\hline $\begin{array}{c}\text { Production } \\
\text { Unit } \\
\text { (Province) }\end{array}$ & $\begin{array}{c}\text { Average Cost } \\
\text { (US\$/tonne) }\end{array}$ & $\begin{array}{c}\text { Cumulative } \\
\text { Production } \\
(\mathbf{m m t})\end{array}$ & $\begin{array}{c}\text { Cumulative } \\
\text { Production } \\
(\mathbf{m m t})\end{array}$ & $\begin{array}{c}\text { Cumulative } \\
\text { Production } \\
(\mathbf{m m t})\end{array}$ \\
\hline a & $\mathbf{2 0 0 5}$ & $\mathbf{2 0 1 2}$ & $\mathbf{2 0 1 7}$ & $\mathbf{2 0 2 7}$ \\
\hline $\mathrm{b}$ & $\$ 213.4$ & 11.7 & 12.7 & 14.1 \\
$\mathrm{c}$ & $\$ 214.7$ & 26.0 & 29.3 & 34.3 \\
$\mathrm{~d}$ & $\$ 214.7$ & 27.1 & 31.6 & 41.7 \\
$\mathrm{e}$ & $\$ 217.3$ & 27.4 & 32.2 & 43.2 \\
$\mathrm{f}$ & $\$ 217.3$ & 27.4 & 32.2 & 43.2 \\
$\mathrm{~g}$ & $\$ 217.3$ & 30.3 & 36.7 & 52.1 \\
$\mathrm{~h}$ & $\$ 223.6$ & 31.7 & 38.7 & 55.2 \\
$\mathrm{i}$ & $\$ 223.6$ & 34.5 & 43.2 & 64.0 \\
$\mathrm{j}$ & $\$ 223.8$ & 50.5 & 43.7 & 67.3 \\
$\mathrm{k}$ & $\$ 223.8$ & 50.7 & 64.2 & 97.0 \\
1 & $\$ 223.8$ & 54.0 & 64.8 & 99.7 \\
$\mathrm{~m}$ & $\$ 238.0$ & 54.2 & 70.1 & 110.3 \\
$\mathrm{n}$ & $\$ 238.0$ & 57.9 & 70.5 & 112.2 \\
o & $\$ 238.0$ & 57.9 & 74.9 & 118.0 \\
\hline
\end{tabular}

Argentina Table 6. Low Growth Case Supply Data for Soybean

\begin{tabular}{ccccc}
\hline $\begin{array}{c}\text { Production } \\
\text { Unit } \\
\text { (Province) }\end{array}$ & $\begin{array}{c}\text { Average Cost } \\
\text { (US\$/tonne) }\end{array}$ & $\begin{array}{c}\text { Cumulative } \\
\text { Production } \\
(\mathbf{m m t})\end{array}$ & $\begin{array}{c}\text { Cumulative } \\
\text { Production } \\
(\mathbf{m m t})\end{array}$ & $\begin{array}{c}\text { Cumulative } \\
\text { Production } \\
(\mathbf{m m t})\end{array}$ \\
\hline $\mathrm{2005}$ & $\mathbf{2 0 1 2}$ & $\mathbf{2 0 1 7}$ & $\mathbf{2 0 2 7}$ \\
\hline $\mathrm{a}$ & $\$ 213.4$ & 10.6 & 10.8 & 11.1 \\
$\mathrm{~b}$ & $\$ 214.7$ & 22.4 & 23.1 & 23.9 \\
$\mathrm{c}$ & $\$ 214.7$ & 22.9 & 23.6 & 24.6 \\
$\mathrm{~d}$ & $\$ 217.3$ & 23.0 & 23.8 & 24.9 \\
$\mathrm{e}$ & $\$ 217.3$ & 23.0 & 23.8 & 24.9 \\
$\mathrm{f}$ & $\$ 217.3$ & 24.7 & 25.6 & 27.0 \\
$\mathrm{~g}$ & $\$ 217.3$ & 25.6 & 26.6 & 28.2 \\
$\mathrm{~h}$ & $\$ 223.6$ & 27.3 & 28.5 & 30.4 \\
$\mathrm{i}$ & $\$ 223.6$ & 27.3 & 28.6 & 30.5 \\
$\mathrm{j}$ & $\$ 223.8$ & 38.9 & 40.9 & 44.0 \\
$\mathrm{k}$ & $\$ 223.8$ & 39.0 & 41.0 & 44.1 \\
1 & $\$ 223.8$ & 40.9 & 43.1 & 46.6 \\
$\mathrm{~m}$ & $\$ 238.0$ & 40.9 & 43.2 & 46.7 \\
$\mathrm{n}$ & $\$ 238.0$ & 43.9 & 46.3 & 50.1 \\
$\mathrm{o}$ & $\$ 238.0$ & 43.9 & 46.3 & 50.1 \\
\hline
\end{tabular}


Argentina Table 7. Supply Potential Data for Corn

\begin{tabular}{ccccc}
\hline $\begin{array}{c}\text { Production } \\
\text { Unit } \\
\text { (Province) }\end{array}$ & $\begin{array}{c}\text { Average Cost } \\
\text { (US\$/tonne) }\end{array}$ & $\begin{array}{c}\text { Cumulative } \\
\text { Production } \\
(\mathbf{m m t})\end{array}$ & $\begin{array}{c}\text { Cumulative } \\
\text { Production } \\
(\mathbf{m m t})\end{array}$ & $\begin{array}{c}\text { Cumulative } \\
\text { Production } \\
\text { (mmt) }\end{array}$ \\
\hline Low Growth & $\mathbf{2 0 0 5}$ & $\mathbf{2 0 1 2}$ & $\mathbf{2 0 1 7}$ & $\mathbf{2 0 2 7}$ \\
Baseline & 140.5 & 14.5 & 14.5 & 14.5 \\
High & $\mathbf{1 4 0 . 5}$ & $\mathbf{2 0 . 8}$ & $\mathbf{2 4 . 7}$ & $\mathbf{3 1 . 3}$ \\
Growth & 140.5 & 31.5 & 46.6 & 81.2 \\
\hline
\end{tabular}

Argentina Table 8. Supply Potential Data for Sugarcane

\begin{tabular}{ccccc}
\hline $\begin{array}{c}\text { Production } \\
\text { Unit } \\
\text { (Province) }\end{array}$ & $\begin{array}{c}\text { Average Cost } \\
\text { (US\$/tonne) }\end{array}$ & $\begin{array}{c}\text { Cumulative } \\
\text { Production } \\
\text { (mmt) }\end{array}$ & $\begin{array}{c}\text { Cumulative } \\
\text { Production } \\
\text { (mmt) }\end{array}$ & $\begin{array}{c}\text { Cumulative } \\
\text { Production } \\
\text { (mmt) }\end{array}$ \\
\hline Low Growth & $\mathbf{2 0 0 5}$ & $\mathbf{2 0 1 2}$ & $\mathbf{2 0 1 7}$ & $\mathbf{2 0 2 7}$ \\
Baseline & 34.3 & 20.2 & 20.9 & 21.9 \\
High & $\mathbf{3 4 . 3}$ & $\mathbf{2 4 . 6}$ & $\mathbf{2 8 . 1}$ & $\mathbf{3 3 . 8}$ \\
Growth & 34.3 & 30.0 & 37.9 & 52.8 \\
\hline
\end{tabular}

Argentina Table 9. Potential Percentage Allocation for Export \& Biofuels

\begin{tabular}{rccc}
\hline & $\begin{array}{c}\text { Percent of } \\
\text { Feedstock }\end{array}$ & $\begin{array}{c}\text { Percent of } \\
\text { Feedstock }\end{array}$ & $\begin{array}{c}\text { Percent of } \\
\text { Feedstock }\end{array}$ \\
\hline Wheat & $\mathbf{2 0 1 2}$ & $\mathbf{2 0 1 7}$ & $\mathbf{2 0 2 7}$ \\
Low Growth & 55 & 51 & 46 \\
Baseline & 62 & 62 & 62 \\
High Growth & 72 & 77 & 80 \\
Soybean & & & \\
Low Growth & 82 & 80 & 77 \\
Baseline & 84 & 84 & 84 \\
High Growth & 86 & 88 & 90 \\
Corn $\quad$ & 30 & 11 \\
Low Growth & 41 & 59 & 59 \\
Baseline & 59 & 78 & 84 \\
High Growth & 73 & 6 & 0 \\
Sugarcane & & 30 & 30 \\
Low Growth & 15 & 48 & 55 \\
Baseline & 30 & & \\
High Growth & 43 & & \\
\hline
\end{tabular}

(see note 6) 


\section{Argentina Table 10. Estimated Cellulosic Supply from Recoverable Crop Residues} (mmt, bone-dry, annual)

\begin{tabular}{|lccccccc|}
\hline & Baseline Case & \multicolumn{7}{c|}{ Low Growth } & High Growth Case & \\
& 2017 & 2027 & 2017 & 2027 & 2017 & 2027 & Cost \\
Wheat straw & 3.4 & 3.7 & 2.6 & 2.6 & 5.5 & 7.1 & $\$ 52$ \\
Bagasse & 3.9 & 4.7 & 2.9 & 3.1 & 5.3 & 7.4 & $\$ 10$ \\
Corn Stover & 7 & 8.8 & 4.1 & 4.1 & 13.1 & 22.9 & $\$ 52$ \\
Total & $\mathbf{1 4 . 3}$ & $\mathbf{1 7 . 2}$ & $\mathbf{9 . 6}$ & $\mathbf{9 . 8}$ & $\mathbf{2 3 . 9}$ & $\mathbf{3 7 . 4}$ & \\
\hline
\end{tabular}

Potential cellulosic feedstock supply is estimated based on the commodity supply case projections in this study. Amounts are in millions of metric tonnes, equivalent bone-dry weight. The supply available for wheat and corn is based on an estimated value of up to $\$ 52$ per metric tonne delivered. Given its present use for fuel and fiber, although bagasse is already available at the mills, it is estimated to have an opportunity cost of approximately $\$ 10$ per metric tonne.

Argentina Table 11. Estimated Cellulosic Supply Including Other Residues* (2017 baseline)

\begin{tabular}{|lcc|}
\hline & $\begin{array}{c}\text { Annual } \\
\text { Supply (mmt) }\end{array}$ & Cost US\$ \\
Agriculture Residues & 14.3 & (see Table 10) \\
Forest Harvest Residue & 0.3 & $\$ 50-\$ 100$ \\
Wood Residue & 0.1 & $\$ 18-\$ 36$ \\
Wood Fuel & 1.4 & $\$ 13$ \\
Crop and Forest Residues & $\mathbf{1 6 . 2}$ & \\
Perennials & & \\
$\quad$ 5\% Arable Land Harvest & 4.7 & $\$ 52$ \\
10\% Arable Land Harvest & 9.5 & $\$ 52$ \\
\hline
\end{tabular}


Brazil Table 1. Sugarcane - Baseline Case Supply Curve Data

\begin{tabular}{|c|c|c|c|c|}
\hline State & $\begin{array}{c}\text { Average } \\
\text { Value } \\
\text { (US\$/tonne) }\end{array}$ & $\begin{array}{l}\text { Cumulative } \\
\text { Production } \\
\quad(\mathbf{m m t})\end{array}$ & $\begin{array}{l}\text { Cumulative } \\
\text { Production } \\
\quad(\mathrm{mmt})\end{array}$ & $\begin{array}{l}\text { Cumulative } \\
\text { Production } \\
\quad(\mathrm{mmt})\end{array}$ \\
\hline & 2005 & 2012 & 2017 & 2027 \\
\hline $\mathrm{a}$ & 9.70 & 10.0 & 11.8 & 15.3 \\
\hline $\mathrm{b}$ & 11.07 & 33.7 & 44.5 & 68.7 \\
\hline $\mathrm{c}$ & 11.52 & 74.3 & 94.3 & 136.2 \\
\hline $\mathrm{d}$ & 12.03 & 427.2 & 526.6 & 725.5 \\
\hline $\mathrm{e}$ & 12.44 & 469.4 & 584.6 & 819.6 \\
\hline $\mathrm{f}$ & 13.07 & 481.6 & 600.0 & 841.7 \\
\hline $\mathrm{g}$ & 13.53 & 490.2 & 613.5 & 868.6 \\
\hline $\mathrm{h}$ & 14.12 & 516.5 & 650.1 & 929.0 \\
\hline $\mathrm{i}$ & 14.22 & 518.4 & 652.1 & 931.2 \\
\hline $\mathrm{j}$ & 14.36 & 542.1 & 675.8 & 954.9 \\
\hline $\mathrm{k}$ & 15.05 & 545.1 & 679.9 & 961.6 \\
\hline 1 & 15.16 & 545.9 & 681.0 & 963.4 \\
\hline $\mathrm{m}$ & 15.71 & 551.5 & 687.1 & 970.2 \\
\hline $\mathrm{n}$ & 16.45 & 558.2 & 697.6 & 991.1 \\
\hline o & 16.60 & 577.9 & 719.1 & 1015.5 \\
\hline $\mathrm{p}$ & 17.60 & 579.2 & 721.1 & 1019.7 \\
\hline $\mathrm{q}$ & 18.23 & 579.3 & 721.3 & 1020.0 \\
\hline $\mathrm{r}$ & 18.50 & 579.3 & 721.4 & 1020.1 \\
\hline $\mathrm{s}$ & 19.42 & 588.0 & 732.7 & 1037.3 \\
\hline $\mathrm{t}$ & 21.68 & 592.0 & 739.0 & 1049.8 \\
\hline $\mathrm{u}$ & 24.75 & 592.2 & 739.2 & 1049.9 \\
\hline $\mathrm{v}$ & 26.70 & 592.2 & 739.2 & 1050.0 \\
\hline w & 27.87 & 593.2 & 740.2 & 1051.1 \\
\hline $\mathrm{x}$ & 34.73 & 593.8 & 740.8 & 1051.7 \\
\hline $\mathrm{y}$ & 82.20 & 593.8 & 740.8 & 1051.7 \\
\hline $\mathrm{z}$ & 100.63 & 594.4 & 741.7 & 1053.1 \\
\hline $\mathrm{ab}$ & 115.69 & 594.4 & 741.7 & 1053.1 \\
\hline
\end{tabular}




\section{Brazil Table 2. Sugarcane - High Growth Case Supply Curve Data}

\begin{tabular}{|c|c|c|c|c|}
\hline State & $\begin{array}{c}\text { Average } \\
\text { Value } \\
\text { (US\$/tonne) }\end{array}$ & $\begin{array}{l}\text { Cumulative } \\
\text { Production } \\
\quad(\mathbf{m m t})\end{array}$ & $\begin{array}{l}\text { Cumulative } \\
\text { Production } \\
\quad(\mathbf{m m t})\end{array}$ & $\begin{array}{c}\text { Cumulative } \\
\text { Production } \\
\quad(\mathrm{mmt})\end{array}$ \\
\hline & 2005 & 2012 & 2017 & 2027 \\
\hline $\mathrm{a}$ & 9.70 & 11.6 & 15.1 & 22.7 \\
\hline $\mathrm{b}$ & 11.07 & 42.7 & 66.2 & 131.5 \\
\hline c & 11.52 & 91.0 & 132.3 & 237.7 \\
\hline d & 12.03 & 514.0 & 712.7 & 1179.1 \\
\hline $\mathrm{e}$ & 12.44 & 570.0 & 804.2 & 1373.6 \\
\hline $\mathrm{f}$ & 13.07 & 584.8 & 825.7 & 1411.3 \\
\hline g & 13.53 & 597.6 & 851.2 & 1485.1 \\
\hline $\mathrm{h}$ & 14.12 & 632.3 & 909.0 & 1610.9 \\
\hline $\mathrm{i}$ & 14.22 & 634.3 & 911.2 & 1613.3 \\
\hline $\mathrm{j}$ & 14.36 & 658.0 & 934.9 & 1637.0 \\
\hline $\mathrm{k}$ & 15.05 & 661.9 & 941.3 & 1650.9 \\
\hline 1 & 15.16 & 662.9 & 943.0 & 1654.2 \\
\hline $\mathrm{m}$ & 15.71 & 669.0 & 949.8 & 1662.5 \\
\hline $\mathrm{n}$ & 16.45 & 678.9 & 969.6 & 1719.6 \\
\hline o & 16.60 & 700.1 & 993.9 & 1749.6 \\
\hline $\mathrm{p}$ & 17.60 & 702.0 & 997.8 & 1760.8 \\
\hline$q$ & 18.23 & 702.2 & 998.1 & 1761.7 \\
\hline $\mathrm{r}$ & 18.50 & 702.2 & 998.3 & 1762.1 \\
\hline $\mathrm{s}$ & 19.42 & 713.3 & 1015.1 & 1794.1 \\
\hline $\mathrm{t}$ & 21.68 & 719.2 & 1026.9 & 1828.4 \\
\hline $\mathrm{u}$ & 24.75 & 719.4 & 1027.1 & 1828.5 \\
\hline $\mathrm{v}$ & 26.70 & 719.4 & 1027.2 & 1828.7 \\
\hline w & 27.87 & 720.4 & 1028.2 & 1829.9 \\
\hline $\mathrm{x}$ & 34.73 & 721.0 & 1028.8 & 1830.5 \\
\hline $\mathrm{y}$ & 82.20 & 721.0 & 1028.8 & 1830.5 \\
\hline $\mathrm{z}$ & 100.63 & 721.8 & 1030.2 & 1833.6 \\
\hline$a b$ & 115.69 & 721.8 & 1030.2 & 1833.6 \\
\hline
\end{tabular}


Brazil Table 3. Sugarcane - Low Growth Case Supply Curve Data

\begin{tabular}{crrrr}
\hline State & $\begin{array}{c}\text { Average } \\
\text { Value } \\
\text { (US\$/tonne) }\end{array}$ & $\begin{array}{c}\text { Cumulative } \\
\text { Production } \\
\text { (mmt) }\end{array}$ & $\begin{array}{c}\text { Cumulative } \\
\text { Production } \\
\text { (mmt) }\end{array}$ & $\begin{array}{c}\text { Cumulative } \\
\text { Production } \\
\text { (mmt) }\end{array}$ \\
\hline a & $\mathbf{2 0 0 5}$ & $\mathbf{2 0 1 2}$ & $\mathbf{2 0 1 7}$ & 2027 \\
b & 9.70 & 8.5 & 9.2 & 10.3 \\
c & 11.07 & 26.4 & 29.8 & 35.8 \\
d & 11.52 & 60.5 & 67.0 & 78.3 \\
e & 12.03 & 354.1 & 387.7 & 445.1 \\
f & 12.44 & 385.8 & 424.1 & 490.1 \\
g & 13.07 & 395.6 & 435.0 & 502.9 \\
h & 13.53 & 401.4 & 442.1 & 512.4 \\
i & 14.12 & 421.1 & 464.8 & 540.7 \\
j & 14.22 & 422.9 & 466.7 & 542.6 \\
k & 14.36 & 446.6 & 490.4 & 566.4 \\
l & 15.05 & 448.9 & 493.0 & 569.6 \\
m & 15.16 & 449.5 & 493.7 & 570.4 \\
n & 15.71 & 454.7 & 499.1 & 576.1 \\
o & 16.45 & 459.2 & 504.6 & 583.5 \\
p & 16.60 & 477.4 & 523.4 & 603.5 \\
q & 17.60 & 478.3 & 524.5 & 605.0 \\
r & 18.23 & 478.3 & 524.6 & 605.1 \\
s & 18.50 & 478.4 & 524.7 & 605.1 \\
t & 19.42 & 485.1 & 532.3 & 614.2 \\
u & 21.68 & 487.8 & 535.5 & 618.7 \\
v & 24.75 & 488.0 & 535.7 & 618.8 \\
w & 26.70 & 488.0 & 535.7 & 618.9 \\
x & 27.87 & 489.0 & 536.7 & 619.8 \\
y & 34.73 & 489.6 & 537.3 & 620.4 \\
Z & 82.20 & 489.6 & 537.3 & 620.5 \\
ab & 100.63 & 490.0 & 537.8 & 621.1 \\
& 115.69 & 490.0 & 537.8 & 621.1 \\
\hline & & & & \\
\hline
\end{tabular}


Brazil Table 4. Corn - Baseline Case Supply Curve Data

\begin{tabular}{|c|c|c|c|c|}
\hline State & $\begin{array}{c}\text { Average } \\
\text { Value } \\
\text { (US\$/tonne) }\end{array}$ & $\begin{array}{l}\text { Cumulative } \\
\text { Production } \\
\quad(\mathbf{m m t})\end{array}$ & $\begin{array}{l}\text { Cumulative } \\
\text { Production } \\
\quad(\mathbf{m m t})\end{array}$ & $\begin{array}{l}\text { Cumulative } \\
\text { Production } \\
\quad(\mathrm{mmt})\end{array}$ \\
\hline & 2005 & 2012 & 2017 & 2027 \\
\hline $\mathrm{a}$ & 87.4 & 0.5 & 0.7 & 1.3 \\
\hline $\mathrm{b}$ & 94.0 & 0.6 & 0.8 & 1.4 \\
\hline $\mathrm{c}$ & 94.3 & 0.6 & 0.9 & 1.6 \\
\hline $\mathrm{d}$ & 96.5 & 0.7 & 1.0 & 1.7 \\
\hline e & 99.4 & 1.5 & 2.0 & 3.1 \\
\hline $\mathrm{f}$ & 103.2 & 1.5 & 2.0 & 3.1 \\
\hline g & 108.2 & 1.7 & 2.3 & 3.6 \\
\hline $\mathrm{h}$ & 109.2 & 2.3 & 3.1 & 4.8 \\
\hline $\mathrm{i}$ & 111.3 & 2.7 & 3.5 & 5.4 \\
\hline $\mathrm{j}$ & 114.4 & 3.1 & 4.0 & 6.0 \\
\hline $\mathrm{k}$ & 118.3 & 3.1 & 4.1 & 6.2 \\
\hline 1 & 124.8 & 3.2 & 4.2 & 6.3 \\
\hline $\mathrm{m}$ & 126.5 & 3.4 & 4.5 & 7.0 \\
\hline $\mathrm{n}$ & 126.9 & 3.5 & 4.6 & 7.1 \\
\hline o & 130.7 & 3.9 & 5.2 & 8.4 \\
\hline $\mathrm{p}$ & 137.8 & 6.8 & 9.3 & 16.0 \\
\hline$q$ & 141.8 & 18.3 & 25.8 & 44.2 \\
\hline $\mathrm{r}$ & 145.5 & 18.5 & 26.0 & 44.4 \\
\hline $\mathrm{s}$ & 146.7 & 18.5 & 26.0 & 44.4 \\
\hline $\mathrm{t}$ & 148.2 & 22.8 & 30.3 & 48.8 \\
\hline $\mathrm{u}$ & 151.2 & 31.3 & 38.9 & 57.4 \\
\hline $\mathrm{v}$ & 153.0 & 34.0 & 41.6 & 60.1 \\
\hline w & 163.4 & 35.5 & 43.1 & 61.5 \\
\hline $\mathrm{x}$ & 168.9 & 36.8 & 44.4 & 62.8 \\
\hline $\mathrm{y}$ & 179.3 & 41.8 & 50.4 & 72.5 \\
\hline $\mathrm{z}$ & 193.8 & 44.7 & 53.4 & 75.5 \\
\hline$a b$ & 205.5 & 45.1 & 54.1 & 76.9 \\
\hline
\end{tabular}

Note: FAPRI (2006) and USDA (2007) baseline projections for Brazil's total corn production coincide at approximately $50 \mathrm{mmt}$ for 2012 and $53 \mathrm{mmt}$ in 2016. 
Brazil Table 5. Corn - High Growth Case Supply Curve Data

\begin{tabular}{|c|c|c|c|c|}
\hline State & $\begin{array}{c}\text { Average } \\
\text { Value } \\
\text { (US\$/tonne) }\end{array}$ & $\begin{array}{l}\text { Cumulative } \\
\text { Production } \\
\quad(\mathbf{m m t})\end{array}$ & $\begin{array}{l}\text { Cumulative } \\
\text { Production } \\
\quad(\mathrm{mmt})\end{array}$ & $\begin{array}{l}\text { Cumulative } \\
\text { Production } \\
\text { (mmt) }\end{array}$ \\
\hline & 2005 & 2012 & 2017 & 2027 \\
\hline $\mathrm{a}$ & 87.4 & 0.6 & 1.1 & 2.9 \\
\hline $\mathrm{b}$ & 94.0 & 0.7 & 1.3 & 3.1 \\
\hline $\mathrm{c}$ & 94.3 & 0.8 & 1.4 & 3.5 \\
\hline $\mathrm{d}$ & 96.5 & 0.9 & 1.5 & 3.8 \\
\hline e & 99.4 & 1.9 & 3.0 & 6.0 \\
\hline $\mathrm{f}$ & 103.2 & 1.9 & 3.1 & 6.0 \\
\hline $\mathrm{g}$ & 108.2 & 2.2 & 3.4 & 6.8 \\
\hline $\mathrm{h}$ & 109.2 & 2.9 & 4.4 & 8.9 \\
\hline $\mathrm{i}$ & 111.3 & 3.3 & 5.1 & 9.9 \\
\hline $\mathrm{j}$ & 114.4 & 3.8 & 5.7 & 10.8 \\
\hline $\mathrm{k}$ & 118.3 & 3.9 & 5.8 & 11.2 \\
\hline 1 & 124.8 & 4.0 & 6.0 & 11.4 \\
\hline $\mathrm{m}$ & 126.5 & 4.3 & 6.6 & 13.2 \\
\hline $\mathrm{n}$ & 126.9 & 4.4 & 6.7 & 13.3 \\
\hline o & 130.7 & 5.0 & 7.8 & 16.5 \\
\hline $\mathrm{p}$ & 137.8 & 8.9 & 14.3 & 32.8 \\
\hline$q$ & 141.8 & 24.5 & 40.9 & 92.2 \\
\hline $\mathrm{r}$ & 145.5 & 24.6 & 41.0 & 92.4 \\
\hline $\mathrm{s}$ & 146.7 & 24.7 & 41.1 & 92.5 \\
\hline $\mathrm{t}$ & 148.2 & 29.0 & 45.5 & 97.0 \\
\hline $\mathrm{u}$ & 151.2 & 37.5 & 54.1 & 105.6 \\
\hline $\mathrm{v}$ & 153.0 & 40.2 & 56.8 & 108.3 \\
\hline w & 163.4 & 41.7 & 58.3 & 109.8 \\
\hline $\mathrm{x}$ & 168.9 & 43.0 & 59.6 & 111.1 \\
\hline $\mathrm{y}$ & 179.3 & 48.9 & 67.5 & 127.0 \\
\hline $\mathrm{Z}$ & 193.8 & 51.9 & 70.5 & 130.1 \\
\hline$a b$ & 205.5 & 52.5 & 71.8 & 133.6 \\
\hline
\end{tabular}


Brazil Table 6. Corn - Low Growth Case Supply Curve Data

\begin{tabular}{|c|c|c|c|c|}
\hline State & $\begin{array}{c}\text { Average } \\
\text { Value } \\
\text { (US\$/tonne) }\end{array}$ & $\begin{array}{l}\text { Cumulative } \\
\text { Production } \\
\quad(\mathbf{m m t})\end{array}$ & $\begin{array}{l}\text { Cumulative } \\
\text { Production } \\
\quad(\mathrm{mmt})\end{array}$ & $\begin{array}{l}\text { Cumulative } \\
\text { Production } \\
\quad(\mathrm{mmt})\end{array}$ \\
\hline & 2005 & 2012 & 2017 & 2027 \\
\hline $\mathrm{a}$ & 87.4 & 1.3 & 1.3 & 1.3 \\
\hline $\mathrm{b}$ & 94.0 & 1.6 & 1.7 & 1.9 \\
\hline $\mathrm{c}$ & 94.3 & 5.7 & 6.4 & 8.0 \\
\hline $\mathrm{d}$ & 96.5 & 6.1 & 6.8 & 8.7 \\
\hline $\mathrm{e}$ & 99.4 & 9.0 & 9.7 & 11.6 \\
\hline $\mathrm{f}$ & 103.2 & 11.1 & 12.4 & 15.7 \\
\hline g & 108.2 & 19.7 & 21.0 & 24.3 \\
\hline $\mathrm{h}$ & 109.2 & 20.0 & 21.4 & 25.0 \\
\hline $\mathrm{i}$ & 111.3 & 24.2 & 25.6 & 29.3 \\
\hline $\mathrm{j}$ & 114.4 & 26.9 & 28.3 & 32.0 \\
\hline $\mathrm{k}$ & 118.3 & 35.4 & 38.8 & 48.2 \\
\hline 1 & 124.8 & 35.8 & 39.4 & 49.0 \\
\hline $\mathrm{m}$ & 126.5 & 35.9 & 39.5 & 49.1 \\
\hline $\mathrm{n}$ & 126.9 & 36.1 & 39.7 & 49.4 \\
\hline o & 130.7 & 37.6 & 41.2 & 50.9 \\
\hline $\mathrm{p}$ & 137.8 & 37.8 & 41.5 & 51.3 \\
\hline $\mathrm{q}$ & 141.8 & 37.9 & 41.5 & 51.3 \\
\hline $\mathrm{r}$ & 145.5 & 37.9 & 41.6 & 51.4 \\
\hline $\mathrm{s}$ & 146.7 & 38.6 & 42.4 & 52.5 \\
\hline $\mathrm{t}$ & 148.2 & 38.8 & 42.6 & 52.9 \\
\hline $\mathrm{u}$ & 151.2 & 38.8 & 42.7 & 53.0 \\
\hline $\mathrm{v}$ & 153.0 & 38.9 & 42.7 & 53.0 \\
\hline w & 163.4 & 39.0 & 42.8 & 53.2 \\
\hline $\mathrm{x}$ & 168.9 & 39.3 & 43.2 & 53.6 \\
\hline $\mathrm{y}$ & 179.3 & 39.4 & 43.2 & 53.7 \\
\hline $\mathrm{z}$ & 193.8 & 39.4 & 43.3 & 53.7 \\
\hline$a b$ & 205.5 & 39.4 & 43.3 & 53.8 \\
\hline
\end{tabular}


Brazil Table 7. Soybean - Baseline Case Supply Curve Data

\begin{tabular}{ccccc}
\hline State & $\begin{array}{c}\text { Average } \\
\text { Value } \\
\text { (US\$/tonne) }\end{array}$ & $\begin{array}{c}\text { Cumulative } \\
\text { Production } \\
\text { (mmt) }\end{array}$ & $\begin{array}{c}\text { Cumulative } \\
\text { Production } \\
\text { (mmt) }\end{array}$ & $\begin{array}{c}\text { Cumulative } \\
\text { Production } \\
\text { (mmt) }\end{array}$ \\
\hline h & $\mathbf{2 0 0 5}$ & $\mathbf{2 0 1 2}$ & $\mathbf{2 0 1 7}$ & $\mathbf{2 0 2 7}$ \\
\hline i & 106.4 & 0.0 & 0.0 & 0.1 \\
j & 154.5 & 26.8 & 34.8 & 49.5 \\
k & 169.1 & 37.0 & 47.8 & 67.4 \\
l & 170.4 & 37.3 & 48.3 & 68.3 \\
m & 172.6 & 37.4 & 48.5 & 68.5 \\
n & 177.1 & 40.0 & 53.4 & 80.3 \\
o & 178.6 & 45.9 & 61.4 & 92.3 \\
p & 178.8 & 46.8 & 63.4 & 98.8 \\
q & 181.1 & 51.4 & 70.2 & 109.9 \\
r & 189.2 & 59.0 & 83.7 & 139.1 \\
s & 192.6 & 61.8 & 87.5 & 144.9 \\
t & 193.5 & 64.1 & 92.9 & 161.9 \\
u & 194.3 & 74.5 & 104.1 & 174.0 \\
v & 195.4 & 77.6 & 107.6 & 178.3 \\
w & 196.0 & 80.0 & 111.9 & 187.1 \\
X & 199.6 & 81.1 & 113.5 & 189.8 \\
y & 208.4 & 82.4 & 117.6 & 209.0 \\
z & 209.1 & 82.4 & 117.6 & 209.0 \\
ab & 272.8 & 82.4 & 117.6 & 209.1 \\
& 411.0 & 82.4 & 117.6 & 209.1 \\
\hline
\end{tabular}

Note: USDA (2007) baseline projections for Brazil's soybean production are approximately $90 \mathrm{mmt}$ in 2012 and $105 \mathrm{mmt}$ in 2016. 
Brazil Table 8. Soybean - High Growth Case Supply Curve Data

\begin{tabular}{ccccr}
\hline State & $\begin{array}{c}\text { Average } \\
\text { Value } \\
\text { (US\$/tonne) }\end{array}$ & $\begin{array}{c}\text { Cumulative } \\
\text { Production } \\
\text { (mmt) }\end{array}$ & $\begin{array}{c}\text { Cumulative } \\
\text { Production } \\
\text { (mmt) }\end{array}$ & $\begin{array}{c}\text { Cumulative } \\
\text { Production } \\
\text { (mmt) }\end{array}$ \\
\hline h & $\mathbf{2 0 0 5}$ & $\mathbf{2 0 1 2}$ & $\mathbf{2 0 1 7}$ & $\mathbf{2 0 2 7}$ \\
i & 106.4 & 0.0 & 0.1 & 0.3 \\
j & 154.5 & 31.5 & 45.4 & 74.3 \\
k & 169.1 & 43.3 & 61.9 & 100.3 \\
l & 170.4 & 43.8 & 62.7 & 102.0 \\
m & 172.6 & 43.9 & 62.9 & 102.4 \\
n & 177.1 & 47.7 & 72.3 & 133.8 \\
o & 178.6 & 54.8 & 83.1 & 152.9 \\
p & 178.8 & 56.2 & 87.6 & 174.9 \\
q & 181.1 & 62.2 & 97.8 & 195.3 \\
r & 189.2 & 73.1 & 122.2 & 266.3 \\
s & 192.6 & 76.5 & 127.3 & 275.7 \\
t & 193.5 & 80.3 & 140.0 & 338.0 \\
u & 194.3 & 91.2 & 151.9 & 351.3 \\
v & 195.4 & 94.6 & 156.1 & 356.8 \\
w & 196.0 & 98.0 & 163.5 & 377.3 \\
x & 199.6 & 99.4 & 165.8 & 382.1 \\
y & 208.4 & 101.9 & 177.9 & 484.2 \\
z & 209.1 & 101.9 & 177.9 & 484.2 \\
ab & 272.8 & 101.9 & 177.9 & 484.7 \\
\hline & 411.0 & 102.0 & 178.0 & 484.8 \\
\hline
\end{tabular}


Brazil Table 9. Soybean - Low Growth Case Supply Curve Data

\begin{tabular}{ccccc}
\hline State & $\begin{array}{c}\text { Average } \\
\text { Value } \\
\text { (US\$/tonne) }\end{array}$ & $\begin{array}{c}\text { Cumulative } \\
\text { Production } \\
\text { (mmt) }\end{array}$ & $\begin{array}{c}\text { Cumulative } \\
\text { Production } \\
\text { (mmt) }\end{array}$ & $\begin{array}{c}\text { Cumulative } \\
\text { Production } \\
\text { (mmt) }\end{array}$ \\
\hline h & $\mathbf{2 0 0 5}$ & $\mathbf{2 0 1 2}$ & $\mathbf{2 0 1 7}$ & $\mathbf{2 0 2 7}$ \\
i & 106.4 & 0.0 & 0.0 & 0.0 \\
j & 154.5 & 22.7 & 26.6 & 32.8 \\
k & 169.1 & 31.5 & 36.7 & 45.0 \\
l & 170.4 & 31.7 & 37.0 & 45.5 \\
m & 172.6 & 31.8 & 37.1 & 45.6 \\
n & 177.1 & 33.5 & 39.6 & 49.9 \\
o & 178.6 & 38.4 & 45.5 & 57.4 \\
p & 178.8 & 39.0 & 46.4 & 59.1 \\
q & 181.1 & 42.5 & 50.9 & 65.1 \\
r & 189.2 & 47.7 & 58.2 & 76.8 \\
s & 192.6 & 50.0 & 61.0 & 80.3 \\
t & 193.5 & 51.3 & 63.2 & 84.7 \\
u & 194.3 & 61.4 & 73.6 & 95.7 \\
v & 195.4 & 64.2 & 76.7 & 99.1 \\
w & 196.0 & 65.9 & 79.1 & 102.8 \\
x & 199.6 & 66.7 & 80.2 & 104.3 \\
y & 208.4 & 67.4 & 81.4 & 107.6 \\
z & 209.1 & 67.4 & 81.4 & 107.6 \\
ab & 272.8 & 67.4 & 81.4 & 107.6 \\
\hline & 411.0 & 67.4 & 81.5 & 107.6 \\
\hline
\end{tabular}


Brazil Table 10. Potential Percentage Allocation for Export \& Biofuels

\begin{tabular}{cccc}
\hline & $\begin{array}{c}\text { Percent of } \\
\text { Feedstock }\end{array}$ & $\begin{array}{c}\text { Percent of } \\
\text { Feedstock }\end{array}$ & $\begin{array}{c}\text { Percent of } \\
\text { Feedstock }\end{array}$ \\
\hline Soybean & $\mathbf{2 0 1 2}$ & $\mathbf{2 0 1 7}$ & $\mathbf{2 0 2 7}$ \\
Low Growth & 65 & 59 & \\
Baseline & 72 & 72 & 45 \\
High Growth & 77 & 81 & 72 \\
Corn & & & 88 \\
Low Growth & 0 & 0 & \\
Baseline & 7 & 30 & 7 \\
High Growth & 20 & & 47 \\
Sugarcane & & 76 & 70 \\
Low Growth & 79 & 82 & 82 \\
Baseline & 82 & 87 & 90 \\
High Growth & 85 & &
\end{tabular}

Brazil Table 11. Estimated Cellulosic Supply from Recoverable Crop Residues (bagasse and corn only; in mmt, bone-dry, annual)

\begin{tabular}{|c|c|c|c|c|c|c|c|}
\hline & Baselin & ase & Low G & wth & High & vth Case & Cost \\
\hline & 2017 & 2027 & 2017 & 2027 & 2017 & 2027 & \\
\hline Bagasse & 104 & 147 & 75 & 87 & 144 & 257 & $\$ 8.4$ \\
\hline $\begin{array}{l}\text { Corn Stover } \\
\text { Total }\end{array}$ & $\begin{array}{c}8 \\
112\end{array}$ & $\begin{array}{c}11 \\
158\end{array}$ & $\begin{array}{c}6 \\
81\end{array}$ & $\begin{array}{c}8 \\
95\end{array}$ & $\begin{array}{c}10 \\
154\end{array}$ & $\begin{array}{c}19 \\
276\end{array}$ & $\$ 39.0$ \\
\hline
\end{tabular}

Brazil Table 12. Estimated Cellulosic Supply Including Other Residues (2017 baseline case)

\begin{tabular}{|lcc|}
\hline & $\begin{array}{c}\text { Supply/Yr } \\
(\mathbf{m m t})\end{array}$ & Cost US\$ \\
Agriculture Residues & 112 & (See Table 11) \\
Forest Harvest Residue & 5.4 & $\$ 50-\$ 100$ \\
Wood Residue & 2.4 & $\$ 18-\$ 36$ \\
Wood Fuel & 31.4 & $\$ 14$ \\
Crop and Forest Residues & $\mathbf{1 5 0 . 2}$ & \\
Perennials & & \\
$\quad$ 5\% Arable Land Harvest & 37 & $\$ 52$ \\
10\% Arable Land Harvest & 73 & $\$ 52$ \\
\hline
\end{tabular}


Canada Table 1. Baseline Case Supply Data for Wheat

\begin{tabular}{ccccc}
\hline State & $\begin{array}{c}\text { Average } \\
\text { Value } \\
\text { (US\$/tonne) }\end{array}$ & $\begin{array}{c}\text { Cumulative } \\
\text { Production } \\
\text { (mmt) }\end{array}$ & $\begin{array}{c}\text { Cumulative } \\
\text { Production } \\
\text { (mmt) }\end{array}$ & $\begin{array}{c}\text { Cumulative } \\
\text { Production } \\
\text { (mmt) }\end{array}$ \\
\hline a & $\mathbf{2 0 0 5}$ & $\mathbf{2 0 1 2}$ & $\mathbf{2 0 1 7}$ & $\mathbf{2 0 2 7}$ \\
\hline b & 96.1 & 10.9 & 10.9 & 10.9 \\
c & 97.7 & 15.4 & 15.9 & 16.5 \\
d & 104.2 & 15.5 & 15.9 & 16.5 \\
e & 105.5 & 23.2 & 23.7 & 24.5 \\
f & 114.6 & 23.2 & 23.8 & 24.5 \\
g & 115.4 & 23.2 & 23.8 & 24.5 \\
h & 119.5 & 23.2 & 23.8 & 24.6 \\
i & 120.3 & 23.5 & 24.3 & 25.4 \\
\hline
\end{tabular}

Canada Table 2. High Growth Case Supply Data for Wheat

\begin{tabular}{ccccc}
\hline State & $\begin{array}{c}\text { Average } \\
\text { Value } \\
\text { (US\$/tonne) }\end{array}$ & $\begin{array}{c}\text { Cumulative } \\
\text { Production } \\
(\mathbf{m m t})\end{array}$ & $\begin{array}{c}\text { Cumulative } \\
\text { Production } \\
(\mathbf{m m t})\end{array}$ & $\begin{array}{c}\text { Cumulative } \\
\text { Production } \\
\text { (mmt) }\end{array}$ \\
\hline & $\mathbf{2 0 0 5}$ & $\mathbf{2 0 1 2}$ & $\mathbf{2 0 1 7}$ & $\mathbf{2 0 2 7}$ \\
\hline a & 96.1 & 10.9 & 10.9 & 10.9 \\
b & 97.7 & 17.8 & 20.6 & 25.7 \\
c & 104.2 & 17.8 & 20.7 & 25.8 \\
d & 105.5 & 26.3 & 29.8 & 35.7 \\
e & 114.6 & 26.4 & 29.9 & 35.9 \\
f & 115.4 & 26.4 & 29.9 & 35.9 \\
g & 119.5 & 26.4 & 29.9 & 35.9 \\
h & 120.3 & 26.6 & 30.2 & 36.3 \\
i & 128.6 & 32.8 & 40.5 & 55.3 \\
\hline
\end{tabular}

Canada Table 3. Low Growth Case Supply Data for Wheat

\begin{tabular}{ccccc}
\hline State & $\begin{array}{c}\text { Average } \\
\text { Value } \\
\text { (US\$/tonne) }\end{array}$ & $\begin{array}{c}\text { Cumulative } \\
\text { Production } \\
\text { (mmt) }\end{array}$ & $\begin{array}{c}\text { Cumulative } \\
\text { Production } \\
\text { (mmt) }\end{array}$ & $\begin{array}{c}\text { Cumulative } \\
\text { Production } \\
\text { (mmt) }\end{array}$ \\
\hline & $\mathbf{2 0 0 5}$ & $\mathbf{2 0 1 2}$ & $\mathbf{2 0 1 7}$ & $\mathbf{2 0 2 7}$ \\
\hline a & 96.1 & 10.9 & 10.9 & 10.9 \\
b & 97.7 & 14.7 & 14.7 & 14.8 \\
c & 104.2 & 14.8 & 14.8 & 14.8 \\
d & 105.5 & 22.3 & 22.3 & 22.3 \\
e & 114.6 & 22.3 & 22.3 & 22.3 \\
f & 115.4 & 22.3 & 22.3 & 22.3 \\
g & 119.5 & 22.3 & 22.3 & 22.3 \\
h & 120.3 & 22.5 & 22.5 & 22.5 \\
i & 128.6 & 25.1 & 25.1 & 25.1 \\
\hline
\end{tabular}


Canada Table 4. Baseline Case Supply Curve Data for Corn

\begin{tabular}{ccccc}
\hline State & $\begin{array}{c}\text { Average } \\
\text { Value } \\
\text { (US\$/tonne) }\end{array}$ & $\begin{array}{c}\text { Cumulative } \\
\text { Production } \\
(\mathbf{m m t})\end{array}$ & $\begin{array}{c}\text { Cumulative } \\
\text { Production } \\
(\mathbf{m m t})\end{array}$ & $\begin{array}{c}\text { Cumulative } \\
\text { Production } \\
(\mathbf{m m t})\end{array}$ \\
\hline & $\mathbf{2 0 0 5}$ & $\mathbf{2 0 1 2}$ & $\mathbf{2 0 1 7}$ & $\mathbf{2 0 2 7}$ \\
\hline $\mathrm{a}$ & $\$ 88.21$ & 8.3 & 10.5 & 14.8 \\
$\mathrm{~b}$ & $\$ 89.86$ & 8.9 & 11.1 & 15.8 \\
$\mathrm{c}$ & $\$ 96.00$ & 8.9 & 11.2 & 15.8 \\
$\mathrm{~d}$ & $\$ 110.75$ & 12.5 & 15.4 & 21.3 \\
$\mathrm{e}$ & $\$ 111.29$ & 12.5 & 15.5 & 21.3 \\
$\mathrm{f}$ & $\$ 123.66$ & 12.5 & 15.5 & 21.5 \\
\hline
\end{tabular}

Canada Table 5. High Growth Case Supply Curve Data for Corn

\begin{tabular}{ccccc}
\hline State & $\begin{array}{c}\text { Average } \\
\text { Value } \\
\text { (US\$/tonne) }\end{array}$ & $\begin{array}{c}\text { Cumulative } \\
\text { Production } \\
(\mathbf{m m t})\end{array}$ & $\begin{array}{c}\text { Cumulative } \\
\text { Production } \\
(\mathbf{m m t})\end{array}$ & $\begin{array}{c}\text { Cumulative } \\
\text { Production } \\
(\mathbf{m m t})\end{array}$ \\
\hline & $\mathbf{2 0 0 5}$ & $\mathbf{2 0 1 2}$ & $\mathbf{2 0 1 7}$ & $\mathbf{2 0 2 7}$ \\
\hline $\mathrm{a}$ & $\$ 88.21$ & 10.6 & 15.5 & 28.0 \\
$\mathrm{~b}$ & $\$ 89.86$ & 11.2 & 16.4 & 29.3 \\
$\mathrm{c}$ & $\$ 96.00$ & 11.2 & 16.4 & 29.3 \\
$\mathrm{~d}$ & $\$ 110.75$ & 15.2 & 21.5 & 36.7 \\
$\mathrm{e}$ & $\$ 111.29$ & 15.2 & 21.5 & 36.7 \\
$\mathrm{f}$ & $\$ 123.66$ & 15.3 & 21.6 & 36.9
\end{tabular}

Canada Table 6. Low Growth Case Supply Curve Data for Corn

\begin{tabular}{ccccc}
\hline State & $\begin{array}{c}\text { Average } \\
\text { Value } \\
\text { (US\$/tonne) }\end{array}$ & $\begin{array}{c}\text { Cumulative } \\
\text { Production } \\
(\mathbf{m m t})\end{array}$ & $\begin{array}{c}\text { Cumulative } \\
\text { Production } \\
(\mathbf{m m t})\end{array}$ & $\begin{array}{c}\text { Cumulative } \\
\text { Production } \\
\text { (mmt) }\end{array}$ \\
\hline & $\mathbf{2 0 0 5}$ & $\mathbf{2 0 1 2}$ & $\mathbf{2 0 1 7}$ & $\mathbf{2 0 2 7}$ \\
\hline a & $\$ 88.21$ & 6.1 & 6.3 & 6.5 \\
b & $\$ 89.86$ & 6.5 & 6.7 & 6.9 \\
c & $\$ 96.00$ & 6.5 & 6.7 & 6.9 \\
d & $\$ 110.75$ & 9.3 & 9.5 & 9.9 \\
e & $\$ 111.29$ & 9.3 & 9.5 & 9.9 \\
f & $\$ 123.66$ & 9.3 & 9.6 & 9.9
\end{tabular}


Canada Table 7. Potential Percentage Allocation for Export \& Biofuels

\begin{tabular}{cccc}
\hline & $\begin{array}{c}\text { Percent of } \\
\text { Feedstock }\end{array}$ & $\begin{array}{c}\text { Percent of } \\
\text { Feedstock }\end{array}$ & $\begin{array}{c}\text { Percent of } \\
\text { Feedstock }\end{array}$ \\
\hline Wheat & $\mathbf{2 0 1 2}$ & $\mathbf{2 0 1 7}$ & $\mathbf{2 0 2 7}$ \\
Low Growth & 63 & 61 & \\
Baseline & 67 & 67 & 56 \\
High Growth & 72 & 76 & 67 \\
Corn & & & 80 \\
Low Growth & 0 & 0 & 0 \\
Baseline & 5 & 5 & 5 \\
High Growth & 22 & 32 & 45 \\
\hline
\end{tabular}

\section{Canada Table 8. Estimated Cellulosic Supply from Recoverable Crop Residues (wheat and corn only; mmt, bone-dry, annual)}

\begin{tabular}{|lccccccc|}
\hline & \multicolumn{3}{c}{ Baseline Case } & \multicolumn{2}{c|}{ Low Growth } & \multicolumn{4}{c|}{ High Growth } & Cost \\
& & & & & & & US\$ \\
Wheat straw & 2017 & 2027 & 2017 & 2027 & 2017 & 2027 & \\
Corn Stover & 4 & 6 & 3 & 3 & 6 & 10 & $\$ 52$ \\
Total & 6 & 7 & 5 & 5 & 8 & 11 & $\$ 52$ \\
\hline
\end{tabular}

Canada Table 9. Estimated Cellulosic Supply including Other Residues* (2017 baseline case)

Canada Cellulosic Supply Summary mmt (millions bone-dry tonnes)

\begin{tabular}{|l|c|c|c|c|}
\hline Source & Total & Available & Realistic/Yr & Est US\$ \\
\hline Mill residues (annual) & 21.2 & 2.7 & 1.1 & $\$ 18$ \\
\hline Mill bark/'hog fuel' (inventory) & 15.7 & 1.6 & 0.7 & $\$ 36$ \\
\hline Agricultural residues (annual) & 56 & 25 & 11 & $\$ 52$ \\
\hline Thinnings/pine beetle (inventory) & 27 & 8 & 4 & $\$ 70$ \\
\hline Forest harvest residues (annual) & 20 & 17 & 5 & $\$ 100$ \\
\hline \multicolumn{1}{|l|}{ Total } & 140 & 55 & 22 & \\
\hline
\end{tabular}

*Agricultural residues based on the ORNL baseline projection; others based on Bradley 2006 (CCS). Prices estimated in 2005US\$/metric tonne. 
China Table 1. Estimated Potential Supply of Corn

\begin{tabular}{ccccc}
\hline $\begin{array}{c}\text { Growth Case } \\
\text { (see } \\
\text { Introduction) }\end{array}$ & $\begin{array}{c}\text { Average } \\
\text { Value } \\
\text { (US\$/tonne) }\end{array}$ & $\begin{array}{c}\text { Cumulative } \\
\text { Production } \\
\text { (mmt) }\end{array}$ & $\begin{array}{c}\text { Cumulative } \\
\text { Production } \\
\text { (mmt) }\end{array}$ & $\begin{array}{c}\text { Cumulative } \\
\text { Production } \\
\text { (mmt) }\end{array}$ \\
\hline Low Growth & $\mathbf{2 0 0 5}$ & $\mathbf{2 0 1 2}$ & $\mathbf{2 0 1 7}$ & $\mathbf{2 0 2 7}$ \\
Baseline & $\$ 139.4$ & 156.2 & 166.7 & 186.9 \\
High Growth & $\$ 139.4$ & $\mathbf{1 7 4 . 5}$ & $\mathbf{1 9 9 . 8}$ & $\mathbf{2 5 5 . 5}$ \\
& $\$ 139.4$ & 195.8 & 242.3 & 363.5
\end{tabular}

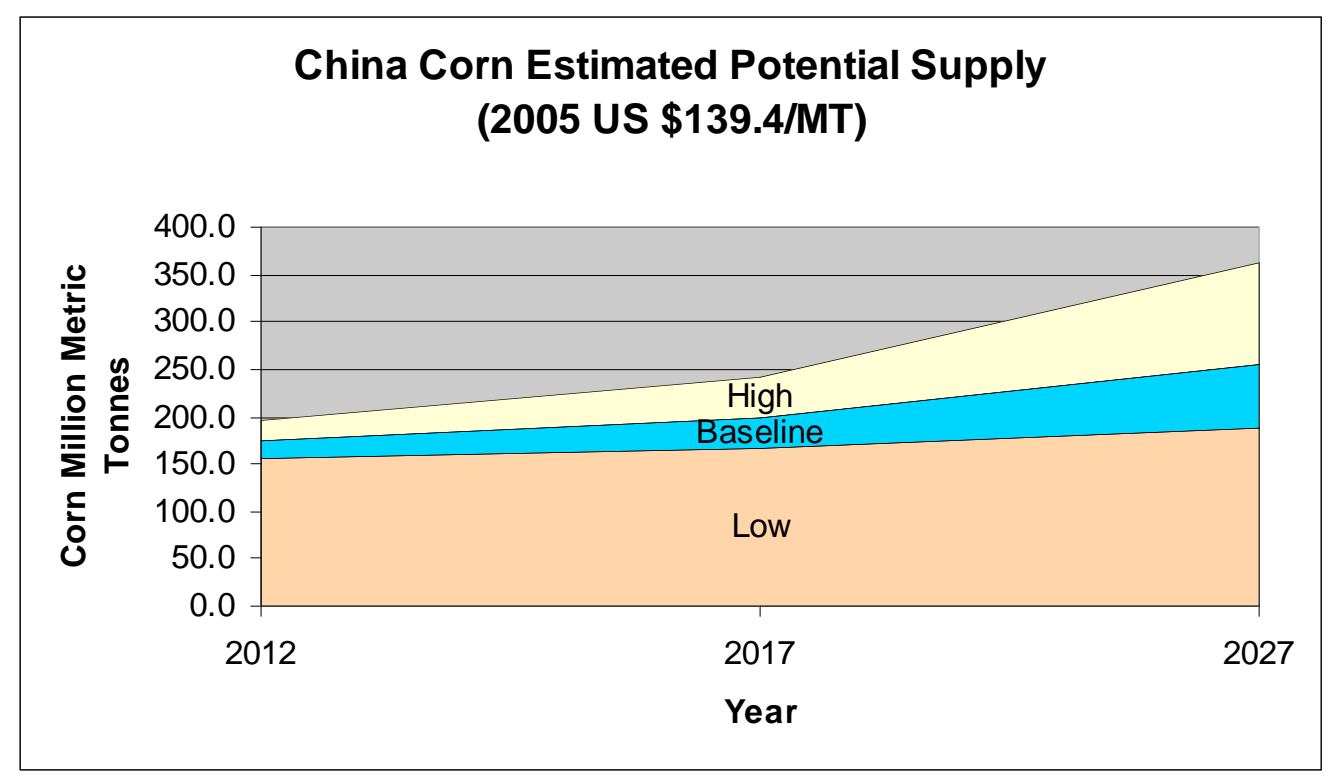


China Table 2. Estimated Potential Supply of Soybean

\begin{tabular}{ccccc}
\hline $\begin{array}{c}\text { Growth Case } \\
\text { (see } \\
\text { Introduction) }\end{array}$ & $\begin{array}{c}\text { Average } \\
\text { Value } \\
\text { (US\$/tonne) }\end{array}$ & $\begin{array}{c}\text { Cumulative } \\
\text { Production } \\
\text { (mmt) }\end{array}$ & $\begin{array}{c}\text { Cumulative } \\
\text { Production } \\
\text { (mmt) }\end{array}$ & $\begin{array}{c}\text { Cumulative } \\
\text { Production } \\
\text { (mmt) }\end{array}$ \\
\hline Low Growth & $\mathbf{2 0 0 5}$ & $\mathbf{2 0 1 2}$ & $\mathbf{2 0 1 7}$ & $\mathbf{2 0 2 7}$ \\
Baseline & $\$ 319.8$ & 18.2 & 18.9 & 19.9 \\
High Growth & $\$ \mathbf{\$ 3 1 9 . 8}$ & $\mathbf{2 2 . 6}$ & $\mathbf{2 5 . 7}$ & $\mathbf{3 0 . 9}$ \\
& $\$ 319.8$ & 28.2 & 35.1 & 48.6
\end{tabular}

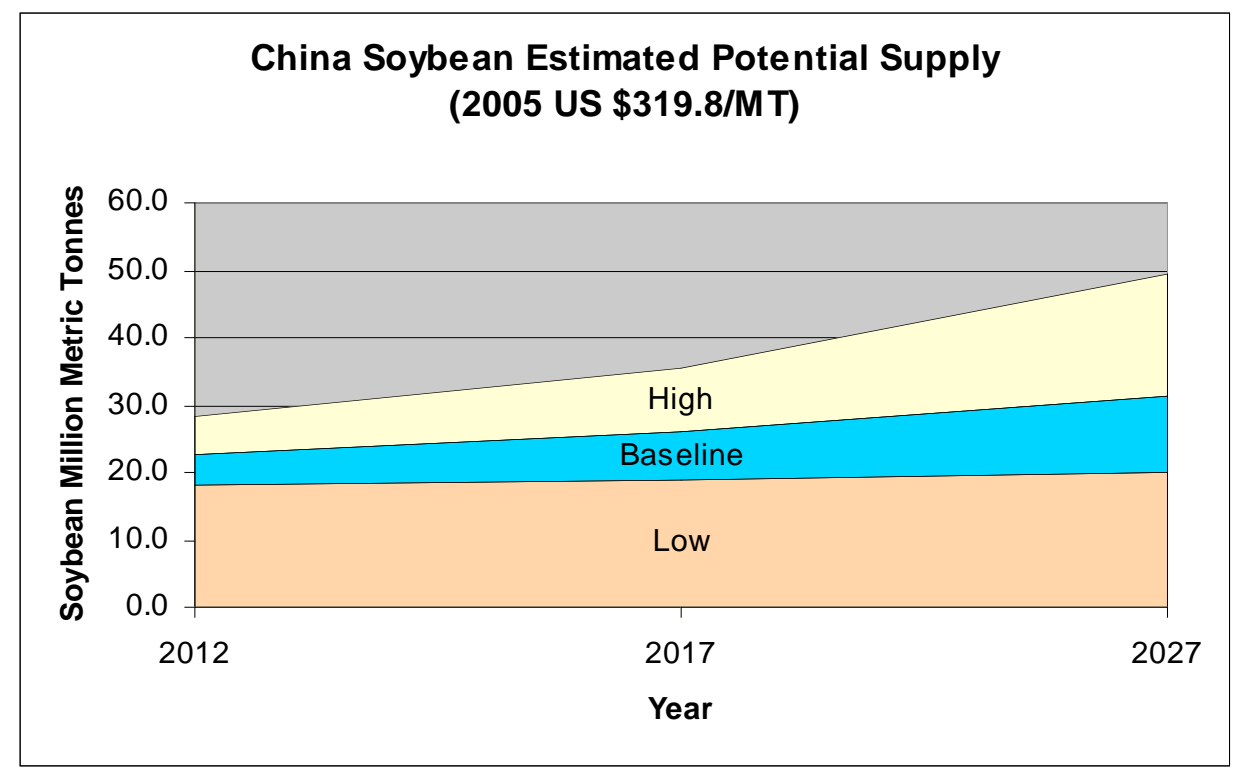


China Table 3. Estimated Potential Supply of Wheat

\begin{tabular}{ccccc}
\hline $\begin{array}{c}\text { Growth Case } \\
\text { (see }\end{array}$ & $\begin{array}{c}\text { Average } \\
\text { Value } \\
\text { Introduction) }\end{array}$ & $\begin{array}{c}\text { Cumulative } \\
\text { Production } \\
\text { (US/tonne) }\end{array}$ & $\begin{array}{c}\text { Cumulative } \\
\text { Production } \\
(\mathbf{m m t})\end{array}$ & $\begin{array}{c}\text { Cumulative } \\
\text { Production } \\
\text { (mmt) }\end{array}$ \\
\hline Low Growth & $\mathbf{2 0 0 5}$ & $\mathbf{2 0 1 2}$ & $\mathbf{2 0 1 7}$ & $\mathbf{2 0 2 7}$ \\
Baseline & $\$ 175.0$ & 98.3 & 98.6 & 99.3 \\
High Growth & $\$ \mathbf{1 7 5 . 0}$ & $\mathbf{1 0 9 . 8}$ & $\mathbf{1 1 3 . 7}$ & $\mathbf{1 2 5 . 1}$ \\
& $\$ 175.0$ & 129.6 & 141.1 & 178.8
\end{tabular}

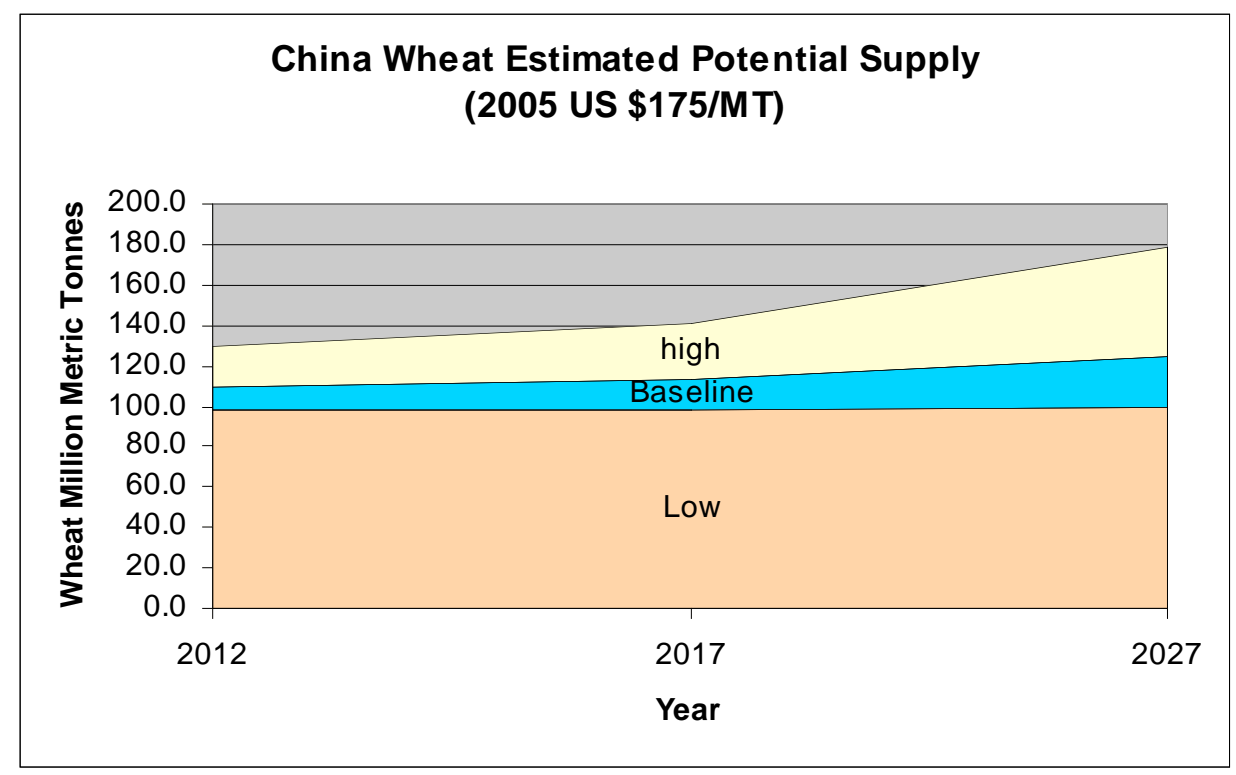


China Table 4. Estimated Potential Supply of Sugarcane

\begin{tabular}{|c|c|c|c|c|}
\hline $\begin{array}{l}\text { Growth Case } \\
\quad \text { (see } \\
\text { Introduction) }\end{array}$ & $\begin{array}{c}\text { Average } \\
\text { Value } \\
\text { (US\$/tonne) }\end{array}$ & $\begin{array}{c}\text { Cumulative } \\
\text { Production } \\
\text { (mmt) }\end{array}$ & $\begin{array}{c}\text { Cumulative } \\
\text { Production } \\
\text { (mmt) }\end{array}$ & $\begin{array}{c}\begin{array}{c}\text { Cumulative } \\
\text { Production } \\
\text { (mmt) }\end{array} \\
\end{array}$ \\
\hline & 2005 & 2012 & 2017 & 2027 \\
\hline Low Growth & $\$ 25.6$ & 93.7 & 96.3 & 100.3 \\
\hline Baseline & $\$ 25.6$ & 118.0 & 133.1 & 160.1 \\
\hline High Growth & $\$ 25.6$ & 148.2 & 183.2 & 254.4 \\
\hline
\end{tabular}

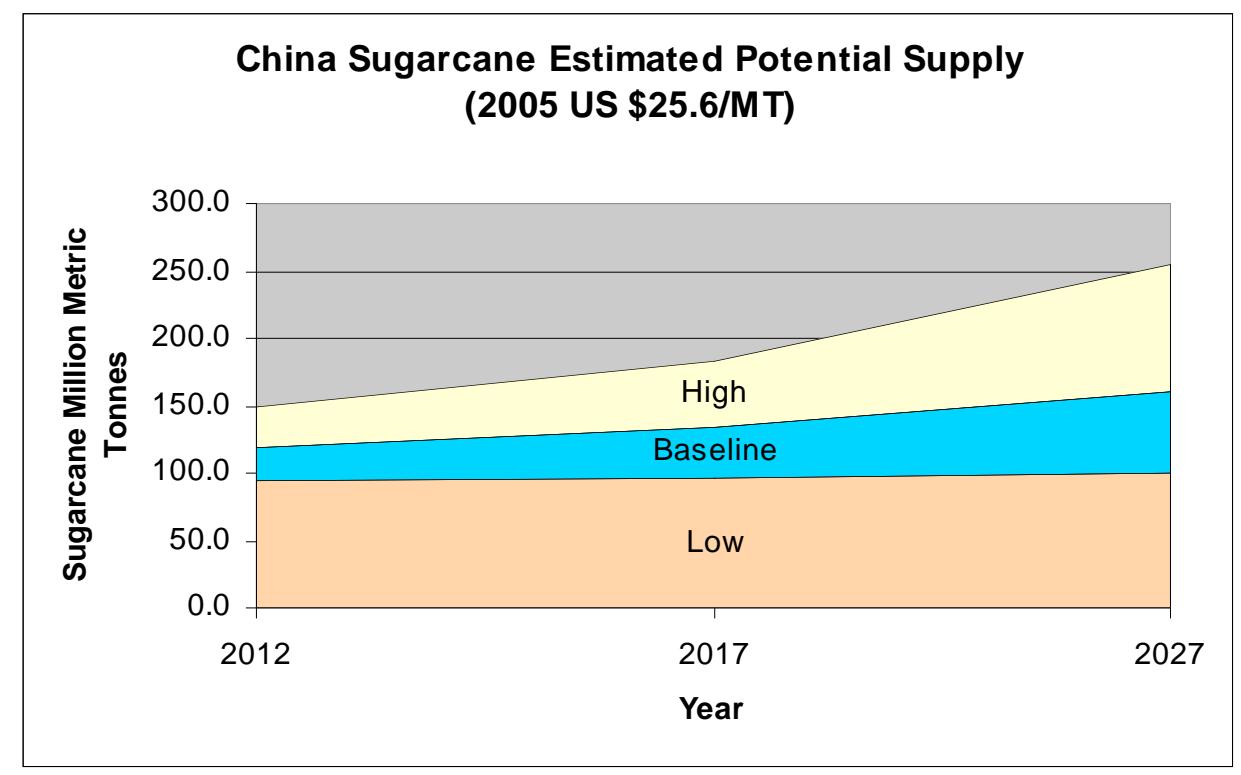


China Table 5. Potential Percentage Allocation for Export \& Biofuels

\begin{tabular}{cccc}
\hline & $\begin{array}{c}\text { Percent of } \\
\text { Feedstock }\end{array}$ & $\begin{array}{c}\text { Percent of } \\
\text { Feedstock }\end{array}$ & $\begin{array}{c}\text { Percent of } \\
\text { Feedstock }\end{array}$ \\
\hline Corn & $\mathbf{2 0 1 2}$ & $\mathbf{2 0 1 7}$ & $\mathbf{2 0 2 7}$ \\
Low Growth & 0 & 0 & 0 \\
Baseline & 2 & 2 & 2 \\
High Growth & 12 & 19 & 31 \\
Soybean & & & \\
Low Growth & 0 & 0 & 0 \\
Baseline & 0 & 0 & 0 \\
High Growth & 20 & 27 & 36 \\
\hline Wheat & & & 0 \\
Low Growth & 0 & 0 & 0 \\
Baseline & 0 & 0 & 30 \\
High Growth & 15 & 19 & 0 \\
Sugarcane & & 0 & 2 \\
Low Growth & 0 & 2 & 38 \\
Baseline & 2 & 29 & \\
High Growth & 22 & & \\
\hline
\end{tabular}

China Table 6. Estimated Cellulosic Supply from Recoverable Crop Residues (bagasse, corn and wheat only; in mmt, bone-dry, annual)

\begin{tabular}{|lccccccc|}
\hline & Baseline Case & \multicolumn{2}{l}{ Low Growth } & \multicolumn{2}{l|}{ High Growth Case } & $\begin{array}{l}\text { Cost } \\
\text { US\$ }\end{array}$ \\
& 2017 & 2027 & 2017 & 2027 & 2017 & 2027 & \\
Bagasse & 9 & 11 & 7 & 7 & 13 & 18 & $\$ 10.0$ \\
Corn Stover & 17 & 22 & 14 & 16 & 21 & 31 & $\$ 39.0$ \\
Wheat Straw & 10 & 11 & 8 & 8 & 12 & 15 & $\$ 39.0$ \\
Total & $\mathbf{3 6}$ & $\mathbf{4 3}$ & $\mathbf{2 9}$ & $\mathbf{3 1}$ & $\mathbf{4 5}$ & $\mathbf{6 4}$ & \\
\hline
\end{tabular}


China Table 7. Estimated Cellulosic Supply Including Other Residues (2017 baseline case)

\begin{tabular}{|lcc|}
\hline & $\begin{array}{c}\text { Supply/Yr } \\
(\mathbf{m m t})\end{array}$ & Cost US\$ \\
Agriculture Residues & 36 & $($ See Table 6) \\
Forest Harvest Residue & 6 & $\$ 50-\$ 100$ \\
Wood Residue & 2.7 & $\$ 18-\$ 36$ \\
Wood Fuel & 29 & $\$ 42$ \\
Crop and Forest Residues & $\mathbf{7 4}$ & \\
Perennials & & \\
$\quad$ 5\% Arable Land Harvest & 1.2 & $\$ 52$ \\
10\% Arable Land Harvest & 2.4 & $\$ 52$ \\
\hline
\end{tabular}


Colombia Table 1. Estimated Potential Supply of Sugarcane

\begin{tabular}{|c|c|c|c|c|}
\hline $\begin{array}{l}\text { Growth Case } \\
\text { (see } \\
\text { Introduction) }\end{array}$ & $\begin{array}{c}\text { Average } \\
\text { Value } \\
\text { (US\$/tonne) }\end{array}$ & $\begin{array}{c}\text { Cumulative } \\
\text { Production } \\
(\mathbf{m m t})\end{array}$ & $\begin{array}{c}\text { Cumulative } \\
\text { Production } \\
\text { (mmt) }\end{array}$ & $\begin{array}{c}\text { Cumulative } \\
\text { Production } \\
\text { (mmt) }\end{array}$ \\
\hline & 2005 & 2012 & 2017 & 2027 \\
\hline Low Growth & $\$ 29.85$ & 37.6 & 39.9 & 43.2 \\
\hline Baseline & $\$ 29.85$ & 44.6 & 52.2 & 65.4 \\
\hline High Growth & $\$ 29.85$ & 52.8 & 68.6 & 100.6 \\
\hline
\end{tabular}

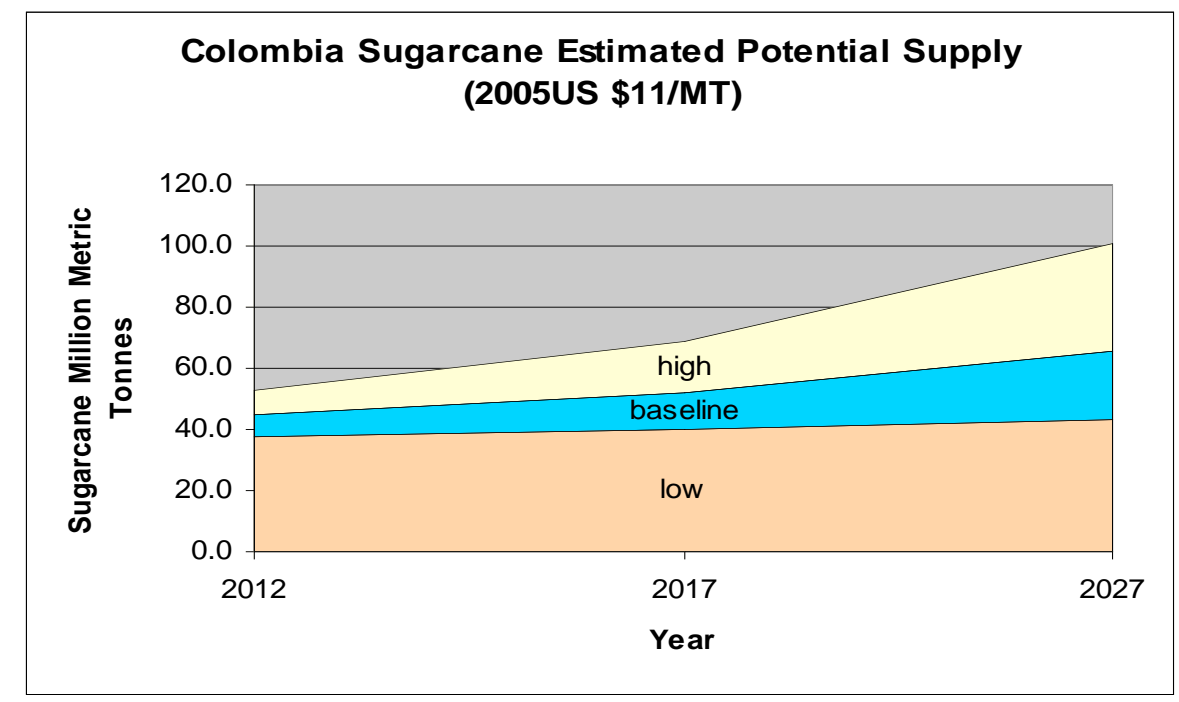

Colombia Table 2. Estimated Potential Supply of Palm Oil

\begin{tabular}{ccccc}
\hline $\begin{array}{c}\text { Growth Case } \\
\text { (see }\end{array}$ & $\begin{array}{c}\text { Average } \\
\text { Value } \\
\text { Introduction) }\end{array}$ & $\begin{array}{c}\text { Cumulative } \\
\text { Production } \\
\text { (US/tonne) }\end{array}$ & $\begin{array}{c}\text { Cumulative } \\
\text { Production } \\
(\mathbf{m m t})\end{array}$ & $\begin{array}{c}\text { Cumulative } \\
\text { Production } \\
\text { (mmt) }\end{array}$ \\
\hline Low Growth & $\mathbf{2 0 0 5}$ & $\mathbf{2 0 1 2}$ & $\mathbf{2 0 1 7}$ & $\mathbf{2 0 2 7}$ \\
Baseline & $\$ 448.50$ & 0.95 & 1.07 & 1.36 \\
High Growth & $\$ 448.50$ & $\mathbf{1 . 3 9}$ & $\mathbf{2 . 0 5}$ & $\mathbf{4 . 7 0}$ \\
& & 1.66 & 2.72 & 7.47
\end{tabular}


Colombia Table 3. Potential Percentage Allocation for Export \& Biofuels

\begin{tabular}{cccc}
\hline & $\begin{array}{c}\text { Percent of } \\
\text { Feedstock }\end{array}$ & $\begin{array}{c}\text { Percent of } \\
\text { Feedstock }\end{array}$ & $\begin{array}{c}\text { Percent of } \\
\text { Feedstock }\end{array}$ \\
\hline Palm Oil & $\mathbf{2 0 1 2}$ & $\mathbf{2 0 1 7}$ & $\mathbf{2 0 2 7}$ \\
Low Growth & 6 & 0 & \\
Baseline & 36 & 36 & 0 \\
High Growth & 46 & 52 & 36 \\
Sugarcane & & & 60 \\
Low Growth & 13 & 3 & 0 \\
Baseline & 26 & 26 & 26 \\
High Growth & 38 & 44 & 52 \\
\hline
\end{tabular}

Colombia Table 4. Estimated Cellulosic Supply from Recoverable Bagasse and Palm Residues (mmt, bone-dry, annual)

\begin{tabular}{|c|c|c|c|c|c|c|c|}
\hline & \multicolumn{2}{|c|}{ Baseline Case } & \multicolumn{2}{|c|}{ Low Growth } & \multicolumn{2}{|c|}{ High Growth } & \multirow{2}{*}{$\begin{array}{l}\text { Cost } \\
\text { US\$ }\end{array}$} \\
\hline & 2017 & 2027 & 2017 & 2027 & 2017 & 2027 & \\
\hline Palm Oil Processing Residue & 1 & 3 & 1 & 1 & 2 & 4 & $\$ 1$ \\
\hline Bagasse & 5 & 6 & 4 & 4 & 6 & 9 & $\$ 17$ \\
\hline Total & 6 & 9 & 5 & 5 & 8 & 14 & \\
\hline
\end{tabular}

Colombia Table 5. Estimated Cellulosic Supply Summary Including Other Residues (2017 baseline case)

\begin{tabular}{|lcc|}
\hline Cellulosic Summary & $\begin{array}{c}\text { Supply/Yr } \\
(\mathbf{m m t})\end{array}$ & Cost US\$ \\
Bagasse and Palm Residues & 6 & (See Table 4) \\
Forest Harvest Residue & 0.2 & $\$ 50-\$ 100$ \\
Wood Residue & 0.1 & $\$ 18-\$ 36$ \\
Wood Fuel & 1.4 & $\$ 42$ \\
Crop and Forest Residues & 7.7 & \\
Perennials & & \\
$\quad$ 5\% Arable Land Harvest & 5 & $\$ 52$ \\
10\% Arable Land Harvest & 10 & $\$ 52$ \\
\hline
\end{tabular}


India Table 1. Baseline Case Supply Potential for Sugarcane

\begin{tabular}{ccccc}
\hline $\begin{array}{c}\text { Production } \\
\text { Unit (State) }\end{array}$ & $\begin{array}{c}\text { Average Cost } \\
\text { (US\$/tonne) }\end{array}$ & $\begin{array}{c}\text { Cumulative } \\
\text { Production } \\
\text { (mmt) }\end{array}$ & $\begin{array}{c}\text { Cumulative } \\
\text { Production } \\
(\mathbf{m m t})\end{array}$ & $\begin{array}{c}\text { Cumulative } \\
\text { Production } \\
\text { (mmt) }\end{array}$ \\
\hline a & $\mathbf{2 0 0 5}$ & $\mathbf{2 0 1 2}$ & $\mathbf{2 0 1 7}$ & $\mathbf{2 0 2 7}$ \\
\hline $\mathrm{b}$ & $\$ 13.89$ & 173.7 & 200.9 & 252.6 \\
$\mathrm{c}$ & $\$ 15.03$ & 174.0 & 201.2 & 252.8 \\
$\mathrm{~d}$ & $\$ 15.10$ & 189.1 & 216.2 & 267.9 \\
$\mathrm{e}$ & $\$ 15.10$ & 189.1 & 216.3 & 267.9 \\
$\mathrm{f}$ & $\$ 15.10$ & 195.1 & 222.9 & 276.0 \\
$\mathrm{~g}$ & $\$ 15.10$ & 211.2 & 223.0 & 276.1 \\
$\mathrm{~h}$ & $\$ 15.10$ & 228.3 & 240.8 & 296.9 \\
$\mathrm{i}$ & $\$ 15.10$ & 230.5 & 262.5 & 328.7 \\
$\mathrm{j}$ & $\$ 15.10$ & 256.1 & 264.8 & 331.2 \\
$\mathrm{k}$ & $\$ 15.10$ & 256.1 & 290.5 & 356.9 \\
1 & $\$ 15.10$ & 256.5 & 290.5 & 356.9 \\
$\mathrm{~m}$ & $\$ 15.10$ & 256.7 & 291.0 & 358.0 \\
$\mathrm{n}$ & $\$ 15.10$ & 275.2 & 291.2 & 358.1 \\
$\mathrm{o}$ & $\$ 15.10$ & 275.6 & 318.5 & 408.5 \\
$\mathrm{p}$ & $\$ 15.10$ & 295.1 & 319.0 & 409.1 \\
$\mathrm{q}$ & $\$ 15.10$ & 295.3 & 338.5 & 428.6 \\
$\mathrm{r}$ & $\$ 15.10$ & 296.7 & 338.6 & 428.8 \\
$\mathrm{~s}$ & $\$ 18.22$ & 296.7 & 340.1 & 430.3 \\
$\mathrm{t}$ & $\$ 18.22$ & 312.7 & 340.1 & 430.3 \\
$\mathrm{u}$ & $\$ 22.55$ & 313.7 & 356.1 & 446.3 \\
$\mathrm{v}$ & $\$ 45.55$ & 313.7 & 357.1 & 447.4 \\
$\mathrm{w}$ & $\$ 97.93$ & 314.7 & 357.1 & 447.4 \\
$\mathrm{x}$ & $\$ 110.00$ & 314.7 & 358.1 & 448.4 \\
$\mathrm{y}$ & $\$ 122.07$ & 314.8 & 358.1 & 448.4 \\
\hline & & & 358.4 & 449.1 \\
\hline
\end{tabular}


India Table 2. High Growth Case Supply Potential for Sugarcane

\begin{tabular}{ccccc}
\hline $\begin{array}{c}\text { Production } \\
\text { Unit (State) }\end{array}$ & $\begin{array}{c}\text { Average Cost } \\
\text { (US\$/tonne) }\end{array}$ & $\begin{array}{c}\text { Cumulative } \\
\text { Production } \\
(\mathbf{m m t})\end{array}$ & $\begin{array}{c}\text { Cumulative } \\
\text { Production } \\
(\mathbf{m m t})\end{array}$ & $\begin{array}{c}\text { Cumulative } \\
\text { Production } \\
\text { (mmt) }\end{array}$ \\
\hline a & $\mathbf{2 0 0 5}$ & $\mathbf{2 0 1 2}$ & $\mathbf{2 0 1 7}$ & $\mathbf{2 0 2 7}$ \\
$\mathrm{b}$ & $\$ 13.89$ & 228.5 & 292.8 & 433.4 \\
$\mathrm{c}$ & $\$ 15.03$ & 228.8 & 293.1 & 433.7 \\
$\mathrm{~d}$ & $\$ 15.10$ & 243.8 & 308.1 & 448.7 \\
$\mathrm{e}$ & $\$ 15.10$ & 243.9 & 308.2 & 448.8 \\
$\mathrm{f}$ & $\$ 15.10$ & 251.3 & 317.3 & 461.4 \\
$\mathrm{~g}$ & $\$ 15.10$ & 251.3 & 317.4 & 461.5 \\
$\mathrm{~h}$ & $\$ 15.10$ & 270.5 & 340.0 & 491.3 \\
$\mathrm{i}$ & $\$ 15.10$ & 296.9 & 379.9 & 567.7 \\
$\mathrm{j}$ & $\$ 15.10$ & 299.2 & 382.5 & 570.7 \\
$\mathrm{k}$ & $\$ 15.10$ & 324.9 & 408.1 & 596.4 \\
1 & $\$ 15.10$ & 324.9 & 408.1 & 596.4 \\
$\mathrm{~m}$ & $\$ 15.10$ & 325.7 & 409.7 & 601.0 \\
$\mathrm{n}$ & $\$ 15.10$ & 325.8 & 409.8 & 601.1 \\
$\mathrm{o}$ & $\$ 15.10$ & 362.4 & 480.0 & 799.0 \\
$\mathrm{p}$ & $\$ 15.10$ & 363.0 & 480.7 & 800.0 \\
$\mathrm{q}$ & $\$ 15.10$ & 382.5 & 500.2 & 819.5 \\
$\mathrm{r}$ & $\$ 15.10$ & 382.7 & 500.5 & 820.1 \\
$\mathrm{~s}$ & $\$ 15.10$ & 384.1 & 501.9 & 821.6 \\
$\mathrm{t}$ & $\$ 18.22$ & 384.1 & 501.9 & 821.6 \\
$\mathrm{u}$ & $\$ 18.22$ & 400.1 & 517.9 & 837.6 \\
$\mathrm{v}$ & $\$ 22.55$ & 401.2 & 519.1 & 839.0 \\
$\mathrm{w}$ & $\$ 45.55$ & 401.2 & 519.1 & 839.0 \\
$\mathrm{X}$ & $\$ 97.93$ & 402.2 & 520.1 & 840.0 \\
$\mathrm{y}$ & $\$ 110.00$ & 402.2 & 520.1 & \\
\hline & $\$ 122.07$ & 402.6 & 521.1 & \\
\hline
\end{tabular}


India Table 3. Low Growth Case Supply Potential for Sugarcane

\begin{tabular}{|c|c|c|c|c|}
\hline $\begin{array}{l}\text { Production } \\
\text { Unit (State) }\end{array}$ & $\begin{array}{c}\text { Average Cost } \\
\text { (US\$/tonne) }\end{array}$ & $\begin{array}{l}\text { Cumulative } \\
\text { Production } \\
\quad \text { (mmt) }\end{array}$ & $\begin{array}{l}\text { Cumulative } \\
\text { Production } \\
\quad(\mathbf{m m t})\end{array}$ & $\begin{array}{l}\text { Cumulative } \\
\text { Production } \\
\quad(\mathbf{m m t})\end{array}$ \\
\hline & 2005 & 2012 & 2017 & 2027 \\
\hline $\mathrm{a}$ & $\$ 13.89$ & 131.0 & 136.4 & 145.2 \\
\hline $\mathrm{b}$ & $\$ 15.03$ & 131.3 & 136.6 & 145.5 \\
\hline $\mathrm{c}$ & $\$ 15.10$ & 146.4 & 151.7 & 160.6 \\
\hline $\mathrm{d}$ & $\$ 15.10$ & 146.4 & 151.7 & 160.6 \\
\hline $\mathrm{e}$ & $\$ 15.10$ & 151.1 & 156.6 & 165.7 \\
\hline $\mathrm{f}$ & $\$ 15.10$ & 151.1 & 156.6 & 165.7 \\
\hline $\mathrm{g}$ & $\$ 15.10$ & 164.6 & 170.5 & 180.2 \\
\hline $\mathrm{h}$ & $\$ 15.10$ & 175.6 & 182.2 & 193.3 \\
\hline $\mathrm{i}$ & $\$ 15.10$ & 177.6 & 184.2 & 195.3 \\
\hline $\mathrm{j}$ & $\$ 15.10$ & 203.2 & 209.9 & 221.0 \\
\hline $\mathrm{k}$ & $\$ 15.10$ & 203.2 & 209.9 & 221.0 \\
\hline 1 & $\$ 15.10$ & 203.4 & 210.1 & 221.2 \\
\hline $\mathrm{m}$ & $\$ 15.10$ & 203.5 & 210.2 & 221.3 \\
\hline $\mathrm{n}$ & $\$ 15.10$ & 212.4 & 220.1 & 233.1 \\
\hline o & $\$ 15.10$ & 212.8 & 220.5 & 233.4 \\
\hline $\mathrm{p}$ & $\$ 15.10$ & 232.3 & 240.0 & 253.0 \\
\hline$q$ & $\$ 15.10$ & 232.3 & 240.1 & 253.0 \\
\hline $\mathrm{r}$ & $\$ 15.10$ & 233.8 & 241.5 & 254.5 \\
\hline $\mathrm{s}$ & $\$ 18.22$ & 233.8 & 241.5 & 254.5 \\
\hline $\mathrm{t}$ & $\$ 18.22$ & 249.8 & 257.5 & 270.5 \\
\hline $\mathrm{u}$ & $\$ 22.55$ & 250.7 & 258.4 & 271.4 \\
\hline $\mathrm{v}$ & $\$ 45.55$ & 250.7 & 258.4 & 271.4 \\
\hline $\mathrm{w}$ & $\$ 97.93$ & 251.7 & 259.4 & 272.4 \\
\hline $\mathrm{x}$ & $\$ 110.00$ & 251.7 & 259.4 & 272.4 \\
\hline $\mathrm{y}$ & $\$ 122.07$ & 251.7 & 259.5 & 272.5 \\
\hline
\end{tabular}


India Table 4. Potential Percentage Allocation for Export \& Biofuels

\begin{tabular}{rccc}
\hline & $\begin{array}{c}\text { Percent of } \\
\text { Feedstock }\end{array}$ & $\begin{array}{c}\text { Percent of } \\
\text { Feedstock }\end{array}$ & $\begin{array}{c}\text { Percent of } \\
\text { Feedstock }\end{array}$ \\
\hline Sugarcane & $\mathbf{2 0 1 2}$ & $\mathbf{2 0 1 7}$ & $\mathbf{2 0 2 7}$ \\
Low Growth & 0 & & \\
Baseline & 5 & 0 & 0 \\
High Growth & 26 & 5 & 5 \\
\hline
\end{tabular}

India Table 5. Estimated Cellulosic Supply from Recoverable Bagasse Residues (mmt, bone-dry, annual)

\begin{tabular}{|lccccccc|}
\hline & \multicolumn{3}{c}{ Baseline Case } & \multicolumn{2}{l|}{ Low Growth } & High Growth Case & $\begin{array}{l}\text { Cost } \\
\text { US } \$\end{array}$ \\
& 2017 & 2027 & 2017 & 2027 & 2017 & 2027 & \\
Bagasse & 50 & 63 & 36 & 38 & 73 & 118 & $\$ 8$ \\
Total & $\mathbf{5 0}$ & $\mathbf{6 3}$ & $\mathbf{3 6}$ & $\mathbf{3 8}$ & $\mathbf{7 3}$ & $\mathbf{1 1 8}$ & \\
\hline
\end{tabular}

India Table 6. Estimated Cellulosic Supply Including Other Residues (2017 baseline case)

\begin{tabular}{|lcc|}
\hline & $\begin{array}{c}\text { Supply/Yr } \\
(\mathbf{m m t})\end{array}$ & Cost US\$ \\
Bagasse Residues & 50 & $\$ 8$ \\
Forest Harvest Residue & 7 & $\$ 50-\$ 100$ \\
Wood Residue & 3 & $\$ 18-\$ 36$ \\
Wood Fuel & 75 & $\$ 42$ \\
Crop and Forest Residues & $\mathbf{1 3 5}$ & \\
Perennials & & \\
$\quad$ 5\% Arable Land Harvest & 0.00 & \\
$\quad$ 10\% Arable Land Harvest & 0.00 & \\
\hline
\end{tabular}


Mexico Table 1. Sugarcane - Baseline Case Supply Curve Data

\begin{tabular}{ccccc}
\hline State* & $\begin{array}{c}\text { Average } \\
\text { Value } \\
\text { (US\$/tonne) }\end{array}$ & $\begin{array}{c}\text { Cumulative } \\
\text { Production } \\
\text { (mmt) }\end{array}$ & $\begin{array}{c}\text { Cumulative } \\
\text { Production } \\
\text { (mmt) }\end{array}$ & $\begin{array}{c}\text { Cumulative } \\
\text { Production } \\
\text { (mmt) }\end{array}$ \\
\hline r & $\mathbf{2 0 0 5}$ & $\mathbf{2 0 1 2}$ & $\mathbf{2 0 1 7}$ & $\mathbf{2 0 2 7}$ \\
\hline S & 27.7 & 5.2 & 6.4 & 8.5 \\
t & 29.8 & 9.8 & 11.4 & 14.0 \\
u & 30.1 & 12.9 & 14.7 & 17.6 \\
v & 31.7 & 14.4 & 16.2 & 19.1 \\
w & 32.6 & 36.4 & 39.3 & 43.7 \\
X & 34.0 & 38.1 & 41.1 & 45.8 \\
y & 34.1 & 39.9 & 43.0 & 47.7 \\
Z & 34.4 & 40.6 & 43.7 & 48.4 \\
aa & 34.7 & 42.1 & 45.2 & 50.0 \\
ab & 36.0 & 44.6 & 47.8 & 52.8 \\
ac & 36.3 & 46.5 & 49.9 & 55.1 \\
ad & 36.7 & 50.1 & 53.7 & 59.2 \\
ae & 36.8 & 56.7 & 60.6 & 66.4 \\
af & 37.3 & 58.8 & 62.8 & 68.8 \\
\hline
\end{tabular}

Mexico Table 2. Sugarcane - High Growth Case Supply Curve Data

\begin{tabular}{ccccc}
\hline State* & $\begin{array}{c}\text { Average } \\
\text { Value } \\
\text { (US\$/tonne) }\end{array}$ & $\begin{array}{c}\text { Cumulative } \\
\text { Production } \\
\text { (mmt) }\end{array}$ & $\begin{array}{c}\text { Cumulative } \\
\text { Production } \\
\text { (mmt) }\end{array}$ & $\begin{array}{c}\text { Cumulative } \\
\text { Production } \\
\text { (mmt) }\end{array}$ \\
\hline r & $\mathbf{2 0 0 5}$ & $\mathbf{2 0 1 2}$ & $\mathbf{2 0 1 7}$ & $\mathbf{2 0 2 7}$ \\
\hline s & 27.7 & 8.3 & 12.5 & 21.8 \\
t & 29.8 & 13.8 & 19.0 & 29.8 \\
u & 30.1 & 17.4 & 23.1 & 34.7 \\
v & 31.7 & 18.9 & 24.5 & 36.2 \\
w & 32.6 & 43.3 & 51.5 & 66.9 \\
x & 34.0 & 45.4 & 54.0 & 69.9 \\
y & 34.1 & 47.3 & 55.9 & 72.0 \\
Z & 34.4 & 48.0 & 56.7 & 72.8 \\
aa & 34.7 & 49.6 & 58.3 & 74.5 \\
ab & 36.0 & 52.4 & 61.4 & 78.2 \\
ac & 36.3 & 54.7 & 64.2 & 81.7 \\
ad & 36.7 & 58.7 & 68.5 & 86.5 \\
ae & 36.8 & 65.9 & 76.4 & 95.4 \\
af & 37.3 & 68.3 & 79.0 & 98.4 \\
& 37.5 & 68.8 & 79.7 & 99.3
\end{tabular}

* Note: Other Mexican states produce insignificant amounts of sugarcane. 
Mexico Table 3. Sugarcane - Low Growth Case Supply Curve Data

\begin{tabular}{ccccc}
\hline State* & $\begin{array}{c}\text { Average } \\
\text { Value } \\
\text { (US\$/tonne) }\end{array}$ & $\begin{array}{c}\text { Cumulative } \\
\text { Production } \\
(\mathbf{m m t})\end{array}$ & $\begin{array}{c}\text { Cumulative } \\
\text { Production } \\
\text { (mmt) }\end{array}$ & $\begin{array}{c}\text { Cumulative } \\
\text { Production } \\
\text { (mmt) }\end{array}$ \\
\hline r & $\mathbf{2 0 0 5}$ & $\mathbf{2 0 1 2}$ & $\mathbf{2 0 1 7}$ & $\mathbf{2 0 2 7}$ \\
\hline s & 27.7 & 3.3 & 3.3 & 3.3 \\
t & 29.8 & 7.1 & 7.2 & 7.2 \\
u & 30.1 & 9.8 & 9.8 & 9.8 \\
V & 31.7 & 11.3 & 11.3 & 11.3 \\
W & 32.6 & 31.2 & 31.2 & 31.3 \\
X & 34.0 & 32.6 & 32.7 & 32.7 \\
y & 34.1 & 34.3 & 34.4 & 34.4 \\
Z & 34.4 & 35.0 & 35.0 & 35.1 \\
aa & 34.7 & 36.4 & 36.5 & 36.5 \\
ab & 36.0 & 38.6 & 38.7 & 38.7 \\
ac & 36.3 & 40.2 & 40.2 & 40.3 \\
ad & 36.7 & 43.6 & 43.6 & 43.7 \\
ae & 36.8 & 49.6 & 49.7 & 49.7 \\
af & 37.3 & 51.5 & 51.6 & 51.7 \\
& 37.5 & 51.8 & 51.9 & 52.0
\end{tabular}

*Note: Other Mexican states produce insignificant amounts of sugarcane. 
Mexico Table 4. Corn - Baseline Case Supply Curve Data

\begin{tabular}{|c|c|c|c|c|}
\hline State & $\begin{array}{c}\text { Average } \\
\text { Value } \\
\text { (US\$/tonne) }\end{array}$ & $\begin{array}{c}\text { Cumulative } \\
\text { Production } \\
(\mathrm{mmt})\end{array}$ & $\begin{array}{l}\text { Cumulative } \\
\text { Production } \\
\text { (mmt) }\end{array}$ & $\begin{array}{c}\text { Cumulative } \\
\text { Production } \\
\text { (mmt) }\end{array}$ \\
\hline & 2005 & 2012 & 2017 & 2027 \\
\hline $\mathrm{a}$ & $\$ 114.91$ & 1.0 & 1.2 & 1.5 \\
\hline $\mathrm{b}$ & $\$ 119.43$ & 8.2 & 10.5 & 15.1 \\
\hline $\mathrm{c}$ & $\$ 125.09$ & 9.6 & 12.5 & 18.3 \\
\hline $\mathrm{d}$ & $\$ 125.21$ & 9.8 & 12.7 & 18.6 \\
\hline $\mathrm{e}$ & $\$ 125.22$ & 11.8 & 15.4 & 22.9 \\
\hline $\mathrm{f}$ & $\$ 129.72$ & 15.5 & 19.8 & 28.6 \\
\hline $\mathrm{g}$ & $\$ 131.21$ & 15.7 & 20.0 & 28.8 \\
\hline $\mathrm{h}$ & $\$ 131.45$ & 16.2 & 20.7 & 29.8 \\
\hline $\mathrm{i}$ & $\$ 132.60$ & 17.9 & 22.6 & 32.1 \\
\hline $\mathrm{j}$ & $\$ 136.41$ & 18.0 & 22.7 & 32.2 \\
\hline $\mathrm{k}$ & $\$ 136.47$ & 18.3 & 23.0 & 32.7 \\
\hline 1 & $\$ 137.49$ & 18.7 & 23.5 & 33.4 \\
\hline $\mathrm{m}$ & $\$ 138.48$ & 18.8 & 23.6 & 33.5 \\
\hline $\mathrm{n}$ & $\$ 144.62$ & 18.8 & 23.7 & 33.6 \\
\hline o & $\$ 148.24$ & 19.7 & 24.6 & 34.6 \\
\hline $\mathrm{p}$ & $\$ 152.64$ & 19.9 & 24.8 & 34.9 \\
\hline$q$ & $\$ 155.24$ & 20.0 & 25.0 & 35.1 \\
\hline $\mathrm{r}$ & $\$ 155.37$ & 21.2 & 26.2 & 36.3 \\
\hline $\mathrm{s}$ & $\$ 157.86$ & 21.8 & 26.7 & 36.9 \\
\hline $\mathrm{t}$ & $\$ 158.19$ & 21.8 & 26.8 & 36.9 \\
\hline $\mathrm{u}$ & $\$ 158.22$ & 21.9 & 26.9 & 37.0 \\
\hline $\mathrm{v}$ & $\$ 159.12$ & 22.0 & 27.0 & 37.1 \\
\hline w & $\$ 165.94$ & 23.4 & 28.4 & 38.5 \\
\hline $\mathrm{x}$ & $\$ 169.44$ & 23.7 & 28.8 & 39.1 \\
\hline $\mathrm{y}$ & $\$ 174.34$ & 23.7 & 28.8 & 39.1 \\
\hline $\mathrm{z}$ & $\$ 175.26$ & 24.6 & 29.7 & 40.0 \\
\hline $\mathrm{a}$ & $\$ 180.72$ & 24.6 & 29.7 & 40.0 \\
\hline $\mathrm{b}$ & $\$ 194.96$ & 24.8 & 29.8 & 40.2 \\
\hline $\mathrm{c}$ & $\$ 201.19$ & 24.8 & 29.9 & 40.3 \\
\hline $\mathrm{d}$ & $\$ 207.39$ & 24.8 & 29.9 & 40.3 \\
\hline $\mathrm{e}$ & $\$ 216.36$ & 26.1 & 31.2 & 41.6 \\
\hline $\mathrm{f}$ & $\$ 226.94$ & 26.7 & 31.8 & 42.2 \\
\hline
\end{tabular}


Mexico Table 5. Corn - High Growth Case Supply Curve Data

\begin{tabular}{|c|c|c|c|c|}
\hline State & $\begin{array}{c}\text { Average } \\
\text { Value } \\
\text { (US\$/tonne) }\end{array}$ & $\begin{array}{c}\text { Cumulative } \\
\text { Production } \\
(\mathbf{m m t})\end{array}$ & $\begin{array}{c}\text { Cumulative } \\
\text { Production } \\
(\mathbf{m m t})\end{array}$ & $\begin{array}{c}\text { Cumulative } \\
\text { Production } \\
\text { (mmt) }\end{array}$ \\
\hline & 2005 & 2012 & 2017 & 2027 \\
\hline $\mathrm{a}$ & $\$ 114.91$ & 1.2 & 1.6 & 2.4 \\
\hline $\mathrm{b}$ & $\$ 119.43$ & 11.2 & 17.0 & 30.7 \\
\hline $\mathrm{c}$ & $\$ 125.09$ & 13.4 & 20.6 & 38.7 \\
\hline $\mathrm{d}$ & $\$ 125.21$ & 13.6 & 20.9 & 39.1 \\
\hline $\mathrm{e}$ & $\$ 125.22$ & 16.6 & 25.8 & 49.4 \\
\hline $\mathrm{f}$ & $\$ 129.72$ & 21.1 & 31.7 & 58.6 \\
\hline $\mathrm{g}$ & $\$ 131.21$ & 21.3 & 31.9 & 58.8 \\
\hline $\mathrm{h}$ & $\$ 131.45$ & 22.1 & 33.0 & 60.8 \\
\hline $\mathrm{i}$ & $\$ 132.60$ & 24.0 & 35.3 & 63.9 \\
\hline $\mathrm{j}$ & $\$ 136.41$ & 24.1 & 35.4 & 64.1 \\
\hline $\mathrm{k}$ & $\$ 136.47$ & 24.5 & 36.0 & 65.4 \\
\hline 1 & $\$ 137.49$ & 25.0 & 36.8 & 66.6 \\
\hline $\mathrm{m}$ & $\$ 138.48$ & 25.1 & 36.9 & 66.8 \\
\hline $\mathrm{n}$ & $\$ 144.62$ & 25.1 & 36.9 & 66.9 \\
\hline o & $\$ 148.24$ & 26.1 & 38.0 & 68.1 \\
\hline $\mathrm{p}$ & $\$ 152.64$ & 26.3 & 38.3 & 68.5 \\
\hline $\mathrm{q}$ & $\$ 155.24$ & 26.5 & 38.4 & 68.6 \\
\hline $\mathrm{r}$ & $\$ 155.37$ & 27.7 & 39.6 & 69.9 \\
\hline s & $\$ 157.86$ & 28.3 & 40.2 & 70.5 \\
\hline $\mathrm{t}$ & $\$ 158.19$ & 28.3 & 40.3 & 70.6 \\
\hline $\mathrm{u}$ & $\$ 158.22$ & 28.4 & 40.4 & 70.7 \\
\hline $\mathrm{v}$ & $\$ 159.12$ & 28.5 & 40.5 & 70.8 \\
\hline w & $\$ 165.94$ & 29.9 & 41.9 & 72.2 \\
\hline $\mathrm{x}$ & $\$ 169.44$ & 30.3 & 42.5 & 73.2 \\
\hline $\mathrm{y}$ & $\$ 174.34$ & 30.3 & 42.5 & 73.2 \\
\hline $\mathrm{z}$ & $\$ 175.26$ & 31.2 & 43.4 & 74.1 \\
\hline $\mathrm{a}$ & $\$ 180.72$ & 31.2 & 43.4 & 74.1 \\
\hline $\mathrm{b}$ & $\$ 194.96$ & 31.4 & 43.6 & 74.6 \\
\hline $\mathrm{c}$ & $\$ 201.19$ & 31.5 & 43.7 & 74.7 \\
\hline $\mathrm{d}$ & $\$ 207.39$ & 31.5 & 43.7 & 74.7 \\
\hline $\mathrm{e}$ & $\$ 216.36$ & 32.7 & 45.1 & 76.1 \\
\hline $\mathrm{f}$ & $\$ 226.94$ & 33.3 & 45.7 & 76.7 \\
\hline
\end{tabular}


Mexico Table 6. Corn - Low Growth Case Supply Curve Data

\begin{tabular}{ccccc}
\hline State & $\begin{array}{c}\text { Average } \\
\text { Value } \\
\text { (US\$tonne) }\end{array}$ & $\begin{array}{c}\text { Cumulative } \\
\text { Production } \\
\text { (mmt) }\end{array}$ & $\begin{array}{c}\text { Cumulative } \\
\text { Production } \\
\text { (mmt) }\end{array}$ & $\begin{array}{c}\text { Cumulative } \\
\text { Production } \\
\text { (mmt) }\end{array}$ \\
\hline a & $\mathbf{2 0 0 5}$ & $\mathbf{2 0 1 2}$ & $\mathbf{2 0 1 7}$ & $\mathbf{2 0 2 7}$ \\
\hline b & $\$ 114.91$ & 0.8 & 0.8 & 0.9 \\
c & $\$ 119.43$ & 5.9 & 6.5 & 7.4 \\
d & $\$ 125.09$ & 6.8 & 7.5 & 8.6 \\
e & $\$ 125.21$ & 7.0 & 7.7 & 8.9 \\
f & $\$ 125.22$ & 8.3 & 9.2 & 10.6 \\
g & $\$ 131.21$ & 11.3 & 12.4 & 14.1 \\
h & $\$ 131.45$ & 11.5 & 12.6 & 14.3 \\
i & $\$ 132.60$ & 13.4 & 13.0 & 14.8 \\
j & $\$ 136.41$ & 13.5 & 14.5 & 16.4 \\
k & $\$ 136.47$ & 13.6 & 14.6 & 16.6 \\
l & $\$ 137.49$ & 13.9 & 15.1 & 16.8 \\
m & $\$ 138.48$ & 14.0 & 15.2 & 17.1 \\
n & $\$ 144.62$ & 14.1 & 15.3 & 17.2 \\
o & $\$ 148.24$ & 14.9 & 16.1 & 17.2 \\
p & $\$ 152.64$ & 15.1 & 16.3 & 18.1 \\
q & $\$ 155.24$ & 15.2 & 16.4 & 18.4 \\
r & $\$ 155.37$ & 16.4 & 17.6 & 19.6 \\
s & $\$ 157.86$ & 16.9 & 18.2 & 20.2 \\
t & $\$ 158.19$ & 17.0 & 18.2 & 20.3 \\
u & $\$ 158.22$ & 17.0 & 18.3 & 20.3 \\
v & $\$ 159.12$ & 17.1 & 18.4 & 20.4 \\
w & $\$ 165.94$ & 18.5 & 19.8 & 21.8 \\
x & $\$ 169.44$ & 18.8 & 20.0 & 22.1 \\
y & $\$ 174.34$ & 18.8 & 20.0 & 22.1 \\
Z & $\$ 175.26$ & 19.7 & 20.9 & 23.0 \\
aa & $\$ 180.72$ & 19.7 & 20.9 & 23.0 \\
ab & $\$ 194.96$ & 19.8 & 21.0 & 23.1 \\
ac & $\$ 201.19$ & 19.8 & 21.1 & 23.2 \\
ad & $\$ 207.39$ & 19.8 & 21.1 & 23.2 \\
ae & $\$ 216.36$ & 21.0 & 22.3 & 24.4 \\
af & $\$ 226.94$ & 21.6 & 22.9 & 25.0 \\
& & & &
\end{tabular}


Mexico Table 7. Potential Percentage Allocation for Export \& Biofuels

\begin{tabular}{cccc}
\hline & $\begin{array}{c}\text { Percent of } \\
\text { Feedstock }\end{array}$ & $\begin{array}{c}\text { Percent of } \\
\text { Feedstock }\end{array}$ & $\begin{array}{c}\text { Percent of } \\
\text { Feedstock }\end{array}$ \\
\hline Sugarcane & $\mathbf{2 0 1 2}$ & $\mathbf{2 0 1 7}$ & $\mathbf{2 0 2 7}$ \\
Low Growth & 1 & 0 & \\
Baseline & 13 & 13 & 0 \\
High Growth & 25 & 31 & 39 \\
Corn & & & \\
Low Growth & 0 & 0 & 0 \\
Baseline & 0 & 0 & 0 \\
High Growth & 11 & 27 & 41 \\
\hline
\end{tabular}

Mexico Table 8. Estimated Cellulosic Supply from Recoverable Crop Residues (bagasse and corn only; mmt, bone-dry, annual)

\begin{tabular}{|c|c|c|c|c|c|c|c|}
\hline \multirow{2}{*}{$\begin{array}{l}\text { Cellulosic } \\
\text { Potential } \\
(\mathbf{m m t})\end{array}$} & \multicolumn{2}{|c|}{ Baseline Case } & \multicolumn{2}{|c|}{ Low Growth } & \multicolumn{2}{|c|}{ High Growth Case } & \multirow{2}{*}{$\begin{array}{l}\text { Cost } \\
\text { US\$ }\end{array}$} \\
\hline & 2017 & 2027 & 2017 & 2027 & 2017 & 2027 & \\
\hline Bagasse & 6 & 6 & 5 & 5 & 7 & 9 & $\$ 17$ \\
\hline Corn Stover & 4 & 6 & 3 & 4 & 6 & 11 & $\$ 39$ \\
\hline Total & 10 & 12 & 8 & 8 & 14 & 20 & \\
\hline
\end{tabular}

Mexico Table 9. Estimated Cellulosic Supply Including Other Residues (2017 baseline case)

\begin{tabular}{|lcc|}
\hline & $\begin{array}{c}\text { Supply/Yr } \\
(\mathbf{m m t})\end{array}$ & Cost US\$ \\
Bagasse and Corn Residues & 10 & (See Table 8) \\
Forest Harvest Residue & 1 & $\$ 50-\$ 100$ \\
Wood Residue & 0.4 & $\$ 18-\$ 36$ \\
Wood Fuel & 7 & $\$ 50$ \\
Crop and Forest Residues & $\mathbf{1 8}$ & \\
Perennials & & \\
$\quad$ 5\% Arable Land Harvest & 1 & $\$ 52$ \\
$10 \%$ Arable Land Harvest & 2 & $\$ 52$ \\
\hline
\end{tabular}




\section{CBI Table 1. Sugarcane - Baseline Case Supply Curve Data Cumulative Projected Production (mmt) by \$ Value}

$\begin{array}{llrrr} & \begin{array}{l}\text { Average } \\ \text { Value } \\ \text { (US\$/tonne) }\end{array} & \begin{array}{l}\text { Cumulative } \\ \text { Production } \\ (\mathrm{mmt})\end{array} & \begin{array}{l}\text { Cumulative } \\ \text { Production } \\ (\mathrm{mmt})\end{array} & \begin{array}{l}\text { Cumulative } \\ \text { Production } \\ (\mathrm{mmt})\end{array} \\ \begin{array}{l}\text { Production unit } \\ \text { Guatemala }\end{array} & \$ 13.80 & 2012 & 2017 & 2027 \\ \text { Honduras } & \$ 14.91 & 32.1 & 26.5 & 32.5 \\ \text { Nicaragua } & \$ 16.26 & 37.2 & 44.0 & 48.9 \\ \text { Dominican Republic } & \$ 16.73 & 43.4 & 51.2 & 56.7 \\ \text { Others } & \$ 23.03 & 56.8 & 66.6 & 85.8 \\ \text { Costa Rica } & \$ 25.93 & 61.1 & 71.4 & 91.3 \\ \text { EI Salvador } & \$ 28.26 & 66.2 & 77.0 & 98.0 \\ \text { Guyana } & \$ 45.45 & 69.5 & 80.4 & 101.6\end{array}$

CBI Table 2. Sugarcane - High Growth Case Supply Curve Data

\begin{tabular}{l|rrrr} 
& $\begin{array}{l}\text { Average } \\
\text { Value } \\
\text { (US\$/tonne) }\end{array}$ & $\begin{array}{l}\text { Cumulative } \\
\text { Production } \\
\text { Production unit }\end{array}$ & \multicolumn{1}{l}{$\begin{array}{l}\text { Cumulative } \\
\text { Production } \\
\text { (mmt) } 2017\end{array}$} & $\begin{array}{l}\text { Cumulative } \\
\text { Production } \\
\text { (mmt) 2027 }\end{array}$ \\
Guatemala & $\$ 13.80$ & 27.4 & 34.3 & 49.1 \\
Honduras & $\$ 14.91$ & 39.7 & 54.1 & 86.5 \\
Nicaragua & $\$ 16.26$ & 45.9 & 62.6 & 99.9 \\
Dominican Republic & $\$ 16.73$ & 53.3 & 72.1 & 114.6 \\
Others & $\$ 23.03$ & 69.2 & 92.5 & 146.4 \\
Costa Rica & $\$ 25.93$ & 74.1 & 98.4 & 154.5 \\
El Salvador & $\$ 28.26$ & 79.9 & 105.3 & 163.8 \\
Guyana & $\$ 45.45$ & 83.4 & 109.0 & 167.9
\end{tabular}

CBI Table 3. Sugarcane - Low Growth Case Supply Curve Data

\begin{tabular}{|c|c|c|c|c|}
\hline Production unit & $\begin{array}{l}\text { Average Value } \\
\text { (US\$/tonne) } \\
2005\end{array}$ & $\begin{array}{l}\text { Cumulative } \\
\text { Production } \\
\text { (mmt) } \\
2012\end{array}$ & $\begin{array}{l}\text { Cumulative } \\
\text { Production } \\
\text { (mmt) } \\
2017\end{array}$ & $\begin{array}{l}\text { Cumulative } \\
\text { Production } \\
\text { (mmt) } 2027\end{array}$ \\
\hline Guatemala & $\$ 13.80$ & 19.9 & 20.5 & 21.4 \\
\hline Honduras & $\$ 14.91$ & 26.1 & 27.0 & 28.4 \\
\hline Nicaragua & $\$ 16.26$ & 30.2 & 31.2 & 32.9 \\
\hline Dominican Republic & $\$ 16.73$ & 35.4 & 36.6 & 38.5 \\
\hline Others & $\$ 23.03$ & 46.5 & 48.1 & 50.7 \\
\hline Costa Rica & $\$ 25.93$ & 50.3 & 51.9 & 54.7 \\
\hline EI Salvador & $\$ 28.26$ & 54.8 & 56.6 & 59.5 \\
\hline Guyana & $\$ 45.45$ & 57.9 & 59.7 & 62.6 \\
\hline
\end{tabular}

As noted in the methodology (Annex 3), the approach used to estimate potential supplies from CBI treated countries as "states" to project overall future production in the region. These figures are not intended to represent individual country projections. 


\section{CBI Table 4. Palm Oil - Baseline Case Supply Curve Data}

$\begin{array}{lclll} & \begin{array}{l}\text { Average } \\ \text { Value } \\ \text { (US\$/ton) }\end{array} & \begin{array}{l}\text { Cumulative } \\ \text { Production } \\ (\text { mmt) } 2012\end{array} & \begin{array}{l}\text { Cumulative } \\ \text { Production } \\ (\mathrm{mmt}) 2017\end{array} & \begin{array}{l}\text { Cumulative } \\ \text { Production } \\ (\mathrm{mmt}) 2027\end{array} \\ \text { Production unit } & 2005 & 0.3 & 0.4 & 0.8 \\ \text { Guatemala } & \$ 240.00 & 0.3 & 0.5 & 0.9 \\ \text { Dominican Republic } & \$ 256.82 & 0.4 & 0.6 & 1.0 \\ \text { Nicaragua/other } & \$ 260.00 & 0.6 & 0.8 & 1.2 \\ \text { Costa Rica } & \$ 331.79 & 0.9 & 1.3 & 1.9\end{array}$

\section{CBI Table 5. Palm Oil - High Growth Case Supply Curve Data}

$\begin{array}{lclllr} & \begin{array}{l}\text { Average } \\ \text { Value } \\ \text { (US\$/ton) }\end{array} & \begin{array}{l}\text { Cumulative } \\ \text { Production } \\ (\mathrm{mmt}) 2012\end{array} & \begin{array}{l}\text { Cumulative } \\ \text { Production } \\ (\mathrm{mmt}) 2017\end{array} & \begin{array}{l}\text { Cumulative } \\ \text { Production } \\ (\mathrm{mmt}) 2027\end{array} \\ \text { Production unit } & 2005 & 0.4 & 0.9 & 2.3 \\ \text { Guatemala } & \$ 240.00 & 0.4 & 0.9 & 2.3 \\ \text { Dominican Republic } & \$ 256.82 & 0.6 & 1.1 & 2.6 \\ \text { Nicaragua/other } & \$ 260.00 & 0.8 & 1.3 & 2.8 \\ \text { Costa Rica } & \$ 331.79 & 0.8 & 2.0 & 4.2 \\ \text { Honduras } & \$ 390.55 & 1.2 & & & \end{array}$

CBI Table 6. Palm Oil - Low Growth Case Supply Curve Data

$\begin{array}{lcllr} & \begin{array}{l}\text { Average } \\ \text { Value } \\ \text { (US\$/ton) }\end{array} & \begin{array}{l}\text { Cumulative } \\ \text { Production } \\ (\mathrm{mmt}) 2012\end{array} & \begin{array}{l}\text { Cumulative } \\ \text { Production } \\ (\mathrm{mmt}) 2017\end{array} & \begin{array}{l}\text { Cumulative } \\ \text { Production } \\ (\mathrm{mmt}) 2027\end{array} \\ \text { Production unit } & 2005 & 0.2 & 0.2 & 0.3 \\ \text { Guatemala } & \$ 240.00 & 0.2 & 0.2 & 0.3 \\ \text { Dominican Republic } & \$ 256.82 & 0.3 & 0.3 & 0.4 \\ \text { Nicaragua/other } & \$ 260.00 & 0.4 & 0.5 & 0.6 \\ \text { Costa Rica } & \$ 331.79 & 0.4 & 0.8 & 1.0\end{array}$

As noted in the methodology (Annex 3), the approach used to estimate potential supplies from CBI treated countries as "states" to project overall future production in the region. These figures are not intended to represent individual country projections. 
CBI Table 7. Potential Percentage Allocation for Export \& Biofuels

\begin{tabular}{|c|c|c|c|}
\hline & $\begin{array}{l}\text { Percent of } \\
\text { Feedstock }\end{array}$ & $\begin{array}{l}\text { Percent of } \\
\text { Feedstock }\end{array}$ & $\begin{array}{l}\text { Percent of } \\
\text { Feedstock }\end{array}$ \\
\hline & 2012 & 2017 & 2027 \\
\hline \multicolumn{4}{|l|}{ Sugarcane } \\
\hline Low Growth & 44 & 38 & 25 \\
\hline Baseline & 54 & 54 & 54 \\
\hline High Growth & 61 & 66 & 72 \\
\hline \multicolumn{4}{|l|}{ Palm Oil } \\
\hline Low Growth & 33 & 21 & 0 \\
\hline Baseline & 49 & 49 & 49 \\
\hline High Growth & 62 & 69 & 76 \\
\hline
\end{tabular}

CBI Table 8. Estimated Cellulosic Supply from Recoverable Bagasse and Palm Residues (mmt, bone-dry, annual)

\begin{tabular}{|lccccccc|}
\hline & \multicolumn{3}{c}{ Baseline Case } & \multicolumn{2}{l}{ Low Growth } & High Growth Case & $\begin{array}{l}\text { Cost } \\
\text { US\$ }\end{array}$ \\
& 2017 & 2027 & 2017 & 2027 & 2017 & 2027 & \\
Bagasse & 9.6 & 12.1 & 7.1 & 7.5 & 13.0 & 20.0 & $\$ 12.00$ \\
Palm Residue & 0.8 & 1.2 & 0.5 & 0.6 & 1.2 & 2.5 & $\$ 1.00$ \\
Total & $\mathbf{1 0 . 3}$ & $\mathbf{1 3 . 3}$ & $\mathbf{7 . 6}$ & $\mathbf{8 . 0}$ & $\mathbf{1 4 . 2}$ & $\mathbf{2 2 . 5}$ & \\
\hline
\end{tabular}

CBI Table 9. Estimated Cellulosic Supply Summary Including Other Residues (2017 baseline case)

\begin{tabular}{|lcc|}
\hline & $\begin{array}{c}\text { Supply/Yr } \\
(\mathbf{m m t})\end{array}$ & Cost US\$ \\
Bagasse and Palm Residues & 10 & $($ See Table 8) \\
Forest Harvest Residue & 1 & $\$ 50-\$ 100$ \\
Wood Residues & 0.5 & $\$ 18-\$ 36$ \\
Wood Fuel & 7 & $\$ 52$ \\
Crop and Forest Residues & $\mathbf{1 9}$ & \\
Perennials & & \\
$\quad$ 5\% Arable Land Harvest & 1 & $\$ 52$ \\
$\quad 10 \%$ Arable Land Harvest & 2 & $\$ 52$ \\
\hline
\end{tabular}


Annex 4 Sugarcane: Aggregate Supply Projections by Country

\begin{tabular}{|c|c|c|c|c|}
\hline & & $\begin{array}{c}\text { Baseline } \\
(\mathrm{mmt})\end{array}$ & $\begin{array}{c}\text { Low Growth } \\
(\mathrm{mmt})\end{array}$ & $\begin{array}{l}\text { High Growth } \\
(\mathrm{mmt})\end{array}$ \\
\hline \multicolumn{5}{|l|}{ Brazil } \\
\hline & 2012 & 594.4 & 490.0 & 721.8 \\
\hline & 2017 & 741.7 & 537.8 & 1030.2 \\
\hline & 2027 & 1053.1 & 621.1 & 1833.6 \\
\hline \multicolumn{5}{|c|}{ Argentina } \\
\hline & 2012 & 24.6 & 20.2 & 30.0 \\
\hline & 2017 & 28.1 & 20.9 & 37.9 \\
\hline & 2027 & 33.8 & 21.9 & 52.8 \\
\hline \multicolumn{5}{|c|}{ Mexico } \\
\hline & 2012 & 59.0 & 52.0 & 69.0 \\
\hline & 2017 & 63.0 & 52.0 & 80.0 \\
\hline & 2027 & 69.0 & 52.0 & 99.0 \\
\hline \multicolumn{5}{|c|}{ Colombia } \\
\hline & 2012 & 44.6 & 37.6 & 52.8 \\
\hline & 2017 & 52.2 & 39.9 & 68.6 \\
\hline & 2027 & 65.4 & 43.2 & 100.6 \\
\hline \multicolumn{5}{|l|}{ CBI } \\
\hline & 2012 & 69.5 & 57.9 & 83.4 \\
\hline & 2017 & 80.4 & 59.7 & 109.0 \\
\hline & 2027 & 101.6 & 62.6 & 167.9 \\
\hline \multicolumn{5}{|l|}{ India } \\
\hline & 2012 & 314.8 & 251.7 & 402.6 \\
\hline & 2017 & 358.4 & 259.5 & 521.1 \\
\hline & 2027 & 449.1 & 272.5 & 844.6 \\
\hline \multicolumn{5}{|l|}{ China } \\
\hline & 2012 & 118.0 & 93.7 & 148.2 \\
\hline & 2017 & 133.1 & 96.3 & 183.2 \\
\hline & 2027 & 160.1 & 100.3 & 254.4 \\
\hline \multicolumn{5}{|l|}{ Total } \\
\hline & 2012 & 1224.9 & 1003.2 & 1507.9 \\
\hline & 2017 & 1456.7 & 1065.9 & 2030.0 \\
\hline & 2027 & 1932.2 & 1173.6 & 3352.8 \\
\hline
\end{tabular}


Annex 4 Soybean: Aggregate Supply Projections by Country

\begin{tabular}{|c|c|c|c|c|}
\hline & & $\begin{array}{c}\text { Baseline } \\
(\mathrm{mmt})\end{array}$ & $\begin{array}{c}\text { Low Growth } \\
\text { (mmt) }\end{array}$ & $\begin{array}{c}\text { High Growth } \\
(\mathrm{mmt})\end{array}$ \\
\hline \multicolumn{5}{|l|}{ Brazil } \\
\hline & 2012 & 82.4 & 67.4 & 102.0 \\
\hline & 2017 & 117.6 & 81.5 & 178.0 \\
\hline & 2027 & 209.1 & 107.6 & 484.8 \\
\hline \multicolumn{5}{|c|}{ Argentina } \\
\hline & 2012 & 50.3 & 43.9 & 57.9 \\
\hline & 2017 & 58.3 & 46.3 & 74.9 \\
\hline & 2027 & 73.8 & 50.1 & 118.0 \\
\hline \multicolumn{5}{|c|}{ Colombia } \\
\hline & 2012 & 0.1 & 0.1 & 0.2 \\
\hline & 2017 & 0.1 & 0.1 & 0.3 \\
\hline & 2027 & 0.1 & 0.1 & 0.6 \\
\hline \multicolumn{5}{|l|}{ China } \\
\hline & 2012 & 22.6 & 18.2 & 28.2 \\
\hline & 2017 & 25.7 & 18.9 & 35.1 \\
\hline & 2027 & 30.9 & 19.9 & 48.6 \\
\hline \multicolumn{5}{|l|}{ Total } \\
\hline & 2012 & 155.5 & 129.5 & 188.2 \\
\hline & 2017 & 201.7 & 146.7 & 288.3 \\
\hline & 2027 & 314.0 & 177.6 & 652.0 \\
\hline
\end{tabular}




\section{Annex 4 Soybean: Example of Supply Curve Functions by Country}
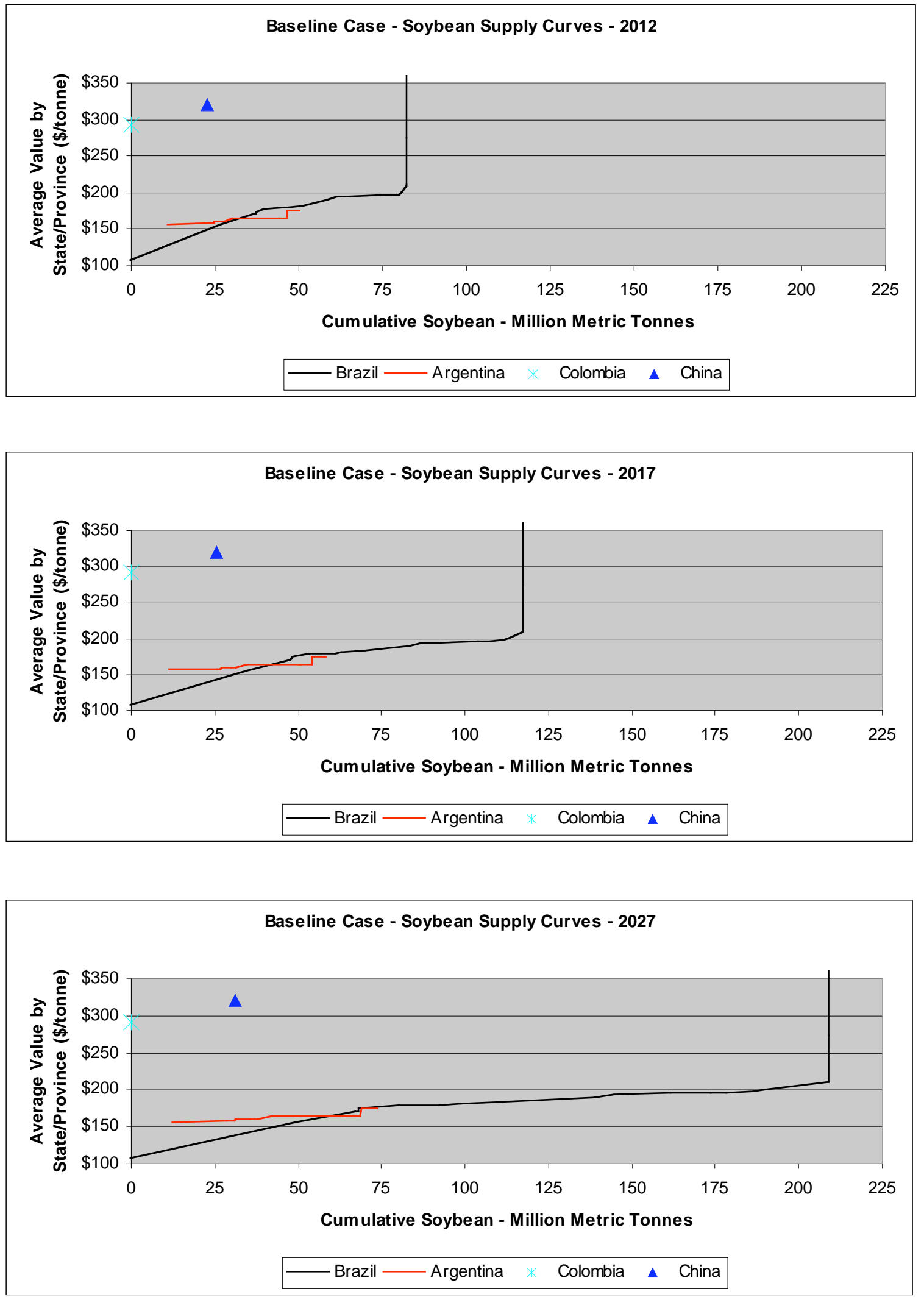
Annex 4 Corn: Aggregate Supply Projections by Country

\begin{tabular}{|lcccc|}
\cline { 3 - 5 } \multicolumn{1}{c}{} & & $\begin{array}{c}\text { Baseline } \\
\text { (mmt) }\end{array}$ & $\begin{array}{c}\text { Low Growth } \\
\text { (mmt) }\end{array}$ & $\begin{array}{c}\text { High Growth } \\
\text { (mmt) }\end{array}$ \\
\hline \multirow{6}{*}{ Brazil } & & & & \\
& 2012 & 45.1 & 39.4 & 52.5 \\
& 2017 & 54.1 & 43.3 & 71.8 \\
& 2027 & 76.9 & 53.8 & 133.6 \\
\hline \multirow{6}{*}{ Argentina } & & & \\
& 2012 & 20.8 & 14.5 & 31.5 \\
& 2017 & 24.7 & 14.5 & 46.6 \\
& 2027 & 31.3 & 14.5 & 81.2 \\
\hline Mexico & & & & \\
& 2012 & 27.0 & 22.0 & 33.0 \\
& 2017 & 31.0 & 23.0 & 46.0 \\
& 2027 & 42.0 & 25.0 & 77.0 \\
\hline Canada & & & & \\
& 2012 & 12.5 & 9.3 & 15.3 \\
& 2017 & 15.5 & 9.6 & 21.6 \\
& 2027 & 21.5 & 9.9 & 36.9 \\
\hline China & & & & \\
& 2012 & 174.5 & 156.2 & 195.8 \\
& 2017 & 199.8 & 166.7 & 242.3 \\
& 2027 & 255.5 & 186.9 & 363.5 \\
\hline Total & & & & \\
& 2012 & 280.0 & 241.4 & 328.1 \\
& 2017 & 325.0 & 257.1 & 428.3 \\
& 2027 & 427.3 & 290.2 & 692.2 \\
\hline
\end{tabular}


Annex 4 Wheat: Aggregate Supply Projections by Country

\begin{tabular}{|lcccc|}
\cline { 3 - 5 } \multicolumn{1}{c}{} & & $\begin{array}{c}\text { Baseline } \\
\text { (mmt) }\end{array}$ & $\begin{array}{c}\text { Low Growth } \\
\text { (mmt) }\end{array}$ & $\begin{array}{c}\text { High Growth } \\
\text { (mmt) }\end{array}$ \\
\hline Argentina & & & \\
& 2012 & 15.1 & 12.7 & 20.7 \\
& 2017 & 16.5 & 12.7 & 26.7 \\
& 2027 & 17.9 & 12.7 & 34.3 \\
\hline Canada & & & & \\
& 2012 & 27.8 & 25.1 & 32.8 \\
& 2017 & 29.9 & 25.1 & 40.5 \\
& 2027 & 33.3 & 25.1 & 55.3 \\
\hline China & & & & \\
& 2012 & 109.8 & 98.3 & 129.6 \\
& 2017 & 113.7 & 98.6 & 141.1 \\
& 2027 & 125.1 & 99.3 & 178.8 \\
\hline Total & & & & \\
& 2012 & 152.7 & 136.1 & 183.1 \\
& 2017 & 160.1 & 136.4 & 208.3 \\
& 2027 & 176.4 & 137.1 & 268.3 \\
\hline
\end{tabular}

Annex 4 Palm Oil: Aggregate Supply Projections by Country

\begin{tabular}{|c|c|c|c|c|}
\hline & & $\begin{array}{c}\text { Baseline } \\
\text { (mmt) }\end{array}$ & $\begin{array}{c}\text { Low Growth } \\
(\mathrm{mmt})\end{array}$ & $\begin{array}{c}\text { High Growth } \\
(\mathrm{mmt})\end{array}$ \\
\hline \multicolumn{5}{|c|}{ Colombia } \\
\hline & 2012 & 1.4 & 0.9 & 1.7 \\
\hline & 2017 & 2.1 & 1.1 & 2.7 \\
\hline & 2027 & 4.7 & 1.4 & 7.5 \\
\hline \multicolumn{5}{|l|}{ CBI } \\
\hline & 2012 & 0.9 & 0.7 & 1.2 \\
\hline & 2017 & 1.3 & 0.8 & 2.0 \\
\hline & 2027 & 1.9 & 1.0 & 4.2 \\
\hline \multicolumn{5}{|l|}{ Total } \\
\hline & 2012 & 2.3 & 1.6 & 2.9 \\
\hline & 2017 & 3.3 & 1.9 & 4.8 \\
\hline & 2027 & 6.6 & 2.3 & 11.6 \\
\hline
\end{tabular}


Annex 4 Cellulosic Crop Residues: Aggregate Supply Projections by Country

\begin{tabular}{|c|c|c|c|c|}
\hline & & $\begin{array}{l}\text { Baseline } \\
(\mathrm{mmt})\end{array}$ & $\begin{array}{c}\text { Low } \\
(\mathrm{mmt})\end{array}$ & $\begin{array}{c}\text { High } \\
(\mathrm{mmt})\end{array}$ \\
\hline \multicolumn{5}{|l|}{ Argentina } \\
\hline & 2017 & 14 & 10 & 24 \\
\hline & 2027 & 17 & 10 & 37 \\
\hline \multicolumn{5}{|l|}{ Brazil } \\
\hline & 2017 & 111 & 81 & 154 \\
\hline & 2027 & 158 & 95 & 276 \\
\hline \multicolumn{5}{|l|}{ Canada } \\
\hline & 2017 & 11 & 8 & 14 \\
\hline & 2027 & 13 & 8 & 22 \\
\hline \multicolumn{5}{|l|}{ China } \\
\hline & 2017 & 33 & 27 & 42 \\
\hline & 2027 & 41 & 29 & 60 \\
\hline \multicolumn{5}{|l|}{ Colombia } \\
\hline & 2017 & 6 & 4 & 8 \\
\hline & 2027 & 9 & 5 & 14 \\
\hline \multicolumn{5}{|l|}{ India } \\
\hline & 2017 & 50 & 36 & 73 \\
\hline & 2027 & 63 & 38 & 118 \\
\hline \multicolumn{5}{|l|}{ Mexico } \\
\hline & 2017 & 10 & 8 & 14 \\
\hline & 2027 & 12 & 8 & 20 \\
\hline \multicolumn{5}{|l|}{$\mathrm{CBI}$} \\
\hline & 2017 & 10 & 8 & 14 \\
\hline & 2027 & 13 & 8 & 22 \\
\hline \multicolumn{5}{|l|}{ Total } \\
\hline & 2017 & 246 & 182 & 344 \\
\hline & 2027 & 326 & 201 & 569 \\
\hline
\end{tabular}


Annex 4 Cellulosic Summary: Total Cellulosic Feedstock including Other Residues

\begin{tabular}{|lcccccc|}
\cline { 2 - 7 } \multicolumn{1}{c|}{} & $\begin{array}{c}\text { Agriculture } \\
\text { Residues* }\end{array}$ & $\begin{array}{c}\text { Forest } \\
\text { Harvest } \\
\text { Residue }\end{array}$ & $\begin{array}{c}\text { Wood } \\
\text { Residue }\end{array}$ & $\begin{array}{c}\text { Wood } \\
\text { Fuel }\end{array}$ & $\begin{array}{c}\text { Perennials } \\
\text { (from 5\% } \\
\text { available land) }\end{array}$ & Total \\
\hline Argentina & 14.3 & 0.3 & 0.1 & 1.4 & 4.7 & 21 \\
\hline Brazil & 111.5 & 5.4 & 2.4 & 31.5 & 36.6 & 187 \\
\hline Canada & 10.6 & 4.2 & 1.9 & 0.6 & 2.7 & 20 \\
\hline China & 33.3 & 6.0 & 2.7 & 28.9 & 1.2 & 72 \\
\hline Colombia & 6.1 & 0.2 & 0.1 & 2.0 & 4.9 & 13 \\
\hline India & 50.2 & 6.9 & 3.1 & 75.2 & 0.0 & 135 \\
\hline Mexico & 10.2 & 0.9 & 0.4 & 6.8 & 1.0 & 20 \\
\hline CBI & 10.3 & 1.0 & 0.5 & 7.4 & 1.0 & $\mathbf{4 8 8}$ \\
\hline Total & $\mathbf{2 4 6 . 4}$ & $\mathbf{2 4 . 9}$ & $\mathbf{1 1 . 2}$ & $\mathbf{1 5 3 . 8}$ & $\mathbf{5 2 . 2}$ &
\end{tabular}

*These are the values for 2017 residues from crops studied, under the baseline case. 